Rosileia Lucia Nierotka

\title{
DESIGUALDADE DE OPORTUNIDADES NO ENSINO SUPERIOR: um estudo de caso sobre acesso e conclusão na UFFS
}

Tese apresentada como requisito parcial para obtenção de Grau de Doutora em Ciências Humanas - Educação pelo Programa de Pós-Graduação em Educação, do Departamento de Educação da PUC-Rio.

Orientadora: Prof ${ }^{a}$. Alicia Maria Catalano de

Bonamino (PUC-Rio)

Co-orientadora: Prof ${ }^{a}$. Felícia Picanço (UFRJ) 
Rosileia Lucia Nierotka

Desigualdade de oportunidades no ensino superior: um estudo de caso sobre acesso e conclusão na UFFS

Tese apresentada como requisito parcial para obtenção de Grau de Doutora em Ciências Humanas - Educação pelo Programa de Pós-Graduação em Educação, do Departamento de Educação da PUC-Rio. Aprovada pela Comissão Examinadora abaixo:

Profa . Alicia Maria Catalano de Bonamino

Orientadora

Departamento de Educação - PUC-Rio

Prof ${ }^{\mathrm{a}}$. Felícia Picanço

Co-orientadora

Departamento de Sociologia - UFRJ

Prof ${ }^{\text {. }}$ Cynthia Paes de Carvalho

Departamento de Educação - PUC-Rio

Profa. Naira da Costa Muylaert Lima Departamento de Educação - PUC-Rio

Profa. Maria Lígia de Oliveira Barbosa

Departamento de Sociologia - UFRJ

Prof. André Ricardo Salata

Programa de Pós-Graduação em Ciências Sociais -

PUCRS

Rio de Janeiro, 16 de dezembro de 2021 
Todos os direitos reservados. A reprodução, total ou parcial, do trabalho é proibida sem autorização da universidade, da autora e do orientador.

\section{Rosileia Lucia Nierotka}

Graduada em Serviço Social, com Especialização Lato Sensu em Gestão Social de Políticas Públicas pela Universidade Comunitária da Região de Chapecó (Unochapecó). Possui Mestrado em Educação pela Universidade Federal da Fronteira Sul (UFFS). Participa do Laboratório de Avaliação da Educação (LAEd/PUC-Rio) e da pesquisa "Políticas Públicas de Ação Afirmativa e Desigualdades Sociais e Raciais na Educação Básica, coordenada pela professora Alicia Bonamino, desenvolvida no LAEd. Atua como Assistente Social na UFFS, na Pró-Reitoria de Assuntos Estudantis (PROAE) e na Unidade do Subsistema Integrado de Atenção à Saúde do Servidor (SIASS UFFS/Chapecó-SC).

Ficha catalográfica

Nierotka, Rosileia Lucia

Desigualdade de oportunidades no ensino superior : um estudo de caso sobre acesso e conclusão na UFFS / Rosileia Lucia Nierotka ; orientadora: Alicia Maria Catalano de Bonamino ; co-orientadora: Felícia Picanço. - 2021.

293 f. : il. color. ; $30 \mathrm{~cm}$

Tese (doutorado)-Pontifícia Universidade Católica do Rio de Janeiro, Departamento de Educação, 2021.

Inclui bibliografia

1. Educação - Teses. 2. Desigualdades educacionais. 3. Ensino superior. 4. Acesso. 5. Evasão de curso. 6. Conclusão. I. Bonamino, Alicia Catalano de. II. Picanço, Felícia Silva. III. Pontifícia Universidade Católica do Rio de Janeiro. Departamento de Educacão. IV. Título. 
Dedico aos meus pais Eleni e Domingos por todo o apoio e incentivo! 


\section{Agradecimentos}

Chegar ao final desse percurso é de uma imensa alegria e gratidão aos que contribuíram tornando essa caminhada possível e como uma experiência de vida e acadêmica tão enriquecedora.

O presente trabalho foi realizado com apoio da Coordenação de aperfeiçoamento de pessoal de Nível Superior - Brasil (Capes) - código de financiamento 001.

Agradeço com muito carinho a minha orientadora, Prof ${ }^{a}$. Alicia Bonamino, e minha co-orientadora, Prof ${ }^{a}$. Felícia Picanço, por toda a competência, parceria e dedicação de vocês no percurso desta pesquisa, além do acolhimento, inspiração e aprendizado compartilhado que tanto contribuíram para o meu desenvolvimento.

Ao Prof. Murilo Marshner Alves de Brito, pela orientação no percurso inicial dessa pesquisa.

À colega Karina Carrasqueira Lopes pela parceria de sempre, amizade e por ter me acompanhado, como pesquisadora auxiliar, na coleta de dados junto ao Inep.

Ao Wellington, meu namorado, por toda a parceria, amor e experiências compartilhadas durante o doutorado, tornando nossos dias mais leves.

Aos meus familiares por todo o carinho, apoio e incentivo, especialmente meus pais, Eleni e Domingos; minha amiga e irmã Rosane; cunhado Gildo; meu irmão Damir, cunhada Janice e meus queridos sobrinhos Bryan e Brenda. Vocês serão sempre o meu porto seguro!

Aos meus colegas de trabalho na UFFS, minha gratidão, especialmente aos que se dedicaram ainda mais durante o meu afastamento para estudos, colegas da PROAE, SIASS e assistentes sociais dos SAEs.

Às queridas colegas da minha turma de Doutorado pela parceria de sempre e demais colegas e amigos que tive o prazer de conhecer no Rio, pela amizade, acolhida e muitas risadas também, em especial Natália e Juliana pela linda amizade construída. Amiga e colega Elise, que me acolheu inicialmente no Rio e demais amigas do apê 501: Ingrid, Lorena, Paula, Gabriela, Carol e amigo Eduardo (família Rio!).

Aos amigos/as de Chapecó, muito obrigada pela amizade e apoio de sempre. Em nome das amigas Amanda e Claudia, estendo a minha gratidão aos demais.

Aos professores da PUC-Rio pelos valorosos conhecimentos e aos demais servidores, especialmente do Departamento de Educação, por todo a atenção e apoio recebido.

Ao Laboratório de Avaliação da Educação (Laed), coordenado pelas Prof ${ }^{a}$ s. Alicia e Naira. Em nome delas, estendo o meu carinho aos demais colegas e amigos desse grupo pelos trocas, amizade, trabalho em equipe e todo o aprendizado compartilhado. 
Ao Laboratório de Diferença, Desigualdade e Estratificação (LeDdE/UFRJ), coordenado pela Prof ${ }^{a}$. Felícia, pelo acolhimento e trocas de experiências entre colegas pesquisadores deste grupo.

Às universidades UFRJ e UERJ pela oportunidade de eu ter cursado vários disciplinas, participado de vários eventos, cursos e demais atividades.

À UFFS por todo o apoio, concessão de horas e afastamento para estudos (Pleduca) e pela liberação de dados para a realização desta pesquisa, especialmente às Pró-Reitorias de Assistência Estudantil e de Graduação; à Procuradoria Educacional e Institucional e às Diretorias de Registro Acadêmico e de Sistemas. Em especial, os colegas: Marcel Eduard Armanini; Cecília Ines Duz de Andrade; Darlan Eziquiel Felisberto da Silva; Pedro Adalberto Aguiar Castro; Cassiano Carlos Zanuzzo; Maiquel Tesser e Elaine Aparecida Lorenzon.

Ao Inep pela concessão de dados para a pesquisa, especialmente ao coordenador do Sedap/Inep, Marco César Araújo Pereira e sua equipe, por toda a atenção e colaboração antes e durante a realização deste trabalho na sala segura do Inep.

Aos professores que participaram nas bancas de Qualificação e de defesa final da tese, por suas valiosas contribuições para esta pesquisa: Felícia Picanço; Maria Ligia de Oliveira Barbosa; Naira Da Costa Muylaert Lima; Cynthia Paes de Carvalho; Andrés Santos Sharpe; Carlos Antonio Costa Ribeiro e André Ricardo Salata.

Finalmente, a todas as pessoas importantes que cruzaram o meu caminho neste percurso, e que de alguma forma contribuíram para a realização desse trabalho. 


\section{Resumo}

Nierotka, Rosileia Lucia; Bonamino, Alicia Maria Catalano de Bonamino; Picanço, Felícia. Desigualdade de oportunidades no ensino superior: um estudo de caso sobre acesso e conclusão na UFFS. Rio de Janeiro, 2021, 293p. Tese de Doutorado - Departamento de Educação, Pontifícia Universidade Católica do Rio de Janeiro.

Nesta pesquisa, exploramos o fenômeno da desigualdade de oportunidades no ensino superior no contexto da Universidade Federal da Fronteira Sul (UFFS), com o objetivo principal de investigar as relações entre gênero, raça e características socioeconômicas dos estudantes, aspectos institucionais e desempenho acadêmico no acesso e na conclusão de curso. A UFFS foi criada em 2009, no contexto da expansão e interiorização do ensino superior público federal no Brasil, com especificidades significativas em sua estrutura, abrangência territorial e perfil dos estudantes. A pesquisa foi desenhada como um estudo de caso e combina estratégias qualitativas e quantitativas. As primeiras envolvem a análise de documentos institucionais. As segundas fazem uso de dados longitudinais dos ingressantes pelo Enem, no período de 2010 a 2018 em análises descritivas e inferenciais de características dos estudantes e institucionais e de suas relações com desfechos como evasão e conclusão. Os principais resultados indicam que as políticas de acesso e de ação afirmativa implementadas na UFFS, incluindo a Lei de Cotas, contribuem de forma significativa para a redução das desigualdades sociais e raciais. Desde sua criação, a UFFS manteve um perfil discente com mais de $90 \%$ de egressos da escola pública, alto percentual de estudantes de origem rural, de trabalhadores e com pais de baixa escolarização e renda. A implementação da Lei de Cotas permitiu o aumento do acesso de estudantes pretos, pardos e indígenas em todas as áreas de conhecimento, inclusive nas mais seletivas, como saúde e engenharias. Na dimensão da evasão e da conclusão do curso, os resultados indicam um peso maior dos aspectos institucionais sobre esses dois desfechos: estudantes que frequentam curso integral e os que recebem alguma modalidade de assistência estudantil e/ou participam de atividades extracurriculares ampliam suas chances de permanência e de conclusão do curso. Outro resultado relevante é que os alunos das áreas rurais 
apresentam maiores percentuais de conclusão e menores percentuais de evasão de curso quando comparados aos estudantes das áreas urbanas. Em termos de gênero e raça, os homens e negros apresentam maiores dificuldades na conclusão de curso. Por fim, o desempenho se mostrou uma questão central na explicação da evasão e da conclusão de curso em associação com características dos estudantes e, principalmente, com o tipo de curso frequentado. Por sua vez, a reprovação se mostrou um fator importante e que afeta a maioria dos ingressantes na UFFS, sejam eles evadidos ou concluintes. Esses resultados indicam a necessidade de implementação de iniciativas institucionais específicas, dirigidas ao fortalecimento da permanência dos estudantes e à redução da evasão e da repetência, além da necessidade de novas pesquisas que acompanhem os resultados dessas iniciativas, e que contribuam para uma melhor compreensão dos fatores associados à evasão de curso e à mobilidade interna e externa dos estudantes da UFFS.

\section{Palavras-Chave}

Desigualdades educacionais; ensino superior; acesso; evasão de curso; conclusão. 


\section{Abstract}

Nierotka, Rosileia Lucia; Bonamino, Alicia Maria Catalano de Bonamino; Picanço, Felícia. Inequality of opportunities in higher education: a case study on access and completion at UFFS. Rio de Janeiro, 2021, 293p. Doctoral Thesis - Departmento de Educação, Pontifícia Universidade Católica do Rio de Janeiro.

This thesis explores the inequality of opportunities in higher education in the case of the Universidade Federal da Fronteira Sul (UFFS). The main objective is to investigate relationships between gender, race and socioeconomic characteristics of the students, institutional aspects and academic performance in undergraduate access and completion. UFFS was created in 2009, reflecting the expansion and internalization of federal public higher education in Brazil in the particularities of its structure, its territorial scope and the profile of its students. The research was designed as a case study and combines qualitative strategies related to the analysis of institutional documents, with quantitative strategies that involve descriptive and inferential analyzes of student characteristics, performance, course and permanence policies and their relationships with outcomes such as dropout and the conclusion, based on the use of longitudinal data of new entrants by Enem, in the period from 2010 to 2018. The main results indicate that the access and affirmative action policies implemented at UFFS, including the Quota Law, contribute significantly to the reduction of social and racial inequalities. Since its creation, UFFS has maintained a student profile with more than $90 \%$ coming from public schools, a high percentage of rural students and workers and children of parents with low education and income. The implementation of the Quotas Law allowed for an increase in the access of black, brown and indigenous students in all areas of knowledge. In the dimension of dropout and completion of the course, the results indicate a greater weight of institutional aspects on these two outcomes: students who attend a full course and those who receive some type of student assistance and/or participate in extracurricular activities increase their chances of staying and completing the course. Another relevant result is that students from rural areas have higher percentages of completion and lower percentages of dropouts when compared to students from urban areas. In terms of gender and race, men and blacks present 
more difficulties in completing an undergraduate when compared with white and women. Finally, performance proved to be a central issue in explaining dropout and course completion in association with student characteristics and especially with the type of course attended. In turn, a failure proved to be an important factor that affects most newcomers to UFFS, whether they are dropouts or graduates. These results indicate the need to implement specific institutional initiatives, aimed at strengthening student retention and reducing dropout and repetition, in addition to the need for further research to monitor the results of these initiatives, and which contribute to a better understanding of the factors associated with course evasion and internal and external mobility of UFFS students.

\section{Keywords}

Educational inequalities; University education; access; course evasion; conclusion. 


\section{Sumário}

1 Introdução

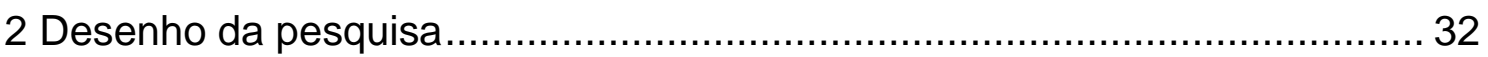

2.1 Análises realizadas .............................................................. 33

2.2 Base de dados utilizadas e tratamento dos dados............................. 37

2.2.1 Base de dados da UFFS ................................................... 37

2.2.2 Bases de dados do Inep ................................................... 38

2.3 Descrição das variáveis ............................................................. 40

2.4 Limites e possibilidades das bases de dados e da pesquisa ................ 45

2.5 Cuidados éticos da pesquisa .................................................... 46

3 Desigualdade de oportunidades no ensino superior: contribuições sociológicas da estratificação educacional.

3.1 Entre a persistência das desigualdades e a democratização na educação superior.

4 Panorama sobre a expansão e interiorização do acesso ao ensino superior brasileiro e a UFFS.............................................................. 71

4.1 Principais programas e políticas para a educação superior ................... 79

$4.2 \mathrm{O}$ contexto de criação da UFFS .................................................. 84

5 Apresentação da UFFS: caracterização institucional e mudanças e permanências no perfil dos ingressantes ............................................ 91

5.1 Caracterização institucional da UFFS ......................................... 91

5.1.1 Currículo, cursos de graduação e comunidade acadêmica .............. 91

5.1.2 Políticas de acesso na UFFS .................................................. 97

5.1.3 Mudanças na oferta, ocupação de vagas e seletividade dos cursos ................................................................................. 103

5.1.4 Políticas de permanência estudantil ........................................ 109

5.2 Mudanças e permanências no perfil socioeconômico e racial dos ingressantes ao longo do tempo ................................................... 115

5.2.1 Origem geográfica dos ingressantes .................................... 115

5.2 .2 Faixa etária ................................................................... 117 


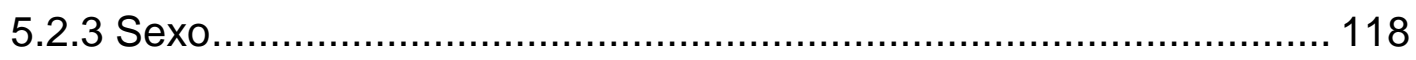

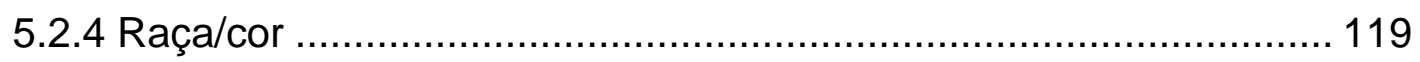

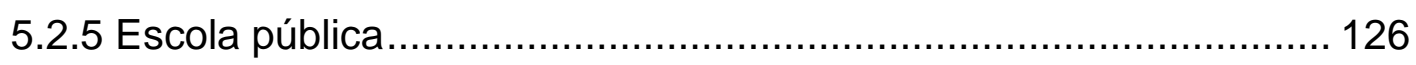

5.2.6 Intervalo de tempo entre Ensino Médio e Ensino Superior .............. 128

5.2.7 Grupo de Inscrição no Processo Seletivo .................................... 129

5.3 Síntese do capítulo: principais resultados ........................................... 130

6 Desigualdades estrututais de gênero e raça na ocupação dos cursos ....... 132

6.1 Caracterização sobre raça e gênero na UFFS ..................................... 135

6.2 Síntese do capítulo: principais resultados ............................................. 149

7 Evasão e conclusão no ensino superior: o que a literatura diz? .................... 151

7.1 Conceitos e modelos analíticos de evasão, retenção e conclusão do

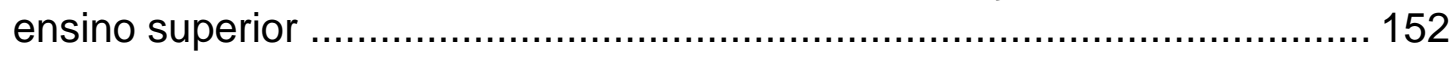

7.2 Fatores associados à evasão e conclusão de cursos ........................... 158

7.3 Principais dimensões de análise de evasão e conclusão de curso

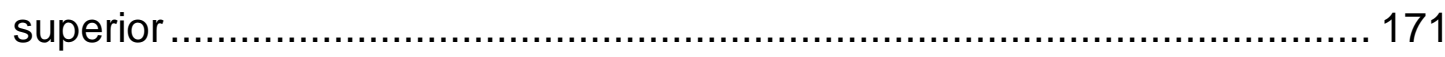

7.4 Considerações e diálogo com o estudo de caso na UFFS .................... 175

8 Desfecho dos ingressantes: evasão e conclusão de curso .......................... 178

8.1 Caracterização dos desfechos de ingressantes na UFFS: coortes

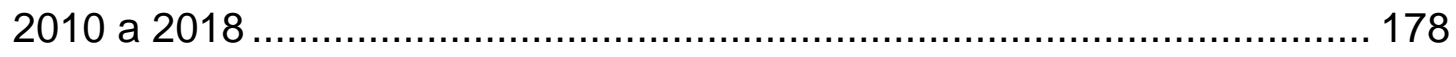

8.2 Análise descritiva de variáveis dependentes e independentes ............. 185

8.3 Análises bivariadas entre variáveis dependentes e independentes ...... 190

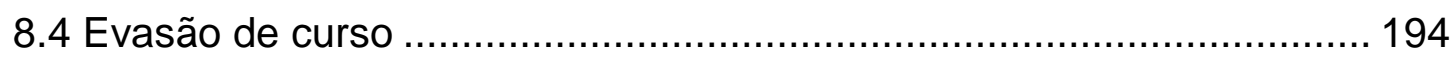

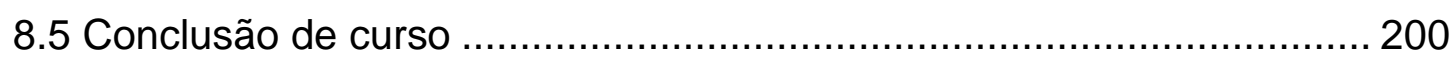

8.6 Síntese do capítulo: principais resultados .......................................... 210

9 Desempenho acadêmico e seus efeitos na conclusão do curso .................. 213

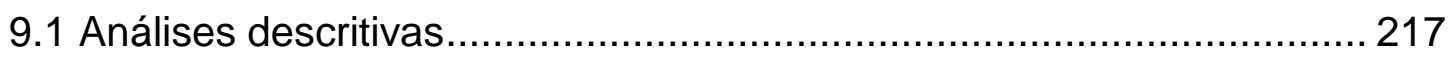

9.2 Chance de conclusão ou evasão de curso: efeitos do rendimento

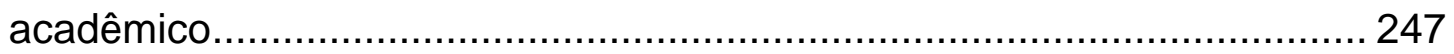

9.3 Síntese do capítulo: principais resultados ............................................ 251

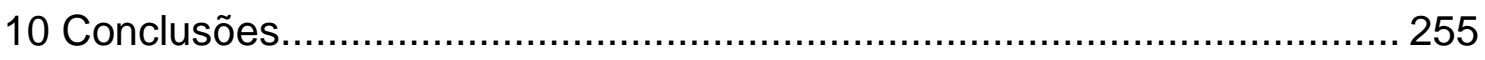




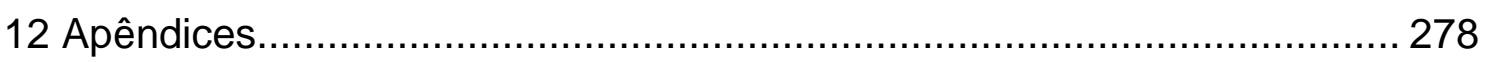

Apêndice 1 - Quadro de cargos e média salarial com referência aos cursos de graduação da UFFS

Apêndice 2 - Distribuição do percentual de ingressantes de origem da escola pública, segundo campus, curso e turno - 2010 a 2018

Apêndice 3 - Distribuição do percentual de ingressantes pretos, pardos e indígenas (PPIs), segundo campus, curso e turno - 2010 a 2018.

Apêndice 4 - Descrição e frequências das variáveis dependente e independentes

13 Anexos

Anexo 1 - Termo de responsabilidade e Termo de liberação de dados para pesquisa

Anexo 2 - Despacho de aprovação de uso de dados protegidos do Inep ... 291 


\section{Lista de Gráficos}

Gráfico 1 - Percentual de ingressantes, segundo modo de ingresso - 2010

a 2018

Gráfico 2 - Porcentagem de matrículas (taxas bruta e líquida) no Brasil 2012-2018

Gráfico 3 - Porcentagem de matrículas da população de 18 a 24 anos (taxa líquida) no Brasil e nas regiões - 2012 - 2018

Gráfico 4 - Porcentagem de matrículas na educação superior da população de 18 a 24 anos (taxa líquida -20,0\%) por renda no Brasil, em 2017

Gráfico 5 - Percentual de vagas reservadas nos campi da UFFS por Estado - 2013.

Gráfico 6 - Número de beneficiários de auxílios socioeconômicos e PBP (2010 - 2020)....

Gráfico 7 - Número de estudantes inseridos em atividades extracurriculares - 2020

Gráfico 8 - Percentuais de ingressantes, segundo a origem geográfica 2010 a 2018

Gráfico 9 - Percentual de ingressantes por campus, segundo a origem geográfica - antes e depois do SiSU.

Gráfico 10 - Percentual de ingressantes PPIs, segundo áreas de conhecimento - 2010 a 2018

Gráfico 11 - Percentual de ingressantes PPIs, segundo campus e sua representação em Santa Catarina - 2010 a 2018.

Gráfico 12 - Percentual de ingressantes PPIs, segundo campus e sua representação no Paraná - 2010 a 2018.

Gráfico 13 - Percentual de ingressantes PPIs, segundo campus e sua representação no Rio Grande do Sul - 2010 a 2018

Gráfico 14 - Percentual de ingressantes, segundo raça/cor e origem geográfica - 2010 a 2018

Gráfico 15 - Percentual de ingressantes, segundo critérios de ensino médio em escola pública e de PPIs - 2010 a 2018.

Gráfico 16 - Distribuição dos ingressantes, segundo sexo_raça - 2010 a 2018

Gráfico 17 - Percentual de ingressantes na faixa etária de 17 a 20 anos, segundo sexo_raça - 2010 a 2018

Gráfico 18 - Percentual de ingressantes na faixa etária de 21 a 24 anos, segundo sexo_raça - 2010 a 2018

Gráfico 19 - Percentual de ingressantes na faixa etária de 25 anos ou mais, segundo sexo_raça -2010 a 2018 .

Gráfico 20 - Percentual de ingressantes egressos de escola pública, segundo sexo_raça - 2010 a 2018 
Gráfico 21 - Percentual de ingressantes em cursos de turno integral, segundo sexo_raça - 2010 a 2018

Gráfico 22 - Percentual de ingressantes em cursos de turno noturno, segundo sexo_raça - 2010 a 2018

Gráfico 23 - Percentual de ingressantes em cursos de turno matutino ou vespertino, segundo sexo_raça - 2010 a 2018.

Gráfico 24 - Percentual de ingressantes em cursos de bacharelados, segundo sexo_raça - 2010 a 2018

Gráfico 25 - Percentual de ingressantes na área de Educação, segundo sexo_raça - 2010 a 2018

Gráfico 26 - Percentual de ingressantes na área de Negócios, administração, direito e ciências sociais, segundo sexo_raça - 2010 a 2018

Gráfico 27 - Percentual de ingressantes na área de Computação e Tecnologias da Informação e Comunicação (TIC), segundo sexo_raça 2010 a 2018

Gráfico 28 - Percentual de ingressantes na área de Engenharia, produção e construção, segundo sexo_raça - 2010 a 2018 ..

Gráfico 29 - Percentual de ingressantes na área de Agricultura,

Silvicultura, Pesca e Veterinária, segundo sexo_raça - 2010 a 2018.

Gráfico 30 - Percentual de ingressantes na área de Saúde e bem-estar, segundo sexo_raça - 2010 a 2018

Gráfico 31 - Percentual de ingressantes em cursos de baixo retorno, segundo sexo raça - 2010 a 2018

Gráfico 32 - Percentual de ingressantes em cursos de médio retorno, segundo sexo_raça - 2010 a 2018

Gráfico 33 - Percentual de ingressantes em cursos de alto retorno, segundo sexo_raça - 2010 a 2018

Gráfico 34- Percentual de ingressantes, segundo situação de matrícula em 2019/2 - 2010 a 2018

Gráfico 35 - Percentuais de ingressantes com situação de evasão de curso, em 2019/2, segundo áreas de conhecimento - 2010 a 2018.

Gráfico 36 - Percentuais de ingressantes com matrícula ativa, em 2019/2, segundo sexo_raça - 2010 a 2018

Gráfico 37 - Percentuais de ingressantes com situação de evasão de curso, em 2019/2, segundo sexo_raça - 2010 a 2018

Gráfico 38 - Percentual de ingressantes com conclusão de curso, em

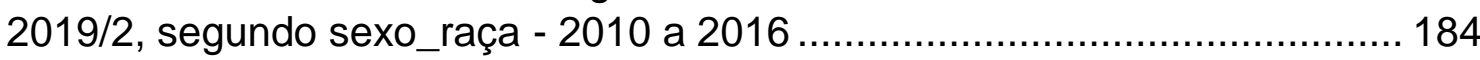

Gráfico 39 - Evasão e conclusão, segundo médias de notas..........................218

Gráfico 40 - Evasão e conclusão, segundo faixa etária ................................2 219

Gráfico 41 - Média de nota, segundo a faixa etária - ingressantes que evadiram o curso

Gráfico 42 - Média de nota, segundo a faixa etária - ingressantes que concluíam o curso

Gráfico 43 - Evasão e conclusão, segundo sexo_raça

Gráfico 44 - Média de nota, segundo sexo_raça - ingressantes que evadiram do curso 
Gráfico 45 - Média de nota, segundo sexo_raça - ingressantes que concluíram o curso

Gráfico 46 - Evasão e conclusão, segundo renda familiar

Gráfico 47 - Média de nota, segundo renda familiar - ingressantes que evadiram do curso.

Gráfico 48 - Média de nota, segundo renda familiar - ingressantes que concluíram o curso

Gráfico 49 - Evasão e conclusão, segundo escolaridade da mãe .................. 225

Gráfico 50 - Média de notas, segundo escolaridade da mãe ingressantes que evadiram ............................................................... 226

Gráfico 51 - Média de notas, segundo escolaridade da mãe ingressantes que concluíram.

Gráfico 52 - Evasão e conclusão, segundo situação de trabalho antes do ingresso.

Gráfico 53 - Média de notas, segundo situação de trabalho no ensino médio - ingressantes que evadiram.

Gráfico 54 - Média de notas, segundo situação de trabalho no ensino médio - ingressantes que evadiram.

Gráfico 55 - Evasão e conclusão, segundo localização da moradia .............. 230

Gráfico 56 - Média de nota, segundo a localização da moradia ingressantes que evadiram

Gráfico 57 - Média de nota, segundo a localização da moradia ingressantes que

Gráfico 58 - Evasão e conclusão de curso, segundo escola pública no Ensino Médio.

Gráfico 59 - Média de notas, segundo escola púbica - ingressantes que evadiram.

Gráfico 60 - Média de notas, segundo escola pública - ingressantes que concluíram

Gráfico 61 - Evasão e conclusão de curso, segundo cotas e ampla concorrência.

Gráfico 62 - Média de notas, segundo cotas e ampla concorrência ingressantes que evadiram

Gráfico 63 - Média de notas, segundo cotas e ampla concorrência ingressantes que concluíram................................................................ 235

Gráfico 64 - Evasão e conclusão de curso, segundo apoio social ................. 237

Gráfico 65 - Média de notas, segundo apoio social - ingressantes que evadiram.....

Gráfico 66 - Média de notas, segundo apoio social - ingressantes que concluíram.

Gráfico 67 - Evasão e conclusão de curso, segundo áreas de conhecimento .

Gráfico 68 - Média de nota, segundo áreas de conhecimento ingressantes que evadiram do curso.

Gráfico 69 - Média de nota, segundo área de conhecimento - ingressantes que concluíram o curso 
Gráfico 71 - Média de notas, segundo turno do curso - ingressantes que evadiram

Gráfico 72 - Média de notas, segundo turno do curso - ingressantes que concluíram

Gráfico 73 - Evasão e conclusão, segundo o campus

Gráfico 74 - Média de notas, segundo o campus - ingressantes que evadiram.

Gráfico 75 - Média de notas, segundo o campus, ingressantes que concluíram

Gráfico 76 - Evasão e conclusão, segundo a condição de reprovação.

Gráfico 77 - Média de notas, segundo condição de reprovação ingressantes que evadiram

Gráfico 78 - Média de notas, segundo condição de reprovação ingressantes que concluíram

Gráfico 79 - Representação gráfica da probabilidade prevista da nota na conclusão de curso (modelo 1) 


\section{Lista de quadros}

Quadro 1 - Descrição de variáveis utilizadas na pesquisa ........................... 41

Quadro 2 - Agregação dos cursos por grandes áreas................................. 44

Quadro 3 - Autores e perspectivas de análise sobre desigualdades na educação superior ............................................................................ 57

Quadro 4 - Modalidades de reserva de vagas no Processo Seletivo da

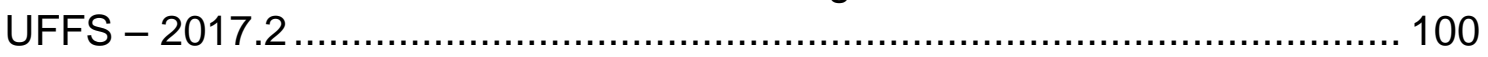

Quadro 5 - Programas e ações de Assistência Estudantil da UFFS - 2019 ... 113 Quadro 6 - Principais dimensões de análise relacionadas à evasão e conclusão de curso superior............................................................ 174 Quadro 7 - Variáveis estatisticamente significativas nos modelos de regressão logística - evasão de curso ....................................................... 196

Quadro 8 - Variáveis estatisticamente significativas nos modelos de regressão logística - conclusão de curso 


\section{Lista de tabelas}

Tabela 1 - Quantidade de ingressantes encontrada nas bases de dados do Inep - 2010, 2013 e 2014

Tabela 2 - Número de IES no Brasil e Região Sul - 1999, 2009 e 2019......... 74

Tabela 3 - Porcentagem de matrículas por sexo e por grau acadêmico -

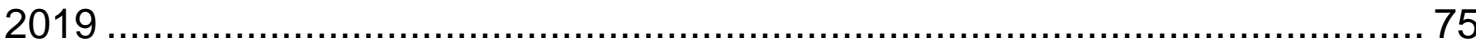

Tabela 4 - Taxa líquida de matrículas, por localidade no Brasil: 2012 -

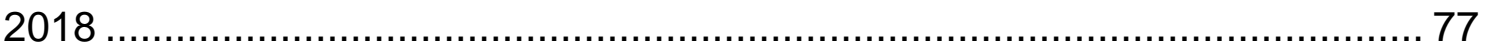

Tabela 5 - Taxa líquida de matrículas por raça/cor no Brasil: 2012 - 2018 ..... 78

Tabela 6 - Número de estudantes e cursos de graduação e pósgraduação por campus - 2019................................................................. 93

Tabela 7 - Cursos e ingressantes do Campus Chapecó - 2010 a 2018 ......... 94

Tabela 8 - Cursos de graduação do Campus Laranjeiras do Sul - 2019 ......... 95

Tabela 9 - Cursos de graduação do Campus Realeza - 2019........................ 95

Tabela 10 - Cursos de graduação do Campus Cerro Largo - 2019.................. 96

Tabela 11 - Cursos de graduação do Campus Erechim - 2019........................ 96

Tabela 12 - Relação entre vagas ofertadas e ocupadas pelo Enem - 2010

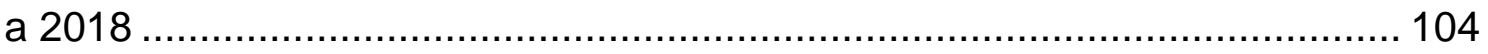

Tabela 13 - Distribuição dos ingressantes, segundo curso/turno/campus -

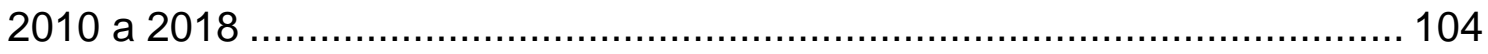

Tabela 14 - Relação candidato/vaga de cursos mais e menos seletivos 2010 e 2018 .

Tabela 15 - Percentual de ingressantes por grandes áreas de conhecimento.

Tabela 16 - Percentual de ingressantes, segundo faixa etária - 2010 a 2018

Tabela 17 - Percentual de ingressantes, segundo sexo - 2010 a $2018 \ldots \ldots \ldots 119$

Tabela 18 - Percentual de ingressantes, segundo raça/cor - 2010 a $2018 \ldots 120$

Tabela 19 - Percentual de ingressantes, segundo ensino médio em escola pública - 2010 a 2018

Tabela 20 - Percentual de ingressantes, segundo intervalo de tempo entre

o Ensino Médio e o Ensino Superior - 2010 a 2018

Tabela 21 - Percentual de ingressantes conforme grupo de Inscrição no

Processo Seletivo da UFFS - 2013 a 2018.

Tabela 22 - Percentual da situação de matrícula em 2019/2 - 2010 a 2018 . 179

Tabela 23 - Descrição da variável dependente de evasão - coortes 2010, 2013 e 2014

Tabela 24 - Descrição da variável dependente de conclusão - coortes 2010, 2013 e 2014

Tabela 25 - Descrição das variáveis independentes - coortes 2010, 2013 e 2014

Tabela 26 - Renda familiar dos ingressantes, segundo sexo e raça/cor 2010, 2013 e 2014 
Tabela 27 - Análise bivariada entre variáveis socioeconômicas, de gênero e raça e variáveis de desfecho - 2010, 2013 e 2014

Tabela 28 - Análise bivariada entre variáveis institucionais e variáveis de desfecho.

Tabela 29 - Variáveis independentes a serem testadas nos modelos 1 e 2 de regressão logística

Tabela 30 - Estimativas ${ }^{A}$ e razão de chance $^{B}$ de modelos finais de regressão logística para estimar a evasão do curso - coortes de 2010, 2013 e 2014

Tabela 31 - Estimativas ${ }^{A}$ e razão de chance ${ }^{B}$ de modelos finais de regressão logística para estimar a conclusão do curso - coortes de 2010 , 2013 e 2014

Tabela 32 - Estimativas (e chances) de modelos de regressão logística para estimar a conclusão do curso 


\section{Lista de figuras}

Figura 1 - Mapa da distribuição espacial dos campi da UFFS nos estados da Região Sul.

Figura 2 - Distribuição de vagas em curso na UFFS, segundo a política de ingresso da UFFS - 2019.2

Figura 3 - Gráfico de bloxplot ............................................................. 217 


\section{Lista de siglas}

CAGED Cadastro Geral de Empregados e Desempregados

CEAGRO Centro de Desenvolvimento Sustentável e Capacitação

Agroecológica

CenSup Censo da Educação Superior

Consuni Conselho Universitário

DINTER Doutorado Interinstitucional

DOE Desigualdade de Oportunidades Educacionais

DRA Diretoria de Registro Acadêmico

EDI Effectively Declining Inequality

EEI Effectively Expanding Inequality

EMI Effectivelly Maintained Inequality

Enade Exame Nacional de Desempenho de Estudantes

Enem Exame Nacional do Ensino Médio

Fetraf-Sul Federação dos Trabalhadores da Agricultura Familiar da

Região Sul

FIES Fundo de Financiamento ao Estudante do Ensino Superior

Fundação Nacional do Índio Fundação Nacional do Índio

GEMAA Grupos de Estudos Multidisciplinar da Ação Afirmativa

IBGE Instituto Brasileiro de Geografia e Estatística

IDH Índice de Desenvolvimento Humano

IES Instituições de Ensino Superior, Instituição de Ensino Superior

IFB Instituto Federal de Educação, Ciência e Tecnologia de Brasília

IFES Instituições Federais de Ensino Superior, Instituições Federais de

Ensino Superior

Incra Instituto Nacional de Colonização e Reforma Agrária

Inep Instituto Nacional de Estudos e Pesquisas Nacionais Anísio Teixeira

ISSP International Social Survey Programme

ITERRA Instituto Técnico de Capacitação e Pesquisa da Reforma

Agrária

LDB Lei de Diretrizes e Bases

MEC Ministério da Educação

MMI Maximally Maintained Inequality, Maximally Maintained Inequality

PBP Programa Bolsa Permanência

PET Programa de Educação Tutorial

PIBIC Programa Institucional de Bolsa de Iniciação Científica

PIBID Programa Institucional de Bolsas de Iniciação à Docência

PIN Programa de Acesso e Permanência dos Povos Indígenas

PNAD Pesquisa Nacinal por Amostra de Domicílios

Pnaes Programa Nacional de Assistência Estudantil

PNE Plano Nacional de Educação

PPIs Pretos, pardos e indígenas

PPV Pesquisa de Padrões de Vida 
PROAE Pró-Reitoria de Assuntos Estudantis

PROEXT Programa de Apoio à Extensão Universitária

PROHAITI Programa de Acesso à Educação Superior da UFFS para

Estudantes Haitianos

Pronacampo Programa Nacional de Educação do Campo

ProUni Programa UNiversidade para Todos

PRP Programa de Residência Pedagógica

RANI Registro Administrativo de Nascimento de Indígena

Reuni Programa de Apoio aos Planos de Reestruturação e Expansão das Universidades Federais

RUs Restaurantes Universitários

SAEB Sistema de Avaliação da Educação Básica

SAEs Setores de Assuntos Estudantis

Sedap Serviço de Acesso a Dados Protegidos

SEPPIR Secretaria Especial de Políticas de Promoção da Igualdade Racial

SGA Sistema de Gestão Integrada

SiSU Sistema de Seleção Unificado, Sistema de Seleção Unificado

SPSS Sistema Statistical Package for Social Sciences

STF Supremo Tribunal Federal

SUS Sistema Único de Saúde

TCLE Termo de Consentimento Livre e Esclarecido

TLE Taxa Longitudinal de Evasão

UERJ Universidade Estadual do Rio de Janeiro

UF Unidade da Federação

UFBA Universidade Federal da Bahia, Universidade Federal da Bahia

UFES Universidade Federal do Espírito Santo

UFF Universidade Federal Fluminense

UFSB Universidade Federal do Sul da Bahia

UFSC Universidade Federal e Santa Catarina

UFSM Universidade Federal de Santa Maria

Unicamp Universidade Estadual de Campinas 


\section{1}

\section{Introdução}

A educação superior desempenha um papel importante para a mobilidade e ascensão social dos indivíduos. Nas últimas décadas, o ensino superior brasileiro vêm passando por muitas transformações, marcadas por um conjunto de políticas educacionais que promoveram a expansão universitária nos segmentos público e privado e a ampliação do acesso e da permanência, a diversificação de estudantes e a interiorização da educação superior pública, a exemplo do Programa de Apoio aos Planos de Reestruturação e Expansão das Universidades Federais (Reuni), do Exame Nacional do Ensino Médio (Enem), do Sistema de Seleção Unificado (SiSU), do Programa Nacional de Assistência Estudantil (Pnaes) e de políticas de ação afirmativa, incluindo a Lei de Cotas (n. 12.711/2012).

Segundo dados do Censo da Educação Superior brasileira, no ano de 1999, o número de matrícula foi de 2.369.945 e o de concluintes de 300.761, passando em 2019, para 8.603.824 e 1.250.076, respectivamente (Inep, 2000; Inep, 2020a), o que indica um crescimento de mais de $200 \%$, tanto de matrículas quanto de concluintes, neste período. A trajetória universitária e sua culminância na conclusão ou na não-conclusão de um curso são marcadas por fenômenos como evasão, retenção e mobilidade dentro de diferentes cursos e instituições.

Em que pese os avanços no acesso e na conclusão do ensino superior que esses dados expressam, o aumento da conclusão da educação básica convive, como mostram Senkevics e Carvalho (2020), com o gargalo no acesso ao Ensino Superior, expressando um deslocamento da seletividade social para a conclusão do ensino médio e para a entrada nas universidades que atinge principalmente os grupos desfavorecidos socioeconomicamente e os negros e indígenas. Segundo os autores, "enquanto para brancos e amarelos a maior dificuldade é ingressar no Ensino Superior, dado que se conclui o Ensino Médio, para os jovens negros e indígenas o principal obstáculo ainda é completar a educação básica” (Senkevics; Carvalho, 2020, p. 340).

Em 2020, entre os jovens brasileiros com idade de 18 a 24 anos, apenas 28,0\% (taxa líquida) estavam cursando ou haviam concluído o ensino superior, sendo que a meta do Plano Nacional de Educação (PNE) para 2024 é de 33\% (InepData, 2021). Segundo dados da Organização para a Cooperação e Desenvolvimento Econômico (OECD, 2021), o Brasil apresentou o maior percentual de jovens de 18 a 24 anos, em 
2020, que não estavam nem estudando e nem trabalhando (35,9\%), próximo apenas do percentual de países como Colômbia $(34,4 \%)$ e Turquia $(32,2 \%)$, também com média acima de 30\%, o que contrasta com a média dos países da OCDE que é de 15,1\%.

A expansão ocorrida nos últimos anos foi acompanhada, assim, da persistência da Desigualdade de Oportunidades Educacionais (DOE), definida por Ribeiro (2009, p. 21) como "o efeito das características, condições e recursos dos pais sobre os resultados educacionais individuais". Destaca-se também o papel que as instituições escolares desempenham na socialização, seleção e até a exclusão dos indivíduos no decorrer do percurso escolar, e sua contribuição para uma maior ou menor estratificação educacional (Valle Silva; Souza, 1986). Além da desigualdade no acesso, estudos mostram também as desigualdades internas, ou horizontais, que se estabelecem na ocupação dos cursos, nos tipos de instituições e/ou grau acadêmico que os estudantes alcançam de acordo com sua origem social (Lucas, 2001; Alon, 2009, Mont’alvão, 2016; Picanço; Morais, 2016, Brito, 2017; Salata, 2018; Carvalhaes; Ribeiro, 2019; Barbosa, 2019; Knop, 2020).

O tema desta pesquisa está relacionado às desigualdades educacionais no acesso e na conclusão de curso superior, em que verificamos como os aspectos relacionados à origem socioeconômica, gênero e raça dos estudantes influenciam a estruturação de oportunidades em diferentes áreas de conhecimento e impactam na conclusão ou evasão do ensino superior. Além da origem socioeconômica, gênero e raça, que são aspectos exógenos na vida dos estudantes, analisamos, também como as características institucionais, ou seja, aspectos relacionados aos diferentes cursos e as políticas de permanência estudantil, influenciam na conclusão ou evasão do ensino superior.

A pesquisa foi realizada por meio de um estudo de caso, tendo como campo empírico uma Instituição de Ensino Superior (IES) pública nova, criada em 2009, no contexto do Reuni: a Universidade Federal da Fronteira Sul (UFFS). Esta Universidade é bastante peculiar por ser multicampus, interestadual, tendo seus campi localizados em municípios de pequeno e médio porte do interior dos três Estados da Região Sul, e que distam até $500 \mathrm{~km}$ entre si e de suas respetivas capitais. A UFFS foi criada originalmente com cinco campi: Chapecó (SC); Laranjeiras do Sul (PR); Realeza (PR); Cerro Largo (RS) e Erechim (RS). Pouco depois, em 2013, foi criado o Campus Passo Fundo (RS), 
para atender ao Programa Mais Médicos ${ }^{1}$ mediante a oferta do curso de Medicina. O recorte temporal desta pesquisa abrange os primeiros 10 anos de funcionamento da UFFS (2009 a 2019), ou seja, uma fase em que o funcionamento pleno da Universidade ocorreu paralelamente à construção e à organização de sua infraestrutura definitiva. $\mathrm{O}$ primeiro processo seletivo de ingresso ocorreu no final de 2009, com o início das atividades letivas em março de 2010.

Atualmente, a UFFS possui em torno de 8.000 estudantes e mais de 40 cursos de graduação, sendo cerca de $50 \%$ na área de licenciaturas, cujo principal turno de oferta é o noturno. Desde o início adotou o Enem como principal forma de ingresso e políticas de ação afirmativa, que resultaram em um perfil discente formado por mais de $90 \%$ dos estudantes originários da escola pública. A reserva de vagas com base na Lei de Cotas ${ }^{2}$ utiliza como referência o percentual de estudantes que cursam o ensino médio em escolas públicas, de acordo com cada Estado. Em 2014, aderiu também ao SiSU, responsável pela seleção de vagas em todo o país a partir da nota do Enem.

Por meio desta pesquisa, buscamos compreender como as desigualdades estruturais de gênero, raça e origem socioeconômica, que atravessam o ensino superior brasileiro, se configuram num cenário de maior inclusão social, como é o caso da UFFS. Um levantamento nacional realizado em 2018 pelo Grupo de Estudos Multidisciplinar da Ação Afirmativa (GEMAA), da Universidade Estadual do Rio de Janeiro (UERJ), sobre a proporção de vagas reservadas nas universidades federais brasileiras mostrou que a UFFS aparece como a IES federal do país com a maior reserva de vagas para estudantes de escola pública, seguida pela Universidade Federal do Sul da Bahia (UFSB). Essas duas IES se destacam pela reserva de vagas acima de $75 \%$ para grupos sociais específicos, enquanto a maioria das instituições destina uma reserva de vagas que oscila entre $51 \%$ e $75 \%$ e, portanto, dentro do que é estipulado pela Lei das Cotas (Freitas et al., 2020). Os dados da UFFS também são confirmados por diversos estudos, como o levantamento anterior do GEMAA, realizado em 2017, por Machado, Bessa \& Feres Júnior (2019), nos estudos nacionais como de Ristoff (2016); Mariano (2016) e

\footnotetext{
${ }^{1}$ O Programa Mais Médicos foi instituído pela Lei n. 12.871, de 22 de outubro de 2013, com a finalidade da formação de recursos humanos na área médica para atuação junto ao Sistema Único de Saúde (SUS). ${ }^{2}$ Lei 12.711, sancionada em agosto de 2012 e implementada a partir de 2013. Prevê a reserva de $50 \%$ das vagas para egressos da escola pública no ensino médio, sendo que a metade deste percentual deve ser reservado para o critério de renda familiar per capita de até 1,5 salários mínimos. E, dentro destes percentuais também devem ser reservadas vagas, de forma proporcional, para autodeclarados pretos, pardos e indígenas.
} 
Santos (2018) e no estudo internacional de McCowan (2019), autores que reconhecem aspectos de inclusão social desta Instituição ${ }^{3}$.

Diversos estudos têm apontado lacunas em relação a pesquisas com dados longitudinais que permitam investigar a estratificação social no ensino superior e suas dinâmicas de gênero, raça e origem socioeconômica nas carreiras universitárias e na conclusão dos cursos (Carvalhaes; Ribeiro, 2019; Knop, 2020; Lima; Campos, 2020; Costa; Picanço, 2020). Senkevics \& Mello (2019) também ressaltam a importância de estudos mais específicos que possam acompanhar a implementação da Lei de Cotas e seus impactos ao longo do tempo.

Na UFFS, por meio de dados longitudinais dos ingressantes no período entre 2010 e 2018, investigamos: o perfil socioeconômico ao longo do tempo; a distribuição dos estudantes nos diferentes cursos, em termos de gênero e raça; e, ainda, como as características socioeconômicas, institucionais e de desempenho impactam nos desfechos dos ingressantes. Buscamos, ainda, estabelecer relações entre o perfil dos estudantes e suas mudanças ao longo do tempo com as diferentes políticas de acesso e suas formas de implementação, tais como bonificação de escola pública, Lei de Cotas e SiSU.

O desempenho neste estudo será analisado por meio de nota de redação no Enem, utilizada para o acesso e notas relativas ao rendimento acadêmico no decorrer do curso. Os desfechos serão verificados a partir da situação de matrícula no segundo semestre de 2019. Entendemos os "desfechos" no sentido dado ao termo por Costa \& Picanço (2020), que consideraram a situação de matrícula de uma coorte de ingressantes verificada em um determinado período de tempo após o acesso (transcorrido o tempo mínimo de integralização do curso). Embora as motivações sejam inúmeras, a evasão é entendida como um desfecho não desejado e a permanência e a conclusão como uma trajetória bem-sucedida.

Nessa perspectiva, o estudo de Fritsch, Jacobus \& Vitelli (2020) analisou o desempenho, em 2015, de uma coorte de ingressantes em 2010, em todas as Instituições de Ensino Superior (IES) brasileiras, públicas e privadas. Os resultados mostraram que,

\footnotetext{
${ }^{3}$ Em 2014, a UFFS conquistou o prêmio: "Guia do Estudante - Destaques de 2014", na categoria inclusão, com o projeto "Política de Ingresso na Graduação", com a garantia de 90\% de estudantes de escola pública. A premiação fez parte dos "Prêmios Santander Universidades" que teve o objetivo de "reconhecer as instituições de ensino superior que mais se destacaram no período de julho de 2013 a junho de 2014" (UFFS, 2014a).
} 
ao final de seis anos, apenas 37,10\% dos ingressantes concluíram a graduação e cerca de $50 \%$ desistiram. As maiores diferenças ocorrem em relação à desistência acumulada dos ingressantes entre 2010 e 2015, entre IES públicas e privadas, 44,43\% e 58,26\%, respectivamente. Já, a conclusão dos cursos ocorre de modo semelhante, ainda que com percentual ligeiramente superior nas IES públicas $(37,61 \%)$, em relação às IES privadas $(34,54 \%)$.

Em geral, os estudos vêm mostrando que a evasão ocorre principalmente nos primeiros anos a partir do ingresso na Universidade (Li; Chagas, 2017; Adachi, 2017; Ferrão; Almeida, 2018). De acordo com estudo de Ristoff (2021), realizado com dados do SiSU, em média, $35 \%$ dos estudantes evadem no primeiro ano e $45 \%$ no segundo ano. Ao analisar dados do Censo da Educação Superior entre 1991 a 2019, o autor sinaliza que, nestes 29 anos, em média se formaram $51 \%$ dos ingressantes no ensino superior.

Neste estudo, além da literatura sociológica da estratificação educacional, realizamos também uma aproximação com a concepção da interseccionalidade, no sentido da articulação de diferentes marcadores sociais de diferença, como gênero e raça, na configuração das desigualdades. Para compreender os desfechos de conclusão e evasão de curso, mobilizamos também um conjunto de estudos empíricos que chamam a atenção para o papel institucional desempenhado pelas políticas e interações estabelecidas com os estudantes e que fomentam a sua permanência (Ferrão; Almeida, 2018; Heringer, 2020a), além de fatores como as características socioeconômicas dos estudantes.

Considera-se, portanto que o inédito desta pesquisa é seu foco no acesso, evasão e conclusão do ensino superior, por meio de um estudo longitudinal em uma IES bastante peculiar como é o caso da UFFS, com potencial de contribuição para o tema da desigualdade de oportunidades educacionais. Nesta perspectiva, o objetivo principal desta pesquisa é: investigar as relações entre gênero, raça e características socioeconômicas dos estudantes, aspectos institucionais e desempenho no acesso e na conclusão de curso no contexto da UFFS. E, buscamos responder as seguintes questões:

a) Quais foram as principais mudanças institucionais ocorridas ao longo do tempo em termos de políticas de acesso, oferta de vagas e seletividade dos cursos? 
b) Como se caracteriza o perfil socioeconômico e de gênero e raça dos ingressantes ao longo do tempo e sua relação com as diferentes políticas de acesso, como bônus, Lei de Cotas e SISU?

c) Como se configuram as desigualdades de gênero e raça no acesso aos cursos, ao longo do tempo?

d) Como as características socioeconômicas, gênero, raça, desempenho e aspectos institucionais impactam no "desfecho" (conclusão ou evasão de curso) dos estudantes?

Consideramos, ainda que a originalidade desta pesquisa está na análise de como as desigualdades se configuram e são enfrentadas e/ou mitigadas a partir de uma experiência universitária que se configura como mais inclusiva, como é o caso da UFFS, além do seu recorte temporal, em que busca caracterizar mudanças institucionais e no perfil dos estudantes ao longo do tempo e aspectos relacionados a suas trajetórias, como desempenho e desfechos (conclusão e evasão).

Portanto, a presente tese, incluindo esta Introdução (capítulo 1), encontra-se estruturada em dez capítulos.

No capítulo 2 apresentamos o desenho da pesquisa, que compreende o estudo de caso sobre a UFFS, a partir de dados longitudinais e que combina estratégias de análises qualitativas (documentos institucionais) e quantitativas (bases de dados secundários da UFFS e do Inep). Detalhamos os procedimentos de coleta de dados e as análises realizadas para atender aos objetivos e questões de pesquisa.

O capítulo 3 apresenta uma reflexão teórica sob o olhar da Sociologia da Educação sobre desigualdade de oportunidades no ensino superior. A partir de uma revisão de literatura, situamos os avanços e lacunas das principais teorias sociológicas na agenda da estratificação educacional, buscando uma aproximação com a presente investigação na UFFS.

O capítulo 4 traça um panorama da recente expansão e interiorização do acesso ao ensino superior brasileiro e das principais políticas e programas implementados, de forma a contribuir para o enfrentamento das desigualdades educacionais ainda persistentes nesta etapa de ensino. Neste contexto situamos, também, o processo de criação da UFFS.

No capítulo 5 apresentamos uma contextualização sobre as principais características da Instituição estudada e o perfil discente ao longo dos anos, 
considerando as mudanças institucionais, principalmente com relação às diferentes políticas de acesso e ações afirmativas da UFFS.

O capítulo 6 versa sobre as dinâmicas e configurações da desigualdade estrutural de raça e de gênero na UFFS, principalmente no acesso e na ocupação dos cursos. Neste capítulo realizamos uma aproximação com a literatura da interseccionalidade e ao final do capítulo traçamos os principais resultados desta análise, e uma articulação desta análise com os capítulos relacionados aos desfechos.

No capítulo 7 realizamos um levantamento de estudos empíricos, especialmente aqueles que se utilizaram de metodologias quantitativas, acerca dos principais conceitos e fatores associados aos desfechos de evasão e conclusão no ensino superior. Nesta literatura, buscamos uma aproximação com os estudos de estratificação educacional e outros estudos que nos possibilitam novas chaves de leitura para comprender a multidimensionalidade que envolve, por exemplo, o fenômeno da evasão.

No capítulo 8 analisamos a dimensão do desfecho (evasão e conclusão de curso), do ponto de vista das características socioeconômicas dos estudantes, gênero, raça, aspectos institucionais e dos cursos, além de desempenho na redação do Enem. Inicialmente contextualizamos a situação de matrícula, em 2019/2 de todas as coortes de ingressantes por meio do Enem. Em seguida realizamos uma análise descritiva e análises bivariadas das variáveis dependentes e independentes e análises inferenciais a partir da técnica de regressão logística sobre as chances de evasão e de conclusão de curso. Tomamos como referência para esta análise apenas as coortes de ingressantes em 2010, 2013 e 2014. Ao longo do capítulo estabelecemos aproximações dos resultados com a literatura e ao final tecemos os principais achados desta análise.

No capítulo 9, realizamos uma análise complementar ao capítulo 8 , sobre desfecho de conclusão de curso, tendo por base apenas a coorte de ingressantes em 2013, e com o acréscimo de variáveis de desempenho, medido por meio da média de notas dos estudantes a partir do seu ingresso.

E, por último, no capítulo 10 sintetizamos os principais resultados e contribuições desta pesquisa, bem como algumas limitações e sugestões para pesquisas futuras. Os resultados desta pesquisa, tomando como estudo de caso a UFFS, assinalam para tendências de democratização do acesso e da permanência no ensino superior, tomando como referência as políticas mais recentes voltadas para a expansão e interiorização da educação superior pública, como o Pnaes e a Lei de Cotas. De modo 
mais específico, destacamos a forma como essa Lei de Cotas foi implementada na UFFS, de forma a manter um alto percentual de estudantes egressos da escola pública e um aumento no acesso de estudantes pretos, pardos e indígenas em todas as áreas do conhecimento, inclusive nas mais seletivas, como saúde e engenharias. Além disso, ressaltamos a significativa presença de estudantes da origem rural, cujos pais possuem baixa escolaridade e renda. Em termos de evasão e de conclusão de curso, os principais resultados mostraram que estudantes com mais idade e homens negros apresentaram menos chances de permanência e de conclusão nos cursos e, estudantes da zona rural apresentaram maior persistência, quando comparados com os da zona urbana. Por sua vez, as características intitucionais possuem um peso maior nos desfechos como evasão e conclusão dos cursos, principalmente quando envolvem o recebimento pelos estudantes de alguma modalidade de assistência estudantil e a participação em atividades extracurriculares, que ampliam a permanência e aumentam as chances da concusão do curso. Por último, destacamos o desempenho, medido pelo rendimento acadêmico a partir do ingresso, como um fator associado à evasão e à conclusão de curso. A reprovação também se mostrou uma questão relevante, pois atinge a maioria dos estudantes da UFFS e suscita a necessidade de políticas institucionais específicas de caráter interseccional voltadas para o enfrentamento das diferenças de idade, gênero e raça dos estudantes, mas também para a ampliação da permanência dos estudantes de um modo geral. 


\section{2 \\ Desenho da pesquisa}

O desenho da pesquisa combina métodos qualitativos (análise de documentos intitucionais) e quantitativos (análise de bases de dados secundários) e examina o caso da Universidade Federal da Fronteira Sul (UFFS), com o objetivo de investigar as relações entre gênero, raça e características socioeconômicas dos estudantes e aspectos institucionais no acesso e na conclusão de curso. A unidade de análise é o estudante que ingressou pelo Enem no período entre 2010 e 2018.

De acordo com John Gerring (2019), um estudo de caso se define como a análise intensiva de um fenômeno espacialmente delimitado, que pode ter componentes qualitativos e quantitativos. Conforme o autor, o estudo de caso pode se utilizar de evidências transversais a múltiplos casos para originar inferências causais e análises longitudinais, ou pode dirigir seu foco para um único caso e para suas variações ao longo do tempo.

A escolha do caso da UFFS se justifica pelas suas políticas de acesso diferenciadas, que a situam como a universidade federal brasileira com o maior percentual de egressos de escola pública entre seus estudantes. Além disso, trata-se de uma IES nova, interestadual e multicampi, cujos campi estão localizados no interior dos três Estados da Região Sul.

O estudo envolve o uso de diferentes bases de dados e de diferentes variáveis, além da análise de documentos institucionais. A análise dos dados qualitativos é de cunho documental e foi realizada a partir da coleta de documentos intitucionais (leis, editais, resoluções e portarias) e teve o propósito de contextualizar a IES estudada em termos da sua criação, localização e características dos cursos, da comunidade acadêmica e das políticas de acesso e de permanência.

A análise dos dados quantitativos foi realizada por meio de estatística descritiva e inferencial de duas dimensões de análise, envolvendo o acesso e o desfecho dos ingressantes. A dimensão de acesso analisa o perfil socioeconômico dos ingressantes ao longo do tempo e sua inserção nas diferentes áreas de conhecimento, considerando aspectos como de gênero e raça/cor. A dimensão desfecho analisa principalmente a situação de evasão ou conclusão de curso, verificada com base na situação de matrícula dos ingressantes, em 2019/2, após um período determinado de tempo. Mais especificamente, a partir de dados longitudinais dos ingressantes na UFFS entre 2010 e 
2018 foi possível acompanhar a integralização da carga horária do curso para as primeiras coortes de estudantes.

\subsection{Análises realizadas}

Para alcançar o objetivo geral e responder às principais questões desta pesquisa, definimos quatro objetivos secundários e em cada um deles mobilizamos referenciais teóricos e metodologias específicas, conforme detalhamento a seguir:

Objetivo 1: Mapear as principais características da UFFS e as mudanças ocorridas ao longo do tempo em relação aos seguintes aspectos: políticas de acesso e permanência; oferta de vagas e seletividade dos cursos de graduação, levando em conta as mudanças institucionais. As fontes utilizadas para atender a este objetivo são documentos institucionais da UFFS, tais como resoluções; portarias; editais, relatórios e outras informações institucionais coletadas no site da universidade. As análises realizadas são de natureza descritiva e se destinam a apresentar um panorama da UFFS, em termos de número de cursos, estudantes, servidores, ocupação e oferta de vagas nos cursos ao longo do tempo, aspectos relacionados ao currículo e às políticas de acesso e de permanência.

Objetivo 2: Mapear o perfil socioeconômico e de gênero e raça dos ingressantes observando as mudanças ocorridas ao longo do tempo e sua relação com as políticas de acesso, como bônus, Lei de Cotas e SiSU. Para este objetivo utilizamos bases de dados da UFFS, relativas ao período 2010 - 2018. As análises são descritivas, e envolvem frequências e análises bivariadas para compreender as variações no perfil dos ingressantes ao longo do tempo e possíveis relações com as políticas de acesso implementadas no período estudado. Os estudos relativos aos objetivos 1 e 2 são apresentados conjuntamente no capítulo 5.

Objetivo 3: Caracterizar como se configuram as desigualdades de gênero e raça no acesso aos cursos, ao longo do tempo. Para atender a este objetivo, que compõe o Capítulo 6, foi utilizada uma base de dados da UFFS referente ao período de 2010 a 2018, cujas variáveis sexo e raça/cor foram agregadas em apenas uma variável, denominada "sexo_raça". As análises são descritivas, realizadas por meio de frequências e análises bivariadas, envolvendo essa dimensão de gênero e raça.

Objetivo 4: Analisar as relações entre características socioeconômicas, gênero, raça, desempenho e aspectos institucionais e o "desfecho" (conclusão ou evasão de 
curso) dos estudantes. Para responder a este objetivo dividimos a análise em dois capítulos (8 e 9). No capítulo 8 utilizamos três bases de dados: a base da UFFS e duas bases do Inep (Enem e CenSup) e realizamos análises descritivas de frequências das variáveis selecionadas, análises bivariadas entre variáveis dependentes e independentes e regressões logísticas para verificar características que impactam nas chances de evasão e conclusão de curso.

O estudo dos desfechos dos ingressantes utiliza inicialmente a base de dados da UFFS em análises descritivas sobre a situação de matrícula em 2019/2 de todas as coortes de ingressantes entre 2010 e 2018. Para estimar os efeitos das variáveis explicativas nas chances de evasão e conclusão de curso, foram selecionadas apenas três coortes de ingressantes: 2010, 2013 e 2014. Como a situação de desfecho observada se refere ao segundo semestre de 2019, nestas três coortes é possível verificar a integralização da carga horária dos cursos de todos os ingressantes, exceto, da turma que ingressou em 2014/2 no curso de Medicina, cuja integralização só ocorre a partir de 2020/1. Ao tomar como referência a situação de matrícula em 2019/2, foi possível abranger um período de quase dez anos desde o ingresso da primeira coorte; um período de sete anos para a coorte de 2013 e de seis anos para a coorte de 2014. Justifica-se, ainda, o recorte dessas coortes de ingressantes pelos seguintes motivos:

- 2010: refere-se à primeira coorte de ingressantes na UFFS e a um dos anos em que foi utilizada na política de ingresso a bonificação da escola pública, juntamente com a nota do Enem. Para cada ano do ensino médio cursado na escola pública foi acrescentada uma pontuação de $10 \%$ na nota do Enem.

- 2013: foi o primeiro ano de ingresso, a partir da mudança na política de ingresso e adesão à Lei de Cotas, em que foi utilizada como referência para a reserva de vagas o mesmo percentual de estudantes egressos do ensino médio público do Censo da Educação Básica de cada Estado. Além disso, a nova política previu uma reserva de vaga específica para estudantes egressos parcialmente do ensino médio público. O ano de 2013 também se justifica por ser o ano em que foi criado o Campus Passo Fundo que, em 2019/2, já teria completado o tempo de integralização da primeira turma do curso de Medicina sediado neste Campus. A partir desse ano observaram-se mudanças no perfil dos estudantes, principalmente em termos de diversificação racial. 
- 2014: foi o primeiro ano de adesão da UFFS ao SiSU na seleção dos estudantes, que até o ano de 2013 utilizava processos seletivos próprios. A adesão ao SiSU também foi um fator de mudanças no perfil universitário, principalmente pelo aumento de ingressantes de outros Estados do país.

Após a integração dessas bases foram realizadas análises descritivas das frequências de variáveis dependentes (também chamadas de variáveis de resposta) e independentes (variáveis explicativas) para as três coortes (Agresti; Finlay, 2012). Nesta etapa da análise, as variáveis de desfecho foram transformadas em variáveis binárias: evasão ("evadiu” ou "não evadiu”) e conclusão ("concluiu" ou "não concluiu”), de modo a caracterizar o desfecho dos estudantes em 2019/2, quando foi verificada sua situação de matrícula. Trata-se de dois grupos de estudantes: o grupo de estudantes que não concluiu, formado por aqueles que evadiram e/ou continuaram com a matrícula ativa, mesmo após o tempo necessário para integralização de carga horária do respectivo curso; e o grupo de estudantes que não evadiu e é formado por aqueles que concluíram ou que continuam com a matrícula ativa.

As variáveis independentes foram divididas em dois blocos: características socioeconômicas e desempenho no Enem ("sexo"; "raça/cor"; "faixa etária"; "renda familiar"; "escolaridade da mãe"; "localização da moradia"; "condição de trabalho"; "escola pública" e "nota da redação no Enem"), e aspectos institucionais e do curso ("campus"; "área de conhecimento"; "retorno econômico"; "turno"; "grau acadêmico"; “apoio social" e "atividade extracurricular").

Em seguida, foram realizadas análises bivariadas entre variáveis dependentes e independentes para verificar o comportamento destas últimas individualmente em relação às variáveis dependentes evasão e conclusão. Por último, realizamos análises multivariadas, por meio de regressões logísticas, para verificar o impacto dessas variáveis nas chances de evasão e conclusão dos cursos pelos estudantes.

A regressão logística é utilizada para variáveis de respostas binárias, ou seja, a variável dependente (y), também é dicotômica e assume duas categorias 0 e 1, expressas por fracasso e sucesso 4 ("não evadiu ou evadiu" e "não concluiu ou concluiu", respectivamente), de modo a permitir estimar a probabilidade associada à ocorrência ou

\footnotetext{
${ }^{4}$ Sucesso representa o resultado de interesse e o outro resultado é representado por fracasso. Conforme Agresti e Finlay (2012, p.266) "a chance de sucesso é definida como: Chance = Probabilidade de sucesso/Probabilidade de fracasso. Se a probabilidade de sucesso $=0,75$, então a probabilidade de fracasso é igual $1-0,75=0,25$ e a chance de sucesso $=0,75 / 0,25=3,0$ ".
} 
não desses eventos em face de um conjunto de variáveis explicativas (Power; Xie, 2000; Agresti; Finlay, 2012). O resultado desta regressão é fornecido em logaritmo da razão de chance (odds ratios), sendo então necessária uma conversão (calcular o log natural por meio do exponencial dos coeficientes do modelo) para obter as chances de o evento acontecer e de o evento não acontecer para diferentes grupos. As razões de chance podem ser lidas em termos percentuais a partir da aplicação da seguinte fórmula ${ }^{5}$ (Power; Xie, 2000):

$$
[\exp (b)-1]^{*} 100
$$

Em relação a este mesmo objetivo, organizamos um capítulo complementar (Capítulo 9), desenvolvido em momento posterior ${ }^{6}$, com a finalidade de inserir também variáveis de desempenho acadêmico dos ingressantes, no decorrer da graduação. Selecionamos apenas a coorte de ingressantes em 2013 na base de dados principal da UFFS, e agregamos informações socioeconômicas obtidas a partir de respostas de estudantes a um questionário socioeconômico e cultural aplicado pela instituição no Processo Seletivo de Ingresso, em 2013, e informações sobre o apoio social (assistência estudantil) recebido por estes estudantes ao longo dos anos, obtidos junto à Pró-Reitoria de Assuntos Estudantis. Como desempenho acadêmico dos estudantes, consideramos as notas obtidas em todas as disciplinas cursadas a partir do ingresso em 2013 até o período máximo de 2019.1 e a soma de reprovações registradas neste período. Estudos desta natureza também foram realizados por Baccaro e Sinyashiki (2014); Rotem, Yair e Shustak (2020) e De Paula (2021). A partir das notas em todas as disciplinas cursadas foi criada uma variável com a média aritmética simples para cada estudante e uma variável com a soma de reprovações. Os dados foram fornecidos pela Diretoria de Registro Acadêmico (DRA), junto à Pró-Reitoria de Graduação.

Nesse capítulo foram realizadas análises descritivas, buscando explorar novas variáveis de rendimento acadêmico e de reprovações e uma análise inferencial, a partir da técnica de regressão logística, para estimar os efeitos de características socioeconômicas, de desempenho e de aspectos institucionais nas chances de conclusão de curso. Maiores detalhamentos sobre a base de dados e as variáveis utilizadas foram explicitadas no capítulo 9.

\footnotetext{
${ }^{5} \mathrm{O}$ “exp (b)" é o exponencial do Beta.

${ }^{6}$ Este capítulo foi construído a partir da indicação da Qualificação II e em momento posterior ao acesso de dados do Inep, que foram acessados diretamente na sala segura da Sedap/Inep. Por isso, foi construído apenas com bases de dados da UFFS, com recorte para o ano de 2013 e a partir de dados socioeconômicos obtidos por questionário socioeconômico do Processo Seletivo da UFFS.
} 


\subsection{Base de dados utilizadas e tratamento dos dados}

Nesta pesquisa utilizamos três bases de dados relacionadas aos ingressantes na UFFS no período entre 2010 e 2018: dados administrativos e socioeconômicos fornecidos pela UFFS, dados do Enem e do Censo da Educação Superior (CenSup) fornecidos pelo Instituto Nacional de Estudos e Pesquisas Nacionais Anísio Teixeira (Inep).

\subsubsection{Base de dados da UFFS}

Esta base de dados é oriunda do Sistema de Gestão Acadêmica (SGA) e contempla informações acadêmicas e institucionais, como situação de matrícula; curso; turno; campus; e sociodemográficas, como sexo; raça/cor, escola pública e idade dos ingressantes na UFFS entre 2010 e 2018. Os dados foram solicitados formalmente e fornecidos pelas Diretorias de Sistemas de Informação e de Registro Acadêmico ${ }^{7}$ da UFFS. A planilha original continha 21.750 estudantes, dos quais foram excluídos 62 que estavam duplicados ${ }^{8} 450$ que estavam vinculados a cursos que foram extintos ${ }^{9} \mathrm{e}$ cujas matrículas foram aditadas ${ }^{10}$ para novos cursos criados. A exclusão ocorreu para aqueles que evadiram dos cursos extintos antes do processo de adição ao novo curso. Considerando as exclusões e todas as formas de ingresso a base ficou com 21.238

\footnotetext{
$7 \mathrm{O}$ banco de dados foi fornecido mediante a assinatura de um Termo de Responsabilidade, com base na Lei de Acesso à Informação (n. 12.527/2011), mantendo o anonimato dos estudantes (Anexo 1).

8 Partiu-se do critério de que um aluno não poderia ocupar duas vagas ao mesmo tempo num mesmo semestre. A exclusão foi realizada por meio da verificação da situação de matrícula excluindo a matrícula no curso em que o aluno estava com desistência formalizada, mantido o outro curso ou o mesmo, apenas em turno diferente. Isso ocorre pela escolha entre duas opções de curso e muitas vezes o aluno é chamado para assumir curso de segunda opção, e, logo em seguida, é chamado para assumir vaga em curso de primeira opção. Ou, matricula-se por uma forma de ingresso, por exemplo (processo seletivo especial) e depois é chamado para assumir uma vaga pelo processo regular do Enem, ou vice-versa.

9 Destes estudantes, 24 eram do Curso de Desenvolvimento Rural e Gestão Agroindustrial (2010-2011), de Laranjeiras do Sul, que foi extinto e, em seu lugar foi criado o Curso de Ciências Econômicas; 27 eram do Curso de Desenvolvimento Rural e Gestão Agroindustrial (2010 e 2011), de Cerro Largo, que foi extinto e, em seu lugar foi criado o Curso de Administração; 228 eram do Curso de Ciências: Biologia, Física e Química (2010, 2011 e 2012), de Cerro Largo, que foi extinto e, em seu lugar foram criados três cursos: Ciências Biológicas; Química e Física; e 171 eram do Curso de Ciências: Biologia, Física e Química (2011 e 2012), de Realeza, que foi extinto e, em seu lugar foram criados os Cursos: Ciências Biológicas; Química e Física. Neste caso, os estudantes puderam optar em se formar em Ciências Naturais ou aditar sua matrícula para os novos cursos. Por ter 12 ingressantes de 2010 que concluíram o curso em Ciências Naturais, este curso foi mantido na base e apenas para o ano de 2010.

10 Ocorreu neste caso a criação de um ou mais novos cursos. O aditamento significa que os alunos tiveram sua matrícula aditada para este novo curso, como se ele tivesse ingressado desde o início de sua matrícula na Universidade neste curso.
} 
estudantes. O Gráfico 1 apresenta a distribuição desses estudantes conforme o modo de ingresso ao longo dos anos.

Gráfico 1 - Percentual de ingressantes, segundo modo de ingresso - 2010 a 2018

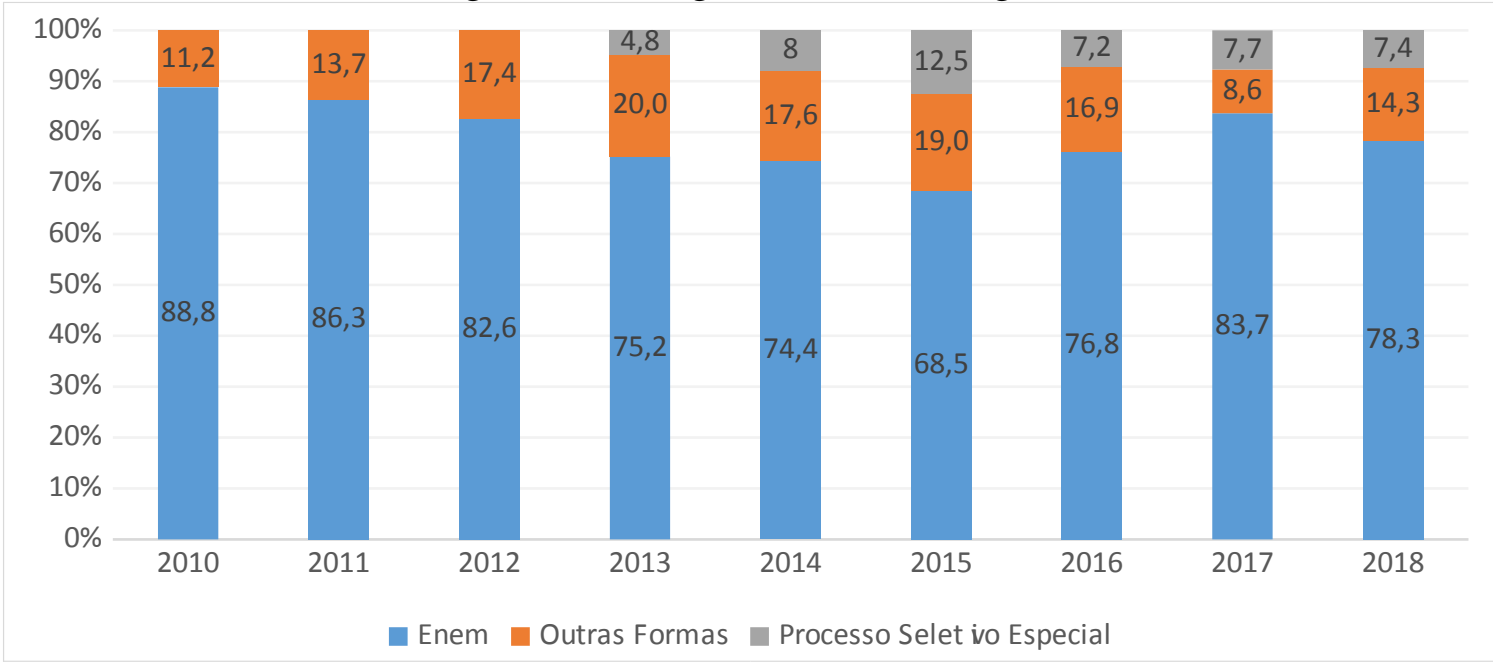

Fonte: Elaboração própria, a partir da base de dados do SGA/UFFS

O recorte desse estudo foi apenas para ingressantes pelo Enem, que corresponde a principal forma de acesso na UFFS, totalizando 16.778 estudantes, em média $79 \%$ das matrículas ao longo dos nove anos. Justifica-se essa escolha pela possibilidade de cruzamento com outras bases, a exemplo do Enem.

Os processos seletivos especiais ocorrem para o atendimento de programas com públicos específicos, como é o caso dos povos indígenas, imigrantes haitianos e filhos de agricultores, e contam com editais e provas específicas, conforme cada tipo de programa. E, as outras formas de ingresso correspondem ao acesso por meio de transferências internas e externas, retorno de aluno em situação de abandono e graduado. Esse processo ocorre por meio de edital específico, a partir de vagas que deixam de ser preenchidas pelo principal processo seletivo (Enem).

\subsubsection{Bases de dados do Inep}

Para fins de complementar a base de dados da UFFS, e tendo o estudante como unidade de análise, buscou-se o acesso junto ao Inep a bases de dados do Enem (2009 a 2017) e do CenSup (2010 a 2018). Estas bases de dados foram integradas à base da UFFS por meio de chaves de ligação, como o CPF e outras específicas fornecidas pelo Inep. Esta parte da pesquisa foi realizada na sala segura do Serviço de Acesso a Dados 
Protegidos $^{11}$ (Sedap), no Inep. A solicitação de uso dos dados foi encaminhada e deferida por meio do Processo n. 23036.001068/2020-56 (Anexo 2), de acordo com a norma do Serviço de Acesso a Dados Protegidos ${ }^{12}$. Para esta finalidade foi necessário também a submissão e aprovação desta pesquisa junto à Câmara de Ética em Pesquisa da PUC-Rio (Parecer n. 110/2019) e a aprovação de pedido de dispensa do Termo de Consentimento Livre e Esclarecido (TCLE), conforme consta no Anexo 3.

A base de dados do Enem contempla informações preenchidas por estudantes no momento da inscrição para a realização deste exame, cuja nota é utilizada para o ingresso na UFFS. Além de dados da inscrição, essa base também contempla dados pessoais, escolares e notas da prova, divididas por áreas de conhecimento, e da redação, além de dados socioeconômicos (renda familiar, escolaridade dos pais, situação de trabalho, acesso a determinados bens), obtidos a partir de um questionário preenchido pelos estudantes. O Enem é um exame nacional em larga escala aplicado todos os anos, para avaliar o desempenho escolar de estudantes concluintes do Ensino Médio. O exame também é realizado por egressos do ensino médio e, a partir de 2009, passou a ser utilizado como um mecanismo de seleção de ingressantes no ensino superior público, sendo utilizado também nas IES privadas.

Conforme já mencionado, optamos pelo recorte destas bases do Inep apenas para três coortes de ingressantes na UFFS (2010, 2013 e 2014). O processo seletivo principal de ingresso na UFFS, neste período, ocorria por meio da nota do Enem, tendo como referência o ano imediatamente anterior ao ingresso, ou até dois anos antes. Por isso, usamos como referência as bases de 2009 (para ingressantes em 2010); as bases de 2011 e 2012 (para ingressantes em 2013) e de 2013 (para ingressantes em 2014). Para os ingressantes na UFFS em 2013, que haviam realizado o Enem nos dois anos anteriores, optou-se por considerar os dados do ano mais recente. A base de dados da UFFS possuía um total de 5.550 ingressantes nestas três coortes, sendo localizados nas bases de dados do Enem 5.252 destes ingressantes $(94,6 \%)$ e 5.274 estudantes $(95,0 \%)$ nas bases do CenSup, conforme especificado na Tabela 1.

\footnotetext{
${ }^{11}$ Este trabalho contou com o apoio de uma pesquisadora auxiliar: Dra. Karina Carrasqueira Lopes (PUCRio). O período de realização desta parte da pesquisa foi de 15 a 25 de setembro de 2020.

${ }^{12}$ Portaria do Inep n. 637, de 17 de julho de 2019.
} 
Tabela 1 - Quantidade de ingressantes encontrada nas bases de dados do Inep - 2010, 2013 e 2014

\begin{tabular}{llllll}
\hline Ano & Ingressantes na UFFS & Enem & \% & CenSup & \% \\
\hline 2010 & 1.852 & 1.787 & 96,6 & 1.764 & 95,2 \\
2013 & 1.882 & 1.752 & 93,1 & 1.791 & 95,2 \\
2014 & 1.816 & 1.713 & 94,3 & 1.719 & 94,6 \\
Total & 5.550 & 5.252 & 94,6 & 5.274 & 95,0 \\
\hline Fonte:
\end{tabular}

Fonte: Elaboração própria, a partir das bases de dados do SGA/UFFS e do Inep (Enem e CenSup)

As bases de dados do CenSup também foram integradas aos dados da UFFS. O Censo da Educação Superior é coletado anualmente e preenchido pelas IES. Para esta pesquisa foram utilizadas apenas informações referentes ao módulo "aluno ${ }^{13}$ ". Nas IES a coleta de dados do censo é realizada por pesquisadores institucionais (PIs), por meio do sistema e-MEC. O tratamento, validação e divulgação deste censo é de responsabilidade do Inep.

O CenSup possui informações sobre as IES públicas e privadas, suas diferentes formas de organização administrativa, seus cursos, vagas oferecidas, número de matrículas, ingressantes, concluintes e dados acadêmicos. Do módulo "aluno" foram extraídas informações apenas sobre a situação de matrícula anual dos estudantes das três coortes (2010, 2013 e 2014) a partir do seu ingresso até o ano de 2019, informações sobre a participação dos estudantes em programas de apoio social (auxílios de moradia, alimentação, transporte e bolsa permanência) e em atividades extracurriculares (pesquisa, estágio, monitoria, extensão). Foi considerado apenas se o estudante foi atendido por alguma modalidade de apoio social e/ou participou de alguma atividade extracurricular (com ou sem bolsa) em algum momento de sua graduação, sem discriminação quanto ao tipo de atividade, valor recebido e/ou tempo de recebimento.

Por fim, após a integração das bases de dados, foram organizadas três bases, uma para cada coorte de ingressantes e os procedimentos de análise estatística foram realizados por meio do software Statistical Package for Social Sciences (SPSS) e software Excel.

\subsection{Descrição das variáveis}

A partir das características das bases de dados disponíveis para este estudo e, tendo como referência estudos semelhantes, como de Pedrosa et al. (2006); Sales Junior

${ }^{13}$ O CenSup conta também com outros módulos como "curso", "docente", "IES". 
et al. (2016); Costa (2018), Knop (2020); Costa \& Picanço (2020) e Rotem; Yair \& Shustak (2020), selecionamos variáveis que apresentavam características institucionais e socioeconômicas dos ingressantes. O Quadro 1 apresenta as variáveis usadas nesta pesquisa, seu respectivo banco de dados de origem e as transformações realizadas em cada uma delas.

Quadro 1 - Descrição de variáveis utilizadas na pesquisa

\begin{tabular}{|c|c|c|c|}
\hline Variável & Categorias & Base & Observações \\
\hline Sexo & $\begin{array}{l}\text { Masculino } \\
\text { Feminino }\end{array}$ & UFFS & \\
\hline Faixa etária & $\begin{array}{l}17 \text { a } 20 \text { anos } \\
21 \text { a } 24 \text { anos } \\
25 \text { a } 30 \text { anos } \\
31 \text { anos ou mais }\end{array}$ & UFFS & $\begin{array}{l}\text { A variável foi criada a partir da data de } \\
\text { nascimento do ingressante e representa a } \\
\text { idade de ingresso na UFFS. Nas regressões } \\
\text { logísticas as duas últimas categorias foram } \\
\text { agrupadas em apenas uma " } 25 \text { anos ou } \\
\text { mais". }\end{array}$ \\
\hline Raça_cor & $\begin{array}{l}\text { Branca } \\
\text { Parda } \\
\text { Preta } \\
\text { Indígena } \\
\text { Amarela } \\
\text { Não Declarada }\end{array}$ & UFFS & $\begin{array}{l}\text { Nas análises de regressão logística esta } \\
\text { variável foi recodificada apenas para dois } \\
\text { grupos: "brancos e amarelos"; e, "pretos, } \\
\text { pardos e indígenas", excluindo-se os "não } \\
\text { declarados". Essa união se justifica pelo } \\
\text { número reduzido de autodeclarados } \\
\text { amarelos, pretos e indígenas. }\end{array}$ \\
\hline Sexo_raça & $\begin{array}{l}\text { Homem branco } \\
\text { Homem negro } \\
\text { Homem outros } \\
\text { Mulher branca } \\
\text { Mulher negra } \\
\text { Mulher outros }\end{array}$ & UFFS & $\begin{array}{l}\text { Esta variável foi criada a partir da junção } \\
\text { das variáveis sexo e raça/cor. A categoria } \\
\text { "negro" inclui "pretos e pardos" e a } \\
\text { categoria de "outros" inclui os } \\
\text { "indígenas", "amarelos", e a categoria } \\
\text { "não declarada". } \\
\text { Na análise de regressão logística não } \\
\text { foram considerados os grupos de "outros". }\end{array}$ \\
\hline $\begin{array}{l}\text { Localização } \\
\text { da moradia }\end{array}$ & $\begin{array}{l}\text { Urbano } \\
\text { Rural }\end{array}$ & Enem & $\begin{array}{l}\text { Foram juntadas em apenas essas duas } \\
\text { categorias. As variáveis comunidade } \\
\text { indígena e quilombola foram juntadas com } \\
\text { a variável "rural". }\end{array}$ \\
\hline $\begin{array}{l}\text { Escolaridade } \\
\text { da mãe }\end{array}$ & $\begin{array}{l}\text { Não soube informar/ não } \\
\text { estudou / até a } 4^{\circ} \text { série } \\
\text { Ensino fundamental } \\
\text { Ensino médio } \\
\text { Ensino superior }\end{array}$ & Enem & $\begin{array}{l}\text { Foram juntadas as categorias "não soube } \\
\text { informar" e "não estudou" com a categoria } \\
\text { "até a } 4 \text { " série"; e, a categoria de "ensino } \\
\text { superior" com "ensino médio" para as } \\
\text { regressões logísticas. Optou-se pela } \\
\text { exclusão da escolaridade do pai, pois a } \\
\text { escolaridade da mãe é semelhante e } \\
\text { contava com menos falta de informações. }\end{array}$ \\
\hline Renda familiar & $\begin{array}{l}\text { De nenhuma renda até } 1 \text { SM } \\
\text { Mais de } 1 \text { até } 2 \text { SM } \\
\text { Mais de } 2 \text { até } 5 \text { SM } \\
\text { Acima de } 5 \text { SM }\end{array}$ & Enem & $\begin{array}{l}\text { A categoria "nenhuma renda" foi juntada } \\
\text { com a categoria "até } 1 \text { SM", e todas as } \\
\text { categorias acima de } 5 \text { SM foram juntadas. }\end{array}$ \\
\hline $\begin{array}{ll}\text { Situação de } \\
\text { trabalho do } \\
\text { estudante no } \\
\text { Ensino Médio }\end{array}$ & $\begin{array}{l}\text { Sim } \\
\text { Não }\end{array}$ & Enem & $\begin{array}{l}\text { As categorias foram juntadas em apenas } \\
\text { essas duas categorias, em que "sim" indica } \\
\text { que o ingressante trabalhava durante o } \\
\text { ensino médio ou já havia trabalhado } \\
\text { durante os estudos; e "não" indica não ter } \\
\text { trabalhado. }\end{array}$ \\
\hline $\begin{array}{l}\text { Origem } \\
\text { geográfica dos }\end{array}$ & $\begin{array}{l}\text { Região Sul } \\
\text { Outras regiões }\end{array}$ & UFFS & $\begin{array}{l}\text { Essa categoria foi criada a partir da } \\
\text { Unidade Federativa (UF) em que o }\end{array}$ \\
\hline
\end{tabular}




\begin{tabular}{|c|c|c|c|}
\hline ingressantes & & & $\begin{array}{l}\text { ingressante concluiu o ensino médio. } \\
\text { Algumas análises foram realizadas apenas } \\
\text { com estas duas categorias e outras com o } \\
\text { desmembramento dos Estados da Região } \\
\text { Sul. }\end{array}$ \\
\hline Escola pública & $\begin{array}{l}\text { Sim } \\
\text { Não }\end{array}$ & UFFS & $\begin{array}{l}\text { As categorias foram juntadas em apenas } \\
\text { essas duas e indicam se o ingressante } \\
\text { estudou ou não o ensino médio integral ou } \\
\text { parcial em escola pública. }\end{array}$ \\
\hline $\begin{array}{ll}\text { Nota } & \text { da } \\
\text { redação } & \text { no } \\
\text { Enem } & \end{array}$ & $\begin{array}{l}\text { Até } 400 \\
\text { Acima de } 400 \text { até } 600 \\
\text { Acima de } 600 \text { até } 800 \\
\text { Acima de } 800 \text { até } 1000 \\
\end{array}$ & Enem & $\begin{array}{l}\text { Para os testes de regressão logística esta } \\
\text { variável foi utilizada como numérica. }\end{array}$ \\
\hline $\begin{array}{l}\text { Intervalo } \\
\text { EM_ES }\end{array}$ & $\begin{array}{l}\text { Até um ano } \\
\text { De } 2 \text { a } 4 \text { anos } \\
\text { Acima de } 5 \text { anos }\end{array}$ & UFFS & $\begin{array}{l}\text { Esta variável foi criada a partir do cálculo } \\
\text { de diferença entre o ano de conclusão do } \\
\text { ensino médio e o ano de ingresso na } \\
\text { UFFS. }\end{array}$ \\
\hline Campus & $\begin{array}{l}\text { Chapecó } \\
\text { Laranjeiras do Sul } \\
\text { Realeza } \\
\text { Cerro Largo } \\
\text { Erechim } \\
\text { Passo Fundo } \\
\end{array}$ & UFFS & \\
\hline $\begin{array}{ll}\text { Grupo } & \text { de } \\
\text { inscrição } & \text { no } \\
\text { Processo } & \\
\text { seletivo } & \text { da } \\
\text { UFFS } & \end{array}$ & $\begin{array}{l}\text { Ampla Concorrência } \\
\text { Escola pública + PPIs } \\
\text { Escola pública + PPI + PCD } \\
\text { Escola pública + PPI + renda } \\
+ \text { PCD } \\
\text { Escola pública + PPIs + } \\
\text { renda } \\
\text { Escola pública }- \text { total } \\
\text { Escola pública + PCD } \\
\text { Escola pública + renda + } \\
\text { PCD } \\
\text { Escola pública parcial } \\
\text { Reserva indígena }\end{array}$ & UFFS & $\begin{array}{l}\text { Indica o grupo de inscrição no Processo } \\
\text { Seletivo da UFFS, a partir de } 2013 \text {, com a } \\
\text { adesão à Lei de Cotas. } \\
\text { PPIs se refere aos autodeclarados pretos, } \\
\text { pardos e indígenas e PCD se refere à } \\
\text { pessoa com deficiência. }\end{array}$ \\
\hline $\begin{array}{l}\text { Turno do } \\
\text { curso }\end{array}$ & $\begin{array}{l}\text { Integral } \\
\text { Noturno } \\
\text { Matutino } \\
\text { Vespertino }\end{array}$ & UFFS & $\begin{array}{l}\text { O vespertino se refere apenas ao curso de } \\
\text { Ciência da Computação, que a partir de } \\
2017 \text { passou de matutino para vespertino. } \\
\text { No teste de regressão logística foi juntada } \\
\text { a categoria vespertino com matutino } \\
\text { (matutino ou vespertino). }\end{array}$ \\
\hline $\begin{array}{l}\text { Grau } \\
\text { acadêmico }\end{array}$ & $\begin{array}{l}\text { Bacharelado } \\
\text { Licenciatura }\end{array}$ & UFFS & \\
\hline $\begin{array}{l}\text { Área de } \\
\text { conhecimento }\end{array}$ & $\begin{array}{l}\text { Educação } \\
\text { Negócios, administração, } \\
\text { direito e ciências sociais } \\
\text { Computação e Tecnologias } \\
\text { da In Informação } \\
\text { Comunicação (TIC) } \\
\text { Engenharia, produção e } \\
\text { construção } \\
\text { Agricultura, Silvicultura, } \\
\text { Pesca e Veterinária } \\
\text { Saúde e bem-estar }\end{array}$ & UFFS & $\begin{array}{l}\text { Esta variável foi criada para a junção dos } \\
\text { cursos nestas áreas com base no "Manual } \\
\text { para classificação dos cursos de } \\
\text { graduação e sequênciais - CINE BRASIL } \\
\text { 2018" (INEP, 2019). }\end{array}$ \\
\hline $\begin{array}{l}\text { Retorno } \\
\text { econômico }\end{array}$ & $\begin{array}{l}\text { Alto retorno } \\
\text { Médio retorno } \\
\text { Baixo retorno }\end{array}$ & UFFS & $\begin{array}{l}\text { Esta variável foi criada com base no } \\
\text { estudo de Knop (2020) e com dados do } \\
\text { Ministério da Economia, por meio do } \\
\text { CAGED (2020). }\end{array}$ \\
\hline
\end{tabular}




\begin{tabular}{|c|c|c|c|}
\hline Apoio social & $\begin{array}{l}\text { Não } \\
\text { Sim }\end{array}$ & CenSup & $\begin{array}{l}\text { As categorias foram juntadas em apenas } \\
\text { essas duas e indicam apenas se o estudante } \\
\text { recebeu ou não, independentemente do } \\
\text { tipo, valor e/ou tempo de apoio recebido. }\end{array}$ \\
\hline $\begin{array}{l}\text { Atividade } \\
\text { extracurricular }\end{array}$ & $\begin{array}{l}\text { Não } \\
\text { Sim }\end{array}$ & CenSup & $\begin{array}{l}\text { As categorias foram juntadas em apenas } \\
\text { essas duas e indicam apenas se o estudante } \\
\text { participou ou não nessas atividades, } \\
\text { independentemente do tipo, tempo e se foi } \\
\text { remunerada ou voluntária. }\end{array}$ \\
\hline $\begin{array}{l}\text { Situação de } \\
\text { matrícula (por } \\
\text { ano) }\end{array}$ & $\begin{array}{l}\text { Matrícula ativa } \\
\text { Evasão de curso } \\
\text { Conclusão de curso }\end{array}$ & Censup & $\begin{array}{l}\text { Foram realizadas as seguintes junções: } \\
\text { matrícula ativa: "cursando/a" e "matrícula } \\
\text { trancada"; evasão de curso: "desvinculado } \\
\text { do curso" e "transferido/a para outro curso } \\
\text { da mesma IES". conclusão de curso: } \\
\text { "formado/a". Estudantes com a situação de } \\
\text { "falecidos" foram excluídos. }\end{array}$ \\
\hline $\begin{array}{l}\text { Desfecho } \\
2019\end{array}$ & $\begin{array}{l}\text { Matrícula ativa } \\
\text { Evasão de curso } \\
\text { Conclusão de curso }\end{array}$ & UFFS & $\begin{array}{l}\text { A categoria "matrícula trancada" foi } \\
\text { juntada com "matrícula ativa"; as } \\
\text { categorias "jubilamento", "cancelamento", } \\
\text { "desistência" e "transferências interna e } \\
\text { externa" se referem a "evasão de curso" e } \\
\text { a categoria "formando" foi juntada com } \\
\text { "conclusão de curso". }\end{array}$ \\
\hline $\begin{array}{l}\text { Evasão de } \\
\text { curso }\end{array}$ & $\begin{array}{l}\text { Não evadiu } \\
\text { Evadiu }\end{array}$ & UFFS & $\begin{array}{l}\text { Esta variável foi criada juntando a situação } \\
\text { de "matrícula ativa" e "conclusão de } \\
\text { curso" na categoria de não evadiu. }\end{array}$ \\
\hline $\begin{array}{l}\text { Conclusão de } \\
\text { curso }\end{array}$ & $\begin{array}{l}\text { Não concluiu } \\
\text { Concluiu }\end{array}$ & UFFS & $\begin{array}{l}\text { Esta variável foi criada juntando a situação } \\
\text { de "matrícula ativa" e "evasão de curso" } \\
\text { na categoria de não concluiu. }\end{array}$ \\
\hline
\end{tabular}

Fonte: Elaboração própria, com base em dados do SGA/UFFS e do Inep (Enem e Censup)

Uma das formas de apresentar os cursos de graduação foi por meio da criação da variável "área de conhecimento". O Quadro 2 mostra a organização dos cursos, segundo a grande área, com base no documento do Inep ${ }^{14}$ (2019) "Manual para classificação dos cursos de graduação e sequênciais - CINE BRASIL 2018”. Foi realizada uma adaptação fundindo a área 3 (Ciências sociais, jornalismo e informação) com a área 4 (Negócios, administração e direito), em uma nova categoria chamada "Negócios, administração, direito e ciências sociais", que abarca o curso de Ciências Econômicas, além de Administração. Essa classificação faz uma distinção quanto ao grau acadêmico dos cursos, portanto, todas as licenciaturas, voltadas para a formação de professores, estão abarcadas na área de Educação ${ }^{15}$.

\footnotetext{
${ }^{14}$ Optou-se por esta classificação do Inep pelo fato de que faz a distinção quanto ao grau acadêmico do curso.

${ }^{15}$ Um curso de bacharelado, por exemplo, em Ciências Biológicas receberia outra classificação.
} 
Quadro 2 - Agregação dos cursos por grandes áreas

\begin{tabular}{|l|l|}
\hline Área de conhecimento & Curso \\
\hline $\begin{array}{l}\text { Educação } \\
\text { (Licenciaturas - formação de } \\
\text { professores) }\end{array}$ & $\begin{array}{l}\text { Ciências Biológicas, Ciências Naturais, Ciências Sociais, Filosofia, } \\
\text { Física, Geografia, História, Interdisciplinar em Educação do Campo } \\
\text { - Ciências Naturais, Matemática e Ciências Agrárias, Letras - } \\
\text { Português e Espanhol, Matemática, Pedagogia e Química }\end{array}$ \\
\hline $\begin{array}{l}\text { Negócios, administração, direito } \\
\text { e ciências sociais }\end{array}$ & Ciências Econômicas e Administração \\
\hline $\begin{array}{l}\text { Computação e Tecnologias da } \\
\text { Informação e Comunicação (TIC) }\end{array}$ & Ciência da Computação \\
\hline $\begin{array}{l}\text { Engenharia, produção e } \\
\text { construção }\end{array}$ & $\begin{array}{l}\text { Engenharia de Alimentos, Arquitetura e Urbanismo e Engenharia } \\
\text { Ambiental e Sanitária }\end{array}$ \\
\hline $\begin{array}{l}\text { Agricultura, Silvicultura, Pesca e } \\
\text { Veterinária }\end{array}$ & Agronomia, Engenharia de Aquicultura e Medicina Veterinária \\
\hline Saúde e bem-estar & Enfermagem, Medicina e Nutrição \\
\hline
\end{tabular}

Fonte: Elaboração própria conforme dados do SGA/UFFS e Inep (2019).

Para compreender o fenômeno de desigualdades conforme a inserção dos estudantes da UFFS em carreiras mais e menos rentáveis, foram reorganizados os cursos conforme o retorno econômico no mercado de trabalho, inspirado na pesquisa de Knop (2020) e com base na tabela salarial disponibilizada pelo Cadastro Geral de Empregados e Desempregados (CAGED), do Ministério da Economia ${ }^{16}$ (Apêndice 1). Os cursos foram divididos em três faixas de retorno:

a) Alto retorno (acima de 6 salários mínimos): Medicina; Agronomia; Ciência da Computação; Ciências Econômicas; Engenharia Ambiental e Sanitária e Arquitetura e Urbanismo.

b) Médio retorno (mais de 3 até 6 salários mínimos): Engenharia de Alimentos; Administração; Engenharia de Aquicultura; Medicina Veterinária; Química; Ciências Sociais; História; Matemática; Enfermagem; Geografia; Física; Ciências Biológicas; Letras - Português e Espanhol e Filosofia.

c) Baixo retorno (até 3 salários mínimos): Filosofia; Ciências Naturais; Interdisciplinar em Educação do Campo - Ciências Naturais, Matemática e Ciências Agrárias; Nutrição e Pedagogia.

\footnotetext{
${ }^{16}$ Os salários são calculados de acordo com informações enviadas pelas empresas mensalmente por meio do sistema Novo Caged, eSocial e Empregador Web do Ministério da Economia. Fonte: Salario.com.br Novo CAGED/eSocial/Empregador Web - Atualização: 30 de julho de 2020. https://www.salario.com.br/tabela-salarial/
} 


\subsection{Limites e possibilidades das bases de dados e da pesquisa}

A junção das três bases de dados impôs alguns limites à pesquisa devido ao número menor de estudantes encontrados na base do Enem e do CenSup. Essa mesma dificuldade também foi verificada por Senkevics e Mello (2019), em estudo que também utilizou bases de Enem e do CenSup de modo integrado. Além disso, as questões e tipos de respostas dos questionários socioeconômicos do Enem não eram iguais ao longo dos anos, o que exigiu adequações e/ou até a exclusão de alguma questão que não estava presente em todos os anos. Destaca-se também, como uma limitação a falta de informação relacionada a algumas variáveis (missings).

Como a base de dados proveniente do Sistema de Gestão Acadêmica da UFFS, não tinha informações socioeconômicas ao longo do tempo (tais como renda familiar e escolaridade dos pais), buscamos a complementação desses dados nas bases do Enem. A UFFS tinha informações socioeconômicas para todos os ingressantes por meio de processo seletivo que utiliza o Enem, apenas até o ano de 2013 quando os processos seletivos eram próprios e não utilizavam o SiSU. Portanto, utilizamos estes dados apenas para a coorte de 2013, junto com os dados referentes ao desempenho dos estudantes e ao apoio social recebido ${ }^{17}$.

Constata-se a importância para a pesquisa que teve o uso da sala da Sedap/INEP, pois permitiu a integração dos dados dos ingressantes da UFFS com outras informações importantes, principalmente socioeconômicas e institucionais. Em que pese, essa integração, outra das limitações dos dados diz respeito à não liberação por parte do Inep da base de dados integrada, uma vez que libera apenas os resultados das análises produzidas naquele espaço. Portanto, todo o trabalho com estas bases de dados precisa ser realizado na sala segura do Sedap, o que demanda muito tempo e o deslocamento do pesquisador até o Inep ${ }^{18}$.

Outra das limitações na análise da evasão e conclusão, diz respeito ao fato de estarmos analisando apenas a evasão de curso, não contemplando, portanto, a mobilidade interna e/ou externa dos estudantes. Além disso, diante dos dados disponíveis, limitamos o recorte da análise apenas aos ingressantes na UFFS por meio do Enem.

\footnotetext{
${ }^{17}$ Esta configuração específica do último capítulo se justifica pela não viabilidade de retomar ao Inep e juntar estes dados de desempenho com aquelas bases do Enem e do CenSup.

${ }^{18}$ Em função da pandemia de COVID-19, o agendamento inicial para essa atividade precisou ser adiado por várias vezes e, quando o serviço reabriu, o horário de atendimento ficou mais reduzido.
} 
Ainda que existam limitações, considera-se que esta pesquisa avança ao utilizar as variáveis gênero e raça de modo articulado e, também, pelo fato de complementar as informações a partir de bancos de dados integrados com os dados da UFFS (Enem e CenSup). Além disso, trata-se de pesquisa que toma como empiria o contexto particular da UFFS e suas especificidades (localização em municípios no interior e interestadual e o perfil socioeconômico e racial menos heterogêneo dos estudantes). A contribuição original desta pesquisa está na apresentação de um panorama longitudinal e quantitativo sobre as oportunidades educacionais que se configuram no acesso e nos desfechos universitários da UFFS, ao longo dos seus primeiros nove anos de existência.

\subsection{Cuidados éticos da pesquisa}

Em todas as etapas desta pesquisa foram considerados todos os cuidados e princípios éticos pertinentes à pesquisa que envolve seres humanos, conforme legislação pertinente ${ }^{19}$. No caso deste estudo o contato com os sujeitos principais (estudantes da UFFS) foi realizado apenas por meio documental, sem coleta de informações diretamente com os participantes, resguardando a confidencialidade dos dados coletados e o anonimato quanto à identificação pessoal dos sujeitos envolvidos.

Foi mantida uma postura ética quanto aos sujeitos da pesquisa, com a garantia do anonimato e confidencialidade das informações disponibilizadas, respeitando sua integridade. Os dados utilizados nesta pesquisa foram solicitados formalmente às Instituições produtoras, como a UFFS e o Inep, com o compromisso de uso exclusivamente para fins de pesquisa acadêmica.

Os sujeitos da pesquisa, bem como a Instituição investigada terão benefícios com esta pesquisa, por meio do conhecimento científico gerado a partir das análises e divulgação dos resultados. Esperamos que os resultados sejam de interesse da comunidade científica e que instiguem a continuidade da pesquisa e outros estudos complementares.

19 Resoluções do Conselho Nacional de Saúde N. 466, de 12 de dezembro de 2012 e N. 510, de 07 de abril de 2016. 


\section{3 Desigualdade de oportunidades no ensino superior:}

A temática da desigualdade de oportunidades educacionais mobiliza pesquisadores de várias áreas de conhecimento, tanto no âmbito nacional quanto internacional. Esta se situa na agenda de pesquisa em estratificação educacional, entendida como o campo que trata do papel de socialização e de seleção desempenhado pela escola. A estratificação educacional, conforme definida por Valle Silva \& Souza (1986, p. 50), “[...] diz respeito à relação entre as características de origem socioeconômica dos alunos na entrada do sistema escolar e as características individuais observáveis na sua saída, bem como os mecanismos através dos quais essa relação é estabelecida".

Conforme Mont`Alvão (2016) o foco principal dos estudos está voltado para a dimensão "vertical" dos processos de estratificação. Esta abordagem analisa os efeitos da origem social dos estudantes sobre seus destinos educacionais, ou seja, as chances de completar as transições educacionais. Em menor número, há também estudos sobre a dimensão horizontal que analisam "[...] em que medida as origens socioeconômicas determinam o tipo ou a qualidade da educação recebida por estudantes ao longo dos pontos de transição do sistema" (Mont`Alvão, 2016, p. 16). Estas diferenças podem aparecer no tipo de educação recebida (vocacional ou acadêmica), de instituição (universidades, faculdades, colleges) e de cursos e campos do saber (ciências médicas, humanas, econômicas). Isso quer dizer que em muitos países o sistema educacional é diversificado e que a continuação escolar pode ter diferentes possibilidades, influenciadas tanto pela origem social quanto pelo desempenho escolar.

No Brasil, as análises acompanharam o desenvolvimento da literatura internacional. Neste campo destacam-se alguns estudos e autores pioneiros como Nelson Valle Silva e Alberto de Mello Souza (1986), Carlos Antônio Costa Ribeiro (2009), além de trabalhos mais recentes, como os de Arnaldo Mont'Alvão (2016); Felícia Picanço e Juliana Morais (2016); Murillo Marschner Alves de Brito (2017); Orcione Aparecida Vieira Pereira (2015; 2016); Anderson Paulino da Silva (2016); Andre Salata (2018); Flavio Carvalhaes e Carlos Antonio Costa Ribeiro (2019); e Maria Lígia de Oliveira Barbosa (2019).

De acordo com Picanço \& Morais (2016), quando se trata das mudanças recentes 
ocorridas no sistema educacional, a principal questão que se coloca aos pesquisadores sobre as desigualdades e estratificação é: “[...] se a expansão educacional reduz as desigualdades sociais proporcionando mais oportunidades para os indivíduos em posições de desvantagens, ou se amplia proporcionalmente mais para os indivíduos em posições de vantagens" (Picanço; Morais, 2016, p. 392).

Ainda, segundo as autoras, na literatura internacional os modelos analíticos e as perspectivas teóricas da estratificação educacional se distanciam e se aproximam de acordo com os fatores escolhidos para sua explicação, como, por exemplo, a seleção por mérito, a industrialização da sociedade, a distribuição de capitais culturais e sociais, a reprodução de classes, os processos de socialização e a escolha racional, que são considerados em algumas perspectivas de análise, como a Teoria da Industrialização ou modernização; Teoria da Reprodução e da Escolha Racional e outros desdobramentos.

A Teoria da Industrialização ou Modernização considera que quanto maior for o desenvolvimento social e econômico de uma sociedade, maiores serão as oportunidades educacionais e ocupacionais, ou seja, o efeito da origem social sobre as trajetórias e resultados educacionais seria menor. A expansão educacional promoveria a equidade entre os indivíduos em termos da aquisição de valores culturais e de acesso a oportunidades educacionais. Logo, todos estariam em condições mais equitativas para competir, dependendo apenas do mérito e do investimento pessoal (Picanço; Morais, 2016).

Essa perspectiva de análise, também conhecida como o paradigma funcionalista, atribuía à escolarização o papel de promover a superação do atraso econômico e do autoritarismo e permitia a construção de uma sociedade mais moderna e justa, baseada na meritocracia e autonomia individual dos indivíduos, uma vez que todos teriam as mesmas oportunidades ao ofertar a educação pública para todos. Conforme destaca Nogueira \& Nogueira (2002, p. 16): “os indivíduos competiriam dentro do sistema de ensino, em condições iguais, e aqueles que se destacassem por seus dons individuais seriam levados, por uma questão de justiça, a avançar em suas carreiras escolares e, posteriormente, a ocupar as posições superiores na hierarquia social”.

Segundo Nogueira \& Nogueira (2002), a partir da década de 1950, foi divulgada uma série de pesquisas quantitativas, patrocinada pelos governos americano e francês, que indicava a manutenção das desigualdades educacionais. Esses estudos passaram a demonstrar que os destinos educacionais estavam relacionados à origem social e que 
não eram apenas fruto das diferenças naturais entre os indivíduos. Portanto, contribuíram para a crise da perspectiva funcionalista e meritocrática, que supunha uma escola neutra em que todos competiam em igualdade de condições, e que aqueles que se destacavam por seus dons individuais avançariam em suas carreiras por uma questão de justiça.

Nesse cenário, os autores franceses Pierre Bourdieu e Jean-Claude Passeron, em sua obra "Les Héritiers" (1964) elaboraram uma resposta crítica às desigualdades escolares, por meio de uma nova interpretação sobre o papel dos sistemas de ensino na sociedade. Segundo a perspectiva bourdieusiana, "a educação [...] perde o papel que lhe fora atribuído de instância transformadora e democratizadora das sociedades e passa a ser vista como uma das principais instituições por meio da qual se mantêm e se legitimam os privilégios sociais" (Nogueira; Nogueira, 2002, p. 17).

Essa teoria, conhecida como a Teoria da Reprodução, postula que a expansão educacional reproduz relações de dominação e posições sociais e não proporciona, efetivamente, uma mudança estrutural ou mobilidade social dos indivíduos. Assim, o sistema educacional é promotor de desigualdade, porque opera com a seleção dos mais aptos, que são aqueles pertencentes às classes dominantes e com maior capital cultural acumulado (Pereira, 2016; Picanço; Morais, 2016).

A Teoria da Reprodução, tendo Bourdieu como uma referência foi um marco importante na compreensão das desigualdades escolares e do papel da escola como um mecanismo de reprodução de desigualdades. O autor estudava a universidade francesa e questionava o fato de que a educação não poderia ser apenas fruto de um mérito, pois os filhos das elites já acessavam as escolas com padrões culturais mais rebuscados. Além disso, partia do ponto de que a Universidade não era neutra e que premiava os mais talentosos, pois quem tinha mais sucesso eram aqueles com maior capital cultural. Mesmo que todos tenham acesso, os recursos que cada um herdou vão continuar pesando, ou seja, as desigualdades entram para dentro das escolas e portanto, a origem social dos indivíduos precisa ser levada em consideração para compreender a educação e a sociedade (informação verbal ${ }^{20}$ )

De acordo com Nogueira \& Catani (2015), o conceito de "capital cultural", na perspectiva de Bourdieu, se refere a um ter, uma aquisição pessoal, algo que se torna

${ }^{20}$ Fala do Prof. Dr. Claudio Marques Martins Nogueira, em curso de Extensão/UFRJ: "Desigualdades escolares e atuação docente", em 09 ago. 2021. 
uma propriedade da pessoa, um habitus. Este capital pode existir sob três formas: no estado incorporado - está ligado a bens duráveis incorporados pelo indivíduo; no estado objetivado - é transmissível em sua materialidade por meio de escritos, livros, quadros, pinturas; no estado institucionalizado - é o reconhecimento institucional que confere o capital cultural por meio de um diploma. Segundo os autores, esse capital foi formulado "[...] para dar conta da desigualdade de desempenho escolar de crianças oriundas de diferentes classes sociais, relacionando o `sucesso escolar`, à distribuição do capital cultural entre as classes e frações de classe" (Nogueira; Catani, 2015, p. 81).

Conforme observa Fresneda (2012), para Bourdieu as desigualdades educacionais são influenciadas pelo nível cultural herdado, que se dá por meio de um sistema de valores interiorizado. O domínio da língua é exemplo de um processo de aprendizagem que pode ser transmitido de pais para fillhos, principalmente no caso das classes mais educadas e essa habilidade pode ser essencial ao êxito escolar. A escola, portanto, se torna um mecanismo de dominação na medida em que naturaliza e legitima diferenças culturais herdadas e as converte em desigualdades sociais legitimadas.

A partir da década de 1970 começa a emergir a Teoria da Escolha Racional, tendo como precursora a obra de Raymond Boudon (1981), intitulada “A Desigualdade das Oportunidades". Nesta obra, o autor desenvolve uma crítica à Teoria da Reprodução, principalmente com relação ao foco na herança cultural para explicar a reprodução das desigualdades educacionais. Para Boudon (1981, p.8), "não se deve imaginar uma ligação mecânica entre a desigualdade das oportunidades escolares e o nível de herança social", ou seja, a redução das desigualdades educacionais não leva necessariamente a uma diminuição da herança social.

A partir de uma perspectiva sistemática, o autor apresenta uma teoria sobre um conjunto de mecanismos que geram a desigualdade de oportunidades escolares e sociais. O foco de sua investigação é a desigualdade de acesso escolar e a mobilidade social, ou seja, como a origem social afeta o acesso aos diversos níveis sócio ocupacionais nas sociedades industriais da Europa Ocidental e da América do Norte. De acordo com Boudon (1981), os indivíduos fazem suas escolhas e investimentos na educação escolar com base na avaliação de custos e benefícios. O campo decisório ocorre de acordo com a posição social que estes ocupam no sistema de estratificação social. Neste sentido, o autor afirmou que a aquisição da educação passa por dois efeitos: primários e secundários. Os efeitos primários são os que criam os diferenciais de desempenho e 
habilidades das crianças no seu alcance inicial, conforme a posição social da família. Assim, existe uma correlação entre o nível escolar e a posição social, no sentido de que crianças em posições de desvantagem, apresentariam níveis menores de habilidades. Os efeitos secundários estão relacionados com as decisões tomadas por estudantes e seus pais diante das opções que são ofertadas pelo sistema educacional, ou seja, são as escolhas tomadas diante de suas posições sociais sobre os riscos, custos e benefícios em permanecer, sair ou mudar o curso das suas carreiras de escolaridade (Pereira, 2016; Picanço; Morais, 2016).

Conforme destacam Picanço e Morais (2016), o autor Goldthorpe (2000), tanto em seus escritos individuais, quanto naqueles em coautoria, a partir de críticas aos autores, como Bourdieu, Passeron e ao próprio Boudon, que explicam a manutenção das desigualdades educacionais a partir da relação entre classe e cultura, imprime em Boudon, a construção da Teoria da Escolha Racional e avança nesta teoria, partindo da explicação dos efeitos primários e secundários na aquisição da educação.

Golthorpe (2007) menciona dois pontos importantes em relação à expansão educacional e suas consequências: primeiro, que ao contrário da Teoria da Reprodução social de Bourdieu, também não se pode subscrever a Teoria da Modernização, na qual a expansão criaria uma sociedade mais "aberta" e "igualitária". As novas oportunidades criadas pelos processos de expansão foram aproveitadas em mesmo grau por filhos de todas as origens sociais, sendo que um número cada vez maior das crianças de origens mais desfavorecidas alcançou níveis mais elevados de realização educacional. E, segundo, que também não se poderia resgatar a Teoria da Reprodução Social de Bourdieu, afirmando que pode ser entendida em termos "relativos", ou seja, que o que se refere pela reprodução "não é mais do que a reprodução ao longo do tempo das probabilidades relativas com as quais as crianças de origens de classe diferentes alcançam certos níveis de sucesso educacional e, além disso, certos níveis de emprego e posições associadas dentro da estrutura de classes" (Golthorpe, 2007, p. 9, tradução própria).

Conforme destaca Brito (2017), no início dos anos 1980, os estudos de Robert Mare $(1980 ; 1981)$ introduziram importantes inovações metodológicas e conceituais na agenda de pesquisa das desigualdades educacionais até então vigentes. O estudo de Mare (1980) foi desenvolvido por meio de regressões logísticas das probabilidades de continuação escolar, abrangendo homens brancos americanos nascidos na primeira 
metade do século XX. Utilizou-se de oito variáveis de background social e seis níveis de escolaridade. O foco desta análise foi na escolaridade cursada, dado que completaram o nível anterior. Os resultados indicam que o nível socioeconômico dos pais influencia nas decisões dos filhos e na continuação escolar. Quando as taxas de continuação escolar são altas, apenas aqueles com uma condição socioeconômica desfavorecida não conseguem prosseguir os estudos.

Segundo Picanço e Morais (2016), os achados de Mare conduziram a novas formas analíticas e teóricas de abordar o tema, uma vez que apontaram as diferentes probabilidades que os indivíduos possuem durante a realização de suas transições educacionais e da seleção que ocorre ao longo deste processo. Conforme o autor, a cada etapa da escolaridade os indivíduos prosseguem ou interrompem seus estudos de acordo com fatores observáveis (origem socioeconômica) e não observáveis (motivação) (Picanço; Morais, 2016).

Nesta mesma direção, Mare \& Chang (2005) sinalizam a escolaridade como um processo dinâmico, sendo este concebido como uma sequência de transições escolares. Ao analisar a estratificação educacional desta forma é possível identificar onde as desigualdades sociais são maiores no processo de escolarização. Além disso, pode-se comparar diferentes sistemas de estratificação e estimar os efeitos das características familiares sobre as escolhas de continuação da escola. Para os autores, os pais podem influenciar ou não os seus descendentes a realizar uma transição educacional, tendo por base não somente os níveis escolares que estes completaram, mas também a forma como essa transição escolar ocorreu.

Segundo esses autores, a tendência de que os filhos possam atingir pelo menos a escolaridade dos pais levanta o questionamento de como essa regularidade ocorre e porque estes são movidos pelas realizações de seus pais. Entre algumas explicações, os estudos da psicologia social destacam a influência socializadora dos pais e de outros, como colegas e professores sobre as expectativas e aspirações dos jovens na sua realização educacional e ocupacional. Outra possibilidade diz respeito à motivação dos pais, aos seus próprios fracassos e sucessos e à busca para seus filhos do alcance de alguns objetivos muitas vezes não atingidos por àqueles. Os estudos de mobilidade profissional destacam que existe uma forte tendência dos filhos herdarem dos pais os seus níveis ocupacionais. 
Portanto, no caso dos pais tentarem fazer com que os filhos ultrapassem sua escolaridade sinaliza para um efeito não-linear e aponta variações na forma como a estratificação social funciona. Várias questões podem estar relacionadas aos efeitos dos pais projetarem as transições escolares dos seus descendentes, como, por exemplo, o sexo dos filhos e o tamanho da família, podendo variar no contexto de cada nação (Mare; Chang, 2005).

Nessa perspectiva da escolha racional destacam-se, ainda, outras contribuições significativas. Primeiramente, situa-se a contribuição de Raftery \& Hout (1993) que ficou conhecida como a hipótese da Desigualdade Maximamente Mantida (Maximally Maintained Inequality - MMI). Os autores analisaram as mudanças nos efeitos da origem social na transição educacional, entre 1908 a 1956, na Irlanda, considerando um contexto de expansão da educação secundária. Para os autores os efeitos da origem social na dimensão educacional são mais fortes na transição para a educação secundária e menos significativos para a transição ao ensino superior, ou seja, quando acessam este nível de ensino encontram barreiras, mas não tão fortes como as encontradas em níveis escolares inferiores. É nas primeiras coortes que a classe social apresenta maiores efeitos. Portanto, MMI significa que se houver expansão das matrículas, esta ocorre para todas as classes sociais e as probabilidades de reduzir as desigualdades vão ocorrer apenas quando as classes sociais mais privilegiadas atingirem um ponto de saturação. Somente então, poderá diminuir a associação entre origem social e educação.

A segunda contribuição é apresentada por Breen \& Jonsson (2000), que inseriram a diferenciação qualitativa do sistema educacional como um importante aspecto para as análises de estratificação educacional, ou seja, “[...] os indivíduos não escolhem apenas sair ou continuar nas transições educacionais, mas também entre os tipos de cursos existentes e para cada caminho possível existe uma probabilidade distinta de seguí-lo" (Picanço; Morais, 2016, p. 397). Os autores propõem um modelo analítico desenvolvido com base em dados da Suécia, baseados na regressão logística multinomial e nas diferentes transições (acadêmica e vocacional). Com isso, concluem que os efeitos de classe nas probabilidades de transição educacional variam de acordo com as escolhas feitas sobre os caminhos vocacional ou acadêmico.

A terceira contribuição é proposta por Lucas (2001), por meio da hipótese da Desigualdade Efetivamente Mantida (Effectivelly Maintained Inequality - EMI), desenvolvida no contexto educacional dos Estados Unidos, na década de 1980, com o 
argumento de que, mesmo em níveis de ensino quase universais, haverá competição quanto à qualidade e tipo de educação alcançada. Este pressuposto se diferencia da MMI, que sugere que em contextos universais de ensino a competição será nula. Segundo o autor, supondo um nível de escolaridade não universal,

[...] os favorecidos socioeconomicamente usam suas vantagens para assegurar esse nível de escolaridade. Uma vez que esse nível de escolaridade se torna quase universal, os favorecidos socioeconomicamente procuram quaisquer diferenças qualitativas que existam nesse nível e utilizam suas vantagens para assegurar uma educação quantitativamente similar, mas qualitativamente melhor (Lucas, 2001, p. 1652, tradução própria).

A questão chave para avaliar a EMI é se a origem social poderá mudar o destino escolar de um estudante. Para uma explicação mais abrangente sobre a relação entre a origem social e os níveis de escolaridade, o autor propôs uma associação entre a literatura das transições educacionais e da mobilidade social, ou seja, como os estudantes se movem dentro de um currículo estratificado. Dessa forma, estimou os efeitos da origem social tanto para realizar uma nova transição, quanto para alcançar um determinado lugar neste currículo. As diferenças qualitativas são consideradas uma importante característica no sistema escolar. Portanto, os pais que dispõem de melhores condições socioeconômicas buscarão usar suas vantagens socioeconômicas para garantir um lugar privilegiado para seus filhos no sistema escolar e garantir tanto qualitativa como quantitativamente os melhores resultados (Lucas, 2001).

Conforme Lucas \& Byrne (2017) a EMI possui duas dimensões que precisam ser analisadas conjuntamente para determinar a dinâmica e as tendências da desigualdade: a qualitativa (o tipo de programa escolar cursado, por exemplo) e a quantitativa (o número de anos de estudo, por exemplo).

Portanto, o contraste entre alunos socioeconomicamente favorecidos e desfavorecidos é consistente com a EMI e se distancia da proposição segundo a qual quando um nível de educação se torna universal os efeitos da origem social declinam a zero. "Essas descobertas têm implicações importantes sobre o entendimento da oferta de oportunidades de educação e do processo de realização educacional” (Lucas, 2001, p. 1680, tradução própria).

A autora Sigal Alon (2009) separa a perspectiva teórica da EMI em duas: a Desigualdade Efetivamente em Expansão (Effectively Expanding Inequality - EEI) e Desigualdade Efetivamente em Declínio (Effectively Declining Inequality - EDI), para 
expressar padrões de um crescimento ou de um declínio nas diferenças quantitativas e qualitativas propostas por Lucas (2001).

A autora tomou como referência o contexto dos EUA, no período entre 1960 a 2005, e desenvolveu um quadro teórico abrangente sobre a evolução da divisão de classes na educação superior. Usou como referência o nível de concorrência nas admissões do ensino superior, abrangendo a oferta de vagas e a demanda por este nível de ensino. As principais questões colocadas para este estudo se referem a como as desigualdades de classe podem crescer em momentos de expansão e o que facilita a melhoria de acesso ao ensino superior dos jovens das camadas mais privilegiadas e sua inclinação para instituições mais seletivas em uma meritocracia ostensiva. Esse estudo buscou ampliar as concepções de desigualdade e explorar as causas que apontam a estratificação de classe, considerando um sistema de educação superior altamente estratificado.

Ainda, segundo a autora, os mecanismos de exclusão e adaptação são elementos centrais que agilizam a escalada da desigualdade de classes. Portanto, a adaptação dos mais privilegiados socioeconomicamente às barreiras de inclusão é o elemento chave para a chamada expansão efetiva da desigualdade. Trata-se, portanto, das estratégias utilizadas pelas famílias socioeconomicamente favorecidas para aumentar as chances de ingresso de seus filhos em cursos e instituições mais seletivas e de maior prestígio social. Isso é observado, por exemplo, quando já no ensino médio esses jovens frequentam escolas particulares e cursos preparatórios para o ensino superior.

O conceito de adaptação é considerado por Alon (2009) como a pedra angular para uma abordagem abrangente sobre a evolução das desigualdades. A desigualdade de classe está fortemente associada ao nível de concorrência. Portanto, a desigualdade declina efetivamente "[...] quando a oferta de vagas supera a demanda, a concorrência nas admissões é baixa, as barreiras de admissão são relaxadas e o sistema póssecundário torna-se mais inclusivo, especialmente nos degraus mais baixos da carreira" (Alon, 2009, p. 749, tradução própria). Por outro lado, a desigualdade de classe se expande de forma efetiva quando o aumento da demanda pelo ensino superior intensifica a competição e a seletividade das instituições. Dessa forma, "a adaptação dos privilegiados às mudanças nas regras segue criando uma polarização de recursos e ampliando a divisão de classes para todos os destinos pós-secundários (Alon, 2009, p. 749, tradução própria). 
A partir deste breve mapeamento teórico, que situou as principais teorias da estratificação educacional que orientam o campo de análise da desigualdade de oportunidades educacionais, o próximo ítem apresentará alguns estudos realizados em diversos países, incluindo o Brasil, que, de algum modo, se aproximam dessas contribuições teóricas, principalmente da MMI e EMI.

\subsection{Entre a persistência das desigualdades e a democratização na educação superior}

De acordo com Pereira (2016), a educação possui um papel privilegiado na distribuição de oportunidades educacionais que se convertem em mecanismos de distribuição de chances econômicas, profissionais e de classe. Portanto, o nível de escolaridade constitui um dos principais caminhos para a mobilidade e ascensão social.

Os estudos a seguir apresentam análises sobre a configuração dos padrões de estratificação na educação superior e suas dimensões (vertical e horizontal). De um modo geral, a maioria apresenta análises comparativas e focaliza o mesmo problema: a relação entre a origem social e o destino educacional em diferentes contextos de expansão da educação superior.

A origem social é uma categoria central nos estudos que operam nesta perspectiva. Os resultados sobre sua relação com o destino educacional, em geral, seguem a tendência da perspectiva de análise da MMI e EMI, quando apontam que as melhores oportunidades educacionais estão entre os grupos privilegiados socioeconomicamente.

Diante disso, primeiramente destacam-se os autores que reforçam uma tendência de análise sobre a persistência das desigualdades na educação superior. Num segundo momento, autores que abordam também outros aspectos do processo de expansão mais recente do ensino superior, tais como a inclusão, a equalização das oportunidades e a democratização. O Quadro 3 apresenta um resumo sobre esses autores e suas perspectivas de análise. 
Quadro 3 - Autores e perspectivas de análise sobre desigualdades na educação superior

\begin{tabular}{|c|c|}
\hline Perspectivas de análise & Autores \\
\hline $\begin{array}{c}\text { Persistência das } \\
\text { desigualdades na educação } \\
\text { superior }\end{array}$ & $\begin{array}{c}\text { Michael Hout (2006); Marie Duru-Bellat, Annick Kieffer e David } \\
\text { Reimer (2008); Theodore P. Gerber e Sin Yi Cheung (2008); Carlos } \\
\text { Antonio Costa Ribeiro (2009); Murillo Marschner Alves de Brito (2017); } \\
\text { Flavio Carvalhaes e Carlos Antonio Costa Ribeiro (2019); Maria Ligia } \\
\text { de Oliveira Barbosa (2019) }\end{array}$ \\
$\begin{array}{c}\text { Inclusão, equalização das } \\
\text { oportunidades e } \\
\text { democratização da educação } \\
\text { superior }\end{array}$ & $\begin{array}{c}\text { Ana Maria F. Almeida e Maurício Ernica (2015); } \\
\text { Orcione Aparecida Vieira Pereira (2015; 2016); Dilvo Ristoff (2016); } \\
\text { Anderson Paulino da Silva (2016); Luiz Carlos Zalaf Caseiro (2016); } \\
\text { Andre Salata (2018); Adriano Souza Senkevics e Ursula Mattioli Mello } \\
\text { (2019) }\end{array}$ \\
\hline
\end{tabular}

Fonte: Elaboração própria

Hout (2006) observa que a maioria dos estudos investiga os padrões de desigualdade intergeracional em apenas um país. $\mathrm{O}$ autor buscou compreender como o background familiar afeta as oportunidades educacionais, avaliando as hipóteses de MMI e EMI para vários países. O autor afirma que a MMI se refere explicitamente à persistência, ao longo do tempo, das barreiras de classe em transições educacionais. Com base no modelo de transições educacionais proposto por Mare (1980, 1993), e por Lucas (1993), e utilizando-se do programa International Social Survey Programme (ISSP), aplicado em 1999, Hout (2006) analisou as desigualdades em 25 países (tais como Irlanda, Noruega, Suécia, França e Alemanha, Espanha, Portugal, entre outros). Os resultados apontam que, desde a década de 1950, as oportunidades educacionais se expandiram em todo o mundo. Os níveis de escolaridade variam amplamente entre os países. O Brasil apresentou a menor média de escolaridade entre os países investigados, evidenciando fortemente os efeitos do background familiar nas chances de progressão para a educação superior.

Nesse ambiente de ampla variação no aumento do nível educacional, a MMI prevê que as barreiras de classe social na educação diminuirão somente em algumas nações. Mais precisamente, a estratificação diminuirá nas nações onde as aspirações das elites são satisfeitas. Segundo Hout (2006, p. 247, tradução própria), "o efeito de background familiar na realização educacional diminuiu nas coortes mais rapidamente a partir de 1950 do que anteriormente. Esse resultado é inconsistente com uma versão 
forte da MMI, mas perfeitamente consistente com a EMI". A MMI não prevê a diminuição desse efeito até à saturação. O autor apontou que MMI e EMI continuam a oferecer uma perspectiva de análise útil sobre a desigualdade de oportunidades educacionais: "A perspectiva MMI / EMI aponta para o acesso universal como uma chave para remover barreiras de classe" (HOUT, 2006, p. 249, tradução própria).

Duru-Bellat; Kieffer \& Reimer (2008) investigaram padrões de desigualdades educacionais, comparando os casos de França e Alemanha (1980 a 2000), com o objetivo de estudar a seletividade social no acesso ao ensino superior nesses países, as variáveis quanto ao tipo de ensino em cada país e o campo de estudo. Considerando as configurações institucionais do ensino superior específicas de cada um desses países, as descobertas desse estudo revelaram que na Alemanha as desigualdades foram observadas principalmente com relação à escolha universitária versus formação profissional. Já na França, onde as instituições terciárias são fortemente diferenciadas, foram observadas maiores desigualdades sociais com relação às escolas das elites em relação às instituições universitárias e outras de formação profissionalizante, de curta duração.

Gerber \& Cheung (2008) traçam uma revisão de estudos, nos últimos 20 anos, sobre as relações entre o tipo de educação pós-secundária recebida e as desigualdades socioeconômicas. Foram revisados estudos que relacionam ao mercado de trabalho, as características institucionais do ensino superior (qualidade e tipo de faculdade) e as experiências na faculdade (campo de especialização, desempenho acadêmico e trajetória). E, também pesquisas que trataram da qualidade da faculdade e campo de especialização como variáveis dependentes, influenciadas por gênero, raça, etnia e status socioeconômico.

Segundo os autores, os estudos mostraram que as diferenças qualitativas na educação estão associadas aos diferentes retornos no mercado de trabalho, e que algumas dessas dimensões qualitativas estão diretamente associadas à origem social e demográfica. Isso explica, por exemplo, como a qualidade de uma instituição, marcada por maiores investimentos em capital humano e social pode levar a salários maiores. Outro aspecto considerado é a trajetória dos estudantes até a obtenção de um grau superior. As trajetórias não tradicionais e as interrupções, geralmente enfrentados pelas classes de origem desfavorecida, atrasam a obtenção de um título, o que pode ter como consequência menores salários. 
Gerber \& Cheung (2008) indicam a necessidade de mais estudos sobre as diferenças baseadas em gênero, raça e classe e a formação das desigualdades no mercado de trabalho. No que concerne à relação de gênero nas escolhas educacionais e profissionais, os estudos vêm apontando que tradicionalmente existe uma concentração das mulheres em áreas como saúde, educação e humanidades, enquanto homens são mais propensos às áreas como engenharia, ciência, matemática e negócios. Porém, em nível global, ainda que de forma modesta existe a tendência de diminuição desta segregação sexual entre essas carreiras. Com maior frequência os pesquisadores apontam que as diferenças de gênero nas aspirações e nos valores de trabalho moldam as escolhas em uma idade ainda jovem, a respeito das habilidades que devem buscar num curso educacional. Para as mulheres, as oportunidades no mercado de trabalho estão mais ligadas ao altruísmo, enquanto para os homens sua perspectiva de emprego ideal está mais ligada a enfatizar a riqueza, o status e o prestígio.

No contexto brasileiro, destaca-se o estudo de Ribeiro (2009) que teve o objetivo de verificar tendências da desigualdade de oportunidades educacionais ao longo do tempo, na reprodução intergeracional da desigualdade. Por meio de dados da Pesquisa de Padrões de Vida (PPV), o estudo mediu efeitos sobre a realização educacional alcançada entre 1996 e 1997 de coortes populacionais que nasceram entre 1932 e 1984, sempre em constraste com as reformas educacionais ocorridas ao longo do tempo e com expansão ocorrida em todos os níveis educacionais neste período. Foram consideradas cinco transições educacionais, desde completar um ano de escola (T1) até ter completado um ano de universidade (T5).

Os principais resultados mostraram que em termos de gênero as vantagens das mulheres sobre os homens tiveram início com as coortes nascidas após 1948 e após 1956. Ou seja, que as mulheres ingressaram e progrediram no ensino superior no período em que houve uma grande expansão da educação em todos os níveis, nos anos 60, 70 e 80. Portanto, as evidências indicaram claramente as vantagens de mulheres em relação aos homens de fazer todas as cinco transições Os efeitos de raça são constantes em todas as transições e os efeitos de classe são mais importantes que os de raça, ainda que eles diminuem constantemente em todas as transições. O efeito de raça aumenta para a última transição, que diz respeito a se ter concluído um ano de ensino superior, dado que se tenha completado o ensino secundário. Ainda que a desigualdade de classe se mostre mais importante que raça, a desigualdade racial é ainda persistente e não 
muda ao longo do tempo, a despeito de toda a expansão do sistema educacional. Com relação à escolaridade da mãe, ocorreu um aumento dos efeitos da educação da mãe para ingressar na universidade, para as coortes nascidas após 1948. E, aqueles que viviam em áreas urbanas apresentaram mais vantagens em relação aos residentes em áreas rurais.

Segundo Mont`Alvão (2016), alguns trabalhos têm indicado padrões distintos de persistência das desigualdades educacionais em contextos de expansão educacional, tais como a coletânea "Stratification in Higher Education" (Shavit et. al. 2007), que analisou dados de 1990 para 15 países. Nos seus resultados postula a relativização da tese sobre a persistência da desigualdade diante da expansão educacional.

[...] mesmo que a desigualdade seja estável entre as coortes, o fato de que a expansão proporciona que indivíduos oriundos de classes sociais baixas acessem níveis educacionais que antes eram barreiras a indivíduos de suas classes representa para os autores um elemento importante de inclusão. Concluem que o processo de expansão educacional é sim uma força equalizadora (Mont`Alvão, 2016, p.15).

Na mesma direção, Mont'Alvão (2016) situa os estudos de Breen et al. (2009, 2010) que analisaram dados para oito países europeus. Os autores indicam que, além da questão de relativização da tese da desigualdade persistente, houve também uma queda na associação entre a origem social e o alcance educacional, ou seja, houve um declínio geral na desigualdade educacional, principalmente entre estudantes de origem rural e trabalhadores manuais. Os achados desse estudo desafiam a hipótese da MMI, que prevê apenas uma diminuição das desigualdades em caso de saturação da demanda.

Os estudos de estratificação do alcance educacional no contexto brasileiro, conforme Mont`Alvão (2016), indicam que o efeito das origens tende a declinar ao longo das transições educacionais, enquanto aumentam as desigualdades nos níveis mais altos do sistema escolar, como é o caso da transição para a conclusão do ensino médio e acesso ao ensino superior, ao longo das coortes. Esse resultado já tinha sido demonstrado em estudo feito por Torche (2010) para Brasil, Chile, Colômbia e México.

Mont'Alvão (2016) situa, ainda, o estudo realizado por Collares (2010), que analisou desigualdades no acesso ao ensino superior com base em dados da Pesquisa Nacional por Amostra de Domicílios (PNAD), entre 1982 e 2006. Os resultados indicaram a persistência e até o aumento do efeito das origens sociais, apontando para a diminuição do efeito da raça ao longo do período. 
Destaca-se, ainda, o estudo de Brito (2017) que teve o objetivo de investigar, ao longo da modernização da sociedade brasileira (entre 1960 e 2010), padrões de associação entre origens sociais e destinos educacionais no nível fundamental, médio e superior. Trata-se, portanto, de um período anterior à aprovação da Lei 12.711/2012 (Lei de Cotas). Os resultados apontam para um aumento das desigualdades no acesso ao ensino superior. Os jovens com origem privilegiada mantiveram maiores chances de acesso. Para todos os níveis educacionais analisados, o autor observa uma hierarquização nas chances de transição conforme os estratos de origem social. As classes de origem mais altas sempre atingem os pontos mais altos de progressão, na perspectiva de universalização de acesso seguindo para os demais estratos. Dada a quase universalidade do acesso ao ensino fundamental, este processo reduz-se na conclusão nesta etapa de escolarização, o que indica uma diminuição das desigualdades por classe para esse segmento.

A investigação realizada por Carvalhaes \& Ribeiro (2019) analisou os diferentes tipos de instituições e cursos, com base nas dimensões horizontal e vertical da estratificação do ensino superior. O objetivo foi avaliar o padrão de expansão do ensino superior no Brasil e a configuração de suas oportunidades. A partir de dados do Censo da Educação Superior, no período entre 2002 e 2010, os autores buscaram descrever a expansão dos cursos de ensino superior e dos diferentes tipos de instituição (pública ou privada). Verificaram a estratificação horizontal no acesso a diferentes cursos, segundo características socioeconômicas, e destacaram de maneira enfática a desigualdade presente neste contexto.

Um estudante de origem privilegiada possui 15 vezes mais chances de acessar o curso de Medicina, em relação àqueles de origem socioecionômica baixa ou média. Além do curso de Medicina, outros cursos também considerados de maior prestígio são mais acessados pelas classes altas, como Relações Internacionais, Arquitetura e Urbanismo e Odontologia. Em contrapartida, jovens com origem socioeconômica baixa têm mais chances de acesso em cursos como Matemática, Pedagogia e Geografia (Carvalhaes; Ribeiro, 2019). Além das variáveis socioeconômicas, os autores consideram, também, gênero e raça para avaliar o padrão de expansão do ensino superior brasileiro e a configuração das oportunidades.

Em termos de gênero, os autores chamam a atenção para o fato de que, embora as mulheres tenham acessado mais o ensino superior que os homens, esta inserção 
ocorre em cursos de menor prestígio. No mercado de trabalho elas geralmente se posicionam em cargos de menor prestígio e recebem salários mais baixos que os homens. A desigualdade de gênero relativa ao acesso a cursos de prestígio diferenciado ainda continua presente, a despeito da expansão do acesso para as mulheres na educação superior ocorrida nas últimas cinco décadas. Segundo os autores, ainda existe uma probabilidade maior de acesso das mulheres em cursos voltados para as áreas de cuidados em saúde e para os homens em cursos nas áreas tecnológicas. Isso não acontece apenas no Brasil, o que mantém forte relação com as desigualdades de gênero no mercado de trabalho.

Com relação à estratificação racial e ao acesso aos diferentes cursos no âmbito da educação superior, Carvalhaes \& Ribeiro (2019) apontam que esta não é muito acentuada, embora esteja presente quando se consolidam as maiores chances de acesso em cursos com maior prestígio para brancos e em cursos com menor prestígio social para negros.

Já o estudo de Salata (2018) buscou verificar se houve redução da desigualdade de acesso ao ensino superior por classe de origem em duas décadas mais recentes (1995 a 2015). Os resultados mostraram que, apesar da expansão ocorrida no ensino superior brasileiro, foi apenas na última década que ocorreu uma redução da desigualdade de acesso ao ensino superior por classe de origem. Na década anterior, de 1995 a 2005, não foi possível verificar tendência de redução dessas desigualdades. Apesar de as desigualdades ainda persistirem nas chances de acesso ao ensino superior, o cenário em 2015 é melhor do que era há duas décadas atrás, mas essa redução da desigualdade parece se combinar com desigualdades qualitativas no interior do sistema, ou seja, a desigualdade horizontal se coloca como uma questão importante.

Ao analisar o acesso à educação superior de jovens entre 18 a 24 anos de idade, por meio de dados da PNAD, no período entre 2004 a 2014, Caseiro (2016) converge no sentido de que houve uma tendência de redução de desigualdades nas diferentes regiões do Brasil para todas as características socioeconômicas testadas, tais como raça/cor, renda domiciliar e situação do domicílio e sexo. Segundo o autor, a expansão ocorrida neste período ocorreu em nível nacional, e proporcionalmente tendeu a contribuir mais para o acesso de grupos historicamente desfavorecidos, como habitantes do campo, negros e indígenas e com menor renda. Desta forma, afirma que ocorre um declínio das desigualdades nas chances de acesso ao ensino superior em todos os extratos sociais, 
antes mesmo da universalização desta etapa de ensino, o que se contrapõe à teoria da MMI.

Enquanto um conjunto de estudos, em especial de autores oriundos dos estudos sociológicos sobre estratificação educacional buscam analisar as chances de realização da transição para o ensino superior (estratificação vertical) e as chances de acesso à determinados cursos e instituições (estratificação horizontal), outro conjunto de estudos, em grande medida oriundos da sociologia da educação, tendem a olhar a questão sobre a perspectiva da democratização do acesso em contextos desiguais e em expansão do ensino superior. Uma referência importante trata de Fraçois Dubet. O autor (Dubet, 2015) destaca as diferentes dimensões da democratização do ensino superior e como estas se articulam em diferentes contextos, produzindo desigualdades escolares distintas. Para o autor, quando os sistemas de ensino são mais abertos, as desigualdades são menores no ingresso, mas se deslocam para dentro do próprio sistema, ou seja, nem todos se apropriam dos benefícios da expansão da mesma forma. Esse fenômeno o autor chamou de "democratizaçao segregativa".

Ainda, para Dubet (2015), cada sociedade constrói seus modelos de democratização do ensino baseada em diferentes concepções de justiça, tais como igualdade de oportunidades, meritocracia e equidade. $\mathrm{O}$ autor reconhece que, na maioria dos países, ocorreu democratização nos sistemas de ensino superior, principalmente por meio do acesso a estudantes das classes sociais mais modestas. Porém, aponta alguns limites que estão imbricados nesse processo de democratização.

Primeiramente, o autor afirma que a expansão não significa necessariamente democratização do acesso, pois este ocorre em níveis desiguais dentro do sistema. Outro limite apontado pelo autor é sobre a disponibilidade de recursos financeiros para manter os estudos, mesmo que o curso seja gratuito. A última dimensão avaliada é a democratização em termos de utilidade dos diplomas, que diz respeito à correlação entre a formação dos estudantes e seus empregos e níveis salariais, sendo que esta relação pode aumentar as desigualdades educacionais.

Ainda que a igualdade de oportunidades no ingresso ao ensino superior tenha variado bastante nos diferentes países, segundo Dubet (2015), ela não se concretiza em nenhum deles, pois essa massificação ocorre de forma desigual e a origem social continua desempenhando um papel fundamental na direção das oportunidades educacionais. 
No Brasil, o estudo realizado por Pereira (2015) sobre a expansão recente ocorrida na educação superior teve o objetivo de verificar se houve democratização no acesso a esse nível de ensino para os grupos desfavorecidos economicamente e socialmente. Os achados desse estudo indicam que houve, no país, nas últimas duas décadas (1995 a 2011), uma maior inclusão de grupos sociais tradicionalmente excluídos, como estudantes com baixa renda, negros e indígenas. Trata-se de um fenômeno social recente, sendo ainda cedo para afirmar se, de fato, a democratização do acesso ao ensino superior se concretizou efetivamente, mas é inegável que as modificações neste sentido já começaram a acontecer.

Com foco na expansão de vagas, interiorização e e ações afirmativas na educação superior, o estudo de Silva (2016) investigou as mudanças no vestibular da Universidade Federal Fluminense (UFF) ocorridas nos anos 2000, a partir da abordagem sobre a estratificação horizontal, que analisa as desigualdades no mesmo nível educacional. Sua principal fonte de dados foram os questionários socioculturais respondidos pelos estudantes de 2005 a 2010. Sua análise enfatizou as diferenças nas escolhas de carreiras universitárias conforme o perfil dos estudantes, de modo a conformar uma "escala de prestígio das carreiras".

Para Silva (2016) a inclusão proveniente dos processos de expansão também resulta em desigualdades de ordem qualitativa. No período estudado, o Reuni constituiu o marco de referência para as principais reformas implementadas pela UFF, pois, no mesmo ano de adesão ao SiSU, esta IES implementou um sistema de bonificação de $10 \%$ na nota final para os candidatos egressos das escolas públicas.

Entre os principais achados, o autor reafirmou as desigualdades em termos raciais, perfil de renda e sexo. A pesquisa tenta chamar a atenção para os aspectos otimistas em relação à expansão de vagas na educação superior, além de destacar os aspectos de maior resistência no sistema educacional, no que tange à estratificação horizontal. A pesquisa apontou a democratização de oportunidades de acesso na UFF para mulheres e pretos, porém, ao comparar o sexo com a escala de prestígio dos cursos, constatou que os homens ampliam suas chances em cursos de maior prestígio social. Com relação ao aspecto racial, destacou que na medida que eleva o prestígio dos cursos há uma tendência decrescente na proporção de candidatos negros e pardos inscritos, já para brancos ocorre ao contrário, aumenta sua participação. 
O autor demonstra que a despeito das reformas ocorridas, a exemplo de uma política de bonificação de escola pública adotada naquela instituição, o vestibular continua a ser visto como uma limitação. Ainda que tenha ocorrido maior inclusão de grupos mais pobres e negros, esta ocorre de modo desigual entre os cursos de maior prestígio. Destacou, ainda, um aumento nos efeitos de renda e de escolas privadas nos resultados de aprovação para cursos de maior prestígio.

Para Ristoff (2016) existe uma tendência de democratização do campus universitário, marcada pelo novo perfil do estudante de graduação. O autor analisou dados do questionário socioeconômico do Exame Nacional de Desempenho de Estudantes (Enade), mais especificamente sobre o terceiro ciclo avaliativo, em 2012, comparando-o com os dois ciclos anteriores entre 2004 a 2009. Buscou traçar um perfil do estudante de graduação, considerando as dimensões da origem escolar (pública ou privada), renda familiar, raça/cor dos universitários, condição de estudante trabalhador e escolaridade dos pais.

O autor menciona que, ainda que a expansão se encontre consolidada, o processo de inclusão ainda se constitui como um desafio. Com relação à renda do campus universitário frente à da população brasileira, o autor sinaliza, ainda, uma discrepância: estudantes do ensino superior, tanto de IES privadas, quanto públicas, são, em média, mais ricos que a população brasileira. Esse resultado comparou a média de renda familiar de até três salários mínimos. Conforme estatística do IBGE, essa renda representa metade da população brasileira (50\%). O questionário do Enade revelou que essa renda representou entre universitários apenas $25 \%$ na rede pública e $23 \%$ na rede privada.

Com relação à faixa de renda com mais de 10 salários mínimos, que representada $7 \%$ da população, o autor chama a atenção para a alta representação, principalmente em cursos com maior demanda como é o caso de Medicina (34\%), Odontologia (28\%) e Direito (24\%). Nesta faixa de renda encontram-se pouco representados os cursos de menor demanda como História (7\%) e Pedagogia (5\%). Em comparação à renda observada em ciclos anteriores do Enade, os dados revelam que no terceiro ciclo já se observa uma democratização de acesso, com a redução do percentual de pessoas com renda mais alta em cursos principalmente nas áreas de Saúde, como Odontologia (com redução de 36,7\%), Medicina (31,6\%) e Medicina Veterinária $(27,9 \%)$. Isso revela que a cada edição do Enade aumenta a representação da população 
pobre nos campi universitários, em cursos de média e alta demanda e decresce o percentual de estudantes das faixas mais altas de renda (Ristoff, 2016).

Outra dimensão observada por Ristoff (2016) que ainda apresenta disparidade é com relação à origem escolar dos estudantes. $\mathrm{O}$ ensino médio brasileiro é majoritariamente público, representando $87 \%$ das matrículas do sistema. Os resultados dessa pesquisa apontaram que, no ano de 2012, 60\% dos estudantes do ensino superior eram oriundos do ensino médio público. Essa disparidade é observada principalmente entre cursos de maior e menor demanda. Entre os cursos que mais se aproximam do percentual de estudantes oriundos do ensino médio público (87\%), estavam Pedagogia $(78,4 \%)$ e História $(66 \%)$ e entre os mais distantes estão os cursos de Medicina $(11,1 \%)$ e Odontologia $(24,6 \%)$.

Com relação à cor/raça dos universitários, Ristoff (2016) assinala que, mesmo de forma lenta, as mudanças ocorridas nos últimos anos são significativas, mas ainda guardam correlações com os demais indicadores, como renda e origem escolar. Observa-se que esses dados representam o perfil universitário antes da Lei das Cotas (2012), o que indica os desafios de inclusão, principalmente em cursos de maior demanda.

O estudo de Almeida \& Ernica (2015) também salienta as desigualdades educacionais, principalmente com relação à renda, abordando a tendência a uma maior inclusão social a partir de políticas afirmativas. Os autores analisaram as características sociais de ingressantes de quatro universidades públicas no estado de São Paulo (USP, Unicamp, UFABC e Unifesp), no ano de 2012. Os resultados identificaram que três destas IES receberam um número significativo de estudantes oriundos de famílias com baixo poder aquisitivo, como resultado de políticas de ações afirmativas adotadas por estas IES. Mesmo assim, ressaltam as segmentações e demais formas de desigualdades presentes no interior destas instituições, principalmente em termos de relação entre origem social dos estudantes e prestígio social dos cursos. A área de saúde, por exemplo, reúne a maioria de estudantes oriundos de grupos sociais mais privilegiados.

Assim, os autores concluem que as políticas afirmativas implementadas nestas IES como esforço para diluir os efeitos das desigualdades sociais no acesso ao ensino superior, garantiram maior inclusão de estudantes com menor renda e escolaridade dos pais, na Unifesp e UFABC. Enquanto isso, a Unicamp e a USP se mantiveram com perfis discentes mais privilegiados, com uma relativa inclusão, conforme o padrão de 
segmentação tradicional do ensino superior brasileiro, ou seja, a reprodução na universidade das frações da elite paulista e brasileira (Almeida; Ernica, 2015).

Senkevics \& Mello (2019) analisaram o perfil socioeconômico e racial dos ingressantes das Instituições Federais de Ensino Superior (IFES) entre 2012 e 2016 tendo como fonte de dados a junção entre os dados do questionário socioeconômico do Enem e dados do Censos da Educação Superior. No total foram abarcadas 104 Instituições Federais de Ensino Superior (IFES) e 300 mil matrículas de ingressantes em cursos de graduação na modalidade presencial, no ano de 2012, e de 327 mil, em 2016. Os autores apontaram que houve um crescimento na participação de todos os grupos contemplados pela Lei de Cotas na maioria absoluta das Instituições, principalmente nas mais seletivas. Para os egresssos do ensino médio público o aumento passou de 55,4 para 63,6\% entre 2012 e 2016, com considerável acréscimo para estudantes pretos, pardos e indígenas. $\mathrm{O}$ crescimento de estudantes de escolas públicas com renda inferior ou igual a 1,5 salário-mínimo ocorreu de forma semelhante ao das faixas superiores de renda. Ainda, assim, destacam o distanciamento que existe entre a população e os universitários, com relação a escola pública e PPIs.

[...] cerca de $86,5 \%$ dos jovens brasileiros que frequentaram o ensino médio em 2016 o fizeram em escolas públicas, entretanto, mesmo após a implementação da Lei de Cotas, apenas $63,6 \%$ dos ingressantes das Ifes cursaram o ensino médio na rede pública. Analogamente, vê-se que apenas $38,4 \%$ dos ingressantes nas Ifes são PPI que frequentaram escolas públicas, enquanto $54,1 \%$ dos jovens brasileiros que frequentaram o ensino médio são desse mesmo grupo demográfico (Senkevics; Mello, 2019, p. 194).

Os autores chamam a atenção também para as disparidades que ainda marcam o acesso e a permanênia, principalmente dos jovens negros e das famílias em maior desvantagem socioeconômica, pois os dados de Inep (2016) apresentam “[...] uma taxa líquida de escolarização de apenas 21,2\% em 2014, sendo 30,6\% para brancos e 14,0\% para negros (autodeclarados pretos e pardos), e 53,6\% para o quintil de renda mais elevado e somente 4,9\% para o menor quintil de renda" (Senkevics; Mello, 2019, p. 188).

Barbosa (2019), ao fazer uma leitura sobre as desigualdades do sistema de ensino superior brasileira fundamentada na literatura teórica e empírica, procurou articular as discussões da sociologia da estratificação e a sociologia da educação para mostrar que apesar de toda a abertura ocorrida no acesso ao ensino superior e das 
políticas de permanência, as características da origem social, gênero e raça dos estudantes ainda constituem fatores relevantes na definição de sua trajetória social e nas chances de se formar ou completar a educação superior. A questão que a autora coloca é: como se explica a permanência do elitismo na educação superior em tempos de expansão?

Sua análise chama a atenção para a seletividade em relação aos cursos e instituições de ensino superior, que se traduzem na manutenção das desigualdades. Por isso se apoia nas teorias da MMI, EMI e EEI. A autora elabora duas hipóteses. A primeira delas é que os estudantes com menor renda escolhem cursos e instituições de menor prestígio social e, consequentemente, com menores retornos econômicos e sociais. A segunda reforça a primeira e se refere aos mecanismos criados pelas próprias instituições que reduzem as escolhas dos estudantes. Uma delas é a presença do viés acadêmico, como modelo institucional único e que dá preferência ao bacharelado, ao passo que torna menos legítimos, por exemplo, os cursos de tecnólogos e as licenciaturas. Os horários e turnos também são fatores que reduzem essas escolhas dos estudantes. A autora reconhece a importância dos cursos noturnos, principalmente para quem trabalha, mas não ignora o fato de que os cursos noturnos em sua maioria são licenciaturas, pelo que acabam tendo este mesmo efeito de canalização dos mais pobres (Barbosa, 2019).

A autora indica a expansão na educação superior não necessariamente como um fator de redução das desigualdades, mas, em certa medida, como um fator de aumento e que no caso brasileiro, pobres, negros e mulheres, em geral, são direcionados para instituições e setores menos prestigiados do sistema. Assim, indica que as perspectivas da MMI, EMI e a perspectiva de EEI são bases teóricas importantes para explicar o aprofundamento das desigualdades no contexto da educação superior brasileira.

Os estudos apresentados procuraram mostrar como autores mobilizam as perspectivas sociológicas da estratificação educacional e da sociologia das desigualdades educacionais para caracterizar o fenômeno da desigualdade de oportunidades na educação superior. A origem social e outros marcadores sociais de diferença, como o sexo e a raça, são características que muitas vezes se traduzem em desigualdades no acesso e na trajetória educacional dos estudantes. Destaca-se também o papel que as instituições escolares desempenham, no sentido da socialização, mas também da seleção e até da exclusão dos indivíduos no decorrer do percurso escolar, 
contribuindo para uma maior ou menor estratificação educacional, conforme demonstram os autores Valle Silva \& Souza (1986).

A educação superior brasileira, marcada historicamente pelo elitismo do perfil discente, vêm experimentando expressiva expansão de suas matrículas e de suas instituições nas últimas décadas, nas redes pública e privada. Esse fenômeno foi impulsionado por um conjunto de políticas e programas, e, mais recentemente, pela Lei n. 12.711/2012, políticas estas voltadas para a democratização do acesso e permanência e diversificação dos perfis discentes, como egressos de escola pública, negros, indígenas, filhos de trabalhadores rurais e pessoas com deficiência.

A expansão do ensino superior nem sempre indica a igualdade de oportunidades, uma vez que o acesso e a permanência na educação superior ainda ocorrem de forma desigual, principalmente para estudantes negros e desfavorecidos socioeconomicamente. A literatura em estratificação educacional aponta para algumas tendências de democratização e inclusão educacional, principalmente nas últimas décadas, mas também assinala a persistência das desigualdades, principalmente as horizontais, que se manifestam no interior do sistema. Portanto, as contribuições das hipóteses como a MMI e EMI e também os seus desdobramentos em EEI e EDI continuam sendo significativos para a análise da desigualdade de oportunidades na educação superior.

A dimensão teórica mobilizada neste capítulo contribui para analisar principalmente o acesso e a ocupação dos cursos de estudantes na UFFS, segundo sua origem social e também para levantar algumas questões importantes, a saber: como as desigualdades estruturais atravessam contextos que sinalizam para uma maior democratização do ensino superior? Após o ingresso, qual a relação entre origem social, gênero e raça e os desfechos de evasão ou conclusão de cursos?

Com o foco principalmente nas características de origem social, constata-se que a literatura da estratificação social apresenta algumas lacunas para a análise de fenômenos tais como a evasão e a conclusão do ensino superior. Para fundamentar a análise sobre os desfechos dos estudantes na UFFS, mobilizamos também uma literatura complementar (Capítulo 7) que considera também o contexto das instituições e seu papel na promoção do sucesso acadêmico. Uma vez tendo superado a barreira de acesso ao ensino superior, a lacuna que se quer preencher será principalmente com estudos de 
caso que mostram como as instituições também importam na condição de permanência e conclusão e/ou evasão de curso.

A partir das políticas mais recentes de inclusão social voltadas para a educação superior brasileira desenha-se um contexto que leva para dentro das IES uma hererogeneidade de estudantes, num deslocamento para dentro da universidade de desigualdades que antes estavam fora das IES. Diante de esse contexto de novas desigualdades, se colocam questões como: Que mecanismos institucionais são mobilizados e como estes importam para atenuar as desigualdades de partida de grupos de diferentes condições socioeconômicas?

A proposta de pesquisar a UFFS situa-se neste contexto de expansão e de interiorização das vagas no ensino superior, mas incorpora, também, políticas mais recentes, como o Enem, Lei de Cotas e SiSU. Trata-se de uma Instituição que foi criada no período de expansão do ensino superior, mas que também utilizou uma política de bonificação de escola pública, antes da Lei de Cotas. Esses fatores mais recentes, permite a esta pesquisa avançar em relação aos estudos de Silva (2016), Brito (2017); Carvalhaes \& Ribeiro (2019) por exemplo, no sentido de colocar novas questões para análise, a saber: como a Lei de Cotas, Enem, SiSU contribuem para reduzir a desigualdade horizontal? No caso da UFFS, que diferenças podem ser verificadas na transição entre política de bonificação de escola pública e Lei de Cotas, principalmente em termos de inclusão racial em carreiras de maior prestígio e/ou maior retorno econômico? 


\section{4 \\ Panorama sobre a expansão e interiorização do acesso ao ensino superior brasileiro e a UFFS}

A educação superior ocupa um importante papel na mobilidade social e na ascensão social dos indivíduos. Conforme destacam Buckner \& Zapp (2021), a partir da segunda década do século XX, a maioria dos países começaram a modernizar e a expandir seus sistemas de ensino superior. Nesse período, a massificação e a privatização passaram a moldar o cenário geral do ensino superior nos países industrializados e como tendência na maioria das regiões do mundo a partir de 1990. Os autores identificam três fases de expansão universitária, em termos globais:

- Antes da Segunda Guerra Mundial - ensino superior mais seletivo e voltado para as elites, e pesquisa voltada para a emergência e o desenvolvimento de nações e indústrias;

- Período pós-guerra - ocorre a massificação do ensino superior, com o objetivo de consolidação do cenário nacional de Bem-estar-social em muitos países ocidentais e a emergência de Estados-nação em muitos países coloniais;

- A partir de 1990 - com o fim da Guerra Fria, o período passa a ser marcado por uma lógica institucional associada ao surgimento de uma política econômica neoliberal, em que os valores de mercado influenciam tanto universidades púbicas quanto privadas. $\mathrm{Na}$ oferta de cursos superiores, existe uma tendência nos setores público e privado de oferta de diplomas mais voltados para negócios, ciência e tecnologia.

No Brasil, diferentemente de outros países da América Latina, por exemplo, a instituição Universidade nasceu de forma tardia, apenas em 1920, com a Universidade do Rio de Janeiro. Durante o período colonial, a educação superior brasileira era destinada às elites que se deslocavam até as universidades da metrópole portuguesa, especialmente em Coimbra e Évora. A partir da chegada da família real no Brasil, em 1808, foram sendo criadas algumas faculdades com cursos isolados, como a Escola de Cirurgia, na Bahia, em 1808 (Mendonça, 2000).

Na década de 1960, inicia no Brasil uma intensa industrialização e aumento da demanda pela educação superior. No seio de um discurso de modernização, a partir da Reforma Universitária de 1968, começaram a ocorrer significativas transformações na 
educação superior. O novo padrão do ensino superior foi marcado pelo fim das cátedras vitalícias e a introdução da organização da estrutura das instituições de ensino superior por departamentos; pela articulação entre ensino e pesquisa, por meio de institucionalização da carreira acadêmica, da graduação à pós-graduação; pela criação de uma política nacional de pós-graduação, a modernização de universidades federais, estaduais e confessionais, que permitiu um crescimento das matrículas, com maior abertura para o setor privado, principalmente por meio de instituições isoladas (Mendonça, 2000; Martins, 2009).

De acordo com Martins (2009) as matrículas na rede privada tiveram um salto de 142 mil para 885 mil alunos no período entre 1965 a 1980. Inicialmente ocorreu a proliferação de estabelecimentos isolados e, na década de 1980, gradualmente foi ocorrendo a transformação destes estabelecimentos em universidades privadas, passando de 20 para 64, com a concentração de um número maior de cursos. Para o autor o novo ensino superior privado de perfil empresarial surge na medida em que as universidades públicas, sobretudo as federais, modernizadas pela Reforma Universitária de 1968, não conseguem atender à crescente demanda por acesso ao ensino superior.

A Constituição de 1988 permitiu uma maior autonomia das universidades, possibilitando as Instituições privadas a criar e extingir seus próprios cursos, sem o controle burocrático de órgãos oficiais. Assim, a década de 1990 iniciou com 62\% das matrículas ofertadas pelo setor privado (Martins, 2009).

No período do governo FHC (1995-2002), uma série de medidas foram adotadas para o ensino superior envolvendo legislações fragmentadas na forma de decretos, que buscavam suprir a falta de orientações da Lei de Diretrizes e Bases (LDB) de 1996 para questões envolvendo este nível de ensino (Cunha, 2003). Esse é o caso, por exemplo, da obrigatoriedade do exame vestibular que vinha sendo utilizado desde 1911 como mecanismo de seleção para o ensino superior e da criação do Enem, em $1998^{21}$ como um exame de avaliação do ensino médio que poderia ser utilizado também para o ingresso no ensino superior. Muitas universidades, principalmente as públicas, não aderiram ao Enem e continuaram por muito tempo utilizando o exame vestibular, como acontece em diversas instituições até os dias de hoje.

A partir de 2003, no governo de Lula, ocorreu um novo direcionamento na educação superior com ênfase no setor público. Em 2004, o governo apresentou uma

${ }^{21}$ Instituído pela Portaria do MEC n. 438, de 28 de maio de 1998. 
proposta de Reforma Universitária, que buscava recuperar o papel do Estado como principal ator na condução do sistema de ensino superior, tendo como uma das medidas a valorização das universidades federais (Martins, 2009). Neste contexto, foi sendo criado um conjunto de ações, programas e políticas educacionais que se propõe a contribuir com a democratização das condições de acesso e permanência desse nível de ensino e para uma maior diversificação dos estudantes universitários, ao contemplar os egressos de escola pública, negros, indígenas, filhos de trabalhadores rurais e pessoas com deficiência.

Portanto, o início do século XXI é marcado por uma série de políticas voltadas para a expansão do acesso, para a interiorização e para a criação de novas instituições públicas de ensino superior. No período entre 2002 e 2019, foram criadas 30 novas universidades públicas, sendo 20 federais, nove estaduais e uma municipal (Inep, 2002; 2020a). Também foi significativa a criação de novos campi universitários federais, que passaram de um total de 148, em 2002, para 321, em 2014. A expansão das vagas públicas por meio da interiorização se diferencia do modelo tradicional de oferta de vagas nas capitais, passando de 114 para 289 o número de municípios atendidos por universidades federais (Brasil, 2014).

Com relação aos cursos e ao perfil de estudantes desses novos campi universitários abertos no interior entre 2003 a 2014, Barbosa \& Campos (2020), identificam similaridades e diferenças regionais. De um modo geral a maior participação de estudantes nestes campi está na área das licenciaturas (25,5\%), principalmente nas Regiões Norte, Nordeste e Centro-Oeste. Nas Regiões Sul e Sudeste a maior concentração está voltada para o setor produtivo e de inovação, nas áreas de "Engenharia, Produção e Construção" e de "Ciências, Matemática e Computação". Os autores chamam atenção para a importância de políticas públicas de permanência implementadas no período principalmente nas regiões mais pobres, que concentram estudantes das licenciaturas, oriundos de escolas públicas, cotistas, que recebem apoio social, autodeclarados pretos ou pardos. Enquanto que, nas Regiões mais ricas do Sul e do Sudeste, que concentram estudantes nas engenharias, predomina um perfil de estudantes com origem nas escolas privadas, não cotistas, autodeclarados brancos e que não recebem apoio social.

Conforme dados do Censo da Educação Superior de 2019 (Inep, 2020a), o Brasil possui um total de 2.608 Instituições de Ensino Superior (IES), sendo 918 localizadas 
nas capitais e 1.690 no interior. Destas IES, 88,4\% são privadas e 11,6\% são públicas. A Tabela 2 mostra o número de IES nas últimas duas décadas no Brasil e na Região Sul e permite observar, um crescimento de IES públicas federais e uma diminuição das públicas estaduais na Região Sul.

Tabela 2 - Número de IES no Brasil e Região Sul - 1999, 2009 e 2019

\begin{tabular}{llll}
\hline & $\mathbf{1 9 9 9}$ & $\mathbf{2 0 0 9}$ & $\mathbf{2 0 1 9}$ \\
\hline Brasil & $\mathbf{1 . 0 9 7}$ & $\mathbf{2 . 3 1 4}$ & $\mathbf{2 . 6 0 8}$ \\
Privada & 905 & 2.069 & 2.306 \\
Pública & 192 & 245 & 302 \\
Federal & 60 & 94 & 110 \\
Estadual & 72 & 84 & 132 \\
Municipal & 60 & 67 & 60 \\
Região Sul & $\mathbf{1 4 8}$ & $\mathbf{3 8 6}$ & $\mathbf{4 1 3}$ \\
Privada & 115 & 347 & 381 \\
Pública & 33 & 39 & 32 \\
Federal & 9 & 15 & 17 \\
Estadual & 17 & 15 & 9 \\
Municipal & 7 & 9 & 6 \\
\hline
\end{tabular}

Fonte: Inep $(2000 ; 2009 ; 2020 a)$

Embora as faculdades representam a maioria das instituições do país $(79,6 \%)$, as 198 universidades $(7,6 \%)$ concentram a maior parte das matrículas $(52,1 \%)$. A maioria das universidades é pública (54,5\%). Em 2019, foram ofertados 40.427 cursos de graduação, sendo $88,7 \%$ presenciais e $11,3 \%$ na modalidade a distância. Os cursos de bacharelados predominam, com 60,4\%; seguidos dos tecnólogos, com 20,8\% e das licenciaturas, com 18,9\% (Inep, 2020a).

O número de vagas ofertado em cursos de graduação em 2019 ultrapassou 16 milhões, sendo $71,6 \%$ de vagas novas. Nestas vagas novas o percentual de ingressantes foi apenas de 26,7\%, com uma ocupação das vagas ofertadas nas IES públicas de 80,9\% e de $23,7 \%$ nas privadas. Na última década, o número de matrículas de graduação aumentou 44,5\%, passando de 5.954.021, em 2009, para 8.603.824, em 2019.

O número de vagas ofertadas em cursos de graduação em 2019 ultrapassou 16 milhões, sendo 71,6\% de vagas novas. Nestas vagas novas o percentual de ingressantes foi de apenas 26,7\%, com uma ocupação das vagas ofertadas nas IES públicas de 80,9\% e de $23,7 \%$ nas privadas. Na última década, o número de matrículas de graduação 
aumentou 44,5\%, passando de 5.954.021, em 2009, para 8.603.824, em 2019. A concentração atual de matrículas está em 75,8\% na rede privada e 24,2\% na rede pública.

A maioria das matrículas no ensino superior é de mulheres $(57,4 \%)$. Conforme mostra a Tabela 3, a representação feminina em cursos de licenciaturas é quase duas vezes a dos homens (Inep, 2009; 2020a).

Tabela 3 - Porcentagem de matrículas por sexo e por grau acadêmico - 2019

\begin{tabular}{llllll}
\hline Sexo & Bacharelado & Licenciatura & Tecnólogo & Não aplicável & Total \\
\hline Feminino & 63,2 & 24,7 & 11,8 & 0,3 & 100 \\
Masculino & 69,3 & 12,8 & 17,5 & 0,4 & 100 \\
\hline
\end{tabular}

Fonte: Inep (2020a)

Em 2001, o Plano Nacional de Educação (PNE) propôs a meta de ampliação das matrículas da educação superior de $12 \%$ para 30\%, para jovens de 18 a 24 anos (BRASIL, 2001a). Já o PNE atualmente vigente (2014-2024) em sua meta 12 propõe "elevar a taxa bruta de matrícula na educação superior para 50\% e a taxa líquida para $33 \%$ da população de 18 a 24 anos, assegurada a qualidade da oferta e expansão para, pelo menos, 40\% das novas matrículas, no segmento público" (Brasil, 2014). O Gráfico 2 mostra o alcance das taxas bruta e líquida ${ }^{22}$ da Educação Superior em 2018, com base em dados do Anuário Brasileiro da Educação Básica 2019.

22 "Taxa bruta se refere o "percentual de pessoas que frequentam cursos de graduação na educação superior em relação à população de 18 a 24 anos" e taxa líquida se refere ao "percentual de pessoas de 18 a 24 anos que frequentam cursos de graduação na educação superior em relação à população de 18 a 24 anos" (Inep, 2014, p. 36). 
Gráfico 2 - Porcentagem de matrículas (taxas bruta e líquida) no Brasil - 2012-2018

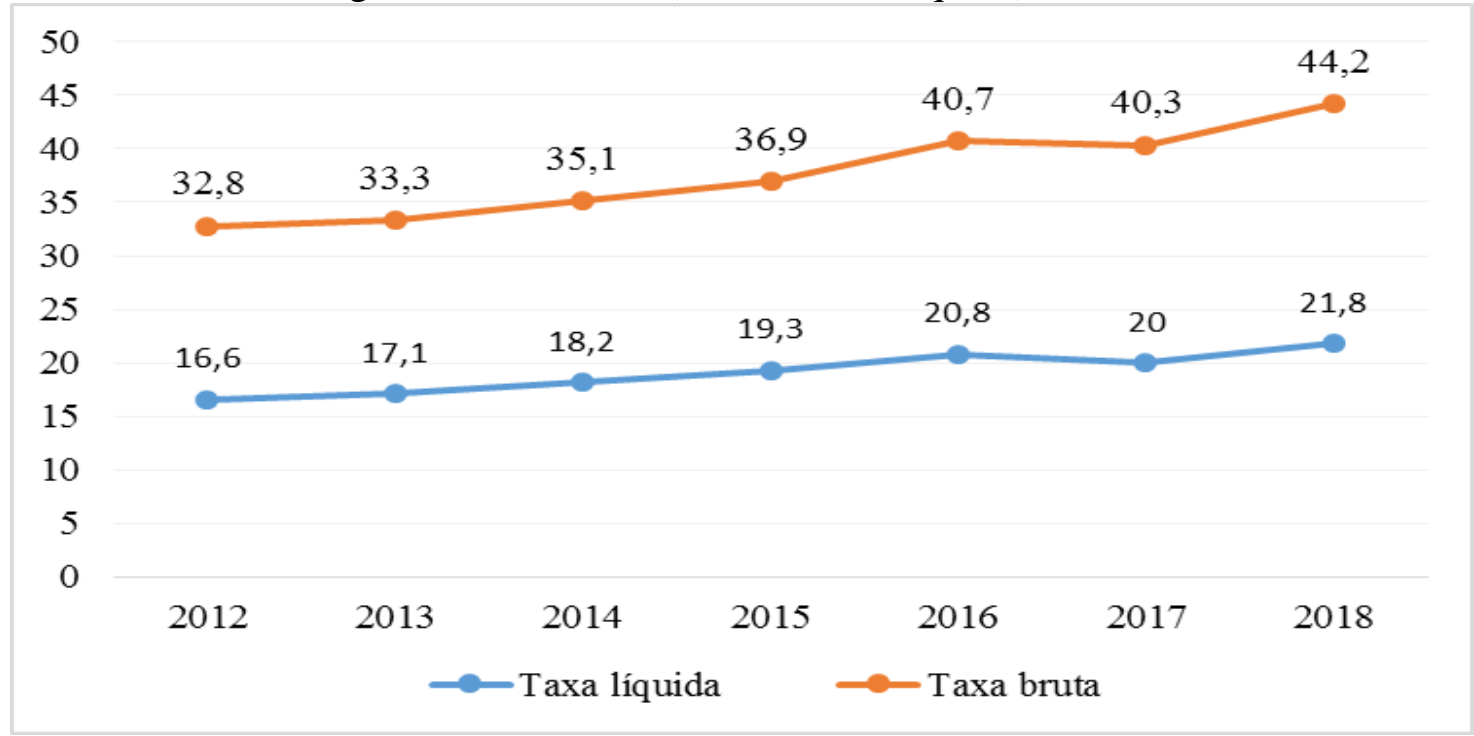

Fonte: Elaboração própria, conforme dados de Todos pela Educação (2019, p 97)

Isso demonstra que apenas $21,8 \%$ dos jovens brasileiros com idade entre 18 a 24 anos estão na educação superior, considerando o ano de 2018. De acordo com a escala proposta por Martin Trow (2005), o ensino superior brasileiro está se encaminhando para a massificação, mas ainda distante da universalização. Segundo essa escala, uma taxa de escolaridade de menos de $15 \%$ retrata um sistema de elite; uma taxa de $15 \%$ a $30 \%$ representa um sistema em trânsito para a massificação; o intervalo de $30 \%$ até 50\%, um sistema de massa e acima de 50\%, um sistema universal (Trow, 2005).

$\mathrm{O}$ acesso ocorre de forma desigual nas diferentes regiões do país (Gráfico 3). A região Centro-Oeste e a Sul possuem a maior taxa líquida de educação superior do Brasil, enquanto as regiões Norte e a Nordeste possuem a taxa menor. Entre as unidades da federação destaca-se o Distrito Federal, localizado na Região Centro-Oeste, com a taxa líquida de $36,5 \%$, a maior do país, que ultrapassa, inclusive, a meta de $33 \%$ prevista pelo PNE para 2024. Por outro lado, o Estado do Pará, localizado na Região Norte concentra a menor taxa líquida, de 14,6\% (Todos pela Educação, 2019). 
Gráfico 3 - Porcentagem de matrículas da população de 18 a 24 anos (taxa líquida) no Brasil e nas regiões - 2012 - 2018

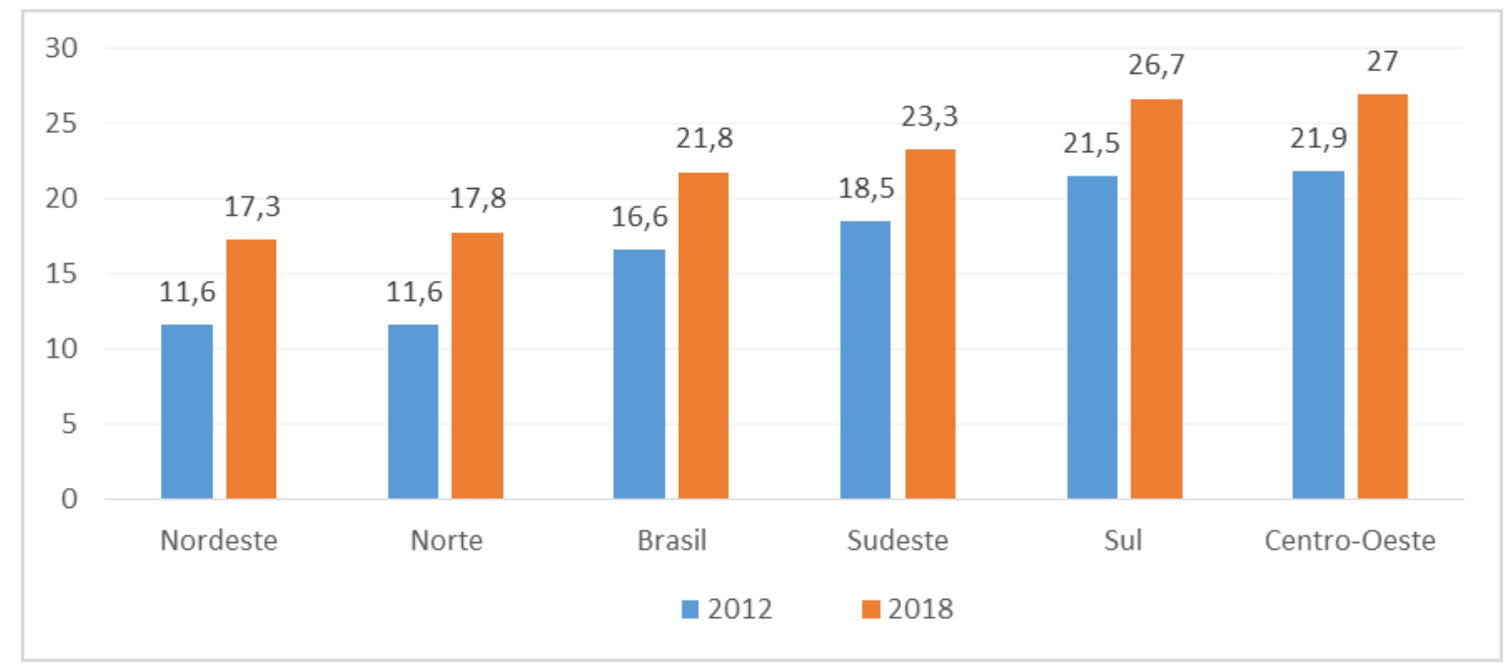

Fonte: Elaboração própria, conforme dados de Todos pela Educação (2019, p. 100).

Em que pese as mudanças mais inclusivas na renda dos estudantes do ensino superior, a origem socieoeconômica ainda constitui uma das principais dimensões das desigualdades na educação superior. Nas IES federais, dados da pesquisa da Associação Nacional dos Dirigentes das Instituições Federais de Ensino Superior (Andifes), realizada em 2018, mostram diferenças regionais significativas. Com relação aos estudantes com renda mensal bruta do grupo familiar de até 3 salários mínimos, nas regiões Sul $(39,9 \%)$ e Norte $(67,4 \%)$ essa diferença chega a 27,5 p.p.. No Nordeste, este percentual é de 62,2\%; no Sudeste de 42,1\% e no Centro-Oeste de 42,9\%. A média geral nesta faixa de renda é de 50,9\% (Andifes, 2019).

Outra dimensão desigual na educação superior é entre jovens das zonas urbana e rural, sendo que jovens das áreas urbanas acessam quase três vezes mais o ensino superior que os da área rural, conforme mostra a Tabela 4.

Tabela 4 -Taxa líquida de matrículas, por localidade no Brasil: 2012 -2018

\begin{tabular}{llllllll}
\hline & $\mathbf{2 0 1 2}$ & $\mathbf{2 0 1 3}$ & $\mathbf{2 0 1 4}$ & $\mathbf{2 0 1 5}$ & $\mathbf{2 0 1 6}$ & $\mathbf{2 0 1 7}$ & $\mathbf{2 0 1 8}$ \\
\hline Urbana & 18,4 & 19,1 & 20,1 & 21,4 & 23,0 & 21,9 & 24,0 \\
Rural & 5,1 & 5,3 & 6,4 & 6,7 & 6,8 & 7,2 & 8,0 \\
\hline
\end{tabular}

Fonte: Elaboração própria, conforme dados de Todos pela Educação (2019, p 97)

Além da desigualdade em termos regionais e segundo a localidade de moradia, situamos também a desigualdade de acesso em termos de raça. Os dados revelam que a 
acessibilidade da juventude negra, em geral tende a ser menor, quando comparada com a branca, conforme apresenta a Tabela 5.

Tabela 5 - Taxa líquida de matrículas por raça/cor no Brasil: 2012 - 2018

\begin{tabular}{llllllll}
\hline & $\mathbf{2 0 1 2}$ & $\mathbf{2 0 1 3}$ & $\mathbf{2 0 1 4}$ & $\mathbf{2 0 1 5}$ & $\mathbf{2 0 1 6}$ & $\mathbf{2 0 1 7}$ & $\mathbf{2 0 1 8}$ \\
Total & 16,6 & 17,1 & 18,2 & 19,3 & 20,8 & 20,0 & 21,8 \\
Brancos & 24,1 & 25,0 & 25,7 & 27,1 & 28,4 & 27,9 & 30,7 \\
Pretos & 9,4 & 9,2 & 10,6 & 12,3 & 13,8 & 14,6 & 15,1 \\
Pardos & 10,6 & 11,3 & 12,6 & 13,7 & 15,2 & 14,6 & 16,3 \\
\hline
\end{tabular}

Nota: “As estatísticas Amarelos, Indígenas e Não Declarado não foram apuradas por não ter observações em quantidade suficiente para garantir a validade estatística". (Todos pela Educação, 2019, p. 139)

Fonte: Elaboração própria, conforme dados de Todos pela Educação (2019, p 97)

A desigualdade de acesso em termos de renda é outra dimensão a ser considerada. Com base em dados de 2017, entre o grupo dos $25 \%$ de jovens mais pobres a taxa de matrícula líquida na educação superior é de 7,2\%, enquanto que entre os $25 \%$ mais ricos, a taxa chega a 48,0\%, conforme demonstra o Gráfico 4 (Todos pela Educação, 2019).

Gráfico 4 - Porcentagem de matrículas na educação superior da população de 18 a 24 anos (taxa líquida -20,0\%) por renda no Brasil, em 2017

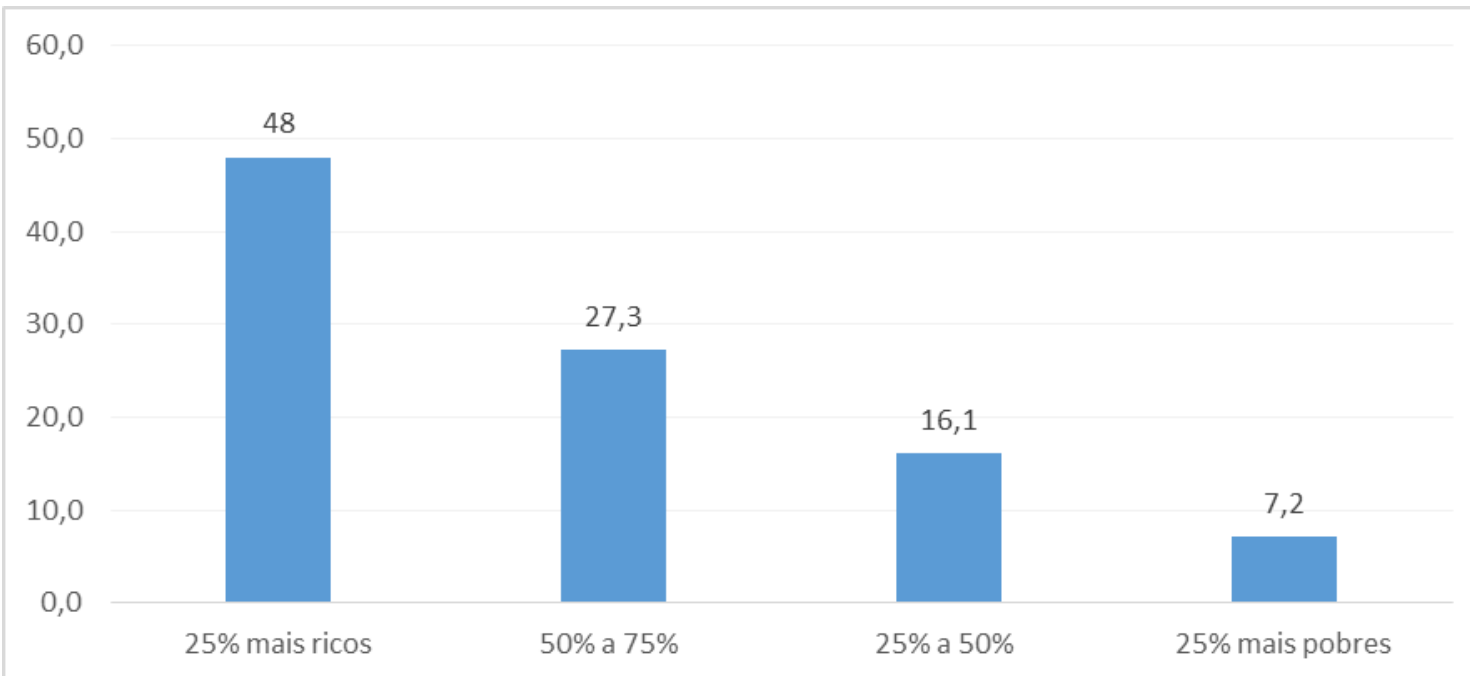

Fonte: Elaboração própria, com base em dados de Todos pela Educação (2019, p 97)

Os dados evidenciam que nas últimas décadas ocorreu uma expansão significativa no ensino superior brasileiro, marcada por novas matrículas, cursos e a criação de novas universidades e campi, principalmente na rede pública e em 
municípios no interior dos estados brasileiros. Ainda assim, 75,8\% das matrículas está concentrada na rede privada.

Apesar da expansão ocorrida, o Brasil ainda está distante da universalização do ensino superior, pois apenas $21,8 \%$ dos jovens brasileiros na faixa etária entre 18 e 24 anos frequentam esta etapa de ensino. A democratização do acesso ao ensino superior ainda se apresenta como um desafio, uma vez que, as desigualdades, principalmente em termos regionais, de renda, raça e de localização da moradia ainda são relevantes. Ou seja, conforme considera Dubet (2015) os benefícios da expansão não são apropriados por todos da mesma forma.

Políticas e programas que acompanharam o processo de expansão, interiorização e as mudanças no perfil socioeconômico e racial dos universitários serão apresentadas na próxima seção.

\subsection{Principais programas e políticas para a educação superior}

A expansão atual das redes de ensino superior públicas e privadas é acompanhada por ações, programas e políticas educacionais que se propõem a contribuir com a democratização das condições de acesso e permanência desse nível de ensino, marcado historicamente pelo elitismo.

Entre as iniciativas que fomentaram principalmente a diversidade e as ações afirmativas na educação superior, destaca-se, primeiramente, a Conferência Mundial de Combate ao Racismo, Discriminação Racial, Xenofobia e Intolerância, realizada em Durban, na África do Sul, em 2001, na qual o Estado brasileiro passou a reconhecer o racismo e se comprometeu com a realização de ações reparatórias. Esse movimento fortaleceu o debate sobre as ações afirmativas, sendo a UERJ a pioneira no Brasil a implementar cotas para estudantes oriundos de escola pública, negros e pessoas com deficiência, em 2003. A partir dessa experiência, outras IES do país também foram criando diversas modalidades de ações afirmativas em suas políticas de ingresso.

No início do governo Lula destaca-se, entre suas primeiras ações, a criação em 2004 da Secretaria Especial de Políticas de Promoção da Igualdade Racial ${ }^{23}$ (SEPPIR),

\footnotetext{
${ }^{23}$ Em 2008, no Governo de Lula, a Secretaria passou a ter status de Ministério; em 2015, no Governo de Dilma Roussef, a SEPPIR foi incorporada ao Ministério das Mulheres, da Igualdade Racial e dos Direitos Humanos, e, em 2017, no Governo de Michel Temer, passou a ser vinculada a uma pasta dentro do Ministério da Justiça e no Governo de Bolsonaro foi incorporada a uma pasta dentro do Ministério da Mulher, da Família e dos Direitos Humanos.
} 
com o objetivo de fomentar políticas públicas voltadas para o enfrentamento do racismo e a promoção da igualdade racial. Nesse mesmo ano, o Governo apresentou ao Congresso Nacional o Projeto de Lei n. 3.627, transformado na chamada Lei de Cotas em 2012, que previa a reserva de vagas nas universidades federais para estudantes egressos de escolas públicas, pretos, pardos e indígenas, e com renda per capita familiar de até 1,5 salário mínimo.

No âmbito da educação superior privada de ensino, destacamos a criação do Fundo de Financiamento ao Estudante do Ensino Superior (FIES), criado em 2001, ainda no Governo FHC, mas que foi alvo de modificações ao longo dos anos. Por meio deste programa os estudantes de graduação podem financiar seus estudos em até 100\%, tendo um prazo de carência para o início do pagamento após o término do curso, mediante condições e regras estabelecidas pelo MEC (Brasil, 2001b). Entre as últimas alterações $^{24}$ do Programa, destaca-se que o FIES, a partir de 2018, passou a conceder financiamentos a juro zero para estudantes com renda per capita de até três salários mínimos. Conforme Ristoff (2016, p. 25) “observa-se que ao final de 2014, das 5,8 milhões de matrículas do setor privado, cerca de 3 milhões $(52,1 \%)$ eram matrículas totalmente financiadas pelo poder público federal". Portanto, essa parceria entre FIES e ProUni consolidou importantes políticas públicas de inclusão na educação superior.

Destacamos, ainda, o Programa Universidade para $\operatorname{Todos}^{25}$ (ProUni), criado em 2004, com o objetivo de conceder bolsa integral e parcial para estudantes de Instituições privadas, por meio de critérios como renda, escola pública, deficiência e condição racial (preto, pardo ou indígena) (Brasil, 2005).

Com o objetivo de ampliar o acesso e a permanência na educação superior pública, em 2007, foi instituído, pelo Decreto n. 6.096, o Programa Reuni com o propósito de adotar uma série de medidas para viabilizar condições para o crescimento da rede federal da educação superior, tendo como algumas de suas diretrizes, a redução da evasão, ocupação de vagas ociosas, mobilidade estudantil, diversificação das modalidades de graduação e o apoio à assistência estudantil (Brasil, 2007).

Ainda, com relação ao apoio à permanência dos estudantes de graduação nas instituições federais de ensino superior, o governo criou em 2007, no âmbito do

\footnotetext{
${ }^{24}$ Lei n. 13.530, de 7 de dezembro de 2017.

${ }^{25}$ Criado pela Medida Provisória n. 213, convertida na Lei n. 11.096/05, em 2005.
} 
Ministério da Educação (MEC), o Programa Nacional de Assistência Estudantil, que foi regulamentado pelo Decreto n. 7.234, em 2010. O programa tem por objetivo apoiar a permanência de estudantes em situação de vulnerabilidade socioeconômica em cursos de graduação nas Instituições Federais de Ensino Superior (Brasil, 2010).

O Enem foi criado em 1998 com o objetivo de avaliar o desempenho do Ensino Médio, mas suas notas já eram utilizadas pelo ProUni para selecionar candidatos ao ensino superior. A partir de 2009, o Enem passou a ser adotado pela maioria das IES, como mecanismo de seleção. Conforme observa Li (2016, p. 23),

\footnotetext{
Em 2009, o Enem passou por uma profunda reestruturação que o fez passar a ser chamado de "O novo Enem". Pela Portaria no 462, o Ministério da Educação apresentou uma proposta de reformulação metodológica do exame com o fim de incentivar a sua utilização como forma de seleção unificada nos processos seletivos das universidades públicas federais. A nova proposta tinha como objetivos democratizar as oportunidades de acesso às vagas federais de ensino superior, possibilitar a mobilidade acadêmica e induzir a reestruturação dos currículos do ensino médio.
}

No âmbito das IES, o Enem aparece com diferentes combinações, a saber: fase única (com 100\% das vagas) e integrada com o SiSU; combinada com vestibular; apenas como primeira fase e como fase única usada para as vagas remanescentes do vestibular ( $\mathrm{Li}, 2016)$.

Um mecanismo que induziu ainda mais a utilização deste exame foi o SiSU, instituído pelas Portarias Normativas N. 2/2010 e N. 21/2012 (Brasil, 2010; 2012). É um sistema de informações gerenciado pelo Ministério de Educação, responsável pela seleção de estudantes para vagas de graduação disponibilizadas pelas instituições de educação superior públicas de todo o país e que se utiliza exclusivamente das notas do Enem. O sistema é autônomo em relação às demais formas de seleção utilizadas pelas instituições e, por meio de termo de adesão, estabelece os critérios para a concorrência pelas vagas, respeitando a Lei de Cotas, e demais reservas de vagas e ações afirmativas específicas de cada IES. Segundo Machado, Bessa \& Feres Júnior (2019) para o ano de 2017 o SiSU foi adotado por 62 universidades federais, e em 23 delas, para 100\% de suas vagas.

Em abril de 2012, após passado alguns anos de muito debate e questionamentos, principalmente com relação às cotas raciais, o Supremo Tribunal Federal (STF) declarou a constitucionalidade da política de cotas utilizada pela UNB. Também foram 
julgadas constitucionais as cotas utilizadas nas universidades estaduais no Rio de Janeiro. Em agosto de 2012, foi sancionada, pela Presidenta Dilma Rousseff, a Lei de Cotas, n. 12.711, que torna obrigatório para todas as universidades e institutos técnicos de ensino médio e da educação superior da rede federal, a reserva de pelo menos $50 \%$ de suas vagas em todos os cursos e turnos para estudantes que cursaram integralmente o ensino médio em escolas públicas, no caso das Universidades, e o ensino fundamental no caso dos Institutos (Brasil, 2012).

No preenchimento das vagas reservadas para egressos de escola pública devem ser reservadas $50 \%$ para estudantes com renda per capita familiar de até um saláriomínimo e meio e 50\% apenas para escola pública, independentemente de renda. Dentro de cada um desses percentuais, deverão ser preenchidas vagas por estudantes autodeclarados pretos, pardos e indígenas (PPIs), com referência na proporção dessa população em cada Estado da federação de acordo com o Censo do Instituto Brasileiro de Geografia e Estatística (IBGE) (Brasil, 2012).

Conforme observam Daflon, Feres Junior \& Campos (2013), a adoção de ações afirmativas já vinha ocorrendo nas IES brasileiras desde o ano de 2002. No período entre 2002 a 2010, 70 IES que adotavam algum tipo de ação afirmativa, sendo a cota a modalidade mais comum, além de outras formas como o acréscimo de vagas e bônus.

Ao analisar o impacto da Lei de Cotas em diferentes estados brasileiros, Carvalhaes et al. (2013) fazem uma crítica à referida Lei, no sentido de sua incapacidade de reverter padrões combinados de desigualdades que caracterizam o Brasil, nas suas diferentes regiões. O estudo das características regionais brasileiras e da aplicação do primeiro ano da Lei de Cotas permite aos autores observarem que existe uma maior concorrência entre as vagas reservadas para os grupos menos privilegiados da população que acumulam desigualdades étnico-raciais e sociais, chegando a ser o dobro em relação aos estudantes com a desvantagem apenas de renda.

Os maiores beneficiários pelas cotas estão entre os grupos com renda familiar per capita acima de 1,5 salários-mínimos, e entre este, os pretos, pardos e indígenas, mais que os brancos. Ao comparar a Região Sul com as demais regiões, cuja proporção de PPIs é menor no total da população, observa-se uma menor desvantagem entre os beneficiários com renda familiar inferior a 1,5 salários-mínimos. Assim, para os pobres e PPIs de Santa Catarina, por exemplo, a concorrência de vagas chega a ser cinco vezes menor do que para este mesmo grupo em estados como Maranhão e Bahia. 
A Lei de Cotas, após a sua aprovação, teria um prazo de quatro anos para sua adequação integral em todas as IES públicas federais brasileiras, e dez anos para ser avaliada. Conforme levantamento realizado por Ristoff (2016), as IES federais em 2015/1 tinham atingido o percentual de 47\% (177.688), de vagas ofertadas para estudantes oriundos de escola pública, superando em $9,5 \%$ o que estava previsto na Lei para o ano de 2015. Das vagas ofertadas, 23\% (82.881) foram reservadas para pretos, pardos e indígenas (PPIs), ou seja, metade das vagas. Considerando que os PPIs representam $52 \%$ na população brasileira, ainda existe uma disparidade nesta oferta, que somente estaria contemplada caso fosse ofertado a esse público 92.397 das vagas.

Por outro lado, segundo o autor, enquanto algumas IES estão cumprindo apenas o que está estritamente previsto como exigência mínima na Lei, outras superaram os percentuais anuais. Na relação das dez IES (três universidades e sete institutos federais) que superaram os percentuais de estudantes oriundos da escola pública previstos pela Lei de Cotas para o ano de 2016, a UFFS aparece em primeiro lugar com 87,0\%, seguida pela UFSB, com 66,1\% e pelo Instituto Federal de Educação, Ciência e Tecnologia de Brasília (IFB), com 59,0\%.

Ao final de 2016, no governo de Michel Temer, foi sancionada a Lei n. 13.409, de 28 de dezembro de 2016, que alterou a Lei de Cotas, para incluir as pessoas com deficiência na reserva de vagas para pretos, pardos e indígenas, respeitando a proporção da unidade federativa em que está instalada a instituição, segundo o último Censo do IBGE (Brasil, 2016). No segundo semestre de 2017, o número de estudantes com deficiência atendidos por esta reserva de vagas foi de 2.840. Um total de 30 universidades federais já havia aderido à Lei e nove já adotavam cotas específicas para esse grupo (Machado; Bessa; Feres Júnior, 2019).

Apesar das políticas voltadas para a democratização de acesso e para a expansão de toda a rede da educação superior, os dados ainda revelam um panorama de desigualdades, principalmente com relação ao baixo acesso a esse nível de ensino, às barreiras econômicas e raciais e às maiores vantagens de acesso aos estudantes oriundos das escolas privadas. 


\subsection{O contexto de criação da UFFS}

No contexto de expansão e interiorização da educação superior brasileira, a UFFS foi criada em 2009 de forma multicampus e interestadual, cujos campi estão localizados na área de abrangência da Mesorregião Grande Fronteira do Mercosul $^{26}$, que é formada por cerca de 400 municípios situados no Sudoeste do Paraná (Campi Laranjeiras do Sul e Realeza), no Oeste de Santa Catarina (Campus Chapecó) e no Noroeste do Rio Grande do Sul (Campi Erechim, Cerro Largo). Nesta mesma região do Rio Grande do Sul, em 2013, foi criado o Campus Passo Fundo, que oferta o curso de Medicina, por meio da Política de Expansão das Escolas Médicas do Brasil. A figura 1 apresenta um mapa com a distribuição espacial dos campi da UFFS, evidenciando a sua característica de interiorização. As cidades em que os campi foram instalados são de diferentes portes e estão distantes das capitais e regiões metropolitanas no mínimo a 289 km (Passo Fundo) e no máximo a 553km (Chapecó).

\footnotetext{
${ }^{26}$ Esse território possui um contigente relativamente baixo de urbanização (65\%), de modo que concentra uma significativa parte de sua população residente na zona rural. Essa Mesorregião surgiu por meio da criação do Fórum de Desenvolvimento Integrado e Sustentável da Mesorregião da Grande Fronteira do Mercosul, tendo seus projetos voltados, por exemplo, para o fortalecimento de agroindústrias familiares, psicultura, setor lácteo, viticultura e apoio ao turismo na região das missões jesuíticas (Demarco; Maia, 2013).
} 
Figura 1 - Mapa da distribuição espacial dos campi da UFFS nos estados da Região Sul

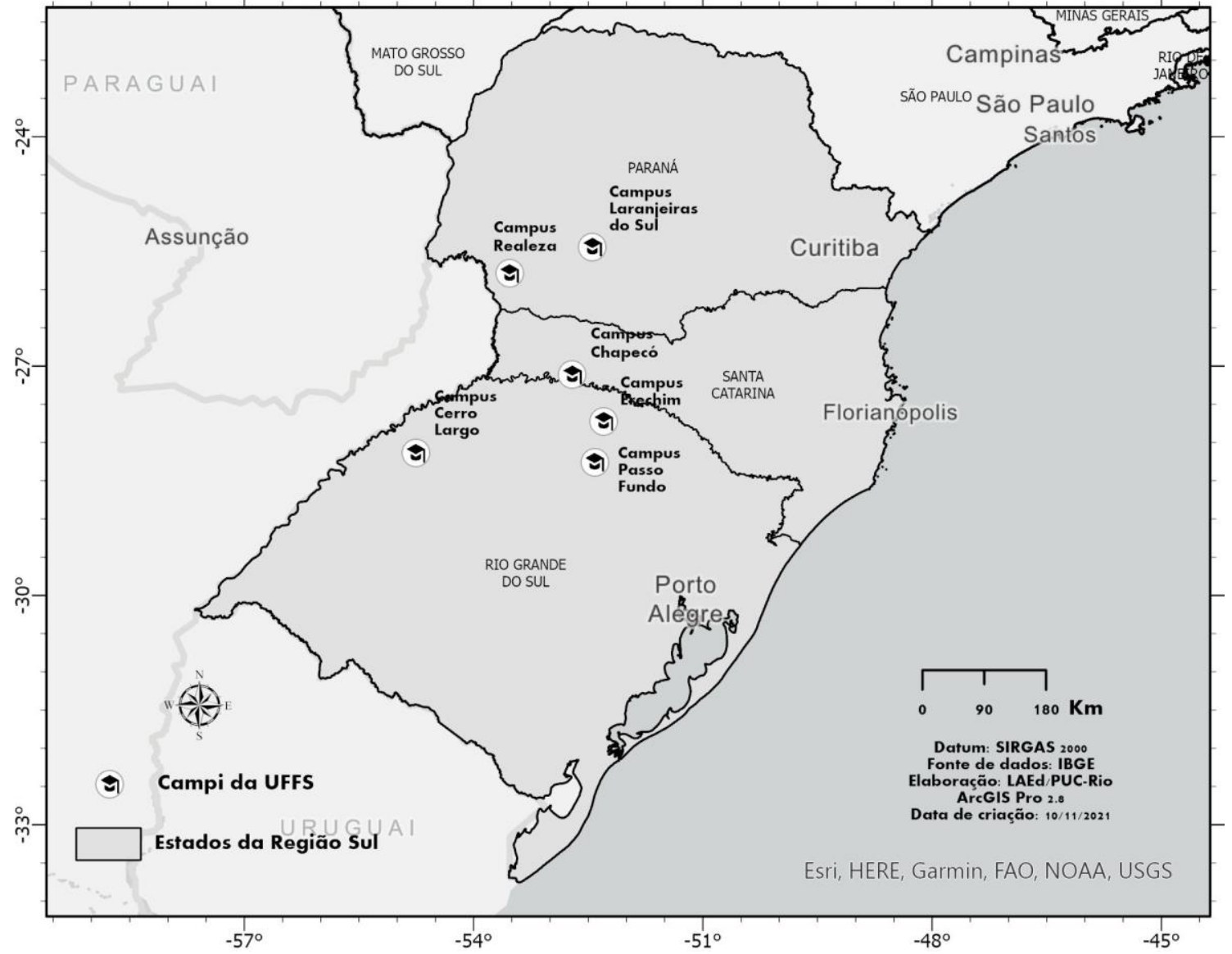

Fonte: Elaborado por Laboratório de Avaliação da Educação (LAEd/PUC-Rio ${ }^{27}$ )

Este vasto território que se organizou e se mobilizou em torno da criação da UFFS passou a se constituir como uma referência no país de organização comunitária e como palco de muitas lutas principalmente ligadas ao acesso à terra e a condições mais dignas para nela permanecer. Trata-se de uma região que teve as primeiras experiências no país de modernização da agroindústria e da agricultura, o que acarretou a expansão dos processos produtivos, novas perspectivas de inclusão, mas também o êxodo rural e grandes concentrações de riqueza e propriedade, e, consequentemente grandes conflitos e exclusão de significativas parcelas dessa população. Sua economia é diversificada, com o desenvolvimento de agricultura (milho, soja...), pecuária (bovinos de corte e de leite, suínos...), fruticultura (cítricos, uva...), silvicultura (reflorestamento, erva-mate), indústria (metal mecânica, moveleira...), comércio e prestação de serviços públicos e privados (UFFS, 2014b).

27 Agradecemos à colaboração da pesquisadora Juliana Cristina Araujo do Nascimento Cock (LAEd/PUC-Rio) na elaboração do Mapa. 
Entre os movimentos que se somaram à luta pela conquista da UFFS e assumiram a liderança do Movimento Pró-Universidade, destacam-se a Federação dos Trabalhadores da Agricultura Familiar da Região Sul (Fetraf-Sul) e a Via Campesina. Essas mobilizações iniciaram-se ainda na década de 1980, no contexto da redemocratização do país, tendo como marcos a Constituição Federal e a nova Lei de Diretrizes e Bases. Com o cenário neoliberal predominante na década de 1990, as mobilizações não foram tão efetivas, mas levaram à criação de um conjunto de universidades comunitárias e estaduais nessa região. Os movimentos continuaram ativos na busca por um ensino superior público e gratuito nessa região interiorizada dos três Estados, como uma condição para o desenvolvimento regional e para a superação de desigualdades históricas de acesso à educação superior (UFFS, 2014b; Trevisol, 2016).

No início do século XXI, no governo de Lula, essa mobilização obteve condições mais favoráveis para a conquista de uma universidade pública, no seio de políticas públicas que fomentaram a ampliação de acesso e permanência da educação superior pública, a exemplo do Programa Reuni. Rorato (2016, p. 220) destaca o protagonismo dos atores territoriais regionais/locais no sentido de questionar e impor reivindicações ao governo federal. "Esses atores aproveitaram uma nova oportunidade que se colocava - possibilidade de fazer parte da política federal de educação -, a partir de um processo de abertura democrática e de valorização dos movimentos sociais".

Em 2005, foi apresentada à Câmara dos Deputados um Projeto de Lei $^{28}$ de criação da UFFS. Em 2006 a Universidade Federal de Santa Catarina (UFSC), por meio de um Grupo de Trabalho (Portaria 356/GR/2006), foi envolvida na criação do projeto preliminar da nova Universidade. A partir de 2006, ocorreu também a unificação dos movimentos sociais, em prol da criação desta nova universidade pública federal e para facilitar a interlocução com o MEC. Naquele mesmo ano uma audiência neste ministério aprovou a proposta de criar uma universidade nova no Sul do país, com abrangência prevista para o Norte do Rio Grande do Sul, o Oeste de Santa Catarina e o Sudoeste do Paraná. Inicialmente o MEC havia proposto a criação de um instituto federal, mas os movimentos sociais reivindicavam a criação de uma universidade federal. Em 2007, além da UFSC, representantes também da Universidade Federal de Santa Maria (UFSM) e técnicos do MEC participaram de uma Comissão de Projetos da Universidade Federal da Fronteira Sul (Portaria n. 948/MEC/2007). O Projeto de Lei

\footnotetext{
${ }^{28}$ Projeto de Lei n. 6.037/2005, apresentado pelo então Deputado Federal Cláudio Vignatti.
} 
voltado para a criação da UFFS foi assinado pelo Presidente da República em 2008 e submetido ao Congresso Nacional. Em fevereiro de 2009, foi criada pelo MEC a Comissão de Implantação da UFFS (Portaria 148/09), sendo designado como presidente desta Comissão, o Professor Dilvo Ristoff (UFSC). Depois de muitas negociações entre o Movimento Unificado (Pró-Universidade) e o MEC, a UFFS foi criada pela Lei n. 12.029, em 15 de setembro de 2009 (Brasil, 2009, UFFS, 2014b; Trevisol, 2016). Conforme Rorato (2016, p. 160):

Dilvo Ristoff desempenhou papel fundamental na negociação com os integrantes do Movimento Pró-Universidade, e todas as questões definidas pela Comissão de Implantação foram discutidas. Um exemplo foi a forma de ingresso. $\mathrm{O}$ Movimento Pró-Universidade havia apresentado aproximadamente dez tipos diferentes de cotas. A proposta de Dilvo Ristoff, que agradou a todos, foi utilizar o fator escola pública, visando garantir que os estudantes de escola pública (onde estudavam as populações excluídas) tivessem acesso diferenciado. Dilvo Ristoff foi eleito reitor pro tempore e organizou todo o processo de implantação da UFFS.

Com relação ao termo "fronteira", Rorato (2016, p. 224) defende a hipótese de que:

[...] a UFFS é muito mais uma universidade de fronteira entre estados do que uma universidade de fronteira com outros países. $O$ próprio nome da universidade suscita essa dúvida. Porém, vimos que esse nome foi uma escolha que acabou ficando por falta de tempo para discutir um nome mais adequado ao perfil dessa instituição e que contemplasse todos os atores territoriais envolvidos. Assim, a fronteira, adicionado o adjetivo sul, ficou por ser definida posteriormente. Podemos ver o quanto a própria UFFS, por meio de seu corpo técnico, tem tentado reforçar a identidade de universidade da fronteira sul, ou da mesorregião fronteira sul.

Com relação à escolha do nome da UFFS, o estudo de Tischer (2016, p.100), indicou que:

\footnotetext{
Os integrantes do Movimento Pró-Universidade Federal preferiam 'Universidade Federal da Agricultura Familiar' ou 'Universidade Federal Popular', em detrimento do critério geográfico e por motivos ideológicos de 'Mercosul'. Por outro lado, integrantes do MEC salientavam o recorte geográfico, assim como integrantes do Fórum da mesorregião, e acabaram por retirar os termos 'Grande' e 'Mercosul' e o nome da Universidade Federal permaneceria com o critério geográfico de escolha.
}

Entre os aspectos que marcaram a origem da UFFS destaca-se, principalmente, o seu cunho público e "popular", uma vez que sua concepção partiu de uma mobilização histórica da sociedade civil organizada em prol da educação superior pública e gratuita (UFFS, 2014b). 
O estudo de Dambrós (2015) teve o objetivo de analisar os dilemas atribuídos ao sentido do termo "popular" da Universidade Federal da Fronteira Sul. Por meio de análise de documentos acerca do processo de criação desta IES e demais documentos institucionais regulatórios de suas políticas nos primeiros cinco anos de existência, a autora concluiu que o termo "popular" é um princípio fundante da UFFS e ganha materialidade principalmente em suas políticas de acesso mais inclusivas.

A predominância e as políticas de acesso que privilegiam a inclusão de estudantes de escolas públicas; a gestão por meio de conselhos que permitem o envolvimento da comunidade na construção das políticas institucionais; a ocupação de temáticas de interesse de base familiar; o princípio de organização interna e o envolvimento dos movimentos sociais; a configuração diferenciada do currículo por meio dos domínios comum, conexo e específico; e o próprio envolvimento do Movimento PróUniversidade no processo de implantação - anunciam que a jovem universidade tem evidenciado em suas bandeiras de ação elementos importantes que podem contribuir para o avanço da reflexão sobre a universidade pública e popular (Dambrós, 2015, p.53).

Contudo, a autora sinaliza que, embora o termo "popular" seja um elemento presente na gênese desta Instituição, o termo se faz presente em parte dos documentos institucionais e em parte encontra-se ausente, o que demonstra não existir um entendimento único em relação ao "popular” desta Instituição.

\begin{abstract}
Apesar de, em parte dos documentos institucionais analisados, prevalecer instituída a intencionalidade de afirmar o caráter popular da universidade, em outra parte esse termo parece não figurar como importante, e isso pode estar, ou não, vinculado aos dilemas presentes em sua configuração. Ainda assim, reafirma-se que o popular se constitui em uma característica importante na constituição da universidade, pois é portador de uma nova utopia social em construção. Ter sido denominada como a primeira universidade pública e popular gerou à UFFS compromisso histórico com o fazer e com as dimensões do popular. Por se converter em qualitativo de educação peculiar, por trazer consigo não só uma concepção política mas também um projeto de sociedade para a qual a responsabilidade social da universidade implica assumir o compromisso de repensar a sociedade a partir dos princípios mais amplos, que se orientam pelas demandas políticas, sociais, culturais, econômicas do País e da classe trabalhadora, esse adjetivo não pode ser visto apenas como uma alegoria (Dambrós, p.100).
\end{abstract}

Portanto, o que se pretende é situar o caráter inovador ${ }^{29}$ desta Instituição, principalmente pelas suas tendências de democratização do acesso ao ensino superior,

\footnotetext{
29 McCowan (2019) destaca alguns modelos de universidades como experimentais, cujas práticas são mais inovadoras e frequentemente são instituições localizadas em regiões mais periféricas, empobrecidas e que visam acomodar populações mais carentes. Entre os exemplos destas novas Universidades, o autor
} 
materializadas, principalmente, em suas políticas de acesso e no perfil diferenciado de seus estudantes, as quais serão aprofundadas ao longo deste trabalho. São características que se distinguem das tradicionais universidades federais brasileiras. Ainda, conforme destaca Dambrós (2015, p.101):

\begin{abstract}
Portanto, o que está em jogo com a característica popular da universidade é uma qualidade referenciada no projeto de sociedade dos movimentos sociais que a conceberam e que é, nitidamente, um projeto mais humano, mais justo e mais democrático. Resta saber, diante de tudo isso, se os atores sociais presentes na universidade estão dispostos a assumir as dimensões do popular da universidade.
\end{abstract}

Ainda, conforme ressaltam autores como Trevisol; Cordeiro e Hass (2011) e Trevisol (2016), atribuiu-se esse significado de "pública e popular" da UFFS, uma vez que foi constituída por meio da luta dos movimentos sociais e da sociedade civil organizada, um movimento, portanto, "de fora para dentro" em prol do ensino superior público para uma região historicamente marginalizada desse acesso. Trevisol (2016) reforça que a concepção de "popular" se traduziu em diretrizes e compromissos desta Universidade, como a inclusão social (políticas de acesso, com foco na escola pública); a gestão democrática (aproximação com a sociedade por meio de conferências; criação de um Conselho Estratégico Social, de caráter consultivo, que envolve lideranças da sociedade); o compromisso com a escola pública (cursos de licenciaturas,

\footnotetext{
situa a University for Development Studies (UDS), criada em 1992, em Gana, na África Ocidental e as universidades federais "temáticas" no Brasil, criadas no Governo Lula, no final da década de 2000, voltadas para regiões mais carentes do país e adicionada a uma missão específica articulada com movimentos sociais. A University for Development Studies (UDS), encontra-se localizada no norte árido e empobrecido e com objetivo de desenvolver a região. Entre os exemplos de universidades federais "temáticas brasileiras, o autor menciona as seguintes experiências: A Universidade Federal da Integração Latino-Americana (UNILA), fundada em 2010, localizada na tríplice fronteira do Brasil, com o Paraguai e a Argentina e com o objetivo de proporcionar um espaço de ensino, pesquisa e serviço comunitário ligados ao contexto latino-americano. É uma instituição bilíngue (português e espanhol), financiada pelo governo brasileiro e que busca um equilíbrio do corpo docente e discente entre o Brasil e demais países da América Latina. Outra universidade criada na mesma época e com perspectiva semelhante é a Universidade da Integração Internacional da Lusofonia Afro-Brasileira (UNILAB), cujo objetivo é a articulação com países africanos de língua portuguesa, principalmente: Angola, Moçambique, São Tomé e Príncipe, Guiné-Bissau e Cabo Verde. A Instituição encontra-se localizada na cidade de Redenção, no Ceará, região empobrecida do Nordeste e que, em 1883, foi a primeira cidade a abolir a escravidão no Brasil. Assim como a Unila, a Unilab também possui metade dos estudantes brasileiros e a outra metade formada por estudantes do exterior. Outra experiência, considerada como "temática" é a UFFS, instituição multicampi, com destaque para sua dimensão inclusiva de estudantes de escola pública e na formação de trabalhadores agrícolas do sul do país. Ainda, outras duas experiências são a Universidade Federal do Oeste do Pará (UFOPA), que visa a cooperação transnacional entre países da floresta amazônica e a Universidade Federal do Sul da Bahia (UFSB), cujo foco é o "engajamento da comunidade, a inclusão digital e a ampla formação pessoal e cívica de áreas desfavorecidas no interior do Nordeste" (McCowan, 2019, p. 106, tradução própria).
} 
especializações e mestrados voltados para a formação de professores da educação básica); e, com a agricultura familiar e agroecologia (oferta de cursos de Agronomia em quatro campi, voltados para fomentar tecnologias e práticas sustentáveis de incentivo aos pequenos produtores rurais).

O projeto institucional da UFFS exprime, portanto, uma lógica institucional própria desde a sua criação. O conceito de lógica institucional foi utilizado por Buckner \& Zapp (2021) no sentido de explicar semelhanças na estrutura organizacional, assim como comportamentos comuns de identidade, ações e propósitos dentro de uma organização. Para os autores, as universidades mais jovens, e principalmente as IES públicas, estão mais sintonizadas com demandas relacionadas à inclusão, equidade e igualdade, enquanto que as IES privadas, principalmente, aquelas criadas a partir de 1990 num contexto da globalização neoliberal, tendem a ser regidas por uma lógica de competitividade e pela busca da oferta de cursos voltados de forma mais direta para o mercado de trabalho.

Por ser considerada uma universidade nova, com apenas 10 anos de existência, muitas mudanças foram acontecendo neste período, desde a construção de sua infraestrutura física, até a formulação de suas primeiras políticas de ensino, pesquisa e extensão. Inicialmente a Universidade teve a UFSC como tutora, que cedeu uma equipe de servidores para atuar na implantação da UFFS. A posse dos primeiros servidores e as atividades acadêmicas iniciaram no primeiro semestre de 2010. 


\section{5 \\ Apresentação da UFFS: caracterização institucional e mudanças e permanências no perfil dos ingressantes}

Esse capítulo se propõe a apresentar a UFFS do ponto de vista de suas características institucionais e do perfil socioeconômico dos ingressantes ao longo do tempo. Busca, portanto, responder a duas questões de pesquisa: Quais foram as principais mudanças institucionais ocorridas ao longo do tempo em termos de políticas de acesso, oferta de vagas e seletividade dos cursos? E, como se caracteriza o perfil socioeconômico e de gênero e raça dos ingressantes ao longo do tempo e sua relação com as diferentes políticas de acesso, como bônus, Lei de Cotas e SiSU?

A estrutura do capítulo encontra-se organizada em duas partes. A primeira delas apresenta uma caracterização institucional da UFFS, com informações e dados a respeito de seu currículo, cursos de graduação, políticas de acesso e permanência e ocupação das vagas ao longo do tempo. As análises realizadas são de cunho descritivo, e fazem uso de dados secundários coletados no site institucional e outros sites oficiais, como do Instituto Brasileiro de Geografia e Estatística (IBGE), documentos institucionais (legislações, relatórios), além de dados da base principal obtida na UFFS. A segunda parte deste capítulo apresenta o perfil dos ingressantes na UFFS pelo Enem, no período entre 2010 e 2018. As análises foram realizadas por meio de estatística descritiva e se utilizaram também da base principal de dados da UFFS. As principais variáveis usadas neste capítulo foram: "origem geográfica"; "faixa etária"; "sexo"; "raça/cor"; "escola pública no Ensino Médio"; "intervalo de tempo entre Ensino Médio e Ensino Superior" e "grupo de inscrição no Processo Seletivo".

\subsection{Caracterização institucional da UFFS}

5.1.1 Currículo, cursos de graduação e comunidade acadêmica

O currículo dos cursos de graduação da UFFS foi organizado entre três domínios formativos: comum, conexo e específico. De acordo com o Regulamento de Graduação, aprovado em 2014 e com alterações realizadas em 2018 e 2019 (UFFS, 2014c), o domínio comum envolve um conjunto de componentes curriculares, aos quais todos os cursos devem destinar uma carga horária mínima de 420 horas e no máximo de 660 horas, e que estão organizados em dois eixos de formação: “contextualização 
acadêmica e formação crítico-social”. Entre alguns dos componentes curriculares do tronco comum, destacamos: Estatística Básica; Leitura e Produção Textual I e II; Introdução à Informática e, à Matemática Instrumental; Iniciação à Prática Científica e História da Fronteira Sul (UFFS, 2012a).

O eixo de contextualização acadêmica tem o objetivo de "desenvolver habilidades e competências de leitura, de interpretação e de produção em diferentes linguagens que auxiliem a se inserir criticamente na esfera acadêmica e no contexto social e profissional" (UFFS, 2014c, p. 11). E, o objetivo do eixo de formação críticosocial visa:

[...] desenvolver uma compreensão crítica do mundo contemporâneo, contextualizando saberes que dizem respeito às valorações sociais, às relações de poder, à responsabilidade socioambiental e à organização sociopolítico-econômica e cultural das sociedades, possibilitando a ação crítica e reflexiva, nos diferentes contextos (UFFS, 2014c, p. 11).

O domínio conexo compreende "o conjunto de componentes curriculares situados na interface entre áreas de conhecimento, objetivando a formação e o diálogo interdisciplinar entre diferentes cursos, em cada campus" (UFFS, 2014c, p. 12). Entre os componentes curriculares, destacamos, por exemplo: Fundamentos da Educação; e, Didática geral, ofertados para todos os cursos de licenciaturas vinculados a área de conhecimento voltada para a formação de professores (UFFS, 2012a).

Por último, o domínio específico abrange "o conjunto de componentes curriculares identificados como próprios de um determinado curso, objetivando prioritariamente a formação profissional" (UFFS, 2014c, p. 12).

Conforme dados obtidos no site institucional junto ao "Relatório Série Histórica da UFFS", em 2018, a UFFS tinha 1.513 servidores, sendo 819 docentes e 694 técnicos administrativos em educação. Em termos acadêmicos ${ }^{30}$, a UFFS iniciou suas atividades em 2010 com 33 cursos de graduação e cerca de 2.160 estudantes, passando, em 2019, para um quadro de 8.921 estudantes, sendo 7.768 da graduação e 1.153 da pósgraduação (especialização, mestrado e residências), e para 46 cursos, sendo 26 licenciaturas e 20 bacharelados, considerando todas as formas de ingresso. Alguns cursos são ofertados em mais de um campus, tais como: Agronomia, Engenharia

30 Os dados foram obtidos pelo site www.uffs.edu.br e também por solicitação por meio do Sistema Eletrônico do Serviço de Informação ao Cidadão (e-SIC). 
Ambiental, Medicina e Letras. No âmbito da pós-graduação a oferta é de 07 cursos de especialização; 15 cursos de mestrado; 62 residências médicas, uma residência multiprofissional e dois cursos de Doutorado Interinstitucional (DINTER), em parceria com a UFSC e UFRJ (UFFS, 2014c).

A Tabela 6 apresenta um resumo sobre a distribuição dos estudantes e dos cursos de graduação e pós-graduação em cada campus no ano de 2019, considerando todas as formas de ingresso.

Tabela 6 - Número de estudantes e cursos de graduação e pós-graduação por campus 2019

\begin{tabular}{llllll}
\hline Campus & $\begin{array}{l}\text { Estudantes } \\
\text { graduação }\end{array}$ & $\begin{array}{l}\text { Cursos } \\
\text { licenciatura }\end{array}$ & $\begin{array}{l}\text { Cursos } \\
\text { bacharelado }\end{array}$ & $\begin{array}{l}\text { Estudantes } \\
\text { pós-graduação }\end{array}$ & $\begin{array}{l}\text { Cursos pós- } \\
\text { graduação }\end{array}$ \\
\hline Chapecó & 2.890 & 7 & 6 & 299 & 15 \\
Laranjeiras do Sul & 915 & 4 & 4 & 172 & 3 \\
Realeza & 914 & 4 & 2 & 107 & 3 \\
Cerro Largo & 1.073 & 4 & 3 & 114 & 4 \\
Erechim & 1.643 & 7 & 4 & 178 & 5 \\
Passo Fundo & 333 & & 1 & 283 & 55 \\
Total & 7.768 & 26 & 20 & 1.153 & 85 \\
\hline
\end{tabular}

Fonte: Elaboração própria, com base em consulta ao site institucional: www.uffs.edu.br e fornecidas pelo canal e-SIC

O município de Chapecó foi escolhido para a localização do Campus-sede da UFFS. Conta com uma população estimada para o ano de 2018 de 216.654 pessoas, conforme dados do IBGE (2019a), sendo a maior cidade e o maior campus entre os demais. Em Santa Catarina, a UFFS é a segunda universidade federal do Estado e se encontra a uma distância de mais de $500 \mathrm{~km}$ da capital.

No ano de 2013, as atividades administrativas de reitoria e do campus foram desmembradas. O Campus Chapecó, em 2019, possuía 13 cursos de graduação, sendo sete licenciaturas e seis bacharelados. Alguns deles apresentam duas ofertas no ano, em turnos diferentes, conforme a Tabela 7. 
Tabela 7 - Cursos e ingressantes do Campus Chapecó - 2010 a 2018

\begin{tabular}{ll}
\hline Licenciatura / turno & Bacharelado / Turno \\
\hline Ciências Sociais - noturno & Administração - matutino e noturno \\
Filosofia - noturno & Agronomia - integral \\
Geografia - noturno & Ciência da Computação - vespertino e noturno \\
História - noturno & Enfermagem - integral \\
Letras (Português e Espanhol) - noturno & Engenharia Ambiental e Sanitária - integral \\
Matemática - noturno & Medicina - integral \\
Pedagogia - matutino e noturno & \\
\hline
\end{tabular}

Fonte: Elaboração própria, com base em consulta ao site institucional: $\underline{\text { www.uffs.edu.br }}$

O município de Laranjeiras do Sul conta com uma população estimada para o ano de 2018 de 32.006 pessoas, conforme dados do IBGE (2019a). O Campus Laranjeiras do Sul está localizado na Região Cantuquiriguaçu, que é formada por 21 municípios localizados no centro-oeste do Estado do Paraná e conta com uma população de 247.384 habitantes, sendo Laranjeiras do Sul o maior deles. Mais de $50 \%$ da população vive na zona rural, sendo mais de $80 \%$ das propriedades voltadas à agricultura familiar. Além disso, esta região agrega a maior reserva indígena do Estado (povos Kaingang e Guarani), o maior assentamento de trabalhadores rurais sem terra da América Latina, além de vários grupos Quilombolas ${ }^{31}$. Segundo Rorato (2016, p. 111) este território também "apresenta baixo grau de desenvolvimento e população muito pobre. Os indicadores de desenvolvimento social e econômico são muito baixos, estando muito abaixo das médias do estado". Dados confirmam, por exemplo, que a Região Cantuquiriguaçu possui o segundo menor Índice de Desenvolvimento Humano (IDH) do Estado ${ }^{32}$.

Em 2019, o Campus Laranjeiras do Sul ofertava oito cursos de graduação, sendo quatro licenciaturas e quatro bacharelados (Tabela 8).

31 Dados obtidos no site: http://www.cantuquiriguacu.com.br/exibenoticia.php?url=maos-a-obrapresidente-da-associacao-dos-municipios-sirlene-svartzbusca-para-capacitacao-e-execucao-de-projetospara-os-municipios-da-cantuquiriguacu\#.YPFa25hKjIV

32 Informações extraídas do site da UFFS: www.uffs.edu.br. 
Tabela 8 - Cursos de graduação do Campus Laranjeiras do Sul - 2019

\begin{tabular}{|c|c|}
\hline Licenciatura / turno & Bacharelado / turno \\
\hline Ciências Biológicas - integral ${ }^{33}$ & Agronomia - integral \\
\hline $\begin{array}{l}\text { Interdisciplinar em Educação do Campo - Ciências } \\
\text { da Natureza }{ }^{34} \text { - noturno }\end{array}$ & Ciências Econômicas - integral \\
\hline $\begin{array}{l}\text { Interdisciplinar em Educação do Campo* - } \\
\text { Ciências Sociais e Humanas }- \text { integral } \\
\text { (Pronacampo/regime de alternância) }\end{array}$ & Engenharia de Alimentos - integral \\
\hline Pedagogia - noturno & Engenharia de Aquicultura - integral \\
\hline
\end{tabular}

Nota: * $\mathrm{O}$ acesso a este curso ocorre por meio de processo seletivo especial

Fonte: Elaboração própria, com base em consulta ao site institucional: www.uffs.edu.br

O município de Realeza conta com uma população estimada para o ano de 2018 de 16.894 pessoas, conforme dados do IBGE (2019a). O Campus Realeza, em 2019, ofertava seis cursos de graduação, sendo quatro licenciaturas e dois bacharelados (Tabela 9).

Tabela 9 - Cursos de graduação do Campus Realeza - 2019

\begin{tabular}{ll}
\hline Licenciatura / turno & Bacharelado / turno \\
\hline Ciências Biológicas - noturno & Medicina Veterinária - integral \\
Física - noturno & Nutrição - integral \\
Letras (Português e Espanhol) - noturno & \\
Química - noturno & \\
\hline
\end{tabular}

Fonte: Elaboração própria, com base em consulta ao site institucional: $\underline{w w w . u f f s . e d u . b r}$

O município de Cerro Largo conta com uma população estimada para o ano de 2018 de 14.074 pessoas, conforme dados do IBGE (2019a). O Campus Cerro Largo, em 2019, ofertava sete cursos de graduação, sendo quatro licenciaturas e três bacharelados (Tabela 10).

33 Este curso foi criado em setembro de 2018, tendo o seu primeiro ingresso em 2019/1.

34 Este curso é novo, cujo primeiro ingresso foi em 2019/1. Foi aprovado pela Resolução n. 13/CONSUNI/UFFS/2018. Nesta mesma Resolução foi extinto o curso de licenciatura em "Interdisciplinar em Educação do Campo: Ciências Naturais, Matemática e Ciências Agrárias". 
Tabela 10 - Cursos de graduação do Campus Cerro Largo - 2019

\begin{tabular}{ll}
\hline Licenciatura / turno & Bacharelado / turno \\
\hline Ciências Biológicas - Integral & Administração - Integral \\
Física - Noturno & Agronomia - Integral \\
Letras (Português e Espanhol) - Noturno & Engenharia Ambiental e Sanitária - Integral \\
Química - Noturno & \\
\hline
\end{tabular}

Fonte: Elaboração própria, com base em consulta ao site institucional: www.uffs.edu.br

O município de Erechim conta com uma população estimada para o ano de 2018 de 105.059 pessoas, conforme dados do IBGE (2019a). O Campus Erechim, em 2019, ofertava de 11 cursos de graduação, sendo sete licenciaturas e quatro bacharelados (Tabela 11).

Tabela 11 - Cursos de graduação do Campus Erechim - 2019

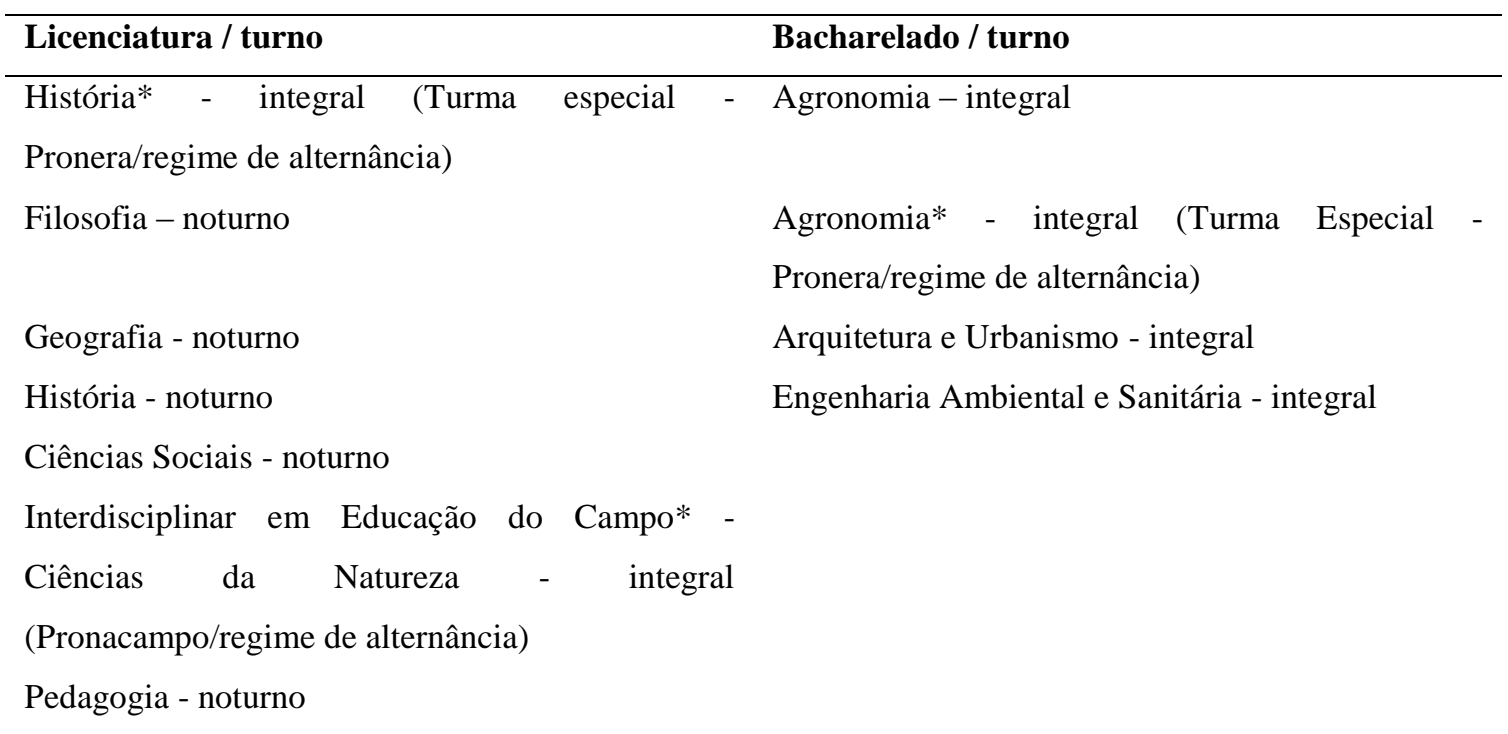

Nota: * O acesso a estes cursos ocorre por meio de processo seletivo especial.

Fonte: Elaboração própria, com base em consulta ao site institucional: $\underline{\text { www.uffs.edu.br }}$

O município de Passo Fundo conta com uma população estimada para o ano de 2018 de 201.767 pessoas, conforme dados do IBGE (2019a). O Campus foi implantado integralmente no ano de 2013, com a oferta do curso de Medicina, em turno integral, sendo o primeiro curso autorizado pelo MEC por meio da Política de Expansão das Escolas Médicas do Brasil. O curso teve início no segundo semestre de 2013. 


\subsubsection{Políticas de acesso na UFFS}

Como forma de seleção de seus estudantes, a UFFS optou desde o início pelo Enem como o seu principal mecanismo de acesso, em conjunto com a bonificação da escola pública que foi sua primeira política de ação afirmativa. No decorrer dos anos, essa universidade foi aprimorando suas formas de ingresso, criando outras ações afirmativas, além de sua adesão à obrigatoriedade da Lei de Cotas.

O ingresso nos primeiros anos da UFFS (2010 a 2012) foi realizado por meio de um processo seletivo próprio, cuja ação afirmativa consistia na bonificação na nota do Enem, conhecida como "Fator Escola Pública". Esta consistia num acréscimo de 10\% sobre a nota final do Enem para cada ano completo do ensino médio estudado em escola pública. Esse fator opera com a seguinte regra de aplicação:

\footnotetext{
I) FatorEP = 1,3 - para o candidato que declarou ter cursado integralmente, com aprovação, todo o ensino médio em escola pública;

II) FatorEP = 1,2 - para o candidato que declarou ter cursado, com aprovação, apenas (duas) séries do ensino médio em escola pública;

III) FatorEP = 1,1 - para o candidato que declarou ter cursado, com aprovação, apenas (uma) série do ensino médio em escola pública; IV) FatorEP = 1,0 - para os demais candidatos (UFFS, 2009, p. 4).
}

Essa política permitiu que a UFFS tivesse um perfil de estudantes majoritariamente oriundo de escolas públicas, chegando a 96,3\%, em 2012. Além disso, neste ano constatou-se entre os ingressantes um público formado por uma maioria de mulheres $(63,5 \%)$, de brancos $(85,5 \%)$, provenientes de famílias com renda familiar de até três salários-mínimos (69,3\%) e na faixa etária de 18 a 24 anos (71,5\%) (Nierotka, 2015; Nierotka; Trevisol, 2016).

A partir da Lei n. 12.711/12, a UFFS aprovou uma nova política de ingresso, por meio da Resolução n. 006/2012 (UFFS, 2012b), em que aderiu de forma integral à Lei de Cotas. Na reserva de suas vagas, passou a aplicar critérios étnico-raciais e de renda, além da escola pública que já era uma prioridade. Interessante destacar a forma de implementação dessa nova política, pois a Lei previa a obrigatoriedade de reservar no mínimo 50\% das vagas para a escola pública. A UFFS, devido a sua política de bonificação inicial, já possuía em seu quadro acadêmico mais de $90 \%$ de estudantes oriundos da escola pública. Portanto, adotou como critério para a reserva de suas vagas a utilização do mesmo percentual de estudantes que conclui o ensino médio na escola 
pública, com base nos dados do Censo Escolar/Inep/MEC de cada Estado em que o campus pertence.

Além disso, a UFFS criou uma ação afirmativa própria destinada a estudantes que concluíram o ensino médio parcialmente em escola pública. No primeiro ano essa reserva foi de $6 \%$ e avaliada a cada ano. Esse percentual é deduzido das vagas destinadas para a ampla concorrência e das vagas destinadas para estudantes oriundos integralmente da escola pública. A primeira aplicação dessa nova política, no ano de 2013, teve uma média de $84 \%$ de vagas reservadas para escola pública integral e $10 \%$ para ampla concorrência, com uma pequena variação em cada Estado, conforme mostra o Gráfico 5.

Gráfico 5 - Percentual de vagas reservadas nos campi da UFFS por Estado - 2013

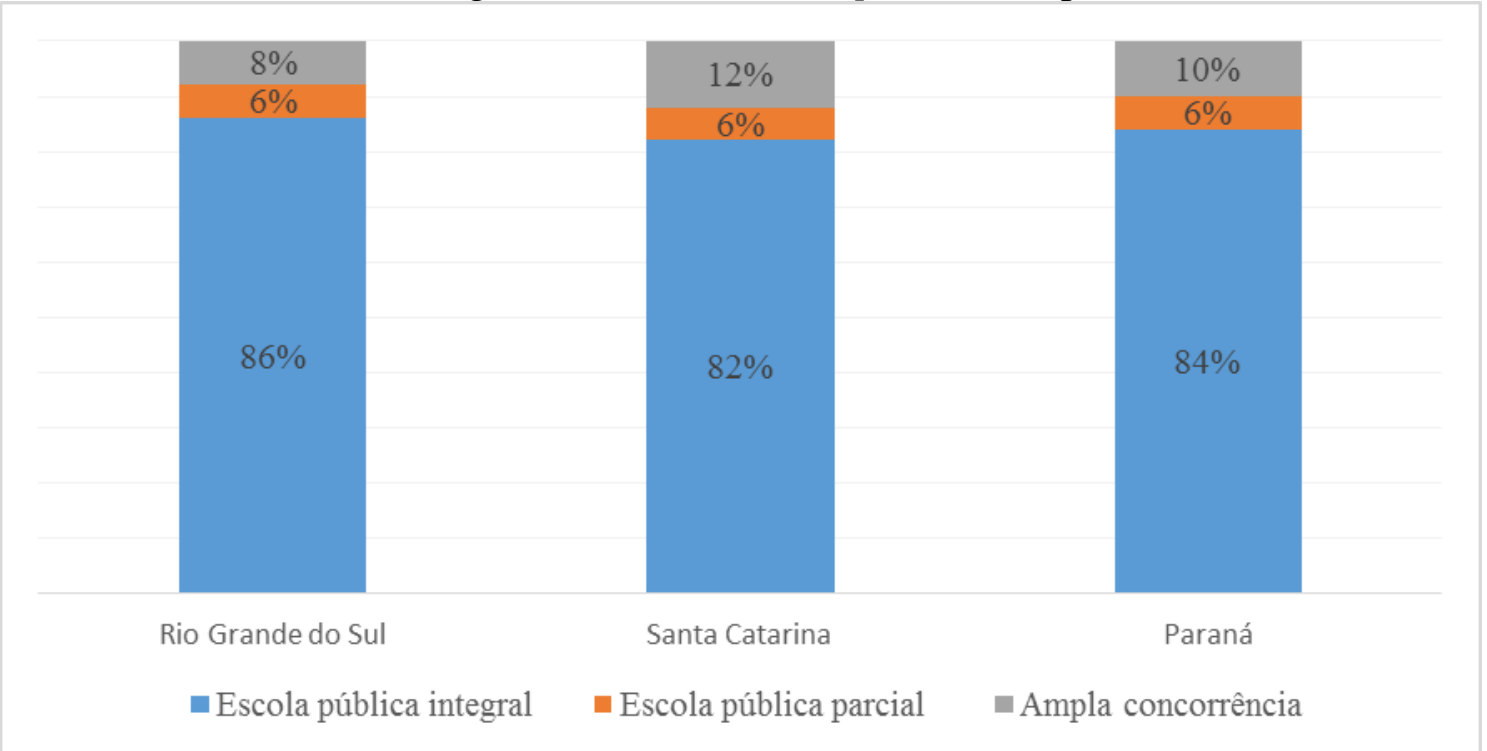

Fonte: Elaboração própria, com base em Nierotka (2015, p. 90)

A partir desse percentual de escola pública, a UFFS faz a reserva de vagas com base na Lei de Cotas, da seguinte forma: $50 \%$ para candidatos com renda de até 1,5 salários mínimos (s.m.) e 50\% com renda superior a 1,5 s.m. Em cada um destes percentuais se aplica a reserva para estudantes pretos, pardos e indígenas, com base nos dados do censo demográfico mais recente do IBGE, para cada Unidade da Federação.

Outro destaque na política foi a inclusão de duas vagas suplementares para cada curso $^{35}$, sendo uma vaga para estudante preto e outra para indígena, nos casos em que,

\footnotetext{
${ }^{35}$ Esta regra não se aplica para cursos em que a Universidade não possui autonomia para suplementar vagas, como é caso de Medicina.
} 
na última chamada, não haja nenhum candidato preto e indígena matriculado. Desde que integre a lista de classificados é chamado o primeiro candidato nesta condição (UFFS, 2012b). Até o ano de 2013, a UFFS operava com processo seletivo próprio e que ocorria em uma única etapa de matrícula anual. No ano de 2014 aderiu ao processo seletivo do SiSU e, com esta adesão, as matrículas passaram a acontecer em duas etapas conforme o semestre de início de cada curso. A política de reserva de vagas foi mantida, apenas com um ajuste para $2 \%$ no percentual reservado à escola pública parcial.

Ao final do ano de 2016, foi aprovada outra mudança na Política de Ingresso, por meio da Resolução n. 8/2016 - CONSUNI/CGAE, que passou a incluir mais uma modalidade de ação afirmativa própria da UFFS, além daquela destinada à escola pública parcial. Esta prevê a reserva de vagas para indígenas, sendo 01 (uma) para cada curso em cada turma de ingresso. Esta ação afirmativa independe de ser estudante de escola pública, apenas exige comprovação de indígena ${ }^{36}$ (UFFS, 2016a) e sua aplicação foi iniciada a partir do primeiro semestre de 2017.

Assim, a reserva de vagas nos cursos de graduação por meio do principal processo seletivo ocorre de acordo com as seguintes modalidades de concorrência:

I - ações afirmativas próprias da UFFS:

a) reserva de vagas para Ensino Médio parcialmente público, com 01 (uma) vaga por curso em cada turma de ingresso;

b) reserva de vagas para Indígenas, com 01 (uma) vaga por curso em cada turma de ingresso;

II - reserva de vagas para Escola Pública, em percentual de vagas igual ao percentual de estudantes do ensino médio matriculados em escolas públicas na Unidade da Federação do local de oferta do curso, de acordo com o último Censo Escolar/INEP/MEC disponível por ocasião do processo seletivo, aplicado sobre o total de vagas, após terem sido descontadas as vagas reservadas às ações afirmativas próprias da UFFS;

III - ampla concorrência, o restante das vagas após terem sido aplicadas as reservas especificadas nos incisos anteriores (UFFS, 2016a, p. 1).

Essa é, portanto, a principal forma de ingresso nesta Universidade, apenas com alguns ajustes ao longo do tempo, como exemplificam a inclusão de reserva de vagas para pessoas com deficiência, a partir do segundo semestre de 2017, em decorrência da Lei n. 13.409/2016, que altera a Lei de Cotas, de modo a incluir também este público. De acordo com o Art. $3^{\circ}$ da referida Lei:

\footnotetext{
${ }^{36}$ A comprovação é realizada por meio de declaração atestada pela Fundação Nacional do Índio (FUNAI) ou Registro Administrativo de Nascimento de Indígena (RANI).
} 
Em cada instituição federal de ensino superior, as vagas de que trata o art. $1^{\circ}$ desta Lei serão preenchidas, por curso e turno, por autodeclarados pretos, pardos e indígenas e por pessoas com deficiência, nos termos da legislação, em proporção ao total de vagas no mínimo igual à proporção respectiva de pretos, pardos, indígenas e pessoas com deficiência na população da unidade da Federação onde está instalada a instituição, segundo o último censo da Fundação Instituto Brasileiro de Geografia e Estatística - IBGE (BRASIL, 2016, p.1).

A materialização dessa política, considerando as ações afirmativas próprias e a distribuição da reserva de vagas com base na Lei de Cotas e suas alterações, pode ser observada no Edital de Ingresso de 2017.2. O/a candidato/a ao se inscrever para a Universidade por meio do SiSU precisa optar por uma das modalidades mostradas no Quadro 4, e precisa apresentar comprovações específicas ${ }^{37}$.

Quadro 4 - Modalidades de reserva de vagas no Processo Seletivo da UFFS - 2017.2

\begin{tabular}{|l|l|}
\hline Modalidade & Comprovação \\
\hline A0 - Ampla concorrência & Não necessita de comprovação \\
\hline $\begin{array}{l}\text { L1 - Renda familiar bruta per capita igual ou inferior a 1,5 } \\
\text { s.m e EP }\end{array}$ & 1) Escola Pública (EP); 2) Renda \\
\hline $\begin{array}{l}\text { L2 - Renda familiar bruta per capita igual ou inferior a 1,5 } \\
\text { s.m., EP e PPI }\end{array}$ & $\begin{array}{l}\text { 1) Escola pública; 2) Renda e 3) Preto, } \\
\text { pardo e indígena (PPI) }\end{array}$ \\
\hline L5 - EP, independentemente da renda & 1) Escola Pública \\
\hline L6 - PPI, independentemente da renda e EP & $\begin{array}{l}\text { 1) Escola Pública; 2) Renda; 3) Preto, } \\
\text { pardos e indígenas }\end{array}$ \\
\hline $\begin{array}{l}\text { L9 - PcD, renda familiar bruta per capita igual ou inferior a } \\
1,5 \text { s.m. e EP }\end{array}$ & $\begin{array}{l}\text { 1) Escola Pública; 2) Renda; 3) } \\
\text { Deficiência }\end{array}$ \\
\hline $\begin{array}{l}\text { L10 - PcD, PPI, renda familiar bruta per capita igual ou } \\
\text { inferior a 1,5 s.m. e EP }\end{array}$ & $\begin{array}{l}\text { 1) Escola Pública; 2) Renda; 3) Pretos, } \\
\text { pardos e indígenas; 3) Deficiência }\end{array}$ \\
\hline L13 - PcD, independentemente da renda e EP & 1) Escola Pública; 2) Deficiência \\
\hline L14 - PcD, PPI, independentemente da renda e EP & $\begin{array}{l}\text { 1) Escola Pública; 2) Deficiência; 3) } \\
\text { Pretos, pardos e indígenas }\end{array}$ \\
\hline Ação afirmativa V542 - Indígena & 1) Indígena \\
\hline Ação afirmativa V543 - EP parcial & 1) Escola pública parcial \\
\hline
\end{tabular}

Fonte: Elaboração própria conforme Edital de Processo Seletivo (UFFS, 2017, p.2).

Com um total de 11 grupos de inscrição, logo se percebeu a dificuldade de

${ }^{37}$ A UFFS criou algumas comissões específicas para averiguar a comprovação de algumas cotas, tais como de renda, a partir de 2013 e de verificação da autodeclaração racial, a partir de 2017. 
preenchimento de vagas nos grupos L10 e L14 que estratificam as pessoas com deficiência dentro das cotas raciais, tendo que acumular, a exemplo do grupo L10, a condição de escola pública, baixa renda, preto, pardo ou indígena e deficiência. Em 2017, no total de todas as vagas reservadas em cada turma e turno, o grupo L10 teve apenas 2 ingressantes e nenhum em 2018. Por sua vez, o grupo L14 teve apenas um ingresso, em 2018. Diante disso, a partir do semestre de 2018.2, houve a exclusão desses dois grupos do processo seletivo, permanecendo com apenas 09 grupos, com a reserva de vagas para PcDs apenas por meio dos grupos L9 (PcD, escola pública e renda familiar per capita de até 1,5 s.m) e L9 (PcD, escola pública, independentemente da renda).

A partir destas mudanças e com base em edital mais recente de 2019.2, a Figura 2 mostra a política de ingresso da UFFS e a distribuição de vagas, segundo estes grupos de inscrição, utilizando como exemplo o curso de Administração. Trata-se da distribuição de 50 vagas ofertadas nesse curso no Estado de Santa Catarina, Campus Chapecó. Observa-se, que apenas 12\% (6 vagas) são destinadas para a ampla concorrência e $86 \%$ para ações afirmativas próprias e conforme a Lei de Cotas.

Figura 2 - Distribuição de vagas em curso na UFFS, segundo a política de ingresso da UFFS - 2019.2

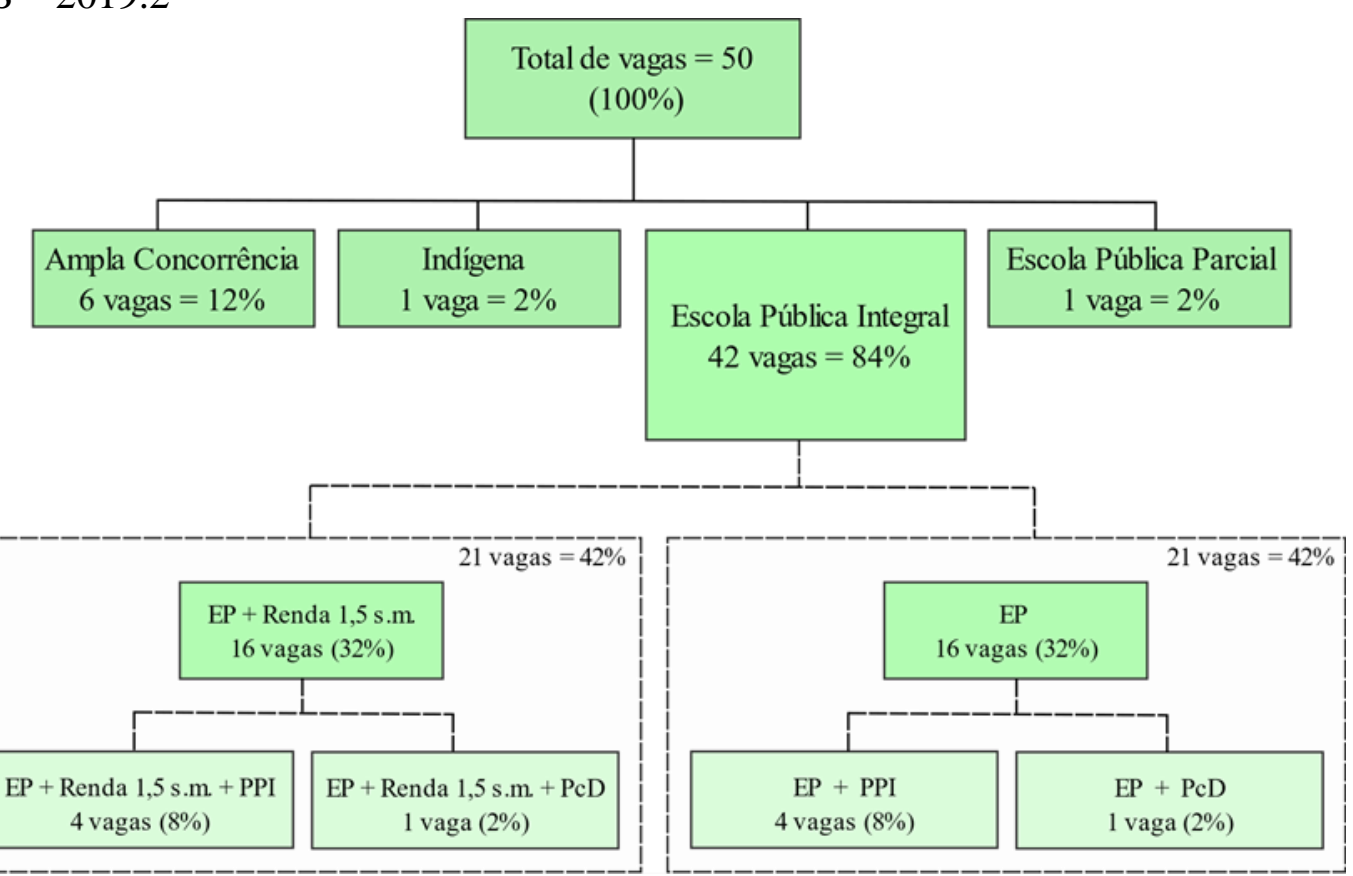

Notas: EP = Escola pública integral; PPI = Pretos, pardos ou indígenas; $\mathrm{PcD}=$ Pessoa com Deficiência. Fonte: Elaboração com base em UFFS (2016a; 2019a). 
Além do Processo Seletivo Regular, que ocorre por meio da utilização da nota do Enem, entre 2013 e 2014, a UFFS criou outras políticas de acesso diferenciado por meio de processos seletivos especiais.

Com a Resolução do Conselho Universitário (Consuni), n. 25, foram aprovados novos cursos de licenciatura. Entre eles, destacam-se os cursos de História e Interdisciplinar em Educação do Campo: Ciências da Natureza (Campus Erechim) e Interdisciplinar em Educação do Campo: Ciências Sociais e Humanas (Campus Laranjeiras do Sul), cuja oferta ocorre por meio de um processo seletivo especial. São cursos que funcionam em regime de alternância, com um período em que os estudantes permanecem na Universidade e outro em suas casas. As vagas são distribuídas de acordo com a Política de Ingresso da UFFS e a Lei de Cotas (UFFS, 2013a).

Os cursos Interdisciplinar em Educação do campo atraem um número expressivo de indígenas. São cursos criados por meio do Programa Nacional de Educação do Campo $\left(\right.$ Pronacampo $^{38}$ ) e destinados à formação de professores para docência na educação básica em escolas localizadas em áreas rurais. Em Laranjeiras do Sul, as atividades acadêmicas deste curso são desenvolvidas nas dependências do Centro de Desenvolvimento Sustentável e Capacitação Agroecológica (CEAGRO), localizado na cidade de Rio Bonito do Iguaçu, PR.

O curso de licenciatura em História, vinculado ao Campus Erechim, é ofertado no município de Veranópolis, RS, por meio de uma parceria entre a UFFS e o Instituto Técnico de Capacitação e Pesquisa da Reforma Agrária (ITERRA). As atividades acadêmicas ocorrem na Sede deste Instituto (UFFS, 2013a). A oferta deste curso é realizada no âmbito do Programa Nacional de Educação na Reforma Agrária ${ }^{39}$ (Pronera), por meio de uma chamada pública de projetos em nível superior realizada pelo Instituto Nacional de Colonização e Reforma Agrária (Incra). Essa chamada era direcionada para instituições privadas sem fins lucrativos, da qual participou o ITERRA. Os beneficiários dos cursos deveriam contemplar populações das áreas de Reforma Agrária: “Os projetos atenderão prioritariamente à população residente em regiões e territórios onde haja alta concentração de famílias assentadas e baixos níveis

\footnotetext{
${ }^{38}$ Edital de Seleção n. 02/2012-SESU/SETEC/SECADI/MEC, de 31 de agosto de 2012.

${ }^{39}$ De acordo com Luz (2018, p.75) o Pronera foi criado em 1998 e constituiu um importante ponto de partida para a educação superior do Movimento dos Trabalhadores Rurais Sem Terra (MST). "Tal programa passou a gerir recursos oriundos do MEC, disponibilizados pelo Instituto Nacional de Colonização e Reforma Agrária (INCRA), cujo objetivo era proporcionar alfabetização e instrução formal em diferentes níveis de ensino para populações assentadas.
} 
de escolaridade" (MDA/INCRA, 2012, p.2).

Ainda, no final de 2013, a UFFS aprovou duas Resoluções no Consuni, que criou o Programa de Acesso à Educação Superior da UFFS para Estudantes Haitianos ${ }^{40}$ (PROHAITI) e o Programa de Acesso e Permanência dos Povos Indígenas ${ }^{41}$ (PIN).

O PHOHAITI oferta vagas suplementares para candidatos haitianos em cursos de graduação, por meio de processo seletivo especial. Sua criação resultou de um convênio entre a Embaixada do Haiti no Brasil e a UFFS, tendo como objetivo "contribuir para integrar os imigrantes haitianos à sociedade local e nacional, por meio do acesso aos cursos de graduação da UFFS, e qualificar profissionais que ao retornar possam contribuir com o desenvolvimento do Haiti” (UFFS, 2013b, p. 1).

O PIN definiu a realização de um "Processo Seletivo Exclusivo Indígena, com 2 (duas) vagas suplementares por curso, excetuando-se aqueles para os quais a Universidade não tem autonomia para ofertar vagas suplementares" (UFFS, 2013c, p. 3), como é o caso dos cursos de Medicina e Enfermagem. Esse foi também um dos motivos que provocou a abertura de mais uma modalidade de ação afirmativa para estudante indígena no Processo Seletivo Regular da Universidade.

Em 2014 a UFFS aprovou também o curso de Agronomia - Bacharelado, também em regime de alternância e com Processo Seletivo Especial para o ingresso (UFFS, 2014d). Este curso é ofertado no Instituto Educar, localizado no Assentamento Annoni, no município de Pontão, RS, e resulta de uma parceria entre esse Instituto, a UFFS e o Instituto Nacional de Colonização e Reforma Agrária - INCRA/Pronera ${ }^{42}$. Esse curso recebe estudantes de todas as regiões do Brasil e, durante o período-escola, ficam alojados nesse Instituto que disponibiliza alimentação e auxílio financeiro da UFFS para custear despesas com transporte e outras demandas relacionadas à permanência dos estudantes.

5.1.3 Mudanças na oferta, ocupação de vagas e seletividade dos cursos

Com relação à oferta e ocupação de vagas ao longo do tempo, a Tabela 12 mostra que, em média, cerca de $90 \%$ das vagas ofertadas pelo Enem foram ocupadas

\footnotetext{
${ }^{40}$ Resolução n. 32/2013 - Consuni/UFFS.

${ }^{41}$ Resolução n. 33/2013 - Consuni/UFFS.

${ }^{42}$ Convênio n. 793553/2013-SICONV.
} 
nesse período. O percentual dos primeiros anos (2010 a 2012) foi menor tendo em vista a exclusão feita na base de 450 estudantes que haviam evadido antes da adição da matrícula para outro curso, conforme já mencionado na metodologia deste estudo. Observa-se uma queda na ocupação de vagas em 2014, primeiro ano de adesão ao SiSU, e novamente em 2018.

Tabela 12 - Relação entre vagas ofertadas e ocupadas pelo Enem - 2010 a 2018

\begin{tabular}{llll}
\hline Ano & Vagas ofertadas & Vagas ocupadas (Enem) & Percentual de ocupação \\
\hline 2010 & 2160 & 1852 & 85,7 \\
2011 & 2160 & 1856 & 85,9 \\
2012 & 2160 & 1981 & 91,7 \\
2013 & 2025 & 1882 & 92,9 \\
2014 & 2075 & 1816 & 87,5 \\
2015 & 1920 & 1805 & 94,0 \\
2016 & 2022 & 1950 & 96,4 \\
2017 & 2022 & 1860 & 92,0 \\
2018 & 2042 & 1776 & 87,0 \\
\hline Total & 18586 & 16778 & 90,3 \\
\hline
\end{tabular}

Fonte: Elaboração própria, a partir da base de dados do SGA/UFFS.

A oferta de vagas pelo Enem diminuiu ao longo dos anos em comparação aos anos iniciais da IES. Com a diminuição na ocupação das vagas nos últimos anos, em 2020, a UFFS, em conjunto com a UFSC, realizou um vestibular unificado com a oferta de $30 \%$ das vagas para cada curso e, as demais vagas (70\%) foram ofertadas pelo processo seletivo da UFFS, com a utilização do Enem.

Ao longo dos anos (2010 a 2018) ocorreram algumas modificações na oferta dos cursos, com a da criação de novos cursos e ajustes na oferta com relação ao número de vagas e turnos. A Tabela 13 apresenta a distribuição dos ingressantes pelo Enem, de 2010 a 2018, segundo o curso, turno e o campus.

Tabela 13 - Distribuição dos ingressantes, segundo curso/turno/campus - 2010 a 2018

\begin{tabular}{lllllllllll}
\hline Curso / turno & $\mathbf{2 0 1 0}$ & $\mathbf{2 0 1 1}$ & $\mathbf{2 0 1 2}$ & $\mathbf{2 0 1 3}$ & $\mathbf{2 0 1 4}$ & $\mathbf{2 0 1 5}$ & $\mathbf{2 0 1 6}$ & $\mathbf{2 0 1 7}$ & $\mathbf{2 0 1 8}$ & Total \\
\hline Campus Chapecó & & & & & & & & & & \\
\hline Ciência da Computação (V) & 48 & 52 & 51 & 48 & 49 & 50 & 50 & 50 & 50 & 448 \\
Ciência da Computação (N) & 51 & 47 & 47 & 45 & 49 & 50 & 50 & 50 & 48 & 437 \\
Matemática (N) & - & - & - & - & 40 & 50 & 50 & 50 & 47 & 237 \\
Engenharia Ambiental e & 45 & 48 & 61 & 50 & 47 & 48 & 50 & 50 & 31 & 430
\end{tabular}

Sanitária (I) 


\begin{tabular}{|c|c|c|c|c|c|c|c|c|c|c|}
\hline Enfermagem (I) & 40 & 37 & 41 & 40 & 40 & 40 & 40 & 40 & 39 & 357 \\
\hline Medicina (I) & - & - & - & - & - & 40 & 40 & 40 & 45 & 165 \\
\hline Agronomia (I) & 50 & 46 & 52 & 52 & 41 & 50 & 50 & 50 & 43 & 434 \\
\hline Administração (M) & 50 & 53 & 50 & 47 & 49 & 50 & 50 & 50 & 50 & 449 \\
\hline Administração (N) & 50 & 52 & 43 & 39 & 48 & 51 & 52 & 50 & 50 & 435 \\
\hline Filosofia (M) & 29 & 20 & 27 & 13 & - & - & - & - & - & 89 \\
\hline Filosofia (N) & 40 & 48 & 34 & 37 & 43 & 42 & 49 & 36 & 22 & 351 \\
\hline Geografia (M) & 27 & 21 & 27 & 20 & 21 & - & - & - & - & 116 \\
\hline Geografia $(\mathrm{N})$ & 45 & 45 & 46 & 40 & 14 & 47 & 51 & 42 & 32 & 362 \\
\hline História (M) & 33 & 37 & 41 & 17 & 46 & - & - & - & - & 174 \\
\hline História (N) & 48 & 48 & 47 & 43 & 21 & 42 & 49 & 49 & 48 & 395 \\
\hline Pedagogia (M) & 38 & 48 & 50 & 48 & 50 & - & 50 & 50 & 42 & 376 \\
\hline Pedagogia (N) & 50 & 53 & 44 & 50 & 37 & 50 & 51 & 50 & 40 & 425 \\
\hline Ciências Sociais (M) & 22 & 32 & 25 & 24 & 12 & - & - & - & - & 115 \\
\hline Ciências Sociais (N) & 42 & 50 & 43 & 43 & 50 & 36 & 44 & 42 & 32 & 382 \\
\hline $\begin{array}{l}\text { Letras - Português e } \\
\text { Espanhol (M) }\end{array}$ & 24 & 30 & 31 & 25 & 26 & - & - & - & - & 136 \\
\hline $\begin{array}{l}\text { Letras - Português e } \\
\text { Espanhol }(\mathrm{N})\end{array}$ & 30 & 32 & 24 & 30 & 11 & 48 & 48 & 50 & 36 & 309 \\
\hline Total & 762 & 799 & 784 & 711 & 694 & 694 & 774 & 749 & 655 & 6622 \\
\hline \multicolumn{11}{|l|}{ Campus Laranjeiras do Sul } \\
\hline $\begin{array}{l}\text { Engenharia de Alimentos } \\
\text { (I) }\end{array}$ & 47 & 46 & 53 & 42 & 41 & 29 & 49 & 42 & 42 & 391 \\
\hline Agronomia (I) & 47 & 49 & 60 & 51 & 53 & 49 & 50 & 49 & 50 & 458 \\
\hline $\begin{array}{l}\text { Engenharia De Aquicultura } \\
\text { (I) }\end{array}$ & 45 & 44 & 53 & 34 & 34 & 31 & 46 & 28 & 39 & 354 \\
\hline $\begin{array}{l}\text { Interdisciplinar em } \\
\text { Educação do Campo: } \\
\text { Ciências Naturais, } \\
\text { Matemática e Ciências } \\
\text { Agrárias (I) }\end{array}$ & 28 & 27 & 31 & 25 & 27 & 23 & 24 & 14 & - & 199 \\
\hline $\begin{array}{l}\text { Interdisciplinar em } \\
\text { Educação do Campo: } \\
\text { Ciências Naturais, } \\
\text { Matemática e Ciências } \\
\text { Agrárias (N) }\end{array}$ & 31 & 24 & 20 & 27 & 21 & 25 & 20 & 13 & 44 & 225 \\
\hline Ciências Econômicas (N) & 38 & 41 & 63 & 50 & 49 & 50 & 50 & 49 & 50 & 440 \\
\hline Pedagogia $(\mathrm{N})$ & - & - & - & - & - & - & - & - & 50 & 50 \\
\hline Total & 236 & 231 & 280 & 229 & 225 & 207 & 239 & 195 & 275 & 2117 \\
\hline \multicolumn{11}{|l|}{ Campus Realeza } \\
\hline Física $(\mathrm{N})$ & 10 & 9 & 14 & 31 & 29 & 30 & 30 & 29 & 30 & 212 \\
\hline Ciências Naturais (N) & 82 & - & - & - & - & - & - & - & - & 82 \\
\hline Química (N) & 29 & 24 & 35 & 30 & 30 & 30 & 29 & 30 & 29 & 266 \\
\hline Ciências Biológicas (N) & 30 & 34 & 47 & 41 & 40 & 40 & 40 & 40 & 39 & 351 \\
\hline Nutrição (I) & 37 & 40 & 38 & 40 & 37 & 38 & 40 & 40 & 40 & 350 \\
\hline Medicina Veterinária (I) & 43 & 49 & 50 & 53 & 50 & 50 & 50 & 50 & 49 & 444 \\
\hline $\begin{array}{l}\text { Letras - Português e } \\
\text { Espanhol }(\mathrm{N})\end{array}$ & 29 & 35 & 31 & 30 & 31 & 30 & 30 & 30 & 30 & 276 \\
\hline Total & 260 & 191 & 215 & 225 & 217 & 218 & 219 & 219 & 217 & 1981 \\
\hline
\end{tabular}




\begin{tabular}{|c|c|c|c|c|c|c|c|c|c|c|}
\hline Física (N) & 11 & 15 & 15 & 30 & 27 & 30 & 31 & 31 & 22 & 212 \\
\hline Química (N) & 14 & 11 & 16 & 30 & 30 & 30 & 29 & 27 & 24 & 211 \\
\hline Ciências Biológicas (I) & 47 & 40 & 73 & 56 & 56 & 51 & 60 & 51 & 44 & 478 \\
\hline $\begin{array}{l}\text { Engenharia Ambiental e } \\
\text { Sanitária (I) }\end{array}$ & 48 & 51 & 54 & 50 & 49 & 49 & 50 & 50 & 47 & 448 \\
\hline Agronomia (I) & 50 & 53 & 54 & 49 & 50 & 56 & 50 & 50 & 50 & 462 \\
\hline Administração (I) & 27 & 43 & 57 & 51 & 50 & 47 & 49 & 50 & 50 & 424 \\
\hline $\begin{array}{l}\text { Letras - Português e } \\
\text { Espanhol }(\mathrm{N})\end{array}$ & 29 & 32 & 35 & 30 & 29 & 30 & 30 & 30 & 30 & 275 \\
\hline Total & 226 & 245 & 304 & 296 & 291 & 293 & 299 & 289 & 267 & 2510 \\
\hline \multicolumn{11}{|l|}{ Campus Erechim } \\
\hline $\begin{array}{l}\text { Engenharia Ambiental e } \\
\text { Sanitária (I) }\end{array}$ & 44 & 46 & 44 & 43 & 38 & 48 & 50 & 47 & 31 & 391 \\
\hline Agronomia (I) & 50 & 49 & 51 & 53 & 51 & 50 & 50 & 50 & 50 & 454 \\
\hline Arquitetura e Urbanismo (I) & 43 & 44 & 49 & 51 & 49 & 50 & 50 & 50 & 50 & 436 \\
\hline Filosofia (N) & 40 & 48 & 50 & 32 & 30 & 34 & 32 & 26 & 26 & 318 \\
\hline Geografia $(\mathrm{N})$ & 49 & 51 & 51 & 51 & 44 & 42 & 44 & 46 & 27 & 405 \\
\hline História Noturno & 46 & 50 & 50 & 48 & 44 & 41 & 43 & 45 & 42 & 409 \\
\hline Pedagogia (N) & 49 & 51 & 51 & 50 & 48 & 50 & 49 & 50 & 50 & 448 \\
\hline Ciências Sociais (N) & 47 & 51 & 52 & 51 & 47 & 39 & 39 & 31 & 24 & 381 \\
\hline Total & 368 & 390 & 398 & 379 & 351 & 354 & 357 & 345 & 300 & 3242 \\
\hline \multicolumn{11}{|l|}{ Campus Passo Fundo } \\
\hline Medicina (I) & - & - & - & 42 & 38 & 39 & 62 & 63 & 62 & 306 \\
\hline
\end{tabular}

Entre 2010 e 2012, as principais mudanças foram a extinção do curso de Ciências: Biologia, Física e Química, ofertado em Cerro Largo e Realeza, e a criação de três cursos separados em cada campus: Ciências Biológicas, Química e Física. Do mesmo modo, a extinção do curso de Desenvolvimento Rural e Gestão Agroindustrial ofertado em Laranjeiras do Sul e Cerro Largo, foi acompanhada da criação dos cursos de Ciências Econômicas e Administração, respectivamente.

Em 2013, ocorreu a adesão ao Programa Mais Médicos e a criação do Campus Passo Fundo para a oferta do curso de Medicina (40 vagas no segundo semestre). A partir de 2016, passou a ter duas ofertas, no primeiro e no segundo semestre, com 31 vagas em cada um.

Em 2014, foi ofertado o novo curso de licenciatura em Matemática, no turno noturno e no Campus Chapecó com 40 vagas, passando para 50 vagas, a partir de 2015. Neste mesmo campus, foi ofertado a partir de 2015 o curso novo de Medicina, com 40 vagas e as licenciaturas em Filosofia, Geografia, História, Pedagogia, Ciências Sociais e Letras passaram a ser oferecidas apenas no turno noturno e não mais em turno matutino 
e noturno. A partir de 2016, apenas o curso de Pedagogia voltou a ser ofertado nos dois turnos. A oferta em turno matutino do curso de Ciências da Computação, a partir de 2017 foi alterada para o turno vespertino ${ }^{43}$.

Em 2018, no Campus Laranjeiras do Sul foram criados os cursos de Pedagogia, ofertado no turno noturno com início em 2018/1 e o curso de Ciências Biológicas, ofertado em turno integral e com início em 2019/1. O curso de Ciências Econômicas passou a ser noturno e não mais integral ${ }^{44}$. E o curso de licenciatura em Interdisciplinar em Educação do Campo: Ciências Naturais, Matemática e Ciências Agrárias ofertado até então em turnos noturno e integral, passou a ser apenas noturno, e teve um aumento do número de vagas de 30 para 50. No final desse mesmo ano, esse curso foi extinto e criado o curso de licenciatura Interdisciplinar em Educação do Campo - Ciências da Natureza, com a oferta apenas em turno noturno. Além dessas mudanças nos turnos e vagas, destacam-se, também, algumas alterações nos nomes e ênfases dos $\operatorname{cursos}^{45}$, como ilustram, por exemplo, o curso de Sociologia que passou a ser denominado Ciências Sociais, ou Engenharia Ambiental que passou a chamar-se Engenharia Ambiental e Sanitária.

No total, 13 cursos novos foram criados no período de 2010 a 2018, sendo nove ofertados pelo Enem e quatro por meio de processos seletivos especiais. Conforme dados disponíveis no site institucional, o primeiro processo seletivo da UFFS, em 2010, teve um total de 11.192 inscritos para 2.160 vagas, passando para 14.000 inscritos, no ano seguinte. Em 2018, a oferta de vagas pelo Enem reduziu para 2.042 e o número de inscritos passou para 25.191. Destes inscritos, $11.920(47,3 \%)$ são candidatos a uma vaga no curso de Medicina, que possui três ofertas por ano. A Tabela 14 apresenta os cinco cursos da UFFS com maior e menor relação candidato/vaga, em 2010 e em 2018.

Observa-se que mesmo em cursos menos seletivos a relação de candidato/vaga aumentou em 2018, o que pode ser um efeito da adesão da UFFS ao SiSU, a partir de 2014, além da grande procura pelo curso de Medicina. Embora a demanda seja alta, a ocupação das vagas não é integral, a exemplo do ano de 2018, cuja ocupação foi de $87 \%$. Esse movimento é observado ao longo dos anos no grande número de chamadas para matrículas que a Universidade realiza para o preenchimento das vagas, mesmo para o curso de Medicina, sendo este um fenômeno nacional. Isso pode indicar que a adesão

\footnotetext{
${ }^{43} \mathrm{Na}$ base de dados o turno deste curso encontra-se padronizado para vespertino em todos os anos.

${ }^{44} \mathrm{Na}$ base de dados o turno deste curso encontra-se padronizado para noturno em todos os anos.

${ }^{45} \mathrm{Na}$ base de dados os nomes dos cursos encontram-se padronizados, conforme as últimas alterações.
} 
ao SiSU, por um lado, apresenta maior mobilidade e oportunidades aos estudantes e, por outro lado, gera também esse cenário de vagas ociosas (Ribeiro; Morais, 2020).

Entre os cursos mais seletivos estão os cursos de bacharelados e entre os menos seletivos os de licenciaturas. O curso de Engenharia Ambiental e Sanitária esteve entre os mais seletivos no primeiro ano, chegando a ter mais de 20 candidatos por vaga. Em 2018 essa relação caiu para cerca de cinco a seis candidatos por vaga. As licenciaturas, em 2018, foram mais seletivas, em relação a 2010.

Tabela 14 - Relação candidato/vaga de cursos mais e menos seletivos - 2010 e 2018

\begin{tabular}{|c|c|c|}
\hline Curso/turno & Campus & Candidato/vaga \\
\hline \multicolumn{3}{|c|}{ Mais seletivos - 2010} \\
\hline Engenharia Ambiental e Energias Renováveis - integral & Chapecó & 22,34 \\
\hline Medicina Veterinária - integral & Realeza & 21,44 \\
\hline Arquitetura e Urbanismo - integral & Erechim & 21,4 \\
\hline Engenharia Ambiental e Energias Renováveis - integral & Cerro Largo & 16,32 \\
\hline Enfermagem - integral & Chapecó & 13,48 \\
\hline \multicolumn{3}{|c|}{ Menos seletivos - 2010} \\
\hline Sociologia - matutino & Chapecó & 0,4 \\
\hline Pedagogia - matutino & Chapecó & 0,5 \\
\hline Geografia - matutino & Chapecó & 0,54 \\
\hline Educação do Campo - integral & Laranjeiras do Sul & 0,7 \\
\hline Filosofia - noturno & Erechim & 0,72 \\
\hline \multicolumn{3}{|c|}{ Mais seletivos -2018} \\
\hline Medicina - integral & Chapecó & 152,68 \\
\hline Medicina $\left(1^{\circ}\right.$ semestre $)$ - integral & Passo Fundo & 111 \\
\hline Medicina $\left(2^{\circ}\right.$ semestre $)$ - integral & Passo Fundo & 76,52 \\
\hline Medicina Veterinária - integral & Realeza & 23,94 \\
\hline Enfermagem - integral & Chapeco & 20,83 \\
\hline \multicolumn{3}{|c|}{ Menos seletivos - 2018} \\
\hline Física - noturno & Cerro Largo & 2,9 \\
\hline Interdisciplinar em Educação no Campo - noturno & Laranjeiras do Sul & 2,96 \\
\hline Geografia - noturno & Erechim & 3,3 \\
\hline Química-noturno & Cerro Largo & 3,33 \\
\hline Ciências Sociais - noturno & Erechim & 3,52 \\
\hline
\end{tabular}

Fonte: Elaboração própria, a partir de dados disponíveis no site institucional da UFFS.

A maior distribuição dos estudantes ao longo do tempo ocorre na área de Educação (cerca de 50\%), que abarca todas as licenciaturas voltadas para a formação de professores. Na sequência estão, respectivamente, a área de "Agricultura", em média de com 15,53\%, e as "Engenharias", com 12,47\%. Em termos nacionais, o Censo da 
Educação Superior de 2019 das IES públicas e na modalidade presencial indicou um número de ingressantes em cursos de licenciaturas de apenas 25,9\%. Esses percentuais também são observados por Barbosa \& Campos (2020) nos campi novos criados a partir de 2013 e localizados no interior, nos quais a área da Educação é predominante (25,50\%), além de uma representação menor nos campi da Região Sul (22,70), nos quais predomina a área de "Engenharia, Produção e Construção" (31,80\%). Esses dados colocam em destaque a particularidade da UFFS na significativa oferta de licenciaturas.

De 2010 para 2018, ocorreu uma redução de cerca de 8,3 p.p. entre os ingressantes em cursos da área de Educação da UFFS, o que se justifica pela redução da oferta do turno matutino para alguns cursos de licenciaturas. Com a criação do curso de Medicina e sua oferta em dois campi, a área de Saúde e bem-estar teve um aumento neste período de cerca de 6.3 p.p.. As demais áreas se mantiveram estáveis. A Tabela 15 apresenta essa distribuição de ingressantes ao longo do tempo nas áreas de conhecimento.

Tabela 15 - Percentual de ingressantes por grandes áreas de conhecimento

\begin{tabular}{|c|c|c|c|c|c|c|c|c|c|c|}
\hline Área de conhecimento & & 2010 & 2011 & 2012 & 2013 & 2014 & 2015 & 2016 & 2017 & 2018 \\
\hline Educação & & 53,9 & 52,0 & 51,0 & 50,6 & 49,8 & 46,5 & 47,3 & 46,3 & 45,6 \\
\hline $\begin{array}{l}\text { Agricultura, Silvicultura, Pesca } \\
\text { Veterinária }\end{array}$ & e & 15,4 & 6 & 2 &, 5 & 15,4 & 8 & 2 & 9 & 15,8 \\
\hline ria, produção e construção & & 12,3 & 12,7 & 13,2 & 12,5 & 12,3 & 12,4 & 12,8 & 12,8 & 11,3 \\
\hline $\begin{array}{l}\text { Negócios, administração, direito } \\
\text { ciências sociais }\end{array}$ & $\mathrm{e}$ & 8,9 & 10,2 & 10,8 & 9,9 & 10,8 & 11,0 & 10,3 & 10,7 & 11,3 \\
\hline $\begin{array}{l}\text { Computação e e Tecnologias } \\
\text { Informação e Comunicação (TIC) }\end{array}$ & da & 5,3 & 5,3 & 4,9 & 4,9 & 5,4 & 5,5 & 5,1 & 5,4 & 5,5 \\
\hline Saúde & & 4,2 & 4,1 & 4,0 & 6,5 & 6,3 & 8,7 & 9,3 & 9,8 & 10,5 \\
\hline Total & & 100 & 100 & 100 & 100 & 100 & 100 & 100 & 100 & 100 \\
\hline
\end{tabular}

Fonte: Elaboração própria a partir de dados do SGA/UFFS

\subsubsection{Políticas de permanência estudantil}

Uma das ações importantes para a permanência dos estudantes de graduação nas instituições federais de ensino superior ocorre por meio do Programa Nacional de Assistência Estudantil (Pnaes). O programa tem por objetivo apoiar a permanência de estudantes em situação de vulnerabilidade socioeconômica em áreas tais como: alimentação, moradia estudantil, transporte, atenção à saúde, esporte, apoio pedagógico (Brasil, 2010).

A concepção de permanência estudantil refere-se a um conjunto de ações mais 
amplas desenvolvidas no âmbito das IES para a inserção plena dos estudantes, tais como iniciação científica, extensão, estágios, monitorias. Trata-se de uma questão complexa e multidimensional que deve considerar fatores materiais e também simbólicos. Envolve o respeito e o combate à discriminação, no sentido de proporcionar a inserção plena dos estudantes no espaço universitário e, também, a assistência estudantil e ações com um foco mais específico, principalmente no atendimento a estudantes em situação de vulnerabilidade scoioeconômica (Vargas; Heringer, 2017; Heringer, 2020a; 2020b).

Na UFFS, a execução da assistência estudantil é organizada pela Pró-Reitoria de Assuntos Estudantis ${ }^{46}$ (PROAE), situada na Reitoria, em conjunto com os Setores de Assuntos Estudantis (SAEs), em cada campus. As equipes de trabalho contam com profissionais, tais como: asssistentes sociais, psicólogos, pedagogos, nutricionistas, administradores e assistentes em administração. Além do apoio financeiro, essas equipes nos SAEs oferecem atendimento aos estudantes nas áreas social, psicológica, pegagógica e demais ações de acolhimento e de promoção de saúde, além da realização dos cadastros socioconômicos.

Na área da alimentação a UFFS conta com a estrutura de cinco restaurantes universitários (RUs), um em cada campus, exceto no Campus Passo Fundo ${ }^{47}$. Estes são custeados com recursos do Pnaes e da Universidade. A operacionalização dos restaurantes e o Programa de Auxílios Socioeconômicos constituem as principais ações de assistência estudantil da UFFS. Conforme o Relatório Anual de Atividades, elaborado pela PROAE (UFFS, 2019b), em 2018 foi investido o valor de R\$ 9.722.501,00 na Assistência Estudantil, em ações como: Auxílios Socioeconômicos (moradia ${ }^{48}$, alimentação, transporte e estudantil); Auxílio Ingresso; Auxílio Emergencial; Auxílio a Permanência dos Povos Indígenas na UFFS, auxílio para participação de estudantes na discussão da minuta da Política de Assistência Estudantil da UFFS e outras ações relativas ao Restaurante Universitário e demais áreas do Pnaes.

Em 2018, foi atendido com auxílios socioeconômicos um total de 2.550

\footnotetext{
${ }^{46}$ Em 2010 a atual PROAE era uma Diretoria de Assuntos Estudantis, passando para o status de Secretaria Especial de Assuntos Estudantis, em 2014 e no final do mesmo ano, transformou-se em PróReitoria. Destacamos que, por se tratar de uma IES nova, os programas de assistência estudantil foram sendo construídos e modificados ao longo do tempo, assim como a UFFS como um todo. O panorama apresentado aqui é de um retrato mais recente.

${ }^{47} \mathrm{Em} 2021$ foi contratado um serviço de alimentação, equivalente a um restaurante universitário.

${ }^{48} \mathrm{O}$ Auxílio Moradia é pago também no mês de janeiro, período de férias dos estudantes.
} 
estudantes de graduação em situação de vulnerabilidade socioeconômica ${ }^{49}$, o que equivale a $31 \%$ dos estudantes da UFFS. Ao comparar os beneficiários e não beneficiários desta política, os dados do referido Relatório demonstram a importância da assistência estudantil para a permanência e o êxito acadêmico, resultando em uma taxa de aprovação de $82 \%$ e de $68 \%$, respectivamente. O mesmo resultado é encontrado em relação à situação de matrícula, com menores taxas de jubilamento, cancelamento, trancamento e desistência entre os beneficiários dos auxílios (UFFS, 2019b).

A PROAE também faz a gestão do Programa Bolsa Permanência (PBP), criado em 2013 pelo governo federal, que destina bolsas aos estudantes indígenas e quilombolas no valor de $\mathrm{R} \$ 900,00$ mensais, com a finalidade de auxiliar em sua permanência. Até o ano de 2015, o PBP também atendia, com uma bolsa de R $\$ 400,00$, estudantes em situação de vulnerabilidade socioeconômica e com uma carga horária de aula mais extensa. Na UFFS apenas estudantes de Medicina atendiam os critérios relacionados à carga horária especificada pelo MEC. No ano de 2018, este Programa beneficiou 392 estudantes, distribuídos em todos os campi e em 21 cursos de graduação. Destes, 31 eram do curso de Medicina e 361 eram indígenas (UFFS, 2019b).

Com base em dados institucionais obtidos junto a UFFS, o Gráfico 6 apresenta o número de estudantes beneficiários de alguma modalidade de auxílio socioeconômico e/ou PBP. Ao longo do tempo, observa-se um aumento no número de beneficiários, o que também se justifica pelo crescimento das matrículas na IES. No entanto, há uma redução no número de beneficiários, a partir de 2018.

Importa destacar que o Pnaes começou a ser executado na UFFS a partir do segundo semestre de 2010, e o PBP, a partir de 2013. O MEC restringiu, a partir de 2016, as novas incrições no PBP apenas para estudantes indígenas e quilombolas e, a partir de 2020, o Programa passou a ser paulatinamente descontinuado pela não abertura de novas inscrições, o que afeta diretamente o direito à permanência dos povos indígenas ingressantes nas universidades federais, e de modo especial na UFFS, que possui ações afirmativas voltadas para este público, para além da Lei das Cotas. Além da descontinuidade deste programa tão relevante para a permanência estudantil, destacase também a insegurança com relação ao próprio orçamento do Pnaes e de outras

\footnotetext{
${ }^{49}$ A condição de vulnerabilidade é comprovada por meio de uma cadastro socioeconômico que gera um Índice de Vulnerabilidade Socioeconômica, conforme metodologia estabelecida em regulamento próprio (UFFS, 2016b).
} 
políticas educacionais, no contexto das reduções de gastos relacionadas a políticas de austeridade implementadas nos últimos governos, como é o caso da Emenda Constitucional n. 95, que limita gastos públicos por 20 anos, aprovada em 2016, durante o Governo Temer e mantida no governo Bolsonaro.

Gráfico 6 - Número de beneficiários de auxílios socioeconômicos e PBP (2010 - 2020)

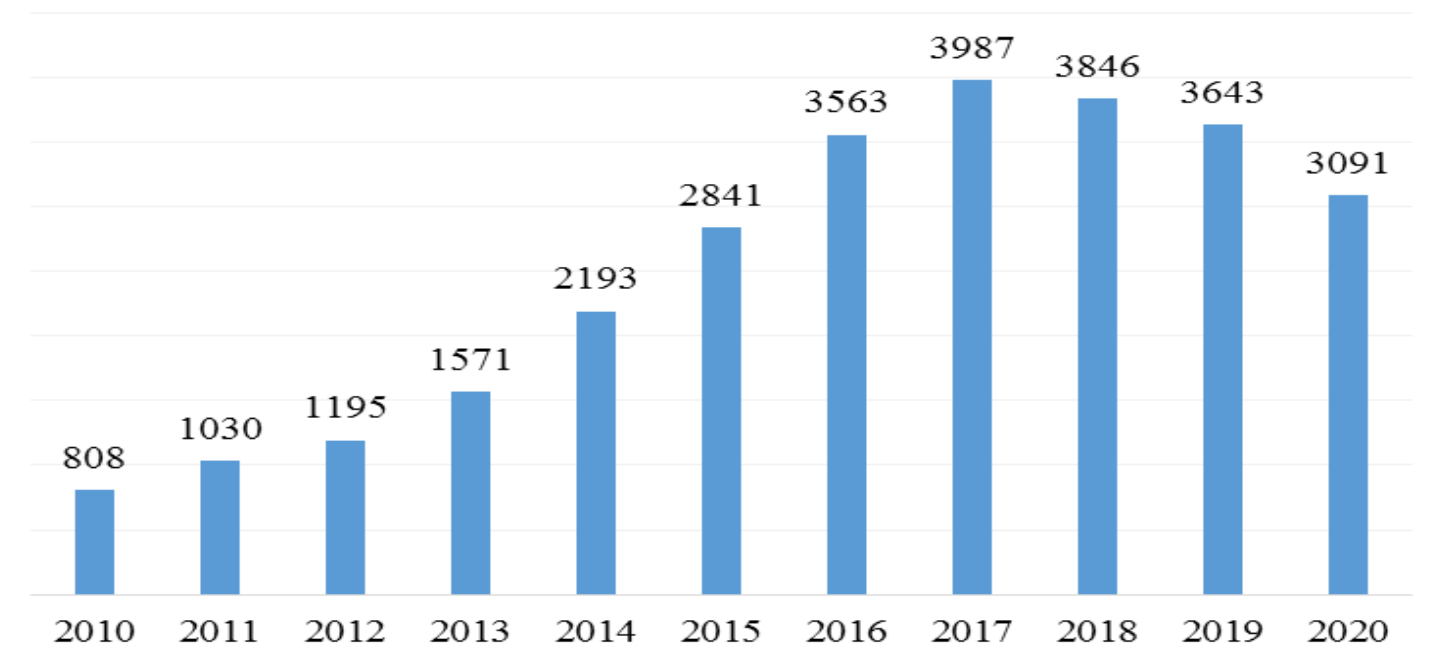

Fonte: Elaboração própria, conforme dados fornecidos pela PROAE/UFFS

Em 2019 após amplo debate entre a PROAE, os SAEs, estudantes e comunidade universitária em geral foi aprovada pelo Conselho Universitário a Política de Assistência Estudantil da UFFS, por meio da Resolução $n$. 10/CONSUNI/CGAE/UFFS/2019. Esse documento sintetiza um conjunto de programas, serviços, projetos e ações da PROAE, em articulação com demais políticas institucionais que visam ao "fortalecimento das condições de permanência, êxito nas atividades acadêmicas e inclusão social dos estudantes da Instituição, de forma a atender a comunidade universitária multicampi, em consonância com o Programa Nacional de Assistência Estudantil (PNAES)" (UFFS, 2019c, p. 1). Destacam-se, neste documento, serviços destinados ao acolhimento, orientação e acompanhamento social, psicológico e pedagógico aos estudantes, e programas como auxílios socioeconômicos, alimentação e nutrição, acompanhamento pedagógico e/ou psicossocial, ações afirmativas, promoção de saúde, esporte e lazer, entre outros.

O Quadro 5 mostra os principais programas e ações de Assistência Estudantil desenvolvidos na UFFS, em 2019. 
Quadro 5 - Programas e ações de Assistência Estudantil da UFFS - 2019

\begin{tabular}{|c|c|c|}
\hline Tipo & Objetivo & Alcance (2019) \\
\hline $\begin{array}{l}\text { Auxílios } \\
\text { Socioeconômicos } \\
\text { (auxílio alimentação, } \\
\text { moradia, transporte, } \\
\text { estudantil e creche) }\end{array}$ & $\begin{array}{l}\text { Apoiar estudantes em situação de } \\
\text { vulnerabilidade socioeconômica, } \\
\text { buscando fortalecer as condições de } \\
\text { permanência, frequência e êxito nas } \\
\text { atividades acadêmicas (UFFS, } \\
\text { 2019b). }\end{array}$ & $\begin{array}{l}\text { Investimento de } 8.428 .045,00 \text { e um } \\
\text { total de } 3.235 \text { beneficiários. } \\
\text { Total de bolsas: Alimentação: } 2.852 \text {; } \\
\text { Moradia: 2.146; Transporte: } 2.143 \text {; } \\
\text { Estudantil: } 2.951 \text {. Os valores variam } \\
\text { conforme o IVS de cada estudante. } \\
\text { Em média é pago um valor de R\$ } \\
350,36 \text { por estudante (PROAE/UFFS, } \\
2020 \text { ). }\end{array}$ \\
\hline Auxílio Emergencial & $\begin{array}{l}\text { Apoiar estudantes “[...] que } \\
\text { apresentam dificuldades } \\
\text { socioeconômicas, de caráter } \\
\text { emergencial e eventual, as quais } \\
\text { agravam a situação de vulnerabilidade } \\
\text { e colocam em risco a sua permanência } \\
\text { na universidade" (UFFS, 2019d). }\end{array}$ & $\begin{array}{l}\text { Investimento de } \mathrm{R} \$ 51.073,00,102 \\
\text { beneficiários e um valor médio de } \mathrm{R} \$ \\
500,76 \text { por estudante (UFFS, 2020). }\end{array}$ \\
\hline Auxílio Ingresso & $\begin{array}{l}\text { Apoiar a permanência de estudantes } \\
\text { nos momentos iniciais da vida } \\
\text { universitária (UFFS, 2019e). }\end{array}$ & $\begin{array}{l}\text { Investimento de R\$ 50.400,00 e } 168 \\
\text { beneficiários (PROAE/UFFS, 2020). }\end{array}$ \\
\hline 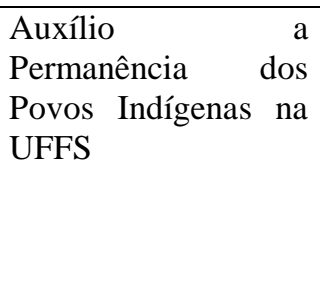 & $\begin{array}{l}\text { Consiste num "auxílio financeiro } \\
\text { provisório que visa suprir as } \\
\text { necessidades de estudante indígenas } \\
\text { ainda não contemplados pelo } \\
\text { Programa Bolsa Permanência - PBP, } \\
\text { do Ministério da Educação (MEC)" } \\
\text { (UFFS, 2019f). }\end{array}$ & 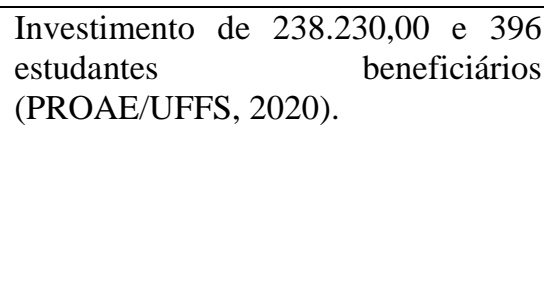 \\
\hline $\begin{array}{l}\text { Restaurante } \\
\text { Universitário } \\
\text { Subsídio } \\
\text { Alimentação }\end{array}$ & $\begin{array}{l}\text { Os RUs são equipamentos que } \\
\text { contribuem para a permanência dos } \\
\text { estudantes e integram a execução da } \\
\text { Política de Assistência Estudantil. } \\
\text { O Subsídio Alimentação é o } \\
\text { pagamento, por parte da UFFS, de } \\
\text { parte do valor da refeição dos } \\
\text { estudantes, tornando o valor mais } \\
\text { acessível, em relação ao valor integral } \\
\text { da refeição (UFFS, 2019c). }\end{array}$ & 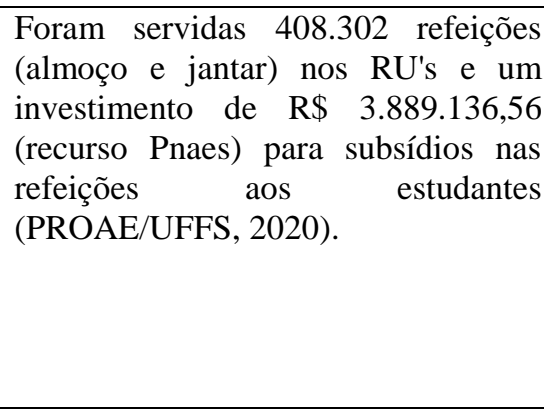 \\
\hline $\begin{array}{l}\text { Programa Bolsa } \\
\text { Permanência (MEC) }\end{array}$ & $\begin{array}{l}\text { Conceder bolsas de permanência para } \\
\text { estudantes sobretudo, quilombolas, } \\
\text { indígenas e em situação de } \\
\text { vulnerabilidade } \\
\text { (MEC, 2013). }\end{array}$ & $\begin{array}{l}\text { Investimento de recursos do MEC de } \\
\mathrm{R} \$ 2.794 .100 \text { totalizando } 3.336 \\
\text { bolsas concedidas e } 423 \text { beneficiários } \\
\text { (PROAE/UFFS, 2020). }\end{array}$ \\
\hline $\begin{array}{l}\text { Plano de } \\
\text { Acompanhamento }\end{array}$ & $\begin{array}{l}\text { Consiste em intervenções realizadas } \\
\text { pelos SAEs para a melhoria do } \\
\text { desempenho acadêmico dos } \\
\text { estudantes, por um período mínimo de } \\
\text { um semestre (PROAE/UFFS, 2018). }\end{array}$ & $\begin{array}{l}\text { Foram acompanhados um total de } \\
264 \text { estudantes (136 no primeiro } \\
\text { semestre e } 128 \text { no segundo semestre) } \\
\text { (PROAE/UFFS, 2020). }\end{array}$ \\
\hline $\begin{array}{lr}\text { Programa } & \text { de } \\
\text { Promoção à } & \text { Saúde } \\
\text { do Estudante } & \end{array}$ & $\begin{array}{l}\text { Desenvolve ações de promoção à } \\
\text { saúde e concede bolsas para } \\
\text { estudantes monitores para atuar junto } \\
\text { às equipes dos SAEs. }\end{array}$ & $\begin{array}{l}\text { Foram concedidas } 06 \text { bolsas no valor } \\
\text { de R\$ 500,00 mensais para } \\
\text { estudantes monitores (UFFS, 2019g). }\end{array}$ \\
\hline
\end{tabular}

Fonte: Elaboração própria conforme dados dispobilizados pela PROAE e no site institucional da UFFS.

Além do apoio social ofertado por meio da Assistência Estudantil, as atividades extracurriculares também contribuem de forma significativa para a permanência 
estudantil. Segundo o Inep (2018, p. 21), essas atividades se referem a "[...] quaisquer tipos de atividades que não estejam incluídas no currículo do curso, cuja função seja a de estimular a interação entre teoria e prática nos alunos participantes”. Destacam-se, por exemplo, o Programa de Apoio à Extensão Universitária (PROEXT); Programa Institucional de Bolsa de Iniciação Científica (PIBIC); Programa de Educação Tutorial (PET); Programa Institucional de Bolsas de Iniciação à Docência (PIBID); Programa de Residência Pedagógica (PRP) e programa de monitorias e de estágios extracurriculares. A participação dos estudantes ocorre por meio da disponibilização de horas, com recebimento de uma bolsa. A seleção ocorre a partir de editais específicos de cada programa, cujos critérios geralmente são meritocráticos e exigem maior desempenho para o acesso e/ ou para a manutenção do bolsista no programa. Em alguns programas, a inserção dos estudantes também pode ocorrer de modo voluntário, sem recebimento de bolsa remunerada. Na UFFS, essas bolsas acadêmicas são cumulativas com os auxílios recebidos na assistência estudantil. No ano de 2020, cerca de $37 \%$ dos alunos da UFFS participam desses programas, sendo 1.247 (14\%) de forma voluntária e 1.989 (23\%) com bolsa, conforme mostra o Gráfico 7 .

Gráfico 7 - Número de estudantes inseridos em atividades extracurriculares - 2020

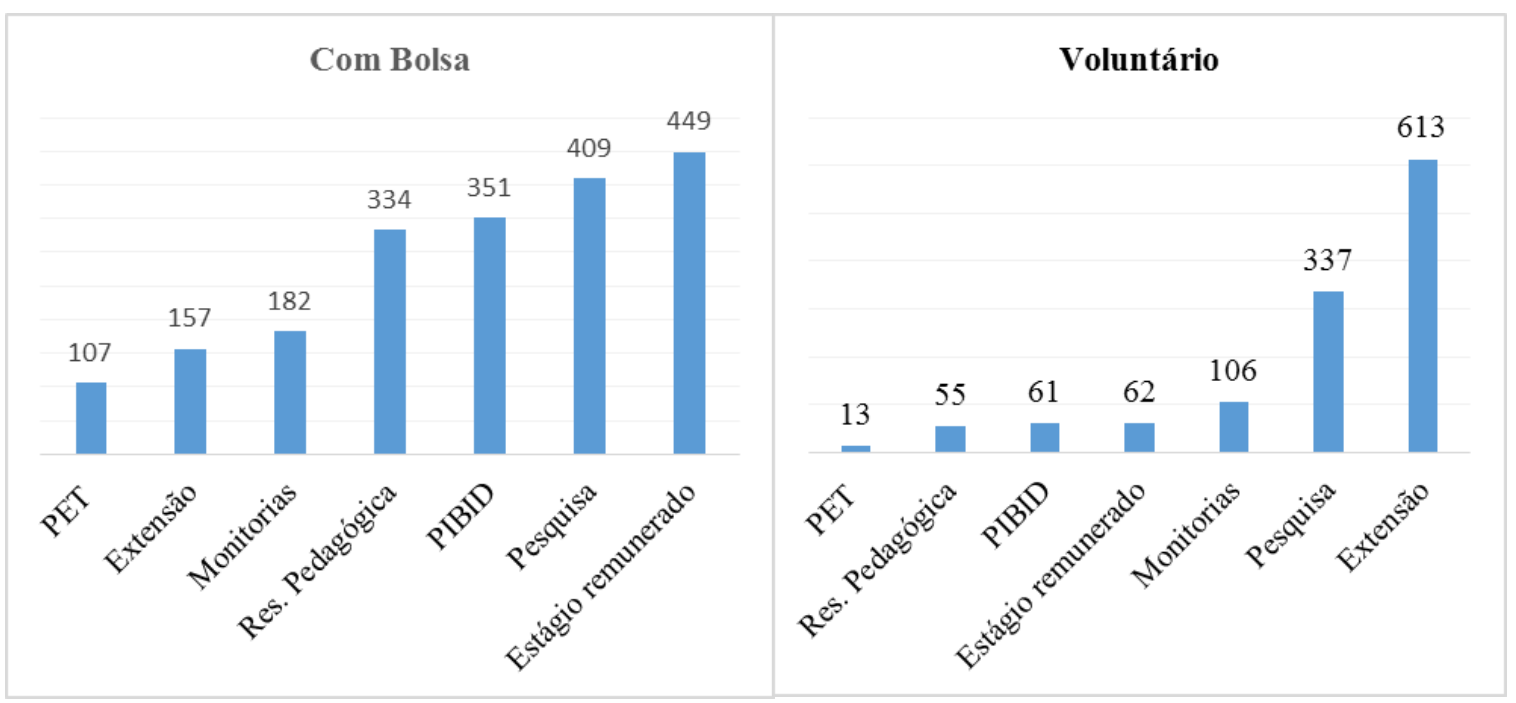

Fonte: Elaboração própria, com base em dados fornecidos pela Procuradoria Educacional Institucional/UFFS

Essas atividades são ofertadas por meio das Pró-Reitorias de Graduação, de Pesquisa e de Extensão e Cultura e Setor de Estágios da UFFS. 


\subsection{Mudanças e permanências no perfil socioeconômico e racial dos ingressantes ao longo do tempo}

\subsubsection{Origem geográfica dos ingressantes}

Uma das questões importantes para essa análise é de onde vem os estudantes da UFFS e se a partir da Lei de Cotas e da adesão ao $\mathrm{SiSU}^{50}$ esse perfil foi modificado. Para isso, foi considerada como proxy $^{51}$ de endereço a variável Unidade Federativa ${ }^{52}$ (UF) em que o ingressante concluiu o Ensino Médio. Os ingressantes foram divididos em duas coortes: 2010 a 2013 (antes do SiSU) e 2014 a 2018 (depois do SiSU). Importante considerar que o ano de 2013 teve a adesão à Lei de Cotas.

Os dados longitudinais (2010 a 2018) mostram que a maioria dos ingressantes concluiu o Ensino Médio na Região Sul, indicando que a comunidade discente da UFFS é regional e oriunda principalmente do estado em que se localiza cada Campus. Ainda que a maioria seja da região, a partir de 2014 observamos que esse perfil foi se modificando, com a atração de estudantes de outros regiões brasileiras. Em 2014, por exemplo, no primeiro ano do SiSU, o percentual de ingressantes de outras regiões praticamente triplicou em relação ao ano anterior. O Gráfico 8 mostra essas mudanças ao longo do tempo.

\footnotetext{
${ }^{50}$ Por meio do SISU os estudantes podem se inscrever com a nota do Enem em duas opções de curso em qualquer IES do país, que tenha feito a adesão ao sistema.

${ }^{51}$ Proxy é uma variável utilizada para substituir outra variável que não é observada diretamente.

5252 Não foi considerado a Unidade Federativa de endereço do ingressante, pelo fato de que este dado pode ser atualizado durante a graduação. O uso da UF de conclusão do Ensino Médio também possui a limitação, caso o estudante da UFFS tenha mudado para um Estado diferente antes do ingresso na UFFS.
} 
Gráfico 8 - Percentuais de ingressantes, segundo a origem geográfica - 2010 a 2018

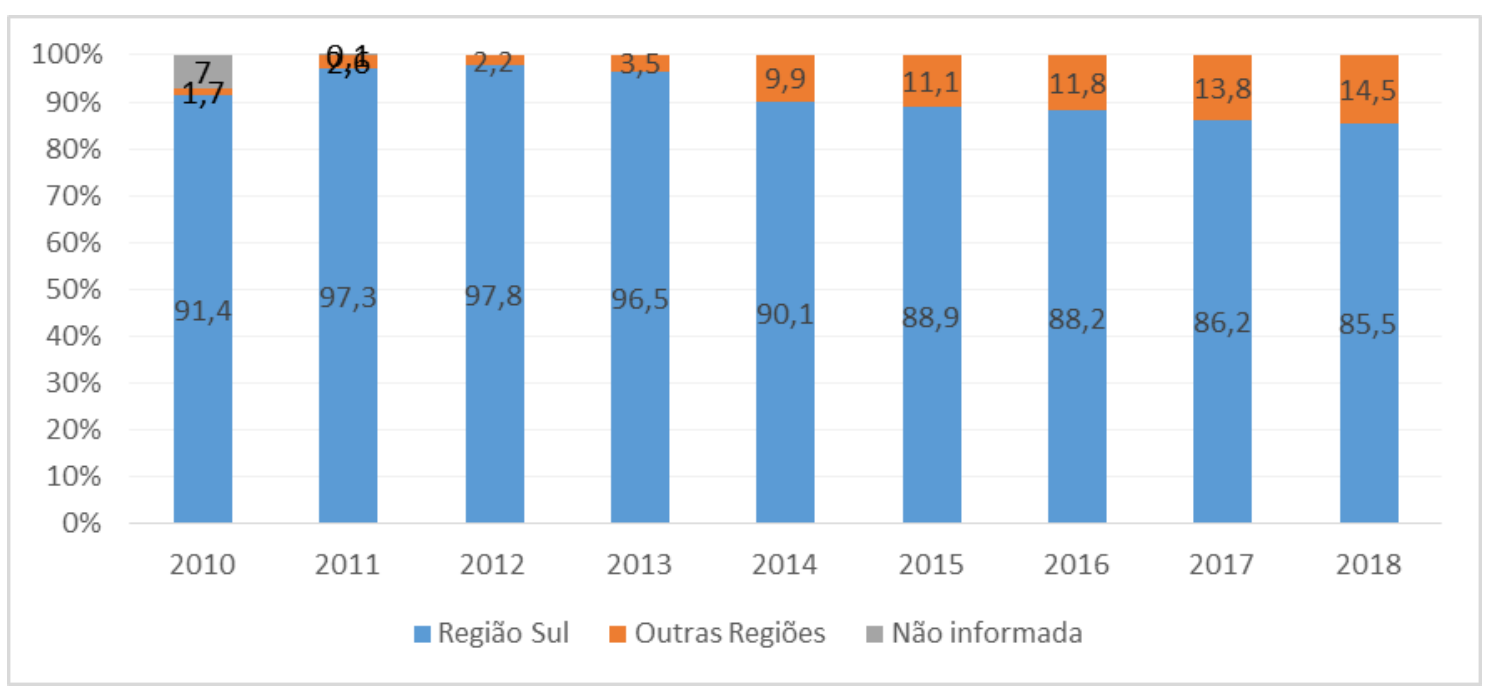

Fonte: Elaboração própria a partir de dados do SGA/UFFS

O Gráfico 9 mostra como essas mudanças ocorreram em cada campus. De um modo geral, a origem principal dos ingressantes é do próprio estado de localização do campus. A partir de 2014, todos os Campi tiveram um aumento de ingressantes de outras regiões, não alterando muito os percentuais para os estados da Região Sul e até diminuindo em alguns campi, exceto o Campus Passo Fundo que teve um aumento de ingressantes de Santa Catarina.

O Campus Chapecó, pela sua localização na divisa do Rio Grande do Sul, atrai mais estudantes desse Estado, seguido de outros estados como Paraná, São Paulo e Minas Gerais. Os Campi do Paraná (Laranjeiras do Sul e Realeza) atraem mais estudantes de Santa Catarina e de São Paulo, principalmente a partir de 2014. Em Laranjeiras do Sul os estudantes de SP representam 11,4\% e em Realeza, 8,3\%. Nos demais campi essa migração de estudantes de São Paulo também foi significativa como, por exemplo, em Erechim, 8,4\% e em Chapeco, 6,4\%.

Os campi localizados no Estado do Rio Grande do Sul atraem mais estudantes de Santa Catarina. O Campus Passo Fundo desde a sua criação já apresentava o maior percentual de ingressantes de outros estados, passando para mais de 40\%, a partir de 2014, principalmente de Santa Catarina, Minas Gerais, Paraná e São Paulo.

Já o Campus Cerro Largo é o que apresenta o menor percentual de estudantes de outros estados, e mesmo a partir de 2014 manteve-se com mais de 90\% de ingressantes oriundos do próprio Estado. A partir de 2014, a migração maior ocorreu entre ingressantes de outros estados, como São Paulo, por exemplo, com 2,2\%, mais que 
Santa Catarina e Paraná juntos que somam 1,4\%. Isso poderia se justificar pelo fato deste Campus estar localizado em município menos populoso e pelo fato de que os curos ofertados neste campus também possuem oferta em campi de outros Estados.

Gráfico 9 - Percentual de ingressantes por campus, segundo a origem geográfica - antes e depois do SiSU

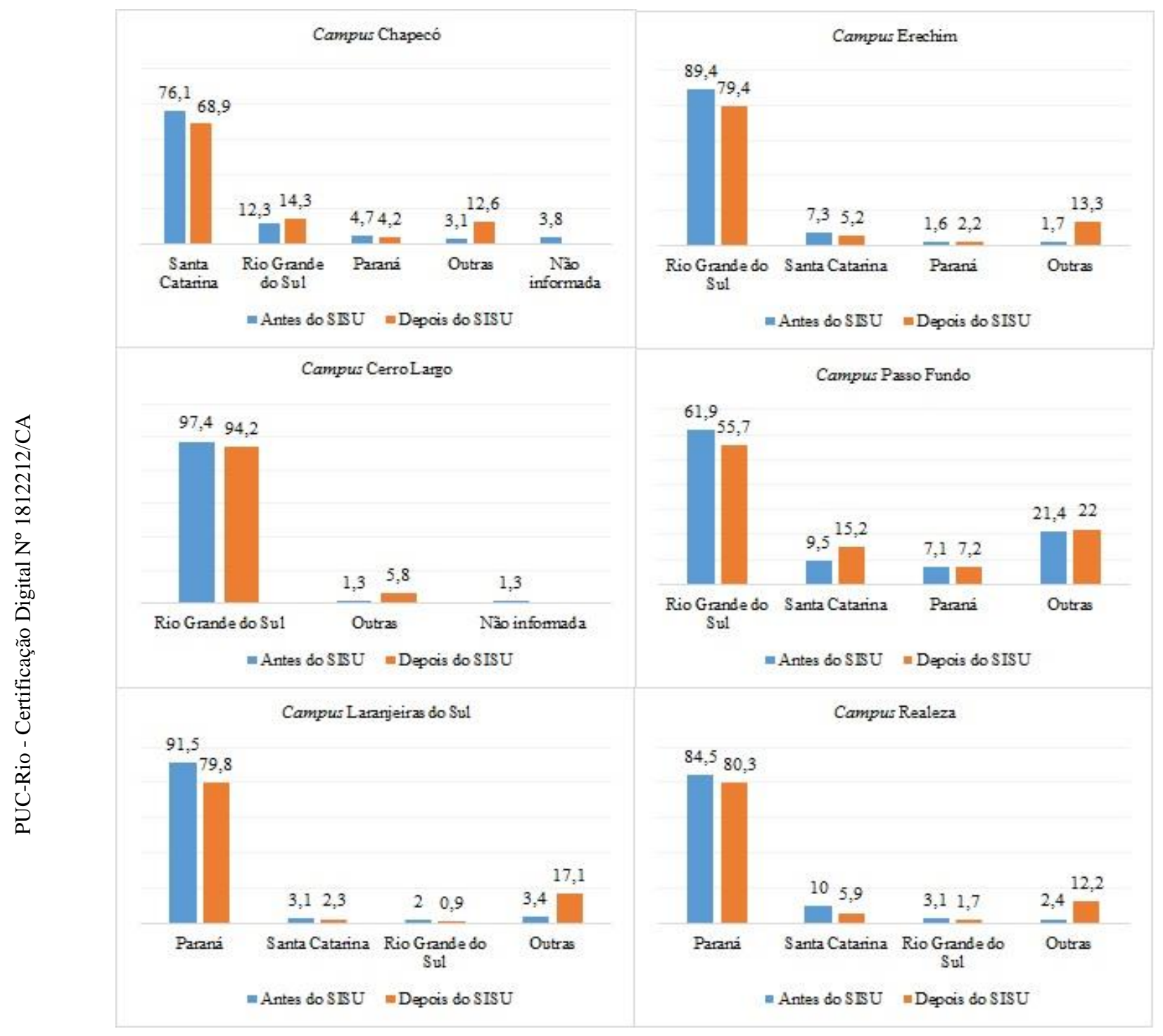

Fonte: Elaboração própria a partir de dados do SGA/UFFS

\subsubsection{Faixa etária}

A maioria dos ingressantes ao longo do período tinha entre 16 a 20 anos. A Tabela 16 apresenta de forma detalhada a distribuição dos ingressantes entre 2010 e 2018. Observa-se, a partir de 2014, que coincide com a adesão ao SiSU e com o 
aumento de estudantes de outras regiões do país, um crescimento anual do percentual de estudantes mais jovens, entre 17 a 20 anos, e a diminuição do ingresso de estudantes a partir de 25 anos.

Tabela 16 - Percentual de ingressantes, segundo faixa etária - 2010 a 2018

\begin{tabular}{llllllllll}
\hline Faixa etária & 2010 & 2011 & 2012 & 2013 & 2014 & 2015 & 2016 & 2017 & 2018 \\
\hline 17 a 20 anos & 55,2 & 53,3 & 57,5 & 55,7 & 60,0 & 59,3 & 62,5 & 63,7 & 64,6 \\
21 a 24 anos & 19,2 & 19,5 & 19,5 & 19,9 & 18,6 & 19,1 & 19,7 & 20,6 & 19,9 \\
25 a 30 anos & 14,1 & 14,4 & 13,6 & 12,5 & 10,9 & 12,1 & 11,0 & 9,4 & 9,3 \\
31 anos ou mais & 11,4 & 12,8 & 9,3 & 11,9 & 10,6 & 9,5 & 6,8 & 6,3 & 6,1 \\
Total & 100 & 100 & 100 & 100 & 100 & 100 & 100 & 100 & 100 \\
\hline
\end{tabular}

Fonte: Elaboração própria a partir de dados do SGA/UFFS

Quanto à distribuição da faixa etária nos diferentes cursos, observa-se que, em algumas licenciaturas e no curso de Medicina, a maioria dos estudantes ingressa com idade superior a 21 anos. Pela seletividade do curso de Medicina supõe-se que o ingresso pode ser mais tardio pelo tempo maior de preparação ou de tentativas de ingresso desde o término do Ensino Médio e, também, por ser um curso muito desejado e, para alguns, a segunda graduação. No caso de algumas licenciaturas menos seletivas, supõe-se que um perfil de ingressantes retorna à Universidade depois de ter deixado de estudar, tendo em vista que a maioria é ofertada em turno noturno e envolve um perfil maior de estudantes trabalhadores, condição esta que também pode explicar o ingresso tardio. Já em cursos como Arquitetura e Medicina Veterinária, observa-se que mais de $80 \%$ dos estudantes ingressam com idades entre 17 a 24 anos.

\subsubsection{Sexo}

A literatura mostra que a presença maior de mulheres no ensino superior se consolidou nas últimas décadas, mas que a desigualdade de gênero continua a se manifestar muitas vezes na ocupação dos cursos e no mercado de trabalho, principalmente quando associada também à raça/cor das estudantes (Gerber; Cheung; 2008; Santos; Bernardino, 2016; Barbosa, 2019; Carvalhaes; Ribeiro, 2019).

Caseiro (2016), ao analisar o acesso ao ensino superior de jovens entre 18 a 24 anos, no período de 2004 a 2014, constatou que as mulheres tiveram 37\% mais chances de acesso em relação aos homens em 2004, crescendo para 52\%, em 2014. Na região 
Sul, ainda que tenha ocorrido uma redução nas chances de acesso das mulheres em relação aos homens, continua sendo a mais elevada do país: em 2004, as chances das mulheres eram 79\% superiores a de homens, reduzindo para 63\%, em 2014.

Na UFFS, a maioria dos ingressantes de 2010 a 2018 são mulheres, totalizando um percentual médio de 58,6\%, com pouca variação ao longo do tempo (Tabela 17). Segundo dados nacionais do Censo da Educação Superior, em 2019, entre as matrículas de todas as IES brasileiras, $57,4 \%$ eram do sexo feminino e 42,6\%, do masculino. Já, quando se estratifica apenas por IES federais, o percentual é de 50,3\% entre as mulheres (Inep, 2020a).

Tabela 17 - Percentual de ingressantes, segundo sexo - 2010 a 2018

\begin{tabular}{llllllllll}
\hline Sexo & $\mathbf{2 0 1 0}$ & $\mathbf{2 0 1 1}$ & $\mathbf{2 0 1 2}$ & $\mathbf{2 0 1 3}$ & $\mathbf{2 0 1 4}$ & $\mathbf{2 0 1 5}$ & $\mathbf{2 0 1 6}$ & $\mathbf{2 0 1 7}$ & $\mathbf{2 0 1 8}$ \\
\hline Masculino & 38,4 & 38,4 & 36,5 & 41,2 & 43,3 & 45,8 & 44,2 & 44,1 & 41,0 \\
Feminino & 61,6 & 61,6 & 63,5 & 58,8 & 56,7 & 54,2 & 55,8 & 55,9 & 59,0 \\
Total & 100 & 100 & 100 & 100 & 100 & 100 & 100 & 100 & 100 \\
\hline
\end{tabular}

Fonte: Elaboração própria a partir de dados do SGA/UFFS

\subsubsection{Raça/cor}

A categoria raça/cor é um importante marcador social para a análise das trajetórias escolares, uma vez que a desigualdade racial se manifesta nas diferentes etapas educacionais, tanto no Brasil como em contextos internacionais (Picanço, 2015; Eller; Diprete, 2018; Barbosa, 2019; Andrade, 2019; Carvalhaes; Ribeiro, 2019).

Em comparação com as demais regiões brasileiras, a Região Sul concentra o maior número de população autodeclarada branca $(78,5 \%)$. Na UFFS este perfil é semelhante e observam-se mudanças ao longo do tempo que podem responder pelo impacto da Lei de Cotas, a partir de 2013. Conforme dados do Censo Demográfico, em 2010, além do alto percentual de brancos, a população da Região Sul também é caracterizada por autodeclarados pardos $(16,5 \%)$, pretos $(4,0 \%)$, amarelos $(0,7 \%)$ e indígenas $(0,3 \%)$. Esses percentuais possuem algumas variações, conforme cada unidade federativa da região.

A partir da Lei de Cotas houve um crescimento de ingressantes negros (pretos e pardos), especialmente de pardos, que ultrapassa inclusive o percentual referente à proporção da população na Região Sul. Somados os pretos, pardos e indígenas (PPIs), em 2010 o percentual era de 13,1\%, passando para 23,8\%, em 2018. Em 2017, o 
percentual de ingressantes brancos foi menor em relação aos demais anos e observou-se um aumento no percentual dos não declarados. Nesse mesmo ano a UFFS passou a ter comissão de heteroidentificação para avaliar a cota racial dos estudantes no ato da matrícula. Até então, o ingresso ocorria apenas pela autodeclaração, o que gerou algumas denúncias de possíveis fraudes na política de cotas. A Tabela 18 mostra a distribuição, segundo raça/cor ao longo do período analisado.

Tabela 18 - Percentual de ingressantes, segundo raça/cor - 2010 a 2018

\begin{tabular}{llllllllll}
\hline Raça/cor & $\mathbf{2 0 1 0}$ & $\mathbf{2 0 1 1}$ & $\mathbf{2 0 1 2}$ & $\mathbf{2 0 1 3}$ & $\mathbf{2 0 1 4}$ & $\mathbf{2 0 1 5}$ & $\mathbf{2 0 1 6}$ & $\mathbf{2 0 1 7}$ & $\mathbf{2 0 1 8}$ \\
\hline Branca & 83,8 & 82,4 & 80,3 & 78,7 & 76,6 & 75,8 & 73,8 & 69,4 & 73,8 \\
Parda & 11,3 & 12,0 & 11,3 & 17,0 & 16,0 & 17,1 & 21,6 & 21,8 & 20,3 \\
Preta & 1,7 & 2,0 & 1,7 & 2,4 & 2,3 & 2,5 & 2,5 & 2,9 & 3,0 \\
Indígena &, 1 &, 1 &, 1 &, 4 &, 4 &, 4 &, 1 &, 5 &, 5 \\
Amarela &, 9 & 1,0 &, 9 &, 9 &, 8 &, 7 &, 9 &, 7 &, 7 \\
Não Declarada & 2,2 & 2,5 & 5,8 &, 6 & 3,9 & 3,5 & 1,2 & 4,7 & 1,9 \\
Total & 100 & 100 & 100 & 100 & 100 & 100 & 100 & 100 & 100 \\
\hline
\end{tabular}

Fonte: Elaboração própria a partir de dados do SGA/UFFS

Uma das questões importantes é como ocorre a estratificação racial por cursos e suas modificações ao longo dos anos. Alguns cursos de bacharelados, como Arquitetura e Urbanismo, Engenharia Ambiental e Agronomia, tinham os maiores percentuais de estudantes brancos e percentuais abaixo de $10 \%$ de estudantes negros. Até 2012, por exemplo, os cursos de Arquitetura e Urbanismo e de Medicina Veterinária não tiveram a presença de estudantes autodeclarados pretos. Observa-se a presença maior de estudantes negros em cursos de licenciaturas, tais como História, Filosofia e Educação do Campo.

No caso dos estudantes indígenas, até 2012, ingressaram apenas cinco nos seguintes cursos: dois em Engenharia Ambiental; um em Ciências Econômicas; um em Geografia e um em Letras. A partir da Lei de Cotas, no período entre 2013 a 2018, houve o ingresso de 40 estudantes indígenas, por meio do Enem. A principal forma de ingresso desses estudantes na UFFS ocorre por meio de processos seletivos especiais como os programas PIN e Pronacampo ${ }^{53}$.

O efeito da Lei de Cotas foi significativo em todos os cursos, pois a partir da adesão da UFFS à mesma ocorreu uma distribuição racial mais próxima da população

\footnotetext{
${ }^{53}$ Entre 2010 a 2018 ingressaram 552 indígenas por meio de processos seletivos especiais e 29 por meio de outras formas como transferências, por exemplo.
} 
da Região Sul. Ainda que a representação de pretos continue abaixo da proporção da população de cada Estado, a mesma ocorreu em todos os cursos. Em cursos como Medicina, Medicina Veterinária e Matemática, por exemplo, o percentual de autodeclarados pretos $^{54}$ é inferior a $1 \%$. Em cursos como Arquitetura e Urbanismo e Engenharia Ambiental houve um crescimento significativo de estudantes negros. Em alguns cursos, estes estudantes ultrapassam esta representação em relação à população estadual, como no caso do Estado do Paraná que tem 28,3\% de pessoas autodeclaradas pretas, pardas e indígenas, e nos cursos de Engenharia de Aquicultura tem 37,3\% de estudantes negros e em Engenharia de Alimentos, 32,3\%, em 2013.

A seguir, descrevemos a composição de estudantes autodeclarados pretos, pardos e indígenas nas diferentes áreas de conhecimento, buscando apresentar um panorama mais geral, sem a separação dos cursos por Estados (Gráfico 10).

Observa-se que a área de Educação, que agrega todos cursos de Licenciaturas e cerca de 50\% das matrículas, já partiu de um percentual maior de PPIs antes da Lei de Cotas, superior a $15 \%$, enquanto as demais áreas, em sua maioria, registram percentuais menores a 15\%, e, no caso da área de Engenharia, menor a 10\%. A partir de 2013 observa-se um aumento de PPIs em todas as áreas de conhecimento, que na maior parte dos casos, ultrapassa 20\%, com destaque para cursos nas áreas de Agricultura, Engenharias e Saúde que partem de percentuais menores.

Atribui-se esse aumento de PPIs em todas as áreas de conhecimento a um possível efeito da Lei de Cotas, cuja reserva de vagas ocorre para todos os cursos e turnos, contribuindo para reduzir a estratificação social interna na ocupação dos cursos. Antes de 2012, com a política apenas de bonificação da escola pública, havia uma subrepresentação deste grupo em alguns cursos.

\footnotetext{
${ }^{54}$ Em Medicina, dos 471 ingressantes nos Campi Passo Fundo e Chapecó, entre 2013 a 2018, apenas quatro eram pretos (0,8\%); em Medicina Veterinária, de 444 ingressantes, entre 2010 a 2018, apenas dois eram pretos (0,5\%); e, em Matemática, de 237 ingressantes, entre 2014 a 2018, apenas dois eram pretos $(0,8 \%)$.
} 
Gráfico 10 - Percentual de ingressantes PPIs, segundo áreas de conhecimento - 2010 a 2018
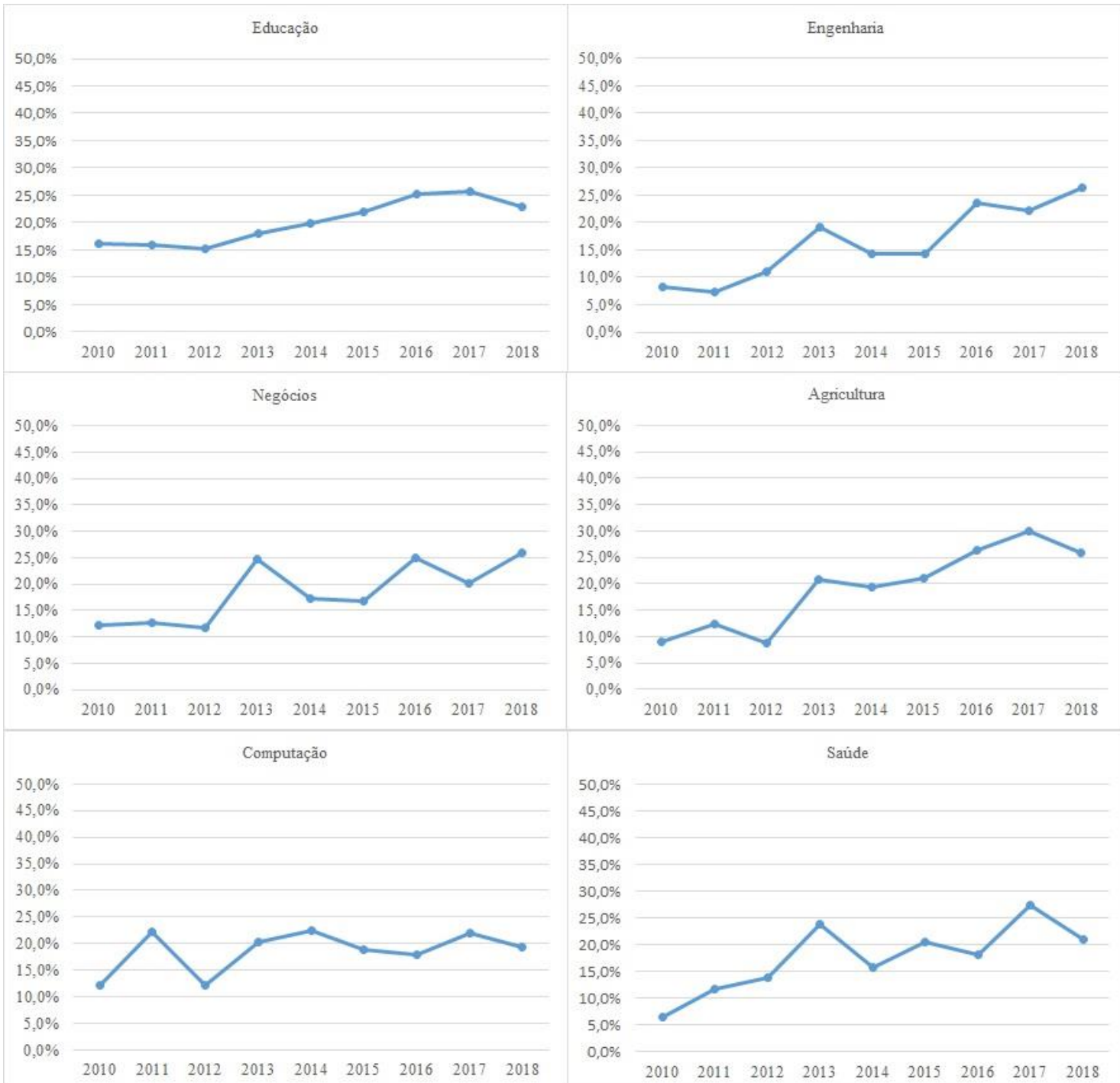

$\begin{array}{lllllllll}2010 & 2011 & 2012 & 2013 & 2014 & 2015 & 2016 & 2017 & 2018\end{array}$

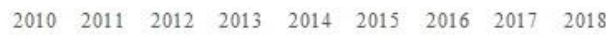

Fonte: Elaboração própria, conforme dados do SGA/UFFS

Como a UFFS encontra-se localizada nos três Estados da Região Sul, buscamos mapear a distribuição racial em cada campus ao longo do tempo, em termos de ingressantes autodeclarados pretos, pardos e indígenas (PPIs), que é um dos critérios da Lei de Cotas. A Região Sul possui uma representação populacional média de 20,9\% de PPIs (IBGE, 2010a). Diante disso, buscamos apresentar um panorama comparativo entre o percentual de estudantes PPIs em cada campus, ao longo do tempo, independentemente do acesso ter sido por cotas, e a representação populacional deste grupo em cada Unidade da Federação (UF), onde o campus da UFFS encontra-se localizado. 
Esse percentual está representado pela linha pontilhada na cor cinza. Os dados mostram que a partir da implementação da Lei de Cotas, em 2013, de um modo geral, o percentual de PPIs ficou mais próxima de sua representação populacional e até a ultrapassou, em algumas situações. É preciso considerar também que existe um pequeno percentual de "não declarados", e que dentro desse grupo também pode haver PPIs.

O Estado de Santa Catarina conta com um percentual de PPIs de 15,6\%, sendo 2,9\% autodeclarados pretos, 12,4\%, pardos e 0,3\%, indígenas (IBGE, 2010a). Conforme mostra o Gráfico 11, no Campus Chapecó, manteve-se desde o início uma representação de PPIs muito próxima a sua representação populacional e até superior, principalmente nos últimos anos, em que ultrapassou os 20\%. Apenas nos anos de 2010 e 2012 (anterior à Lei de Cotas) este grupo esteve sub-representado. Os dados revelam o potencial inclusivo deste Campus, corroborando com o estudo de Mello e Senkevics (2020), que analisam os impactos da Lei de Cotas, no período entre 2012 e 2016, e encontram resultados positivos para o Estado de Santa Catarina com um aumento relativo de $103 \%$ dos ingressantes, de 18 a 24 anos, PPIs e de baixa renda. Ao comparar o diferencial na participação deste grupo nas IFES e na população, os autores encontraram neste Estado, em termos relativos, a maior redução desta diferença, representado, em termos relativos por $91 \%$, de modo a quase eliminação da desigualdade, seguido dos Estados do Tocantins (86\%) e do Ceará (77\%).

Gráfico 11 - Percentual de ingressantes PPIs, segundo campus e sua representação em Santa Catarina - 2010 a 2018

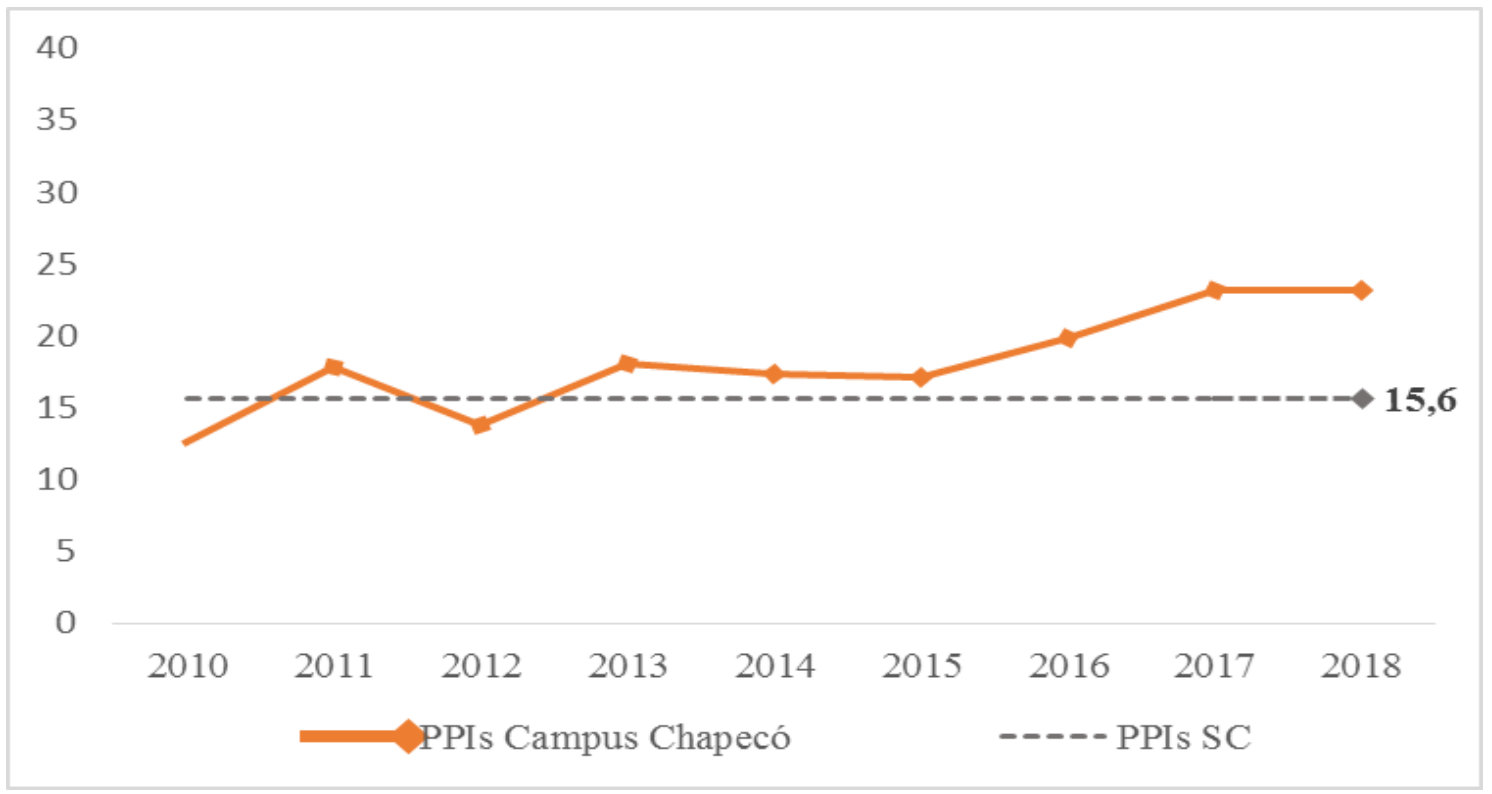

Fonte: Elaboração própria, conforme dados do SGA/UFFS e IBGE (2010a) 
O Estado do Paraná possui um percentual de PPIs de 28,5\%, sendo 3,2\% autodeclarados pretos, 25,1\% pardos e 0,3\% indígenas (IBGE, 2010a). Conforme apresentado no Gráfico 12, o Campus Realeza, em três anos, não teve o percentual de ingressantes PPIs na mesma proporção do Estado. Já no Campus Laranjeiras do Sul, os percentuais ultrapassaram em até 10 p.p. ou mais a proporção deste grupo no Estado, atingindo um patamar de quase 40\%, em 2016 e 2017. Neste Campus, chama a atenção principalmente a presença de PPIs, em cursos como o de licenciatura em Interdisciplinar em Educação do Campo: Ciências Naturais, Matemática e Ciências Agrárias (noturno), que, em 2017, por exemplo, chegou a 53,8\%. Outros cursos também se destacam com mais de $30 \%$ ou $40 \%$ de presença de estudantes do grupo PPIs, a depender do ano, como Engenharia de Alimentos; Engenharia de Aquicultura e Agronomia. Uma das características deste Campus é sua localização na Região Cantuquiriguaçu, onde a maioria da população se concentra na área rural e há expressiva presença de trabalhadores de assentamentos rurais, de reservas indígenas e de grupos de quilombolas.

Gráfico 12 - Percentual de ingressantes PPIs, segundo campus e sua representação no Paraná - 2010 a 2018

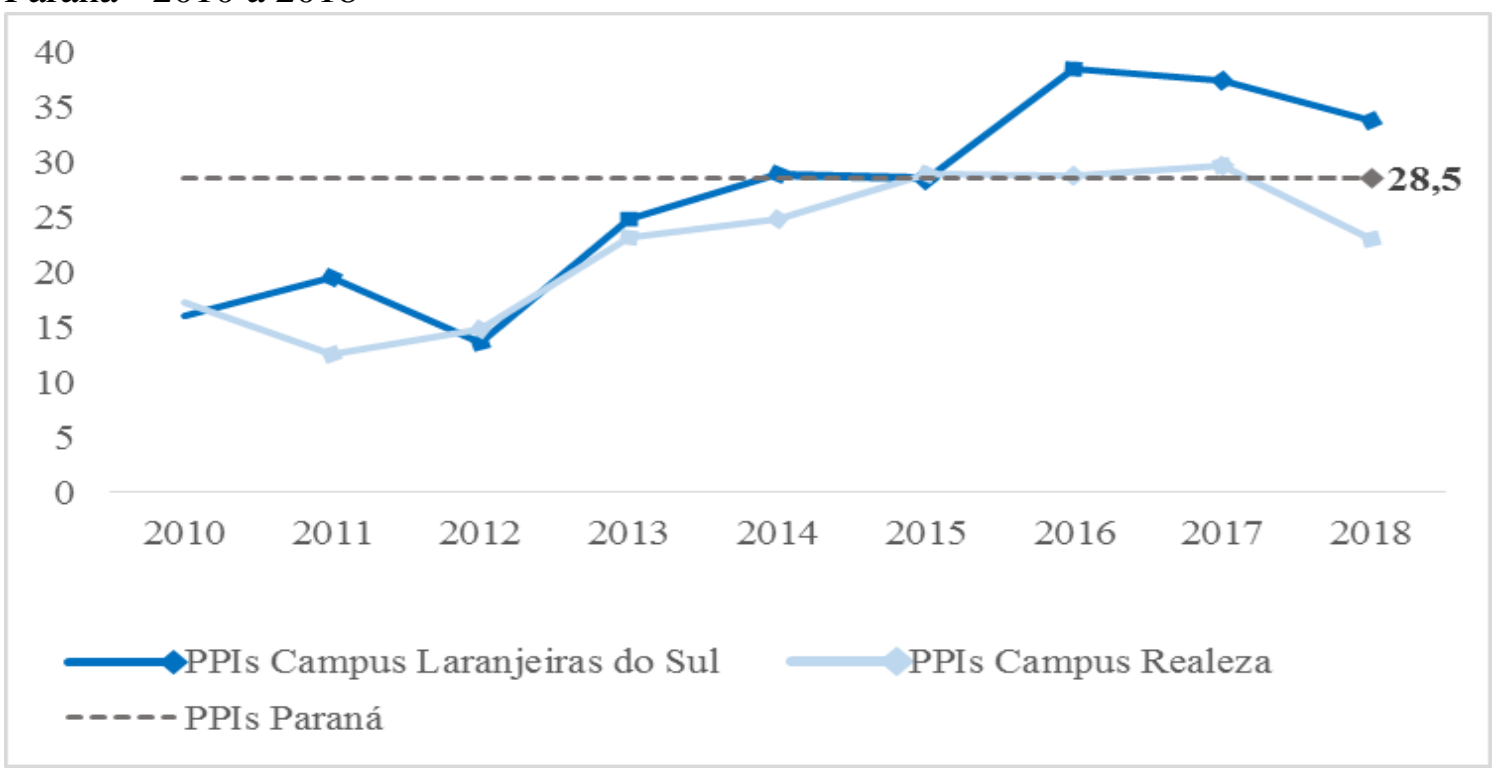

Fonte: Elaboração própria, conforme dados do SGA/UFFS e IBGE (2010a)

O Estado do Rio Grande do Sul possui o percentual de PPIs de 16,5\%, sendo $5,6 \%$ autodeclarados pretos, 10,6\% pardos e 0,3 indígenas (IBGE, 2010a). No Gráfico 13 observa-se que antes da Lei de Cotas havia uma sub-representação de PPIs nos 
campi Cerro Largo e Erechim, tendo um aumento a partir de 2013 e principalmente nos últimos anos a partir de 2016, com percentuais acima da sua representação populacional do Estado. O Campus Passo Fundo, que oferta apenas o curso de Medicina, apresentou no ano de sua criação, em 2013, um percentual de 28,6\% de estudantes pretos, pardos e indígenas, com quedas nos anos posteriores, uma sub-representação em 2015 e novo crescimento em 2016 e 2017. Em 2018, os percentuais dos três campi ficaram próximos a $20 \%$, ou seja, acima de sua representação populacional. Constata-se os efeitos positivos da Lei de Cotas, no sentido de contribuir para o aumento das oportunidades de acesso ao ensino superior para estudantes pretos, pardos e indígenas, inclusive em cursos de maior seletividade, como é o caso de Medicina.

Gráfico 13 - Percentual de ingressantes PPIs, segundo campus e sua representação no Rio Grande do Sul - 2010 a 2018

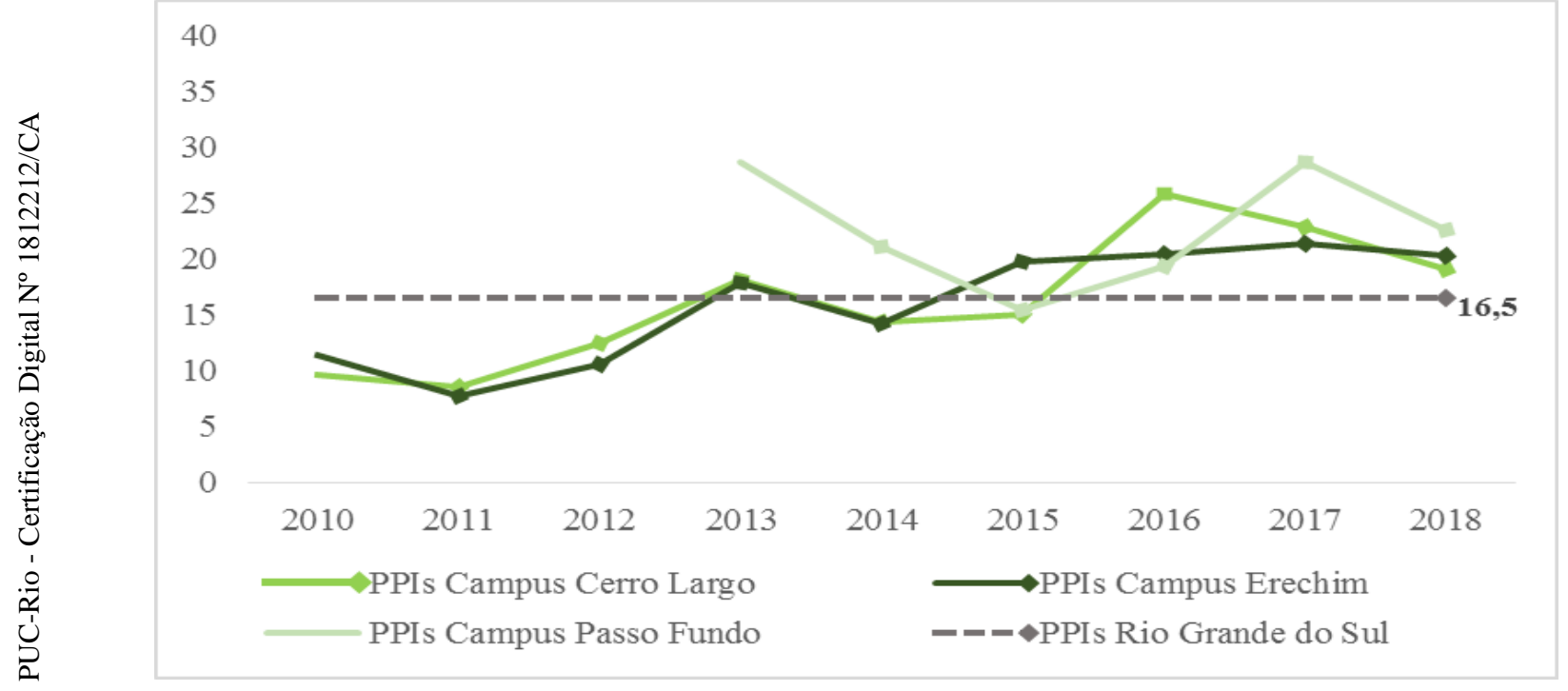

Fonte: Elaboração própria, conforme dados do SGA/UFFS e IBGE (2010a).

Uma importante questão que se coloca nessa análise é de onde vem os estudantes negros (pretos e pardos) e brancos da UFFS? A partir do SiSU, a cada ano, o percentual de estudantes brancos da Região Sul vem diminuindo concomitantemente ao crescimento dos estudantes brancos e de estudantes negros vindos de outras regiões, ou seja, que concluíram o Ensino Médio nessas outras regiões, (de 10\% a 15\%). Em 2013, apenas $1,7 \%$ dos estudantes, tanto brancos quanto negros eram de outras regiões, passando em 2018 para 6,3\% e 7,3\%, respectivamente. A maioria dos estudantes na categoria racial "outros" (amarelos, indígenas e não declarados) concluiu o Ensino Médio na Região Sul. O primeiro ano de funcionamento da UFFS teve um percentual 
maior de alunos brancos e negros vindos de outras regiões, quando comparado aos anos imediatamente posteriores. O Gráfico 14 apresenta a distribuição dos ingressantes ao longo dos anos, segundo raça/cor e região de endereço.

Gráfico 14 - Percentual de ingressantes, segundo raça/cor e origem geográfica ${ }^{55}$ - 2010 a 2018

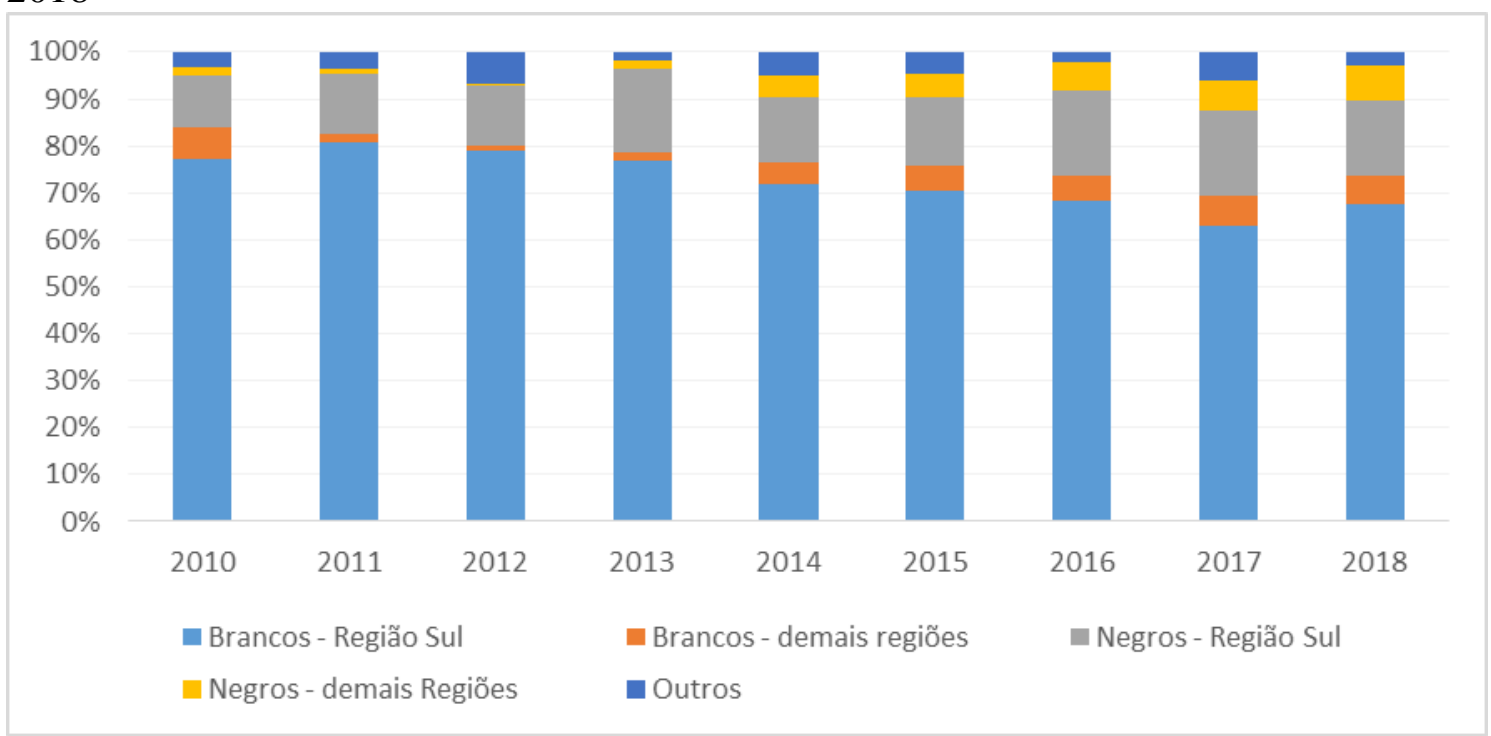

Fonte: Elaboração própria a partir de dados do SGA/ UFFS

\subsubsection{Escola pública}

Ser estudante egresso de escola pública é uma característica da maioria dos estudantes da UFFS, desde o primeiro ingresso em 2010. Isso se deve principalmente às políticas de ações afirmativas desta Universidade que priorizaram este critério desde o início da sua implementação (Nierotka; Trevisol, 2016). A partir da Lei de Cotas, esse percentual manteve-se alto (mais de 90\%), muito além dos 50\% previstos legalmente, sendo ainda maior do que o próprio percentual aplicado para reserva de vagas desta IES (média de 84\%). Isso indica que uma parte significativa dos estudantes que ingressam na modalidade de ampla concorrência, de 2013 a 2018, também são egressos de escola pública $(45,3 \%$, em média).

Na UFFS, a média acumulada entre 2010 e 2018 de ingressantes que estudaram todo o ensino médio ou parte dele em escola pública é de 94,2\%. Conforme dados do último Censo da Educação Básica (Inep, 2020b), no Brasil, 87,5\% das matrículas de Ensino Médio estão em Instituições públicas e na Região Sul, esse percentual é de

55 Para este gráfico a categoria "não informada" da UF de conclusão de Ensino Médio (2010 e 2011) foi juntada na categoria "outras regiões". 
$86,9 \%$. Isso também pode indicar que, como a UFFS está localizada no interior dos três Estados, a presença de escolas privadas pode ser menor, principalmente em municípios menos populosos. Portanto, uma questão que se coloca é a seguinte: é o critério "escola pública" adotado pela UFFS que promove este perfil de estudantes ou este se deve à majoritária presença regional de escolas públicas de Ensino Médio? Segundo a pesquisa da Andifes (2019), em 2018, o percentual médio de estudantes que participaram deste estudo e que eram egressos do ensino médio em escolas públicas nas IES federais era 64,7\%. A Tabela 19 apresenta o percentual de ingressantes da UFFS ao longo dos anos, segundo escola pública.

Tabela 19 - Percentual de ingressantes, segundo ensino médio em escola pública - 2010 a 2018

\begin{tabular}{llllllllll}
\hline Escola pública & $\mathbf{2 0 1 0}$ & $\mathbf{2 0 1 1}$ & $\mathbf{2 0 1 2}$ & $\mathbf{2 0 1 3}$ & $\mathbf{2 0 1 4}$ & $\mathbf{2 0 1 5}$ & $\mathbf{2 0 1 6}$ & $\mathbf{2 0 1 7}$ & $\mathbf{2 0 1 8}$ \\
\hline Estudou & 95,1 & 96,9 & 96,7 & 93,4 & 93,2 & 93,6 & 93,4 & 92,4 & 93,4 \\
Não estudou & 4,9 & 3,1 & 3,3 & 6,6 & 6,8 & 6,4 & 6,6 & 7,6 & 6,6 \\
Total & 100 & 100 & 100 & 100 & 100 & 100 & 100 & 100 & 100 \\
\hline
\end{tabular}

Fonte: Elaboração própria a partir de dados do SGA/UFFS

Ao cruzar a característica ter estudado em escola pública com o tipo de curso é importante olhar dois cenários, antes da Lei de Cotas, quando a política de acesso era a de bonificação de escola pública, e depois da Lei de Cotas, que incluiu a renda e a raça/cor dos estudantes.

Em cursos mais seletivos, como, por exemplo, Arquitetura e Urbanismo, Enfermagem e Medicina Veterinária, o percentual médio de estudantes egressos de escola pública foi maior quando o ingresso ocorreu por meio da política de bonificação (100\% ou muito próximo disso), em comparação aos anos posteriores. A partir de 2013, esses cursos diminuíram em até 10 p.p o perfil de estudantes egressos de escola pública, e, ainda assim, se aproximam da proporção de estudantes que cursam o Ensino Médio em escola pública. Conforme dados do Censo Escolar, cerca de $87 \%$ dos estudantes da Região Sul estudam em escolas públicas (Inep, 2020b).

Em alguns cursos de Licenciaturas, por exemplo, que, em geral são menos seletivos, os percentuais de escola pública eram menores que 90\%. Ciências Sociais, por exemplo, em 2012, tinha um percentual de 86,5\% e, em 2013, foi para 91,5\% e Geografia, estava com $88,8 \%$ e passou para $89,2 \%$. 
Por outro lado, alguns cursos, como Educação do Campo e Nutrição continuaram com percentuais altos de egressos de escola pública (100\% e 97,5, respectivamente). Portanto, consideramos que o maior efeito da Lei de Cotas, principalmente em cursos mais seletivos, foi em termos raciais, já que, a política anterior de bonificação da escola pública já tinha uma abrangência maior. Destacamos, por exemplo, alguns cursos como: Medicina Veterinária, que em 2012 tinha um percentual de 8,0\% de PPIs e passou para 32,1\%, em 2013; Enfermagem, de 9,8\%, passou para 30,0\% e, Arquitetura e Urbanismo, de 6,1\%, passou para 21,6\%, em 2013.

O Gráfico 15 resume a informação geral sobre escola e PPIs, ao longo do tempo, mostrando que, a partir de 2013, os percentuais de ingressantes por escola pública tiveram uma leve diminuição, enquanto que os de PPIs aumentaram. No Apêndice 2 e no Apêndice 3 apresentamos esses dados de escola pública e de PPIs detalhados por campus, curso e turno, ao longo do tempo.

Gráfico 15 - Percentual de ingressantes, segundo critérios de ensino médio em escola pública e de PPIs - 2010 a 2018

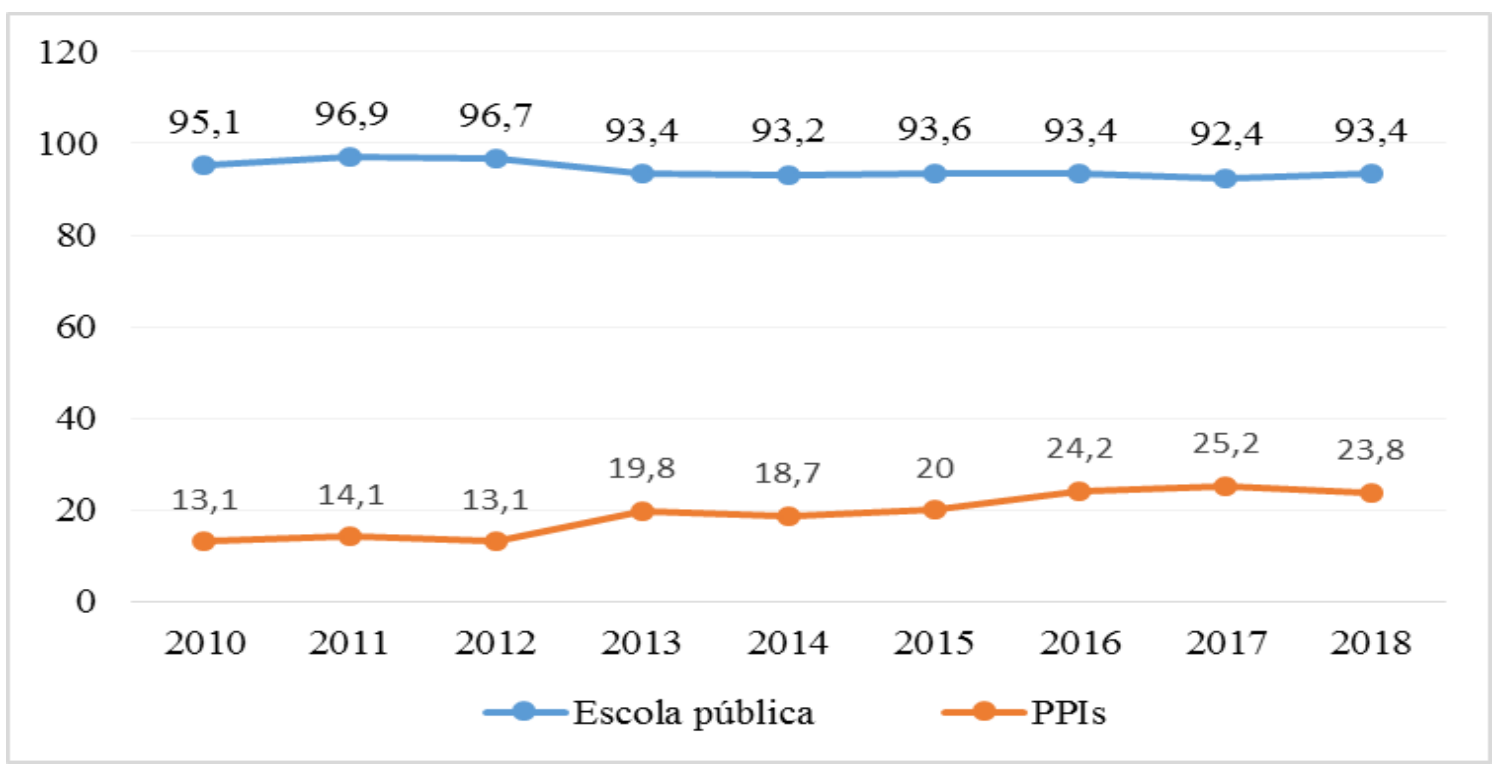

Fonte: Elaboração própria a partir de dados do SGA/UFFS

5.2.6 Intervalo de tempo entre Ensino Médio e Ensino Superior

Outra característica que os dados permitem analisar é o intervalo de tempo entre o término do ensino médio e o ingresso no ensino superior e como isso ocorreu ao longo do tempo. A maioria dos estudantes ingressou na Universidade num período de até 3 
anos após a conclusão do Ensino Médio. A partir do SiSU, e ao longo dos anos, os estudantes estão ingressando ainda mais jovens, conforme já verificado na descrição da faixa etária. Também é menor o intervalo entre o término do Ensino Médio e o acesso ao Ensino Superior (até um ano), conforme pode ser observado na Tabela 20.

Tabela 20 - Percentual de ingressantes, segundo intervalo de tempo entre o Ensino Médio e o Ensino Superior - 2010 a 2018

\begin{tabular}{llllllllll}
\hline Intervalo & $\mathbf{2 0 1 0}$ & $\mathbf{2 0 1 1}$ & $\mathbf{2 0 1 2}$ & $\mathbf{2 0 1 3}$ & $\mathbf{2 0 1 4}$ & $\mathbf{2 0 1 5}$ & $\mathbf{2 0 1 6}$ & $\mathbf{2 0 1 7}$ & $\mathbf{2 0 1 8}$ \\
\hline Até 1 ano & 37,5 & 36,3 & 35,0 & 36,6 & 42,3 & 45,0 & 45,7 & 47,7 & 42,7 \\
2 a 3 anos & 23,1 & 22,5 & 27,7 & 26,2 & 23,5 & 20,5 & 23,5 & 24,2 & 28,3 \\
4 a 6 anos & 15,7 & 15,6 & 15,1 & 14,7 & 13,4 & 14,4 & 14,5 & 14,8 & 14,1 \\
7 a 9 anos & 9,9 & 10,9 & 9,5 & 9,5 & 8,5 & 6,9 & 6,9 & 5,5 & 6,0 \\
10 anos ou & 13,8 & 14,6 & 12,6 & 13,1 & 12,3 & 13,2 & 9,4 & 7,7 & 8,8 \\
mais & 100 & 100 & 100 & 100 & 100 & 100 & 100 & 100 & 100 \\
Total &
\end{tabular}

Fonte: Elaboração própria a partir de dados do SGA/UFFS

\subsubsection{Grupo de Inscrição no Processo Seletivo}

A Tabela 21 mostra como ocorreu a distribuição dos estudantes, segundo o grupo de inscrição no processo seletivo, a partir da nova política de ingresso adotada na UFFS em 2013, com a Lei de Cotas. A partir de 2017, com a adesão à Lei n. 13.409/2016, ocorre a reserva de vagas também para pessoas com deficiência, além de uma cota especial que a UFFS criou para estudantes indígenas consistente na reserva de uma vaga em cada curso, independentemente da Lei de Cotas.

Observou-se que a maior ocupação de vagas ocorreu no grupo com critério apenas de escola pública, independentemente de raça/cor e renda. No segundo semestre de 2018 ocorreu uma mudança na reserva de vagas para pessoas com deficiência, permanecendo apenas dois grupos: um deles sendo para PCD + escola pública e o outro para PCD + escola pública + renda. Ao analisar os dados, pontua-se que essa alteração possa ter ocorrido em função da baixa ocupação de pessoas com deficiência em vagas reservadas nestes grupos, que incluíam, também, critérios raciais, além da escola pública e renda. 
Tabela 21 - Percentual de ingressantes conforme grupo de Inscrição no Processo Seletivo da UFFS - 2013 a 2018

\begin{tabular}{lllllll}
\hline Grupo de Inscrição_PS & $\mathbf{2 0 1 3}$ & $\mathbf{2 0 1 4}$ & $\mathbf{2 0 1 5}$ & $\mathbf{2 0 1 6}$ & $\mathbf{2 0 1 7}$ & $\mathbf{2 0 1 8}$ \\
\hline Ampla concorrência & 12,3 & 10,0 & 9,1 & 8,6 & 9,5 & 13,4 \\
Escola pública + PPIs & 7,1 & 5,9 & 7,2 & 7,4 & 7,3 & 5,6 \\
$\begin{array}{l}\text { Escola pública + PPIs + PCD } \\
\text { Escola pública + PPIs + renda + PCD }\end{array}$ & & & & & &, 1 \\
$\begin{array}{l}\text { Escola pública + PPIs + renda } \\
\text { Escola pública - total }\end{array}$ & 9,0 & 5,4 & 5,7 & 7,0 & 6,5 & 5,1 \\
Escola pública + PCD & 32,7 & 42,9 & 43,6 & 39,5 & 40,3 & 41,0 \\
Escola pública + renda & & & & &, 4 &, 4 \\
$\begin{array}{l}\text { Escola pública + renda + PCD } \\
\text { Escola pública parcial }\end{array}$ & 34,3 & 34,2 & 33,4 & 35,8 & 33,7 & 32,4 \\
Reserva indígena & 4,6 & 1,6 & 1,1 & 1,6 & 1,5 &, 7 \\
Total & & & & &, 5 &, 4 \\
\hline
\end{tabular}

Nota: PPIs = Pretos, pardos e indígenas; PCD = Pessoa com deficiência

Fonte: Elaboração própria a partir de dados do SGA/UFFS

\subsection{Síntese do capítulo: principais resultados}

Neste capítulo apresentamos algumas características da UFFS, que a situam de um modo bastante particular em relação as demais Instituições Federais de Ensino Superior (IFES), principalmente pela sua estrutura interestadual, pelas suas políticas de acesso com foco na escola pública e pelos tipos de cursos, que se concentram na área de formação de professores $(50 \%)$ e são ofertados principalmente no período noturno, de modo a propiciar a conciliação entre trabalho e estudo.

Ao longo do tempo, observaram-se muitas mudanças e adaptações nos turnos dos cursos e a criação de novos cursos, inclusive com modalidades diferenciadas, como é o caso do regime de alternância. Nas políticas de acesso, destaca-se principalmente a forma como a UFFS implementou a Lei de Cotas, mantendo altos os percentuais de egressos da escola pública, além de ações afirmativas próprias, presentes no seu ingresso principal e nos processos seletivos especiais (Pin, Prohaiti, Pronera).

Com relação à organização curricular, identificou-se que a UFFS apresenta uma diretriz voltada para a inclusão social, pois além dos conteúdos específicos de cada curso, possui um domínio formativo comum a todos os cursos com foco nos eixos de “contextualização acadêmica e formação crítico-social” (UFFS, 2014c).

As políticas de permanência estudantil na UFFS foram se consolidando ao longo do tempo, e, com um marco, em 2018, com a aprovação da Política Estudantil da UFFS. Essa política, em consonância com o Pnaes, caracteriza-se como um importante ato 
normativo que sintetiza um conjunto de programas, ações e serviços da assistência estudantil, que, articuladas com demais políticas institucionais e acadêmicas, visam o fortalecimento das condições de permanência estudantil.

O perfil socioconômico e racial dos ingressantes também foi se modificando ao longo do tempo, e esteve associado a iniciativas e mudanças institucionais e fatores exógenos, tais como as alterações nas formas de acesso pela adoção do bônus para escola pública, e pela adesão à Lei de Cotas e ao SiSU. Uma das principais características observadas nos ingressantes na UFFS ao longo do tempo é a sua origem escolar, ou seja, mais de $90 \%$ cursaram todo o ensino médio ou parte dele em escolas públicas. Essa característica predominou nas primeiras coortes de ingressantes, com a política de ingresso com base em bônus para escola pública e se manteve estável a partir da adesão à Lei de Cotas, como consequência da forma institucional mais ampla e inclusiva de a UFFS interpretar esse critério.

A partir da Lei de Cotas, verificamos um aumento dos percentuais de ingressantes pretos, pardos e indígenas em todas as áreas de conhecimento, com aumento significativo principalmente em áreas que partiram de percentuais menores de inclusão racial, como é o caso dos cursos das áreas de engenharias e de agricultura. Até o ano de 2012, esse grupo de estudantes estava sub-representado na maioria dos cursos. Ao longo do tempo, em praticamente todos os campi da UFFS o percentual de ingressantes PPIs chegou a ultrapassar o percentual de sua representação populacional, conforme o Estado em que o respectivo campus encontra-se instalado.

A partir de 2014, ano em que ocorreu a adesão da UFFS ao SiSU, observou-se aumento de ingressantes de outras regiões do país, além dos estados da Região Sul, em praticamente todos os campi da UFFS, com menores proporções no Campus Cerro Largo.

Com relação ao sexo, a presença feminina é majoritária entre os ingressantes na UFFS ao longo do tempo, ainda que, embora nas últimas coortes seja possível observar um aumento na presença masculina. São majoritariamente estudantes que ingressam na UFFS na faixa etária de até 20 anos, e num intervalo entre o término do ensino médio e o ingresso no ensino superior que pode chegar até 3 anos. A partir de 2014, observa-se, ainda, um aumento no percentual de estudantes jovens, com até 20 anos.

O próximo capítulo trata da caracterização do perfil dos ingressantes, e da ocupação dos cursos segundo raça e gênero, ao longo do tempo. 


\title{
6 \\ Desigualdades estrututais de gênero e raça na ocupação dos cursos
}

Este capítulo busca responder a seguinte questão de pesquisa: Como se configuram as desigualdades estruturais em termos de gênero e raça na ocupação dos cursos da UFFS? Partimos de uma hipótese prévia, segundo a qual, apesar de a Lei de Cotas ter fomentado uma maior inclusão racial, haveria a manutenção de desigualdades de gênero e raça na ocupação de cursos, principalmente naqueles de menor retorno econômico.

$\mathrm{Na}$ análise das desigualdades, a variável de "sexo" é entendida nos termos de Santos \& Bernardino (2016, p. 74). Para os autores:

\begin{abstract}
O conceito de sexo se refere a homens e mulheres, de acordo com a sua identidade civil, e gênero diz respeito à construções simbólicas em torno do feminino e do masculino, ou seja, às características e expectativas sociais atribuídas ao indivíduo a depender do seu sexo. Essas características são construídas de formas diferentes e implicam na formação de um sistema de desigualdade entre os gêneros.
\end{abstract}

As variáveis "sexo" e "raça" foram mobilizadas neste capítulo de forma agregada, a partir da construção de uma nova variável chamada "sexo_raça", buscando uma aproximação com a abordagem interseccional (Crenshaw, 1989; Bairros, 1995; Collins, 2015; Guidens; Sutton, 2017; Medeiros, 2019).

A abordagem interseccional oferece contribuições tanto teóricas quanto metodológicas para a pesquisa, uma vez que dialoga com as múltiplas experiências e manifestações da desigualdade e promove o entrelaçamento entre categorias como sexo e raça ao invés de tratá-las de forma isolada (Crenshaw, 1989). Pretende-se, portanto, situar o debate sobre a interseccionalidade na configuração da desigualdade de gênero e raça no ensino superior e sua contribuição às análises desses marcadores sociais da diferença.

O conceito de interseccionalidade foi construído no âmbito do feminismo negro, e cunhado pela norte-americana Kimberle Crenshaw, em 1989, como uma crítica à teoria feminista. Segundo a autora, ao levar em conta a discriminação apenas pelo sexismo, a teoria feminista estaria contribuindo para a marginalização do racismo ao qual também estão sujeita as mulheres negras. Para conceituar a interseccionalidade Kimberle Crenshaw faz uma analogia com a interseção de um tráfego com idas e vindas 
em quatro direções. A discriminação neste cruzamento pode fluir tanto para uma direção quanto para outra. Mulheres negras experimentam efeitos combinados de discriminação com base em seu gênero e raça, e/ou a discriminação apenas como mulheres negras. Essa abordagem tem influenciado outros estudos e oferece uma chave importante de análise porque permite romper com a reprodução de concepções dominantes de discriminação que consideram o tema apenas sob o ponto de vista de um único eixo categórico (Crenshaw, 1989).

Para a autora brasileira Luíza Bairros (1995) a experiência de ser mulher não está vinculada a uma única identidade, ela é construída social e historicamente. Nesse sentido raça, gênero e classe só podem ser entendidas em sua multidimensionalidade, em termos dos diferentes feminismos, e do Movimento Negro e de mulheres negras. Trata-se de reconhecer as diferentes experiências de ser mulher (vivida por meio de raça) e de ser negro (vivida por meio do gênero). São dimensões que não podem ser separadas, o que torna improdutivo o debate sobre se a prioridade do movimento de mulheres negras seria o racismo ou o sexismo.

$\mathrm{Na}$ pesquisa desta Tese, a aproximação com a interseccionalidade nos proporcionou uma chave de leitura que propõe caracterizar melhor de quais mulheres e de quais homens estamos falando e, a partir disso, compreender como se distribuem as oportunidades e como se manifestam as desigualdades.

Na concepção de Giddens \& Sutton (2017, p. 155), “a pesquisa interseccional estuda as maneiras pelas quais as variadas formas de diferenças se inter-relacionam em casos específicos, e pode resultar em análises bastante complexas de vidas reais de modo como são vividas". Essa abordagem, segundo a perspectiva dos autores, não é meramente descritiva, uma vez que busca compreender como se estruturam as relações de poder na sociedade, na produção de discriminação e desigualdade. A abordagem interseccional pode ser entendida ao mesmo tempo como uma teoria, quando faz a descrição sobre essa diversidade da vida social e como uma metodologia para trazer essa vida social "para um foco mais aguçado na interação entre posições sociais". Tratase de uma abordagem criada "para oferecer considerações mais abrangentes e válidas sobre experiências divergentes" (Giddens; Sutton, 2017, p. 155).

Medeiros (2019) apresenta a perspectiva da interseccionalidade como um ganho analítico das múltiplas formas de desigualdade. O autor reconstrói o debate conceitual, buscando aproximar os estudos de interseccionalidade com o campo de análise de 
políticas públicas. Inicialmente contextualiza a origem do termo e seus desdobramentos posteriores, buscando apresentar as ideias centrais que permanecem e ganham força nos estudos atuais sobre interseccionalidade. Uma dessas contribuições é a noção de mapeamento social ou a dimensão de localização social das desvantagens e privilégios a que estão submetidos os diferentes grupos que se situam em diferentes pontos do mapa social. Essa perspectiva interseccional questiona concepções ainda muito presentes nas pesquisas de ciências sociais e que envolvem a tendência a analisar ainda de maneira isolada essas diferentes formas de subordinação social. Isso "acaba por ocultar os efeitos das formas cruzadas de exclusão e marginalização social, que só são percebidos quando concebidos como efeitos qualitativamente distintos daqueles que derivam de condições específicas quando tomadas isoladamente" (Medeiros, 2019, p. 90).

Patrícia Hill Collins (2015) argumenta sobre a necessidade de criação de novas categorias de análise que incluam classe, gênero e raça como estruturas distintas e imbricadas de opressão. Em sua contribuição no pensamento feminista contemporâneo, a autora redefine essas categorias e aprofunda o entendimento sobre as diferentes formas de opressão, buscando um afastamento do caráter de quantificação ou hierarquização das opressões. A questão que coloca é a seguinte: “Como raça, classe e gênero funcionam como sistemas paralelos e imbricados que moldam essa mesma relação básica de dominação e subordinação?” (Collins, 2015, p.19). Ao assumir essas categorias de forma conjunta, as análises possibilitam assumir que raça, classe e gênero estão presentes de forma imbricada em qualquer cenário, mesmo que em alguns seja mais visível do que em outros.

O diálogo acerca das categorias raça e gênero também se situa na concepção de justiça social defendida pela filósofa norte-americana Nancy Fraser (2006). A justiça social, para Fraser, envolve duas dimensões: uma voltada para a redistribuição (igualdade), sendo esta necessária para o enfrentamento da injustiça econômica decorrente da forma de apropriação de bens e riquezas produzidas socialmente; e outra voltada para o reconhecimento (diferença) e para o enfrentamento da injustiça e desrespeito cultural a que grupos estão submetidos.

\footnotetext{
A "raça" também é, portanto, um modo bivalente de coletividade com uma face econômico-política e uma face cultural-valorativa. Suas duas faces se entrelaçam para se reforçarem uma à outra, dialeticamente, ainda mais porque as normas culturais racistas e eurocêntricas estão institucionalizadas no Estado e na economia, e a desvantagem econômica sofrida pelas pessoas de cor restringe sua "voz" (Fraser, 2006, p. 236).
} 
Para as análises realizadas nesse capítulo foi utilizado apenas a base de dados principal da UFFS, com informações acerca dos ingressantes por meio do Enem, entre 2010 e 2018. A variável "raça" foi agregada em apenas três categorias: "branco", "negro $56 "$ (preto e pardo) e "outro 57 " (amarelo, indígena e não declarado) e a variável sexo é composta pelas categorias "masculino" e "feminino". A comparação leva em conta os grupos de estudantes compostos por homens e mulheres branco/as e negros/as.

Por meio de estatística descritiva e tendo como principal referência a variável "sexo_raça" (homem branco, homem negro, mulher branca e mulher negra) realizamos análises bivariadas com outras variáveis como: "faixa etária"; "escola pública no ensino médio"; "turno do curso"; "grau acadêmico"; "área de conhecimento" e "retorno econômico do curso". Além disso, utilizamos o ano de ingresso, linha de base para mapear essas características ao longo do tempo.

\subsection{Caracterização sobre raça e gênero na UFFS}

Inicialmente, apresentamos a distribuição desses grupos ao longo do tempo (2010 a 2018). A partir da Lei de Cotas ocorreu um aumento de homens e mulheres negras e uma diminuição de mulheres brancas. A presença de homens brancos quase não se modificou ao longo do tempo, permanecendo em torno de $30 \%$, conforme mostra o Gráfico 16. O grupo de mulheres negras aumentou em 6.1 p.p. entre 2010 e 2018, atingindo o percentual de 13,9\%, em 2018. O percentual de homens negros aumentou em 4.1 p.p. nesse mesmo período, e atingiu um percentual máximo de 11,5\%, em 2017, caindo para 9,3\%, em 2018. No caso das mulheres brancas, ocorreu uma diminuição de 8.1 p.p., mas ainda assim é o segmento racial mais representativo na UFFS.

\footnotetext{
56 Justificamos que esta junção foi realizada para facilitar a análise, pelo fato dos percentuais de estudantes pretos serem menores.

${ }^{57}$ Esta junção foi realizada também em função de os percentuais de estudantes amarelos e indígenas serem menores.
} 
Gráfico 16 - Distribuição dos ingressantes, segundo sexo_raça - 2010 a 2018

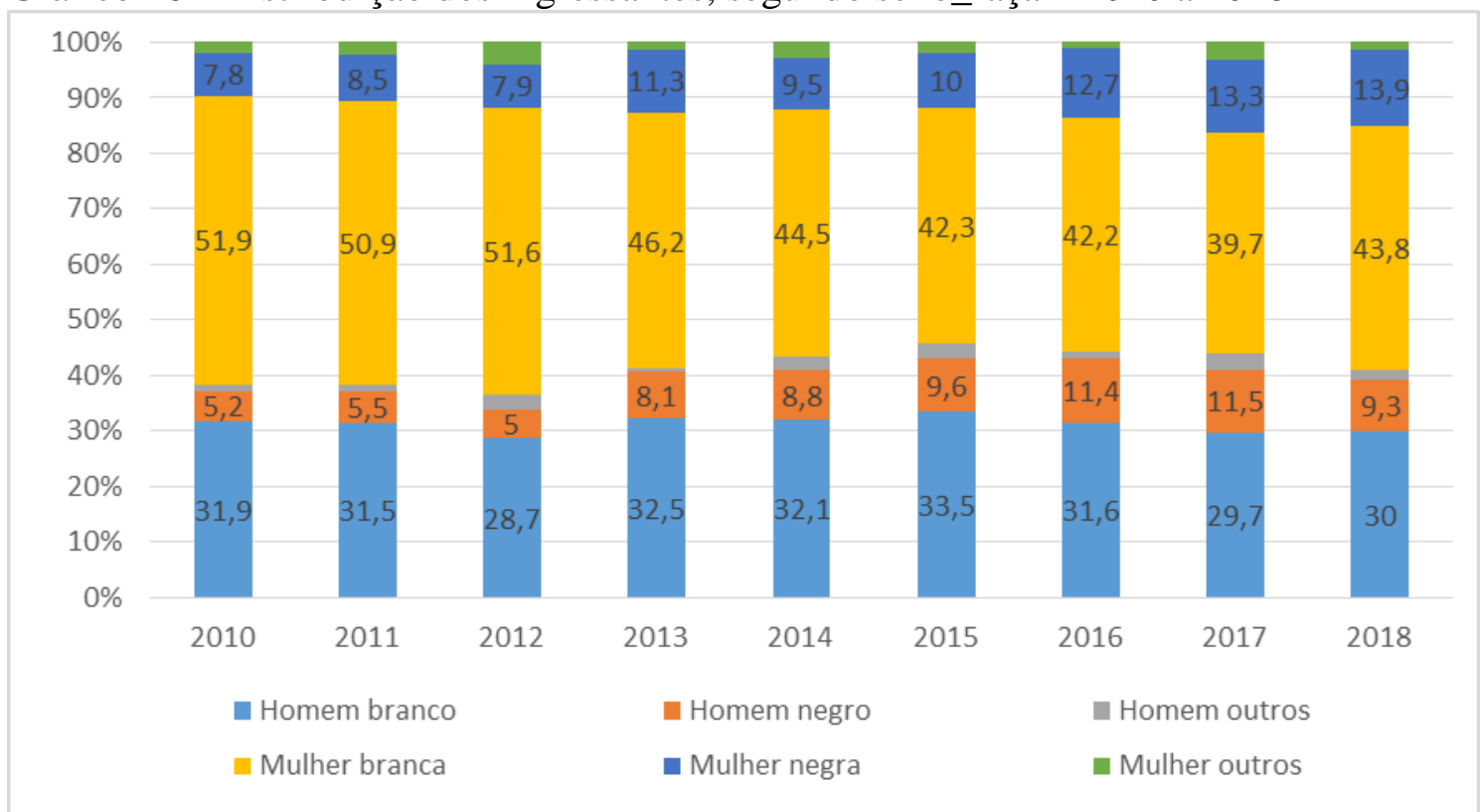

Fonte: Elaboração própria a partir de dados do SGA/UFFS

A idade é um importante marcador de diferença que pode se traduzir em desigualdades no acesso ao ensino superior. Os Gráficos 17, 18 e 19 mostram a faixa etária no momento do ingresso de homens e mulheres brancos e negros, ao longo do tempo, e trazem dados importantes para responder se existem diferenças na faixa etária dos ingressantes, segundo gênero e raça.

A partir de 2014, ano em que a UFFS aderiu ao SiSU, observou-se em todos os grupos um aumento do ingresso na faixa etária mais jovem (17 a 20 anos). Para os homens negros esse aumento foi de quase 10 p.p.. Esse aumento foi progredindo com algumas quedas ao longo dos anos, exceto para o grupo das mulheres brancas que chegou em 2018 a um patamar de 72,2\%, com uma diferença em torno de 20 p.p. em relação aos homens negros e de 10 p.p. relativamente às mulheres negras e aos homens brancos. Os homens negros tendem a ingressar mais tarde no ensino superior quando comparados aos demais grupos.

Os percentuais mais altos de homens e mulheres mais velhos ingressando na UFFS, principalmente nos primeiros anos do curso, também podem ser explicados pela localização desta IES em regiões no interior dos três Estados e distantes das capitais, que oportunizou o acesso a um curso superior público e gratuito, suprindo uma demanda que poderia estar reprimida. 
Gráfico 17 - Percentual de ingressantes na faixa etária de 17 a 20 anos, segundo sexo_raça - 2010 a 2018

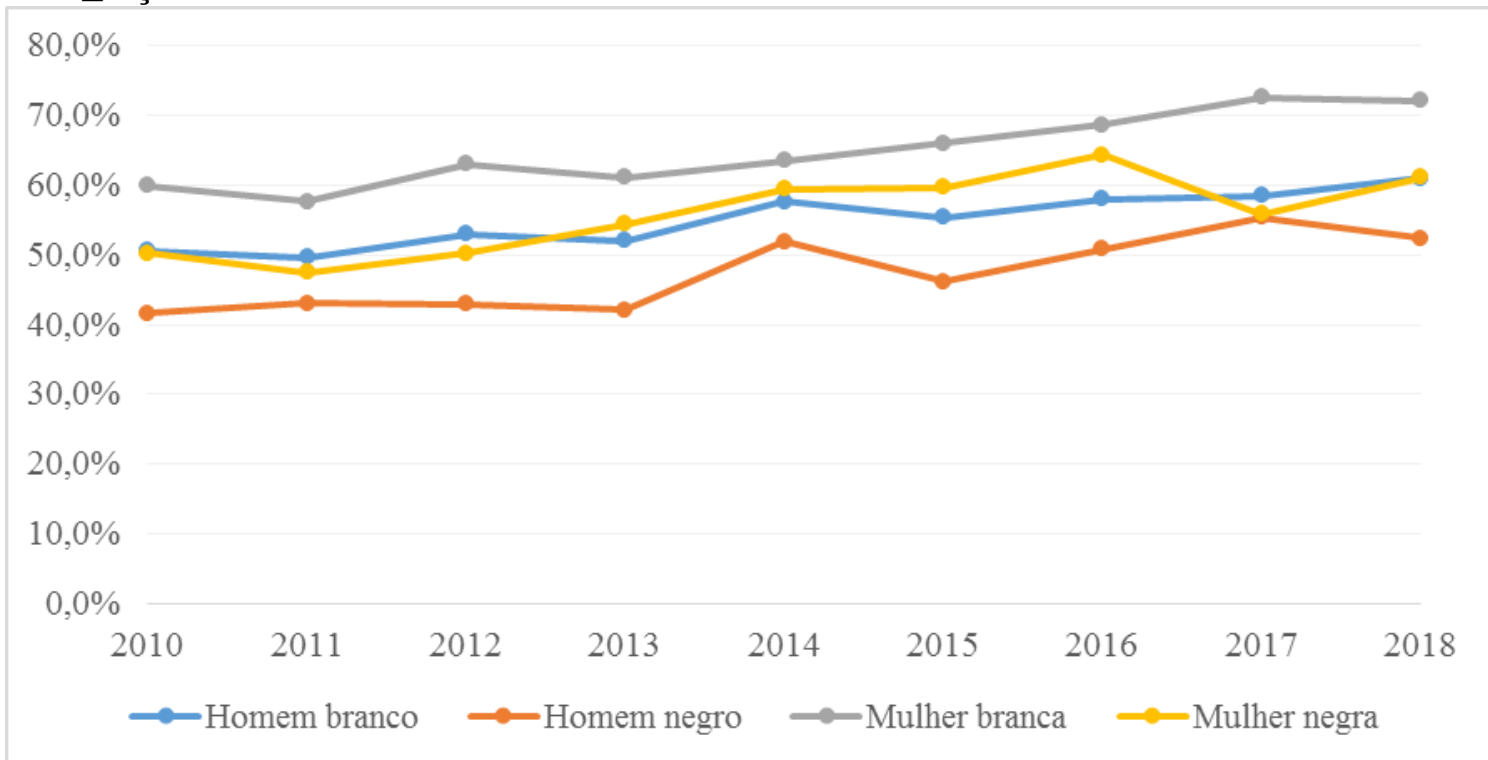

Fonte: Elaboração própria a partir de dados do SGA/UFFS

Gráfico 18 - Percentual de ingressantes na faixa etária de 21 a 24 anos, segundo sexo_raça - 2010 a 2018

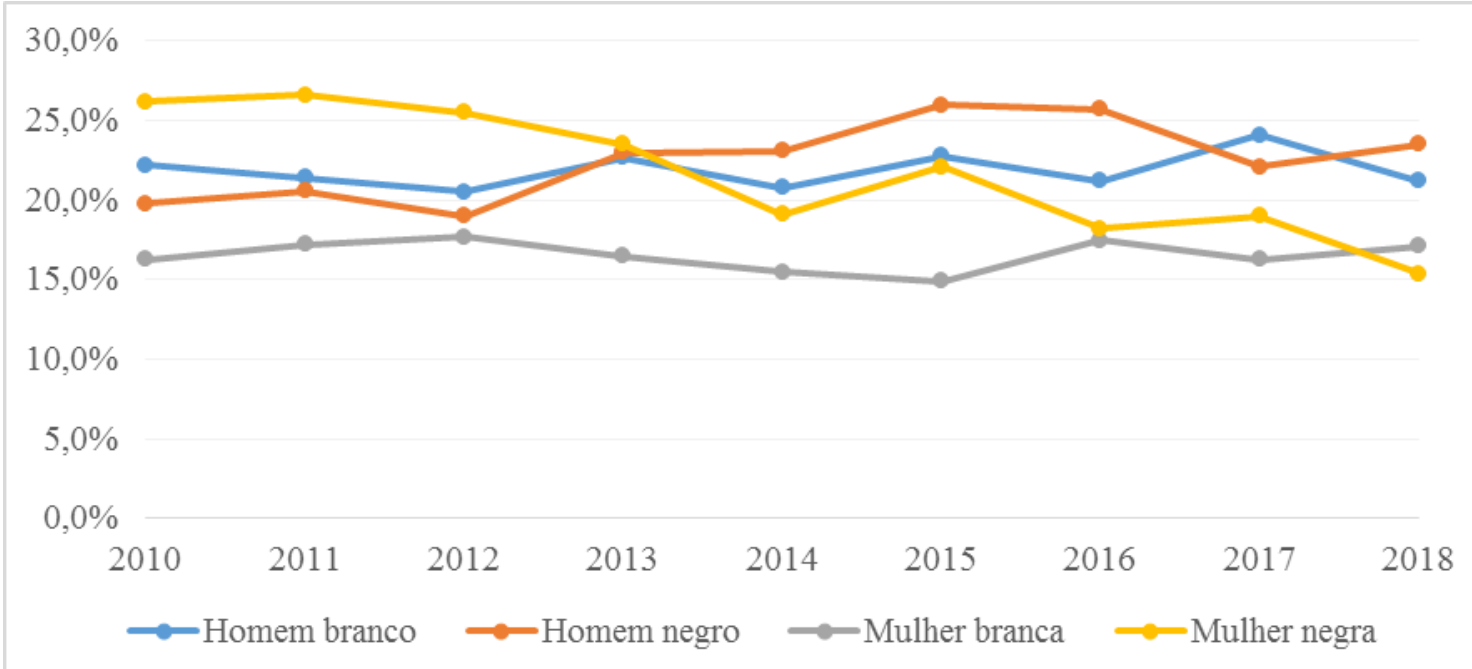

Fonte: Elaboração própria a partir de dados do SGA/UFFS 
Gráfico 19 - Percentual de ingressantes na faixa etária de 25 anos ou mais, segundo sexo_raça - 2010 a 2018

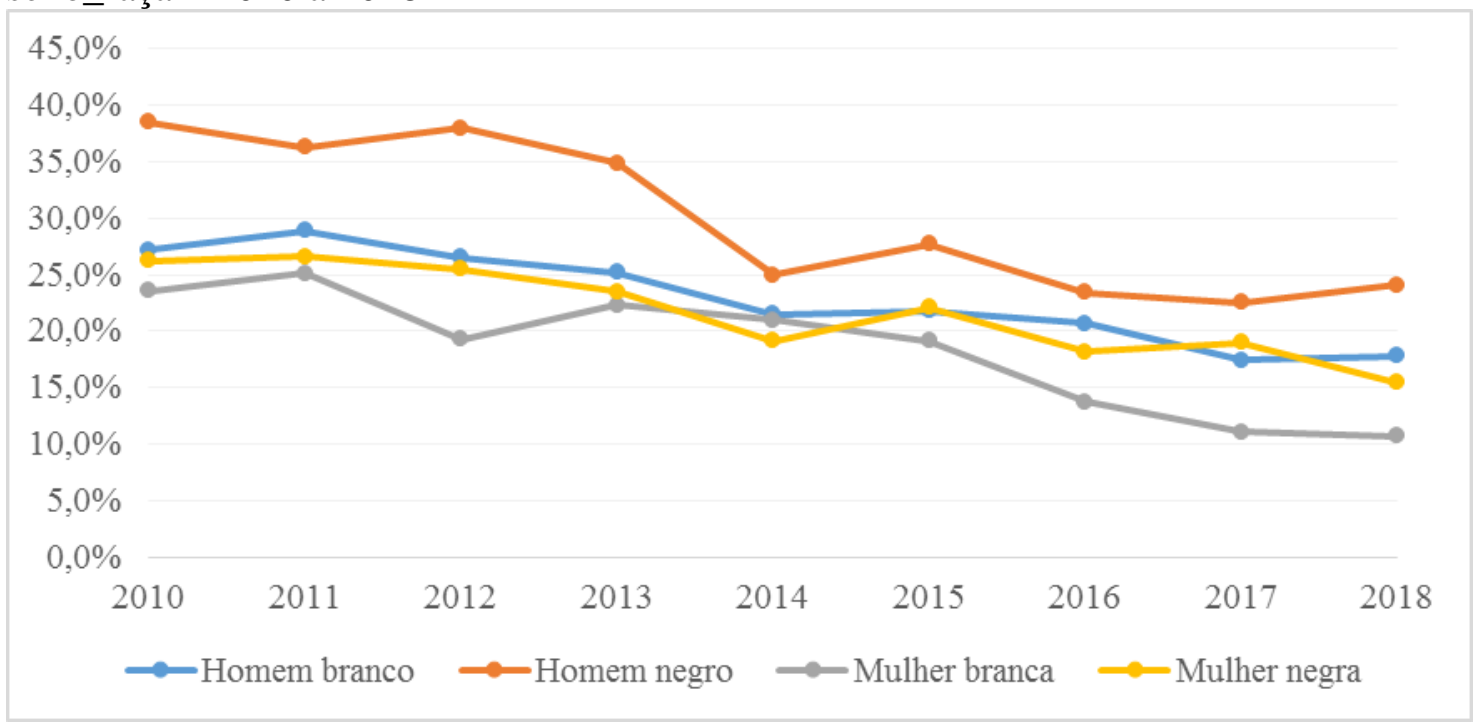

Fonte: Elaboração própria a partir de dados do SGA/UFFS

Com relação à variável escola pública no Ensino Médio (integral ou parcial), observou-se que ao longo do tempo todos os grupos mantiveram percentuais acima de 90\%. O percentual de homens brancos egresssos da escola pública em 2010 era próximo ao das mulheres brancas e negras; a partir de 2013, este percentual foi diminuindo. No primeiro ano o percentual de homens negros foi menor em relação aos demais grupos (91,7\%), com aumentos e quedas ao longo do tempo, atingindo 97,0\%, em 2018. Nos últimos anos, ingressantes negros (homens e mulheres) ficaram com percentuais mais altos de escola pública em relação aos brancos (Gráfico 20). 
Gráfico 20 - Percentual de ingressantes egressos de escola pública, segundo sexo_raça 2010 a 2018

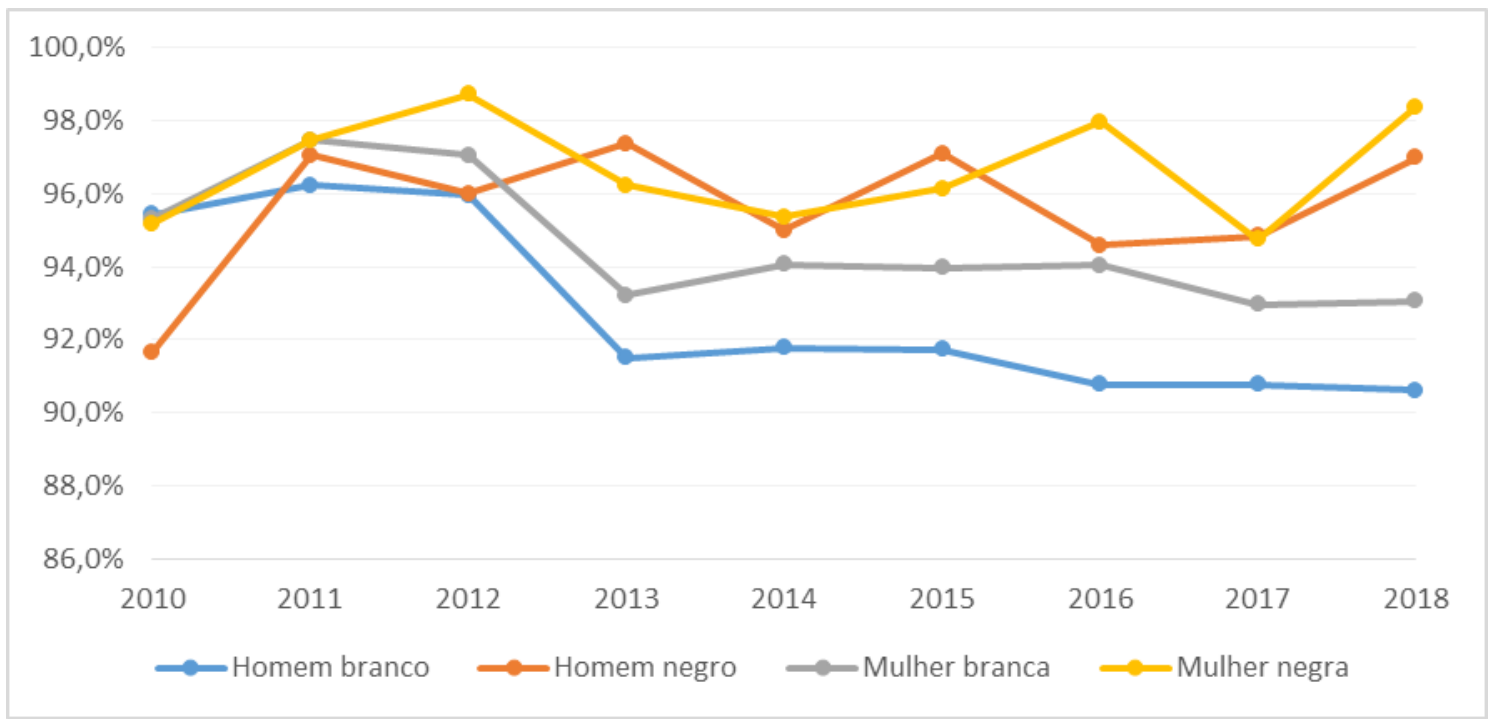

Fonte: Elaboração própria a partir de dados do SGA/UFFS

Uma das constatações recorrentes da literatura é a desigualdade de gênero e raça na ocupação dos diferentes cursos de graduação, de forma tal que estudantes mais pobres, negros e mulheres tendem a se inserir em cursos de menor prestígio, cursos noturnos e de licenciaturas (Barbosa, 2019; Carvalhaes; Ribeiro, 2019). A questão que se coloca é como essa diferenciação ocorre na UFFS?

O Gráfico 21, mostra que o grupo de mulheres negras possui os menores percentuais de participação em cursos de turno integral, principalmente em 2010 e 2011, quando atingem um patamar menor de $30 \%$, se comparado aos homens negros. Esses percentuais aumentam ao longo do tempo, indicando que o acesso a cursos de turno integral ficou menos desigual entre os diferentes grupos raciais analisados.

Os turnos noturnos iniciaram com uma presença maior de estudantes negros, homens e mulheres. Ao longo do tempo, principalmente, a partir de 2013, essas diferenças foram sendo diluídas, ficando todos os grupos (homens e mulheres, negros e brancos) com percentuais muito próximos (Gráfico 22). O mesmo ocorre com os turnos matutino ou vespertino, que iniciam com um percentual maior de mulheres negras e, a partir de 2013, os percentuais ficam mais próximos, com redução a partir de 2014 para todos os grupos, fato que acompanha a redução da oferta de cursos de licenciatura neste turno (Gráfico 23). 
Gráfico 21 - Percentual de ingressantes em cursos de turno integral, segundo sexo_raça -2010 a 2018

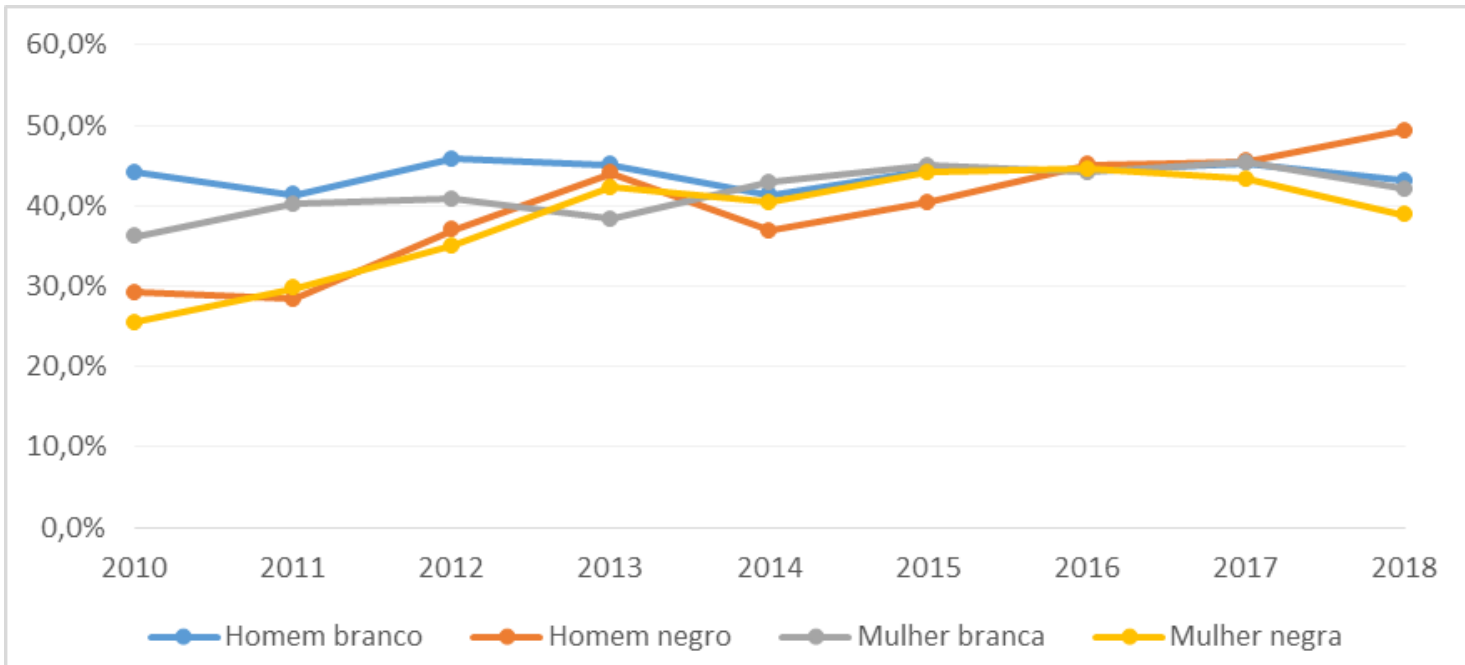

Fonte: Elaboração própria a partir de dados do SGA/UFFS

Gráfico 22 - Percentual de ingressantes em cursos de turno noturno, segundo sexo_raça -2010 a 2018

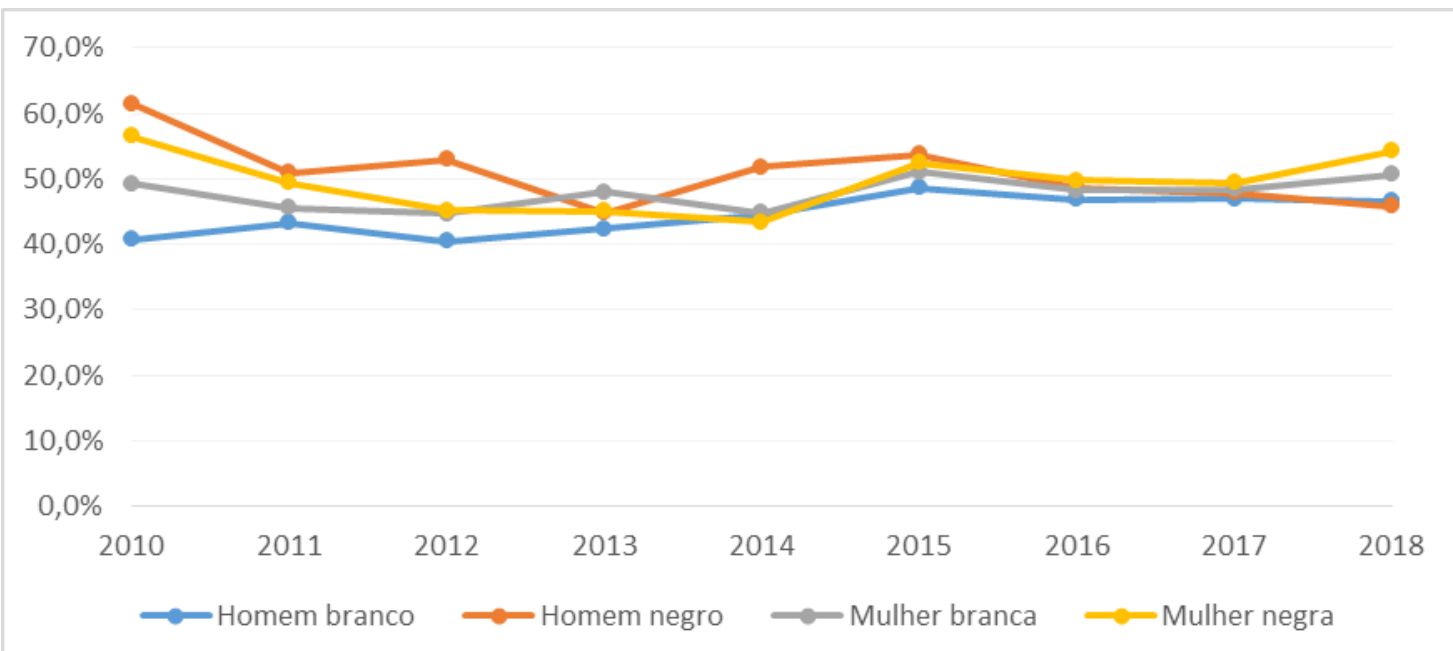

Fonte: Elaboração própria a partir de dados do SGA/UFFS 
Gráfico 23 - Percentual de ingressantes em cursos de turno matutino ou vespertino, segundo sexo_raça - 2010 a 2018

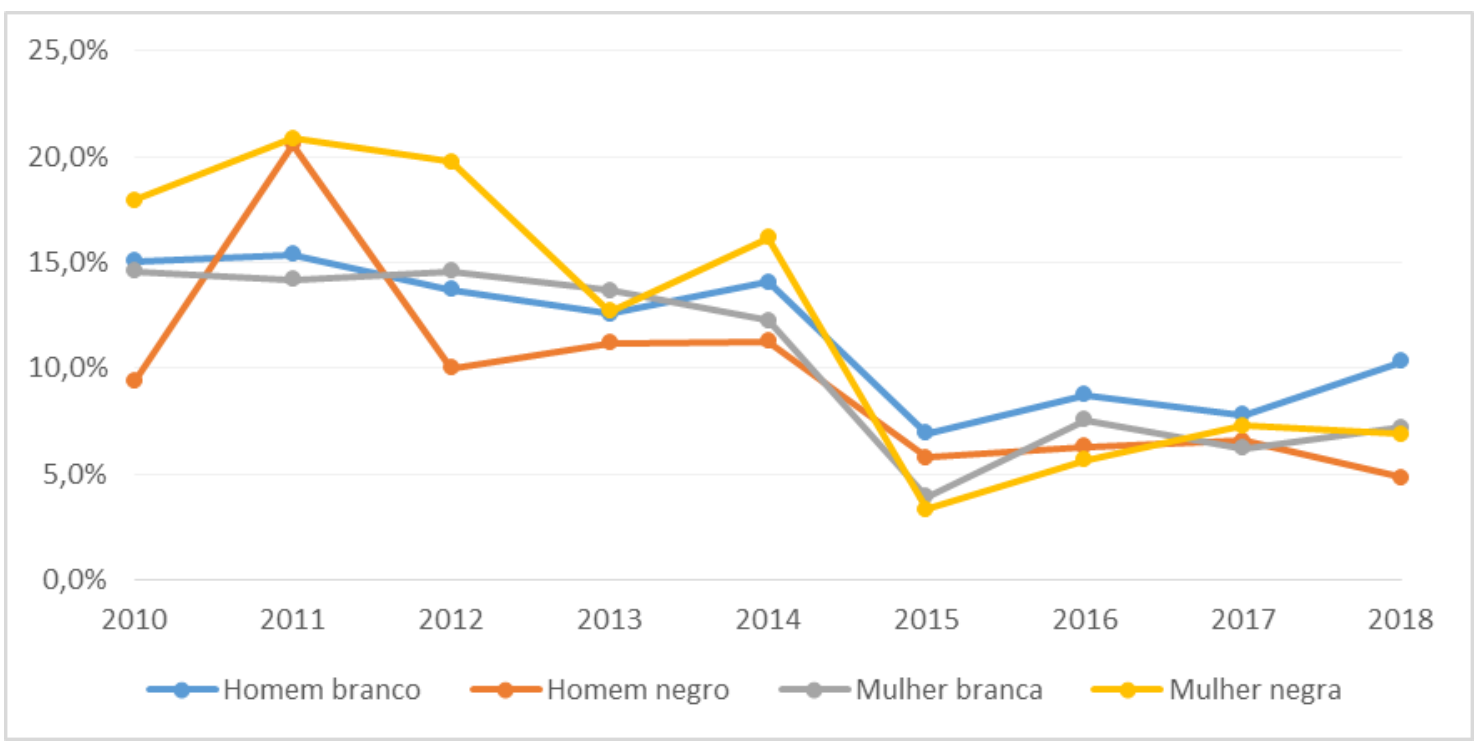

Fonte: Elaboração própria a partir de dados do SGA/UFFS

A seguir, analisamos a participação dos ingressantes, segundo o grau acadêmico dos cursos. O Gráfico 24 mostra que existe uma estratificação por gênero e raça na participação em cursos de bacharelados e licenciaturas. Em geral, as mulheres brancas e negras estão subrepresentadas nos cursos de bacharelados e sobrerepresentadas nas licenciaturas, reproduzindo um padrão de desigualdade de gênero pelo qual as mulheres, embora sejam maioria na universidade, ocupam cursos com menor retorno financeiro (Carvalhaes; Ribeiro, 2019). Segundo Knop (2020, p. 103): “[...] ao que parece, a estrutura social de construção dos gêneros acaba perpetuando padrões de escolha de carreiras universitárias que, por sua vez, contribuem para a segregação horizontal por gênero no ensino superior".

Os homens brancos, com $60 \%$, constituem o maior grupo nos bacharelados e apresenta poucas modificações ao longo do tempo. O grupo de homens negros tinha, nos primeiros anos, percentuais inferiores a 50\% nos bacharelados, mas apresentou um aumento significativo em 2013, a partir da Lei de Cotas, passando de 48,0\%, em 2012, para 61,8\%, em 2018, o maior percentual alcançado dentre os demais grupos. Isso demonstra que as políticas reduziram as desigualdades de acesso de homens negros ao longo do tempo em cursos de bacharelados.

As mulheres brancas atingiram o percentual de 50,9\% de participação em cursos de bacharelados, em 2017. Ao longo dos anos a participação nos bacharelados foi se 
modificando, com aumentos e quedas, mas sempre no patamar entre 40 e 50\%. Assim como os homens negros, as mulheres negras também aumentaram sua participação em cursos de bacharelados de forma mais significativa a partir de 2013, saindo de $36,3 \%$, em 2012, para 48,2\%, em 2018. Esse percentual possivelmente capte os efeitos da Lei de Cotas na redução da desigualdade racial, com maiores oportunidades de acesso para pessoas negras nos diferentes cursos.

Gráfico 24 - Percentual de ingressantes em cursos de bacharelados, segundo sexo_raça 2010 a 2018

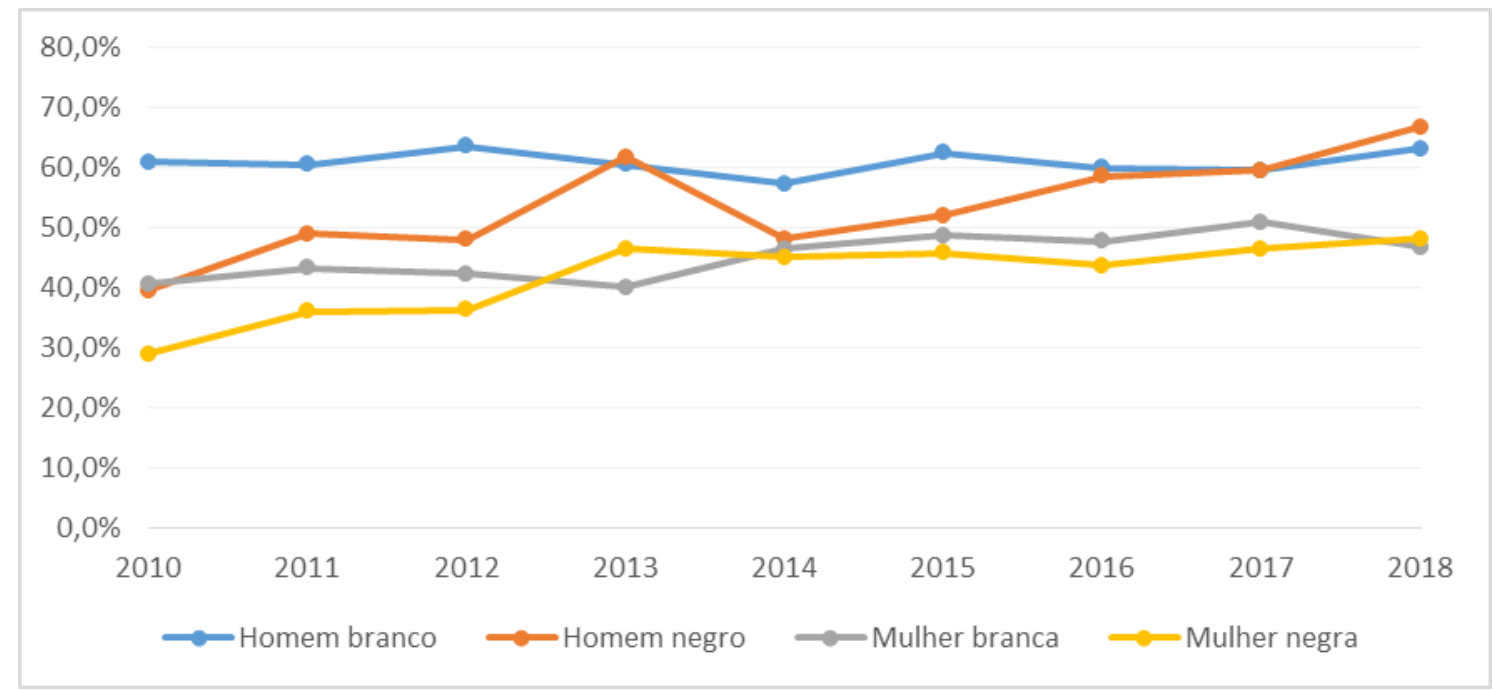

Fonte: Elaboração própria a partir de dados do SGA/UFFS

Para compreender ainda mais a dimensão racial e de gênero na ocupação dos cursos segundo as grandes áreas de conhecimento, apresentaremos de forma gráfica como a distribuição de homens e mulheres, negros e brancos ocorreu ao longo do tempo.

$\mathrm{Na}$ área de Educação, que combina todos os cursos de licenciaturas, a participação de mulheres sempre foi maior (Gráfico 25). Ao longo dos anos ocorreu uma diminuição do ingresso de todos os grupos nesta área de conhecimento, principalmente de homens negros e de mulheres negras, que aumentaram sua participação em outras áreas, principalmente a partir de 2013, sem necessariamente seguir um padrão, pois o percentual varia a cada ano. Por alguns anos existiu um padrão de ocupação maior nas licenciaturas por mulheres brancas e negras e por homens negros, em relação aos homens brancos. Em 2013 e a partir de 2016 existe uma diferença mais marcante de gênero, ou seja, um padrão de ocupação diferenciado entre homens e mulheres, independentemente de raça/cor. De todo modo, pode-se indicar que 
a Lei de Cotas parece ter alterado a trajetória de inserção de estudantes negros nas diferentes áreas de conhecimento, reduzindo as desigualdades de oportunidades.

Gráfico 25 - Percentual de ingressantes na área de Educação, segundo sexo_raça - 2010 a 2018

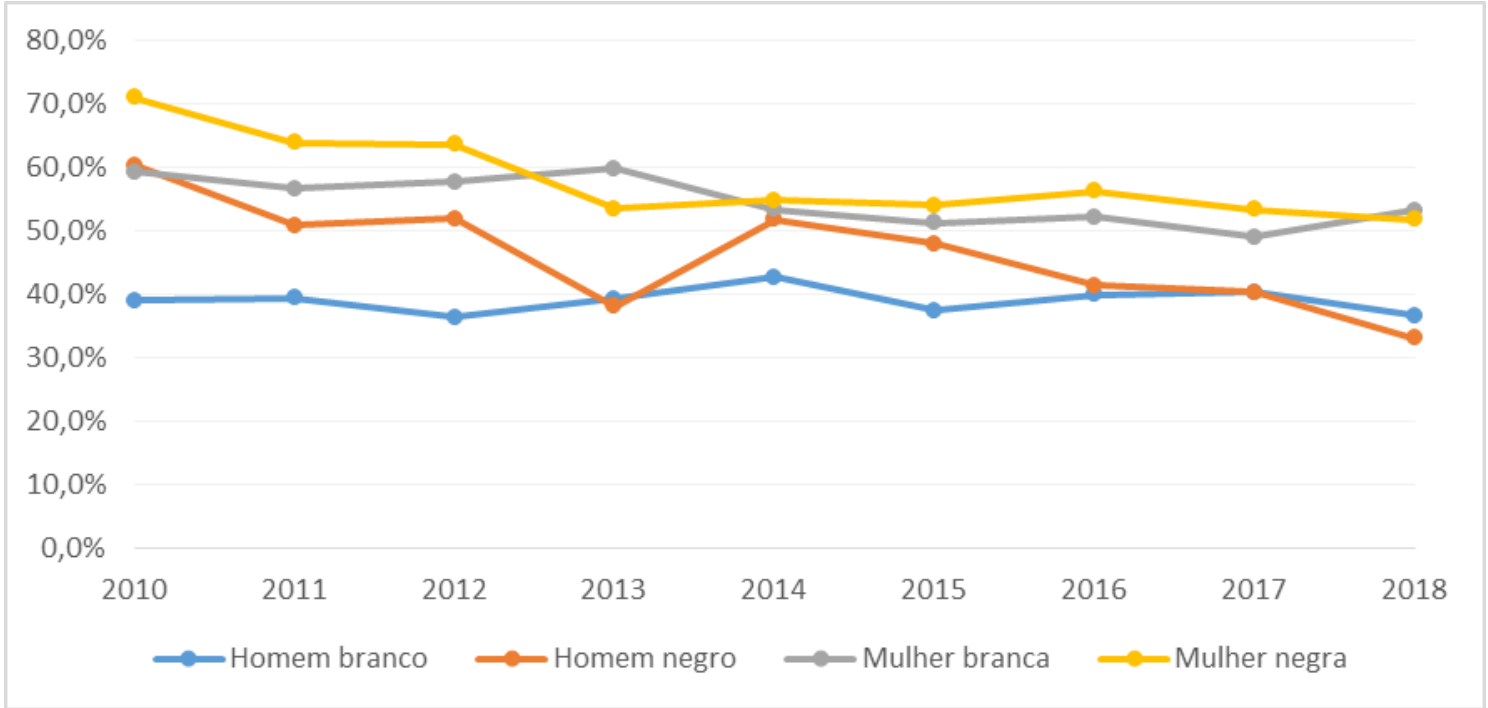

Fonte: Elaboração própria conforme dados do SGA/UFFS

$\mathrm{Na}$ área de Negócios, administração, direito e ciências sociais, que envolve os cursos de Administração e de Ciências Econômicas, não existe um padrão de ocupação, e sim uma movimentação em direção à inserção de todos os grupos. Em 2010, os homens negros tiveram uma inserção menor em relação aos demais grupos, e em 2016 e 2018 essa relação se inverte (Gráfico 26). 
Gráfico 26 - Percentual de ingressantes na área de Negócios, administração, direito e ciências sociais, segundo sexo_raça - 2010 a 2018

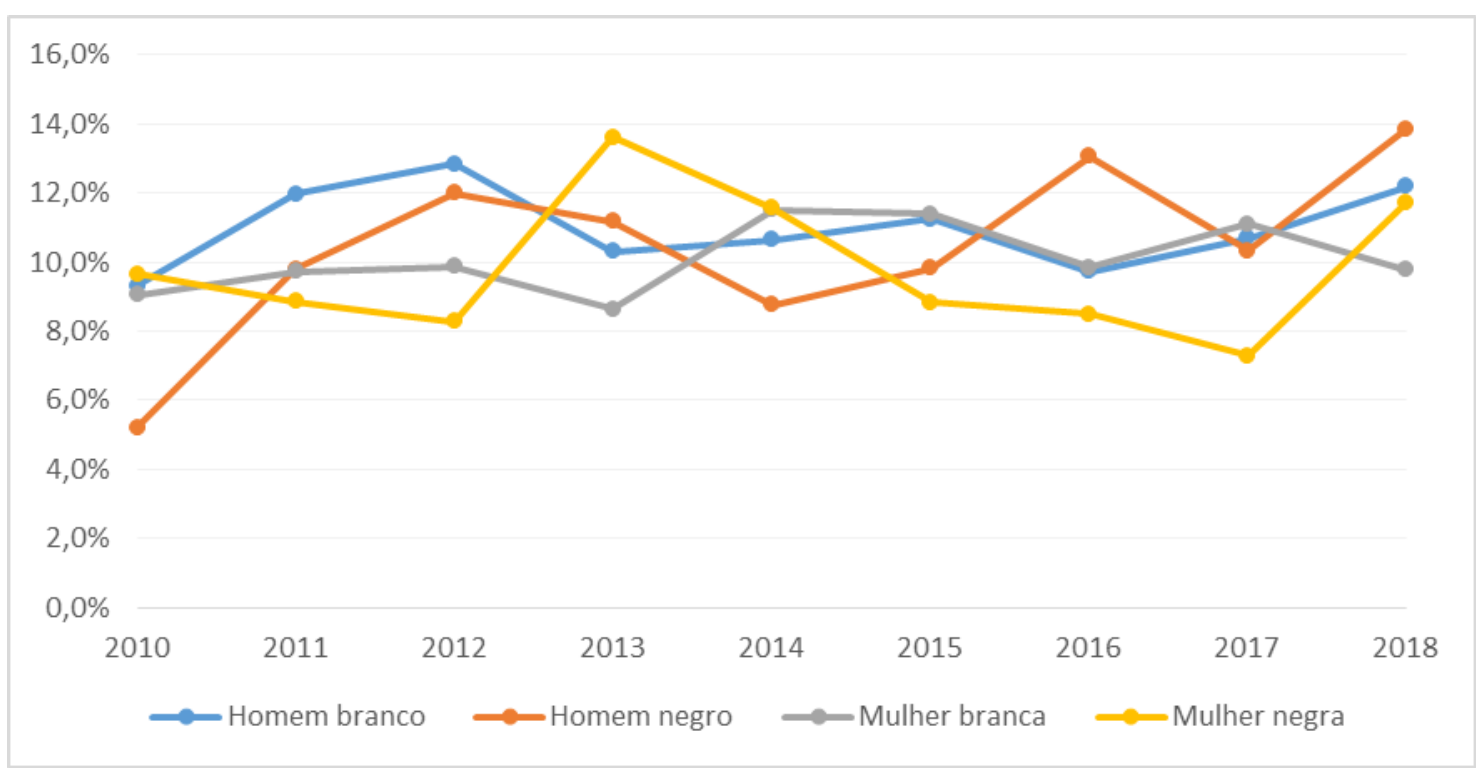

Fonte: Elaboração própria conforme dados do SGA/UFFS

A área de Computação, que se refere ao curso de Ciências da Computação, é ocupada principalmente por homens. Existe, portanto, uma diferença marcada por gênero nesta área. A presença de mulheres, tanto brancas quanto negras, é baixa, tendo as mulheres brancas atingido um percentual máximo de $2 \%$, em 2010, e as mulheres negras, de 3,8\%, em 2011. Embora com diferenças não muito acentuadas, os homens brancos ao longo do tempo tiveram uma ocupação maior em relação aos homens negros, exceto no ano de 2011, quando esse grupo teve uma inserção maior e com uma diferença mais acentuada. Entre as mulheres, as negras utltrapassam as brancas nesta área, na maioria dos anos (Gráfico 27). 
Gráfico 27 - Percentual de ingressantes na área de Computação e Tecnologias da Informação e Comunicação (TIC), segundo sexo_raça - 2010 a 2018

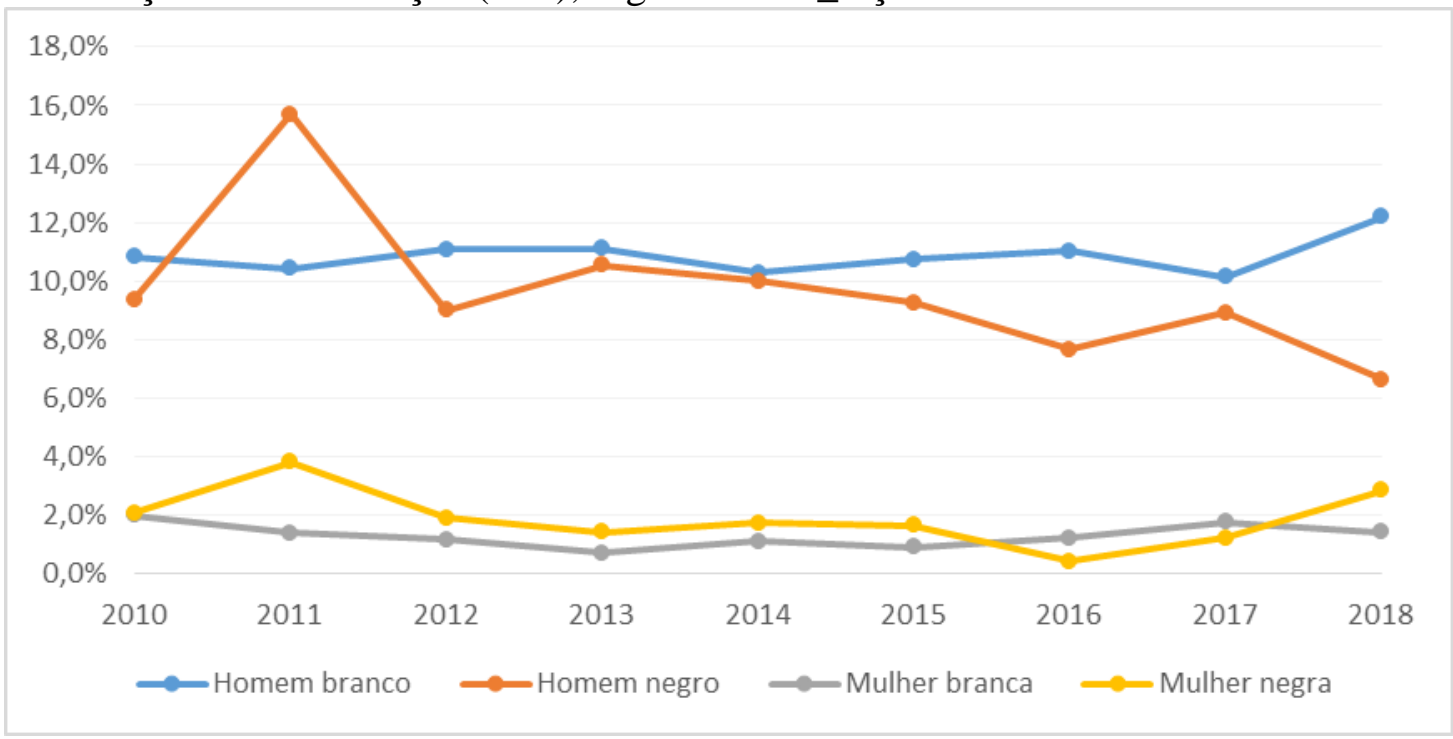

Fonte: Elaboração própria conforme dados do SGA/UFFS

A área de Engenharia, produção e construção, composta pelos cursos de

Engenharia de Alimentos, Arquitetura e Urbanismo e Engenharia Ambiental e Sanitária, teve, nos dois primeiros anos, um padrão de ocupação maior de homens brancos e mulheres brancas, em relação aos homens negros e às mulheres negras. A partir de 2012, estudantes negros aumentaram sua participação nesta área, aproximando-se dos demais grupos (Gráfico 28).

Gráfico 28 - Percentual de ingressantes na área de Engenharia, produção e construção, segundo sexo_raça - 2010 a 2018

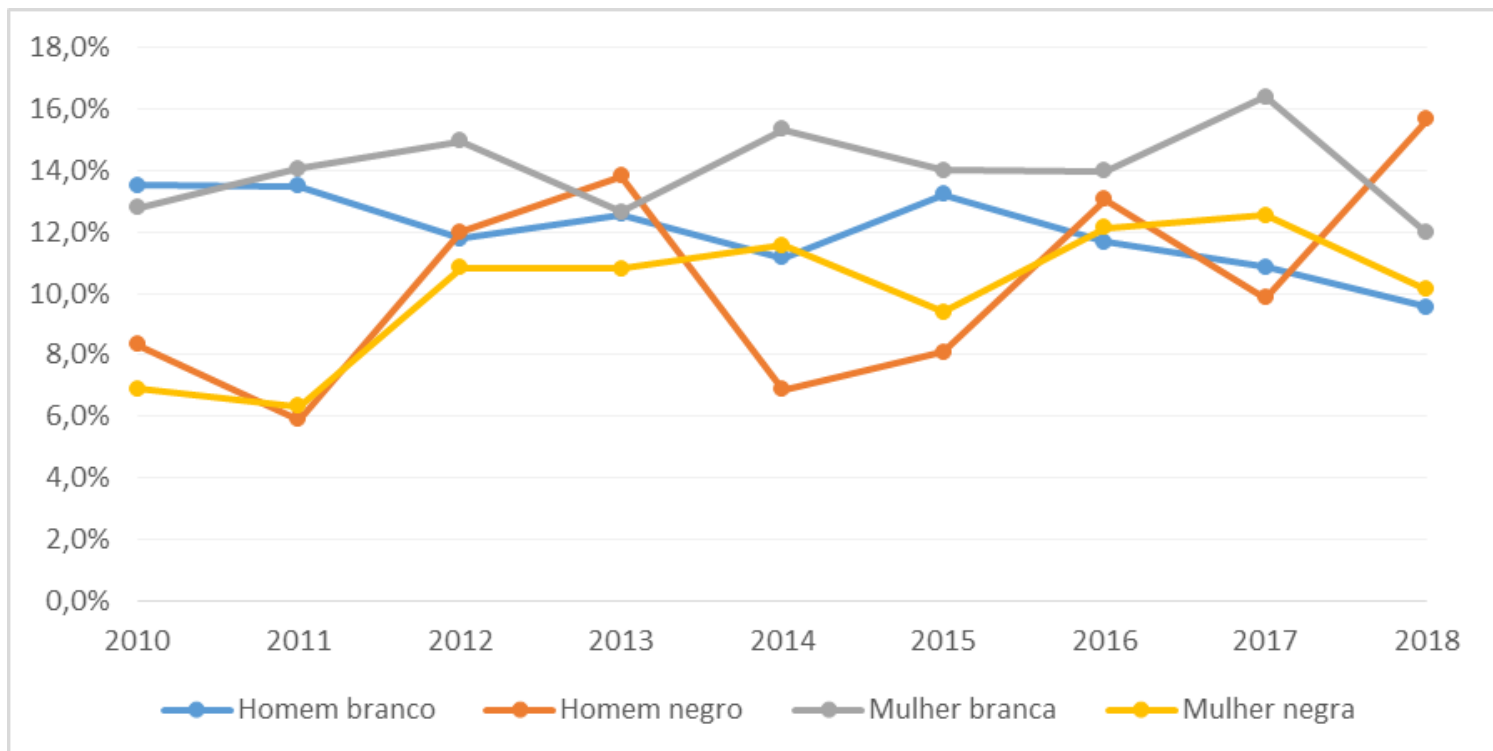

Fonte: Elaboração própria conforme dados do SGA/UFFS 
A área da Agricultura, Silvicultura, Pesca e Veterinária, que envolve os cursos de Agronomia, Engenharia de Aquicultura e Medicina Veterinária, tem uma participação maior de homens ao longo do tempo. Até 2012, os homens brancos tinham uma participação ainda maior, mantendo uma distância significativa inclusive com relação aos homens negros. A partir de 2013, essa diferença começa a diminuir, e nos últimos anos, o percentual de homens negros ultrapassam o dos brancos. Isto ocorre também com as mulheres, que em 2013 já ultrapassam as mulheres brancas. A participação das mulheres negras teve um crescimento significativo nesta área, partindo de 6,9\%, em 2010 e chegando a 14,2\%, em 2018 (Gráfico 29).

Gráfico 29 - Percentual de ingressantes na área de Agricultura, Silvicultura, Pesca e Veterinária, segundo sexo_raça - 2010 a 2018

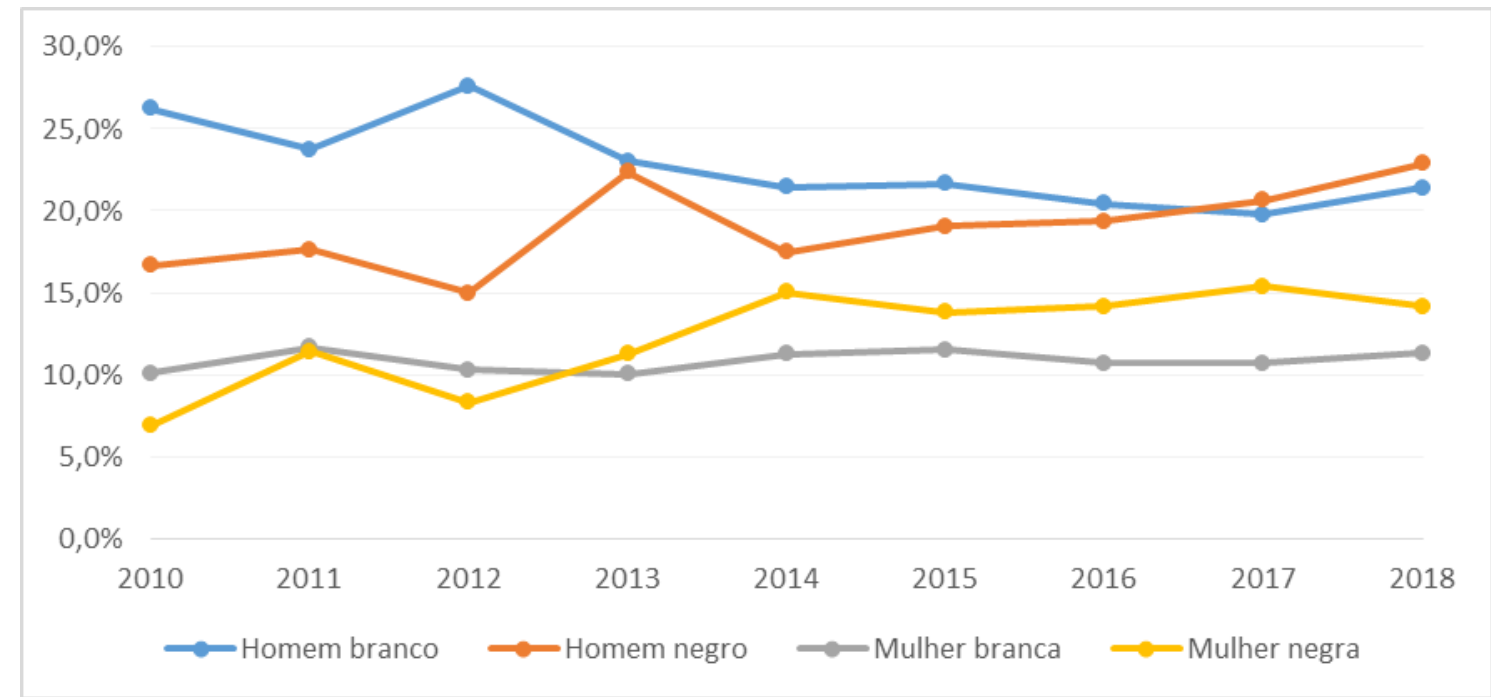

Fonte: Elaboração própria conforme dados do SGA/UFFS

A área de Saúde e Bem-estar, que envolve os cursos de Nutrição, Enfermagem e Medicina, tem uma presença maior de mulheres. A partir de 2013, com a criação de curso de Medicina, aumentou a participação de todos os grupos, e ao longo dos anos as diferenças de gênero foram menores. $\mathrm{O}$ ingresso de homens negros nesta área apenas se iniciou em 2013 (Gráfico 30). 
Gráfico 30 - Percentual de ingressantes na área de Saúde e bem-estar, segundo sexo_raça - 2010 a 2018

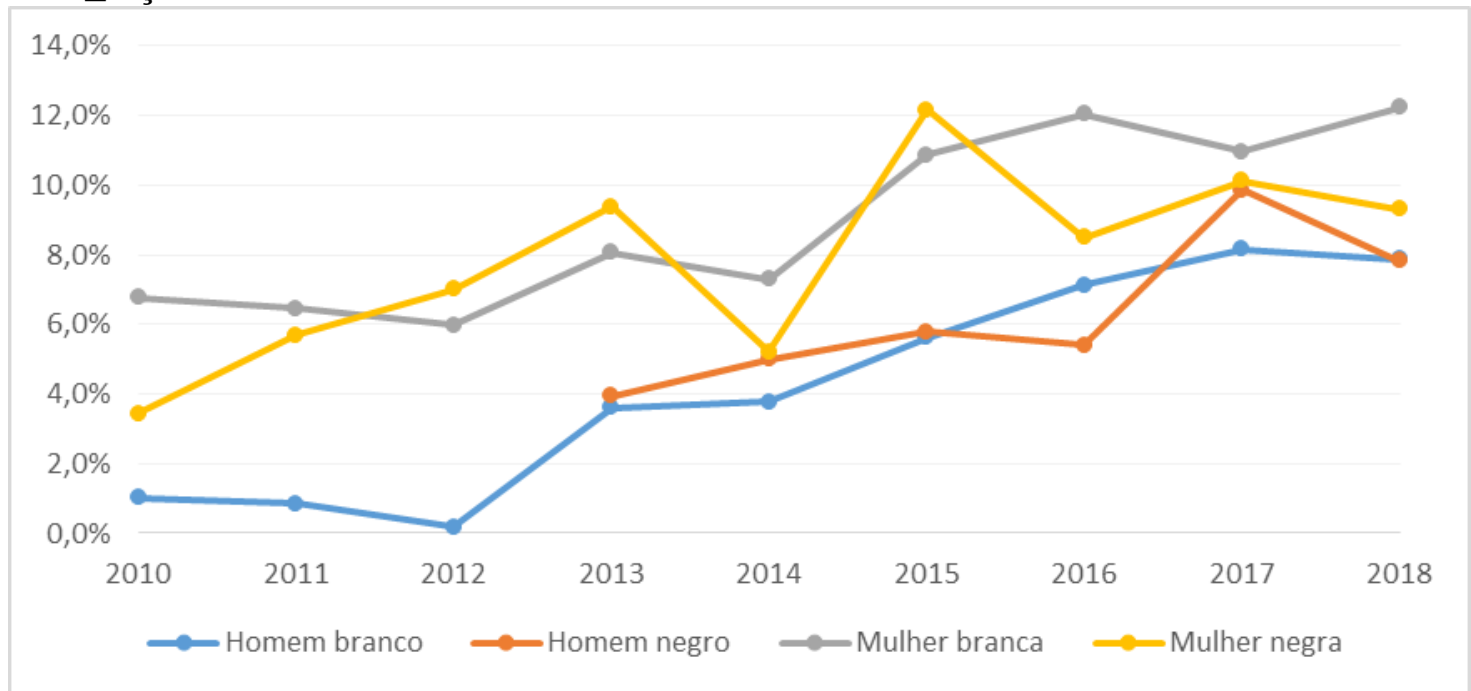

Fonte: Elaboração própria conforme dados do SGA/UFFS

Acerca das diferenças que existem tradicionalmente entre homens e mulheres em determinadas carreiras profissionais, Gerber \& Cheung (2008) consideram que as escolhas dos cursos educacionais em uma idade jovem já são moldadas por estas diferenças, que fazem com que para as mulheres as oportunidades no mercado de trabalho se encontrem mais ligadas ao altruísmo, sendo a perspectiva de emprego ideal para os homens mais ligada a enfatizar à riqueza, ao status e ao prestígio.

Dentro das áreas de conhecimentos há profissões que possuem um maior retorno econômico em termos salariais. Conforme mostra a literatura, a estratificação social por gênero, origem socioeconômica e raça/cor se manifesta tanto no acesso à universidade e às carreiras quanto ao mercado de trabalho. Nesses casos, a inclusão de estudantes com baixo nível socioeconômico, mulheres e negros, na universidade e no mercado de trabalho tende a ocorrer em carreiras com menor retorno econômico (Picanço, 2015; Carvalhaes; Ribeiro, 2019; Barbosa, 2019).

Conforme dados da Pesquisa Nacional por Amostra de Domicílios Contínua 2018 (IBGE, 2019b), ao verificar rendimento de pessoas ocupadas de 14 anos ou mais de idade, segundo o sexo e a raça, existe uma vantagem maior de homens brancos em relação aos demais grupos, sendo que a maior distância ocorre com as mulheres pretas ou pardas, que auferem apenas $44,4 \%$ da renda dos homens brancos, ou seja, menos da metade. As mulheres brancas aparecem no segundo grupo com maiores vantagens, tanto com relação às mulheres pretas e pardas, quanto aos homens pretos e pardos $(58,6 \% \mathrm{e}$ $74,1 \%$, respectivamente). 
Knop (2020) analisou desigualdades internas no ensino superior e evidenciou a estratificação por raça e, principalmente, por renda familiar, escolaridade do pai e gênero. A autora considera que, nos últimos anos, houve uma diminuição da desigualdade racial, o que também foi constatado por autores como Carvalhaes \& Ribeiro (2019).

Os Gráficos 31, 32 e 33 mostram a distribuição dos estudantes ao longo dos anos em cursos de alto, médio e baixo retorno, segundo gênero e raça/cor. Os resultados evidenciam que a desigualdade racial foi maior nos primeiros anos e, que ao longo do tempo, a distância entre brancos e negros diminuiu em cursos de maior retorno econômico. Já a desigualdade de gênero se mostra mais persistente ao longo do tempo, tendo uma diferença de mais de 20 p.p. entre homens e mulheres no acesso aos cursos de alto retorno. As mulheres negras tiveram um aumento significativo no acesso de cursos de alto retorno, passando de 10,3\%, em 2010 para 26,3\%, em 2018. A Lei de Cotas se mostrou importante para a redução da desigualdade racial, mas a desigualdade de gênero se manteve mais estável. Ou seja, embora as mulheres sejam maioria na universidade, em termos relativos, elas ocupam cursos de baixo e médio retorno econômico, principalmente nas áreas das licenciaturas.

Gráfico 31 - Percentual de ingressantes em cursos de baixo retorno, segundo sexo_raça 2010 a 2018

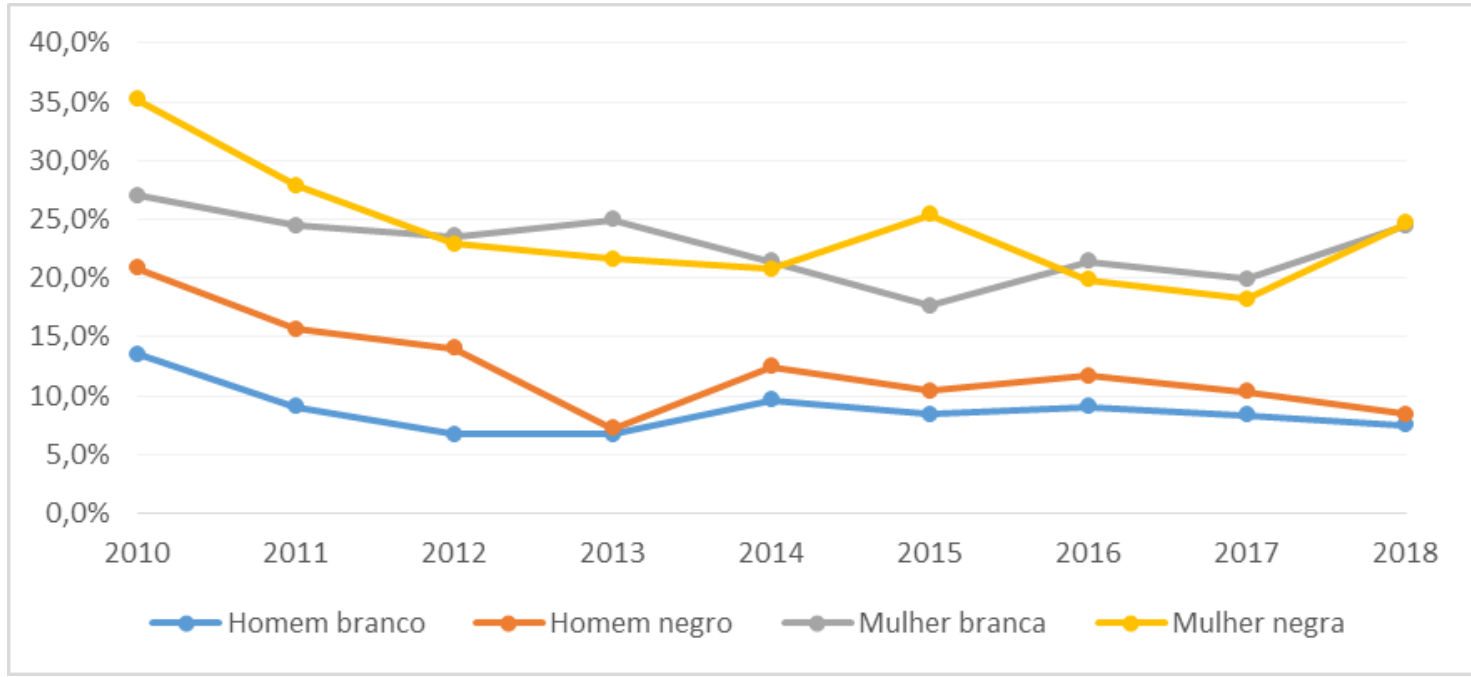

Fonte: Elaboração própria a partir de dados do SGA/UFFS 
Gráfico 32 - Percentual de ingressantes em cursos de médio retorno, segundo sexo_raça - 2010 a 2018

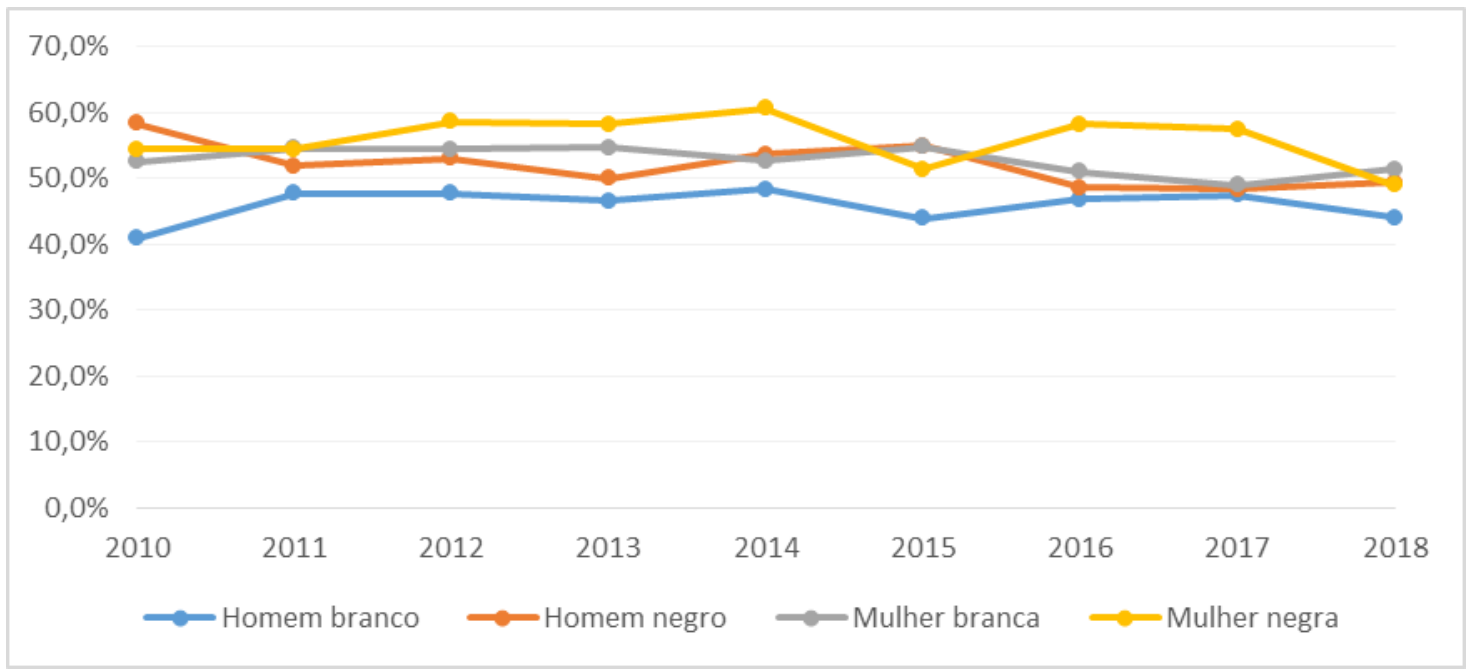

Fonte: Elaboração própria a partir de dados do SGA/UFFS

Gráfico 33 - Percentual de ingressantes em cursos de alto retorno, segundo sexo_raça 2010 a 2018

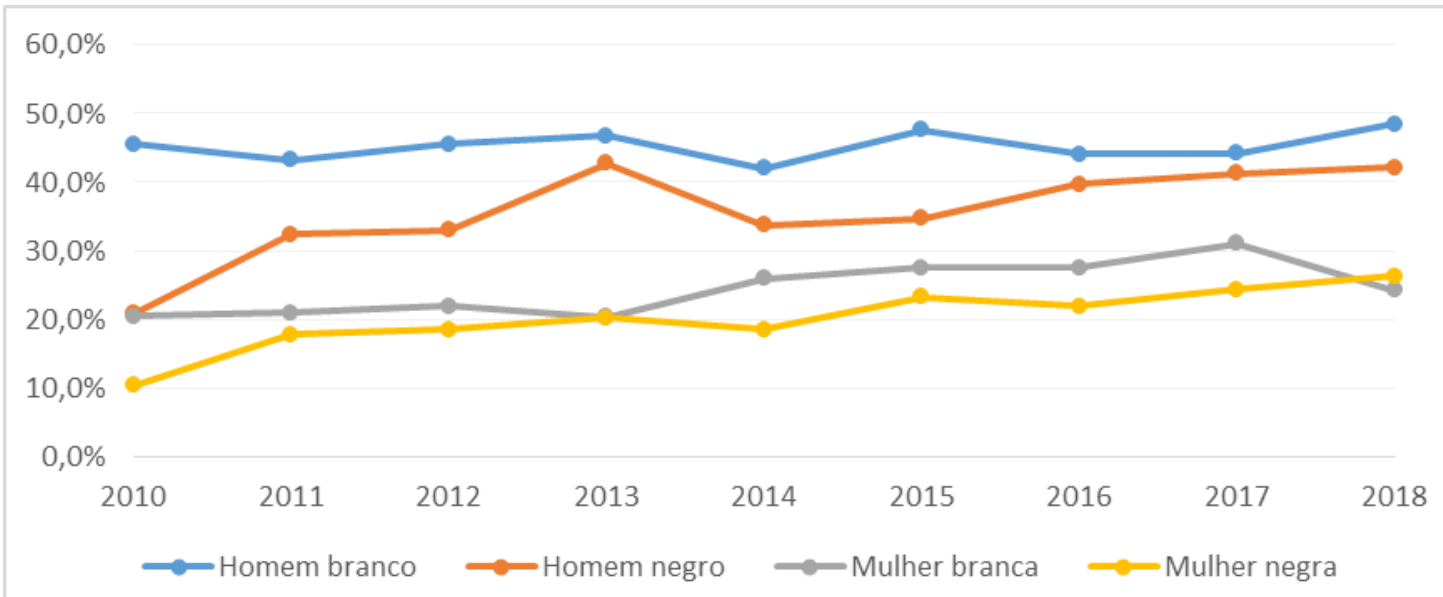

Fonte: Elaboração própria a partir de dados do SGA/UFFS

\subsection{Síntese do capítulo: principais resultados}

A principal contribuição desse capítulo foi de analisar como se configura a desigualdade estrutural de raça e gênero no acesso e na ocupação dos cursos da UFFS, ao longo do tempo. Em relação à nossa hipótese inicial, segundo a qual haveria a manutenção da desigualdade racial e de gênero, os dados mostraram que esta última é mais persistente.

A partir da Lei de Cotas houve importantes avanços com relação ao aumento de estudantes negros (homens e mulheres) em todos os cursos, inclusive nos de maior 
retorno econômico. As políticas de ações afirmativas não abrangem a questão de gênero. Neste caso, ainda que as mulheres na UFFS sejam maioria, sua presença ainda é mais significativa em cursos de licenciaturas e em outros de menor retorno econômico.

A abordagem interseccional apresenta contribuições importantes para pensar as múltiplas experiências de desigualdades com relação a marcadores de gênero, raça, idade. A partir dos dados analisados, observou-se a importância da análise das categorias "sexo" e "raça" de forma agregada, na ocupação dos cursos. No que tange ao lugar ocupado por homens e mulheres, negros e brancos no contexto de inclusão social promovido pela UFFS, observou-se que os homens brancos possuem maiores vantagens na ocupação de cursos com maior retorno econômico, em relação aos demais grupos analisados.

O marcador social idade também é relevante para caracterizar desigualdades no acesso ao ensino superior, principalmente no caso de homens negros que ingressam de forma mais tardia, expressando as desvantagens desse grupo social acumuladas desde a educação básica (Senkevics; Carvalho, 2020).

Nos próximos capítulos analisaremos os desfechos dos ingressantes na universidade, em termos das trajetórias, do rendimento acadêmico, da evasão e conclusão dos cursos, considerando características de gênero e raça e demais aspectos socioeconômicos, institucionais e relacionados aos cursos. 


\section{7}

\section{Evasão e conclusão no ensino superior: o que a literatura diz?}

O objetivo deste capítulo é apresentar diferentes estudos empíricos e as metodologias utilizadas na investigação de temas como evasão e conclusão de curso superior e na exploração de fatores associados às trajetórias e desfechos dos estudantes no ensino superior após o acesso.

No caso do estudo da evasão na educação superior, a literatura considera que se trata de um fator multidimensional, com presença nos sistemas universitários a nível mundial. Essa condição, impossibilitaria, para Borges (2019, p. 92), a criação de "um tipo ideal que concilie todas essas dimensões e que possamos usar como chave interpretativa para todos os casos".

No estudo da evasão e da conclusão de cursos de graduação, uma dimensão que precisa ser considerada diz respeito às mudanças na educação superior brasileira, principalmente no início do século XXI. Em pouco mais de uma década, foi criado um conjunto de políticas públicas que promoveu a expansão universitária, principalmente por meio da ampliação de acesso e da permanência, da diversificação dos estudantes e da interiorização da educação superior pública, a exemplo do Reuni; Enem; SiSU; Pnaes e Lei de Cotas.

A literatura tem mostrado que a evasão ocorre principalmente nos primeiros anos a partir do acesso na Universidade. Ristoff (2021) sinaliza que, nas últimas décadas, cerca de $51 \%$, em média, dos que ingressaram se formam.

A evasão estudantil no ensino superior na concepção de Silva Filho et al. (2007) é considerada um problema que afeta sistemas educacionais a nível mundial e as perdas de estudantes que iniciam e não concluem seus cursos se traduzem em desperdícios em termos sociais, acadêmicos e econômicos. Os autores analisaram, por meio de dados do Inep, de 2001 a 2005, os índices de evasão de forma regional e por tipo de instituição, comparando também com dados internacionais. A evasão foi considerada sob dois aspectos: evasão anual média que mede o percentual de estudantes matriculados num curso e que no ano seguinte não têm se formado e não fizaram a rematrícula; e evasão total que mede o número de estudantes que tendo entrado num determinado curso, ao final de um certo número de anos não obteve seu diploma. No período considerado pelo autor, a evasão anual média das IES foi de $22 \%$. As IES públicas têm oscilado em torno dos $12 \%$, variando entre 9 e $15 \%$, e as IES privadas mostraram uma oscilação em torno 
de $26 \%$. Ao analisar a evasão por áreas de conhecimentos, comparando-as com a taxa nacional, as áreas de Educação; Saúde e Bem-estar Social e Agricultura e Veterinária tiveram taxas menores de evasão média anual, enquanto as áreas de Ciências, Matemática e Computação e de Serviços registraram maior evasão. Quando observadas essas taxas por regiões, Norte e Nordeste possuem a menor taxa de evasão no período. As taxas de evasão observadas em universidades e centros universitários é menor quando comparada com as faculdades.

A seguir, apresentamos modelos teóricos de análise e conceitos relacionados com a permanência/retenção, conclusão e evasão de curso superior. E, na sequência, uma revisão de estudos mais gerais e estudos de caso, principalmente quantitativos, que apontam fatores e características associadas aos desfechos dos estudantes após o acesso. Encerramos o capítulo com uma síntese das principais dimensões de análises e variáveis utilizadas.

\subsection{Conceitos e modelos analíticos de evasão, retenção e conclusão do ensino superior}

A literatura sobre estratificação educacional apresenta uma chave de leitura importante para a análise da desigualdade de oportunidades no ensino superior, principalmente na perspectiva da desigualdade horizontal e vertical, considerando a relação entre a origem social do estudante e seu alcance educacional (Mont’Alvão, 2016; Brito, 2017). Características como raça, gênero e condição socioeconômica se mostram importantes dimensões de análise da desigualdade de acesso e de conclusão do ensino superior, assim como as desigualdades internas que se manifestam nas escolhas de IES, de cursos e de modalidades de ensino (Salata, 2018; Carvalhães; Ribeiro, 2019; Barbosa, 2019).

Constata-se que existe ainda uma lacuna de estudos que considerem, pelo menos em parte, a multidimensionalidade de fatores relacionados à evasão e à conclusão da graduação, além das características socioeconômicas dos estudantes, principalmente aspectos relacionados às instituições de ensino superior. Fenômenos como a evasão e a conclusão de um curso superior são abordados também a partir de outros modelos analíticos e de diferentes perspectivas teóricas, como os modelos clássicos de retenção desenvolvidos por Vicent Tinto (1975) e John Bean (1980), nos Estados Unidos, no decorrer do século XX e que influenciam a compreensão brasileira sobre o tema. 
O modelo de integração estudantil, desenvolvido por Tinto, a partir de 1975, se destaca como uma importante contribuição para a literatura acerca da temática relativa à evasão e à conclusão no ensino superior. $\mathrm{O}$ autor abordou de forma longitudinal a persistência do estudante até a conclusão da graduação e os fatores associados, considerando características como motivação, desempenho, atributos pessoais e a interação entre aluno e instituição. A evasão para $\mathrm{o}$ autor estaria associada principalmente a fatores como desempenho acadêmico e integração do estudante no ambiente universitário (Ambiel, 2015; Sales Junior et al., 2016; Li; Chagas, 2017, Costa; Gouveia, 2018).

O modelo de atrito desenvolvido por Bean (1980) acrescenta aspectos comportamentais (permanecer ou abandonar) como importantes preditores de persistência (Cabrera et al., 1992; Gouveia; Costa, 2018).

O modelo causal de Bean (1980) é semelhante ao que James Price utilizou em 1977 para analisar a rotatividade de funcionários nas organizações. Para tanto, considerou que os determinantes organizacionais podem afetar a satisfação e, por consequência, influenciar na permanência ou na evasão. Seu modelo considera como variáveis independentes nas chances de evasão, a satisfação, o compromisso institucional, determinantes organizacionais e variáveis de background. $\mathrm{O}$ comprometimento com a instituição e o desempenho se mostraram importantes na persistência tanto de homens quanto de mulheres. Outros fatores se mostraram importantes, ainda que de modo distinto para homens e mulheres, como o desempenho no ensino médio, a expectativa do curso universitário na obtenção de um emprego, a integração por meio do pertencimento a associações no campus e a satisfação (esta de modo mais significativo para as mulheres).

O modelo integrado de permanência, desenvolvido por Cabrera et al. (1992), a partir dos modelos de Tinto e Bean, considera que nos dois modelos a persistência dos estudantes é resultado de um conjunto de interações que ocorrem ao longo do tempo. Os autores também convergem na importância dada às características pré-universitárias e à influência na persistência da correspondência bem sucedida entre estudante e sua instituição. Para os autores o modelo de integração de Tinto enfatiza principalmente o compromisso institucional, enquanto o modelo de Bean considera também o papel de fatores externos à instituição, como a influência da família e dos amigos, nas atitudes e decisões dos estudantes. A correspondência entre as características sociais do indivíduo 
e as da instituição molda, portanto, dois compromissos individuais: o compromisso de concluir o curso e o compromisso com a instituição.

Ao entrevistar estudantes egressos de escolas públicas que ingressaram em cursos de alto prestígio em duas universidades brasileiras (pública e privada), Aguiar Neto (2019, p. 195) confirma a influência da família no sucesso escolar dos filhos, ainda que a maioria deles atribue o êxito ao seu próprio mérito:

[...] se trata de indivíduos oriundos de famílias motivadoras, `arquitetas`, educadoras, que valorizam o conhecimento e o saber-fazer e que sustentam, mesmo que de forma precária, o projeto escolar de seus filhos. Dito de outro modo, nossos entrevistados são estudantes que, mesmo em meio a dificuldades econômicas ou estruturais, se apresentam como recebedores de suporte financeiro e/ou emocional por parte de seus familiares, com vínculos firmes entre eles e os núcleos socializadores de sua vizinhança.

Na década de 1990, destaca-se também a obra "A condição de estudante: a entrada na vida universitária", do autor francês Alain Coulon, publicada no Brasil em 2008. Esta obra apresenta uma reflexão sobre a entrada de estudantes das camadas populares nas universidades públicas na França, a partir do questionamento às altas taxas de evasão encontradas. Com a interpretação de dados obtidos em pesquisa etnográfica sobre as etapas vivenciadas pelos estudantes a partir de seu ingresso na Universidade, o autor desenvolveu o conceito de "afiliação estudantil". Essas etapas caracterizam um período de estranhamento, de aprendizagem e o tempo de afiliação. Trata-se de uma etapa de transição do aluno do ensino médio para afiliar-se ao novo status social de estudante universitário, diante de um contexto marcado por novos códigos e desafios. A afiliação é um momento considerado de sucesso, porque expressa o momento em que o estudante consegue compreender os códigos institucionais e intelectuais que regem a vida universitária. O autor destaca também o papel da instituição neste processo, no sentido de construir uma pedagogia de afiliação (Avila, 2011).

Ao revisar a literatura acerca da temática da retenção no ensino superior, Tinto (2006) aponta três desafios que precisam ser considerados: ação institucional; a implementação de programas e o desafio contínuo de promover o sucesso de estudantes de baixa renda. $\mathrm{O}$ primeiro desafio diz respeito às práticas institucionais que precisam ser realizadas para promover o chamado engajamento do estudante, principalmente no primeiro ano da graduação. Ações de preparação docente são fundamentais, 
considerando a relação entre as práticas pedagógicas e a retenção. O segundo desafio diz respeito à eficácia na implementação de programas que possam produzir efeitos na retenção dos estudantes. Os programas precisam atentar para questões como a duração, continuidade, institucionalização e avaliação. Já o terceiro desafio diz respeito às lacunas no acesso e na conclusão do ensino superior entre alunos de baixa e de alta renda. As ações institucionais precisam considerar a equidade e a promoção da retenção, considerando a diversidade e a maior dificuldade de permanência entre estudantes de baixa renda. Trata-se de um contexto no qual se fazem necessárias ações institucionais que envolvam maior preparação acadêmica dos docentes e um esforço colaborativo para promover a aprendizagem de todos os estudantes de forma equitativa.

De acordo com Tinto (2017, p, 2, tradução nossa) a persistência do estudante até a sua graduação, pode ser entendida como “[...] outra forma de falar de motivação. É a qualidade que permite a alguém continuar em busca de um objetivo mesmo quando surgem desafios". O autor considera que as universidades precisam atuar no sentido de influenciar nessa motivação para que os estudantes permaneçam, persistam e consigam concluir sua graduação. $\mathrm{O}$ autor destaca três dimensões fundamentais para a motivação: a auto-eficácia, como sendo algo apreendido e não herdado, como o sentimento de sentir-se capaz para executar determinadas tarefas e para atingir certos objetivos; o sentido de pertença, relacionado à interação e ao vínculo do estudante com a comunidade universitária; e a percepção de valor do currículo, relacionado à relevância deste para a aprendizagem, a participação universitária e o próprio futuro do estudante.

A partir dos conceitos de integração social e acadêmica de Tinto $(1975,1999)$ e de afiliação estudantil de Coulon (2008), Heringer (2020a), por meio de um estudo recente realizado na Universidade do Texas em Austin, EUA, apresenta uma releitura desta literatura, trazendo também os conceitos de "engajamento estudantil" e de "senso de pertencimento", e partir de autores como Kahu (2013); Herpen et ali. (2020) e Owolabi (2018). Esses conceitos formam um conjunto e se referem a fatores associados ao sucesso acadêmico. A ideia de "engajamento estudantil", na concepção de Kalu (2013), consiste na "atitude de envolvimento e compromisso do aluno com seu desenvolvimento como estudante, implicando também num compromisso recíproco da instituição em viabilizar os melhores meios para que este pleno engajamento aconteça" (Heringer, 2020a, p. 3). O senso de pertencimento, conforme Herpen et ali (2020) e Owolabi (2018), refere-se a "um conjunto de fatores que fazem com que os estudantes 
se sintam parte da instituição, se sintam respeitados e apoiados, se sintam 'em casa' o que contribuiria de forma significativa para seu sucesso acadêmico" (Heringer, 2020a, p. 4).

Heringer (2020a) considera que a permanência estudantil possui uma complexa multidimensionalidade e deve levar em conta fatores não apenas materiais, mas também simbólicos, culturais e psicológicos. A autora chama atenção para o papel institucional no desenvolvimento de ações de permanência e, no caso do Brasil, para o fato de que o próprio conceito de assistência estudantil deveria ser repensado no sentido de promover o engajamento estudantil e a ampliação do senso de pertencimento, considerando esses aspectos multidimensionais. A crítica da autora é no sentido de que muitas ações e políticas institucionais de apoio acadêmico, de assistência estudantil e de permanência ocorrem de modo desarticulado e são realizadas por diferentes atores e instâncias dentro das IES.

O estudo exploratório de Costa \& Gouveia (2018) analisou 23 modelos de retenção, no sentido de persistência e permanência nos cursos, considerando as oito últimas décadas e diferentes países. Além do modelo interativo desenvolvido por Tinto, os autores sinalizam que a retenção tem sido analisada por outras perspectivas teóricas, a saber: a psicológica, a sociológica, a econômica, a organizacional e a complementar ou integrativa (que toma essas últimas perspectivas de modo conjunto). Com base na literatura, os autores adotaram a seguinte definição: "retenção é a capacidade institucional para manter e apoiar os estudantes da admissão até alcançar a graduação com sucesso" (Costa; Gouveia, 2018, p. 163). As principais variáveis e indicadores relacionados à taxa de retenção listadas pelos autores foram: preparação acadêmica; integração social e acadêmica; compromisso com a Instituição e com o objetivo; ambiente (relacionado a questões financeiras, familiares e de trabalho) e a características relacionadas aos antecedentes escolares.

O estudo pioneiro realizado nas instituições públicas de Ensino Superior brasileiras, em 1996, por uma Comissão Especial no âmbito do Ministério da Educação e Cultura (MEC, 1996, p. 56), conceitua evasão como "a saída definitiva do aluno de seu curso de origem, sem concluí-lo”. A evasão também pode ser considerada em nível de instituição e de sistema. O estudo do MEC apontou três prováveis fatores do abandono da graduação: a) características individuais do estudante (escolha precoce do curso; motivação; trajetória escolar anterior); b) fatores internos às instituições 
(currículos desatualizados; projetos pedagógicos dos cursos; falta de programas institucionais voltados aos estudantes); e, c) fatores externos à instituição (dificuldades financeiras; falta de reconhecimento social da carreira escolhida).

A evasão pode indicar também uma situação apenas de mobilidade. Para Ristoff (1999) parte significativa do que é considerado evasão, não se refere necessariamente à fuga e sim a uma busca pela realização pessoal. A mobilidade retrata, portanto, a saída do estudante de um curso, e em muitos casos, também o acesso a outro na mesma IES ou em outra distina, indicando a sua permanência no sistema de ensino superior. Li \& Chagas (2017) também consideram a migração como um "investimento", no qual a decisão de migrar consideraria os custos e benefícios e a expectativa por retornos futuros como fatores importantes.

O estudo de Lima Junior et al. (2019) fez uso de dados longitudinais de 2002 a 2008 da Universidade de Brasília, e verificou que o número de matrículas novas neste período era $12 \%$ superior ao número de pessoas distintas, ou seja, uma parte significativa de estudantes reingressa no ensino superior, indicando a mobilidade entre cursos na mesma Instituição. Os autores criaram dois indicadores: Taxa Longitudinal de Evasão (TLE) e Taxa Longitudinal de Retenção (TLR). O fenômeno da retenção é verificado apenas para os estudantes que já concluíram seu curso. No período analisado, a taxa de retenção média para toda a universidade foi de $61,2 \%$. Isso significa que apenas quatro em cada dez estudantes se formaram no tempo previsto. O estudo considera a evasão como uma condição de mobilidade, ou seja, como apenas evasão do curso. A taxa de evasão verificada em cada coorte de estudantes após oito anos do ingresso variou de 19,4\% a 28,5\%, com um aumento nas últimas coortes.

O documento sobre a metodologia de Cálculo de Indicadores de Fluxo da Educação Superior, divulgado pelo Inep em 2017, também apresenta conceitos relacionados à trajetória acadêmica a partir do ingresso: permanência, desistência e conclusão, que indicam, respectivamente, o percurso, o insucesso e o sucesso. $\mathrm{O}$ percurso sinaliza uma "[...] condição de movimento e pode ser derivada em medidas mais ou menos satisfatórias à medida que o discente cumpra ou não a carga horária necessária para o cumprimento do itinerário". O insucesso e o sucesso [...] "representam uma condição terminativa em relação ao percurso" (Inep, 2017, p. 9).

A literatura nacional e internacional busca explicar quais fatores mais influenciam na evasão e/ou na conclusão ou não de um curso universitário. Em termos 
metodológicos, os estudos diferem nas formas adotadas para medir as condições de trajetória e os desfechos no ensino superior, a depender dos conceitos, objetivos e dados disponibilizados e/ou produzidos para esse fim. De um modo geral, os fatores associados à evasão, permanência e conclusão encontram-se relacionados às características pessoais, familiares e escolares dos estudantes; a aspectos institucionais; ao desempenho nas disciplinas e outros relacionados à escolha, motivação e compromisso com o curso (Baggi; Lopes, 2011; Morosini et al., 2012; Santos Junior; Real, 2020; Munizaga; Cifuentes; Beltrán, 2018; Costa; Gouveia, 2018; Costa; Picanço, 2020).

Diante da diversidade de metodologias e de abordagens utilizadas para analisar a evasão, a permanência e a conclusão da graduação, o próximo item apresenta uma revisão de literatura com base em diferentes estudos, majoritariamente quantitativos, que apresentam importantes resultados e tendências de análise, principalmente em contextos mais recentes de expansão e de uma maior heterogeneidade de estudantes na educação superior.

\subsection{Fatores associados à evasão e conclusão de cursos}

No sentido de mapear os principais fatores associados ao fato de um estudante de ensino superior permanecer e concluir um curso de graduação ou abandoná-lo, buscouse nesta revisão de literatura trazer estudos mais amplos, em nível nacional, e que se utilizam, principalmente, de dados oficiais do Inep, e, estudos de caso específicos de IES, que analisam dados institucionais e/ou dados obtidos por meio de questionários/entrevistas com estudantes. Além disso, apresentam-se alguns estudos de revisão acerca dessa temática.

Ao tratar sobre causas de abandono estudantil e de permanência no ensino superior no contexto da América Latina e Caribe, por meio de uma revisão sistemática de estudos, considerando o período de 1990 a 2016, Munizaga; Cifuentes \& Beltrán (2018) identificaram 111 variáveis relacionadas a esse fenômeno, agrupadas nos seguintes fatores, por ordem de predominância: "Individual" e "Acadêmico", seguidos de "Institucional", "Econômico" e "Cultural”. A maioria dos estudos não considera todos esses fatores de forma simultânea e, segundo os autores, ainda predominam estudos 
centrados na caracterização e na descrição dos estudantes que abandonam, o que sinaliza para uma etapa ainda inicial de estudos na América Latina e Caribe.

Dentre os estudos com foco na evasão no ensino superior brasileiro, destacam-se as revisões realizadas por Morosini et al. (2012) e por Santos Junior \& Real (2020). A primeira revisão considera o período entre 2000 a 2011 e um corpus de sete trabalhos; o segundo focaliza o período a partir de 1990 e 72 trabalhos desenvolvidos em diferentes áreas do conhecimento (Educação, Administração, Psicologia).

Entre os principais fatores associados à evasão, Morosini et al. (2012) destacam: aspectos financeiros e de ordem familiar; escolha do curso e relação com colegas e com a universidade; aspectos relacionados ao desempenho nas disciplinas; prestígio dos cursos, da profissão escolhida e da Instituição; situação de trabalho e incompatibilidade com as atividades do curso e aspectos relacionados à motivação e compromisso com o curso. Já os resultados de Santos Junior \& Real (2020) mostram a diversidade existente na abordagem do tema, que envolve características do período anterior ao ingresso, o perfil dos estudantes e aspectos institucionais como fatores que podem estar associados à evasão, além de considerar, também, as estratégias adotadas pelas IES para controlar a evasão e sua relação com algumas políticas, como ProUni e cotas. Os autores sinalizam que houve um aumento de estudos nesta temática, principalmente a partir de 2010, com destaque para o fomento de políticas voltadas para o acesso e a permanência estudantil e que exigem um acompanhamento mais sistemático.

Com recorte mais específico nas instituições federais brasileiras, Gilioli (2016) considera a evasão como um fenômeno mundial e a multifatorialidade de suas causas, como as características individuais dos estudantes, desempenho e escolha de curso em primeira e segunda opção. A criação do Sistema de Seleção Unificado (SiSU) em 2010 permitiu, segundo o autor, o aumento de mobilidade geográfica, o que não significa que se possa atribuir ao SiSU o papel de fator único e determinante da evasão. Estudos levantados pelo autor identificaram que, em algumas IES, a evasão aumentou e em outras diminuiu, a depender de cada curso, área de conhecimento, grau acadêmico e do tipo de modalidade de evasão verificada (cancelamento de matrícula, jubilamento). Gilioli (2016) considera, ainda, que a evasão ocorre principalmente nos dois primeiros anos, encontrando-se bastante associada ao ingresso em curso de segunda opção, o que permite migrar para outro curso de sua opção assim que conseguir vaga dentro da própria IES e/ou em outra IES. A migração geográfica ocorre também quando 
estudantes conseguem inicialmente uma vaga muito distante de sua residência e migram para uma IES mais próxima, assim que conseguem uma vaga. Neste cenário, segundo Ristoff (1999), este tipo de evasão deve ser compreendido como uma situação de mobilidade.

O estudo de Ribeiro \& Morais (2020) também identifica relações entre a evasão e o ingresso pelo SiSU em segunda opção de curso. Os autores aplicaram questionários a estudantes que ingressaram em cursos de bacharelados interdisciplinares, em segunda opção na Universidade Federal da Bahia (UFBA). Na maioria dos casos, o ingresso em segunda opção foi apontado como uma possibilidade de acessar o ensino superior. Ainda que não atribuam ao SiSU uma responsabilidade direta pela evasão, os autores concluem que o acesso facilitado e a lógica de seleção adotada pelo SiSU aumentam as escolhas de forma imatura e o ingresso em cursos muitas vezes não desejados, o que pode levar a uma relação mais distante com o curso e até a evasão. Destacam a importância da orientação profissional no âmbito das IES para que os estudantes possam aprimorar suas escolhas profissionais e planejar suas carreiras, além de outras ações destinadas a garantir condições de permanência, principalmente de estudantes desfavorecidos socioeconomicamente.

Do mesmo modo, Li \& Chagas (2017) buscaram compreender a evasão e a migração estudantil a partir dos impactos das políticas do Enem e do SiSU, considerando dados do Inep e de ingressantes no ensino superior no período entre 2006 e 2014. Os principais resultados indicaram que a adesão ao SiSU aumenta a probabilidade de migração de estudantes entre Estados (interestadual) e reduz a probabilidade de migração entre municípios no mesmo Estado (intraestadual). Identificaram também uma probabilidade de evasão elevada no primeiro ano, assim como de mudança de instituição antes do término de graduação. Os principais resultados deste estudo mostram que: estudantes mais velhos, mulheres, cotistas e aqueles que recebem apoio social possuem menor probabilidade de migrar; a evasão é menor no primeiro ano para estudantes negros e aqueles que recebem apoio social; egressos de escolas públicas no ensino médio tendem a mudar menos de instituição; e a mudança de Instituição é maior entre estudantes cujos pais possuem ensino superior. Os autores destacam a importância do apoio social recebido pelos estudantes para a redução da evasão estudantil e permanência na IES, mas não necessariamente no mesmo curso. 
De Paula (2021) investigou a evasão no ensino superior público federal e sua relação com as desigualdades sociais, com base numa coorte de ingressantes em 2016, em nível federal (conjunto de universidades federais), local (Universidade Federal de Minas Gerais) e individual (entrevista com estudantes). Analisou a evasão levando em conta a origem socioeconômica dos estudantes e características institucionais, como o tipo de curso e IES, buscando diferenciar os tipos de evasão de curso, da Instituição e do sistema. Entre seus principais achados destacam-se: a) a origem social não tem uma influência direta na evasão, principalmente da instituição, porém os alunos das camadas populares evadem de forma mais involuntária, e muitas vezes a evasão encontra-se associada, por exemplo, à menor disponibilidade de recursos financeiros, motivações de trabalho e responsabilidades externas à vida acadêmica, enquanto alunos de classes mais altas evadem por motivações mais voltadas, por exemplo, à perda de interesse pelo curso ou pela busca de alternativas mais satisfatórias. Portanto, os estudantes das camadas populares encontram-se mais vulneráveis em relação à evasão do sistema de ensino superior, ou seja, neste tipo de evasão, a origem social parece ter maior influência; b) fatores relacionados aos tipos de cursos explicam mais a evasão, seja do curso, da instituição ou do sistema, que os fatores socioeconômicos dos estudantes. Estudantes no período noturno e em cursos de licenciatura têm maior probabilidade de evasão.

No âmbito das universidades federais brasileiras e com dados do Inep, Costa (2018) acompanhou uma coorte de ingressantes no período entre 2011 e 2016 por meio de análise de sobrevivência, buscando compreender fatores associados à evasão e à permanência. Os resultados demonstraram que, até 2016, 41,2\% dos ingressantes de 2011 haviam evadido do curso, principalmente no segundo ano. Entre os fatores relacionados com o tema, o estudo destaca: evasão maior na Região Sul e em cursos de IES localizadas no interior, em relação a IES de capitais; homens evadem mais; autodeclarados pardos apresentaram a menor evasão e pretos a maior evasão (taxas de sobrevivência de $71,4 \%$ e $61,1 \%$, respectivamente); estudantes de licenciaturas e de cursos noturnos evadem mais; ser beneficiário de programas de apoio social auxilia na permanência dos estudantes. A taxa de sobrevivência desse grupo foi de 70,3\%, quando comparada aos não beneficiários desses programas. Um dos principais achados do estudo foi a forte influência que a participação em atividades extracurriculares teve na redução do risco de evadir (99\% por ano de participação). 
Também na perspectiva de análise de sobrevivência, o estudo de Saccaro, França \& Jacinto (2019) analisou fatores associados à evasão em cursos nas áreas de ciências naturais e engenharias em instituições privadas e públicas do Brasil, com base nos dados do Censo da Educação Superior, no período de 2009 a 2014. Os resultados apontaram fatores que contribuem para a evasão ou permanência, tais como: a) características dos estudantes: as mulheres são mais persistentes; estudantes que recebem algum tipo de apoio financeiro nas IES privadas ou públicas evadem menos; b) características dos cursos: sobrevivência em cursos de 5 anos é maior do que em cursos de 4 anos; quem ingressa pelo Enem sobrevive mais em relação as outras formas de ingresso; na área de ciências naturais a sobrevivência é menor que nas engenharias; alunos de cursos concorridos tendem a evadir menos; considerando as características das Instituições, c) a sobrevivência nas IES públicas é maior; d) nas instituições com mais infraestrutura como biblioteca e laboratórios a evasão é menor e, e) a região Nordeste apresenta a maior sobrevivência, ou seja, é a região em que os estudantes evadem menos.

Ainda com relação à evasão de curso no contexto nacional, De Paula \& Nogueira (2020) analisaram, com base em dados do Censo da Educação Superior, características sociodemográficas e escolares dos estudantes e variáveis organizacionais (tipo de curso e de IES) mais associadas à evasão de curso. Tomaram como referência os ingressantes em toda a rede federal de ensino superior no ano de 2012 e a situação de matrícula em 2017. Seus resultados mostraram que quase metade dos alunos havia evadido do curso de origem entre o primeiro e o segundo ano de ingresso. Com relação às características sociodemográficas e escolares dos estudantes os autores destacaram que a evasão de curso é maior entre homens e pessoas com mais de 15 anos de idade. Raça/cor e origem escolar (escola pública e privada) têm pouca diferença entre os grupos. Nos grupos de ingresantes por cotas e ampla concorrência, os autores identificaram maior evasão no de ampla concorrência e, ao separar por tipos de cotas, observaram mais evasão entre os cotistas raciais. Já com relação às características organizacionais, os resultados indicaram que a evasão de curso é maior nos Institutos Federais do que nas universidades federais; nas licenciaturas e curso de tecnólogos e nos cursos de turno noturno.

Com objetivo de construir e validar uma escala com os principais motivos que poderiam influenciar na evasão do ensino superior, Ambiel (2015) aplicou questionários 
para estudantes de instituições públicas e privadas de todo o país e obteve os seguintes resultados, agregados em sete itens: 1) Motivos institucionais (ex. dificuldade de relacionamento com os professores); Motivos pessoais (problema de saúde na familiar; incerteza quanto ao curso certo); 3) Motivos relacionados à falta de suporte financeiro (Dificuldades de conciliar trabalho e estudo; não ter tempo para participar de atividades extracurriculares); 4) Motivos relacionados à carreira (preocupação com o mercado de trabalho); 5) Motivos relacinado ao desempenho acadêmico (desempenho baixo em algumas disciplinas); 6) Motivos interpessoais (dificuldade de relacionamento com colegas) e 7) Motivos relacionados à autonomia (responsabilidade de morar longe da família).

Com foco na conclusão de cursos de graduação, o estudo de Knop (2020) abordou as desigualdades internas no ensino superior e investigou efeitos de origem social nas chances de concluir os cursos de graduação, considerando diferentes áreas de formação dos graduandos e setores institucionais (público e privado). Utilizou-se de dados do questionário socioeconômico do Enade de ingressantes e concluintes no ensino superior e modelos logísticos e multinomiais. Seus resultados mostraram que a origem socioeconômica continua sendo um fator importante na conclusão dos cursos, assim como a escolaridade do pai, ainda que esta última se mostra menos determinante. Constatou que quanto maior a renda familiar, maiores as chances de conclusão de diferentes cursos, e principalmente cursos de retorno econômico mais alto no mercado de trabalho, tanto em IES públicas, quanto privadas. A estratificação é maior entre os estudantes segundo os cursos com retorno socioeconômicos distintos que por setores institucionais público ou privado. Ou seja, ainda que tenham sido expandidas as chances de acesso para estudantes de mais baixa renda, permanecem diferenças de perfil segundo o retorno econômico dos diferentes cursos. Além disso, estudantes negros e indígenas e de pais com baixa escolaridade têm menos chances de concluir cursos com maior retorno econômico. Estudantes em posição socioeconômica vantajosa, com pai de alta escolaridade, egressos de ensino médio privado, os que não conciliam trabalho e estudo, homens, brancos ou de origem asiática possuem maior probabilidade de concluir cursos de retorno econômico alto no setor público. Outro resultado relevante é que estudantes de origem socioeconômica alta, caso não consigam acesso em IES públicas (mais seletivas), optam pelo setor privado e por cursos com maior retorno econômico, uma vez que conseguem arcar com custos de mensalidades. 
A origem socieoconômica, o gênero e a raça se apresentam como características importantes na definição da trajetória e no desfecho dos estudantes (Barbosa, 2019; Knop, 2020). Em estudo de caso sobre a UFRJ, Costa \& Picanço (2020) compararam o perfil de ingressantes brancos e negros e seus desfechos quanto à evasão e conclusão de curso antes e depois da Lei de Cotas (2012 e 2013), e observaram mudanças no perfil socioeconômico e racial de ingressantes, com maior concentração de estudantes negros, pobres e de escola pública, a partir de 2013. Em termos culturais, esses grupos (brancos e negros) não apresentam muitas diferenças, mas existem diferenças nas condições socioeconômicas e em sua distribuição desigual nos cursos, com uma presença mais significativa de negros em cursos como licenciaturas e letras e de brancos em cursos de engenharia. Essa diferença entre brancos e negros ocorre principalmente em cursos que envolvem habilidades/interesses específicos, como matemática, artes e estatística (Costa; Picanço, 2020). Por meio de regressões logísticas para verificar efeitos de condições socioeconômicas, escolares e culturais nos desfechos de evasão e conclusão, os autores também mostraram que tanto para brancos quanto para negros, o fato de ser homem reduz a chance de conclusão e aumenta a chance de evasão nos cursos, do mesmo modo que apresentar situação de trabalho ao ingressar na Universidade. $\mathrm{O}$ índice socioeconômico nas chances de conclusão para os estudantes negros passou a ter efeitos apenas em 2013, a partir da Lei de Cotas, enquanto que, para os estudantes autodeclarados brancos a condição socioeconômica já tinha efeitos na chance de conclusão antes mesmo de 2013. Esse resultado indica que estudantes com menor índice socioeconômico possuem menos chance de concluir os cursos. $\mathrm{O}$ fato de ter feito cursinho pré-vestibular também influencia de modo positivo na conclusão do curso para estudantes negros. No desfecho de evasão de curso, para estudantes brancos o fato de trabalhar, ter filhos e baixo status socioeconômico aumenta as chances de evasão; enquanto que para os estudantes negros o fato de ter filhos não influencia nas chances de evasão, mas sim o fato de ter realizado cursinho.

O estudo de Eller \& Diprete (2018), realizado nos Estados Unidos, busca compreender as motivações relacionadas ao hiato entre estudantes negros e brancos na conclusão de cursos de bacharelados, com duração de quatro anos. Os índices de conclusão dos primeiros são menores em relação aos segundos. Por meio de variáveis de desempenho acadêmico, relacionadas à entrada e à conclusão; fatores dos estudantes e das instituições, o principal resultado do estudo foi a associação entre o desempenho 
acadêmico nessa lacuna entre pretos e brancos, ou seja, o recurso mais essencial para a persistência universitária é a nota alta antes da entrada e durante a faculdade. Também destacam como fatores importantes para a conclusão, o engajamento social e a resiliência de estudantes negros desde a entrada na faculdade.

Ainda no contexto dos Estados Unidos, o estudo de Eller (2019) chama atenção para o papel das instituições sobre o desempenho dos estudantes. Em geral as universidades com maiores taxas de graduação são avaliadas como as melhores, mas o desafio que se coloca é avaliar de que forma essas instituições contribuem para a igualdade de oportunidades e se a equidade e a excelência andam juntas, ou seja, avaliar se os resultados são equitativos, por exemplo, para estudantes pretos e brancos e para estudantes de baixa renda. A autora investigou efeitos da desigualdade de gênero, raça e classe na conclusão dos cursos, comparando estes efeitos em diferentes estabelecimentos de ensino superior, no contexto norte-americano. Os resultados apontaram que os diferentes estabelecimentos possuem efeitos na produção de taxas médias de conclusão, mas que raramente se traduzem em efeitos igualmente benéficos para todos os grupos raciais ou de renda. Apenas uma faculdade aumentou de modo mais uniforme as chances para todos os grupos. As evidências mostram que parte das desigualdades são explicadas pelas características das próprias instituições, como o tamanho e suas experiências de acolhimento e orientação dos estudantes. Segundo a autora, por vezes se responsabiliza apenas os estudantes e suas características pelos resultados educacionais, sem se considerar a importância do papel das instituições nesses resultados, e sua contribuição na produção e legitimação de desigualdades no ensino superior.

No conjunto de ações desenvolvidas pelas IES para promover a permanência e a conclusão e para reduzir a evasão destaca-se a importância das políticas de assistência estudantil (apoio social), por meio de auxílios e bolsas para estudantes em situação de vulnerabilidade socioeconômica e programas de atividades extracurriculares, por meio de bolsas de estágio, iniciação científica, extensão. Diversos estudos realizados em diferentes contextos têm mostrado associações positivas entre essas políticas e o sucesso acadêmico na graduação, como de Alon (2007); Sales Júnior et al., 2016; Costa, 2018; Saccaro; França; Jacinto, 2019. No contexto dos EUA, Alon (2007) mostrou uma associação positiva entre ajuda financeira e persistência de estudantes negros e hispânicos em faculdades seletivas dos Estados Unidos, em relação aos estudantes 
brancos. As políticas voltadas para o apoio financeiro por meio de concessão de bolsas se mostraram mais efetivas que os empréstimos/financiamentos. $\mathrm{O}$ estudo destacou a importância do apoio financeiro para compensar diferenças no ponto de partida dos estudantes decorrentes das características socioeconômicas de grupos minoritários (negros e hispânicos).

Ainda, com o objetivo de identificar fatores relacionados à evasão e conclusão no ensino superior, destacam-se os seguintes estudos de casos: Pedrosa et al. (2006); Rotem, Yair \& Shustak (2020); Baccaro \& Shinyashiki (2014); Sales Junior et al. (2016); Ferrão \& Almeida (2018); Ribeiro \& Morais (2020); Adachi (2017); Zago, Paixão \& Pereira (2016); Fassina (2018); Reis (2019) e Vidi (2020).

O estudo de Pedrosa et al. (2006) teve o objetivo de analisar o desempenho de graduandos, a partir de um banco de dados acadêmicos e socioeconômicos com 6.701 estudantes admitidos na Universidade Estadual de Campinas (Unicamp); no período entre 1994 a 1997, por meio de vestibular, em diferentes cursos. A variável dependente "desempenho relativo" considerou características como notas na entrada e na saída, tempo de permanência na IES e situação de matrícula no início de 2005. Um conjunto de variáveis independentes foram usadas, para caracterizar a situação econômica e social do grupo familiar; os pais e o estudante; questões acadêmicas e a escolha da Instituição. Sexo e idade foram usados como variáveis de controle, e também um esquema hierárquico para a construção de modelos de regressão linear e logístico. Os resultados mostraram que estudantes oriundos de ambientes mais desfavorecidos em termos socioeconômicos e educacionais apresentaram um desempenho relativamente melhor que os extratos socioeconômicos mais elevados. A autora chamou esse fenômeno de resiliência educativa. Estudantes de escola pública, por exemplo, e aqueles pertencentes a extratos inferiores do índice socioeconômico e educacional da família tiveram desempenho melhor que os de escola privada e os de extratos superiores, o que motivou a Unicamp a estabelecer programas de ações afirmativas beneficiando estudantes da escola pública. A expressão resiliência educacional usada pelos autores busca indicar que as desvantagens em períodos anteriores de vida se traduziram posteriormente em desempenho educacional superior. Ser mulher; mais jovem; ter estudado em escolas técnicas no ensino médio e de tempo integral; não ter frequentado curso preparatório e não falar uma segunda língua também integram o conjunto de variáveis mais associadas ao desempenho relativo maior. Com base nesses resultados, 
os autores sugerem que é possível aumentar a participação de jovens talentosos provenientes de camadas socioeconômicas e educacionais mais desfavorecidas (Pedrosa et al., 2006).

O estudo de Rotem, Yair \& Shustak (2020), no contexto da Universidade Hebraica de Jerusalem, em Israel, investigou a relação entre ações afirmativas e mérito no ensino superior israelense e concluiu que é possível que as universidades abram mais suas portas para as ações afirmativas, sem prejudicar a meritocracia. As principais questões levantadas pelos autores foram: é possível rejeitar candidatos com base no mérito para garantir vagas para estudantes de minorias? Estes últimos estariam fadados a ter taxas de evasão mais altas? É possível aumentar a diversidade sem diminuir os padrões acadêmicos e sem aumentar as taxas de evasão? O estudo aborda o dilema da inclusão em relação ao padrão de evasão, por meio da análise de 41.483 estudantes de graduação do período entre 2002 a 2015. Cerca de 5\% dos estudantes foram considerados elegíveis para uma ação afirmativa exclusiva de Israel. Os resultados mostraram que estudantes não elegíveis para as ações afirmativas partem das mesmas taxas de desistência que estudantes elegíveis e outros grupos de risco. Por isso, o estudo sugere que as universidades se abram mais para as ações afirmativas.

Como variável dependente o estudo utilizou taxas de graduação versus evasão escolar e mostrou que estudantes beneficiários da ação afirmativa possuem um desempenho acadêmico realmente tão bom quanto os demais estudantes. Por meio de uma série de testes estatísticos e de controles, os autores mostraram que as taxas de evasão e a média de notas de alunos de ações afirmativas são iguais aos da população estudantil em geral. Os autores apontam que existe uma lacuna na compreensão da relação entre políticas de ação afirmativa e abandono ou retenção. Dentre os muitos fatores de risco associados com a evasão e/ou conclusão de curso, este estudo, com base nos dados de Israel, mostra o desempenho com um forte fator de risco. O desempenho considera o rendimento em termos de notas dos estudantes no primeiro ano. As reprovações, portanto, são tidas como um fator de risco e, neste sentido, o desempenho se torna o cerne da questão (Rotem, Yair; Shustak, 2020).

Ainda com relação ao desempenho, o estudo realizado por Baccaro \& Shinyashiki (2014), teve o objetivo de analisar a relação entre o desempenho no vestibular, características sociodemográficas e o rendimento acadêmico de estudantes na USP. Os autores consideraram desempenho e rendimento acadêmico como sinônimos. 
Usaram desempenho como variável dependente, considerando a média final da nota ponderada dos estudantes que concluíram o curso. Como variáveis independentes, foram utilizadas características socioeconômicas e desempenho no vestibular. O estudo considerou um único grupo de estudantes, a partir de todas as entradas em 2005, 2006 e 2007, e focalizou a situação de matrícula em 2014, excluindo os estudantes que ainda não tinham o rendimento final, ou seja, os que ainda estavam cursando, os desistentes e transferidos, restando apenas $70 \%$ de concluintes. Por meio de métodos descritivos e correlacionais (regressão múltipla) os principais resultados apontaram que existe uma relação significativa entre desempenho no vestibular e rendimento acadêmico, já que pontuações mais altas no vestibular estão associadas a rendimentos acadêmicos mais altos. Outra associação positiva do rendimento foi encontrada com relação ao estudante ser branco e da área de humanidades. Em contrapartida, o fato de ser homem, possuir mais bens, ter estudado ensino fundamental e médio em escolas particulares, nota de corte alta na área de conhecimento impactou de forma negativa no rendimento acadêmico. $\mathrm{O}$ estudo aponta como limitação o fato de ter investigado apenas o impacto do rendimento nos concluintes e ressalta a necessidade de verificar as mesmas características também nos estudantes que evadem e em outros contextos institucionais.

Por meio de questionários socioeconômicos aplicados no vestibular da Universidade Federal do Espírito Santo (UFES) e análises de regressão logística e tabelas de contingência, Sales Junior et al. (2016) analisaram uma coorte de ingressantes de 2006 e sua condição de evadido ou formado em 2012, seis anos após o ingresso. Entre os fatores mais associados à evasão destacam-se: o fato de ser cotista; o uso de internet para manter-se informado, em relação ao uso da televisão; não recebimento de assistência estudantil; não participação em estágio e em pesquisa e o desempenho estudantil, por meio de reprovações, de modo que cada ano de reprovação acarreta maior chance de evasão. As condições financeiras da família, como renda familiar, por exemplo, não mostraram impactos na condição de evadir ou permanecer, mas a condição de trabalho de estudantes no momento do vestibular pode derivar em maior evasão. Quanto maior a nota de redação no Enem, menor a evasão.

De modo similar, o estudo de Ferrão \& Almeida (2018) analisou uma coorte de ingressantes em 2015, na Universidade do Minho, em Portugal, e utilizou como medida de persistência os que permaneceram um ano após o ingresso. Por meio de modelagem multinível mostraram que: a) mulheres e indivíduos de até 19 anos persistem mais; b) 
estudantes que não reprovaram na educação básica apresentam maior persistência no primeiro ano do ensino superior; c) a influência da nota de classificação do ingresso foi positiva para a permanência, mas apenas para o nível de significância de 10\%; d) a probabilidade de alunos matriculados em cursos de primeira opção é quase duas vezes maior em relação aos não admitidos em primeira opção, sendo este o principal achado do estudo. Para a condição socioeconômica das famílias, medida pelo nível de escolaridade, os autores não encontraram evidências associadas à persistência estudantil. Para os autores "o efeito da admissão ao curso da primeira opção parece captar a motivação e o compromisso do estudante em concluir o curso com sucesso" (Ferrão; Almeida, 2018, p. 682). O sucesso acadêmico e a persistência são resultados da interação entre aluno-instituição. Portanto o papel dos docentes e os programas que a instituição oferece são determinantes neste processo, e não apenas as características dos estudantes. A escolha do curso e da Universidade, seriam, assim, uma primeira interação aluno-instituição, e de algum modo esta escolha pode estar relacionada com as características socioeconômicas e com o desempenho dos estudantes no processo de admissão.

Adachi (2017) desenvolveu pesquisa com o objetivo de identificar experiências universitárias, utilizando-se de dados institucionais e de entrevistas com estudantes concluintes e não concluintes de um conjunto de cursos na USP, cujo ingresso ocorreu por meio de vestibular nos períodos de 2002, 2003 e 2004. O estudo mostra, uma maior incidência de evasão no início dos cursos, e, principalmente, em cursos cuja nota de ingresso e relação candidato por vagas é mais baixa. E também que as mulheres concluem mais e que a classificação no vestibular e a condição socioeconômica não interferem na conclusão, mas que a idade e ter uma titulação anterior ao ingresso afetam as chances de conclusão.

No contexto da UFFS, Zago, Paixão \& Pereira (2016) conduziram pesquisa utilizando-se da aplicação de questionários a estudantes evadidos. Os resultados apontaram que o fenômeno da evasão de curso está associado à mobilidade intra e interinstitucional e ocorre de forma mais significativa no primeiro ano de graduação, encontrando-se associado também à condição de estudante e trabalhador.

A pesquisa de Fassina (2018) também aplicou questionário a estudantes da UFFS matriculados em 2018/1 e confirma que conciliar trabalho com estudo (estudante 
trabalhador e/ou trabalhador estudante ${ }^{58}$ ) é um dos fatores que dificulta a permanência de estudantes.

Ainda, no contexto da UFFS, o estudo de Reis (2019) investigou o fenômeno de evasão discente, tendo como foco oito cursos de graduação do Campus Erechim, no período entre 2013 a 2017. A autora, por meio de análise de dados institucionais e aplicação de questionários com estudantes evadidos, identificou uma evasão média de $44,4 \%$, com maior tendência nos primeiros semestres cursados. O estudo mostrou ainda que estudantes beneficiários de auxílios socioeconômicos da assistência estudantil e de bolsas acadêmicas (iniciação científica, extensão) evadem menos dos cursos, ou igual aos egressos de escola pública em relação aos de escola particular, sendo maior a evasão entre estudantes pretos e pardos em relação aos brancos e de cursos de licenciaturas, em relação aos de bacharelados. As análises dos dados coletados junto a estudantes evadidos mostraram como principais fatores motivadores da evasão e externos a UFFS, tais como: as dificuldades financeiras e dificuldades com transporte $(35 \%$ e $32 \%$, respectivamente). No âmbito interno, foram identificados fatores relacionados às dificuldades de acesso e aos valores dos auxílios socioeconômicos (20\%) e das bolsas acadêmicas (22\%), além da ausência de moradia estudantil (20\%).

Destaca-se, ainda, o estudo de Vidi (2020) que analisou dados institucionais de ingressantes de 2009 a 2019 na UFFS, em todas as modalidades de ingresso, com o objetivo de caracterizar o fenômeno da evasão. Os resultados apontaram uma evasão média neste período de $51,30 \%$ e os perfis de estudantes evadidos. No perfil de estudantes com o menor índice de evasão $(29,85 \%)$ estão as mulheres na faixa etária entre 17 a 21 anos, brancas, residentes na Região Sul, sem deficiência, egressas de escola pública e com renda de até 1,5 salários mínimos. No perfil de estudantes com o maior índice de evasão $(80,18 \%)$ encontram-se homens e mulheres na faixa etária entre 22 a 38 anos, sem deficiência, residentes na Região Sul, independentemente de raça/cor, egressos de escolas públicas e privadas e de todos os turnos de curso e ingressantes por editais de retorno de aluno graduado e de aluno com abandono, ou seja, que já haviam abandonado um curso na UFFS; e, na modalidade de inscrição de ampla concorrência.

\footnotetext{
${ }^{58}$ Conceito definido por Moraes et al. (2011, p. 210), com base em Romanelli (1994), da seguinte forma: "Estudante/trabalhador: trabalha, no entanto, ainda é dependente financeiramente de seus familiares; Trabalhador/estudante: Além de não depender dos familiares, contribui muitas vezes, para o orçamento doméstico. A família não tem condições financeiras para mantê-lo e/ou não julga a escolarização universitária relevante investimento para o filho. Assim, o estudo depende do investimento, disposição e aspirações pessoais deste último, incentivadas às vezes, pela família”.
} 
Os resultados evidenciam que estudantes cotistas de escola pública e de baixa renda apresentam menores índices de evasão.

Por fim, destacamos um relatório produzido pela Pró-Reitoria de Graduação da UFFS referente ao período de 2010 a 2018/1 e a todas as formas de ingresso, segundo o qual a principal forma de evasão de cursos ocorre por meio do cancelamento de matrícula pela própria IES (quando o estudante não oficializa a sua saída e não renova seu vínculo por meio de rematrícula), seguida da desistência pelo próprio estudante, quando a sua saída é oficializada. A maior evasão concentra-se nos cursos de licenciatura, sendo menor a evasão entre estudantes com apoio estudantil (UFFS, 2018).

\subsection{Principais dimensões de análise de evasão e conclusão de curso superior}

A literatura mostrou, portanto, a utilização de diferentes metodologias e, ao mesmo tempo, a falta de um consenso sobre como avaliar a trajetória dos estudantes após o ingresso. Isso pode estar relacionado aos diferentes dados institucionais acessados pelos pesquisadores e mesmo aos recortes específicos de cada estudo, dada a diversidade do sistema de ensino superior brasileiro (Costa; Picanço, 2020). Ainda assim, destaca-se a importância das pesquisas que se utilizam de dados secundários, sejam institucionais e/ou censitários.

Observa-se que a maioria dos estudos se concentra em análises de coortes de ingressantes e no acompanhamento da situação de sua matrícula após alguns anos, dado ou não o tempo da integralização do curso, ou mesmo, após um ano do ingresso. Constata-se que ainda são raros os estudos que analisem o fenômeno da evasão de uma forma mais completa, ou seja, que consigam captar a evasão não apenas de curso, mas também da IES e mesmo do sistema. O principal foco de análise está concentrado ainda na evasão de curso e em alguns casos da IES. Iniciativas de estudos como de Li \& Chagas (2017) e Lima Junior et al. (2019) conseguiram captar aspectos relacionados à mobilidade dos estudantes.

Conforme Ristoff (2021, p.12), nem toda evasão deve ser compreendida como sinônimo de despreparo, fracasso ou ainda sobre o cifrão economicista de perda de recursos investidos. É necessário olhar também “[...] sob a ótica da mobilidade natural dos indivíduos em contextos sociais que são sempre mais dinâmicos do que as rígidas estruturas educacionais". Para o autor, ainda que envolvam recursos, estes não são 
totalmente desperdiçados, pois estudantes que passam um ou dois anos num curso, ou mesmo os que se formam e não atuam na área de formação, adquiriram algum conhecimento e aprenderam coisas importantes para a vida. Grande parte da evasão ocorre também pelo fato de que as oportunidades profissionais nem sempre são atraentes e valorizadas e/ou satisfatórias.

O autor aponta que o grande estudo sobre a evasão e mobilidade estudantil ainda precisa ser realizado, e que, a partir de 2009, com dados do Inep que consideram o CPF dos estudantes torna-se mais simples a verificação do que acontece com a trajetória de estudantes e dos profissionais já formados, em cada curso, IES, unidade da federação e/ou região do país. Levantamentos como de perfil socioeconômico e cultural dos estudantes, abandono de um curso para outro e/ou para outra IES, mudança de cidade, de uma IES pública para uma privada, desempenho, entre outras questões seriam muito importantes para compreender melhor de que evasão se está falando e orientar os gestores quanto às práticas administrativas e pedagógicas mais assertivas e recomendáveis.

Outro aspecto importante está relacionado ao desempenho positivo de estudantes oriundos de ações afirmativas ou aqueles mais desfavorecidos socioeconomicamente e/ou egressos de escolas públicas em relação aos demais estudantes. A categoria desempenho considera variáveis como de rendimento acadêmico medido por meio de notas antes do ingresso (Enem, vestibular e outros processos seletivos) e/ou durante a graduação e até mesmo na conclusão da graduação (Pedrosa et al., 2006; Baccaro; Shinyashiki, 2014; Rotem; Yair; Shustak, 2020). Esses estudos sinalizam, portanto, a necessidade de as universidades abrirem mais suas portas para jovens de diferentes origens sociais e para ações afirmativas, sem comprometer, portanto o mérito acadêmico. Já, Eller \& Diprete (2018) e Eller (2019) chamam a atenção para as características e o papel institucional em promover o desempenho dos estudantes e o engajamento social, buscando superar lacunas entre brancos e negros, por exemplo, considerando o contexto norte-americano.

Por outro lado, estudos como de Knop (2020), chamam a atenção para as desigualdades horizontais ainda presentes no ensino superior, principalmente em cursos de maior retorno econômico em IES públicas, de modo que estudantes brancos com posição socioeconômica mais vantajosa possuem maiores chances de conclusão. 
A partir da literatura aqui mobilizada, observa-se que ainda existe uma lacuna em relação aos estudos longitudinais e quantitativos sobre desfechos, principalmente sobre a conclusão nos cursos de ensino superior. Conhecer o perfil e demais características de ingressantes que evadem do seu curso de origem e também dos que conseguem obter o sucesso de conclusão se mostram importantes, principalmente nos períodos mais recentes, considerando as políticas como Lei de Cotas, SiSU e Pnaes.

De um modo geral, a literatura mostrou que existe um consenso sobre alguns fatores e características da evasão e conclusão de curso, tais como: a evasão ocorre mais no início dos cursos e é maior em IES privadas; mulheres são mais persistentes; ingressantes em curso de segunda opção, em cursos noturnos, em licenciaturas e aqueles que conciliam trabalho com estudo tem mais dificuldade de permanência; recebimento de apoio financeiro e participação em atividades extracurriculares aumentam as chances de conclusão e diminuem chances de evasão. Por outro lado, algumas variáveis se comportam de modo diferente para os fenômenos de evasão e de conclusão, conforme cada contexto e/ou metodologia utilizada, como por exemplo: condição socioeconômica; rendimento acadêmico e/ou situação de conclusão de curso de estudantes cotistas.

Baseada nesta revisão de literatura pode-se resumir algumas dimensões de análise que se mostraram importantes para compreender as trajetórias dos estudantes após o seu ingresso, ou seja, que podem estar relacionados à situação de evasão ou de conclusão em diferentes cursos e áreas do conhecimento. Destacam-se três dimensões: características socioeconômicas e educacionais; características institucionais e de escolha dos cursos e desempenho e/ou rendimento acadêmico. O Quadro 6 mostra as principais variáveis que são utilizadas nestas dimensões: 
Quadro 6 - Principais dimensões de análise relacionadas à evasão e conclusão de curso superior

\begin{tabular}{|c|c|c|}
\hline Dimensões & Variáveis & Autores \\
\hline $\begin{array}{l}\text { Características } \\
\text { socioeconômicas e } \\
\text { educacionais }\end{array}$ & $\begin{array}{l}\text { Idade no ingresso; sexo; raça/cor; renda } \\
\text { familiar /posse de bens; escolaridade dos } \\
\text { pais; cotista; situação de trabalho antes } \\
\text { e/ou durante a graduação; tipo de escola } \\
\text { cursada no ensino fundamental e/ou } \\
\text { médio; modalidade do ensino médio; } \\
\text { curso preparatório para o ingresso; falar } \\
\text { mais de uma língua; possuir filhos. }\end{array}$ & $\begin{array}{l}\text { Pedrosa et al. (2006); Baccaro \& } \\
\text { Shinyashiki (2014); Zago, Paixão \& } \\
\text { Pereira (2016); Sales Junior et al. } \\
\text { (2016); Li \& Chagas (2017); } \\
\text { Adachi (2017); Ferrão \& Almeida } \\
\text { (2018); Costa (2018); Fassina } \\
\text { (2018); Saccaro, França \& Jacinto } \\
\text { (2019); Costa \& Picanço (2020); } \\
\text { Rotem; Yair \& Shustak (2020); } \\
\text { Knop (2020); Reis (2019); Vidi } \\
\text { (2020); De Paula \& Nogueira } \\
\text { (2020); De Paula (2021) }\end{array}$ \\
\hline $\begin{array}{l}\text { Características } \\
\text { institucionais e de } \\
\text { escolha dos cursos }\end{array}$ & $\begin{array}{l}\text { Apoio Social; } \\
\text { extracurriculares; }\end{array} \begin{array}{r}\text { atividades } \\
\text { financiamento } \\
\text { estudantil; área de estudo /conhecimento; } \\
\text { curso de primeira opção; turno do curso; } \\
\text { grau acadêmico; retorno econômico do } \\
\text { curso; tipo de IES; região da IES; } \\
\text { localização da IES }\end{array}$ & $\begin{array}{l}\text { Alon (2007); Silva Filho et al. } \\
\text { 2007); Baccaro \& Shinyashiki } \\
\text { (2014); Adachi (2017); Costa } \\
\text { (2018); Ferrão \& Almeida (2018); } \\
\text { Eller (2019); Saccaro, França \& } \\
\text { Jacinto (2019); Reis (2019); } \\
\text { Heringer (2020a); Rotem; Yair \& } \\
\text { Shustak (2020); De Paula \& } \\
\text { Nogueira (2020); De paula (2021) }\end{array}$ \\
\hline $\begin{array}{l}\text { Desempenho e/ou } \\
\text { rendimento } \\
\text { acadêmico }\end{array}$ & $\begin{array}{l}\text { Média de notas na graduação; } \\
\text { reprovações no ensino médio e/ou na } \\
\text { graduação; classificação /nota do } \\
\text { Enem/vestibular e/ou outro exame de } \\
\text { ingresso; relação candidato/vaga; número } \\
\text { de créditos cursados }\end{array}$ & $\begin{array}{l}\text { Baccaro \& Shinyashiki (2014); } \\
\text { Sales Junior et al. (2016); Adachi } \\
\text { (2017); Eller \& Diprete (2018); } \\
\text { Rotem; Yair \& Shustak (2020); } \\
\text { Ferrão \& Almeida (2018) }\end{array}$ \\
\hline
\end{tabular}

Fonte: Elaboração própria

Além destas características, destacam-se outras tanto internas às Instituições quanto externas e que muitas vezes podem ser captadas principalmente em estudos mais qualitativos, como por exemplo: a influência de amigos e familiares nas decisões de evasão; a valorização profissional da carreira escolhida; relação estabelecida com professores e colegas e motivação e compromisso com o curso (Morosini et al., 2012; Ambiel, 2015; Ristoff, 2021). A literatura chama atenção principalmente para o papel e responsabilidade das Instituições no sentido de promover ações e políticas para o engajamento estudantil e o senso de pertencimento, no sentido atribuído por Heringer (2020a). Por isso, destaca-se também a importância de estudos de caso que possam mostrar experiências diferenciadas de políticas de ações afirmativas e de permanência 
que buscam promover a equidade, a inclusão e compensar as desigualdades de partida dos estudantes.

\subsection{Considerações e diálogo com o estudo de caso na UFFS}

Nossa revisão de estudos mostra que o caminho percorrido pelos universitários após o acesso no ensino superior é diverso, assim como os fatores que estão relacionados a concluir, a desistir ou mesmo a trocar de curso. Em média, dos que acessam uma graduação, cerca de 50\% obtém o diploma (Fritsch; Jacobus; Vitelli, 2020; De Paula; Nogueira, 2020; Ristoff, 2021). Uma das limitações ainda encontradas na literatura é a dificuldade de acompanhar a trajetória dos estudantes para além da evasão de curso, e mesmo após a sua conclusão. Ristoff (2021) chama atenção para uma ressignificação da evasão, quando ela ocorre por exemplo como uma condição de mobilidade, tendo inclusive o SiSU como uma possibilidade. Para o autor, no tempo em que o estudante permanece na Universidade existe uma condição de aprendizagem e isso significa um ganho e não uma perda.

Os resultados deste estudo apontam que as metodologias para medir a evasão e conclusão são diversas, mas que existe uma tendência para a análise de coortes de ingressantes e a verificação de seu status de matrícula ao longo do tempo. Ressalta-se a importância dos estudos longitudinais e que exploram dados secundários já existentes obtidos diretamente nas IES, quanto aqueles censitários, obtidos em órgãos oficiais como o Inep. Estudos de caso se mostram importantes e se fazem necessários para mostrar principalmente os aspectos institucionais, ou seja, as políticas de acesso e permanência existentes e a forma como estas são implementadas, assim como outras ações e iniciativas que contribuem para promover a afiliação estudantil, a interação aluno-universidade, o engajamento estudantil.

Os estudos sinalizam para a importância de considerar características institucionais e desempenho, para além das características socioeconômicas ao analisar fatores relacionados a evasão e conclusão de curso superior, ou seja, não se trata apenas de responsabilizar os estudantes, a partir de sua condição socioeconômica e demais características pessoais pelo seu sucesso acadêmico (Eller, 2019, Heringer, 2020a).

A partir de um olhar sobre as políticas de inclusão mais recentes no ensino superior, tanto no Brasil quanto em outros contextos, a literatura destaca a importância das ações afirmativas no acesso e na ocupação dos diferentes cursos, considerando as 
mudanças no perfil social, cultural e racial dos estudantes. Em termos de rendimento acadêmico, evasão e mesmo de conclusão de curso, a literatura vem sinalizando para a permanência de estudantes cotistas de modo semelhante aos demais. Ainda assim, há que se considerar a dimensão da desigualdade horizontal ainda presente, principalmente nas escolhas de cursos e instituições, que carregam forte relação com a origem social dos estudantes.

Com relação ao estudo de caso junto à UFFS, ainda que limitado apenas aos ingressantes por meio do Enem, espera-se avançar em relação a algumas lacunas e/ou sugestões mostradas na literatura. Uma primeira questão que se destaca é a relevância de estudar a UFFS, enquanto uma IES que se difere bastante em relação às suas políticas de ações afirmativas. Outra questão é a abrangência deste estudo nas dimensões do acesso, evasão e conclusão dos cursos em todos os campi da UFFS, buscando dialogar também com a literatura da estratificação social, já apresentada em capítulo anterior e com esta literatura mais relacionada com a temática da evasão, permanência e conclusão de curso. Observou-se nos estudos em geral e principalmente na UFFS que a conclusão de curso ainda é pouco explorada, por isso a relevância desta pesquisa no sentido de abranger os desfechos dos estudantes e características relacionadas, seja de evasão ou de conclusão. Por ser considerada uma IES bastante jovem, estudos desta natureza ainda são escassos e fazem necessário, podendo apresentar contribuições para a direção de políticas de permanência.

Ainda que se reconheça a importância do acompanhamento dos estudantes, considerando a mobilidade para outros cursos e a retenção (permanência no curso além do tempo de integralização), a análise dos desfechos dos ingressantes na UFFS considera um acompanhamento longitudinal a partir de coortes de estudantes e sua situação de matrícula após um determinando número de anos, levando em conta apenas a evasão de curso e alguma menção descritiva a respeito da mobilidade por meio de transferências internas e/ou externas na Universidade e a situação de matrícula ativa, que de algum modo, sinaliza possibilidades de retenção.

Entre os aspetos relativos à originalidade da pesquisa na UFFS, destacam-se, ainda, a a utilização de diferentes bases de dados, buscando cruzar informações do Censo, Enem e da própria Instituição e o uso de inferências estatísticas para analisar evasão e conclusão de curso e características associadas. Entre as variáveis a serem utilizadas e que estão disponíveis nos bancos de dados, destaca-se que existe uma 
aproximação com a literatura, com foco nas características socioeconômicas e educacionais dos estudantes, aspectos institucionais e dos cursos e também relacionados ao desempenho.

Entre as variáveis, destacamos a utilização nesta pesquisa de algumas ainda pouco exploradas na literatura, tais como: localização da moradia do estudante (zona urbana e rural); sexo e raça de modo integrado, pois permite, caracterizar melhor as peculiaridades entre homens e mulheres brancos e negros e, variáveis relacionadas ao desempenho acadêmico, antes e após o acesso.

Considera-se que pesquisas empíricas desta natureza avançam no conhecimento do campo sobre desigualdade de oportunidades educacionais em um contexto de expansão, de novas políticas voltadas para o ensino superior e novos estudantes que adentram nas universidades públicas. 


\section{8 \\ Desfecho dos ingressantes: evasão e conclusão de curso}

Esse capítulo busca responder a seguinte questão de pesquisa: "como as características socioeconômicas, gênero, raça, desempenho e aspectos institucionais impactam no "desfecho" (conclusão ou evasão de curso) dos estudantes?

O capítulo encontra-se estruturado em mais quatro partes: inicialmente apresentamos uma caracterização sobre os desfechos de ingressantes na UFFS, na qual mobilizamos dados apenas da base principal da UFFS, considerando o período entre 2010 e 2018; em seguida, selecionamos apenas as coortes de ingressantes de 2010, 2013 e 2014, a partir da junção da base de dados da UFFS e as bases do Inep (Enem e Censup) e realizamos uma análise descritiva das variáveis dependentes e independentes e na sequência apresentamos análises bivariadas entre estas variáveis. Por último, apresentamos os modelos de regressão logística para estimar efeitos das características socioeconômicas, desempenho da nota de redação do Enem, aspectos institucionais e dos cursos nas chances de evasão e conclusão de curso. Por último, tecemos algumas considerações parciais desse capítulo.

\subsection{Caracterização dos desfechos de ingressantes na UFFS: coortes 2010 a 2018}

A situação do desfecho dos ingressantes é analisada a partir da situação de matrícula verificada em 2019/2, momento em que a base de dados foi gerada pela UFFS, por meio do Sistema de Gestão Acadêmica (SGA). Esta seção de análise será desenvolvida apenas com a base de dados da UFFS, considerando todas as coortes de ingressantes (2010 a 2018). Essa escolha para medir possíveis desfechos de ingressantes se aproxima de alguns estudos que também acompanham coortes de ingressantes, como de Sales Junior (2016); Ferrão e Almeida (2018); Costa (2018); Costa e Picanço (2020); De Paula e Nogueira (2020); Knop (2020), ainda que em contextos diferentes e com dados e metodologias específicas. O Sistema SGA/UFFS gera diferentes situações de matrícula, conforme apresentado na Tabela 22 considerando todas as coortes de ingressantes ${ }^{59}$.

\footnotetext{
${ }^{59}$ Ao realizar esta análise, é importante destacar que para as coortes mais recentes, ou seja, para quem ingressou nos anos mais recentes, os percentuais de conclusão são menores e até inexistentes, ao passo que, aumentam os percentuais daqueles com matrícula ainda ativa.
} 
Tabela 22 - Percentual da situação de matrícula em 2019/2 - 2010 a 2018

\begin{tabular}{llllllllll}
\hline Situação de matrícula 2019/2 & $\mathbf{2 0 1 0}$ & $\mathbf{2 0 1 1}$ & $\mathbf{2 0 1 2}$ & $\mathbf{2 0 1 3}$ & $\mathbf{2 0 1 4}$ & $\mathbf{2 0 1 5}$ & $\mathbf{2 0 1 6}$ & $\mathbf{2 0 1 7}$ & $\mathbf{2 0 1 8}$ \\
\hline Desistente & 10,3 & 11,9 & 9,6 & 9,3 & 11,3 & 9,5 & 11,4 & 9,5 & 7,0 \\
Formando & &, 1 & &, 1 &, 2 &, 1 & & & \\
Graduado & 40,5 & 35,8 & 31,9 & 27,3 & 19,2 & 2,9 &, 2 & & \\
Jubilado &, 9 & 1,0 &, 6 & 1,8 & 2,1 & 1,9 & 1,6 &, 2 & \\
Transferido Internamente & 5,9 & 4,9 & 7,4 & 6,4 & 6,2 & 4,4 & 4,2 & 3,3 & 1,9 \\
Transferido &, 3 &, 4 &, 7 &, 5 &, 9 &, 9 &, 7 &, 6 &, 4 \\
Matrícula Ativa & 1,2 & 3,8 & 5,0 & 10,0 & 19,7 & 41,2 & 49,2 & 55,6 & 68,4 \\
Matrícula Cancelada & 40,4 & 41,7 & 44,0 & 43,5 & 38,9 & 37,5 & 31,3 & 28,2 & 18,9 \\
Matrícula Trancada &, 4 &, 5 &, 8 & 1,1 & 1,5 & 1,6 & 1,4 & 2,5 & 3,4 \\
Mobilidade & & & & & &, 1 &, 1 &, 1 & \\
Total & 100 & 100 & 100 & 100 & 100 & 100 & 100 & 100 & 100 \\
\hline
\end{tabular}

Fonte: Elaboração própria a partir de dados do SGA/UFFS

Para caracterizar a trajetória dos ingressantes e seus possíveis desfechos, a situação de matrícula foi agregada em três categorias: "matrícula ativa", "evasão de curso" e "conclusão".

Na situação de "matrícula ativa" foi agregada também à situação de matrícula trancada, por entender que neste caso o estudante permanece com o vínculo institucional, e a situação de mobilidade. A mobilidade se refere aos estudantes que se encontravam estudando temporariamente em outra IES, no Brasil ou em país estrangeiro, mas com vínculo na UFFS. Apenas três estudantes estavam nesta condição, em 2019/2.

A "evasão de curso" foi considerada a partir da agregação das seguintes categorias: jubilamento, cancelamento, desistência e transferências interna e externa. Trata-se, portanto, de uma microevasão, apenas do seu curso de origem e não necessariamente da IES e/ou do sistema (MEC, 1996). Nas duas primeiras situações o desligamento é realizado pela Universidade, a partir do não cumprimento de requisitos exigidos para manter a matrícula ativa. O jubilamento, por exemplo, ocorre quando:

I - o discente não concluir o curso no dobro do tempo de integralização da matriz prevista no Projeto Pedagógico do Curso; II - o discente que reprovar em todos os componentes curriculares nos quais esteja matriculado em três semestres letivos, consecutivos ou não. III - o estudante que reprovar por frequência em todos os componentes curriculares nos quais esteja matriculado em um semestre letivo (UFFS, 2014c, p. 31).

A desistência ocorre quando é realizado o pedido formal por parte do estudante e o cancelamento da matrícula é realizado quando o estudante não procede à renovação da 
matrícula nos prazos previstos no calendário acadêmico. A principal forma de saída dos estudantes dos cursos é por meio da não renovação do vínculo com a Instituição, tendo assim sua matrícula cancelada. No período de 2010 a 2018, o percentual médio acumulado de matrículas canceladas foi de $36,2 \%$. Essa situação pode ser revertida por meio de editais específicos que ofertam vagas para retorno do aluno-abandono. Os ingressantes em 2012 e 2013 registraram um maior número de matrículas canceladas. Já as desistências ocorreram em maior quantidade entre ingressantes nos anos de 2011 e 2016 e totalizaram um percentual médio acumulado de $10 \%$, ao longo dos 9 anos. A condição de jubilamento foi maior para as coortes de ingressantes em 2013, 2014 e 2015 e totalizaram um percentual acumulado de 1,1 ao longo do período.

As transferências de curso, seja para outro curso dentro da própria IES ou para outra IES, embora consideradas para esta análise como evasão de curso, indicam, portanto, uma situação de mobilidade dos estudantes. A transferência interna também é considerada nos casos em que o estudante permanece no mesmo curso, mas solicita apenas a troca de turno ou de campus. A situação de matrícula como "transferência interna" indica a permanência do estudante na Instituição, em 2019/2, mas em curso, turno e/ou campus diferente de seu curso original. Em média, 5\% dos ingressantes entre 2010 e 2018 permaneciam na UFFS com a condição de transferência interna.

A categoria "conclusão" foi formada pela agregação também da situação de Aluno(a) Formando(a), que caracteriza o processo de tramitação burocrática entre a finalização do curso e a formatura.

O Gráfico 34 mostra a situação de matrícula dos ingressantes na UFFS entre 2010 e 2018, considerando as agregações na situação de matrícula, em 2019/2. O maior percentual de conclusão foi o da coorte de ingressantes em 2010. Ao longo dos anos, esse percentual foi diminuindo, tendo um aumento, por exemplo, dos percentuais de evasão e de estudantes em situação de matrícula ativa na UFFS. No período entre 2010 e 2013, a média acumulada de conclusão foi de 33,9\%.

Até 2014, a evasão de curso manteve-se com percentuais semelhantes e acima de $55 \%$. A partir daquele ano ocorreu um decréscimo, o que também se justifica pelo aumento de matrículas ativas e pela não integralização dos cursos, principalmente nos anos mais recentes. As coortes de 2010 a 2013, teriam em 2019/2, em uma situação ideal, a integralização da carga horária de todos os cursos. Em termos relativos, a matrícula ativa dos ingressantes nestas coortes representou em média 5,7\%, o que 
sugere uma condição de possível retenção, tendo as reprovações como uma possível causa. Essa condição de retenção, entendida como a situação de permanência no curso, mesmo tendo esgotado o prazo da integralização (MEC, 1996), precisa ser analisada com cautela, uma vez que os estudantes ainda não concluíram o percurso, e têm alguns caminhos possíveis (evasão ou a conclusão). Autores como Lima Junior et al. (2019), consideram o fenômeno de retenção somente a partir dos que já concluíram o curso.

Scher \& Oliveira (2020), por meio de estudo de caso no Campus Realeza da UFFS sobre as trajetórias de 572 estudantes atendidos pela Assistência Estudantil entre 2010 e 2016, chamaram atenção para o fenômeno da reprovação que pode levar à retenção e mesmo à evasão nos cursos, pois mais da metade dos estudantes atendidos pela assistência estudantil e que permaneciam com a matrícula ativa apresentavam reprovação e, entre os que já evadiram nesse período, a maioria também apresentava reprovação. Desses estudantes atendidos por alguma modalidade de assistência estudantil, 65,6\% haviam concluído o curso, o que indica a contribuição dessa política para a permanência e a conclusão. Sales Junior et al. (2016) também encontraram resultados que indicam uma forte associação entre variáveis de desempenho acadêmico e a forma de saída: quanto maior o número de reprovações, maior é a chance de evasão.

Ao analisar, por exemplo, os ingressantes em 2018 e sua situação de matrícula, no ano seguinte (2019/2), a permanência era de $71,7 \%$, o que indica que cerca de $30 \%$ já não permaneciam no curso de origem, após o primeiro ano de ingresso.

Gráfico 34- Percentual de ingressantes, segundo situação de matrícula em 2019/2 - 2010 a 2018

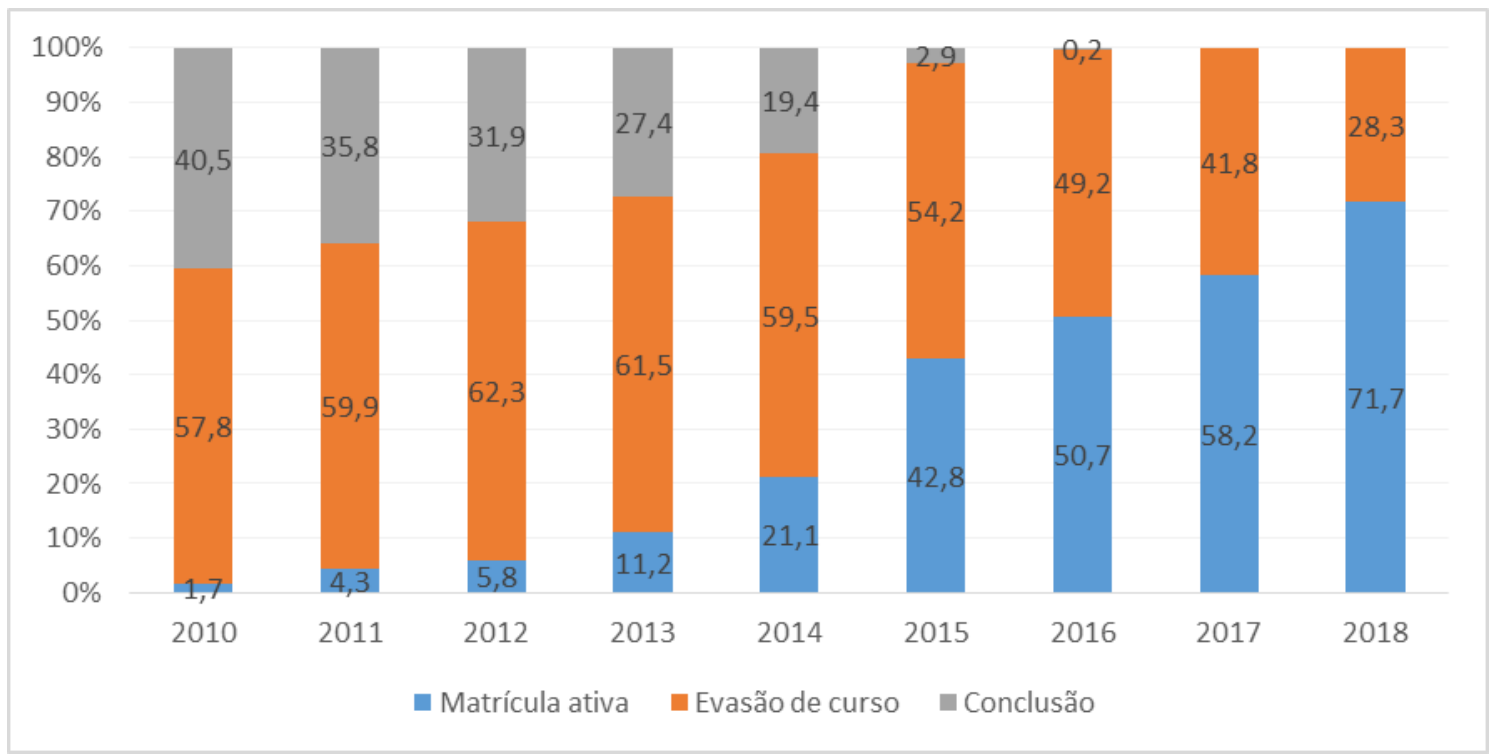

Fonte: Elaboração própria a partir de dados do SGA/UFFS 
Ao verificar a evasão, segundo as áreas de conhecimento (Gráfico 35), observase que ao longo do tempo os ingressantes nas áreas de saúde e agricultura evadiram menos. Já nas áreas de Computação e Educação a evasão foi maior, principalmente até 2014. Essa tendência de evasão maior na área de Computação e menor nas áreas de Saúde e Agricultura também foi encontrada em estudo em nível nacional realizado por Silva Filho et al. (2007). Ao desagregar os dados, mais detalhado por tipo de evasão, observou-se que, em termos relativos, a área da Computação, principalmente até 2014, registrou os maiores percentuais de transferências (interna ou externa), o que indica uma condição de mobilidade, ou seja, uma parte deste estudantes evadiram apenas deste curso, mas permaneceram na UFFS em outro curso e/ou fizeram transferência para outra IES. No caso da área da Educação, que abarca todas as licenciaturas, as pesquisas em geral têm mostrado uma tendência de maior evasão (Adachi, 2017; Costa, 2018, De Paula, 2021). Ao verificar o detalhamento da condição de matrícula por cursos, é necessário ponderar, por exemplo, que o curso de Pedagogia é bastante particular, pois está entre os cursos da UFFS com maiores percentuais de conclusão. Trata-se do único curso de licencitura que se manteve com a oferta em dois turnos (matutino e noturno).

Para a maioria das áreas de conhecimento, as coortes de ingressantes a partir de 2014 tiveram quedas nos percentuais de evasão, principalmente a área de Computação. Ao levar em conta que, a partir de 2014, passamos a ter cursos com prazos de integralização ainda vigentes, não se pode concluir que a evasão necessariamente diminuiu, uma vez que passamos a ter mais estudantes cuja matrícula ainda estava ativa.

Gráfico 35 - Percentuais de ingressantes com situação de evasão de curso, em 2019/2, segundo áreas de conhecimento - 2010 a 2018

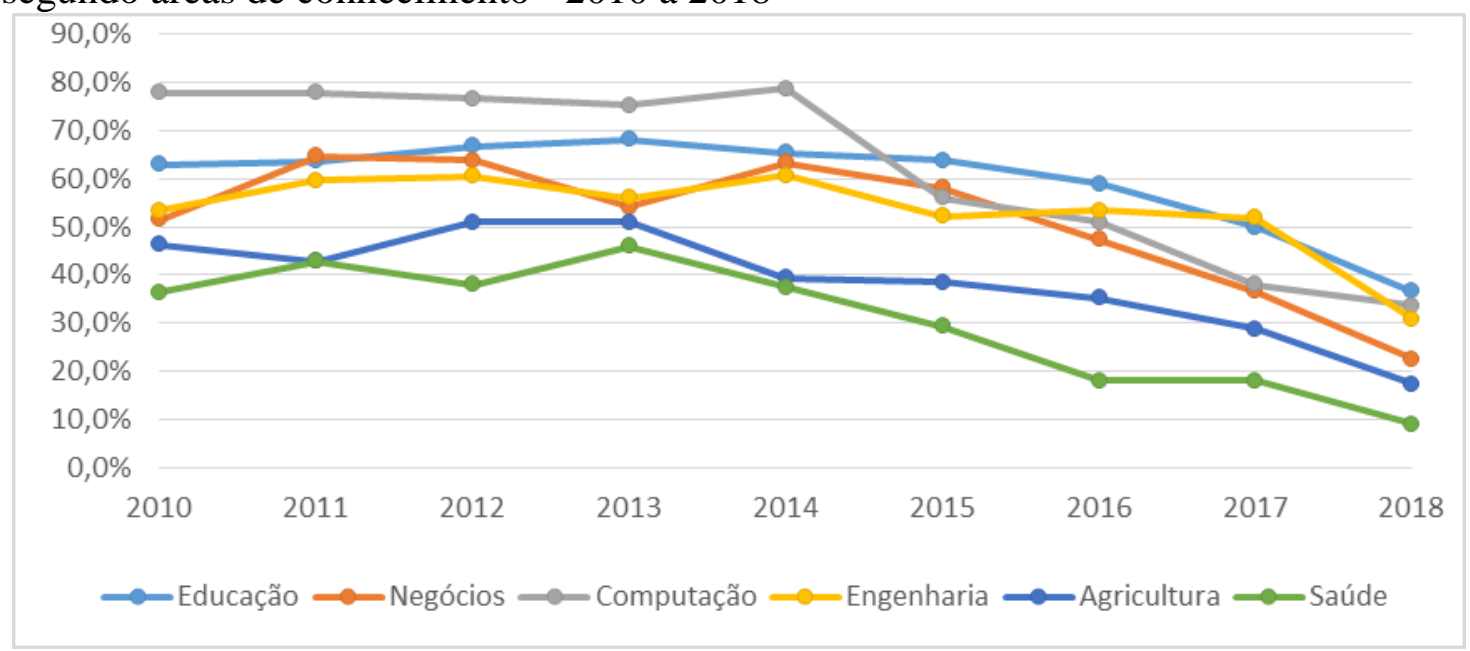

Fonte: Elaboração própria, conforme dados do SGA/UFFS 
Os Gráficos 36, 37 e 38 mostram os desfechos dos estudantes segundo gênero e raça/cor. Ao verificar a situação de matrícula ativa, em relação às primeiras coortes de ingresso, ainda que as diferenças entre os grupos sejam pequenas, observa-se que homens negros tendem a prolongar mais a sua estadia na universidade, o que pode indicar situações de reprovações e/ou trancamento nos cursos. Já, para as coortes mais recentes, em que a situação de matrícula ativa indica a permanência nos cursos, as mulheres brancas se sobressaem em relação aos demais grupos.

Gráfico 36 - Percentuais de ingressantes com matrícula ativa, em 2019/2, segundo sexo_raça - 2010 a 2018

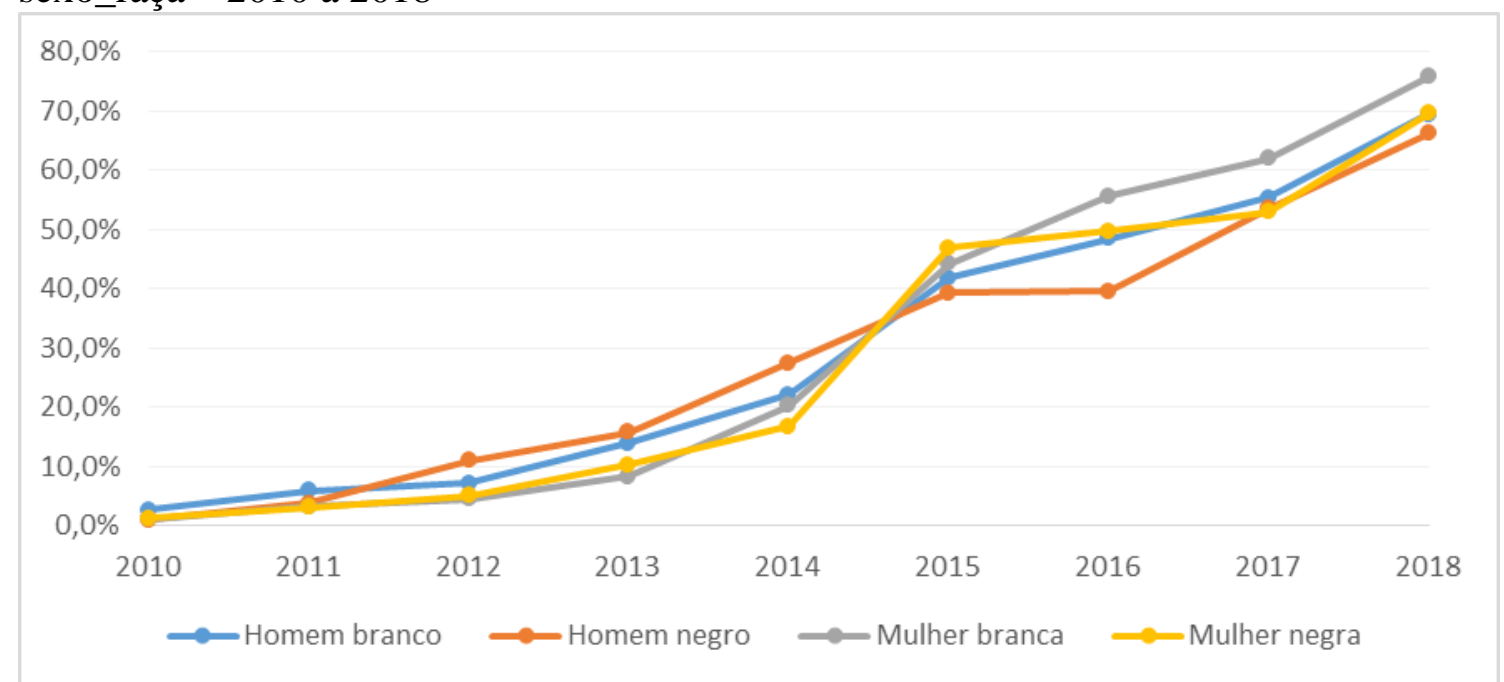

Fonte: Elaboração própria a partir de dados do SGA/UFFS

No que se refere à evasão de curso, mesmo com dados são próximos entre os grupos, percebe-se um hiato maior entre homens negros em relação às mulheres brancas, para a maioria das coortes. 
Gráfico 37 - Percentuais de ingressantes com situação de evasão de curso, em 2019/2, segundo sexo_raça - 2010 a 2018

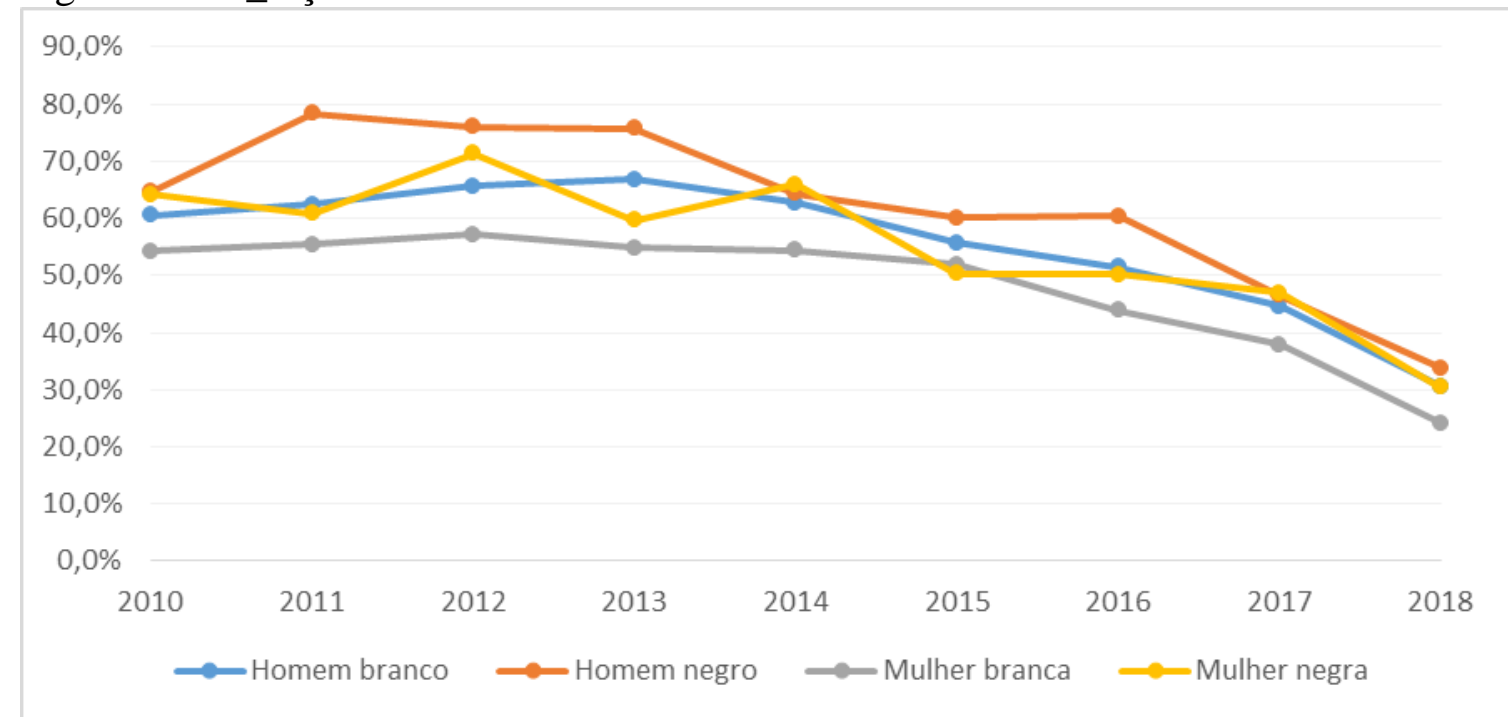

Fonte: Elaboração própria a partir de dados do SGA/UFFS

Essa diferença entre mulheres brancas e homens negros é ainda mais pronunciada no desfecho de conclusão dos cursos. Mulheres negras e homens brancos possuem percentuais mais próximos entre si. Na coorte de ingressantes em 2016, houve apenas um percentual baixo de conclusão de curso entre as mulheres brancas.

Gráfico 38 - Percentual de ingressantes com conclusão de curso, em 2019/2, segundo sexo_raça - 2010 a 2016

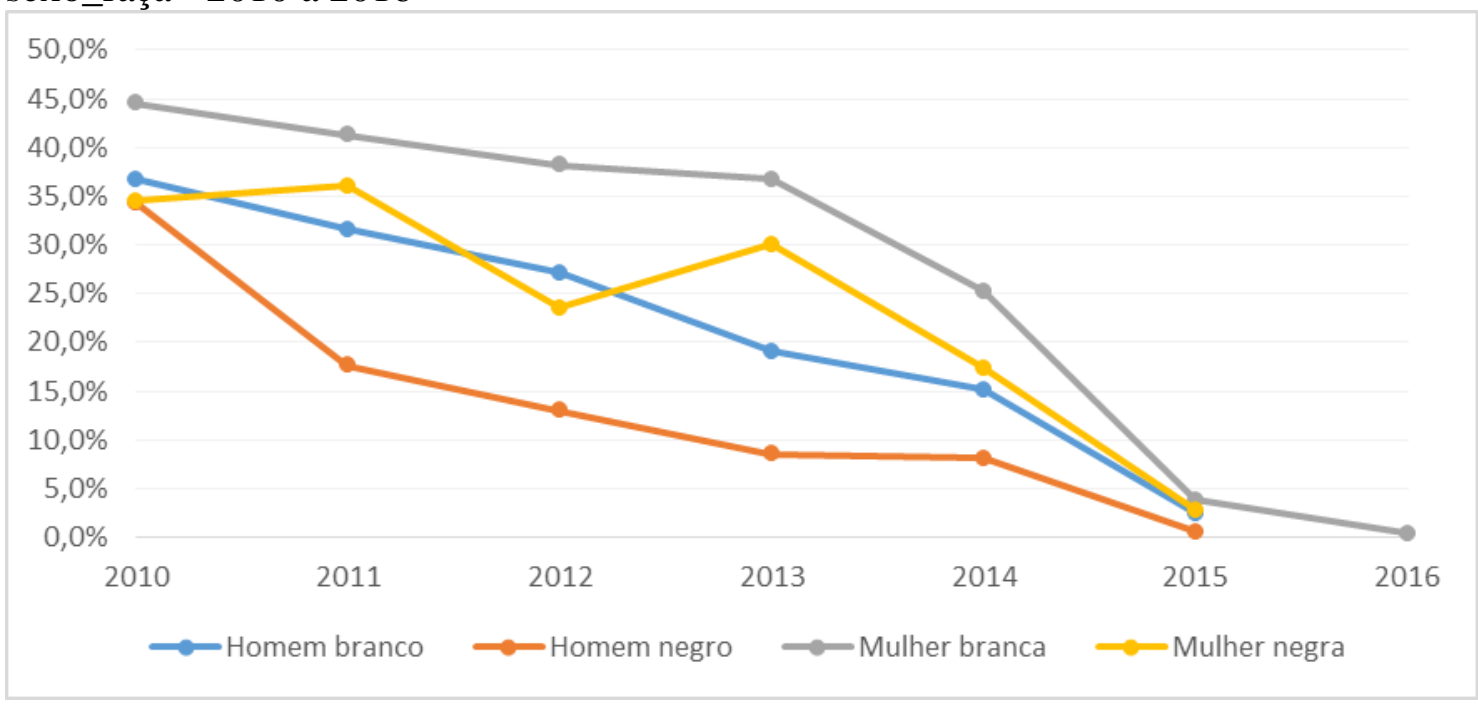

Fonte: Elaboração própria a partir de dados do SGA/UFFS

De um modo geral, embora homens negros tenham se aproximado ao longo do tempo dos homens brancos no acesso aos diferentes cursos, como também ocorreu com as mulheres negras em relação às brancas, os dados sinalizam que as trajetórias, 
principalmente de conclusão ainda parecem ser distintas entre os grupos de sexo e cor. Ou seja, os homens brancos concluem mais os cursos que os homens negros e mulheres brancas concluem mais que mulheres negras, ainda que essas diferenças sejam pequenas em algumas coortes. Isso sinaliza que as políticas voltadas à permanência estudantil precisam ter uma atenção especial em relação ao grupo de estudantes negros, para que possa haver um aumento na igualdade de oportunidades de obtenção de um diploma.

Portanto, no contexto da UFFS, pode-se dizer que houve redução na desigualdade racial em termos de acesso aos diferentes cursos, principalmente a partir da Lei de Cotas, mas que esta desigualdade parece se manter mais ativa no desfecho de conclusão. A desigualdade de gênero em termos de acesso se faz presente principalmente em cursos de maior retorno econômico. Na conclusão de curso, são as mulheres e principalmente brancas que atingem melhores resultados. Raça e gênero se apresentam como variáveis importantes para ser testadas nos modelos de regressão logística para compreender se estatisticamente essas diferenças são significativas.

\subsection{Análise descritiva de variáveis dependentes e independentes}

Nesta seção analisamos os desfechos agregados em termos de evasão ou de conclusão de curso. Foi realizada a junção dos três bancos de dados (SGA/UFFS, Enem/Inep e CenSup/Inep) e três coortes de ingressantes na UFFS, em 2010, 2013 e 2014. A partir da integração das bases foi considerado como referência de ingressantes em cada coorte, o número da frequência das variáveis dependentes, ainda que, nos testes de regressão, são eliminados automaticamente os ingressantes que possuem missings nas variáveis independentes.

As Tabelas 23 e 24 apresentam as variáveis dependentes de evasão e de conclusão, com suas respectivas frequências. Observa-se que a coorte de ingressantes de 2010 apresentou maiores percentuais de conclusão ${ }^{60}$, em relação às coortes mais recentes de 2013 e 2014, o que pode estar associado à maior retenção dos estudantes, além do período de integralização do curso ser mais curto nestas últimas coortes.

\footnotetext{
${ }^{60}$ Comparar essas coortes entre si exige cautela, uma vez que quanto mais antiga for a coorte de ingresso, maiores são as possibilidades de integralização dos cursos.
} 
Tabela 23 - Descrição da variável dependente de evasão - coortes 2010, 2013 e 2014

\begin{tabular}{lllllll}
\hline \multirow{2}{*}{ Desfecho em 2019/2 } & \multicolumn{2}{c}{$\mathbf{2 0 1 0}$} & $\mathbf{2 0 1 3}$ & \multicolumn{2}{c}{$\mathbf{2 0 1 4}$} \\
\cline { 2 - 7 } & Frequência & \% & Frequência & \% & Frequência & \% \\
\hline Não evadiu (0) & 773 & 43,3 & 686 & 39,2 & 711 & 41,5 \\
Evadiu (1) & 1014 & 56,7 & 1066 & 60,8 & 1002 & 58,5 \\
Total & 1787 & 100 & 1752 & 100 & 1713 & 100
\end{tabular}

Fonte: Elaboração própria a partir das bases de dados do SGA/UFFS e Enem

Tabela 24 - Descrição da variável dependente de conclusão - coortes 2010, 2013 e 2014

\begin{tabular}{lllllll}
\hline \multirow{2}{*}{ Desfecho em 2019/2 } & \multicolumn{2}{c}{$\mathbf{2 0 1 0}$} & \multicolumn{2}{c}{$\mathbf{2 0 1 3}$} & \multicolumn{2}{c}{$\mathbf{2 0 1 4}$} \\
\cline { 2 - 7 } & Frequência & \% & Frequência & \% & Frequência & \% \\
\hline Não concluiu (0) & 1045 & 58,5 & 1259 & 71,9 & 1369 & 79,9 \\
Concluiu (1) & 742 & 41,5 & 493 & 28,1 & 344 & 20,1 \\
Total & 1787 & 100 & 1752 & 100 & 1713 & 100 \\
\hline
\end{tabular}

Fonte: Elaboração própria a partir das bases de dados do SGA/UFFS e Enem

A Tabela 25 apresenta as variáveis independentes, com suas respectivas frequências, e como foram organizadas suas categorias para serem utilizadas nos modelos de regressão logística. Os dados mostram que o perfil socioeconômico dos estudantes teve alguma alteração a partir de 2013 e 2014, ainda que, em níveis mais modestos, quando comparado com o ano de 2010: ocorreu uma diminuição de mulheres brancas e um aumento de estudantes negros, tanto de homens, quanto de mulheres; aumento de estudantes do sexo masculino; a renda teve um aumento, passando para um pouco mais de $50 \%$ com renda familiar acima de cinco salários-mínimos; aumentou o percentual de ingressantes mais jovens e cujas mães possuem mais escolaridade; diminuiu o percentual de estudantes que apresentavam situação de trabalho durante o ensino médio e a nota da redação no Enem diminuiu para os ingressantes nas coortes de 2013 e 2014. A origem de estudantes de escola pública manteve-se praticamente estável, acima de $93 \%$.

Em termos institucionais houve uma diminuição na participação de estudantes em atividades extracurriculares e no recebimento de apoio social; aumentou o acesso de estudantes em cursos de alto e médio retorno econômico e houve uma diminuição de ingressantes na área de educação e um aumento na área de saúde, o que se justifica pela criação do Campus Passo Fundo que passou a ofertar o curso de Medicina. 
Tabela 25 - Descrição das variáveis independentes - coortes 2010, 2013 e 2014

\begin{tabular}{|c|c|c|c|c|c|c|}
\hline \multicolumn{7}{|c|}{ Características socioeconômicas, gênero e raça e desempenho no Enem } \\
\hline \multirow[b]{2}{*}{ Sexo_raça } & \multicolumn{2}{|c|}{2010} & \multicolumn{2}{|c|}{2013} & \multicolumn{2}{|l|}{2014} \\
\hline & Frequência & $\%$ & Frequência & $\%$ & Frequência & $\%$ \\
\hline Mulher branca (cat. de referência) & 927 & 53,6 & 810 & 47,1 & 760 & 46,8 \\
\hline Mulher negra & 141 & 8,2 & 198 & 11,5 & 165 & 10,2 \\
\hline Homem branco & 572 & 33,1 & 567 & 33,0 & 548 & 33,7 \\
\hline Homem negro & 90 & 5,2 & 145 & 8,4 & 151 & 9,3 \\
\hline Total & 1730 & 100 & 1720 & 100 & 1624 & 100 \\
\hline Missing & 57 & & 32 & & 89 & \\
\hline \multicolumn{7}{|l|}{ Sexo } \\
\hline Feminino (cat. de referência) & 1102 & 61,7 & 1029 & 58,7 & 973 & 56,8 \\
\hline Masculino & 685 & 38,3 & 723 & 41,3 & 740 & 43,2 \\
\hline Total & 1787 & 100 & 1752 & 100 & 1713 & 100 \\
\hline \multicolumn{7}{|l|}{ Raça/cor } \\
\hline $\begin{array}{l}\text { Brancos e amarelos (cat. de } \\
\text { referência) }\end{array}$ & 1516 & 86,7 & 1392 & 79,9 & 1323 & 80,4 \\
\hline Pretos, pardos e indígenas & 233 & 13,3 & 350 & 20,1 & 323 & 19,6 \\
\hline Total & 1749 & 100 & 1742 & 100 & 1646 & 100 \\
\hline Missing & 38 & & 10 & & 67 & \\
\hline \multicolumn{7}{|l|}{ Faixa etária } \\
\hline Até 20 anos (cat. de referência) & 992 & 55,5 & 985 & 56,2 & 1055 & 61,6 \\
\hline De 21 a 24 anos & 342 & 19,1 & 352 & 20,1 & 298 & 17,4 \\
\hline De 25 anos ou mais & 453 & 25,3 & 415 & 23,7 & 359 & 21,0 \\
\hline Total & 1787 & 100 & 1752 & 100 & 1712 & 100 \\
\hline Missing & & & & & 1 & \\
\hline \multicolumn{7}{|l|}{ Renda familiar } \\
\hline $\begin{array}{l}\text { Nenhuma renda até } 2 \text { SM (cat. de } \\
\text { referência) }\end{array}$ & 689 & 43,8 & 386 & 24,1 & 372 & 24,4 \\
\hline Mais de 2 até $5 \mathrm{SM}$ & 691 & 43,9 & 321 & 20,1 & 366 & 24,0 \\
\hline Acima de $5 \mathrm{SM}$ & 193 & 12,3 & 893 & 55,8 & 785 & 51,5 \\
\hline Total & 1573 & 100 & 1600 & 100 & 1523 & 100 \\
\hline Missing & 214 & 12 & 152 & & 190 & \\
\hline \multicolumn{7}{|l|}{ Localização da moradia } \\
\hline Rural (cat. de referência) & 436 & 25,5 & 464 & 26,5 & 436 & 25,5 \\
\hline Urbana & 1277 & 74,5 & 1288 & 73,5 & 1277 & 74,5 \\
\hline Total & 1713 & 100 & 1752 & 100 & 1713 & 100 \\
\hline \multicolumn{7}{|l|}{ Escolaridade da mãe } \\
\hline Até $4^{a}$ série (cat. de referência) & 665 & 42,0 & 621 & 35,4 & 551 & 32,2 \\
\hline Ensino Fundamental Completo & 397 & 25,1 & 438 & 25,0 & 441 & 25,7 \\
\hline Ensino Médio ou superior & 520 & 32,9 & 693 & 39,6 & 721 & 42,1 \\
\hline Total & 1582 & 100 & 1752 & 100 & 1713 & 100 \\
\hline Missing & 205 & & & & & \\
\hline \multicolumn{7}{|c|}{ Condição de trabalho do estudante no ensino médio } \\
\hline Sim (cat. de referência) & 1103 & 71,3 & 849 & 52,7 & 969 & 56,6 \\
\hline Não & 445 & 28,7 & 761 & 47,3 & 744 & 43,4 \\
\hline Total & 1548 & 100 & 1610 & 100 & 1713 & 100 \\
\hline Missing & 239 & & & & & \\
\hline
\end{tabular}




\begin{tabular}{|c|c|c|c|c|c|c|}
\hline \multicolumn{7}{|l|}{ Escola pública } \\
\hline Estudou na EP (cat. de referência) & 1702 & 95,2 & 1640 & 93,6 & 1596 & 93,2 \\
\hline Não estudou na EP & 85 & 4,8 & 112 & 6,4 & 117 & 6,8 \\
\hline Total & 1787 & 100 & 1752 & 100 & 1713 & 100 \\
\hline \multicolumn{7}{|l|}{ Nota da redação no Enem ${ }^{61}$} \\
\hline Até 400 & 55 & 3,1 & 235 & 13,4 & 133 & 7,8 \\
\hline Acima de 400 até 600 & 569 & 31,8 & 897 & 51,2 & 882 & 51,5 \\
\hline Acima de 600 até 800 & 965 & 54,0 & 521 & 29,8 & 605 & 35,3 \\
\hline Acima de 800 até 1000 & 198 & 11,1 & 98 & 5,6 & 93 & 5,4 \\
\hline Total & 1787 & 100 & 1751 & 100 & 1713 & 100 \\
\hline Missing & & & 1 & & & \\
\hline
\end{tabular}

\section{Características institucionais e dos cursos}

2010

2013

2014

\section{Campus}

Chapecó (cat. de referência)

Frequência \%

Frequência \%

Frequência \%

Laranjeiras do Sul

729

230

$40,8 \quad 656$

$37,4 \quad 640$

37,4

Realeza

249

$12,9 \quad 211$

$12,0 \quad 219$

12,8

Cerro Largo

$13,9 \quad 214$

$12,2 \quad 217$

12,7

Erechim

218

$12,2 \quad 276$

$15,8 \quad 282$

16,5

Passo Fundo

361

$20,2 \quad 355$

$20,3 \quad 317$

18,5

Total

1787

$100 \quad 1752$

$2,3 \quad 38$

2,2

Área de conhecimento

Educação (cat. de referência) 960

162

$53,7 \quad 872$

$100 \quad 1713$

100

Negócios, administração, direito e 162

ciências sociais

Computação e Tecnologias da 93

Informação e Comunicação (TIC)

Engenharia, produção e construção 220

$93-5,2$

Agricultura, Silvicultura, Pesca e 276

Veterinária

Saúde e bem-estar

76
1787

Total

$9,1 \quad 173$

$49,8 \quad 838$

48,9

Retorno econômico

Alto retorno (cat. de referência)

496

$5,2 \quad 88$

$9,9 \quad 181$

10,6

Médio retorno

887

404

$12,3 \quad 226$

$5,0 \quad 93$

5,4

Baixo retorno

1787

$15,4 \quad 276$

$12,9 \quad 211$

12,3

Total

$4,3 \quad 117$

$15,8 \quad 275$

16,1

\section{Turno do curso}

Integral (cat. de referência)

672

$100 \quad 1752$

$6,7 \quad 115$

6,7

Noturno

861

$27,8 \quad 552$

$100 \quad 1713$

100

Matutino ou vespertino

Total

254

$49,6 \quad 906$

$31,5 \quad 543$

31,7

$22,6 \quad 294$

$51,7 \quad 896$

52,3

$100 \quad 1752$

$16,8 \quad 274$

16,0

$100 \quad 1713$

100

Grau acadêmico

Bacharelado (cat. de referência)

$\begin{array}{llllll}827 & 46,3 & 880 & 50,2 & 875 & 51,1 \\ 960 & 53,7 & 872 & 49,8 & 838 & 48,9 \\ 1787 & 100 & 1752 & 100 & 1713 & 100\end{array}$

Total

$37,6 \quad 744$

$42,5 \quad 730$

42, 6

$48,2 \quad 784$

$44,7 \quad 739$

43,1

$14,2 \quad 224$

$12,8 \quad 244$

14,2

1787

$100 \quad 1752$

$100 \quad 1713$

100

$100 \quad 1752$

100

${ }^{61}$ Nos modelos de regressão logística essa variável foi usada de modo numérico e não categórico. 


\begin{tabular}{lllllll} 
Apoio Social $^{6 \mathbf{2}}$ & & & & & & \\
Não (cat. de referência) & 856 & 48,5 & 1163 & 64,9 & 1000 & 58,2 \\
Sim & 908 & 51,5 & 628 & 35,1 & 719 & 41,8 \\
Total & 1764 & 100 & 1791 & 100 & 1719 & 100 \\
$\begin{array}{l}\text { Missing } \\
\text { Atividade extracurricular }\end{array}$ & 23 & & & & & \\
Não (cat. de referência) & 1005 & 57,0 & 1218 & 68,0 & 1105 & 64,3 \\
Sim & 759 & 43,0 & 573 & 32,0 & 614 & 35,7 \\
Total & 1764 & 100 & 1791 & 100 & 1719 & 100 \\
Missing & 23 & & & & & \\
\hline
\end{tabular}

Fonte: Elaboração própria a partir das bases de dados do SGA/UFFS; Enem e CenSUP

Buscou-se também verificar como se distribui a característica renda familiar entre os diferentes grupos em termos de sexo_raça e nas diferentes coortes. Observou-se que em todos os grupos ocorreu um aumento de renda familiar a partir de 2013 (Tabela 26). Os homens brancos possuem percentuais mais altos de renda familiar e as mulheres negras percentuais menores, principalmente em 2010 e 2013. Ao analisar a quantidade de pessoas na família, cerca de $50 \%$ apresentavam até três pessoas e cerca de $50 \%$, quatro ou mais pessoas no grupo familiar.

Tabela 26 - Renda familiar dos ingressantes, segundo sexo e raça/cor - 2010, 2013 e 2014

\begin{tabular}{lllll}
\hline Sexo_raça & $\begin{array}{l}\text { Nenhuma renda até 2 } \\
\text { SM }\end{array}$ & Mais de 2 até 5 SM & Acima de 5 SM & Total \\
\hline $\mathbf{2 0 1 0}$ & & & & \\
Mulher branca & 47,7 & 41,3 & 11,0 & 100 \\
Mulher negra & 56,7 & 35,0 & 8,3 & 100 \\
Homem branco & 33,3 & 50,2 & 16,5 & 100 \\
Homem negro & 45,0 & 48,8 & 6,3 & 100 \\
$\mathbf{2 0 1 3}$ & & & 54,7 & \\
Mulher branca & 23,3 & 22,1 & 48,9 & 100 \\
Mulher negra & 27,4 & 23,7 & 59,6 & 100 \\
Homem branco & 23,9 & 16,5 & 59,0 & 100 \\
Homem negro & 23,7 & 17,3 & & 100 \\
2014 & & 49,1 & 100 \\
Mulher branca & 25,7 & 25,1 & 48,0 & 100 \\
Mulher negra & 24,3 & 27,6 & 56,4 & 100 \\
Homem branco & 23,1 & 20,5 & 48,5 & 100 \\
Homem negro & 24,6 & 26,9 & & \\
\hline
\end{tabular}

Fonte: Elaboração própria a partir das bases de dados do SGA/UFFS e Enem.

${ }^{62}$ Como esta variável foi retirada da base do CenSup o total está se referindo aos ingressantes da UFFS localizados nesta base. O mesmo ocorre para a variável Atividade Extracurricular. 


\subsection{Análises bivariadas entre variáveis dependentes e independentes}

Com as coortes de ingressantes em 2010, 2013 e 2014 realizamos inicialmente análises bivariadas, buscando estabelecer possíveis relações entre a evasão e conclusão de curso (variáveis dependentes), características socioeconômicas, gênero e raça dos ingressantes e aspectos institucionais e dos cursos (variáveis independentes), conforme mostra a Tabela 27. Com relação às variáveis "sexo" e "raça", analisadas conjuntamente e de forma separada, os dados sinalizam para diferenças nos desfechos: de um modo geral as mulheres tendem a concluir mais em relação aos homens e; entre os homens, os negros apresentam situação de maior desvantagem em termos de evasão e conclusão.

A idade de ingresso dos estudantes na graduação também mostra influência nos desfechos: aqueles que estão na faixa etária mais jovem tendem a evadir menos e a concluir mais os cursos, em relação às demais faixas etárias.

Ao cruzar a renda familiar com o desfecho dos estudantes, observou-se que os percentuais são bastante próximos nas três coortes, com uma diferença maior na coorte de 2010. Nesta coorte, em que a maioria dos ingressantes tinha uma renda familiar de até 5 s.m. esse grupo era quem evadia menos e concluía mais os cursos. A partir de 2013, quando os ingressantes passaram a ter uma renda mais homogênea (cerca de 50\% dos estudantes com renda familiar de até 5 s.m. e pouco mais de $50 \%$ com renda familiar acima de 5 s.m.), os percentuais de conclusão e de evasão ficaram mais próximos, com pequenas diferenças entre os grupos. A dimensão de renda familiar parece não influenciar diretamente no desfecho.

A escolaridade da mãe também não apresenta diferenças na evasão ou na conclusão de curso. A situação de trabalho durante o ensino médio e a condição de desfecho apresentou variações, conforme a coorte de ingresso. Em 2010, por exemplo, o percentual de evasão foi maior entre os que trabalharam antes do ingresso na UFFS e o de conclusão foi menor. Nas demais coortes ocorreu o contrário, com percentuais maiores de conclusão e menores de evasão de curso entre os que trabalharam.

O fato de ter estudado em escola pública no ensino médio não apresenta diferença significativa em termos de evasão e de conclusão nos cursos. A localização da moradia indica uma diferença maior tanto na evasão quanto na conclusão de curso: os ingressantes oriundos da área rural apresentam menor evasão e maior conclusão em relação aos da zona urbana. 
No que se refere às características institucionais e desfecho de evasão e conclusão (Tabela 28), a variável campus indica diferenças na evasão e conclusão dos cursos: o Campus Laranjeiras do Sul apresenta o maior percentual de evasão e o menor de conclusão; o Campus Passo Fundo apresentou, para a coorte de 2013, o percentual mais alto de conclusão de curso, em relação aos demais campi e o menor percentual de evasão. Em seguida, aparecem os campi Realeza e Cerro Largo também com percentuais menores de evasão e maiores de conclusão, em relação aos demais.

Conforme já verificado, entre as áreas de conhecimento existem diferenças, principalmente para as de Saúde e de Agricultura que são mais persistentes, com maiores percentuais de conclusão e menores percentuais de evasão. Já a área da Computação apresenta os menores percentuais de conclusão e os maiores de evasão, em relação às demais. No que se refere à inserção dos ingressantes em cursos de maior e menor retorno econômico, as diferenças são pequenas na evasão e conclusão de curso. O turno dos cursos mostra uma diferença maior: ingressantes em turno matutino ou vespertino apresentam maior evasão em relação ao turno integral. E o turno noturno apresenta o menor percentual de conclusão.

Quanto ao recebimento de apoio social e à participação em atividades extracurriculares, os ingressantes que não recebem ou não participam tendem a ter percentuais maiores de evasão e a concluir menos os cursos.

Tabela 27 - Análise bivariada entre variáveis socioeconômicas, de gênero e raça e variáveis de desfecho ${ }^{63}$ - 2010, 2013 e 2014

\begin{tabular}{lllllll}
\hline \multicolumn{1}{c}{ Sexo_raça } & \multicolumn{3}{c}{ Evadiu } & \multicolumn{3}{c}{ Concluiu } \\
\cline { 2 - 7 } & $\mathbf{2 0 1 0}$ & $\mathbf{2 0 1 3}$ & $\mathbf{2 0 1 4}$ & $\mathbf{2 0 1 0}$ & $\mathbf{2 0 1 3}$ & $\mathbf{2 0 1 4}$ \\
\hline Mulher branca & 54,4 & 54,0 & 53,6 & 45,7 & 37,8 & 26,2 \\
Mulher negra & 63,1 & 59,1 & 64,8 & 35,5 & 30,8 & 18,2 \\
Homem branco & 59,8 & 66,5 & 61,5 & 37,4 & 19,9 & 15,7 \\
Homem negro & 62,2 & 75,9 & 63,6 & 36,7 & 7,6 & 8,6 \\
Sexo & & & & & & \\
Feminino & 54,4 & 55,4 & 55,4 & 44,4 & 35,9 & 24,9 \\
Masculino & 60,6 & 68,6 & 62,6 & 36,9 & 17,2 & 13,8 \\
Raça/cor & & & & & & \\
Brancos e amarelos & 55,8 & 59,5 & 57,0 & 42,4 & 30,1 & 21,7 \\
Pretos, pardos e & 62,7 & 65,7 & 64,7 & 36,1 & 20,9 & 13,3 \\
indígenas & & & & & &
\end{tabular}

Faixa etária

${ }^{63} \mathrm{O}$ total de $100 \%$ se completa entre o percentual que "evadiu", mostrado na tabela, com quem "não evadiu", que não foi mostrado na tabela. Por exemplo, em 2010, se 53,6\% das mulheres brancas evadiram, o restante $(46,4 \%)$ não evadiu, ou seja, continua com a matrícula ativa ou concluiu o curso. 


\begin{tabular}{|c|c|c|c|c|c|c|}
\hline Até 20 anos & 47,3 & 53,2 & 52,2 & 51,3 & 35,7 & 24,6 \\
\hline De 21 a 24 anos & 64,3 & 65,6 & 65,4 & 33,9 & 23,3 & 12,4 \\
\hline De 25 anos ou mais & 71,7 & 74,9 & 71,3 & 25,8 & 14,2 & 12,8 \\
\hline \multicolumn{7}{|l|}{ Escolaridade da mãe } \\
\hline Até $4^{\mathrm{a}}$ série & 58,6 & 62,3 & 60,1 & 40,2 & 28,0 & 21,8 \\
\hline Ensino Fundamental & 52,1 & 56,8 & 60,1 & 45,8 & 31,1 & 20,4 \\
\hline $\begin{array}{l}\text { Ensino Médio ou } \\
\text { Superior } \\
\text { Renda familiar }\end{array}$ & 56,0 & 62,0 & 56,3 & 42,9 & 26,4 & 18,6 \\
\hline Nenhuma até 2 s.m. & 53,4 & 59,8 & 57,3 & 45,3 & 26,4 & 21,0 \\
\hline Mais de 2 até 5 s.m. & 57,0 & 60,1 & 62,0 & 41,2 & 28,7 & 17,8 \\
\hline Acima de 5 s.m. & 62,7 & 61,7 & 58,0 & 36,3 & 28,7 & 21,5 \\
\hline \multicolumn{7}{|c|}{ Situação de trabalho no ensino médio } \\
\hline Sim & 61,4 & 54,3 & 53,0 & 37,2 & 34,5 & 22,1 \\
\hline Não & 43,4 & 66,6 & 65,6 & 55,1 & 22,9 & 17,5 \\
\hline \multicolumn{7}{|c|}{ Localização da moradia } \\
\hline Rural & 40,7 & 48,5 & 47,7 & 57,8 & 41,4 & 29,1 \\
\hline Urbana & 62,4 & 65,3 & 62,2 & 36,3 & 23,4 & 17,0 \\
\hline \multicolumn{7}{|l|}{ Escola pública } \\
\hline Estudou na EP & 55,9 & 60,4 & 58,2 & 42,5 & 28,7 & 20,4 \\
\hline Não estudou na EP & 74,1 & 67,0 & 62,4 & 22,4 & 20,5 & 15,4 \\
\hline
\end{tabular}

Fonte: Elaboração própria com base nos dados do SGA/UFFS, Enem e CenSUP

Tabela 28 - Análise bivariada entre variáveis institucionais e variáveis de desfecho

\begin{tabular}{lllllll}
\hline \multicolumn{1}{c}{ Campus } & \multicolumn{3}{c}{ Evadiu } & \multicolumn{3}{c}{ Concluiu } \\
\cline { 2 - 7 } & $\mathbf{2 0 1 0}$ & $\mathbf{2 0 1 3}$ & $\mathbf{2 0 1 4}$ & $\mathbf{2 0 1 0}$ & $\mathbf{2 0 1 3}$ & $\mathbf{2 0 1 4}$ \\
\hline Chapecó & 63,1 & 66,5 & 63,9 & 34,6 & 22,3 & 17,2 \\
Laranjeiras do Sul & 61,7 & 73,5 & 68,0 & 36,5 & 19,9 & 13,2 \\
Realeza & 48,2 & 57,5 & 46,1 & 50,2 & 29,9 & 28,6 \\
Cerro Largo & 41,3 & 47,1 & 50,0 & 57,8 & 40,9 & 27,0 \\
Erechim & 56,0 & 59,2 & 62,5 & 42,9 & 29,9 & 21,1 \\
Passo Fundo & & 30,0 & 13,2 & & 55,0 &, 0 \\
Área de conhecimento & & & & & \\
Educação... & 62,0 & 67,5 & 64,3 & 36,4 & 24,1 & 18,3 \\
Negócios... & 50,6 & 53,2 & 63,5 & 48,1 & 35,3 & 21,5 \\
Computação... & 77,4 & 76,1 & 77,4 & 17,2 & 5,7 & 10,8 \\
Engenharia... & 51,8 & 56,2 & 60,2 & 46,8 & 28,8 & 17,1 \\
Agricultura... & 44,9 & 49,6 & 38,5 & 53,3 & 38,0 & 27,6 \\
Saúde... & 35,5 & 46,2 & 37,4 & 64,5 & 40,2 & 26,1 \\
Retorno econômico & & & & & & \\
Alto retorno & 50,4 & 54,0 & 52,1 & 47,6 & 31,5 & 18,6 \\
Médio retorno & 56,6 & 65,0 & 60,7 & 41,9 & 24,7 & 19,6 \\
Baixo retorno & 64,9 & 60,9 & 63,9 & 33,2 & 32,3 & 24,5 \\
Turno de educação & & & & & & \\
Integral & 46,4 & 50,9 & 48,5 & 52,2 & 36,4 & 24,2 \\
Noturno & 61,6 & 68,9 & 67,7 & 36,4 & 21,0 & 13,7
\end{tabular}




\begin{tabular}{|c|c|c|c|c|c|c|}
\hline $\begin{array}{l}\text { Matutino ou } \\
\text { vespertino } \\
\text { Apoio social }\end{array}$ & 67,7 & 65,6 & 60,7 & 30,7 & 25,4 & 27,0 \\
\hline Não & 73,6 & 74,3 & 69,0 & 24,5 & 16,5 & 13,8 \\
\hline Sim & 39,8 & 35,1 & 44,2 & 58,6 & 50,0 & 28,6 \\
\hline \multicolumn{7}{|c|}{ Atividades extracurriculares } \\
\hline Não & 81,2 & 78,4 & 77,0 & 17,1 & 12,0 & 7,6 \\
\hline Sim & 23,1 & 22,9 & 25,9 & 75,1 & 62,6 & 42,0 \\
\hline
\end{tabular}

Fonte: Elaboração própria com base nos dados do SGA/ UFFS, Enem e CenSUP

A partir deste conjunto de variáveis, apresentaremos dois modelos de regressão logística, aplicados com as mesmas variáveis para estimar evasão e conclusão de curso, em cada coorte. Essas variáveis foram escolhidas com base na literatura e nos dados disponíveis e estão relacionadas a características socioeconômicas dos estudantes e de desempenho no Enem e aspectos institucionais e dos cursos.

O primeiro modelo considerou um conjunto menor de variáveis, sendo que as variáveis "sexo" e "raça/cor" foram agregadas e, no segundo modelo, essas variáveis foram analisadas de forma separadas, juntamente a um conjunto maior de variáveis. Nesse modelo foram acrescentadas também as variáveis "escolaridade da mãe"; "escola pública" e "nota da redação no Enem". A maioria das variáveis é comum aos dois modelos.

Ao testar vários modelos, verificou-se que algumas variáveis socioeconômicas perdiam a significância estatística ao serem acrescentadas outras de cunho institucional. Além disso, ao acrescentar muitas variáveis institucionais relacionadas ao curso (grau acadêmico, turno, área de conhecimento), também perdia a significância estatística. Por isso, optou-se pela inclusão de apenas uma variável relacionada ao curso, em cada modelo. A Tabela 29 apresenta as variáveis testadas em cada modelo e, em cada coorte de ingressantes.

Tabela 29 - Variáveis independentes a serem testadas nos modelos 1 e 2 de regressão logística

\begin{tabular}{ll}
\hline Modelo 1 & Modelo 2 \\
\hline Sexo_raça & Sexo \\
Faixa etária & Raça/cor \\
Renda familiar & Faixa etária \\
Situação de trabalho no ensino médio & Escolaridade da mãe \\
Localização de moradia & Renda familiar \\
Campus & Situação de trabalho no ensino médio \\
\hline
\end{tabular}




\begin{tabular}{ll}
\hline Apoio Social & Localização de moradia \\
Atividades extracurriculares & Escola pública \\
& Nota da redação no Enem \\
& Turno \\
& Apoio Social \\
& Atividades extracurriculares \\
\hline
\end{tabular}

Fonte: Elaboração própria.

\subsection{Evasão de curso}

A forma como estamos medindo a evasão de curso se refere à situação de matrícula em 2019/2, independentemente de qual o motivo e a forma de evasão (transferência interna, externa, cancelamento de matrícula, desistência), após transcorridos quase seis anos desde o ingresso do estudante. Por meio da técnica de regressão logística, buscamos verificar a probabilidade de o estudante ter evadido de seu curso de origem, em relação aos que não evadiram. Na coorte de 2010, um total de $56,7 \%$ dos ingressantes evadiram; na coorte de 2013 foram 60,8\% de evadidos e na de $2014,58,5 \%$.

Testamos as chances de evasão do curso do ponto de vista das características socioeconômicas, gênero e raça dos estudantes, desempenho no Enem (nota na redação) e dos aspectos institucionais e dos cursos. Com dados do CenSup e por meio de uma verificação da situação de matrícula em cada ano, verificamos que a evasão ocorre principalmente nos três primeiros anos após o ingresso. A literatura, tanto nacional, como internacional, já vem mostrando esta tendência de evasão, principalmente nos dois primeiros anos (Adachi, 2017; Ferrão; Almeida, 2018; Costa, 2018; Ristoff, 2021).

A Tabela 30 apresenta os modelos 1 e 2 de regressão logística para estimar chances de evasão para as coortes de ingressantes em 2010, 2013 e 2014. 
Tabela 30 - Estimativas ${ }^{\mathrm{A}}$ e razão de chance $^{\mathrm{B}}$ de modelos finais de regressão logística para estimar a evasão do curso - coortes de 2010, 2013 e 2014

\begin{tabular}{|c|c|c|c|c|c|c|}
\hline Variáveis & 2010 & & 2013 & & 2014 & \\
\hline & Modelo 1 & Modelo 2 & Modelo 1 & Modelo 2 & Modelo 1 & Modelo 2 \\
\hline \multicolumn{7}{|c|}{ Características socioeconômicas, gênero e raça e desempenho no Enem } \\
\hline \multicolumn{7}{|l|}{$\begin{array}{l}\text { Sexo_raça: } \\
\text { Mulher branca }\end{array}$} \\
\hline Mulher negra & $\begin{array}{l}0,224 \\
(1,251)\end{array}$ & & $\begin{array}{l}0,175 \\
(1,191)\end{array}$ & & $\begin{array}{l}0,384 \\
(1,468)\end{array}$ & \\
\hline Homem branco & $\begin{array}{l}-0,219 \\
(0,803)\end{array}$ & & $\begin{array}{l}0,174 \\
(1,190)\end{array}$ & & $\begin{array}{l}-0,085 \\
(0,918)\end{array}$ & \\
\hline Homem negro & $\begin{array}{l}-0,048 \\
(0,953)\end{array}$ & & $\begin{array}{l}0,186 \\
(1,204)\end{array}$ & & $\begin{array}{l}0,186 \\
(1,205)\end{array}$ & \\
\hline Sexo: masculino & & $\begin{array}{l}-0,292^{*} \\
(0,747)\end{array}$ & & $\begin{array}{l}0,205 \\
(1,228)\end{array}$ & & $\begin{array}{l}-0,046 \\
(0,955)\end{array}$ \\
\hline $\begin{array}{l}\text { Raça/cor: Pretos, } \\
\text { pardos e indígenas } \\
\text { Faixa etária: Até } \\
20 \text { anos }\end{array}$ & & $\begin{array}{l}0,236 \\
(1,266)\end{array}$ & & $\begin{array}{l}0,087 \\
(1,091)\end{array}$ & & $\begin{array}{l}0,291 \\
(1,338)\end{array}$ \\
\hline 21 a 24 anos & $\begin{array}{l}0,488^{* *} \\
(1,630)\end{array}$ & $\begin{array}{l}0,575^{* *} \\
(1,777)\end{array}$ & $\begin{array}{l}0,151 \\
(1,163)\end{array}$ & $\begin{array}{l}0,010 \\
(1,010)\end{array}$ & $\begin{array}{l}0,419^{*} \\
(1,520)\end{array}$ & $\begin{array}{l}0,244 \\
(1,277)\end{array}$ \\
\hline 25 anos ou mais & $\begin{array}{l}0,493 * * \\
(1,637)\end{array}$ & $\begin{array}{l}0,570^{* *} \\
(1,768)\end{array}$ & $\begin{array}{l}0,431^{*} \\
(1,539)\end{array}$ & $\begin{array}{l}0,284 \\
(1,329)\end{array}$ & $\begin{array}{l}0,217 \\
(1,243)\end{array}$ & $\begin{array}{l}0,112 \\
(1,118)\end{array}$ \\
\hline \multicolumn{7}{|l|}{$\begin{array}{l}\text { Escolaridade da } \\
\text { mãe: Até } 4^{a} \text { série }\end{array}$} \\
\hline $\begin{array}{l}\text { Ensino } \\
\text { Fundamental } \\
\text { Completo }\end{array}$ & & $\begin{array}{l}-0,113 \\
(0,893)\end{array}$ & & $\begin{array}{l}-0,228 \\
(0,796)\end{array}$ & & $\begin{array}{l}0,076 \\
(1,079)\end{array}$ \\
\hline $\begin{array}{l}\text { Ensino Médio ou } \\
\text { superior }\end{array}$ & & $\begin{array}{l}0,054 \\
(1,055)\end{array}$ & & $\begin{array}{l}0,036 \\
(1,037)\end{array}$ & & $\begin{array}{l}-0,123 \\
(0,884)\end{array}$ \\
\hline \multicolumn{7}{|l|}{$\begin{array}{l}\text { Renda familiar: } \\
\text { Nenhuma renda } \\
\text { até } 2 \text { SM }\end{array}$} \\
\hline $\begin{array}{l}\text { Mais de } 2 \text { até } 5 \\
\text { SM }\end{array}$ & $\begin{array}{l}-0,162 \\
(0,851)\end{array}$ & $\begin{array}{l}-0,165 \\
(0,848)\end{array}$ & $\begin{array}{l}0,216 \\
(1,241)\end{array}$ & $\begin{array}{l}0,203 \\
(1,225)\end{array}$ & $\begin{array}{l}0,293 \\
(1,341)\end{array}$ & $\begin{array}{l}0,221 \\
(1,247)\end{array}$ \\
\hline Acima de $5 \mathrm{SM}$ & $\begin{array}{l}0,144 \\
(1,154)\end{array}$ & $\begin{array}{l}0,096 \\
(1,101)\end{array}$ & $\begin{array}{l}0,051 \\
(1,052)\end{array}$ & $\begin{array}{l}0,028 \\
(1,028)\end{array}$ & $\begin{array}{l}0,003 \\
(1,003)\end{array}$ & $\begin{array}{l}-0,009 \\
(, 991)\end{array}$ \\
\hline $\begin{array}{l}\text { Situação de } \\
\text { trabalho: Não } \\
\text { Localização da } \\
\text { moradia: urbana }\end{array}$ & $\begin{array}{l}-0,268 \\
(0,765) \\
0,343^{*} \\
(1,409)\end{array}$ & $\begin{array}{l}-0,307 \\
(0,736) \\
0,286 \\
(1,332)\end{array}$ & $\begin{array}{l}-0,200 \\
(0,819) \\
0,440^{* *} \\
(1,552)\end{array}$ & $\begin{array}{l}-0,229 \\
(0,795) \\
0,430^{* *} \\
(1,537)\end{array}$ & $\begin{array}{l}0,057 \\
(1,059) \\
0,262 \\
(1,300)\end{array}$ & $\begin{array}{l}-0,018 \\
(0,982) \\
0,419^{* *} \\
(1,520)\end{array}$ \\
\hline $\begin{array}{l}\text { Escola pública: } \\
\text { Não estudou } \\
\text { Nota da redação } \\
\text { no Enem }\end{array}$ & & $\begin{array}{l}0,458 \\
(1,581) \\
-0,001 \\
(0,999) \\
\end{array}$ & & $\begin{array}{l}0,254 \\
(1,289) \\
-0,002 * * \\
(0,998) \\
\end{array}$ & & $\begin{array}{l}-0,199 \\
(0,820) \\
-0,001 \\
(0,999) \\
\end{array}$ \\
\hline \multicolumn{7}{|c|}{ Características institucionais e do curso } \\
\hline \multicolumn{7}{|l|}{ Turno: integral } \\
\hline Noturno & & $\begin{array}{l}-0,144 \\
(0,866)\end{array}$ & & $\begin{array}{l}0,313 * \\
(1,368)\end{array}$ & & $\begin{array}{l}0,599 * * \\
(1,820)\end{array}$ \\
\hline $\begin{array}{l}\text { Matutino ou } \\
\text { vespertino }\end{array}$ & & $\begin{array}{l}0,872^{* *} \\
(2,391)\end{array}$ & & $\begin{array}{l}0,522^{*} \\
(1,685)\end{array}$ & & $\begin{array}{l}0,183 \\
(1,200)\end{array}$ \\
\hline
\end{tabular}

\footnotetext{
${ }^{64}$ As categorias em itálico são as categorias de referência. No caso das categorias dicotômicas a categoria de referência é a que está omitida, por exemplo, no caso de sexo, a categoria de referência é "feminino".
} 


\begin{tabular}{|c|c|c|c|c|c|c|}
\hline \multicolumn{7}{|l|}{ Campus: Chapecó } \\
\hline Laranjeiras do Sul & $\begin{array}{l}0,361 \\
(1,435)\end{array}$ & & $\begin{array}{l}0,687 * * \\
(1,987)\end{array}$ & & $\begin{array}{l}0,577 * \\
(1,781)\end{array}$ & \\
\hline Realeza & $\begin{array}{l}-0,324 \\
(0,723)\end{array}$ & & $\begin{array}{l}-0,316 \\
(0,729)\end{array}$ & & $\begin{array}{l}-0,653^{* *} \\
(0,521)\end{array}$ & \\
\hline Cerro Largo & $\begin{array}{l}-0,479^{*} \\
(0,619)\end{array}$ & & $\begin{array}{l}-0,671 * * \\
(0,0511)\end{array}$ & & $\begin{array}{l}-0,541 * * \\
(0,521)\end{array}$ & \\
\hline Erechim & $\begin{array}{l}-0,316 \\
(0,729)\end{array}$ & & $\begin{array}{l}-0,599 * * \\
(0,550)\end{array}$ & & $\begin{array}{l}0,042 \\
(1,043)\end{array}$ & \\
\hline Passo Fundo & & & $\begin{array}{l}-1,140 * \\
(0,320)\end{array}$ & & $\begin{array}{l}-3,185^{* *} \\
(0,041)\end{array}$ & \\
\hline Apoio Social: Sim & $\begin{array}{l}-0,747 * * \\
(0,474)\end{array}$ & $\begin{array}{l}-0,755^{* *} \\
(0,470)\end{array}$ & $\begin{array}{l}-1,146^{* *} \\
(0,318)\end{array}$ & $\begin{array}{l}-1,031 * * \\
(0,357)\end{array}$ & $\begin{array}{l}-0,742^{* *} \\
(0,476)\end{array}$ & $\begin{array}{l}-0,583^{* *} \\
(0,558)\end{array}$ \\
\hline $\begin{array}{l}\text { Atividade } \\
\text { extracurricular: } \\
\text { Sim }\end{array}$ & $\begin{array}{l}-2,295^{* *} \\
(0,101)\end{array}$ & $\begin{array}{l}-2,438 * * \\
(0,087)\end{array}$ & $\begin{array}{l}-2,106 * * \\
(0,122)\end{array}$ & $\begin{array}{l}-2,086^{* *} \\
(0,124)\end{array}$ & $\begin{array}{l}-2,087 * * \\
(0,124)\end{array}$ & $\begin{array}{l}-2,153 * * \\
(0,116)\end{array}$ \\
\hline Constante & $1,558 * *$ & $2,172 * *$ & $1321 * *$ & $1,840 * *$ & $1,256^{* *}$ & $1,152 * *$ \\
\hline $\begin{array}{l}\text { N. de casos } \\
\text { válidos }\end{array}$ & 1443 & 1452 & 1377 & 1396 & 1390 & 1408 \\
\hline $\mathrm{R}^{2} \mathrm{~N}$ & 0,443 & 0,461 & 0,433 & 0,418 & 0,377 & 0,355 \\
\hline
\end{tabular}

Notas: **significante a $1 \%$; *significante a $5 \%$. ${ }^{\mathrm{A}} \mathrm{O}$ valor fora dos parênteses é a estimação do Beta (logaritmo da chance); ${ }^{\mathrm{B}} \mathrm{O}$ valor entre parêntesis é o exponencial do Beta (razão de chance)

Fonte: Elaboração própria, com base nos dados da UFFS, Enem e CenSup

De um modo resumido, o Quadro 7 apresenta as variáveis que estavam mais associadas à evasão de curso.

Quadro 7 - Variáveis estatisticamente significativas nos modelos de regressão logística evasão de curso

\begin{tabular}{clll}
\hline $\begin{array}{l}\text { Variável } \\
\text { dependente }\end{array}$ & $\mathbf{2 0 1 0}$ & $\mathbf{2 0 1 3}$ & $\mathbf{2 0 1 4}$ \\
& & Variáveis independentes & \\
\cline { 2 - 4 } & Sexo & Faixa etária & \\
& Faixa etária & Faixa etária \\
Evasão de & Localização de moradia & Localização de moradia & Localização da moradia \\
& & Nota da redação no Enem & \\
& Turno & Turno & Turno \\
& Campus & Campus & Campus \\
& Apoio social & Apoio social & Apoio social \\
& Ativ. extracurricular & Ativ. extracurricular & Ativ. extracurricular
\end{tabular}

Fonte: Elaboração própria

Ao analisar as características socioeconômicas, gênero e raça nas chances de evasão, verificou-se que as variáveis sexo e raça/cor, como variáveis de efeito, quando testadas de modo separado ou agregadas, não se revelaram estatisticamente significativas, salvo a variável sexo para a coorte de ingressantes em 2010 (modelo 2), em que os homens tiveram menos chances de evadir do curso em relação às mulheres. $\mathrm{O}$ estudo de Vidi (2020), sobre a UFFS, identificou evasão maior tanto para homens e 
mulheres, independentemente de cor/raça, que ingressaram com mais idade (22 a 38 anos). Outros estudos como de Costa e Picanço (2020) e De Paula (2021), também não encontraram associações entre raça/cor e evasão, mas sim para a variável sexo, com percentuais maiores de evasão entre homens.

Ao iniciar a construção dos modelos com a inclusão de apenas variáveis socioeconômicas algumas se mostraram significativas, mas quando acrescentadas variáveis relacionadas à Instituição e ao curso, como campus, turno do curso, apoio social e atividades extracurriculares, as variáveis socioeconômicas perdiam a significância estatística, o que pode indicar que variáveis de cunho institucional têm maior peso para estimar as chances de evasão.

Além de sexo e raça/cor, outras variáveis que não tiveram significância estatística para as chances de evasão foram a renda familiar, escolaridade da mãe, escola pública e situação de trabalho durante o ensino médio, mesmo depois de muitos testes. Isso também pode indicar que para o caso da UFFS, com um perfil mais homogêneo de estudantes de escola pública, essas variáveis podem estar correlacionadas ou confundidas com outras variáveis. Freitas e colegas (2020), por exemplo, utilizam a escola pública como proxy de renda para os estudantes cotistas, conforme a Lei de Cotas, dado a dificuldade de se obter esse dado de forma comprobatória no Brasil ${ }^{65}$. A escolaridade dos pais também é utilizada para determinar a posição socioeconômica da família, como, por exemplo, Carvalhaes \& Ribeiro (2019).

De todo modo, isso aponta que a evasão ocorre para todos os grupos, independentemente dessas características, como renda, escolaridade da mãe, escola pública. Outros estudos também têm mostrado que a condição socioeconômica não influencia na evasão de curso (Sales Junior et al., 2016; Adachi, 2017; Ferrão; Almeida; 2018). Conforme De Paula (2021) a origem social dos estudantes não influencia diretamente na evasão de curso, mas tem um peso maior na evasão do sistema. Além disso, o autor destaca que, de algum modo, a origem social influencia nos sentidos e nas motivações da evasão: alunos das camadas populares evadem de forma mais involuntária, motivadas muitas vezes pelos menores recursos econômicos e necessidade de trabalho, por exemplo, enquanto que as motivações da evasão de estudantes das

\footnotetext{
${ }^{65}$ Neste estudo, os autores fizeram um recorte com três grupos: "racial, o não-racial e o de pessoas com deficiência".
} 
camadas mais altas ocorrem de modo mais voluntário, na busca por melhores perspectivas.

As variáveis socioeconômicas que apresentaram significância estatística em todas as coortes para estimar as chances de evasão foram a idade e a localização de moradia. A faixa etária foi estatisticamente significativa para os dois modelos de 2010: estudantes que ingressaram na faixa etária entre 21 a 24 anos e com 25 anos ou mais tiveram $63 \%{ }^{66}$ mais chances de evadir que os mais jovens na faixa etária entre 17 a 20 anos. Na coorte de 2013, os ingressantes na faixa etária de 25 anos ou mais (modelo 1) e, na coorte de 2014, os ingressantes entre 21 a 24 anos tiveram mais chances de evasão (modelo 1). Quanto à localização de moradia, os residentes na área urbana tiveram mais chances de se evadir do curso que os da área rural, principalmente na coorte de 2013 (55\% e 53\%, modelo 1 e 2, respectivamente). Esse é um achado importante e pode estar associado ao desenho institucional multicampi da UFFS, voltado para a interiorização da educação superior pública numa região com baixa urbanização relativa, comparativamente às demais regiões brasileiras. Segundo o estudo realizado por Reche (2018), o fato de a UFFS ter campi localizados em municípios no interior com diferentes portes permitiu maior acesso e mobilidade dos estudantes da própria região, sem a necessidade de migrar para outra cidade ou Estado para estudar. A implantação da UFFS modificou, portanto, a dinâmica regional no destino dos estudantes.

Em estudo semelhante no contexto da UFMG, De Paula (2021) verificou que estudantes oriundos de cidades localizadas no interior de Belo Horizonte e de outros estados apresentaram percentuais mais elevados de permanência, tanto no curso, quanto na Instituição, em relação aos estudantes residentes em Belo Horizonte e na Região Metropolitana.

Com relação ao desempenho anterior ao ingresso na UFFS, a nota da redação do Enem foi estatisticamente significativa apenas para a coorte que ingressou em 2013: quanto maior a nota, menor a chance de evasão de curso. Nesta coorte, a nota de redação do Enem foi mais baixa em relação às demais coortes: cerca de $65 \%$ dos ingressantes tiveram nota de até 600. Isso sinaliza que o desempenho do ingressante antes do ingresso pode influenciar em sua trajetória de permanência ou evação do curso.

\footnotetext{
${ }^{66}$ Esse resultado da razão de chance interpretado em percentual é realizado a partir da aplicação da fórmula: $[\exp (\mathrm{b})-1]^{*} 100$, em que o $\operatorname{Exp}(\mathrm{b})$ é o exponencial do Beta (Power; Xie, 2000).
} 
O resultado de que a nota de redação do Enem influencia na evasão de curso também foi encontrado no estudo de Sales Junior et al. (2016) para a UFES.

As características da Instituição e as relacionadas aos cursos parecem estar mais associadas com a evasão, o que também se confirmou na pesquisa realizada por De Paula (2021). Em todas as coortes e modelos testados os ingressantes que receberam alguma modalidade de apoio social ou que participaram de alguma modalidade de atividade extracurricular, mesmo que de modo voluntário, no decorrer da graduação tiveram menos chances de evadir do curso. Para os ingressantes em 2013, por exemplo, os que foram beneficiários da assistência estudantil tiveram 68\% (modelo 1) e 64\% (modelo 2) menos chances de evasão de curso, em relação aos não beneficiários dessas políticas. Já os que participaram em atividades extracurriculares (estágio, iniciação científica, extensão) tiveram cerca de $90 \%$ menos chances de evasão de curso.

Esses resultados sinalizam para a importância dessas políticas na permanência e redução da evasão, estão em linha com a literatura (Costa; 2018; Saccaro; França; Jacinto, 2019; Scher; Oliveira, 2020). Sales Junior et al. (2016), para o caso da UFES, mostram que, em média, os estudantes que recebem assistência estudantil possuem $65 \%$ menos chances de evasão.

As variáveis do turno do curso e o campus também se mostraram estatisticamente significativas nos modelos. Outras variáveis institucionais e acadêmicas também foram testadas como o grau acadêmico, área de conhecimento e retorno econômico e apenas a área de conhecimento apresentou significância estatística. Com relação à evasão, De Paula (2021) não encontrou diferenças expressivas com relação ao grau acadêmico e turno, mas observou percentuais muito superiores para alunos de curso noturno e de licenciaturas.

Em todos as coortes, o turno do curso foi estatisticamente significativo nas chances de evasão, com algumas variações: na coorte de 2010, por exemplo, os ingressantes em turnos matutino ou vespertino apresentaram 2,3 vezes mais chances de evasão em relação aos cursos de turno integral (modelo 2); na coorte de 2013, os ingressantes nos turnos noturno, $37 \%$, e do matutino ou vespertino, $68 \%$ mais chances. E, na coorte de 2014, os ingressantes em cursos noturnos, apresentaram 82\% mais chances de evasão. Adachi (2017); Costa (2018); UFFS (2018) também reportaram tendências maiores de evasão em cursos noturnos e de licenciaturas. Importante destacar que a escolha de um curso noturno e a condição de permanência dos estudantes pode 
estar associada com demais características socioeconômicas como idade, condição de trabalho e renda familiar (Barbosa, 2019; Zago; Paixão; Pereira, 2016; Fassina, 2018).

No que se refere aos ingressantes em diferentes campi, a categoria de referência é o Campus Chapecó por agregar o maior número de cursos e de ingressantes. Em todas as coortes, ingressantes no Campus Cerro Largo apresentaram menos chances de evasão de curso em relação ao Campus Chapecó; outros campi, como Erechim (coorte de 2013) e Passo Fundo (coortes 2013 e 2014) também apresentaram menos chances de evasão de curso. E, o Campus Laranjeiras do Sul (coortes 2013 e 2014) apresentou mais chance de evasão de curso em relação ao Campus Chapecó (99\% e 78\% mais chances, respectivamente). Ao desagregar estes dados, considerando a situação de transferência interna dos estudantes e os diferentes campi, observamos que os campi Laranjeiras do Sul e Chapecó possuem os maiores percentuais de estudantes nesta condição, indicando maior mobilidade entre os cursos nestes campi.

A hipótese é que esses dados podem estar relacionados ao desenho dos cursos em cada campus. Passo Fundo, por exemplo, que oferta apenas o curso de Medicina possui baixa evasão, pois se trata de um curso de alta concorrência e com melhores expectativas em relação ao mercado de trabalho. Estudos como de Adachi (2017); Saccaro, França \& Jacinto (2019) mostraram que a evasão é menor em cursos mais concorridos. Baccaro \& Shinyashiki (2014) apontam, que de algum modo, existe uma associação entre cursos mais concorridos e maior rendimento acadêmico.

\subsection{Conclusão de curso}

Nesta etapa do estudo estamos considerando os ingressantes das coortes de 2010, 2013 e 2014 que tiveram como desfecho a conclusão do curso, conforme sua condição de matrícula verificada em 2019.2, exceto para a turma de ingressantes no curso de Medicina em 2014, pois ainda não havia integralizado a carga horária mínima, em 2019.2. Importante lembrar que dentro do grupo que não concluiu, encontram-se os estudantes que evadiram do curso ou continuavam com a matrícula ativa, mesmo após o prazo mínimo de integralização de sua carga horária, o que pode indicar situações como de reprovações e/ou trancamento do curso. Esses estudantes podem ainda traçar um desfecho de conclusão ou de evasão.

Quanto mais antiga é a coorte de ingressantes mais fácil se torna a verificação dos dados relativos ao desfecho de conclusão. Com base nos dados considerados nesta 
etapa de análise, entre os que ingressaram em 2010, 41,5\% concluíram o curso; de 2013, $28,1 \%$ e de 2014, 20,1\%. O uso da coorte de ingressantes em 2014 é considerada, portanto, uma limitação, para analisar a conclusão do curso, pois ao verificar os oito cursos que, em tese, teriam recém-integralizado sua carga horária, ao final do semestre de 2019/1, observou-se que parte significativa dos ingressantes ainda estavam com matrícula ativa, chegando a ultrapassar $30 \%$ em alguns cursos, como, por exemplo, Medicina Veterinária; Agronomia e Letras. Por outro lado, isso também sinaliza que, em geral, os estudantes da UFFS não concluem o curso no seu tempo de integralização.

A Tabela 31 mostra os modelos 1 e 2 de regressão logística para estimar as chances de conclusão dos cursos, tomando como base as mesmas variáveis usadas nos modelos relacionados à evasão de curso.

Tabela 31 - Estimativas ${ }^{\mathrm{A}}$ e razão de chance ${ }^{\mathrm{B}}$ de modelos finais de regressão logística para estimar a conclusão do curso - coortes de 2010, 2013 e 2014

\begin{tabular}{|c|c|c|c|c|c|c|}
\hline \multirow[t]{2}{*}{ Variáveis } & \multicolumn{2}{|c|}{2010} & \multicolumn{2}{|c|}{2013} & \multicolumn{2}{|c|}{2014} \\
\hline & Modelo 1 & Modelo 2 & Modelo 1 & Modelo 2 & Modelo 1 & Modelo 2 \\
\hline \multicolumn{7}{|c|}{ Características socioeconômicas, gênero e raça e desempenho no Enem } \\
\hline \multicolumn{7}{|l|}{$\begin{array}{l}\text { Sexo_raça: } \\
\text { Mulher branca }\end{array}$} \\
\hline Mulher negra & $\begin{array}{l}-0,283 \\
(0,753)\end{array}$ & & $\begin{array}{l}-0,261 \\
(0,771)\end{array}$ & & $\begin{array}{l}-0,280 \\
(0,756)\end{array}$ & \\
\hline Homem branco & $\begin{array}{l}0,120 \\
(1,128)\end{array}$ & & $\begin{array}{l}-0,604 * * \\
(0,547)\end{array}$ & & $\begin{array}{l}-0,424 * \\
(0,654)\end{array}$ & \\
\hline Homem negro & $\begin{array}{l}0,114 \\
(1,121)\end{array}$ & & $\begin{array}{l}-1,431 * * \\
(0,239)\end{array}$ & & $\begin{array}{l}-1,268 * * \\
(0,282)\end{array}$ & \\
\hline Sexo: masculino & & $\begin{array}{l}0,206 \\
(1,229)\end{array}$ & & $\begin{array}{l}-0,718 * * \\
(0,488)\end{array}$ & & $\begin{array}{l}-0,559 * * \\
(0,572)\end{array}$ \\
\hline $\begin{array}{l}\text { Raça/cor: pretos, } \\
\text { pardos e indígenas }\end{array}$ & & $\begin{array}{l}-0,212 \\
(0,809)\end{array}$ & & $\begin{array}{l}-0,429 * \\
(0,651)\end{array}$ & & $\begin{array}{l}-0,476^{*} \\
(0,621)\end{array}$ \\
\hline $\begin{array}{l}\text { Faixa etária: até } \\
20 \text { anos }\end{array}$ & & & & & & \\
\hline 21 a 24 anos & $\begin{array}{l}-0,497 * * \\
(0,608)\end{array}$ & $\begin{array}{l}-0,582 * * \\
(0,559)\end{array}$ & $\begin{array}{l}-0,209 \\
(0,811)\end{array}$ & $\begin{array}{l}-0,056 \\
(0,945)\end{array}$ & $\begin{array}{l}-0,484^{*} \\
(0,617)\end{array}$ & $\begin{array}{l}-0,404 \\
(0,668)\end{array}$ \\
\hline 25 anos ou mais & $\begin{array}{l}-0,509 * * \\
(0,601)\end{array}$ & $\begin{array}{l}-0,559 * * \\
(0,572)\end{array}$ & $\begin{array}{l}-0,556 * * \\
(0,574)\end{array}$ & $\begin{array}{l}-0,426 \\
(0,653)\end{array}$ & $\begin{array}{l}-0,193 \\
(0,824)\end{array}$ & $\begin{array}{l}-0,119 \\
(0,888)\end{array}$ \\
\hline \multicolumn{7}{|l|}{$\begin{array}{l}\text { Escolaridade da } \\
\text { mãe: até } 4^{a} \text { série }\end{array}$} \\
\hline $\begin{array}{l}\text { Ens. Fundamental } \\
\text { Completo }\end{array}$ & & $\begin{array}{l}0,085 \\
(1,089)\end{array}$ & & $\begin{array}{l}0,069 \\
(1,072)\end{array}$ & & $\begin{array}{l}-0,254 \\
(0,776)\end{array}$ \\
\hline $\begin{array}{l}\text { Ensino Médio ou } \\
\text { superior }\end{array}$ & & $\begin{array}{l}-0,028 \\
(0,972)\end{array}$ & & $\begin{array}{l}-0,136 \\
(0,873)\end{array}$ & & $\begin{array}{l}-0,247 \\
(0,781)\end{array}$ \\
\hline \multicolumn{7}{|l|}{$\begin{array}{l}\text { Renda familiar: } \\
\text { nenhuma renda } \\
\text { até } 2 \text { SM }\end{array}$} \\
\hline $\begin{array}{l}\text { Mais de } 2 \text { até } 5 \\
\text { SM }\end{array}$ & $\begin{array}{l}0,139 \\
(1,149)\end{array}$ & $\begin{array}{l}0,131 \\
(1,139)\end{array}$ & $\begin{array}{l}-0,200 \\
(0,819)\end{array}$ & $\begin{array}{l}-0,119 \\
(0,888)\end{array}$ & $\begin{array}{l}-0,250 \\
(0,779)\end{array}$ & $\begin{array}{l}-0,123 \\
(0,884)\end{array}$ \\
\hline
\end{tabular}




\begin{tabular}{|c|c|c|c|c|c|c|}
\hline Acima de $5 \mathrm{SM}$ & $\begin{array}{l}-0,102 \\
(0,903)\end{array}$ & $\begin{array}{l}-0,082 \\
(0,922)\end{array}$ & $\begin{array}{l}0,160 \\
(1,174)\end{array}$ & $\begin{array}{l}0,189 \\
(1,208)\end{array}$ & $\begin{array}{l}0,134 \\
(1,143)\end{array}$ & $\begin{array}{l}0,117 \\
(1,124)\end{array}$ \\
\hline $\begin{array}{l}\text { Situação de } \\
\text { trabalho: não }\end{array}$ & $\begin{array}{l}0,246 \\
(1,279)\end{array}$ & $\begin{array}{l}0,287 \\
(1,332)\end{array}$ & $\begin{array}{l}0,343^{*} \\
(1,409)\end{array}$ & $\begin{array}{l}0,283 \\
(1,327)\end{array}$ & $\begin{array}{l}0,161 \\
(1,175)\end{array}$ & $\begin{array}{l}0,266 \\
(1,305)\end{array}$ \\
\hline $\begin{array}{l}\text { Localização da } \\
\text { moradia: urbana }\end{array}$ & $\begin{array}{l}-0,322 * \\
(0,725)\end{array}$ & $\begin{array}{l}-0,265 \\
(0,767)\end{array}$ & $\begin{array}{l}-0,610 * * \\
(0.544)\end{array}$ & $\begin{array}{l}-0,557 * * \\
(0.573)\end{array}$ & $\begin{array}{l}-0,390^{*} \\
(0.677)\end{array}$ & $\begin{array}{l}-0,566 * * \\
(0,568)\end{array}$ \\
\hline $\begin{array}{l}\text { Escola pública: } \\
\text { não estudou }\end{array}$ & & $\begin{array}{l}-0,466 \\
(0,628)\end{array}$ & & $\begin{array}{l}-0,513 \\
(0,599)\end{array}$ & & $\begin{array}{l}-0,106 \\
(0,899)\end{array}$ \\
\hline Nota da redação & & 0,001 & & $0,002 * *$ & & $0,002^{*}$ \\
\hline no Enem & & $(1,001)$ & & $(1,002)$ & & $(1,002)$ \\
\hline \multicolumn{7}{|c|}{ Características institucionais e do curso } \\
\hline \multicolumn{7}{|l|}{ Turno: integral } \\
\hline Noturno & & $\begin{array}{l}0,130 \\
(1,139)\end{array}$ & & $\begin{array}{l}-0,323 \\
(0,724)\end{array}$ & & $\begin{array}{l}-0,759 * * \\
(0,468)\end{array}$ \\
\hline $\begin{array}{l}\text { Matutino ou } \\
\text { vespertino }\end{array}$ & & $\begin{array}{l}-0,936 * * \\
(0,392)\end{array}$ & & $\begin{array}{l}-0,448 \\
(0,639)\end{array}$ & & $\begin{array}{l}0,400 \\
(1,491)\end{array}$ \\
\hline Campus: Chapecó & & & & & & \\
\hline Laranjeiras do Sul & $\begin{array}{l}-0,324 \\
(0,724)\end{array}$ & & $\begin{array}{l}-0,237 \\
(0,789)\end{array}$ & & $\begin{array}{l}-0,653^{*} \\
(0,521)\end{array}$ & \\
\hline Realeza & $\begin{array}{l}0,404 * \\
(1,498)\end{array}$ & & $\begin{array}{l}0,365 \\
(1,441)\end{array}$ & & $\begin{array}{l}0,492 * \\
(1,636)\end{array}$ & \\
\hline Cerro Largo & $\begin{array}{l}0,562 * * \\
(1,754)\end{array}$ & & $\begin{array}{l}0,831 * * \\
(2,296)\end{array}$ & & $\begin{array}{l}0,408 \\
(1,504)\end{array}$ & \\
\hline Erechim & $\begin{array}{l}0,396^{*} \\
(1,486)\end{array}$ & & $\begin{array}{l}0,724 * * \\
(2,063)\end{array}$ & & $\begin{array}{l}0,184 \\
(1,202)\end{array}$ & \\
\hline Passo Fundo & & & $\begin{array}{l}1,174^{*} \\
(3,236)\end{array}$ & & & \\
\hline Apoio Social: sim & $\begin{array}{l}0,782 * * \\
(2,186)\end{array}$ & $\begin{array}{l}0,801 * * \\
(2,228)\end{array}$ & $\begin{array}{l}1,035^{* *} \\
(2,815)\end{array}$ & $\begin{array}{l}0,903 * * \\
(2,468)\end{array}$ & $\begin{array}{l}0,550 * * \\
(1,732)\end{array}$ & $\begin{array}{l}0,375^{*} \\
(1,455)\end{array}$ \\
\hline $\begin{array}{l}\text { Atividade } \\
\text { extracurricular: } \\
\text { sim }\end{array}$ & $\begin{array}{l}2,305 * * \\
(10,027)\end{array}$ & $\begin{array}{l}2,437 * * \\
(11,442)\end{array}$ & $\begin{array}{l}2,008 * * \\
(7,452)\end{array}$ & $\begin{array}{l}1,979 * * \\
(7,232)\end{array}$ & $\begin{array}{l}1,933 * * \\
(6,909)\end{array}$ & $\begin{array}{l}2,014 * * \\
(7,490)\end{array}$ \\
\hline Constante & $-1,691 * *$ & $-2,093 * *$ & $-1,906 * *$ & $-2,487 * *$ & $-2,208 * *$ & $-2,454 * *$ \\
\hline N. casos válidos & 1443 & 1452 & 1377 & 1396 & 1369 & 1387 \\
\hline $\mathrm{R}^{2} \mathrm{~N}$ & 0,449 & 0,464 & 0,434 & 0,424 & 0,301 & 0,317 \\
\hline
\end{tabular}

O Quadro 8 apresenta de um modo resumido as variáveis que apresentaram significância estatística para explicar a conclusão de curso. 
Quadro 8 - Variáveis estatisticamente significativas nos modelos de regressão logística conclusão de curso

\begin{tabular}{llll}
\hline \multirow{2}{*}{$\begin{array}{c}\text { Variáveis } \\
\text { dependentes }\end{array}$} & $\mathbf{2 0 1 0}$ & $\mathbf{2 0 1 3}$ & $\mathbf{2 0 1 4}$ \\
\cline { 2 - 4 } & & Variáveis independentes & \\
\hline Conclusão de & & Sexo_raça & Sexo_raça \\
curso & & Sexo & Sexo \\
& & Raça/cor & Faixa etária \\
& Faixa etária & Faixa etária & Localização de moradia \\
& Localização de moradia & Localização de moradia & Nota da redação no Enem \\
& & Nota da redação no Enem & Turno \\
& Turno & Campus & Campus \\
& Campus & Apoio social & Ativ. extracurricular \\
& Apoio social & Ativ. extracurricular & \\
& Ativ. extracurricular & &
\end{tabular}

Fonte: Elaboração própria

Nas chances de conclusão dos cursos, as variáveis de sexo e raça/cor foram estatisticamente significativas apenas nas coortes de 2013 e 2014, e para os dois modelos, em que testamos essas variáveis de modo agregado (sexo_raça) e separadamente. Essas duas coortes ingressaram nos dois primeiros anos da aplicação da Lei de Cotas na UFFS. Os homens possuem menos chances de conclusão de curso em relação às mulheres e aos estudantes autodeclarados pretos, pardos e indígenas em relação aos brancos e amarelos. Quando agregamos as variáveis sexo_raça, constatamos que os homens negros têm $71 \%$ menos chances de concluir, em relação às mulheres brancas, e os homens brancos, 34\% menos chances. A categoria de "mulheres negras" não apresentou significância estatística, o que indica não haver diferenças na conclusão de cursos em relação às mulheres brancas.

Em que pese um estudo recente do IBGE (2019b) constate com base em uma série de indicadores educacionais relacionados aos estudantes pretos e pardos, que houve melhoras nas trajetórias entre 2016 e 2018, a desigualdade racial continua evidente, principalmente nos níveis mais elevados do sistema de ensino. Na educação superior, "a proporção de jovens de 18 a 24 anos de idade de raça/cor branca que frequentavam ou já haviam concluído o ensino superior $(36,1 \%)$ era quase o dobro da observada entre aqueles de raça/cor preta ou parda (18,3\%)" (IBGE, 2019b, p. 7). Uma das condições para frequentar o ensino superior é ter completado o ensino médio. $\mathrm{O}$ estudo do IBGE mostrou, ainda, que, em 2018, a taxa de ingresso no ensino superior era de $53,2 \%$ na população branca e de $35,4 \%$ na população preta e parda. A não 
continuidade dos estudos pode ser observada pela condição de trabalho, sendo maior no grupo de pardos e pretos $(61,8 \%)$. A taxa de conclusão do ensino médio, ainda que tenha aumentado desde 2016, para a população preta e parda $(58,1 \%)$ é menor que a taxa da população branca $(76,8 \%)$. As mulheres tendam a ter indicadores educacionais maiores em relação aos homens de mesma raça/cor, mas os homens brancos possuem taxa de conclusão do ensino médio maior $(72,0 \%)$ que as mulheres pretas ou pardas (67,6\%). Conforme Senkevics \& Carvalho (2020), um dos maiores obstáculos para jovens negros e indígenas, ainda é de completar a educação básica.

Outra questão que chama atenção é a incidência de violência, medida pela taxa de homicídio que acomete mais jovens entre 15 a 29 anos, especialmente pretos e pardos, que tem aumentado entre 2012 e 2017: “[...] nesse grupo, a taxa chegou a 98,5 em 2017, contra 34,0 entre os jovens brancos. Considerando os jovens pretos ou pardos do sexo masculino, a taxa, inclusive, chegou a atingir 185,0" (IBGE, 2019b, p.10).

A partir da Lei de Cotas, homens e mulheres negras alcançaram mais oportunidades de acesso nos diferentes cursos da UFFS, e especialmente os homens negros acessaram mais cursos de bacharelados e de maior retorno econômico, se aproximando do acesso dos homens brancos, em termos relativos, assim como as mulheres negras aumentaram seu acesso em todos os cursos, se aproximando do acesso das mulheres brancas. Portanto, ainda que esta inclusão tenha ocorrido, os homens negros não concluem do mesmo modo que os demais, e os homens negros ingressam com mais idade, sendo a idade também um marcador de diferença importante a ser considerado no desfecho de evasão e de conclusão de curso.

No desfecho de conclusão de curso, de modo semelhante ao que encontramos para o desfecho de evasão de curso, as características socioeconômicas de renda familiar, escolaridade da mãe e origem de escola pública não apresentaram significância estatística em nenhuma das coortes de ingressantes, o que pode se justificar pelo perfil mais homogêneo de estudantes, sendo a maioria oriunda da escola pública, cujos pais possuem menor renda e escolarização. Portanto, tais características parecem não influenciar diretamente nos desfechos em termos de evasão ou conclusão dos cursos, que se mostram associados a outras características como idade, raça/cor, condição de trabalho, sexo. Esses resultados, principalmente para renda familiar e escolaridade da mãe, se sustentaram também nas análises bivariadas que resultaram em percentuais de evasão e conclusão de curso muito próximos para todos os grupos de renda e 
escolaridade. Apenas os resultados relacionados com escola pública nas análises bivariadas apontavam menores percentuais de evasão e maiores de conclusão de curso para estudantes de escola pública em relação aos demais, porém, estas diferenças não foram estatisticamente significativas nos testes de regressão logística, em nenhuma das coortes de ingressantes.

O fato de a renda familiar e a escolaridade da mãe não apresentarem diferença nas chances de evasão e de conclusão pode ser considerado um achado e que se difere, por exemplo, dos resultados do estudo de Knop (2020), que aponta a renda familiar como um fator importante na conclusão dos cursos, tanto para IES públicas, quanto privadas, pois quanto maior a renda familiar, maiores são as chances de conclusão de diferentes cursos, especialmente em cursos de maior retorno econômico. Por outro lado, estudos como de Pedrosa et al, (2006); Ferrão \& Almeida (2018) e Baccaro \& Shinyashiki (2014) também não encontraram associações entre renda familiar e escolaridade dos pais no desempenho acadêmico, conclusão ou evasão de curso. De Paula \& Nogueira (2020, p. 168), chamam atenção para a seletividade que ocorre ainda antes do acesso ao ensino superior: "outro aspecto diz respeito ao fato de que os estudantes tenderem a escolher e a ingressar em cursos e instituições compatíveis com o seu perfil social e escolar, reduzindo assim o possível efeito desses fatores sobre suas trajetórias após o ingresso".

A origem socioeconômica é ainda marcante no acesso ao ensino superior, conforme mostram estudos de Brito (2017), Salata (2018), Carvalhaes \& Ribeiro (2019), ainda que a sociedade, nas últimas décadas, tenha se mostrado mais democrática e aberta para uma maior diversificação dos universitários. Ao comparar o setor público e privado, os achados de Brito (2017) sinalizam que as oportunidades de acesso ao ensino superior tendem a ser mais igualitárias para jovens de distintas origens sociais no setor público, sendo os padrões de estratificação por classe de origem mais pronunciadas no setor privado. Segundo o autor, esse resultado pode sugerir um efeito positivo das políticas de ações afirmativas e dos maiores investimentos no setor público, considerando o período da primeira década do século XXI.

O estudo de Caseiro (2016), referente ao período entre 2004 a 2014, constatou que, ainda que persistam as desigualdades estruturais no acesso ao ensino superior, existe uma tendência de redução das desigualdades. Com relação à renda, este foi o único critério em que houve uma redução do efeito para todas as regiões do país neste 
período. Para o caso da UFFS, os resultados mostram que, por meio de suas políticas mais inclusivas e ações afirmativas, foi possível romper em boa medida com barreiras socioeconômicas no acesso, contribuindo para a igualdade de oportunidades, ainda que alguns desafios ainda se façam presentes na permanência e na conclusão dos cursos.

Das características socioeconômicas e de gênero e raça, além de "raça/cor" e "sexo", também foram estatisticamente significativas as variáveis "faixa etária" e "localização da moradia", para as três coortes; enquanto a "situação de trabalho" se mostrou significativa apenas para a coorte de ingressantes em 2013 e "nota da redação no Enem" para as coortes 2013 e 2014.

A faixa etária teve significância estatística principalmente na coorte de 2010, nos dois modelos e para as duas faixas etárias, ou seja, ingressantes com 21 anos ou mais tiveram menos chances (cerca de 40\%) de conclusão de curso, com relação aos mais jovens entre 17 a 20 anos. Em 2010, em termos relativos, o acesso de estudantes com mais idade foi maior em relação às coortes mais recentes. Na coorte de 2013 e 2014, quando as variáveis de sexo_raça passaram a ter significância estatística, a idade teve um peso menor e de forma semelhante ao encontrado com relação à chance de evasão, em apenas um modelo em cada coorte: em 2013, apenas os ingressantes de 25 anos ou mais tiveram menos chances de concluir o curso, comparado com o grupo de referência (17 a 20 anos), e, na coorte de 2014, os ingressantes na faixa etária entre 21 a 24 anos tiveram menos chances de conclusão. Estas mesmas faixas etárias também tiveram mais chances de evasão do curso.

Com relação à localização de moradia, o estudo de Caseiro (2016) mostrou que de um modo geral o acesso de jovens entre 18 a 24 anos que vivem nas áreas rurais cresceu, proporcionalmente mais, que o acesso de jovens das áreas urbanas no decênio de 2004 a 2014. Ao analisar, segundo as diferentes regiões, esse não foi o caso das Regiões Norte, Sul e Centro-Oeste, em que as chances de acesso para os habitantes das áreas urbanas cresceram.

Na UFFS, a inserção de jovens oriundos da zona rural (mais de 25\%) é bastante significativa, sendo superior à proporção da população rural da Região Sul, que conforme o Censo do IBGE (2010b) é de 15,7\%, e mais condizente com o percentual de sua área de abrangência: a Mesorregião Grande Fronteira do Mercosul, em que cerca de $35 \%$ de sua população vive na zona rural (Demarco; Maia, 2013), tendo regiões como a 
que pertence o Campus Laranjeiras do Sul (Região Cantuquiriguaçu ${ }^{67}$ ), com mais de $50 \%$ da população nesta condição.

Conforme já verificado para a condição de evasão, a localização da moradia tem se mostrado um fator explicativo relevante também para a condição de conclusão do curso: ingressantes que residiam na zona urbana antes do ingresso têm menos chances de concluir o curso, em comparação aos da zona rural. Esta variável teve significância estatística nas três coortes, principalmente na coorte de 2013: estudantes de origem urbana têm $45 \%$ menos chances de concluir o curso em relação aos da zona rural (modelo 1). Esse resultado também chama atenção no sentido de problematizar o que acontece com os estudantes da zona urbana e com o processo de interiorização das universidades que parece atrair mais os jovens da zona rural que os da zona urbana.

A maior persistência dos jovens oriundos da zona rural na UFFS pode estar associada às oportunidades que essa Universidade apresenta devido a sua localização em municípios no interior dos três Estados, em uma região com forte vocação agrícola, além de suas políticas de ingresso voltadas para estudantes de escolas públicas, que é o caso da maioria dos jovens da zona rural. $\mathrm{O}$ fato de ter um campus universitário federal e gratuito próximo de sua residência facilita o acesso por meio de transportes locados, podendo permanecer residindo com a família no campo ou mesmo para os que precisam migrar para a cidade do campus da UFFS ainda assim permanecem mais próximos de suas famílias, podendo contar com este apoio familiar em termos de alimentação, por exemplo (Reche, 2018). O estudo de Nierotka (2015) sobre a coorte de ingressantes na UFFS, em 2012, mostrou que 85,9\% dos estudantes residiam na cidade do campus ou em cidades próximas, num raio de até $90 \mathrm{~km}$ de distância. Esse é um dos achados importantes dessa pesquisa e que podem traduzir os efeitos positivos da característica multicampus e da interiorização do ensino superior público, além da presença universitária em municípios de diferentes portes.

Conforme o estudo de Zago (2016), que entrevistou universitários e suas famílias no Oeste de Santa Catarina, onde se encontra localizado um dos campi (Chapecó), a migração dos jovens do campo para a cidade em busca do ensino superior é incentivada pela família para romper com a tradição de poucos anos de escolaridade

\footnotetext{
${ }^{67}$ Informações obtidas no site: http://www.cantuquiriguacu.com.br/exibenoticia.php?url=maos-a-obrapresidente-da-associacao-dos-municipios-sirlene-svartzbusca-para-capacitacao-e-execucao-de-projetospara-os-municipios-da-cantuquiriguacu\#.YPFa25hKjIV
} 
dos pais e com o destino de agricultor para os filhos, dada as dificuldades vivenciadas na agricultura familiar, principalmente pelo endividamento e a falta de reconhecimento profissional. Segundo a autora, o prolongamento da escolarização de filhos de agricultores para além do ensino fundamental é relativamente recente. Portanto, a persistência dos jovens da zona rural no ensino superior e, principalmente das mulheres, se deve em grande parte pela aposta por uma condição de trabalho melhor a que já experimentaram na atividade rural desde muito cedo, além de aspectos também como a independência financeira.

Com relação à situação de trabalho antes do ingresso na UFFS, esta característica apenas foi significativa em um dos modelos testados para ingressantes em 2013: os que não trabalhavam antes do ingresso na universidade tiveram $40 \%$ mais chances de concluir o curso. Esse resultado não foi constatado nas análises bivariadas, para a coorte de 2013 e encontra algum respaldo em estudos como de Sales Júnior et al. (2016) e de Fassina (2018), que apontam o fato de estar trabalhando antes do ingresso e/ou durante a graduação, como um dificultador da permanência no curso, podendo, em alguma medida, até derivar em evasão do curso.

A nota da redação no Enem é considerada uma condição de desempenho no Ensino Médio e junto com as demais notas compõem a nota geral do Enem, sendo esta também utilizada na seleção dos ingressantes na UFFS. Observou-se que os ingressantes em 2013 e 2014 tiveram a nota da redação menor (a maioria até 600 pontos) em relação à coorte de ingressantes em 2010 (a maioria superior a 600 pontos). Isso indica que, de algum modo, essa nota também pode impactar na trajetória acadêmica e nos desfechos do estudante, como de conclusão e/ou de evasão no curso. Nos modelos testados, a nota de redação do Enem foi estatisticamente significativa apenas nas coortes de 2013 e 2014: quanto maior é a nota, maior é a chance de conclusão do curso. Portanto, o desempenho, desde o ensino médio é uma característica importante na trajetória acadêmica. Os resultados de Eller \& Diprete (2018), ao verificar lacunas na conclusão entre brancos e negros, nos EUA, concluíram que a nota antes da entrada na faculdade constituiu um dos recursos essenciais na persistência universitária. Um dos aspectos importantes a serem verificados, em pesquisas futuras, é se existem diferenças entre as notas de desempenho no ensino médio em termos de sexo e raça, já que esta condição parece estar associada ao desfecho de conclusão de curso superior. $\mathrm{O}$ 
próximo capítulo aprofundará o desempenho após o ingresso na Universidade, por meio do rendimento acadêmico (média de notas).

Com relação às características institucionais e relacionadas aos cursos, todas as variáveis testadas nesses modelos apresentaram significância estatística e em todas as coortes, exceto o turno do curso para a coorte de 2013. Os ingressantes em 2010 nos cursos de turnos matutino ou vespertino apresentaram $61 \%$ menos chances de conclusão em relação aos de turno integral e, os ingressantes em 2014 em cursos noturnos apresentaram $53 \%$ menos chances que os de turno integral.

Estudantes que foram apoiados pela assistência estudantil durante a graduação apresentaram maiores chances de concluir os cursos, em todas as coortes de ingressantes e modelos testados. Em 2013, por exemplo, os que receberam assistência estudantil em algum momento da graduação apresentam 2,8 vezes mais chances de concluir o curso, em relação aos que não receberam.

Da mesma forma, a participação em atividades extracurriculares teve impacto positivo nas chances de conclusão, em todos os modelos e coortes, a partir de 6 vezes mais chances, em relação aos que não participaram, independentemente do recebimento ou não de bolsa. Estes resultados vão ao encontro da literatura nacional e internacional e reforçam a importância dessas políticas de permanência estudantil na trajetória de sucesso estudantil e na redução da evasão de curso. Destacamos que, além da inserção dos estudantes em atividades que podem estar relacionadas com o seu curso, o recebimento da bolsa, quando a participação não ocorre de forma voluntária, também contribui como apoio financeiro, principalmente para estudantes em situação de vulnerabilidade socioeconômica, podendo ser acumulada com o apoio da assistência estudantil.

No que se refere aos efeitos dos diferentes campi nas chances de conclusão dos cursos, observou-se que na coorte de 2010, os campi Cerro Largo, Realeza e Erechim tiveram mais chances de conclusão com relação ao Campus Chapecó (categoria de referência). Na coorte de ingressantes em 2013, os campi Cerro Largo, Erechim e Passo Fundo tiveram mais chances de conclusão e na coorte 2014, o Campus Realeza teve mais chance de conclusão e Laranjeiras do Sul menos chances, com relação ao Campus Chapecó. Esses resultados parecem estar mais associados aos tipos de cursos que cada campus possui e também foram observados para a condição de evasão de curso. 


\subsection{Síntese do capítulo: principais resultados}

A partir das análises realizadas com relação aos desfechos (evasão e conclusão de curso) dos ingressantes na UFFS, os resultados desta pesquisa traduzem algumas especificidades em relação a outros estudos e/ou outras IES que precisam ser consideradas: sua configuração multicampi, interestadual e sua localização no interior; suas políticas de acesso e de permanência diferenciadas; os cursos oferecidos e o perfil universitário. Pode-se dizer que os percentuais de evasão e conclusão da UFFS não são discrepantes da realidade das demais IES brasileiras (Fritsch, Jacobus; Vitelli, 2020).

Para analisar os resultados encontrados para a UFFS retomamos o conceito de lógica institucional atribuído por Buckner \& Zapp (2021), pertinente ao caso da UFFS, por se tratar de uma IES nova, que nos anos analisados estava ainda em processo de implantação. Além disso, a oferta de curso possui uma vocação voltada para a formação de professores (cerca de $50 \%$ dos cursos são de licenciaturas) e para fomentar agricultura familiar e agroecológica na região, além do compromisso desta IES com a escola pública e a inclusão social (mais de 90\% dos estudantes são egressos da escola pública). Ressalta-se, também, a interiorização do ensino superior público, a partir da localização dos campi da UFFS e da oferta de cursos noturnos, o que facilita o acesso para estudantes trabalhadores e também da zona rural.

Ao retomar o objetivo principal deste capítulo de "analisar as relações entre características socioeconômicas, gênero, raça, desempenho e aspectos institucionais e o “desfecho" (conclusão ou evasão de curso) dos estudantes", é possível tecer algumas considerações:

1) O desfecho de evasão e/ou de conclusão de curso na UFFS estão associados fortemente com a idade de ingresso do estudante, tipo de curso frequentado e demais aspectos institucionais e do curso, como, por exemplo, o turno do curso e as políticas de permanência estudantil. Os resultados mostraram a relevância, na trajetória acadêmica dos estudantes, do apoio social recebido por meio das políticas de assistência estudantil e da participação em programas de atividades extracurriculares, ainda, que nesta última, a inserção em algumas modalidades pode ocorrer também de forma voluntária, sem uma bolsa remunerada. Em geral, esses programas incentivam e ao mesmo tempo têm como condicionalidade a exigência de rendimento acadêmico dos estudantes. Além de contribuir para a melhoria do desempenho, estas ações corroboram com a integração estudantil no ambiente universitário e o compromisso do estudante com a Instituição e 
desta com o estudante (Tinto, 1975; Bean, 1980; Cabrera et al., 1992; Sales Junior et al., 2016; Li; Chagas, 2017; Costa; Gouveia, 2018; De Paula, 2021).

2) O fato de o estudante ter cursado a escola pública, ter origem popular (pais com menos escolarização e renda) não teve influência direta na evasão ou conclusão de curso. Ainda que algumas mudanças tenham ocorrido nas políticas de acesso da UFFS, manteve-se um perfil socioeconômico dos ingressantes mais homogêneo em termos de renda familiar, escola pública e escolaridade dos pais. Conforme destacam De Paula e Nogueira (2020, p. 168), muitas vezes os estudantes tendem a escolher os cursos e as instituições de ensino compatíveis com seu perfil social e escolar, o que explica a redução dos efeitos dessas características socioeconômicas em suas trajetórias a partir do ingresso.

3) O fato de ser estudante da zona rural apresentou-se como uma característica de maior permanência e conclusão de curso na UFFS.

4) O desempenho anterior ao ingresso na UFFS (nota de redação no Enem) se relaciona com o aumento na conclusão do curso.

4) Em termos de raça/cor e sexo, existem diferenças apenas na conclusão de curso, ou seja, homens e mulheres brancos/as e negros/as evadem dos cursos, mas na conclusão, as mulheres principalmente brancas apresentaram maior persistência. Os homens brancos e negros concluem menos que as mulheres brancas, e principalmente os homens negros, que apresentam $71 \%$ de chances menores de concluir quando comparados às mulheres brancas. Essa diferenciação entre raça/cor e sexo foi mais evidente a partir da Lei de Cotas (nas coortes de 2013 e de 2014), quando ocorreu uma maior diversificação racial em todos os cursos e turnos. Diante disso, ressalta-se a necessidade de fortalecer a oferta de políticas de apoio pedagógico e de permanência estudantil, no sentido de compensar possíveis desvantagens apresentadas pelos estudantes.

Entre os resultados dos modelos de regressão logística para a coorte de ingressantes de 2010, quando homens e mulheres negros eram mais pobres e se inseriam mais em cursos de licenciaturas, a diferença racial na conclusão não aparecia. $\mathrm{Na}$ medida em que esses estudantes se inserem mais em todas as áreas de conhecimento, principalmente os homens em cursos de bacharelados, suas trajetórias de conclusão começam a se diferenciar. Portanto, essa condição pode sinalizar para uma maior demora na integralização dos cursos, ou seja, para um aumento das reprovações e/ou do 
trancamento dos cursos, o que demanda maior apoio acadêmico. Homens brancos também possuem menores chances de conclusão de cursos em relação às mulheres brancas.

O presente estudo mostra as desigualdades estruturais e persistentes no ensino superior mesmo em Instituições que se propõem a ser mais inclusivas como a UFFS, contribuindo, ao mesmo tempo, também para mostrar situações de rompimento com a desigualdade de oportunidades e casos de sucesso entre estudantes das camadas populares no acesso e conclusão do ensino superior público em diferentes áreas de conhecimento. Essas contribuições somam-se aos estudos, como de Zago (2006, p. 226), que considerou como casos "atípicos" ou "trajetórias excepcionais" nos meios populares, e que inovam pelo interesse em casos que fogem à tendência dominante focada mais no fracasso escolar nestes grupos sociais. Nesta mesma linha também se situa o estudo de Aguiar Neto (2019), que focaliza os alunos da escola pública que alcançaram sucesso no ensino superior em cursos de alto prestígio, considerados como casos de "exceção" ou trajetórias de sucesso consideradas "improváveis".

O próximo capítulo avança no sentido de compreender melhor a dinâmica do desempenho acadêmico durante a graduação e sua influência no desfecho, em termos de evasão ou conclusão de curso. 


\section{9 Desempenho acadêmico e seus efeitos na conclusão do curso}

Este capítulo também trata do tema dos desfechos de forma complementar ao capítulo anterior. Ambos buscam responder a uma questão comum: "como as características socioeconômicas, gênero, raça, desempenho e aspectos institucionais impactam no "desfecho" (conclusão ou evasão de curso) dos estudantes? Neste caso, o objetivo é explorar o desempenho, conceito que, em linha com Baccaro \& Sinyashiki (2014), é considerado como sinônimo de rendimento acadêmico, e medido por meio da média simples de todas as notas obtidas pelos estudantes durante a graduação, ou enquanto permaneceram com a matrícula ativa que foi verificada ao final do primeiro semestre de 2019. Também de forma complementar, foi organizada uma variável com a soma de todas as reprovações obtidas durante a graduação. Neste capítulo, optamos pelo acompanhamento apenas de uma coorte de estudantes que ingressou em 2013 por meio do Enem e de sua situação de matrícula em 2019.2, que compreende até o final do primeiro semestre daquele ano. Justifica-se o uso desta coorte por corresponder ao primeiro ano de implementação da Lei de Cotas. Numa situação ideal, essa coorte teria integralizado sua carga horária nos diferentes cursos ao final de cerca de seis anos após o ingresso. Trata-se de um capítulo complementar, fruto de uma decisão tomada em momento posterior à solicitação e obtenção do acesso às bases de dados do INEP, e, portanto, que faz uso apenas das bases de dados da UFFS.

A amostra para essa análise foi adaptada a partir de metodologia utilizada em estudos de Baccaro \& Sinyashiki (2014); Rotem, Yair \& Shustak (2020) e De Paula (2021), que medem o desempenho por meio de notas obtidas pelos estudantes na graduação. Baccaro \& Sinyashiki (2014) utilizaram o desempenho como variável dependente, medida pelo rendimento acadêmico e obtida a partir da média ponderada das notas durante a graduação, em relação as características sociodemográficas de estudantes concluintes de graduação em uma universidade paulista.

Já Rotem, Yair \& Shustak (2020) utilizaram o desempenho como variável independente e como variável dependente as taxas de evasão e de conclusão, excluindo os ingressantes que ainda estavam com matrícula ativa ao final do período analisado pelos autores. O contexto deste estudo foi a Universidade Hebraica de Jerusalém, no período de 2002 a 2015. Nesse estudo, foi considerado como desempenho o rendimento acadêmico, verificado por meio de notas dos estudantes no primeiro ano. Os resultados 
mostraram que o desempenho dos estudantes oriundos de ações afirmativas era similar aos seus pares normativos e que a reprovação foi considerada como um fator de risco para estudantes oriundos das ações afirmativas. Neste sentido, o desempenho se torna o cerne da questão.

De Paula (2021), avalia o efeito do desempenho acadêmico sobre a evasão de curso e da instituição e faz uso da média ponderada obtida pelo estudante nas disciplinas (Rendimento Semestral Global - RSG), cujo valor variou de 0 a 5 . O autor menciona que um dos limites dessa forma de medir a aprendizagem do estudante e seu papel na evasão é a forte associação entre a RSG e evasão. Diante disso, questiona se a intenção de evadir por parte do estudante poderia levar a um desinvestimento no curso e ao baixo rendimento ou se esse desempenho (RSG) poderia funcionar como uma variável independente e, de fato, explicar, em alguma medida, a aprendizagem no curso e a própria evasão. Outro limite identificado pelo autor foi a existência de um número considerável de estudantes com uma média zero de RSG, o que indica que a saída destes estudantes pode ter ocorrido logo no primeiro ou segundo semestre, sem ter cursado plenamene as discplinas. Ao utilizar os dados da UFFS, compartilho também destas limitações apresentadas por De Paula (2021).

Na base da UFFS, utilizada neste estudo, foram mantidos apenas os estudantes com desfechos de "evasão" e "conclusão" de curso ${ }^{68}$ e excluídos àqueles que se encontravam com matrícula ativa (210 estudantes), totalizando 1.672 estudantes, sendo $1.157^{69}$ $(69,2 \%)$ na condição de evadidos do curso e 515 (30,8\%) de concluintes. Justificamos que a exclusão destes 210 estudantes com a matrícula ativa foi uma escolha metodológica baseada em metodologia semelhante adotada por Rotem, Yair \& Shustak (2020).

As variáveis "sexo" e "raça/cor" foram utilizadas de modo agregado, para observar como gênero e raça interagem na estrutura das desigualdades educacionais em termos de desempenho, resultando nas categorias: "mulher branca"; mulher negra"; "homem branco" e "homem negro". Conforme já observado em capítulos anteriores, essa

\footnotetext{
${ }^{68}$ Conforme já considerado no capítulo anterior, na "evasão de curso" consideramos as seguintes situações de matrícula: jubilamento, cancelamento, desistência e transferências interna e externa. Na "conclusão de curso" é considerado também situação de "aluno(a) formando(a).

${ }^{69}$ Destes evadidos do curso, não foi encontrada a informação de nota para 64 casos, mantendo-os como ausentes no sistema, sempre que utilizada a informação de nota.
} 
interação é relevante em termos de acesso, ocupação dos cursos e nos desfechos no ensino superior.

Ainda que com o foco na educação básica, situa-se o estudo de Ernica \& Rodrigues (2020). Os autores analisam o desempenho de estudantes de escolas públicas de diferentes grupos sociais no município de São Paulo, a partir da interação entre marcadores sociais como raça, gênero e condição socioeconômica. Os resultados indicam que as estruturas de raça e gênero são preditoras importantes de resultados educacionais e estão na origem de padrões de desigualdades. No caso paulistano, identificaram um padrão em em que as meninas brancas e pardas apresentaram um maior desempenho, e, em qualquer contexto observado, as maiores desvantagens em termos de oportunidades educacionais foram entre os meninos pretos, e, de forma ainda mais aguda, entre aqueles com o menor nível socioeconômico.

$\mathrm{Na}$ base principal da UFFS, agregamos dados relacionados ao rendimento acadêmico dos estudantes, considerado por meio da média de notas obtidas nas disciplinas em cada semestre ${ }^{70}$, até 2019.1 para os concluintes ou até o semestre cursado para os que evadiram do curso. A partir dessas médias semestrais e por disciplina, criamos uma variável com a média simples para cada estudante. Além disso, foi criada também uma variável com a situação de reprovação, a partir da soma de reprovações de cada estudante, considerando todos os tipos: nota, frequência e/ou nota e frequência ${ }^{71}$.

Ao analisarmos a distribuição de notas entre os estudantes que evadiram do curso observou-se que cerca de $15 \%$ estavam com a média de nota equivalente a 0,0 , o que pode indicar a evasão de curso e/ou da própria instituição logo após o ingresso ou mesmo após o primeiro semestre. Situação semelhante foi constatada também por De Paula (2021) com mais de $80 \%$ de estudantes nesta situação e evadidos da instituição.

Em seguida, foi incluída nesta base também a variável "apoio social"72 (referente ao recebimento de alguma modalidade de assistência estudantil) e variáveis socioeconômicas, como "localização de moradia", "escolaridade da mãe", "renda familiar" e "situação de trabalho" durante o Ensino Médio, obtidas a partir das

\footnotetext{
70 Justifico que não foi possível obter junto à Pró-Reitoria de Graduação índices relacionados ao desempenho, como por exemplo, o Índice de Aproveitamento Acumulado (IAA), que considera notas e carga horária matriculada.

71 Conforme consta no Regulamento da Graduação da UFFS, a avaliação do estudante em cada componente curricular é assim considerada: "Art. 80. O estudante que alcançar nota final igual ou superior a 6,0 (seis) e frequência mínima de $75 \%$ (setenta e cinco por cento), está aprovado no componente curricular" (UFFS, 2014, p.36).

${ }^{72}$ Este dado se refere ao fato de ter sido beneficiário de assistência estudantil e/ou Bolsa Permanência do MEC em algum momento desde o ingresso até o final de 2018.
} 
respostas a um questionário socioeconômico e cultural aplicado aos estudantes no Processo Seletivo de ingresso realizado pela UFFS em 2013 ${ }^{73}$. A descrição e frequências da variável dependente (“concluiu ou evadiu”) e das principais variáveis independentes (características socioeconômicas dos estudantes, aspectos relacionados à instituição, ao curso e ao desempenho), utilizadas neste capítulo, podem ser visualizadas no Apêndice 4.

No capítulo anterior, verificamos que a variável de desempenho, medida pela “nota da redação do Enem" foi estatisticamente significativa no desfecho de evasão e de conclusão de curso, para a coorte de ingressantes em 2013 (quanto maior é nota da redação no Enem, menores são as chances de evasão e maiores as chances de conclusão de curso). Neste capítulo, exploramos os efeitos do desempenho dos ingressantes no decorrer da graduação no desfecho e conclusão ou evasão de curso.

Este capítulo se divide em duas partes. A primeira explora de forma descritiva a variável dependente, relacionada ao desfecho de conclusão ou evasão de curso, e as seguintes variáveis independentes ("faixa etária", "sexo_raça", "situação de trabalho", "localização de moradia", "escola pública”, "situação de cotista", "renda familiar", "escolaridade da mãe", “campus”, "turno do curso", "apoio social”, “área de conhecimento", "média de notas" e "reprovações"), por meio de análises bivariadas.

Ainda nesta etapa de análise descritiva dos dados, com a finalidade de explorar melhor a variável "média de notas" foram realizados cruzamentos com as demais variáveis independentes, buscando verificar como a nota varia diante de algumas características socioeconômicas, institucionais e de escolha do curso, assumindo esta, portanto, a condição de variável dependente. Essas análises foram realizadas de modo separado para o grupo que evadiu e para o grupo que concluiu o curso. Os resultados foram apresentados de maneira gráfica por meio de boxplot (diagrama de caixa), conforme mostra a Figura 3, que é formado pelo primeiro e terceiro quartil e pela mediana. A mediana é a medida central da amostra e cada quartil representa $25 \%$ da amostra. O boxplot ou "caixa" contém os $50 \%$ centrais da distribuição. As linhas que se

\footnotetext{
${ }^{73}$ Estas bases de dados referente ao questionário socioeconômico aplicado no processo seletivo e de apoio social foram fornecidas pela PROGRAD e Diretoria de Sistemas da UFFS e não haviam sido utilizadas nos capítulos anteriores.
} 
estendem da caixa possuem o valor máximo e o mínimo, exceto para valores atípicos ${ }^{74}$, representados no software SPSS por $o$ (outliers) e * (valores ainda mais distantes).

Figura 3 - Gráfico de bloxplot

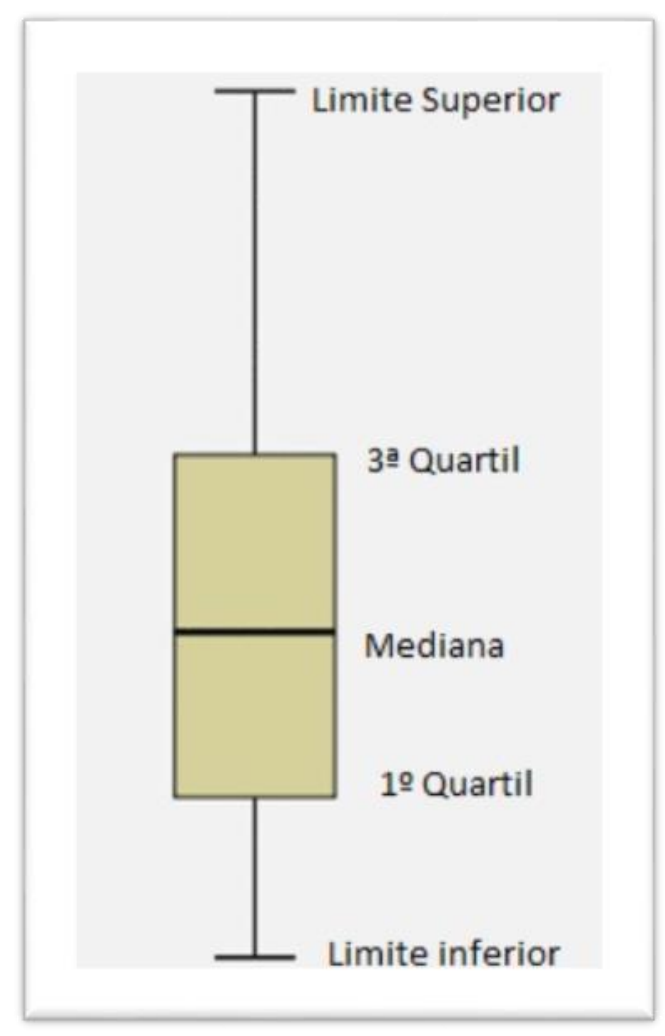

Fonte: Elaboração própria

Na segunda parte analisamos, por meio da técnica estatística de regressão logística, a associação entre a "média de nota" e demais variáveis independentes na condição de concluir ou evadir do curso.

\subsection{Análises descritivas}

Conforme verificamos no capítulo anterior, algumas características socioeconômicas dos ingressantes e da Instituição e/ou do curso estão mais associadas à condição de concluir ou evadir do curso de graduação. Além das análises bivariadas, apresentadas nesta seção, realizamos também testes de Qui-Quadrado de Pearson, para verificar se o resultado encontrado é fruto do acaso entre as variáveis. O resultado mostrou diferenças estatisticamente significativas de $1 \%$ para a maioria das variáveis

\footnotetext{
${ }^{74}$ Segundo Agresti \& Finlay (2012, p.71) "uma observação é um valor atípico se estiver a mais do que 1,5 (IIQ) acima do quartil superior ou a mais do que 1,5 (IIQ) abaixo do quartil inferior".
} 
selecionadas, o que indica haver uma associação entre essas variáveis, mas não o quão forte é esta associação (Agresti; Finlay, 2012). As variáveis "escola pública", “escolaridade da mãe" e "renda familiar" não apresentaram significância estatística neste teste.

Iniciamos a análise com a variável de rendimento acadêmico (média de notas) em relação à "evasão" e "conclusão" de curso. Ao verificar a distribuição da média da amostra entre o grupo que evadiu do curso e o que concluiu, observa-se que a nota é relevante, dada a diferença entre os grupos. Mais de $75 \%$ dos estudantes que evadiram do curso tinham média de nota inferior a 6,0 e uma mediana menor que 4,0. Ainda assim, e por se tratar apenas de evasão de curso, existem estudantes que evadiram com média acima de 6,0, inclusive acima de 9,0. Já o grupo que concluiu possui uma mediana próxima a 8,0. Isso indica que o rendimento acadêmico é um fator importante e que de algum modo pode contribuir para explicar o desfecho dos estudantes no curso (Gráfico 39).

Gráfico 39 - Evasão e conclusão, segundo médias de notas

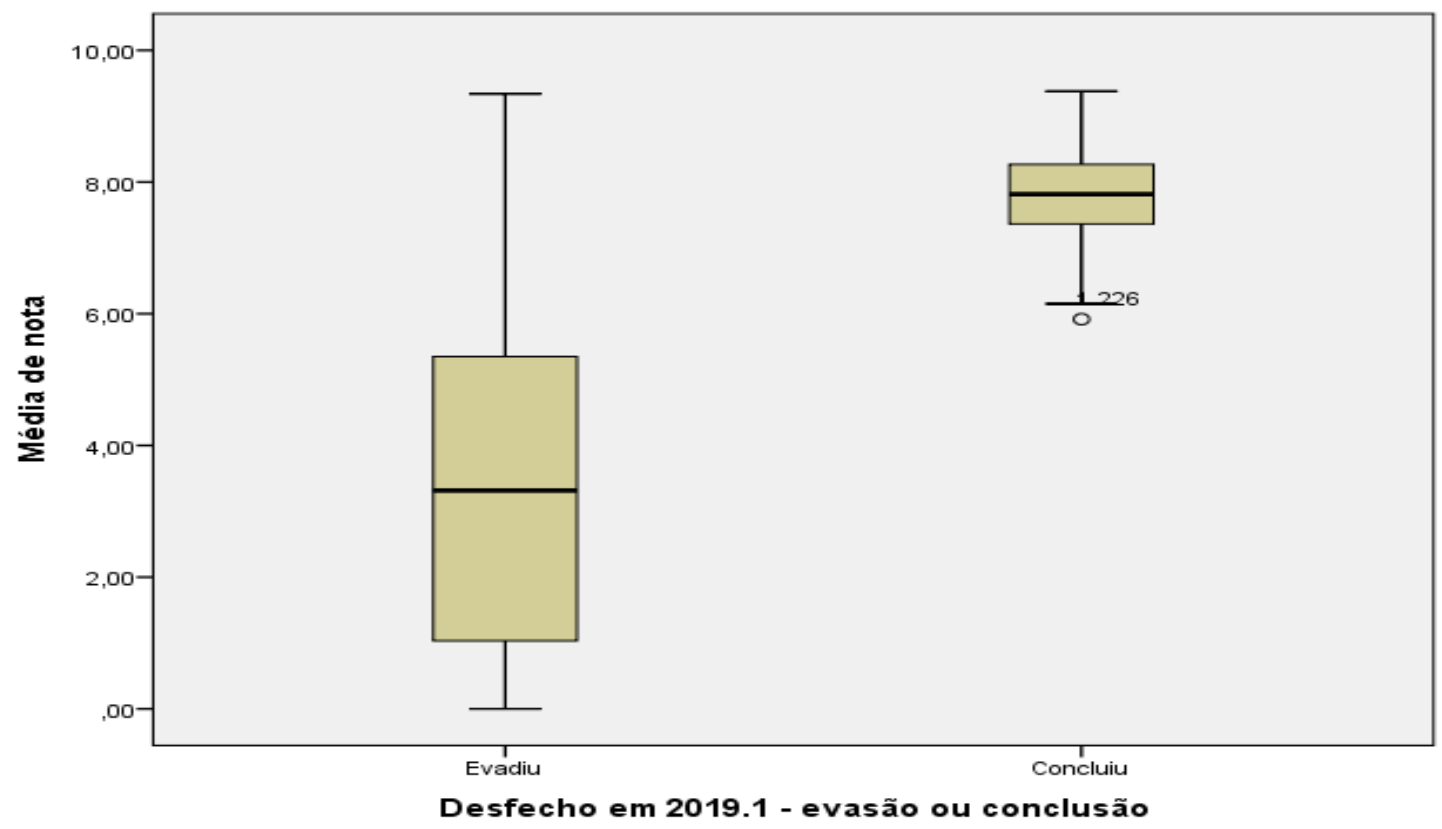

Fonte: Elaboração própria, a partir da base de dados da UFFS.

Entre as características dos estudantes, a idade de ingresso na graduação é um marcador de diferença que pode influenciar na escolha do curso e inclusive no desfecho. Observa-se que a maioria dos estudantes da UFFS ingressa na faixa etária entre 17 a 20 anos e os que ingressam acima desta faixa etária tendem a cursar mais cursos de 
licenciaturas, exceto no curso de Medicina, no qual os estudantes ingressam, em geral, com mais idade.

O Gráfico 40 mostra que conforme aumenta a faixa etária, maiores são os percentuais de evasão, sendo os ingressantes mais jovens os que apresentam os percentuais mais altos em termos de conclusão de curso.

Gráfico 40 - Evasão e conclusão, segundo faixa etária

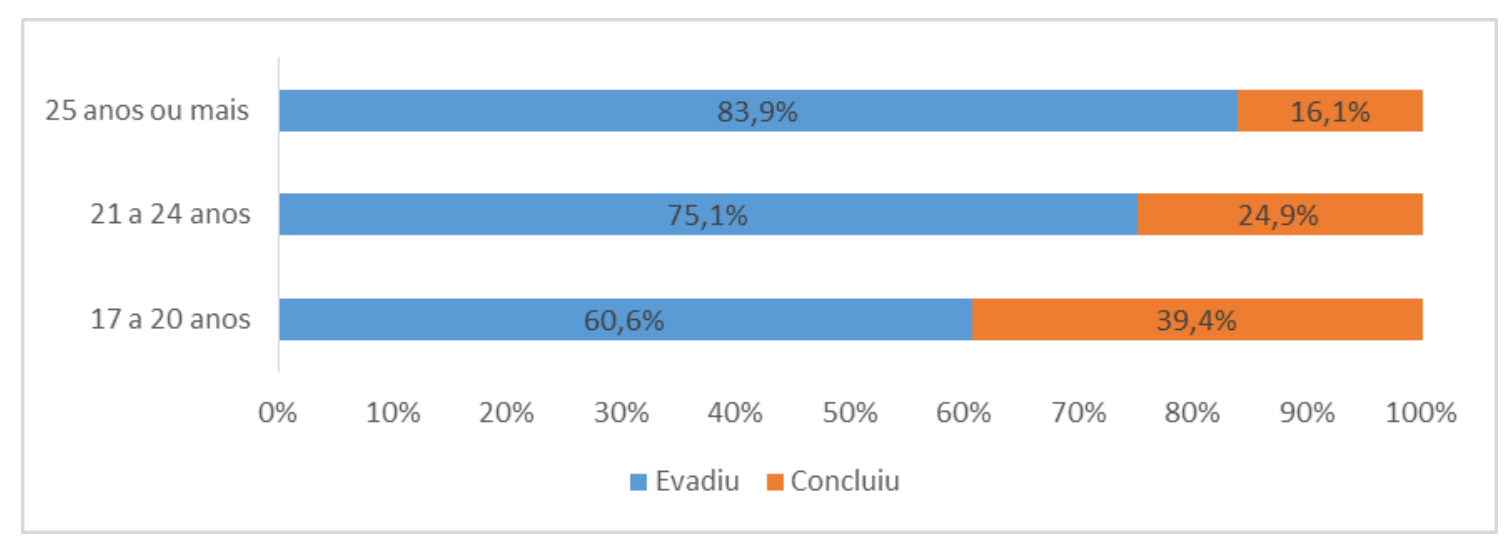

Fonte: Elaboração própria, a partir de bases de dados da UFFS

Ao cruzar a faixa etária com a variável média de notas observou-se que no grupo dos que evadiram do curso, a mediana de notas foi levemente superior para a faixa etária mais jovem (17 a 20 anos), mas com pouca diferença em relação às demais faixas etárias. Com relação aos que concluíram o curso, observa-se que a distribuição das notas foi muito semelhante entre as faixas etárias (Gráficos 41 e 42). 
Gráfico 41 - Média de nota, segundo a faixa etária - ingressantes que evadiram o curso

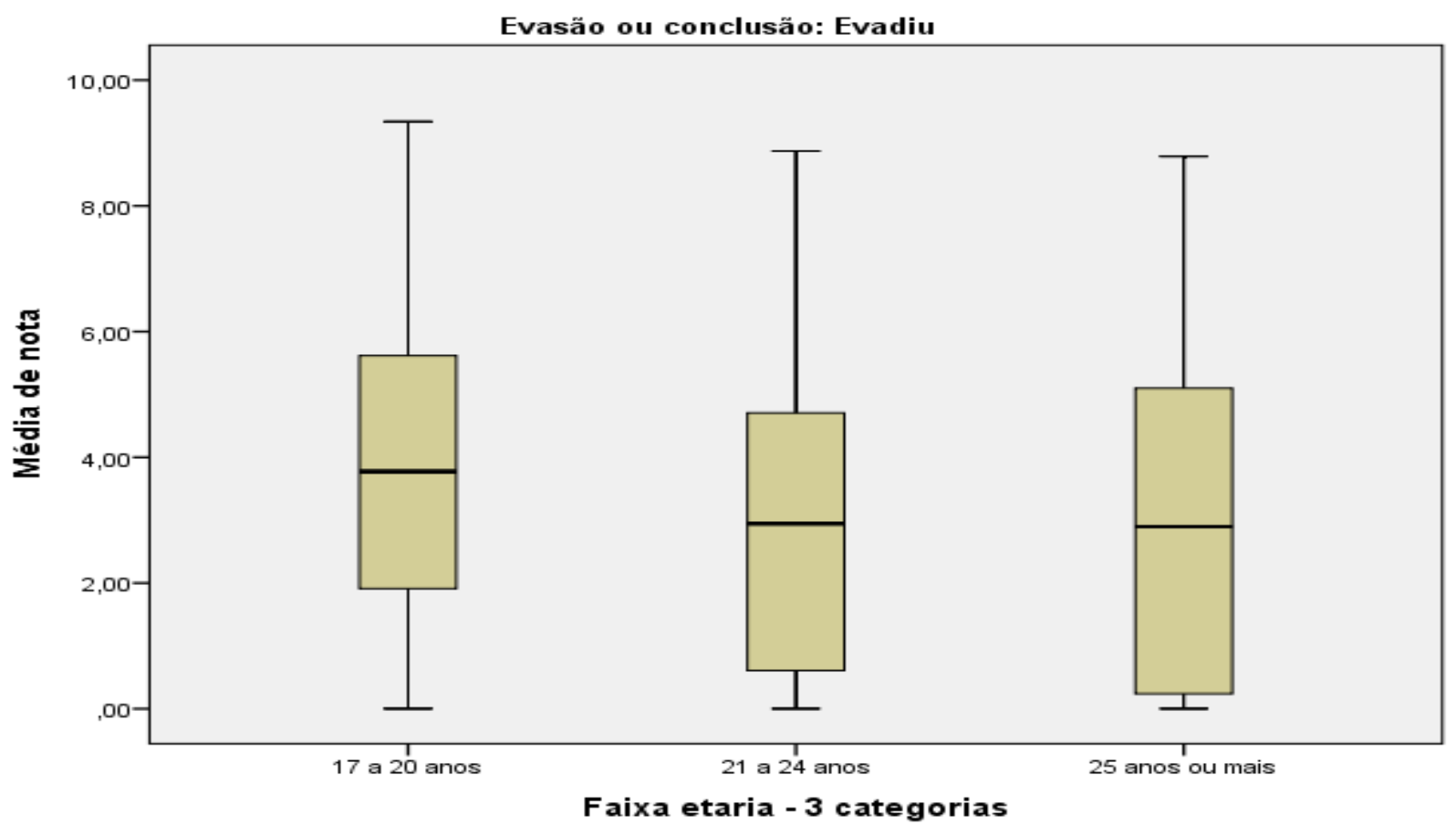

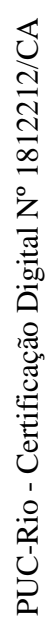

Fonte: Elaboração própria, conforme base de dados da UFFS

Gráfico 42 - Média de nota, segundo a faixa etária - ingressantes que concluíam o curso

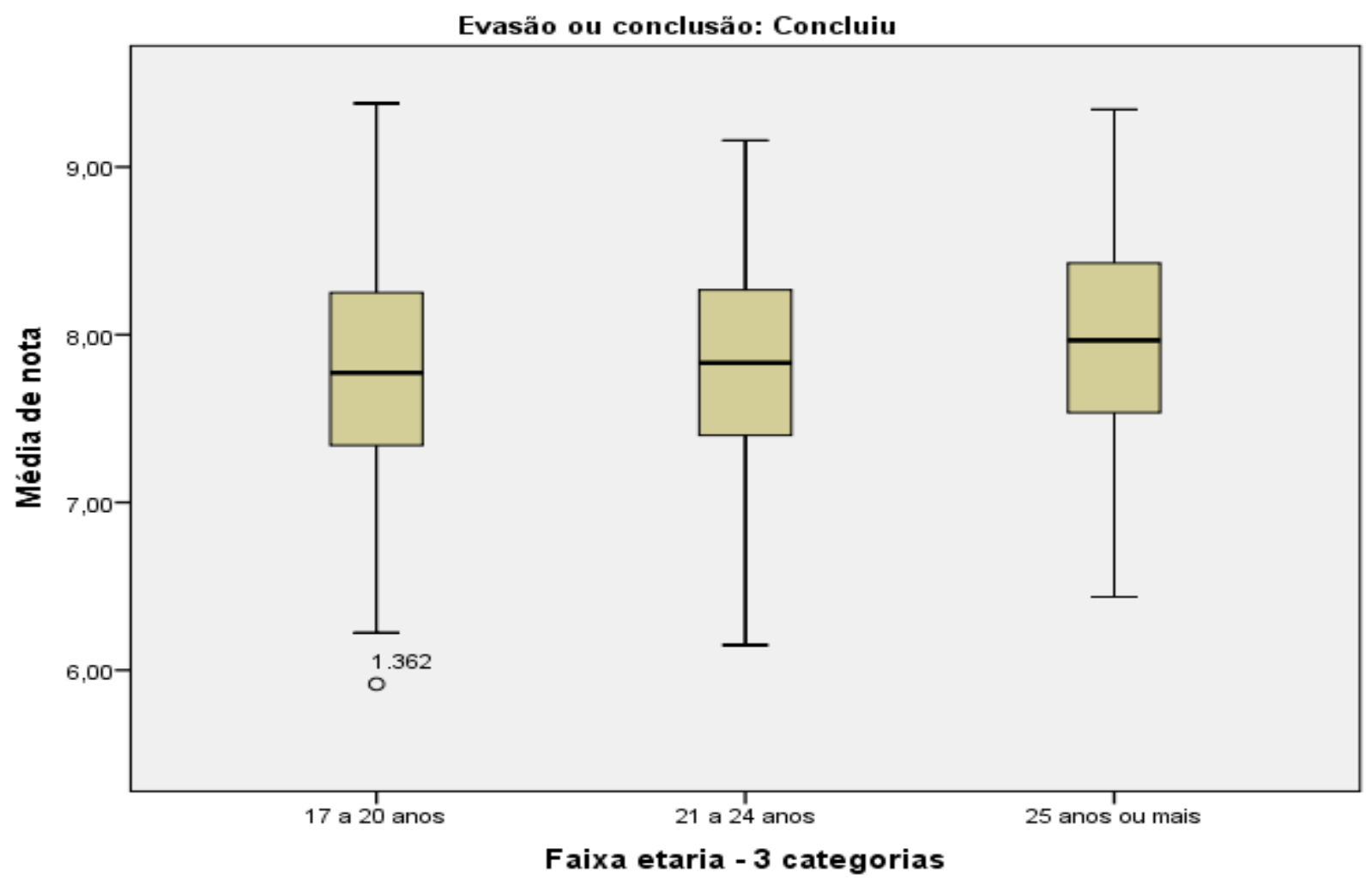

Fonte: Elaboração própria, conforme base de dados da UFFS 
Conforme já foi verificado em capítulos anteriores, a ocupação dos cursos possui uma estratificação marcada por sexo, em que as mulheres tendem a fazer suas escolhas principalmente em carreiras consideradas como "femininas", como em áreas de saúde e de licenciaturas. Ao ser considerada também a variável raça/cor observam-se diferenças entre estes grupos em termos de conclusão e de evasão de curso: maiores vantagens das mulheres em relação aos homens e, principalmente, das mulheres brancas em relação aos homens negros (Gráfico 43).

Gráfico 43 - Evasão e conclusão, segundo sexo_raça

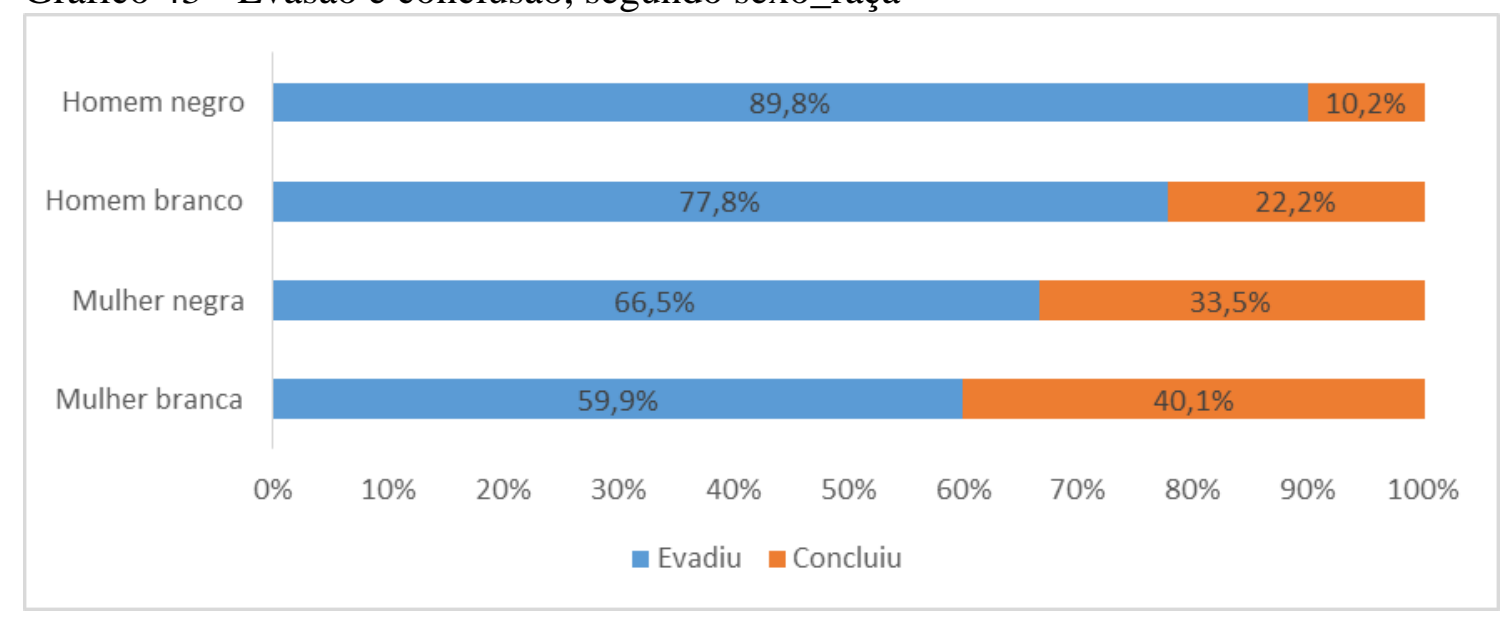

Fonte: Elaboração própria, a partir de bases de dados da UFFS

Os Gráficos 44 e 45 presentam a média de notas segundo "sexo_raça” de forma separada para o grupo que evadiu e para o que concluiu o curso. Entre os que evadiram, observa-se uma diferença principalmente no grupo de homens negros, cuja mediana é menor, com uma concentração de notas mais baixas em relação aos demais grupos na distribuição dos $75 \%$ da amostra ( $3^{\circ}$ quartil). Isso indica que, em termos de notas, a questão racial parece estar interferindo mais no grupo dos que não permanecem no curso. Esses resultados se aproximam do estudo realizado por Ernica \& Rodrigues (2020), que observam um padrão de desempenho semelhante na educação básica, que confere maiores desvantagens educacionais aos homens negros, mais especificamente entre os autodeclarados pretos. No grupo de concluintes as distribuições de notas se assemelham mais, embora as mulheres brancas possuem mediana de notas levemente superiores aos demais grupos. 
Gráfico 44 - Média de nota, segundo sexo_raça - ingressantes que evadiram do curso

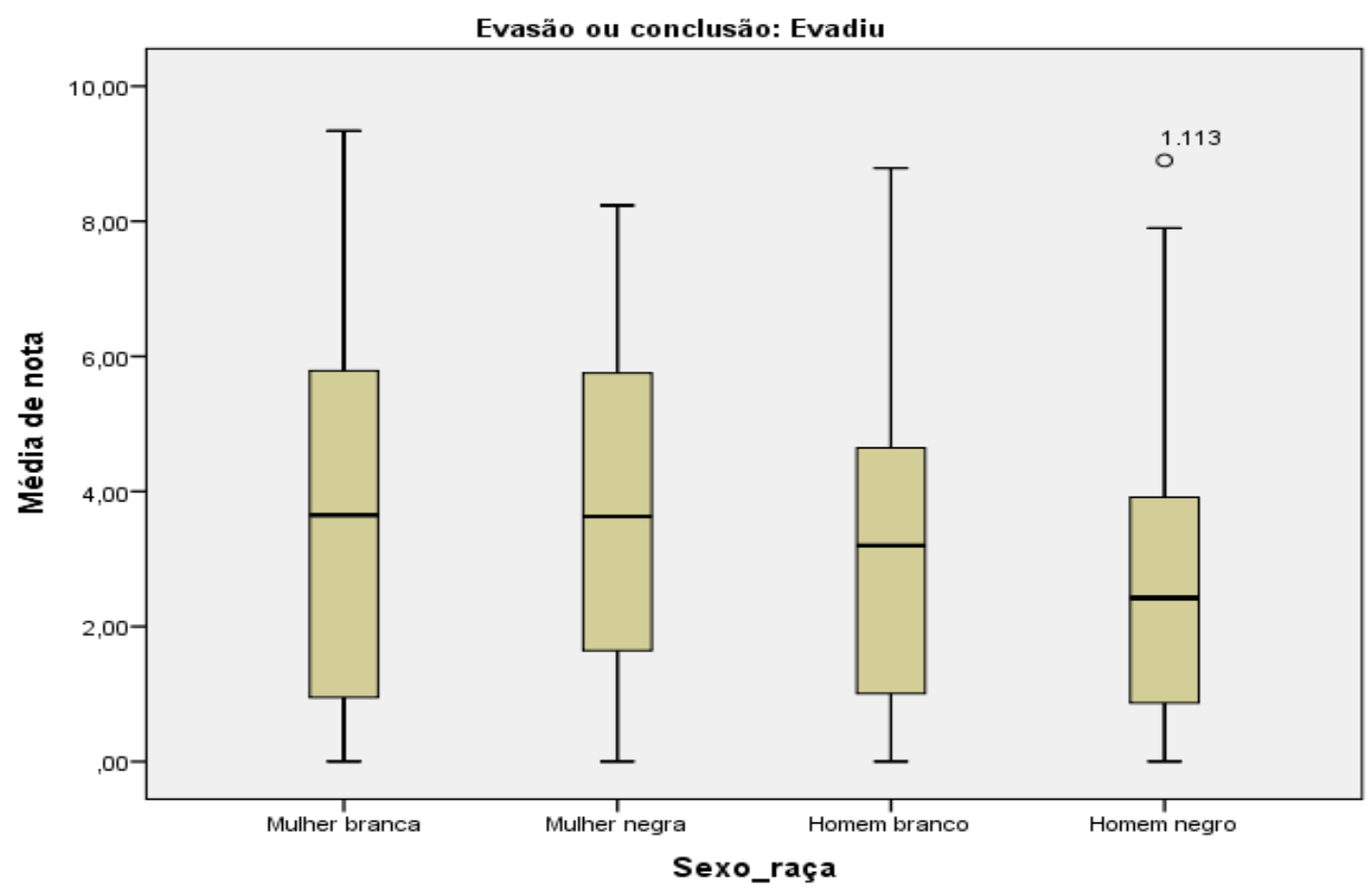

Fonte: Elaboração própria, a partir de bases de dados da UFFS

Gráfico 45 - Média de nota, segundo sexo_raça - ingressantes que concluíram o curso

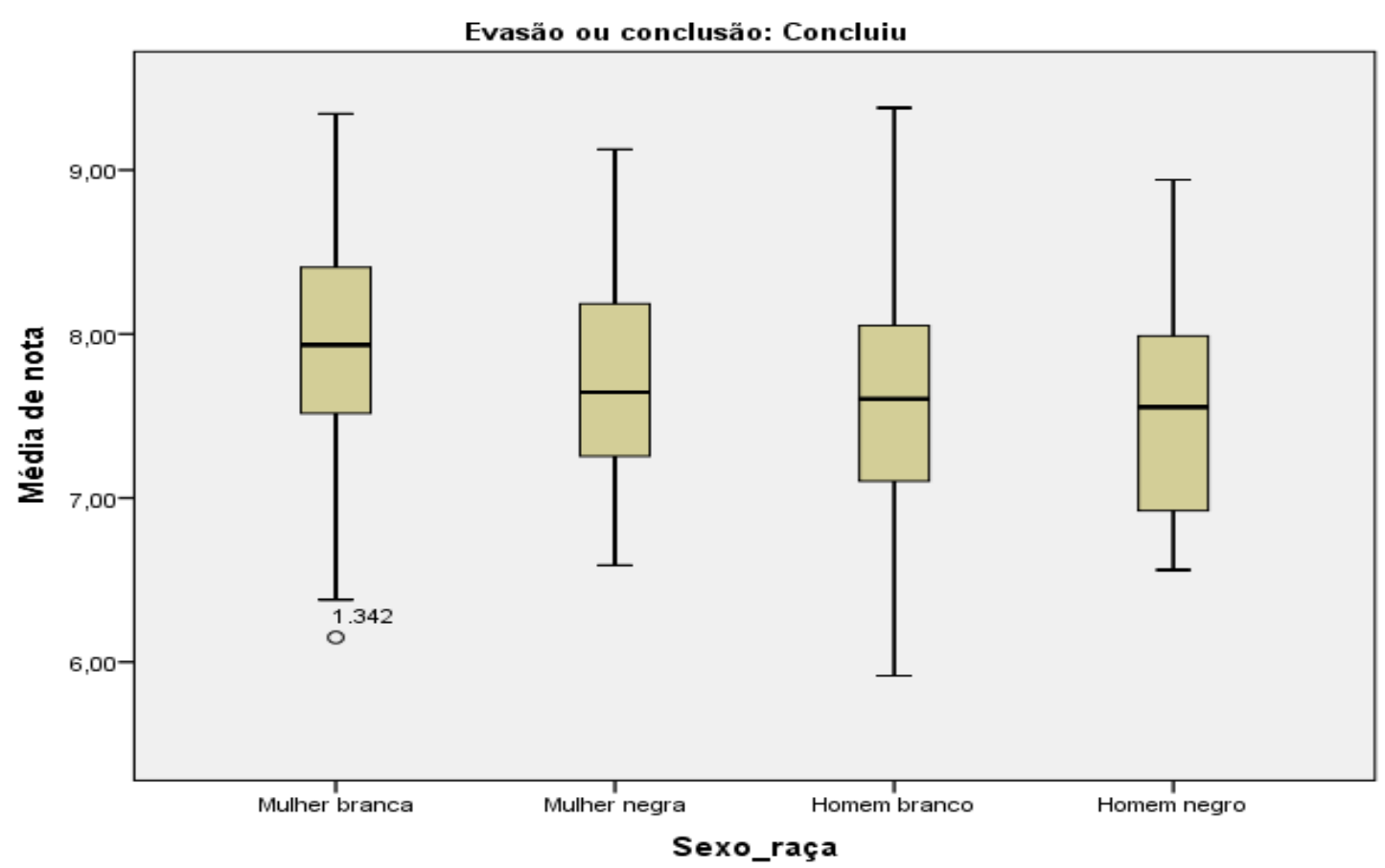

Fonte: Elaboração própria, a partir de bases de dados da UFFS 
A renda familiar é uma das variáveis que, conforme verificado no capítulo anterior, não apresenta diferenças estatisticamente significativas no desfecho dos estudantes. No Gráfico 46 é possível observar que a diferença na conclusão de curso entre os que possuem maior e menor renda é pequena.

Gráfico 46 - Evasão e conclusão, segundo renda familiar

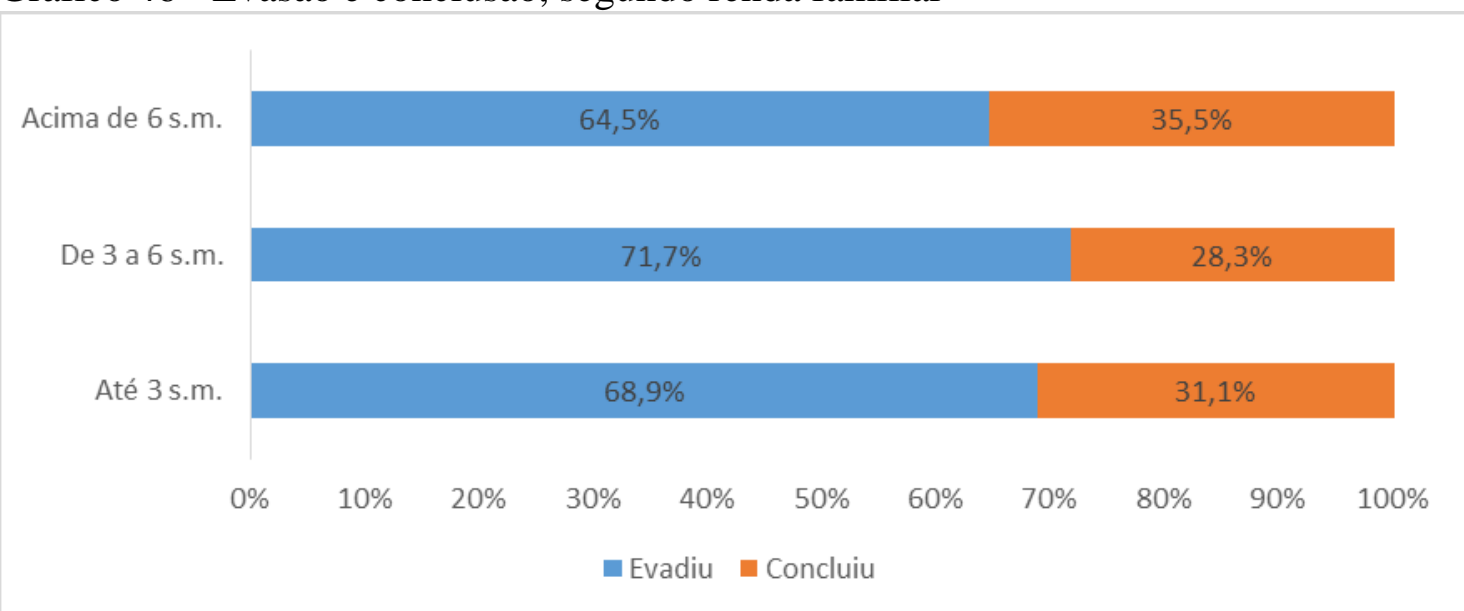

Fonte: Elaboração própria, a partir de bases de dados da UFFS

Ainda que não se mostra estatisticamente significativa para o desfecho "evasão" ou "conclusão" de curso, ao cruzar a variável renda familiar com a média de notas observou-se que tanto para os que evadiram quanto no grupo de concluintes a mediana de notas é semelhante entre os grupos e levemente superior para aqueles com maior renda familiar (Gráficos 47 e 48). Pedrosa et al. (2006), também encontraram resultados de desempenho inclusive superiores para estudantes de extratos socioeconômicos desfavorecidos na Unicamp, e denominaram este fenômeno de "resiliência educativa", ou seja, quando as desvantagens em períodos anteriores de vida se traduzem em um melhor desempenho educacional em momento posterior.

A evasão de curso também pode indicar uma situação de mobilidade para outro curso de graduação na mesma ou em outra Instituição. Conforme já observado por De Paula (2021), estudantes com melhores condições socioeconômicas tendem mais a se evadir dos cursos de modo voluntário, em busca de melhores perspectivas, enquanto os estudantes das camadas populares, tendem mais a evadir de modo involuntário, motivados, muitas vezes, por dificuldades financeiras e/ou acadêmicas. Neste sentido, considera-se que a origem social é um marcador social importante a ser considerado na trajetória dos estudantes, pela força que exerce na escolha do curso e/ou instituição e na trajetória após o ingresso. 
Gráfico 47 - Média de nota, segundo renda familiar - ingressantes que evadiram do curso

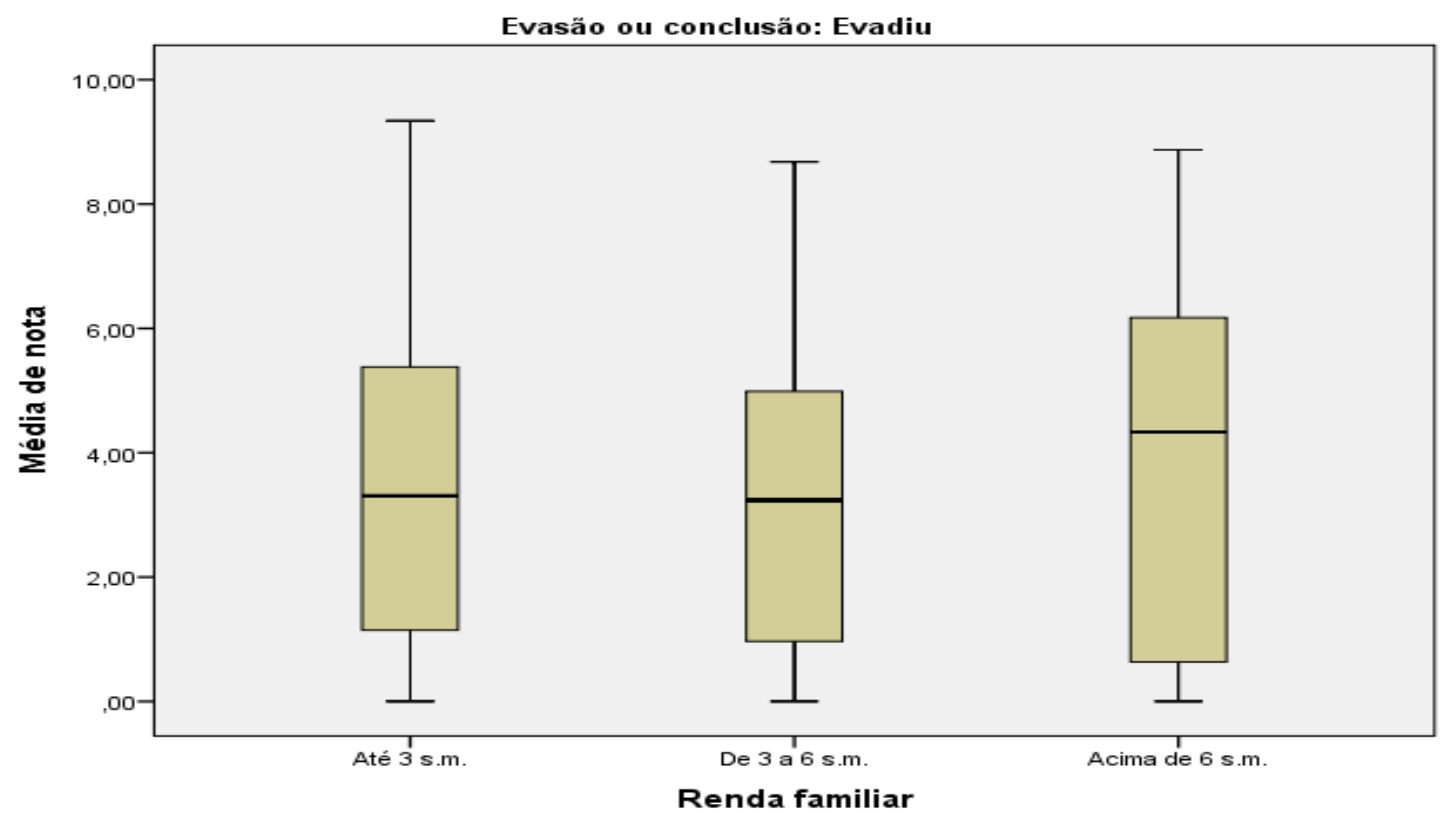

Fonte: Elaboração própria, a partir de bases de dados da UFFS

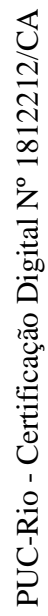

Gráfico 48 - Média de nota, segundo renda familiar - ingressantes que concluíram o curso

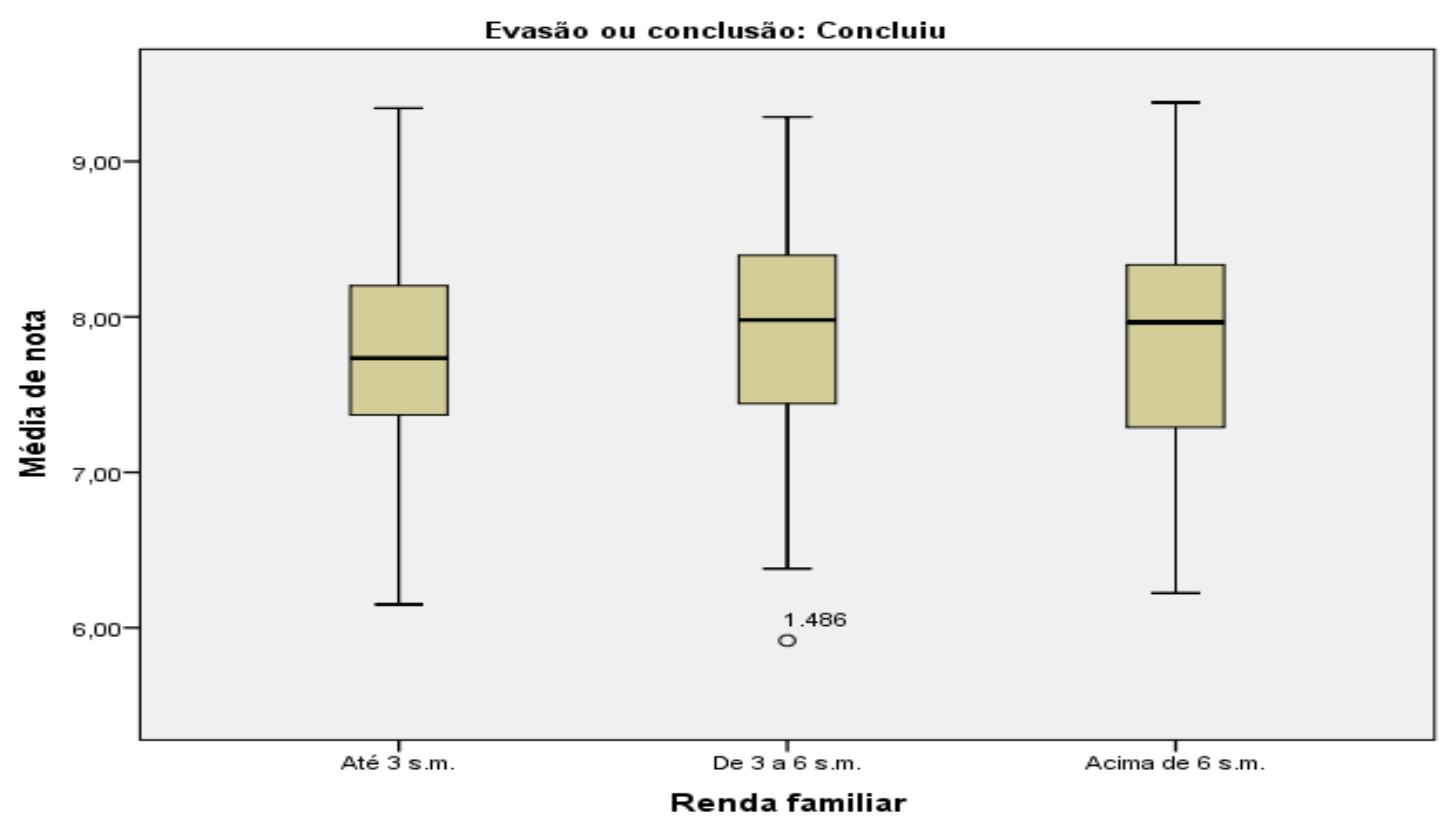

Fonte: Elaboração própria, a partir de bases de dados da UFFS

Da mesma forma que a renda familiar, a escolaridade da mãe indica não interferir no desfecho dos ingressantes no ensino superior. Conforme mostra o Gráfico 49, evasão e conclusão são semelhantes e variam segundo a escolaridade da mãe, sendo o menor 
percentual de conclusão encontrado entre ingressantes cuja mãe é mais escolarizada (ensino superior). Esses resultados se aproximam do estudo de Pedrosa e colegas (2006), por exemplo, que já haviam identificado maior desempenho, entre estudantes das camadas desfavorecidas, de modo que, escolaridade dos pais e condição socioeconômica podem não estar diretamente associados ao desempenho dos estudantes na graduação.

Gráfico 49 - Evasão e conclusão, segundo escolaridade da mãe

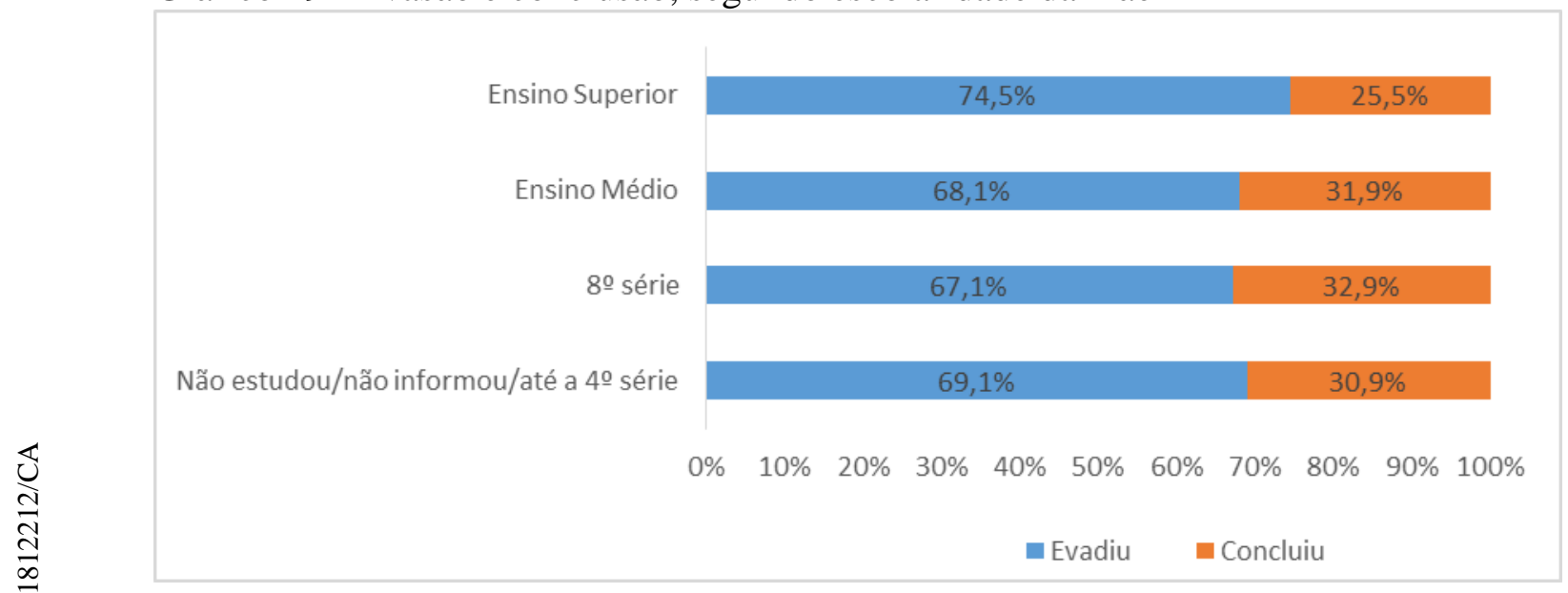

Fonte: Elaboração própria, a partir de bases de dados da UFFS

Ao cruzar com a média de notas observou-se também não haver diferenças com relação ao nível de escolarização da mãe dos estudantes da UFFS (Gráficos 50 e 51). 
Gráfico 50 - Média de notas, segundo escolaridade da mãe - ingressantes que evadiram

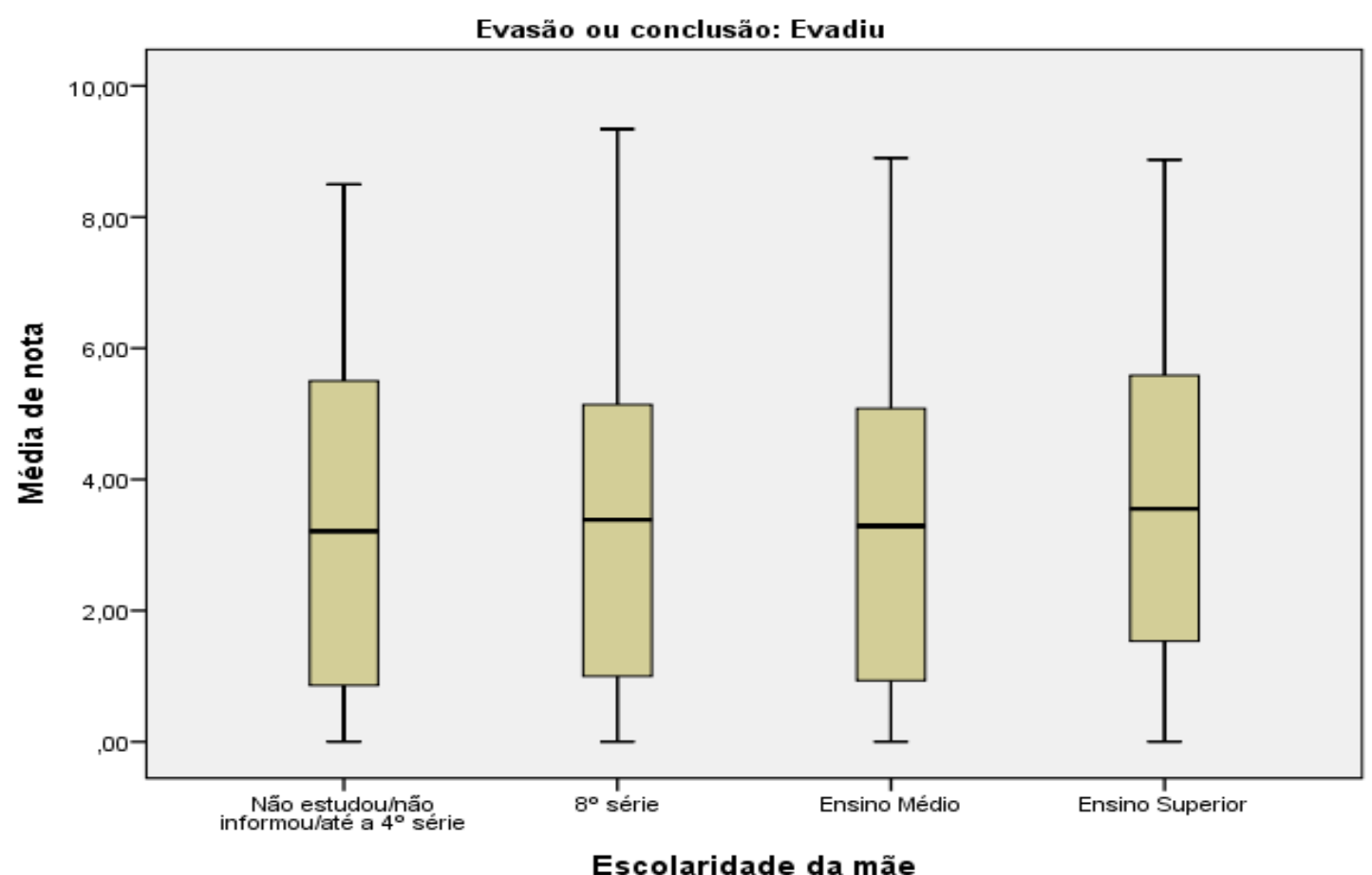

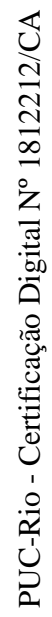

Fonte: Elaboração própria, a partir de base de dados da UFFS

Gráfico 51 - Média de notas, segundo escolaridade da mãe - ingressantes que concluíram

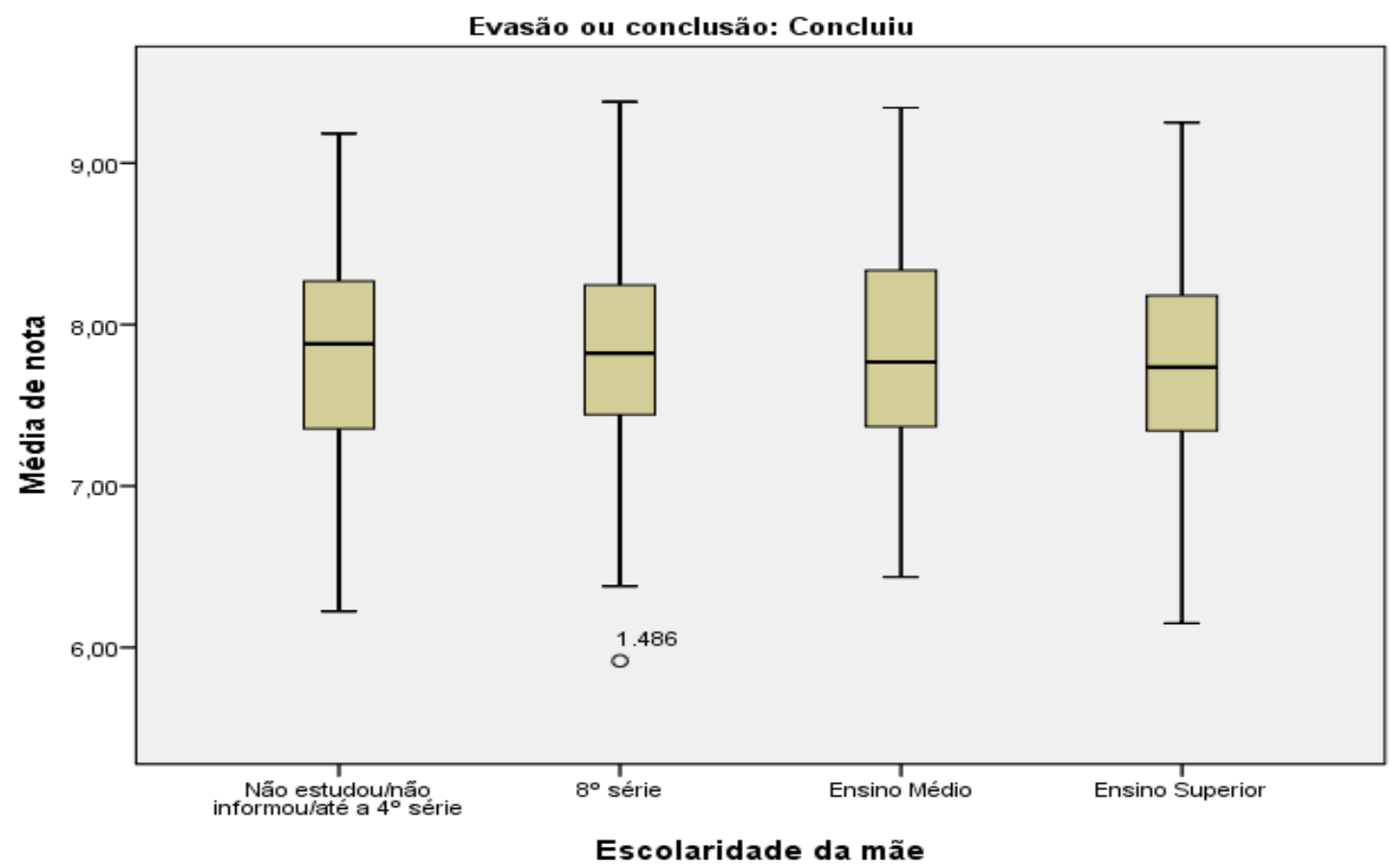

Fonte: Elaboração própria, a partir de base de dados da UFFS 
Os dados sinalizam que, ao romper as barreiras de acesso ao ensino superior, o desempenho em termos de notas quanto nas chances de conclusão de curso de ingressantes mais pobres e cujos pais possuem baixa escolaridade é semelhante aos demais ingressantes com melhores condições socioeconômicas.

O fato de não encontrar efeitos de renda e de escolaridade dos pais nas chances de conclusão e de evasão de curso e apenas pequenas diferenças em relação ao rendimento dos estudantes e à condição de renda familiar é um achado importante deste estudo, porque pode estar sinalizando para algum avanço na redução da desigualdade de oportunidades. Em termos do desempenho no Enem, por exemplo, conforme mostra o estudo de Figueirêdo, Nogueira \& Santana (2014), a renda familiar constitui um dos fatores mais incisivos da desigualdade de oportunidade educacional, seguido da escolaridade da mãe e outros fatores, como a escolaridade do pai; o tipo de escola frequentado; localidade de residência e sexo. Quanto melhores são as oportunidades, expressas em termos de renda e escolaridade dos pais (backgound familiar), maior é o desempenho no Enem. Os achados deste estudo também encontraram impacto positivo na nota do Enem para estudantes residentes na área urbana, do sexo feminino, autodeclarados brancos, com origem em escolas privadas e cujas escolas possuíam melhores resultados no Sistema de Avaliação da Educação Básica (SAEB).

Conforme Bertolin, Amaral \& Almeida (2019) os atributos do curso de graduação podem estar mais relacionados ao desempenho que as condições socioeconômicas dos estudantes. Com base em dados do Enade, os autores buscaram estabelecer relações entre o desempenho de universitários de camadas populares com aspectos de background destes estudantes e atributos qualitativos relacionados aos cursos de graduação, tais como infraestrutura e aspectos pedagógicos. Para isso, selecionaram estudantes com condições socioeconômicas semelhantes de dois cursos (Direito e Administração) e compararam a média de notas destes com a média nacional destes cursos. Os resultados mostraram que as médias de notas de concluintes dos meios populares foram superiores à média nacional, o que indica que aspectos dos cursos de graduação podem compensar em alguma medida as fragilidades socioeconômicas, o que significa que as notas parecem estar mais relacionadas aos atributos de um determinado curso. Em edição do Enade de 2009, por exemplo, a média dos estudantes de meios populares na área do Direito foi de 56,27, enquanto que a média nacional foi de 52,02, e na Administração, a diferença foi de foi 40,69 para 37,5, respectivamente. 
Na coorte de ingressantes em 2013, mais de 50\% declararam que trabalhavam antes do ingresso na UFFS. O maior percentual de conclusão de curso encontra-se no grupo dos que não haviam trabalhado neste período, conforme mostra o Gráfico 52. A condição de trabalho, tendo permanecido no decorrer da graduação, pode influenciar inclusive na escolha do tipo de curso e turno e também pode resultar em menor conclusão de curso e/ou a evasão do curso. Estudantes em situação de trabalho na graduação tendem a cursar mais as licenciaturas e no período noturno.

Gráfico 52 - Evasão e conclusão, segundo situação de trabalho antes do ingresso

Não trabalhou antes do ingresso

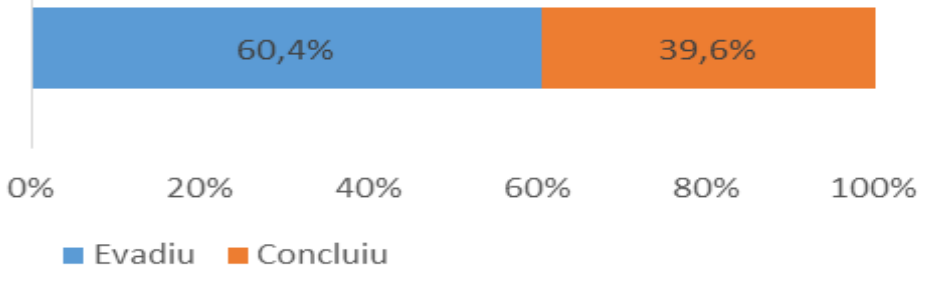

Fonte: Elaboração própria, a partir de bases de dados da UFFS

Ao cruzar esta variável com a média de notas, observou-se que praticamente não existem diferenças entre os evadidos e os que concluíram o curso (Gráficos 53 e 54). 
Gráfico 53 - Média de notas, segundo situação de trabalho no ensino médio ingressantes que evadiram

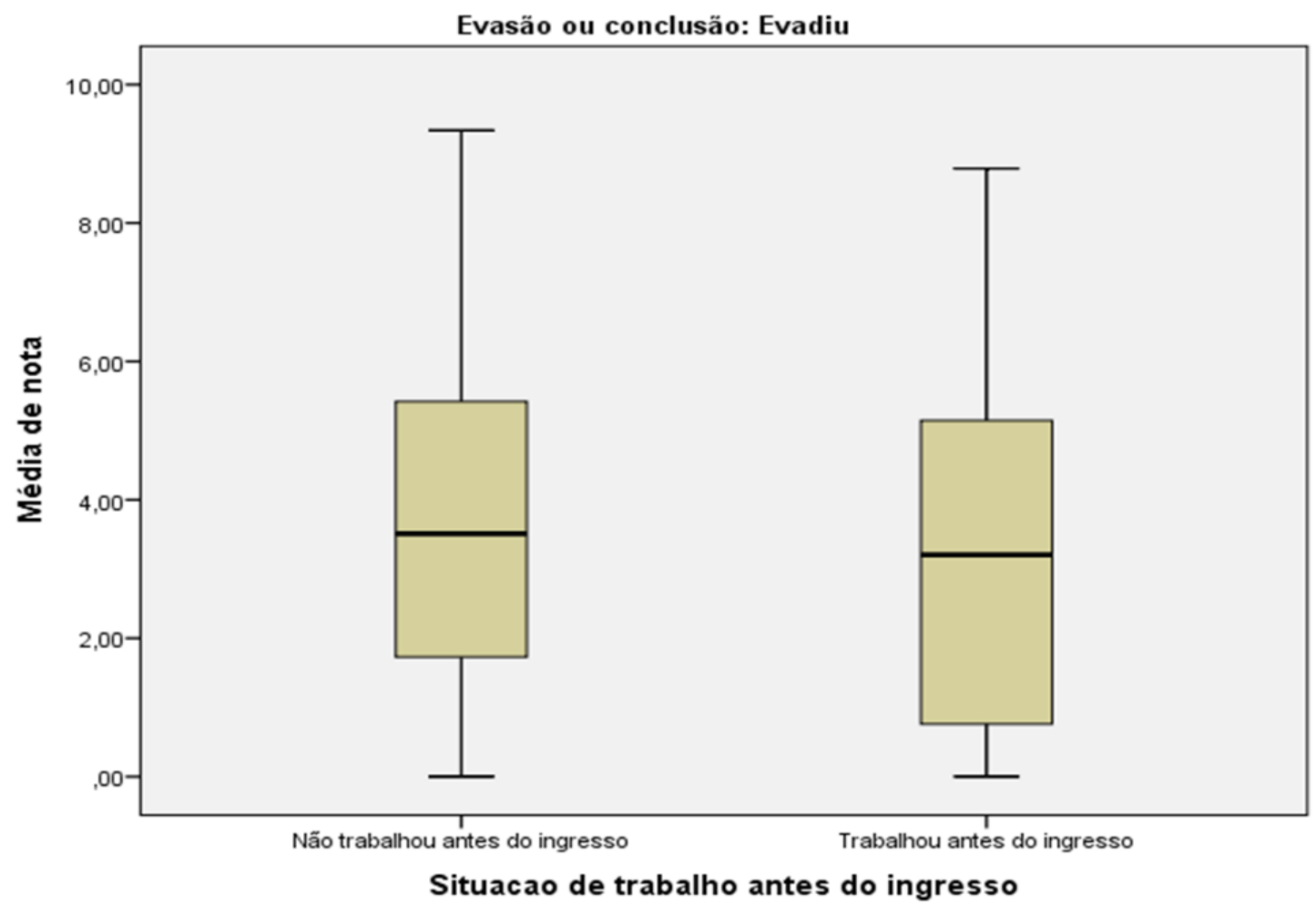

Fonte: Elaboração própria, a partir de bases de dados da UFFS

Gráfico 54 - Média de notas, segundo situação de trabalho no ensino médio ingressantes que evadiram

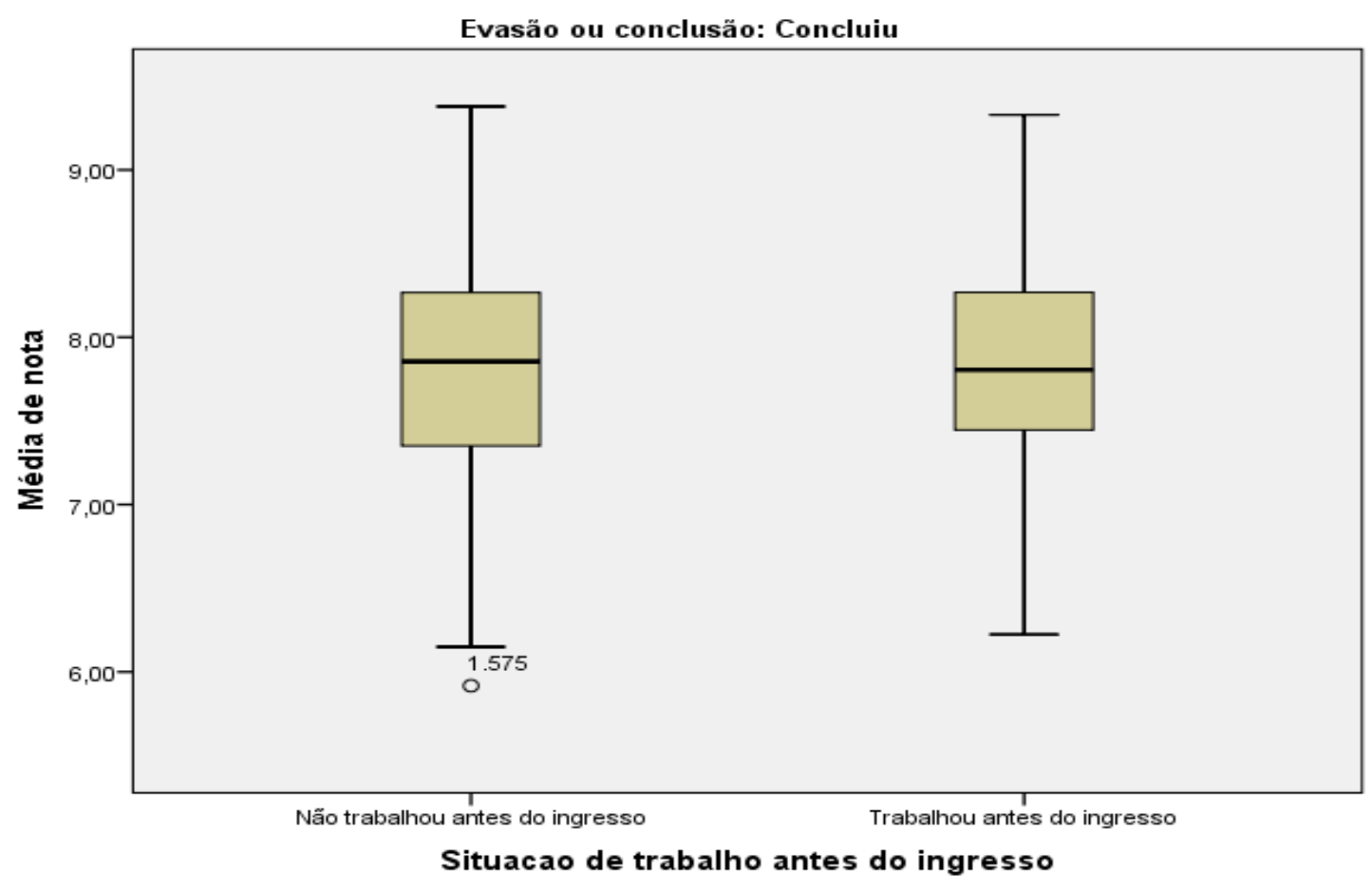

Fonte: Elaboração própria, a partir de bases de dados da UFFS 
A localização da moradia chama atenção para o fato de que estudantes da zona rural tendem a evadir menos dos cursos e a concluir mais, conforme mostra o Gráfico 55. Os modelos de regressão logística do capítulo anterior mostraram que esta variável foi estatisticamente significativa tanto nas chances de evasão, quanto de conclusão de curso.

Gráfico 55 - Evasão e conclusão, segundo localização da moradia

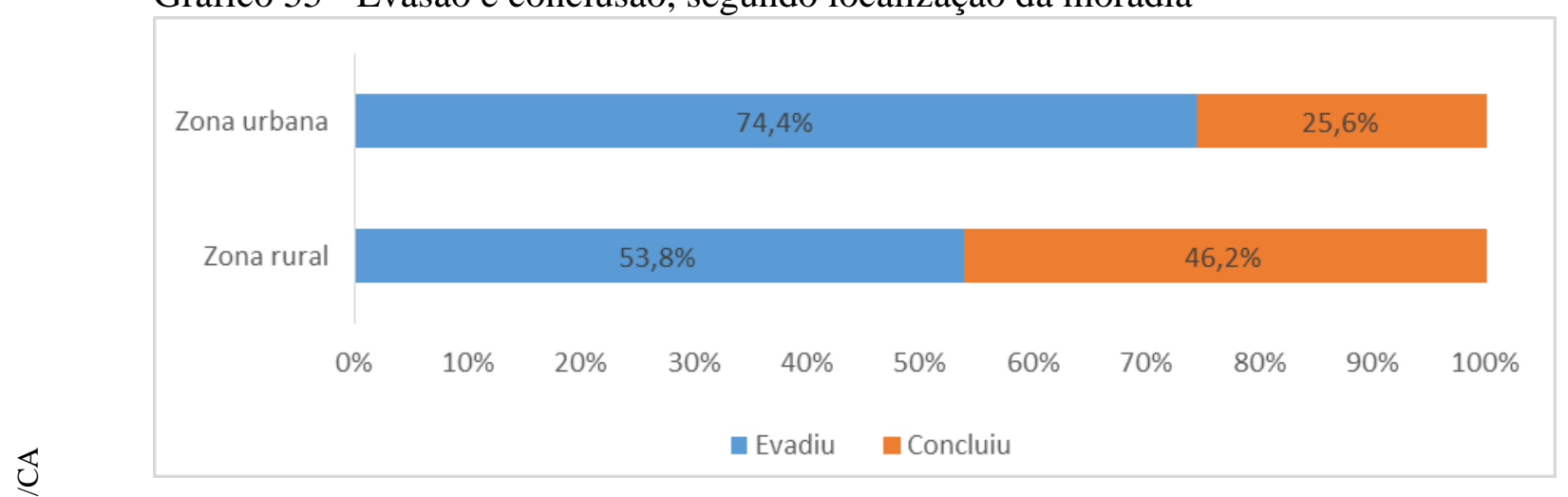

Fonte: Elaboração própria, a partir de bases de dados da UFFS

Ao cruzar a variável "média de nota" com localização da moradia, observou-se que entre os que evadiram as notas de estudantes da zona rural são ligeiramente superiores aos da zona urbana, embora a maioria dos evadidos do curso possua média inferior a 6,0 (Gráfico 56). Entre os que concluíram o curso não há diferenças na média de notas entre estudantes das zonas rural e urbana (Gráfico 57). 
Gráfico 56 - Média de nota, segundo a localização da moradia - ingressantes que evadiram

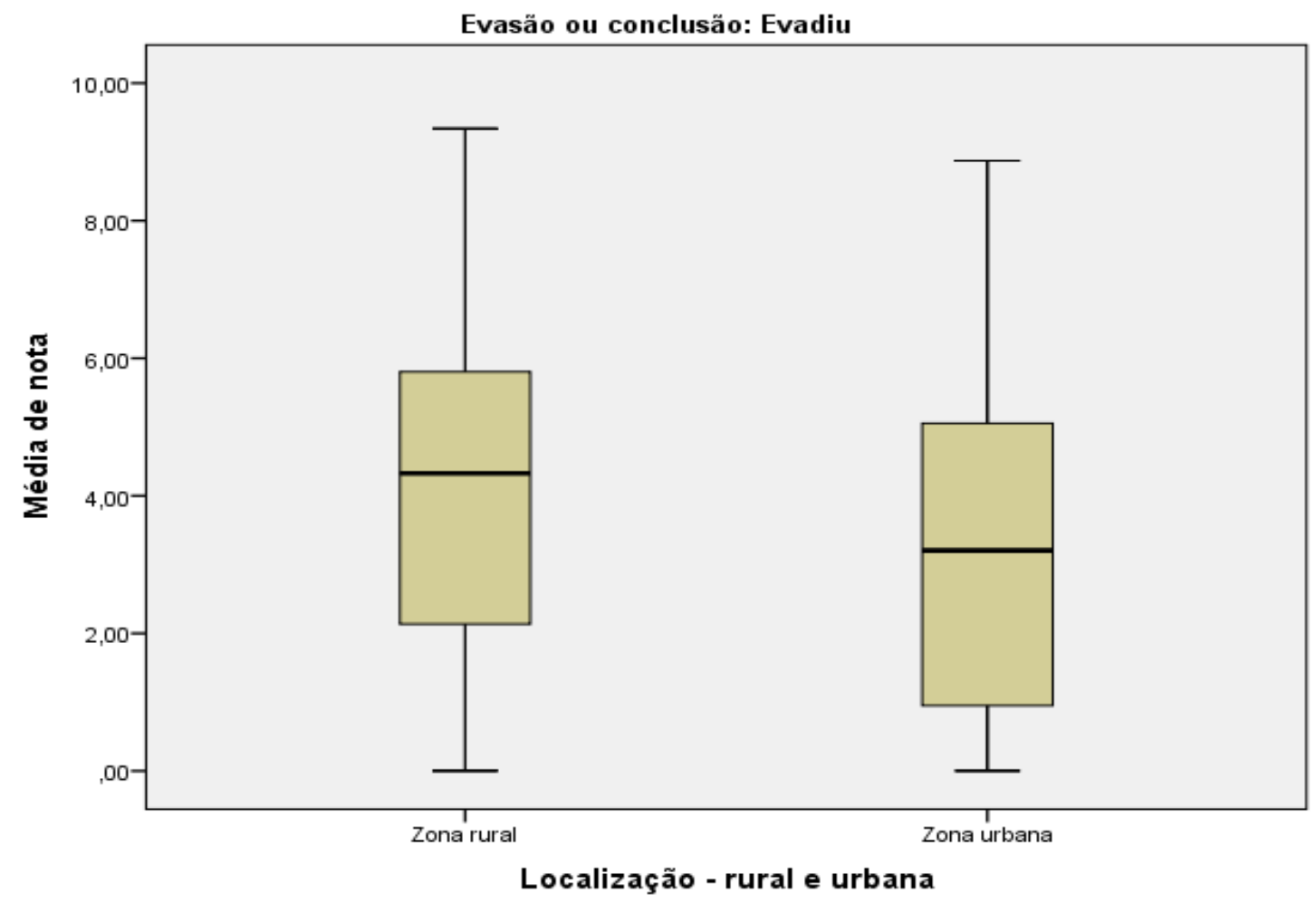

Fonte: Elaboração própria, segundo base dados da UFFS

Gráfico 57 - Média de nota, segundo a localização da moradia - ingressantes que concluíram

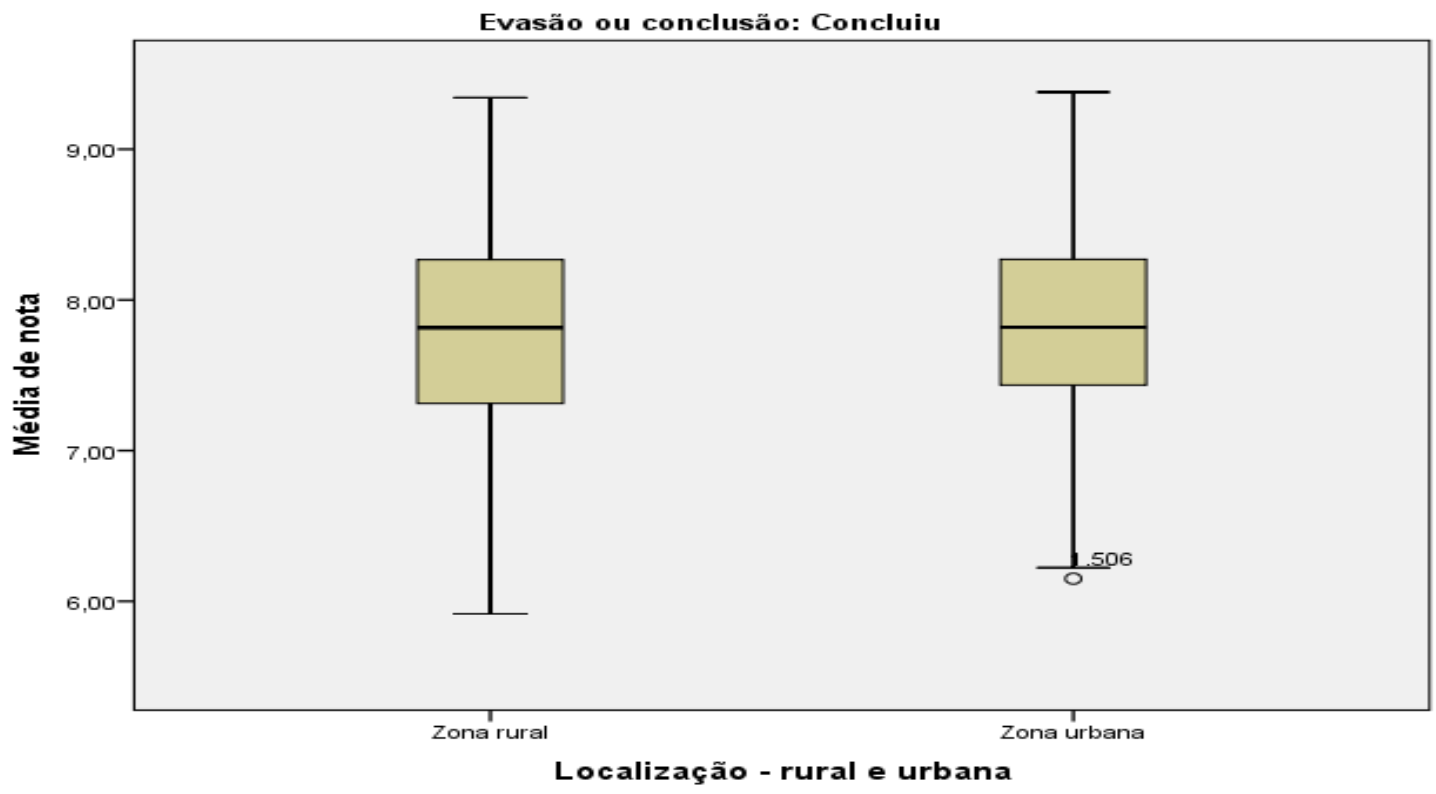

Fonte: Elaboração própria, conforme base de dados da UFFS 
Com relação à origem escolar dos estudantes e conforme já verificado nas regressões logísticas apresentadas no capítulo 8, não existem diferenças quanto à evasão ou conclusão de curso entre os que estudaram ou não em escola pública no Ensino Médio. O Gráfico 58 apresenta uma pequena diferença nos percentuais de evasão e de conclusão, tendo os egressos de escola pública maiores percentuais de conclusão.

Gráfico 58 - Evasão e conclusão de curso, segundo escola pública no Ensino Médio

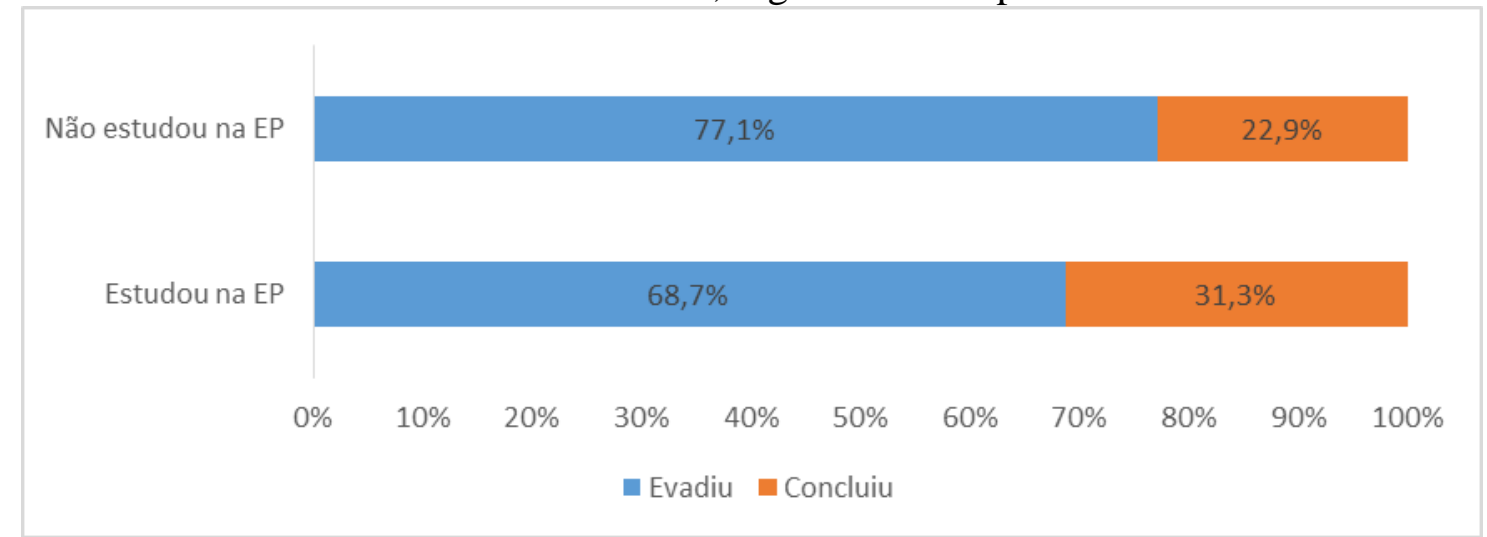

Fonte: Elaboração própria, a partir da base de dados da UFFS

Em termos de rendimento acadêmico, observou-se que entre os que evadiram do curso as médias são semelhantes (Gráfico 59). A mediana de notas é ligeiramente superior para os que não estudaram em escola pública e concluíram o curso (Gráfico $60)$. 
Gráfico 59 - Média de notas, segundo escola púbica - ingressantes que evadiram

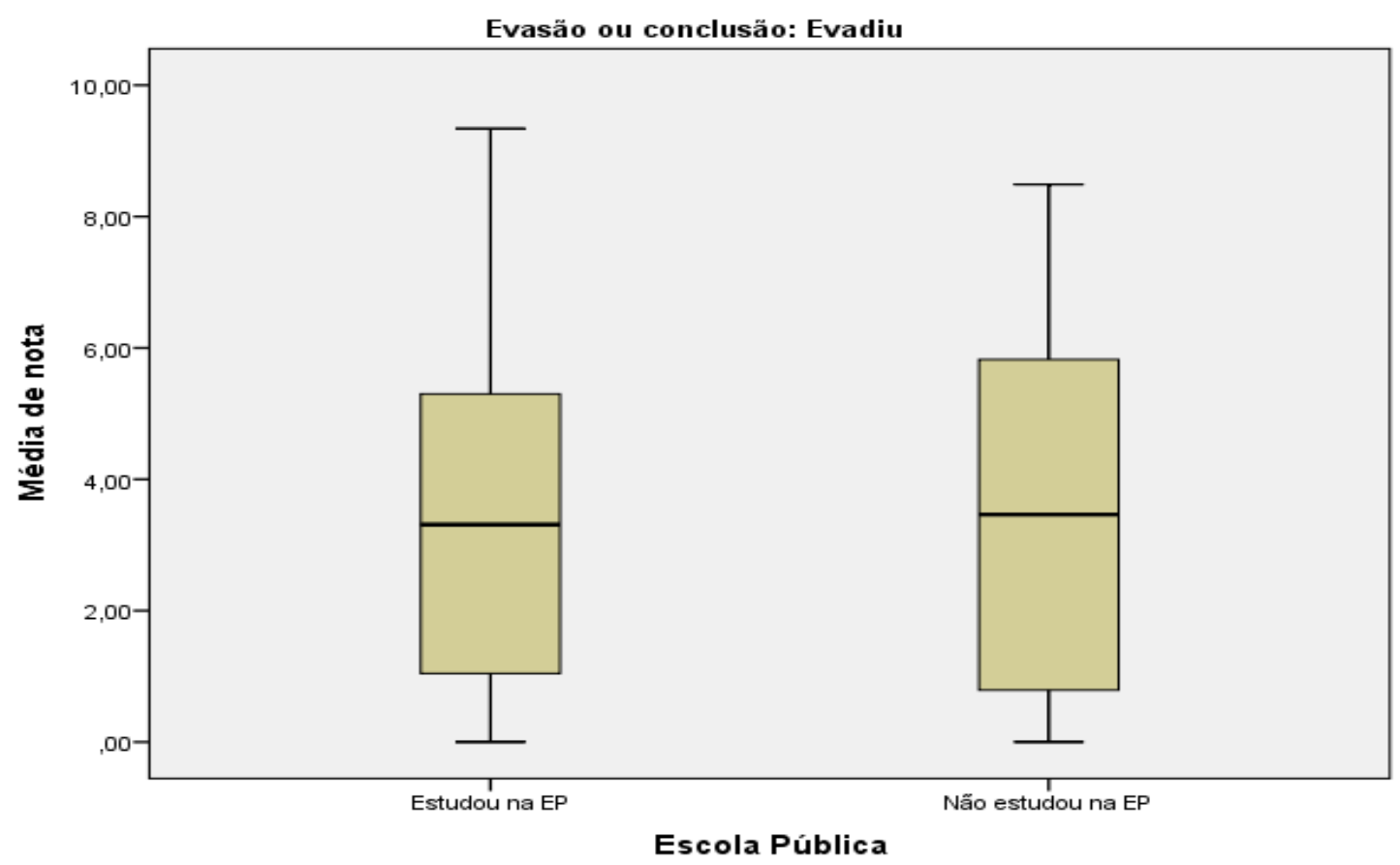

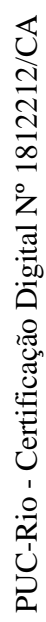

Fonte: Elaboração própria, conforme base de dados da UFFS

Gráfico 60 - Média de notas, segundo escola pública - ingressantes que concluíram

Evasão ou conclusão: Concluiu

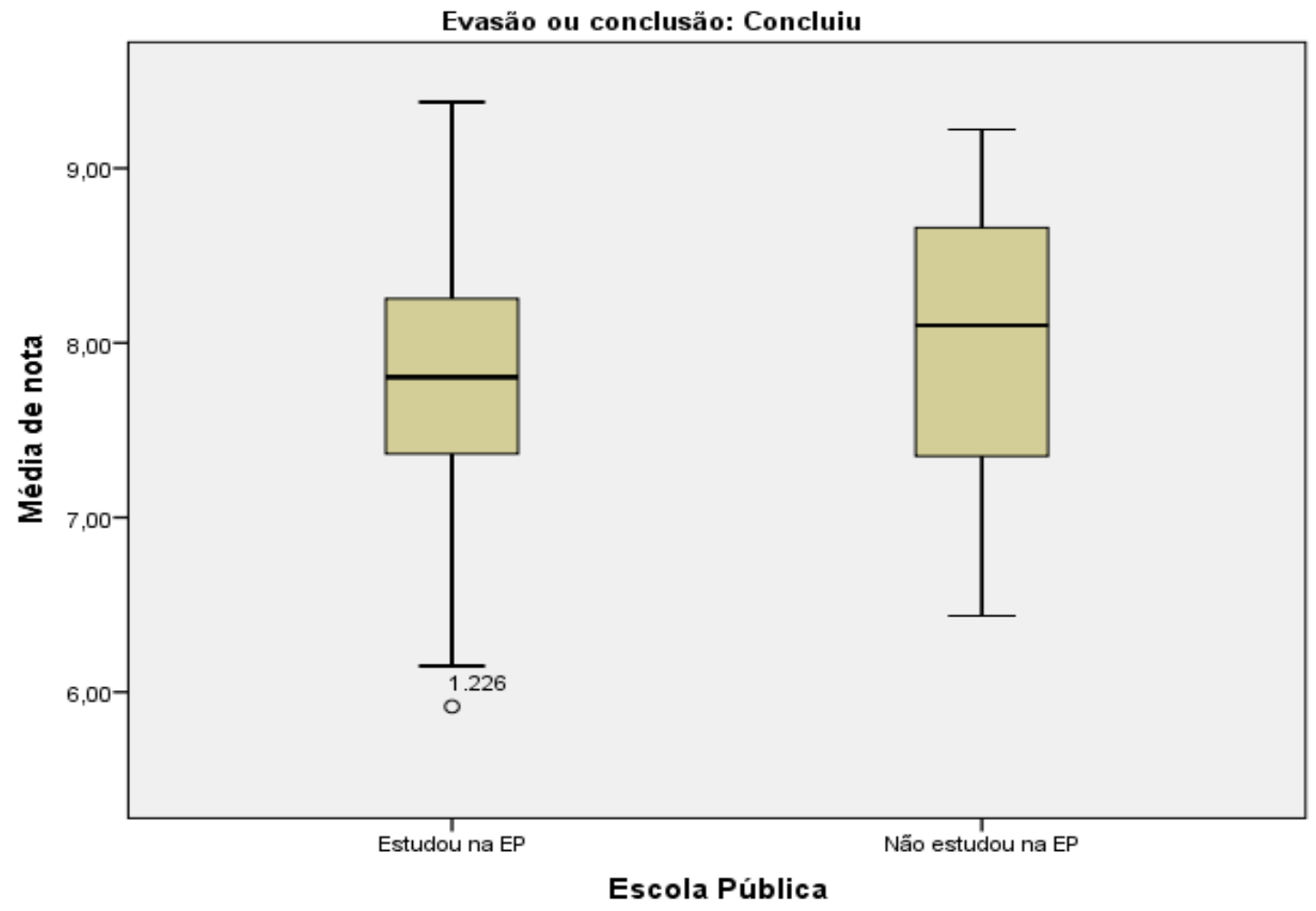

Fonte: Elaboração própria, conforme base de dados da UFFS 
Ainda com relação à escola pública, foi verificada a condição de desfechos dos ingressantes, considerando o ingresso por cotas e por ampla concorrência. Na UFFS os não cotistas são minoria, sendo em 2013, apenas 12,1\%, cujo ingresso ocorreu por ampla concorrência, e 87,9\% são cotistas. Deste percentual, 72,0\% ingressaram por escola pública parcial ou integral sem critério racial e 15,9\% ingressaram pelos critérios de escola pública e raça/cor. Nesses dois grupos de escola pública também encontra-se incluso o critério de renda familiar per capita de até 1,5 salários mínimos e independentemente de renda.

Conforme o Gráfico 61 os egressos de escolas públicas, independentemente da condição de renda, possuem os maiores percentuais de conclusão de curso e os menores percentuais de evasão, com resultados superiores aos ingressantes por ampla concorrência e por origem na escola pública e raça/cor, sendo este último o grupo que possui o maior percentual de evasão e o menor percentual de conclusão.

Gráfico 61 - Evasão e conclusão de curso, segundo cotas e ampla concorrência

Escola pública parcial e integral
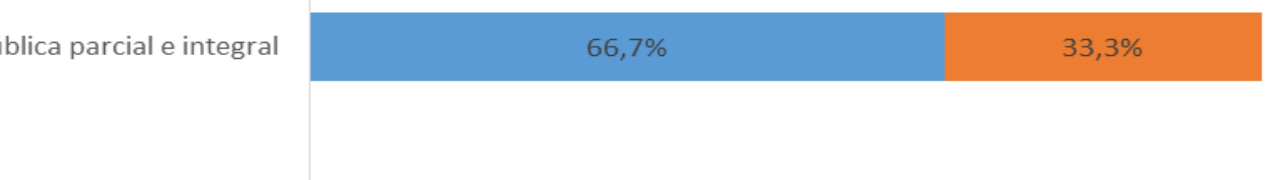

Ampla concorrência

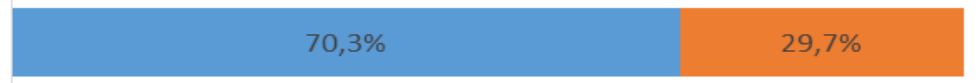

Escola pública e étnico

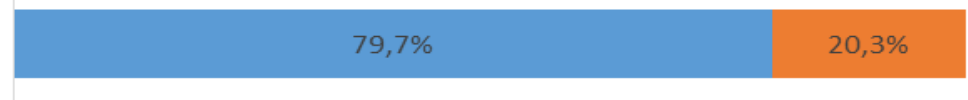

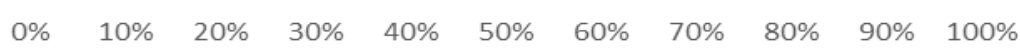

- Evadiu $\quad$ Concluiu

Fonte: Elaboração própria, conforme base de dados da UFFS

Na UFFS, o perfil mais homogêneo de estudantes provenientes da escola pública, é acompanhado em geral por médias de notas semelhantes entre estudantes cotistas e não cotistas. Observamos que entre o grupo de cotistas de escola pública e PPI a mediana é ligeiramente inferior, principalmente em relação ao grupo de ampla concorrência, tando entre os que evadiram, quanto entre os concluintes (Gráficos 62 e 63). 
Gráfico 62 - Média de notas, segundo cotas e ampla concorrência - ingressantes que evadiram

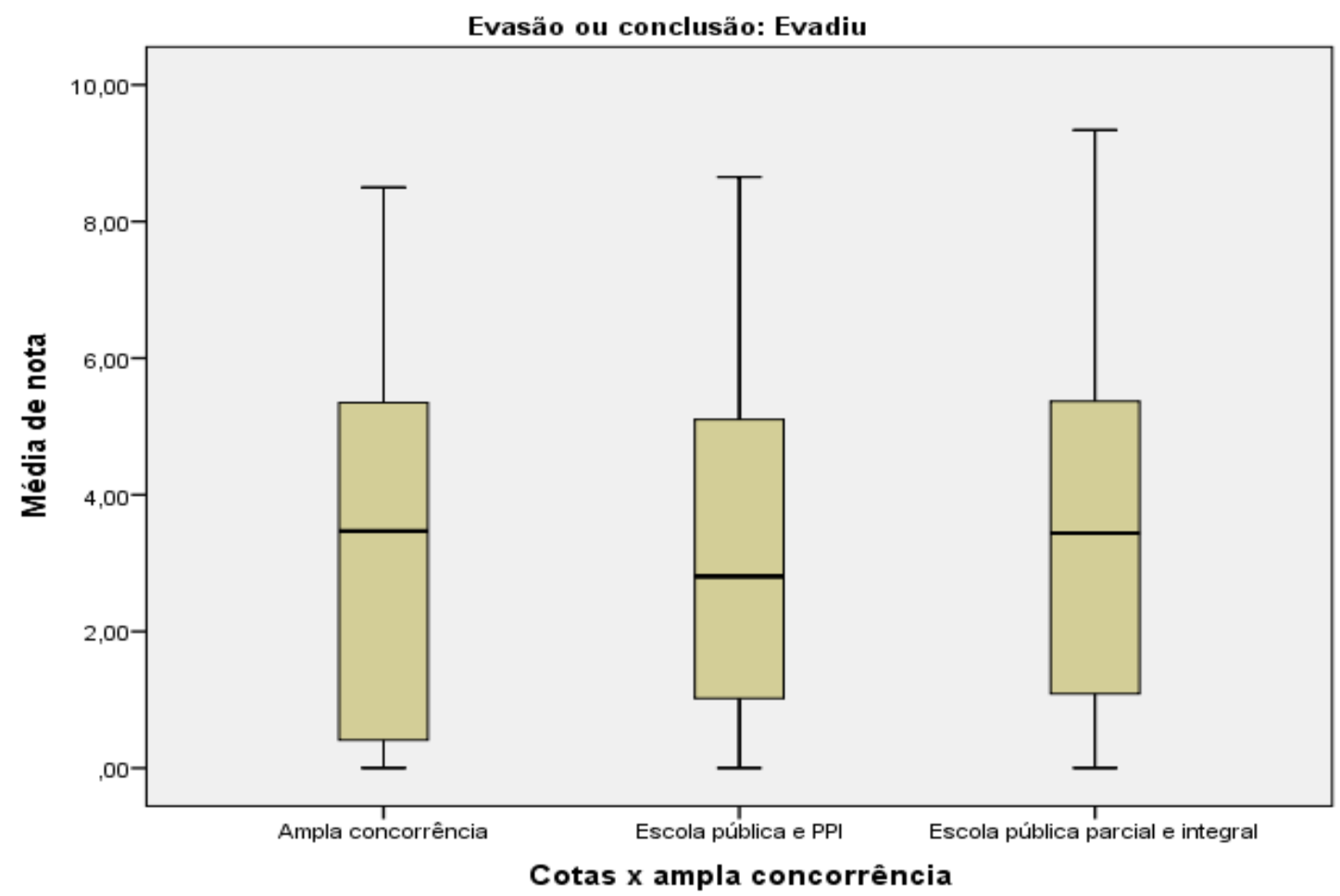

Fonte: Elaboração própria, conforme base de dados da UFFS

Gráfico 63 - Média de notas, segundo cotas e ampla concorrência - ingressantes que concluíram

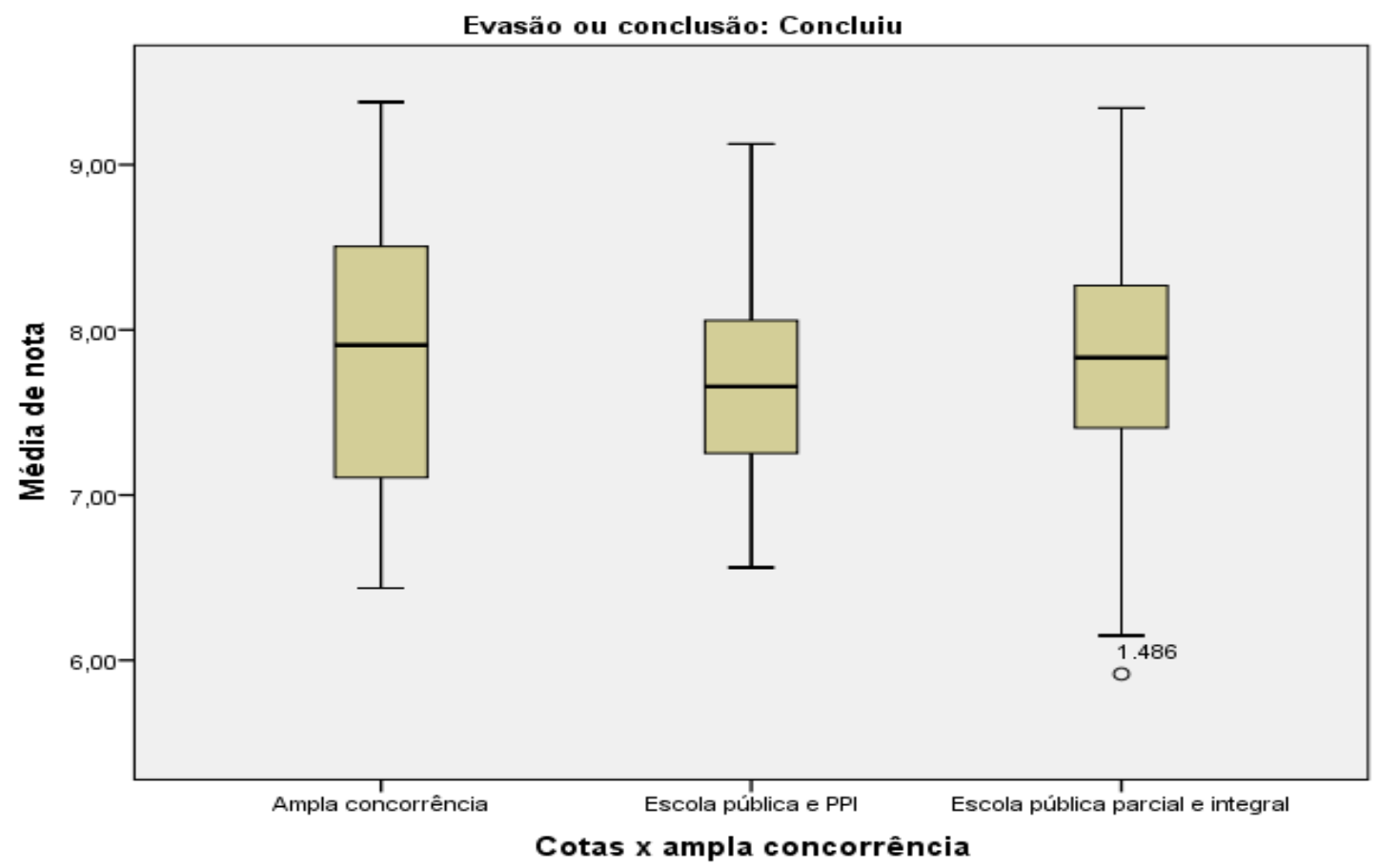

Fonte: Elaboração própria, a partir de base de dados da UFFS 
Tanto no contexto internacional, como é o caso do estudo de Rotem, Yair \& Shustak (2020) na Universidade de Jerusalém, quanto no contexto brasileiro, estudos vêm sinalizando que em termos de rendimento acadêmico praticamente não existem diferenças entre estudantes cotistas e não cotistas (Queiroz et al., 2015; Santos; Almeida; Castro, 2017; Wainer; Merguiso, 2017). Por outro lado, estudos como de Mendes Junior (2014) e Peixoto et al. (2016) apontam para diferenças de desempenho entre cotistas e não cotistas, em termos de coeficientes de rendimentos, principalmente em cursos mais concorridos.

Queiroz et al. (2015) analisaram o desempenho de ingressantes na Universidade Federal de Uberlândia (UFU), no primeiro semestre de 2013, buscando estabelecer compararações entre ingressantes pelas diferentes modalidades de cotas estabelecidas pela Lei 12.711/12 e por ampla concorrência. Os resultados também apontam não haver diferença estatística no rendimento acadêmico entre tais grupos, mas sim entre as notas de estudantes pertencentes ao Programa Alternativo de Ingresso no Ensino Superior (Paies), um programa de ações afirmativas próprio da IES, criado ainda antes da Lei de Cotas. As notas deste grupo são menores em relação aos demais grupos.

Ao verificar diferenças no desempenho do Enade em 2014, entre cotistas e não cotistas de universidades federais localizadas em Minas Gerais, com base na Lei de Cotas, Santos, Almeida \& Castro (2017) aplicaram teste de diferenças entre médias e concluíram pela não existência de diferenças. Quando analisaram a existência de diferenças em relação aos cursos, observaram que para a maioria dos 29 cursos testados não existem diferenças no desempenho de cotistas e não cotistas, salvo para os cursos de Pedagogia e de Ciências Biológicas.

Para Wainer \& Melguiso (2017, p.12) “os alunos que se beneficiaram de uma política de inclusão não terminam do ensino superior como profissionais de menor qualidade". Os autores analisaram, por meio de notas do Enade ao final do curso (2012 a 2014), os conhecimentos obtidos por estudantes que ingressaram por cotas, por razões sociais ou raciais, que receberam financiamento do FIES ou bolsa de ProUni, em relação aos seus colegas que não foram beneficiários de nenhuma dessas modalidades de inclusão social. Os resultados mostraram que não existe diferença prática de conhecimento entre cotistas e não cotistas, considerando que esse exame avalia tanto conhecimentos específicos dos cursos, quanto habilidades gerais de raciocínio. 
Importante destacar que o ingresso dos cotistas considerados nesse estudo ocorreu antes da Lei de Cotas.

Da mesma forma os estudos de Mendes Junior (2014), a partir de dados da Universidade Estadual do Rio de Janeiro (UERJ) e de Peixoto at al., (2016), com dados da Universidade Federal da Bahia, utilizam-se de dados anteriores a Lei de Cotas, cujo ingresso ocorria pelo vestibular em ambas universidades. Ao analisar coeficientes médios de rendimentos, os autores encontraram uma diferença em torno de 6,5\% entre cotistas e não cotistas. O foco por cursos e/ou áreas de conhecimentos se mostra uma análise importante, pois quanto maior foi a concorrência maior foi a diferença de nota. Os achados de Mendes (2014), que comparou também diferenças entre cotistas e não cotistas, em termos de evasão e conclusão de curso, concluiu que os cotistas se mostraram mais persistentes, apresentando maiores percentuais de graduação nos cursos, ainda que com coeficientes de rendimentos médios menores.

Conforme já verificado no capítulo anterior em relação às características institucionais e do curso, o apoio social (assistência estudantil) é um fator que contribui para maiores percentuais de conclusão e para sua redução na evasão do curso. O Gráfico 64 sinaliza essas diferenças entre os percentuais de evasão e de conclusão, segundo o recebimento ou não de apoio social.

Gráfico 64 - Evasão e conclusão de curso, segundo apoio social

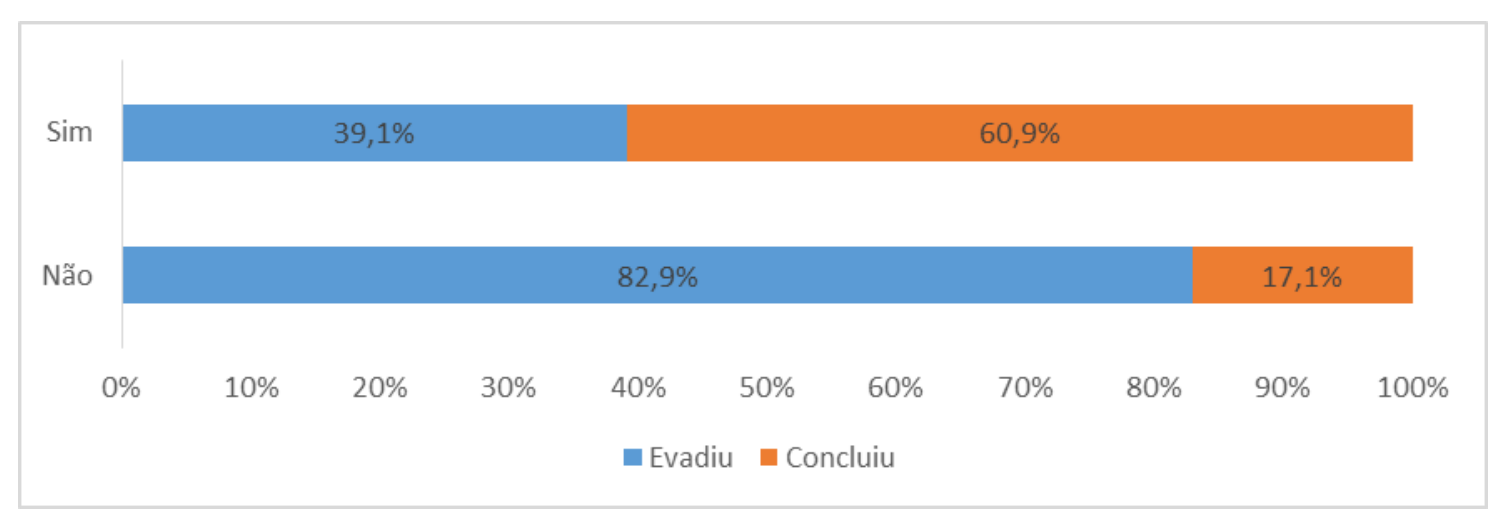

Fonte: Elaboração própria, a partir de bases de dados da UFFS

Ao verificar a média de notas, segundo o apoio social recebido pelos ingressantes observou-se que entre os que evadiram do curso, a mediana de nota é superior para os que receberam apoio social. Entre os que concluem o curso a mediana praticamente não tem diferença entre quem recebeu ou não apoio social (Gráficos 65 e 66). Isso indica 
que estudantes com notas mais baixas e que não são beneficiários da assistência estudantil tendem a evadir mais dos cursos de origem.

Gráfico 65 - Média de notas, segundo apoio social - ingressantes que evadiram

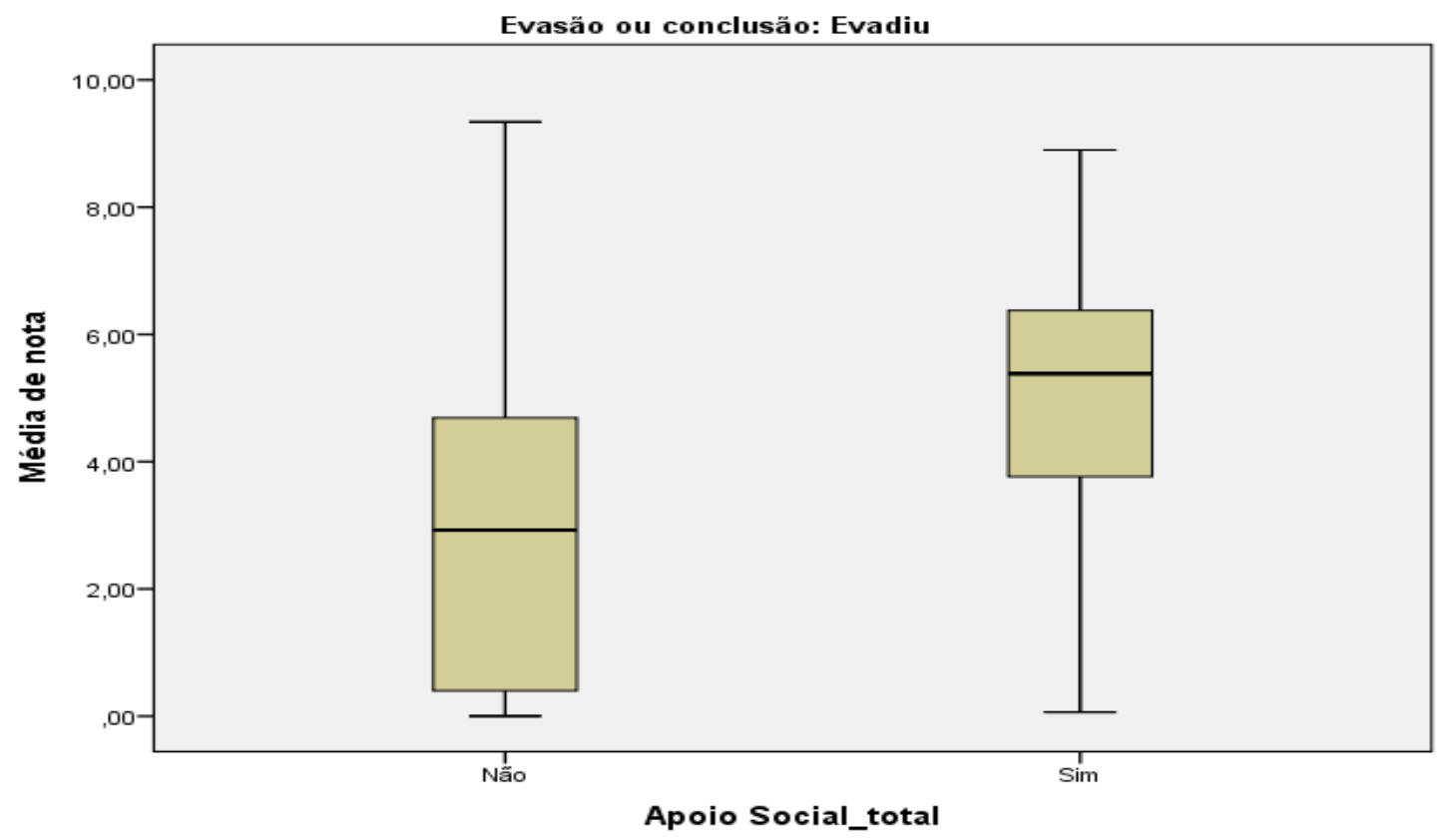

Fonte: Elaboração própria, a partir da base de dados da UFFS

Gráfico 66 - Média de notas, segundo apoio social - ingressantes que concluíram

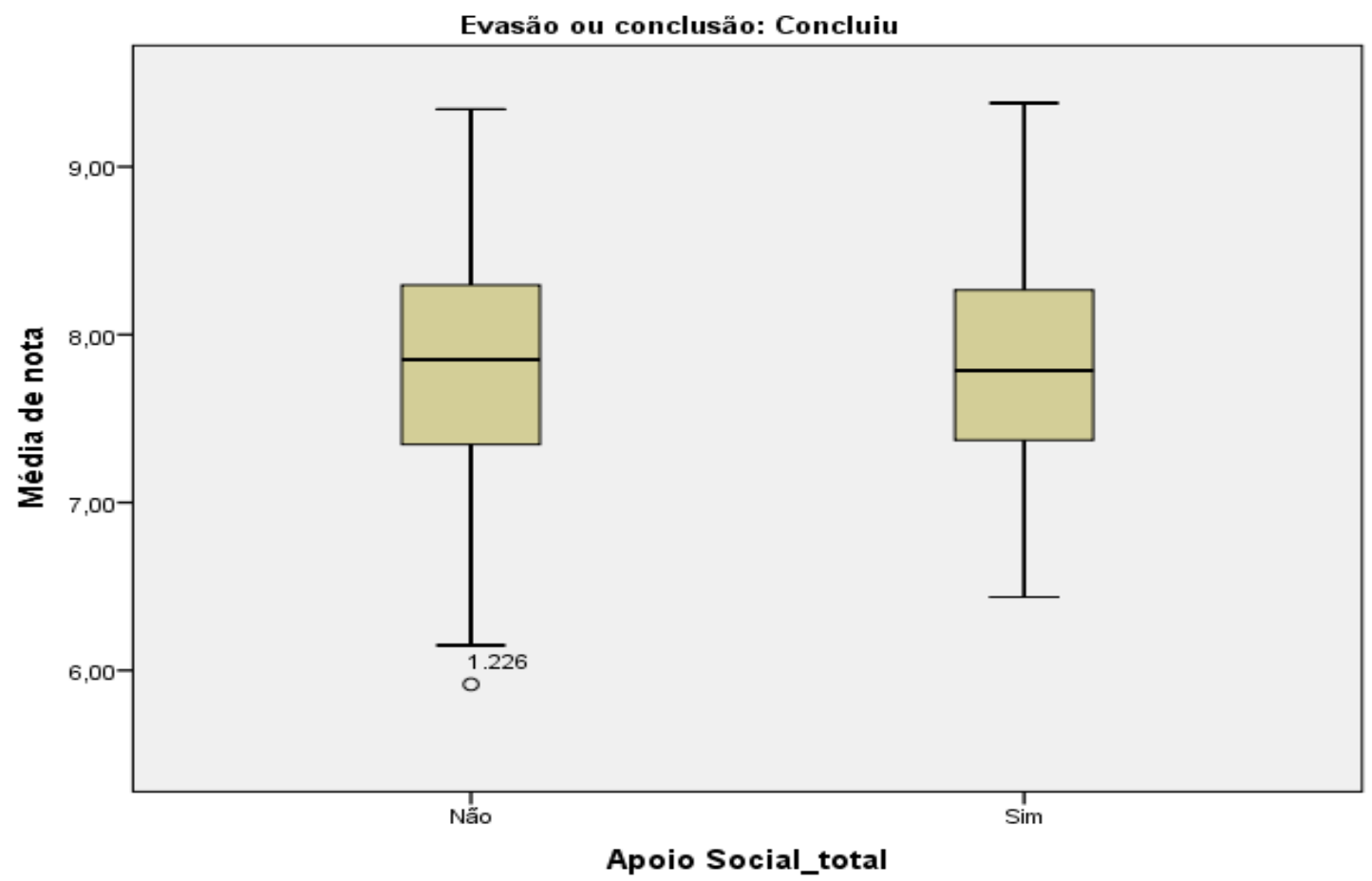

Fonte: Elaboração própria, a partir de base de dados da UFFS 
Ao verificar o curso por meio de área de conhecimento observa-se que a conclusão do curso na área da Computação e Tecnologias é a menor em relação as demais áreas, seguido da área de Educação que integra todas as licenciaturas. As áreas de saúde e de agricultura concentram percentuais maiores de conclusão nos cursos (Gráfico 67).

Gráfico 67 - Evasão e conclusão de curso, segundo áreas de conhecimento

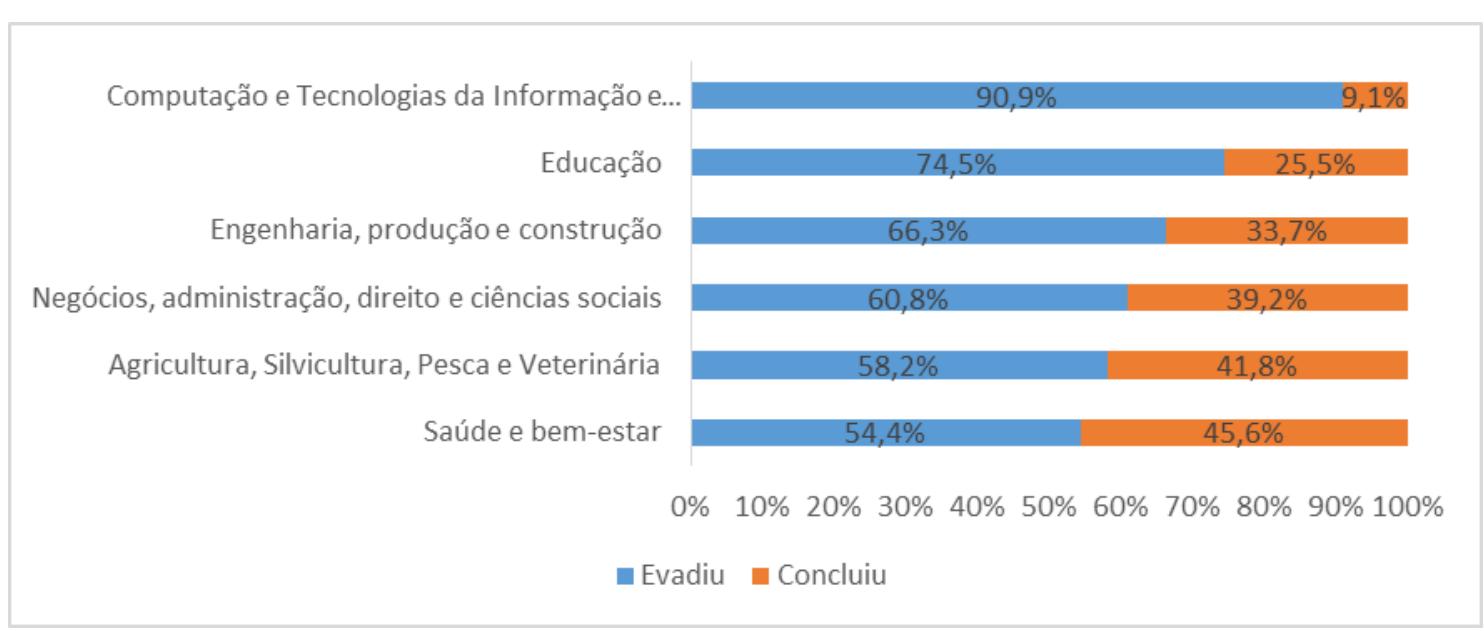

Fonte: Elaboração própria, a partir de bases de dados da UFFS

Com relação à média de notas segundo a área de conhecimento, observa-se que, no grupo dos que evadiram, a área de saúde possui notas mais altas que as demais áreas, o que pode sinalizar apenas uma transferência de curso para outro curso e/ou IES. A área da computação possui a mediana e notas menores em relação às demais (Gráfico 68).

Já no grupo dos que concluíram o curso, a área de saúde também possui a mediana mais alta, acima de 8,0, e notas mais altas e com menor variação, cujo limite inferior inicia acima de 7,0 e se estende até próximo de 9,0. Neste grupo apareceram alguns casos atípicos, com notas abaixo de 7,0. Em seguida, a área da Educação também se destaca em relação às demais áreas de conhecimento com mediana levemente superior e mais próxima de 8,0. A área da agricultura possui as notas mais baixas em relação às demais áreas: a maioria dos estudantes (75\%) não ultrapassa a média de nota 8,0 . Os dados demonstram que o desempenho dos estudantes varia conforme a área de conhecimento: estudantes de cursos de licenciaturas, por exemplo, têm melhores resultados em termos de notas e tendem a ter menores resultados em termos de conclusão de curso; na área da agricultura ocorre o inverso, com maiores índices de conclusão, mesmo com notas menores, se comparado com demais áreas (Gráfico 79). 
Gráfico 68 - Média de nota, segundo áreas de conhecimento - ingressantes que evadiram do curso

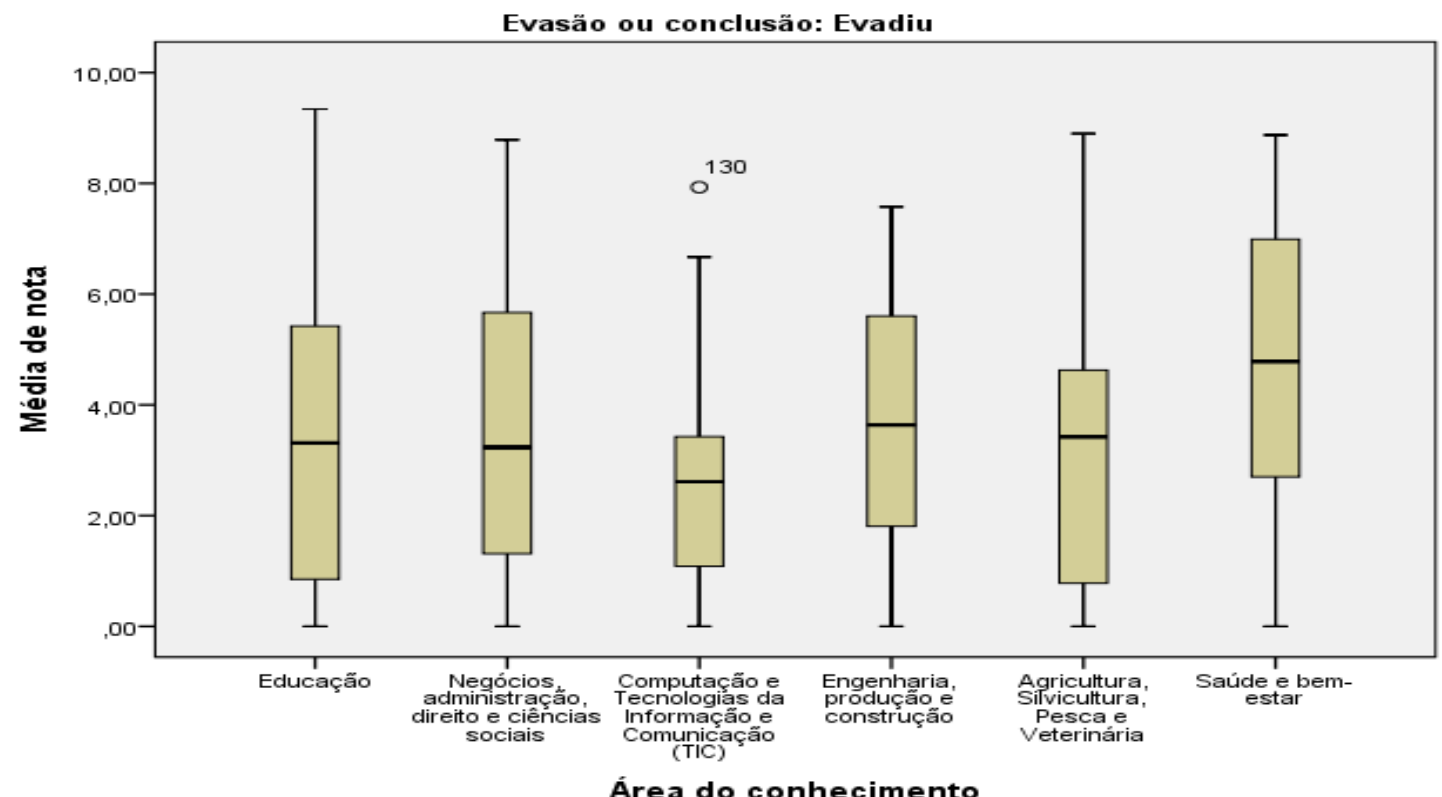

Fonte: Elaboração própria, a partir de bases de dados da UFFS

Gráfico 69 - Média de nota, segundo área de conhecimento - ingressantes que concluíram o curso

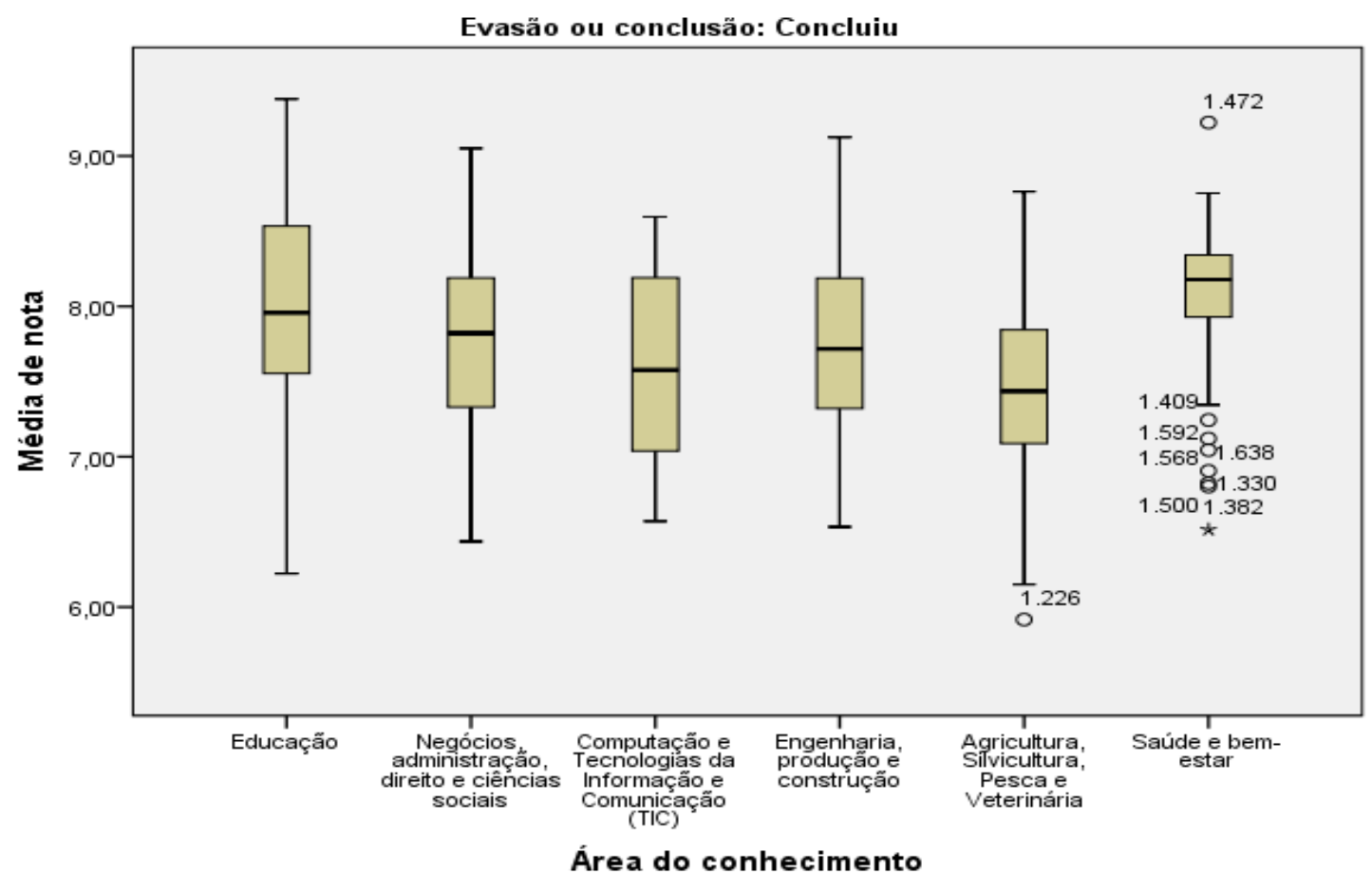

Fonte: Elaboração própria, a partir de bases de dados da UFFS 
Com relação ao turno do curso, observa-se que os ingressantes em turno integral tendem a ter maiores percentuais de conclusão e uma diferença maior em relação aos que cursam o turno noturno, como mostra o Gráfico 70.

Gráfico 70 - Evasão e conclusão, segundo turno do curso

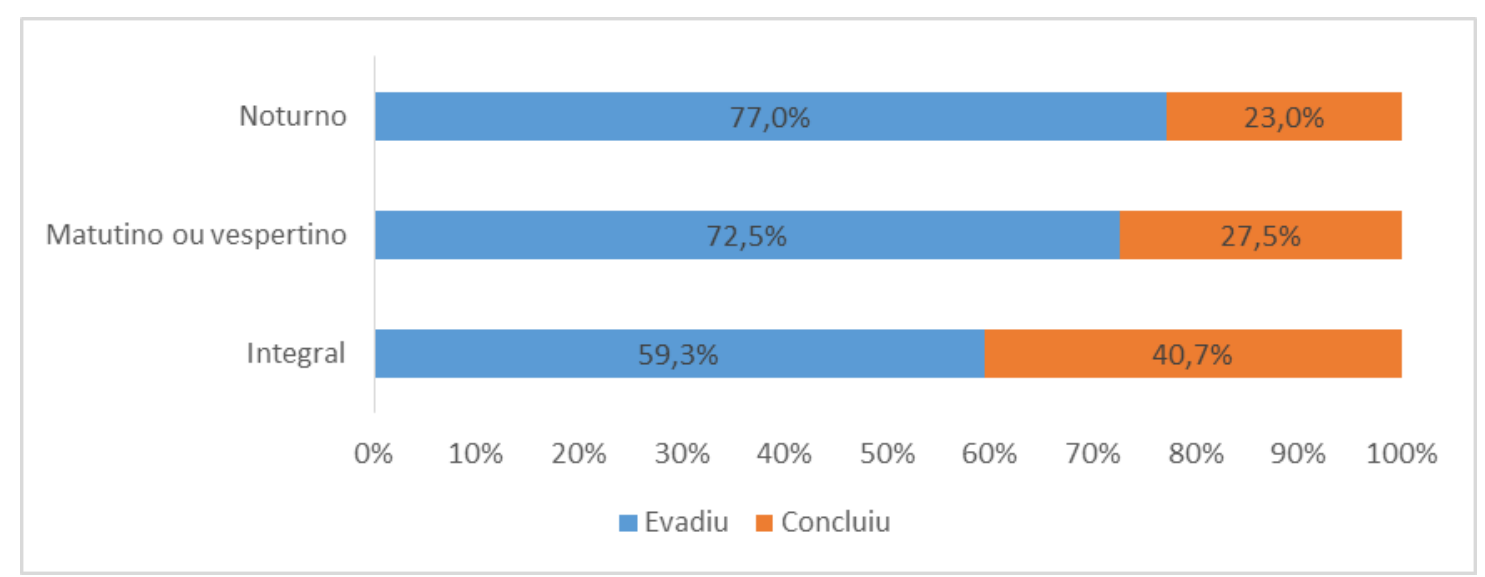

Fonte: Elaboração própria, a partir de bases de dados da UFFS

Conforme observado, os concluintes na área de educação, que envolve todas as licenciaturas, possuem notas maiores, depois da área da saúde. Ao verificar a média de notas conforme o turno do curso, observou-se que entre os que evadiram as medianas de notas são mais próximas, sendo ligeiramente menores para os ingressantes em turno noturno (Gráfico 71). Já entre os concluintes as notas são ligeiramente superiores para as turnos noturnos e matutinos em relação ao turno integral, o que se justifica pelo fato destes turnos concentrarem mais cursos de licenciaturas (Gráfico 72). 
Gráfico 71 - Média de notas, segundo turno do curso - ingressantes que evadiram

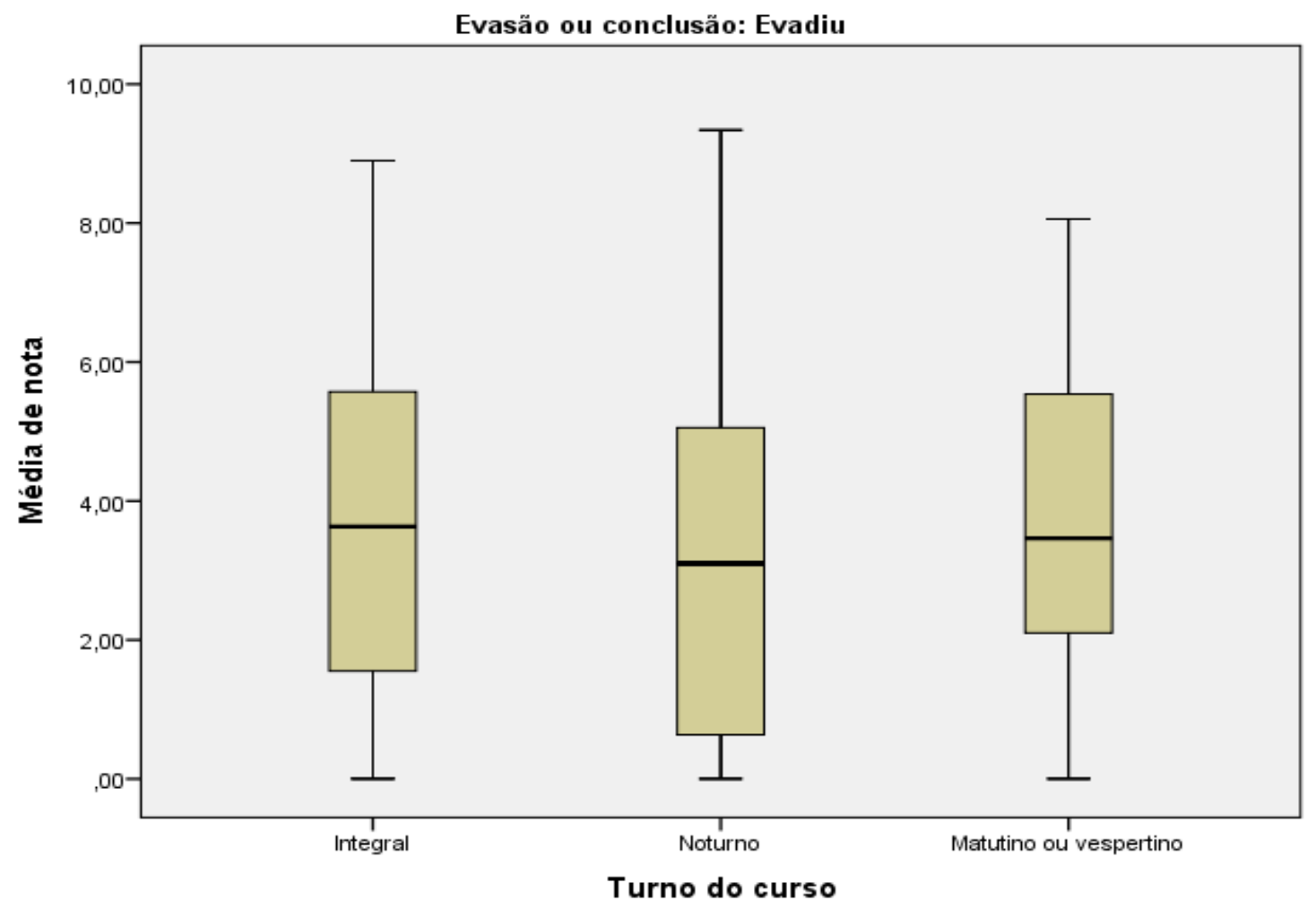

Fonte: Elaboração própria, conforme base de dados da UFFS

Gráfico 72 - Média de notas, segundo turno do curso - ingressantes que concluíram

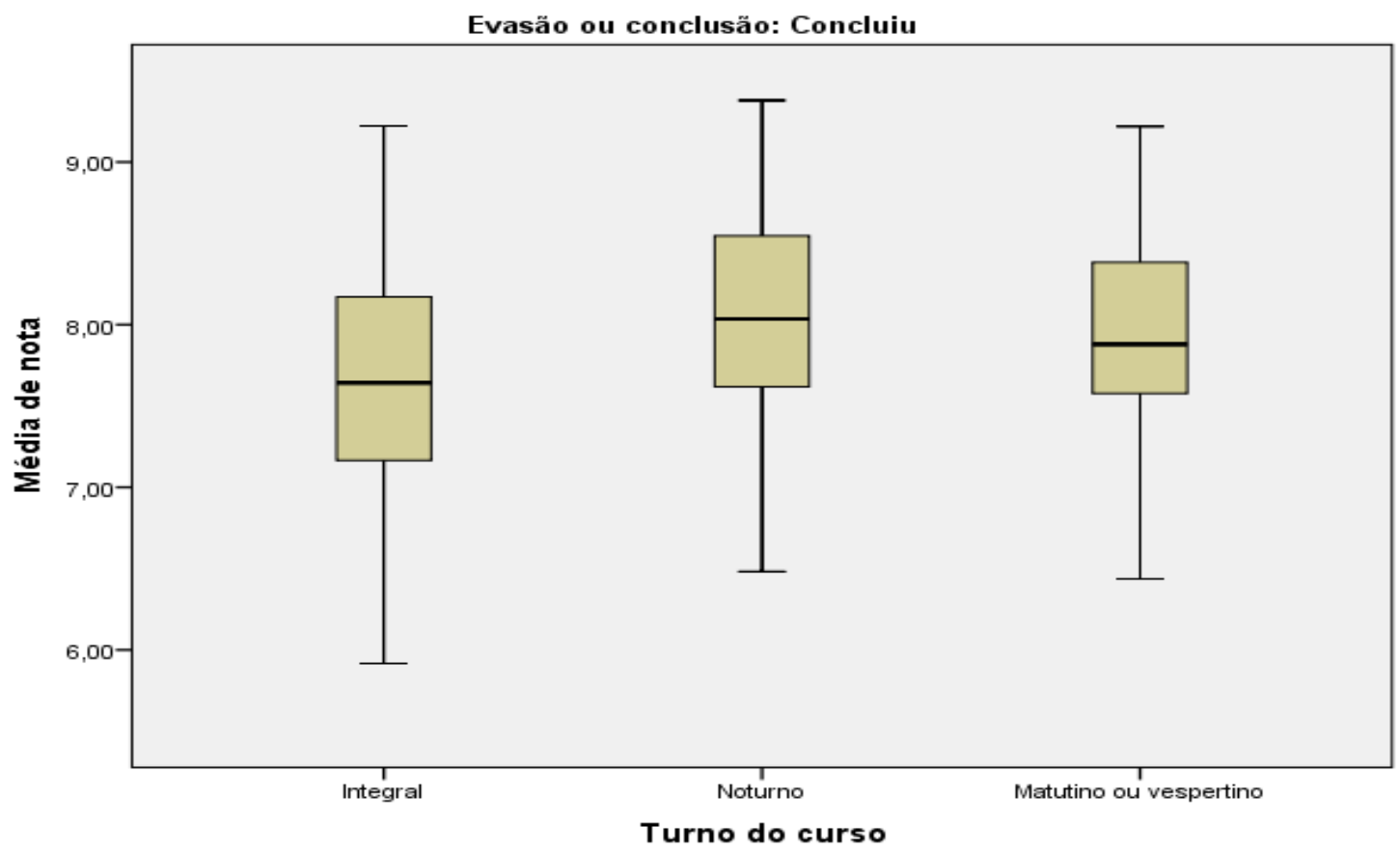

Fonte: Elaboração própria, conforme base de dados da UFFS 
Com relação ao campus de ingresso dos estudantes, o Gráfico 73 apresenta a relação desta variável com evasão e conclusão de curso. Os campi Passo Fundo e Cerro Largo possuem maiores percentuais de conclusão de curso, enquanto que Laranjeiras do Sul e Chapecó aparecerem com os menores percentuais.

Gráfico 73 - Evasão e conclusão, segundo o campus

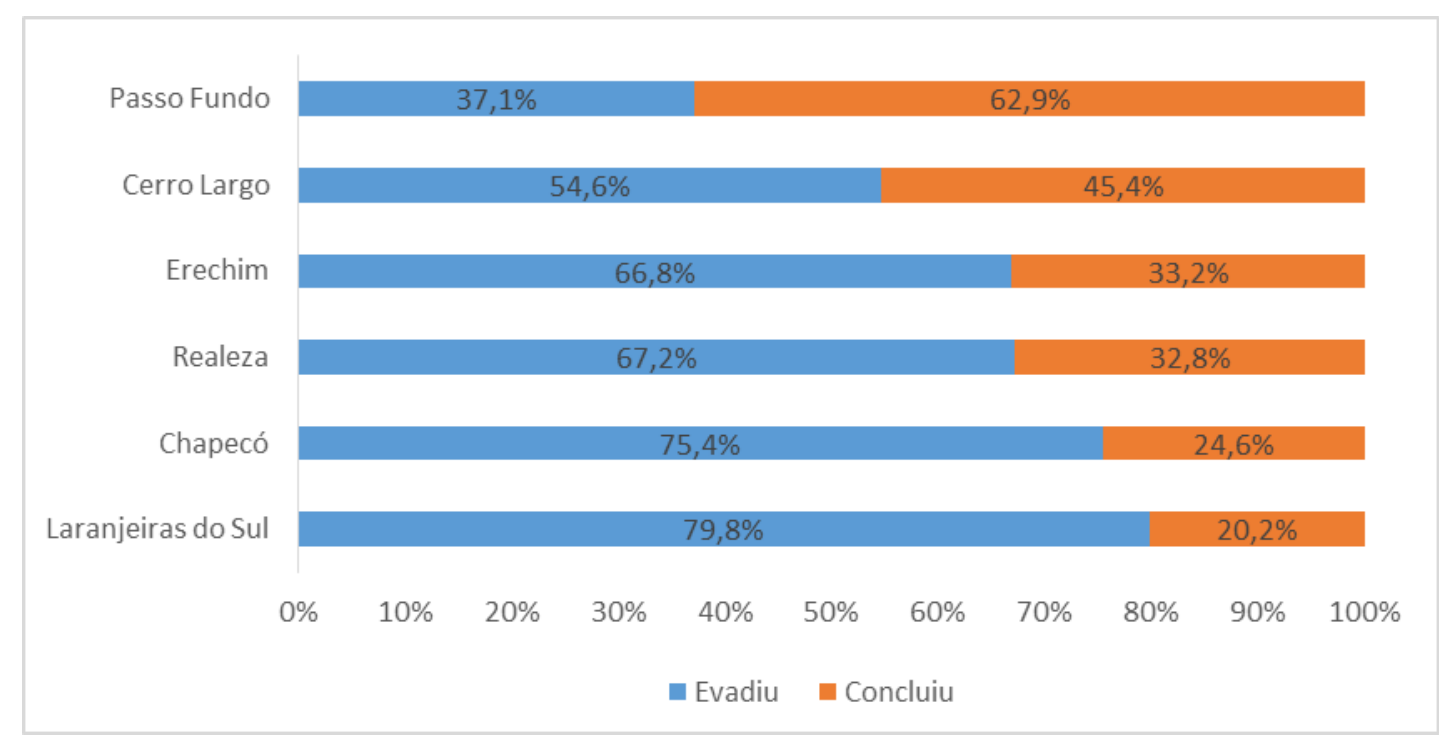

Fonte: Elaboração própria, a partir de banco de dados da UFFS

Ao verificarmos a média de notas segundo os diferentes campi, observou-se que entre os que evadiram do curso as medianas de notas e a maioria da distribuição se concentra abaixo de 6,0, exceto para o Campus Passo Fundo que ultrapassa a nota 6,0 (Gráfico 74). Para os que concluíram o curso, observou-se que o Campus Passo Fundo possui a mediana mais alta, acima de 8,0 e próxima dos campi Erechim e Chapecó que possuem mais cursos de licenciaturas. Campus Passo Fundo possui pouca variabilidde na distribuição das notas, com o limite inferior próximo a 8,0 e o limite máximo próximo a 9,0. Os campi Laranjeiras do Sul, Cerro Largo e Realeza possuem mediana semelhante, sendo que Laranjeiras do Sul possui menor variabilidade na distribuição de notas, com $75 \%$ da amostra com nota inferior a 8,0 e limite superior que não atinge a nota 9,0 (Gráfico 75).

De um modo geral, os dados indicam que as notas estão associadas com a evasão do curso, sendo que a maioria dos evadidos possui média de nota inferior a 6,0, exceto para cursos como Medicina em que a evasão do curso ocorre em sua maioria mesmo 
com notas mais altas, acima da média 6,0. Para os concluintes, observa-se que a nota varia bastante conforme cada curso e que existe uma tendência das médias serem maiores em cursos na área da saúde e em algumas licenciaturas. Cursos como Química e Física, por exemplo, tendem a ter notas mais baixas em relação a outras licenciaturas, e o curso de Agronomia possui bons percentuais de conclusão, ainda que as notas não sejam tão elevadas. Há, portanto, que se ponderar o significado das notas em cada curso, uma vez que as próprias avaliações tendem a ser diferentes em cursos, por exemplo, nas áreas de exatas e engenharias em relação a cursos mais voltados para a área das humanas.

Gráfico 74 - Média de notas, segundo o campus - ingressantes que evadiram

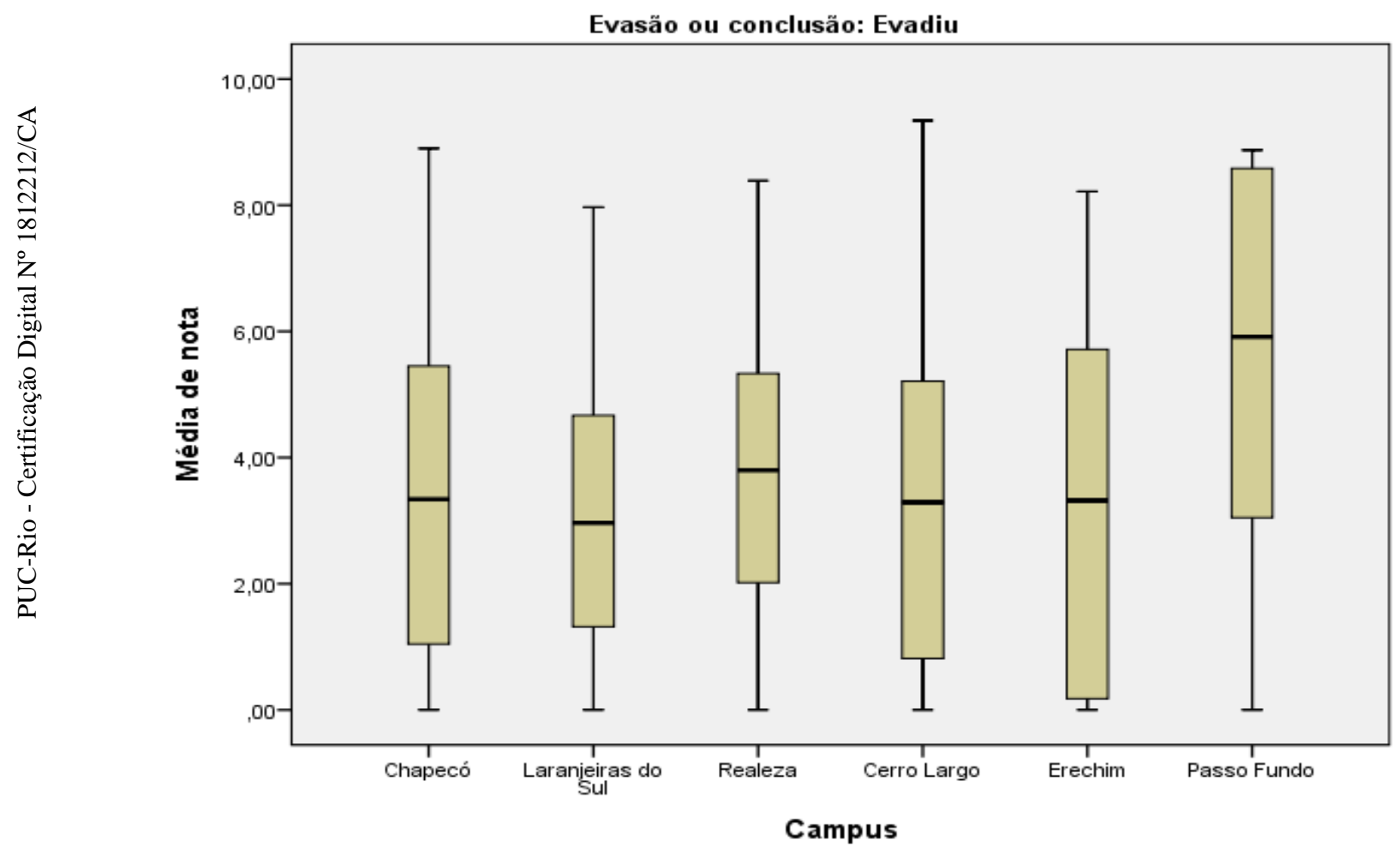

Fonte: Elaboração própria, a partir de banco de dados da UFFS 
Gráfico 75 - Média de notas, segundo o campus, ingressantes que concluíram

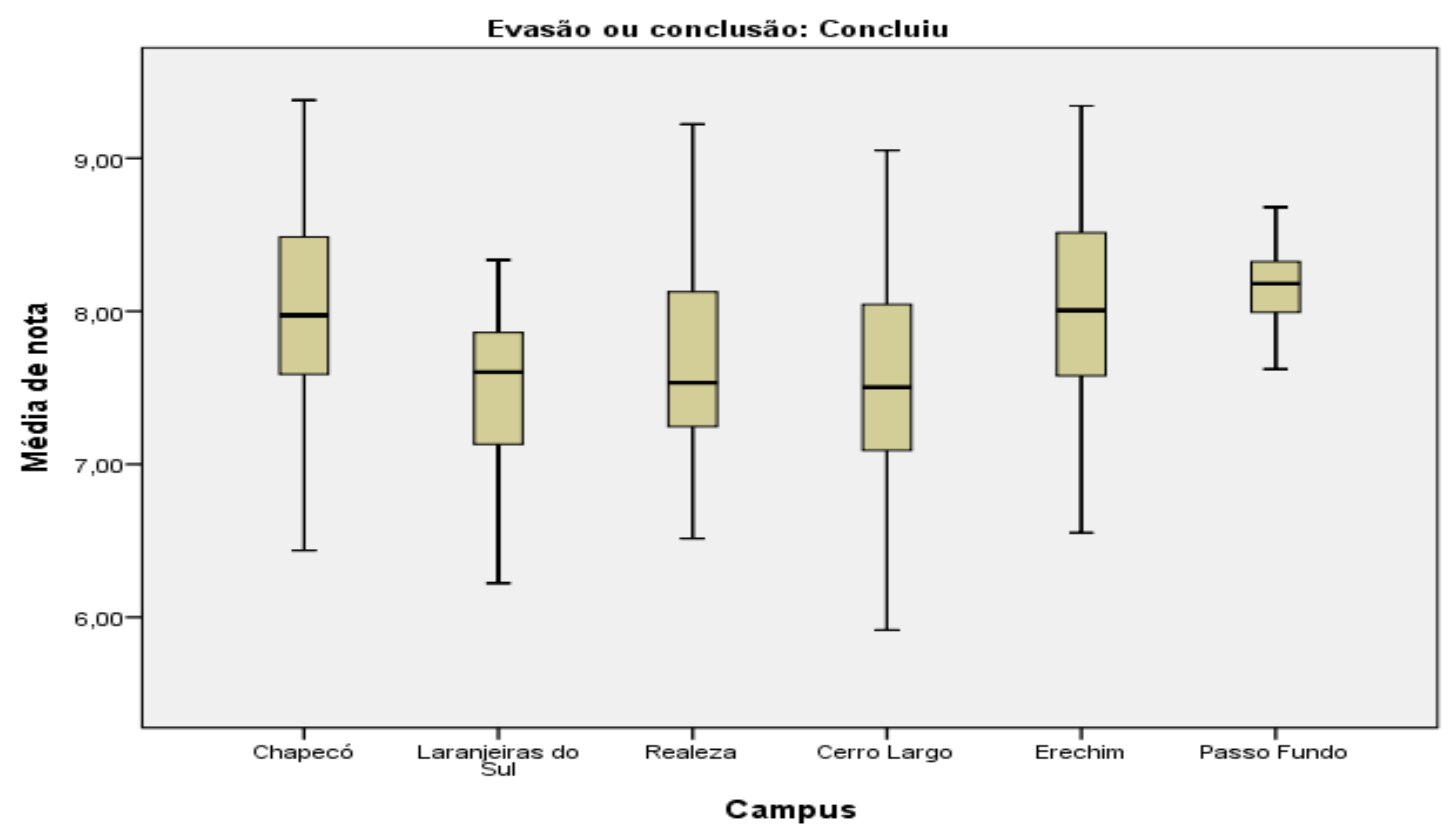

Fonte: Elaboração própria, conforme base de dados da UFFS

A reprovação é a condição de significativa maioria dos ingressantes na UFFS: em torno de $80 \%$ dos que ingressaram em 2013 tiveram reprovações ao longo do curso, independentemente de seu desfecho. Ao verificar a condição de reprovação em disciplinas e os desfechos dos estudantes, nota-se uma diferença significativa entre os que reprovaram e os que não reprovaram, com um percentual maior de conclusão de curso neste último grupo, conforme mostra o Gráfico 76.

Gráfico 76 - Evasão e conclusão, segundo a condição de reprovação

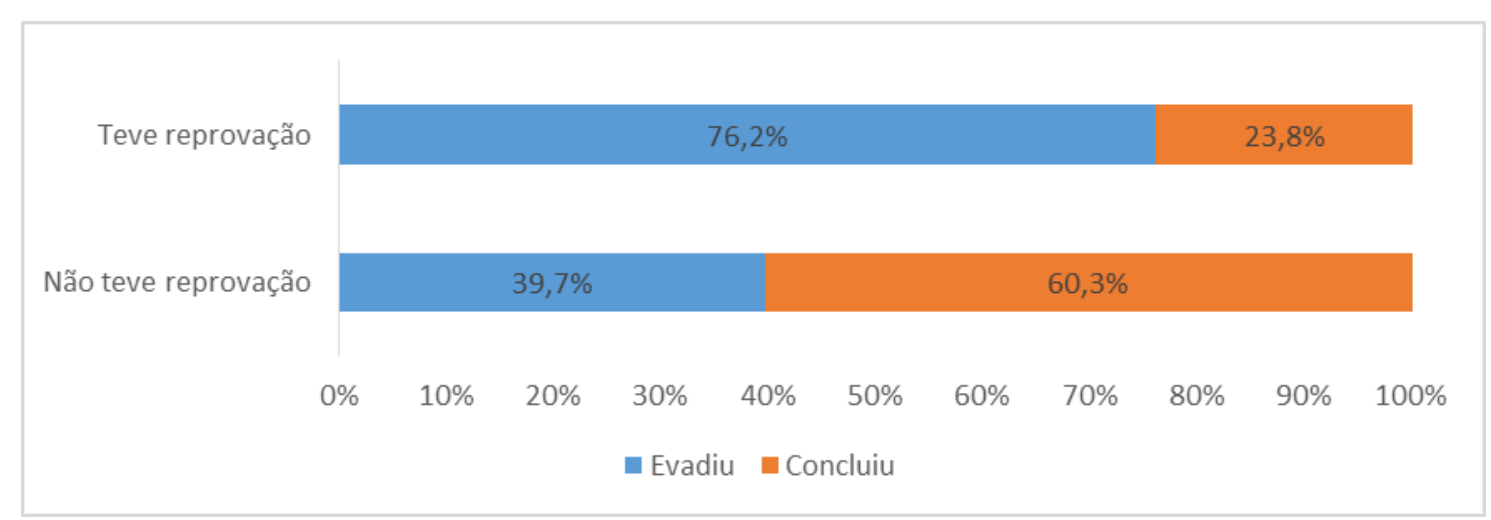

Fonte: Elaboração própria, a partir de bases de dados da UFFS 
Com relação ao rendimento acadêmico, observou-se que entre os estudantes que evadiram do curso as médias de notas daqueles que possuíam reprovações eram muito distantes daquelas dos estudantes que evadiram do curso sem reprovações, com uma mediana próxima de 4,0 para os primeiros e próxima de 8,0 para os estudantes sem reprovações (Gráfico 77). A questão que se coloca é: será que os estudantes que evadiram do curso com boas notas e sem ter reprovações se desligaram também da Universidade e do sistema de ensino superior? E, do outro lado, para onde foram aqueles com reprovações e cujas notas também foram inferiores? Parece haver mais possibilidades de mobilidade interna ou externa para o primeiro grupo e indícios de que a condição de reprovação pode ocasionar evasão. Nesta coorte de ingressantes em 2013, no grupo dos que evadiram, $89 \%$ dos estudantes tiveram reprovações. Estudos como de Sales Junior et al. (2016); Scher \& Oliveira (2020) e de Rotem; Yair \& Shustak (2020) apontam as reprovações como um fator de risco para a evasão universitária. Entre os que concluíram o curso, $62 \%$ tiveram reprovações ao longo do percurso (Gráfico 78).

Gráfico 77 - Média de notas, segundo condição de reprovação - ingressantes que evadiram

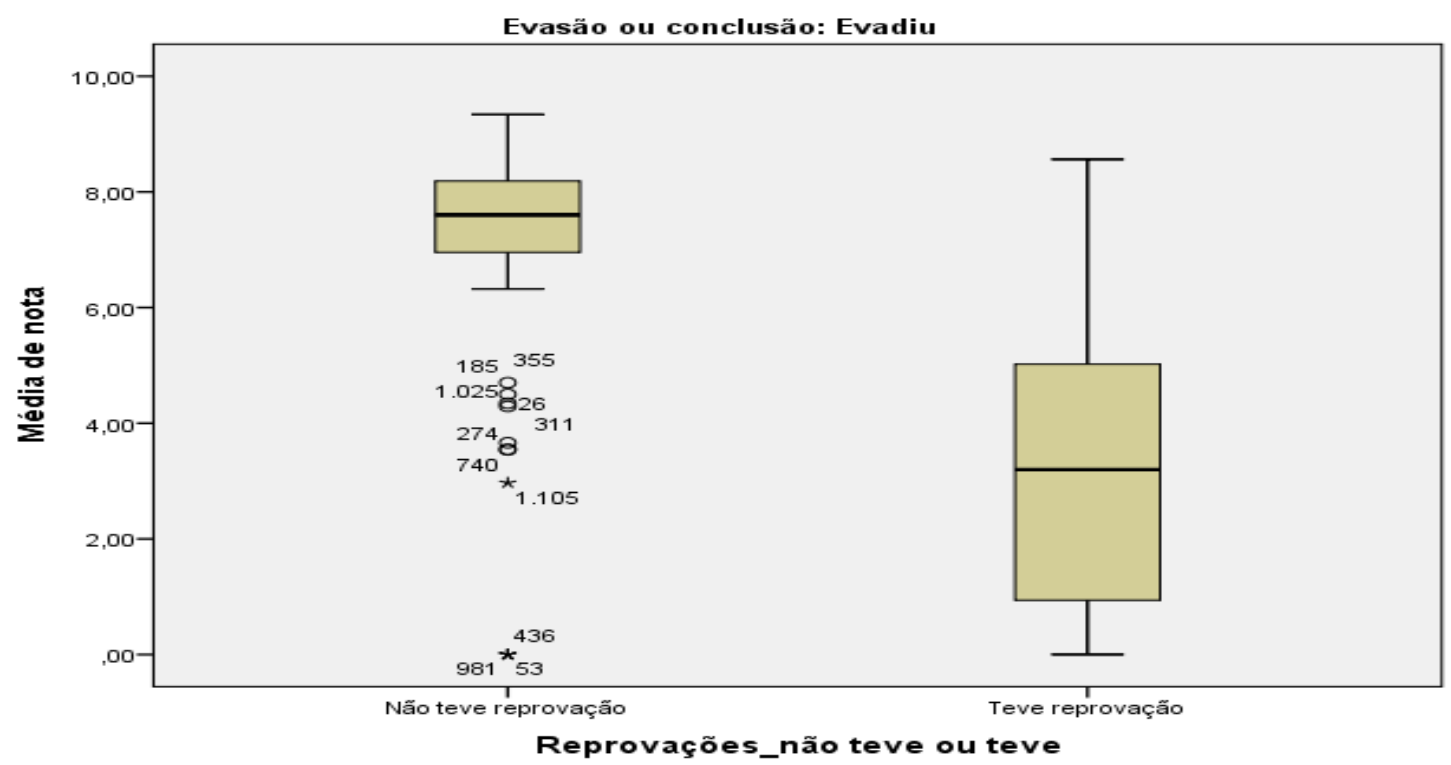

Fonte: Elaboração própria, a partir de bases de dados da UFFS 
Gráfico 78 - Média de notas, segundo condição de reprovação - ingressantes que concluíram

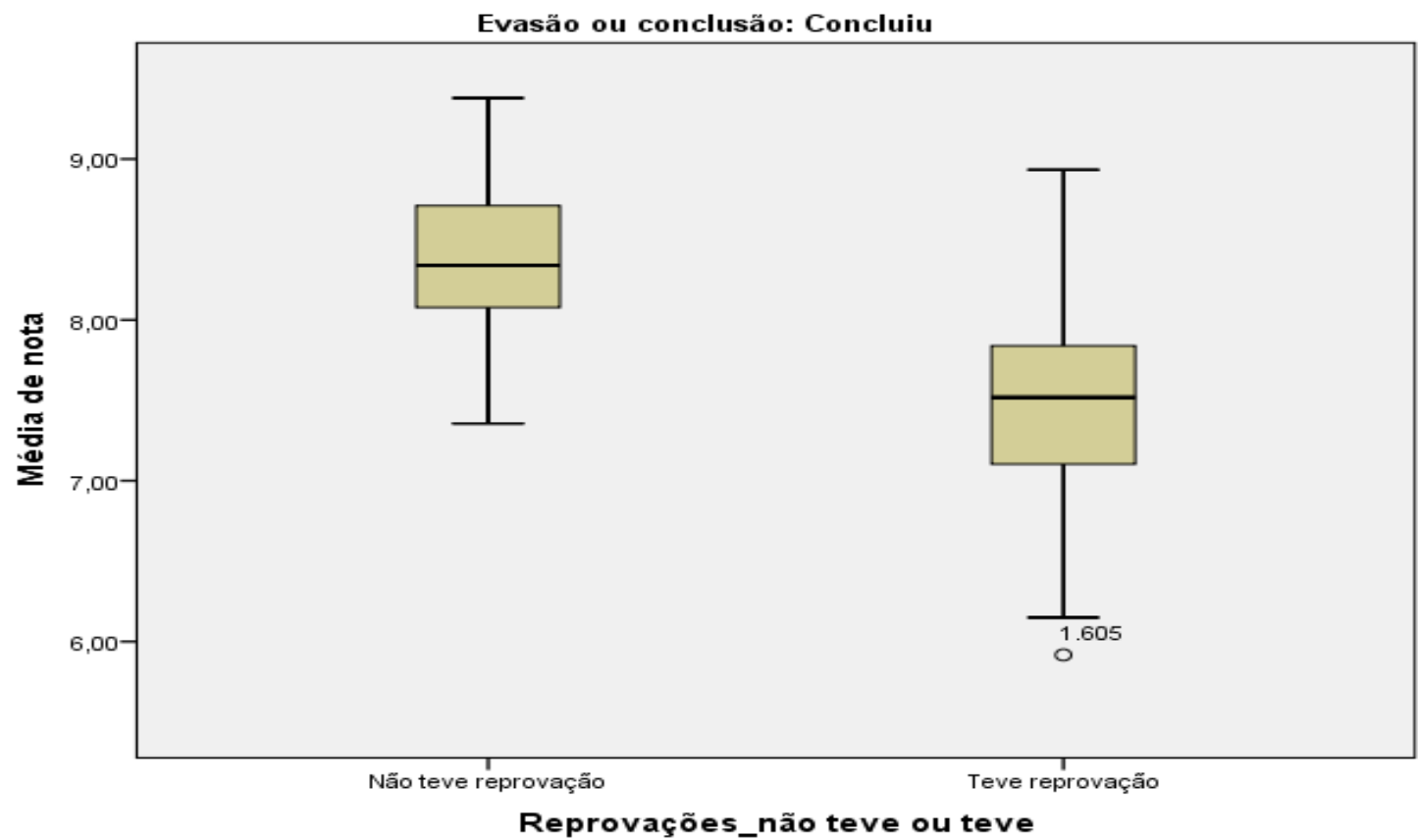

Fonte: Elaboração própria, a partir de bases de dados da UFFS

O próximo passo é verificar o nível de associação entre algumas destas variáveis nas chances de conclusão de curso, por meio de regressões logísticas. A variável "média de nota" será utilizada como variável independente. A reprovação não será apresentada nas regressões, pois ela se sobrepõe à medida nota, mas é importante destacar que ao ser testada se mostrou significativa nas chances de conclusão do curso, ou seja, quanto maior é o número de reprovações, menores são as chances de conclusão.

\subsection{Chance de conclusão ou evasão de curso: efeitos do rendimento acadêmico}

Nesta análise utilizamos modelos de regressão logística para verificar principalmente os efeitos da variável de rendimento acadêmico nas chances de conclusão de curso. Neste caso a variável dependente (y) é dicotômica e assume a categoria de "0" para a condição de "evadiu" e "1" para "concluiu" (Agresti; Finlay, 2012).

Com relação às características institucionais e do curso optamos por apresentar dois modelos mais enxutos, incluindo em ambos a variável "apoio social" e num 
modelo a variável "turno do curso" e no outro a variável "área de conhecimento". Nesta análise não foi incluída a variável campus.

Os resultados mostraram que para as características socioeconômicas dos estudantes, apenas a idade nos dois modelos e a situação de trabalho antes do ingresso em apenas um dos modelos (modelo 2) foram estatisticamente significativas para a conclusão de curso: quanto maior é a idade no ingresso menores são as chances de conclusão de curso e estudantes que trabalharam antes do ingresso na UFFS apresentaram 44\% menos de chances de conclusão. As variáveis "sexo_raça" e "localização de moradia" foram estatisticamente significativas quando não inserida a variável "média de notas". Isso demonstra que a média de notas é fundamental na explicação da conclusão de curso e que pode haver uma sobreposição com outras variáveis e/ou uma correlação significativa. O desempenho pode já estar incluído nas outras variáveis socioeconômicas. Quanto maior é a nota dos estudantes maiores são as chances de concluir um curso e menores as chances de evasão.

Ao se referir às características institucionais e relacionadas aos cursos de graduação, verificou-se que os ingressantes que foram beneficiados com apoio social, por meio da assistência estudantil em algum momento da graduação, possuem duas vezes mais chances de concluir o curso, em relação aos que não foram beneficiários. No contexto recente de expansão do ensino superior, Heringer (2020b) e Dias \& Sampaio (2020) destacam a importância das políticas de assistência estudantil. Para os autores, as ações afirmativas no ensino superior foram um dos fatores para a ampliação de vagas e abertura para um novo público de universitários, que passaram a demandar das IES políticas voltadas à permanência e de assistência estudantil. Essas ações de permanência visam atender não apenas as dimensões materiais e financeiras, mas também simbólicas, acadêmicas, culturais e pedagógicas. A dimensão simbólica, por exemplo, se refere a questões sobre como o estudante se vê e é visto no espaço universitário, as possíveis situações de preconceito e discriminação às quais os estudantes podem estar acometidos, dificultando o sentido de pertencimento àquele ambiente (Heringer, 2020b). A ausência de serviços de apoio pedagógico, por exemplo, ainda é um desafio nas IES, conforme foi diagnosticado em pesquisas como do Fonaprace (Fórum Nacional dos PróReitores de Assuntos Estudantis). 
Quanto ao turno do curso, os estudantes que cursam graduação no período noturno possuem $55 \%^{75}$ menos chances de conclusão, em relação aos de turno integral. No que se refere às áreas de conhecimento, verificou-se que os ingressantes em cursos nas áreas de Engenharia, Produção e Construção possuem duas vezes mais chances de conclusão de curso, em relação à área de Educação e na área de Agricultura, Silvicultura, Pesca e Veterinária, as chances de concluir são 5,7 vezes a mais que as da área da Educação. Isso sinaliza a distinção que existe entre as diferentes áreas do conhecimento cursadas pelos estudantes e seu desfecho de conclusão. Uma hipótese quanto a este resultado é a valorização profissional e prestígio de determinadas carreiras em detrimento de outras, a exemplo de um curso de Medicina em relação a um curso de licenciatura. Outra questão importante é o turno do curso, que de algum modo pode estar selecionando um determinado perfil de estudantes, como de trabalhadores. Em consonância com a literatura, cursar um curso noturno, em geral, tem mostrado menos chances de conclusão e mais chances de evasão, em relação a um curso de turno integral, por exemplo.

A Tabela 32 apresenta os resultados dos modelos de regressão logística para estimar a conclusão de curso.

Tabela 32 - Estimativas (e chances) de modelos de regressão logística para estimar a conclusão do curso

\begin{tabular}{|c|c|c|c|c|c|c|}
\hline \multirow[b]{2}{*}{ Variáveis independentes } & \multicolumn{3}{|c|}{ Modelo 1} & \multicolumn{3}{|c|}{ Modelo 2} \\
\hline & B & Sig. & $\operatorname{Exp}(\mathbf{B})$ & B & Sig. & $\operatorname{Exp}(\mathbf{B})$ \\
\hline Sexo_raça: mulher branca & & 0,355 & & & 0,554 & \\
\hline Mulher negra & 0,207 & 0,489 & 1,230 & 0,215 & 0,482 & 1,240 \\
\hline Homem branco & 0,399 & 0,133 & 1,491 & 0,077 & 0,781 & 1,080 \\
\hline Homem negro & $-0,347$ & 0,507 & 0,707 & $-0,576$ & 0,264 & 0,562 \\
\hline Idade no ingresso & $-0,053$ & 0,009 & 0,948 & $-0,043$ & 0,045 & 0,958 \\
\hline Situação de trabalho: sim & $-0,415$ & 0,074 & 0,661 & $-0,583$ & 0,014 & 0,558 \\
\hline Localização da moradia: urbana & $-0,270$ & 0,252 & 0,763 & $-0,233$ & 0,344 & 0,792 \\
\hline Média de notas & 2,175 & $\mathbf{0 , 0 0 0}$ & 8,804 & 2,281 & $\mathbf{0 , 0 0 0}$ & 9,782 \\
\hline Apoio social: sim & 0,822 & $\mathbf{0 , 0 0 0}$ & 2,275 & 0,865 & $\mathbf{0 , 0 0 0}$ & 2,375 \\
\hline Turno: integral & & 0,003 & & & & \\
\hline Turno noturno & $-0,818$ & 0,001 & 0,441 & & & \\
\hline Turno matutino ou vespertino & $-0,566$ & 0,093 & 0,568 & & & \\
\hline Área de conhecimento: Educação & & & & & 0,000 & \\
\hline Negócios, administração, direito... & & & & 0,578 & 0,103 & 1,783 \\
\hline
\end{tabular}

${ }^{75}$ Esse resultado da razão de chance interpretado em percentual é realizado a partir da aplicação da fórmula: [exp (b) -1]*100, em que o Exp (b) é o exponencial do Beta (Power; Xie, 2000). 
Computação...

$1,300 \quad 0,140 \quad 3,671$

Engenharia, produção e construção

$0,751 \quad \mathbf{0 , 0 3 5} 2,118$

Agricultura, Silvicultura, Pesca e Veterinária

$1,753 \quad \mathbf{0 , 0 0 0} \quad 5,774$

Saúde e bem-estar

Constante

$\begin{array}{lll}-0,379 & 0,323 \quad 0,685\end{array}$

N. casos válidos

$-13,704 \quad 0,000 \quad 0,000$

$-15,3860,000$

0,000

$\mathrm{R}^{2} \mathrm{~N}$

1577

1577

0,820

0,828

Nota: 1) B=é a estimação do Beta (logaritmo da chance); Sig.= Significância estatística a 5\%; Exp. (B) = é o exponencial do Beta (razão de chance). 2) As categorias em itálico são as categorias de referência. No caso das categorias dicotômicas a categoria de referência é a que está omitida, por exemplo, no caso de "localização de moradia", a categoria de referência é "rural".

Fonte: Elaboração própria, a partir de bases de dados da UFFS

A análise deste capítulo permitiu visualizar que o rendimento acadêmico é um importante preditor no desfecho dos ingressantes em termos de conclusão ou de evasão de curso. O Gráfico 79, de dispersão, apresenta a probabilidade predita ou prevista da média da nota (eixo horizontal) em relação ao evento de conclusão do curso (eixo vertical): na medida em que a nota aumenta, maior é a probabilidade de concluir o curso.

Gráfico 79 - Representação gráfica da probabilidade prevista da nota na conclusão de curso (modelo 1)

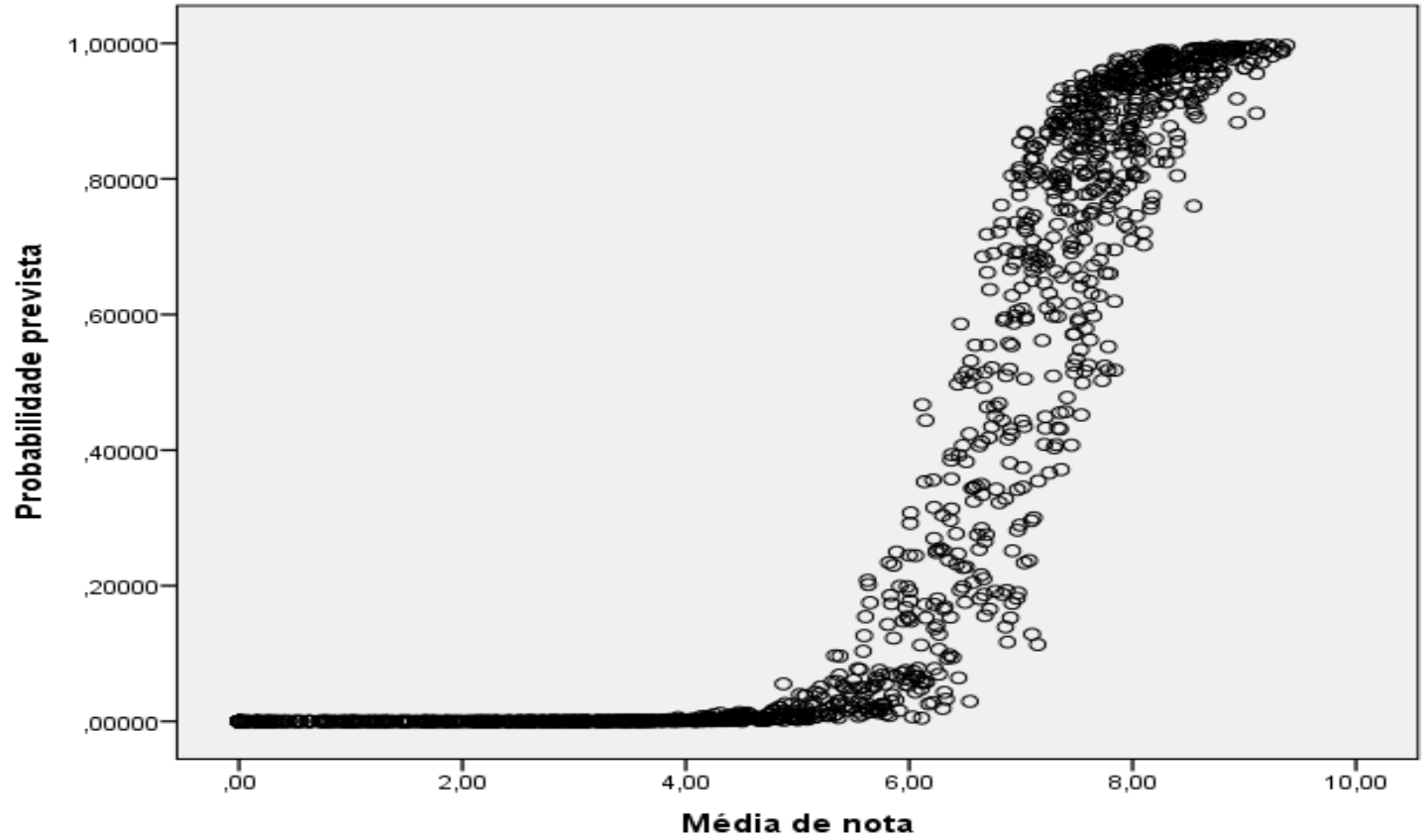

Fonte: Elaboração própria, conforme base de dados da UFFS

Verificamos, ainda, o impacto positivo de políticas de apoio social na conclusão de cursos e das próprias características do curso (turno e área de conhecimento). Com relação às características socioeconômicas dos estudantes, novamente foi possível 
observar a idade e também a condição de trabalho como variáveis explicativas do sucesso acadêmico, em termos de conclusão do curso.

\subsection{Síntese do capítulo: principais resultados}

A coorte de ingressantes em 2013 na UFFS foi a primeira a ingressar pela Lei de Cotas, e um ano antes do acesso ocorrer também por meio do SISU. Conforme verificado nos capítulos anteriores, este ano marcou uma maior diversificação dos estudantes, principalmente em termos raciais, e em todos os cursos e turmas. Homens e mulheres negros/as que, até 2012, concentravam-se principalmente em cursos de licenciaturas, passaram a aumentar sua presença em todos os cursos, e os homens, principalmente, em cursos de bacharelados. Esse foi um importante efeito da Lei de Cotas, especialmente pela forma como esta Lei foi implementada na UFFS, mantendo percentuais altos de reserva de vagas para egressos de escola pública.

Este capítulo, ainda que limitado a apenas uma coorte de ingressantes, teve o objetivo de complementar as análises sobre os desfechos, considerando os efeitos do desempenho acadêmico (notas e reprovações), e, de modo mais específico, como o rendimento acadêmico impacta nas chances de concluir ou evadir do curso. Também, a partir de análises descritivas, buscamos verificar quais características parecem estar mais associadas a esse rendimento acadêmico, tanto no grupo dos que abandonaram o curso, quanto no grupo dos que concluíram.

No que se refere às características socioeconômicas, constatamos mais uma vez que a escolaridade dos pais e a renda familiar não implicam diretamente em maior evasão e/ou menor conclusão dos cursos, ainda que, em termos de rendimento acadêmico, as notas tanto daqueles que evadiram quanto dos que concluíram, se mostraram levemente superiores para os ingressantes com maior renda familiar. Ao inserir o desempenho (médias de notas) como uma variável explicativa no modelo de regressão logística para estimar os efeitos de conclusão de curso, chamamos a atenção para o peso desta variável, que faz com que, por exemplo, as variáveis como sexo_raça e localização de moradia passem a não ter mais efeitos. Pode-se considerar que o desempenho possui maior poder explicativo na condição de desfecho (conclusão ou evasão) e pode traduzir essas outras variáveis.

Dos que ingressaram pelo principal processo seletivo na UFFS, em 2013, após seis anos, constatamos que mais de $60 \%$ haviam evadido de seu curso de origem. Buscou-se 
atentar, inicialmente, para a seguinte questão: como a nota varia neste grupo que evadiu e no grupo que concluiu o curso, segundo características socioeconômicas, gênero e raça dos estudantes e aspectos intitucionais e relacionados aos diferentes cursos de graduação?

Para a maioria das variáveis analisadas, as médias de notas dos que evadiram do curso eram semelhantes e têm mediana abaixo de 6,0. Constatou-se que esta mediana foi ainda menor entre homens negros; ingressantes com renda familiar de até 3 salários mínimos; estudantes da área urbana; entre cotistas de escola pública e raça/cor; entre os que não receberam apoio social; cursantes da área de conhecimento da Ciência da Computação; em turno noturno e entre os que tiveram reprovações durante o curso. Entre o grupo dos que não reprovaram e evadiram do curso a mediana de notas foi maior que 6,0 .

No grupo dos que concluíram o curso, as medianas de notas em geral foram acima de 6,0, sendo levemente superiores para algumas características, tais como: mulher branca; renda familiar acima de 3 s.m.; origem escolar diferente de escola pública; ingresso por ampla concorrência; entre os que não apresentaram reprovação: turno noturno e cursos de graduação nas áreas de saúde e de educação.

Ainda que alguns grupos apresentaram rendimento acadêmico ligeiramente superior, não significa que os resultados em termos de conclusão sejam necessariamente maiores para esses grupos. Um exemplo disso são os cursos na área de conhecimento da educação, que, em termos de notas possuem melhores desempenhos, mas com taxas menores de conclusão. Já a área de agricultura, por exemplo, que possui médias de notas levemente inferiores em relação aos demais grupos, tem altos percentuais em termos de conclusão. O curso escolhido é, portanto, um atributo importante no direcionamento do desfecho e do rendimento acadêmico, conforme já observado por Bertolin, Amaral e Almeida (2019). Mesmo, dentro da área da educação (formação de professores), existem diferenças no desempenho entre os diferentes cursos: Pedagogia, por exemplo, é um curso com altos percentuais de conclusão e baixa evasão e com uma grande diferença em relação a outros cursos, por exemplo Ciências Sociais e Fisolofia.

Uma característica importante que os dados desta pesquisa sinalizam é para a questão racial e mais especificamente para as diferenças no desempenho entre homens negros, tanto em termos de rendimento acadêmico quanto em termos de desfecho de conclusão dos cursos. Em 2010 quando estes ingressantes estavam mais concentrados 
nas licenciaturas esta diferença não aparecia e, a partir de 2013, com a Lei de Cotas, quando ocorreu uma maior diversificação racial em todos os cursos, essas diferenças se manifestam principalmente entre os homens negros, que passam a ocupar mais cursos de bacharelados, por exemplo.

Isso indica a importância das políticas de permanência, como aquelas voltadas ao apoio social, atividades extracurriculares, apoio pedagógico, para que possíveis desvantagens entre estudantes possam ser superadas ou pelo menos reduzidas durante a graduação, promovendo o sucesso acadêmico para todos os grupos independentemente de suas características como raça/cor, condição de trabalho durante o ensino médio e idade. Trata-se, portanto de proporcionar o que as autoras Feliceti \& Morisoni (2009, p.12) chamam de equidade nos resultados, ou seja, "medidas de apoio e acompanhamento para ajudar os alunos que têm maiores dificuldades, principalmente se estas forem de origem socioeconômica". Enquanto a equidade de acesso se refere a todos terem as mesmas condições de competir, para ser uma competição justa as ações afirmativas voltadas para a permanência se mostram um grande aliado.

Os dados desta pesquisa mostram que as políticas de acesso da UFFS proporcionaram uma maior inclusão social e, principalmente, a partir da Lei de Cotas, uma maior diversificação racial em todos os cursos. Os ingressantes, em sua maioria, são de origem popular, segundo os critérios escola pública, renda familiar e escolaridade dos pais e essas variáveis parecem não interferir diretamente no desfecho de conclusão ou de evasão dos cursos e nem no desempenho durante a graduação.

Com relação aos percentuais mais elevados de evasão na UFFS, é preciso tecer algumas considerações. A evasão de curso em muitas situações expressa apenas a mobilidade para outro curso e/ou IES. No caso estudado é preciso considerar que a UFFS possui cerca de $50 \%$ de cursos voltados para as licenciaturas. Tendo em vista, principalmente o desprestígio destas carreiras no mercado de trabalho, a evasão nesta área tende a ser maior. Neste sentido, observa-se, que a UFFS possui uma lógica institucional que se difere das demais IES brasileiras, em que a oferta de cursos de licenciaturas é de apenas 18,9\%, e mesmo quando comparada à oferta de licenciaturas em novos campi universitários, criados entre 2003 e 2014, e cuja oferta de licenciaturas é de 25,5\% (Inep, 2020a; Barbosa; Campos, 2020; Buckner; Zapp, 2021).

A reprovação em disciplinas é uma realidade para a maioria dos ingressantes da UFFS, que pode estar motivada por defasagens em etapas anteriores da escolaridade, 
por razões socioeconômicas ou pela trajetória escolar prévia na escola pública (Feliceti; Morosini, 2009; Figueirêdo, Nogueira; Santana, 2014). Conforme verificamos neste estudo, a reprovação pode indicar um alto risco de evasão, principalmente quando está associada a menores médias nas notas. Por outro lado, a reprovação pode também indicar a persistência dos estudantes na graduação até a conclusão, pois entre os que concluem, mais de $60 \%$ tiveram reprovações, o que sinaliza situação de retenção, ou seja, a maioria dos que se formam na UFFS demoram mais tempo que o previsto. Um exemplo disso, pode ser constatado nesta mesma coorte de ingressantes em 2013, que, após seis anos de ingresso, além dos que concluíram ou evadiram do curso, mais de $10 \%$ ainda permanecia na UFFS, tendo a reprovação como uma possível causa.

De um modo geral, os resultados indicam a importância do desempenho acadêmico no desfecho de conclusão ou de evasão de curso, ainda que este não traduza necessariamente o processo de aprendizagem como um todo, uma vez que foi verificado apenas do ponto de vista das médias de notas e reprovações. 


\section{0}

\section{Conclusões}

Nesta pesquisa, exploramos o fenômeno da desigualdade de oportunidades no ensino superior no contexto da UFFS, com o objetivo principal de investigar as relações entre características socioeconômicas dos estudantes, aspectos institucionais e o desempenho acadêmico e o acesso e a conclusão de curso.

Dialogamos com a literatura sociológica no campo da estratificação social e realizamos uma aproximação com a abordagem interseccional buscando compreender a relação entre a origem social dos estudantes e seu alcance educacional e como as desigualdades estruturais, principalmente de gênero e raça, se configuram na ocupação de cursos e nas trajetórias dos estudantes (evasão, conclusão e desempenho acadêmico).

Mobilizamos diferentes estudos que nos mostraram os avanços obtidos nas últimas décadas no ensino superior brasileiro e nas demais etapas da escolarização, em termos de expansão, interiorização e democratização do acesso e da permanência, especialmente para públicos abrangidos pelas políticas de ação afirmativa: pretos, pardos, indígenas, pessoas com deficiência, estudantes das áreas rurais e com menor poder aquisitivo. Ainda que persistam muitas desigualdades no ensino superior, as pesquisas vêm mostrando efeitos positivos de políticas educacionais recentes na redução das desigualdades sociais e raciais. A presente pesquisa se situa nessa perspectiva e no contexto da experiência da UFFS, que se mostra um caso particular diante de suas características em termos da inclusão social, desde a sua criação.

O estudo levou em conta duas principais dimensões de análise: acesso e permanência (desfechos: evasão e conclusão de curso) ao longo do tempo, buscando sempre estabelecer relações entre as características socioeconômicas e raciais dos estudantes e aspectos da Instituição e dos cursos. O recorte temporal abrangeu os primeiros nove anos de existência desta instituição (2010 a 2018) e a principal unidade de análise foram todos os ingressantes nesta IES, por meio do Enem. Além de documentos e legislações institucionais, utilizamos diferentes fontes de dados secundários, que permitiram elaborar diferentes desenhos metodológicos para atender aos objetivos propostos. Destacamos a relevância da utilização de bases de dados secundários para a pesquisa educacional, tanto as bases no âmbito da Instituição estudada, quanto o acesso aos dados do Enem e do Censo Superior, recortados para a 
UFFS, obtidos na Sala Segura do Inep, sendo este um espaço ainda pouco explorado por pesquisadores da área da Educação.

Na dimensão do acesso buscamos responder aos objetivos de mapear as principais características da UFFS e o perfil socioeconômico e racial dos ingressantes ao longo do tempo. Além disso, por meio de uma aproximação com a abordagem interseccional, buscamos mapear também como se configuram as desigualdades de raça e gênero no acesso aos cursos de graduação.

Os resultados mostraram os avanços das políticas de acesso e das ações afirmativas adotadas nesta Instituição, inicialmente com bônus da escola pública e, em seguida, pela forma como implementou a Lei de Cotas. São políticas que trouxeram para o espaço universitário mais de $90 \%$ de egressos da escola pública de nível médio e um percentual significativo de estudantes da zona rural, cuja maioria representa a primeira geração da família a acessar o ensino superior. A principal contribuição da Lei de Cotas foi o aumento de ingressantes pretos, pardos e indígenas em todos os cursos de graduação, de modo que a representação desse público ficou mais próxima e até superou a sua representação populacional, conforme cada Estado do campus. Isso revela a importância desta IES no enfrentamento às desigualdades sociais e raciais. O desenho institucional com uma grande oferta de cursos noturnos também constitui um elemento importante de democratização do acesso, principalmente para estudantes trabalhadores e/ou trabalhadores estudantes (Moraes et al., 2011). A adesão ao SiSU, a partir de 2014, permitiu diversificar ainda mais o público estudantil, principalmente com o aumento de estudantes de diferentes regiões do país e com um perfil ainda mais jovem que em anos anteriores.

Com relação à ocupação dos cursos, em termos de raça e gênero, os resultados sinalizam que a partir da Lei de Cotas, homens e mulheres negras aumentaram sua participação em todas as áreas de conhecimento, ficando mais próximos do padrão de ocupação de homens e mulheres brancas. A desigualdade estrutural de gênero permanece de modo mais persistente: ainda que as mulheres sejam maioria, em termos relativos os homens predominam na ocupação de cursos considerados de maior retorno econômico.

Na dimensão da permanência, em que buscamos compreender o desfecho dos estudantes (evasão e conclusão de curso), partimos inicialmente de uma revisão de literatura com um conjunto de estudos empíricos com diferentes abordagens 
metodológicas, que analisaram características associadas com a evasão e conclusão de curso, tanto do ponto de vista das características dos estudantes, quanto das instituições e dos cursos, além de outros aspectos como o desempenho acadêmico antes e depois do ingresso, motivação, apoio de familiares e amigos e valorização das carreiras no mercado de trabalho.

Tendo essa revisão como referência e com uso de dados secundários, as análises empíricas buscaram atender ao objetivo de "analisar as relações entre características socioeconômicas, gênero, raça, desempenho e aspectos institucionais e o desfecho (conclusão ou evasão de curso) dos estudantes".

Como um dos limites desta pesquisa, reconhecemos a análise da evasão apenas do ponto da saída do curso de origem, pois, muitas vezes, essa condição pode indicar apenas uma mobilidade para outro curso dentro ou fora da própria IES, e não necessariamente a exclusão de estudantes do sistema de ensino superior de forma definitiva (De Paula, 2021; Ristoff, 2021). Esse estudo em particular abre novas questões para pesquisas futuras, no sentido de investigar como ocorre essa movimentação/mobilidade entre os ingressantes na UFFS, seja entre cursos de um mesmo campus, entre os diferentes campi da UFFS e/ou para outras Instituições. Outro tema que mereceria o interesse de futuras pesquisas é o mapeamento dos percentuais e motivações de reingresso dos estudantes que abandonam a UFFS, sem deixar de mencionar também a possibilidade de explorar melhor as motivações relacionadas à evasão de curso e ao elevado percentual de reprovações, entre os estudantes que levam um tempo maior na UFFS para a integralização dos cursos. Esses novos estudos poderão vir a subsidiar políticas institucionais de enfrentamento da evasão e da retenção, aumentando as chances de permanência e de conclusão nos cursos.

Os resultados desta pesquisa indicaram que a evasão de curso se encontra menos associada às características sociais e econômicas dos estudantes (sexo, raça/cor, renda, escolaridade dos pais, escola pública) e mais associada às características do curso, tais como o turno e principalmente com o acesso aos recursos da assistência estudantil e à participação em atividades extracurriculares, neste último caso, ainda que de modo voluntário. Contudo, a idade se mostrou como um marcador social que apresenta maiores chances de evasão do curso. O fato de um estudante ingressar de modo mais tardio no ensino superior pode estar relacionado a sua condição socioeconômica, que 
precisa trabalhar, possui filhos e/ou que não teve oportunidade em momentos anteriores. Essas dificuldades podem acarretar o abandono de curso antes de sua conclusão.

Em geral, esses resultados estão em linha com a literatura sobre o fenômeno da evasão de curso. Um dos achados originais desta pesquisa é o que mostra a maior persistência dos estudantes oriundos da zona rural (com menores chances de evasão e maiores chances de conclusão de curso). Esse fenômeno contribui para a mitigação das desigualdades históricas em termos educacionais para jovens da zona rural em relação aos da zona urbana e demonstra a importância desta Instituição no processo de interiorização e democratização da educação superior pública.

As análises dos estudantes que concluíram o curso, em relação as que ainda estavam com a matrícula ativa no curso e/ou haviam evadido, mostram associações com as variáveis sexo e raça: de um modo geral, os homens apresentaram menos chances de conclusão, em relação às mulheres brancas, especialmente os homens negros. E, entre as mulheres negras, quando comparadas com as brancas, não foram observadas diferenças. Esses resultados foram identificados apenas para as coortes de ingressantes de $2013 \mathrm{e}$ de 2014, a partir da Lei de Cotas e do SiSU. Quanto mais antiga é a coorte de ingresso, mais fácil é a verificação dos percentuais de conclusão de curso, haja vista, que a condição de reprovação é um fenômeno presente na maioria dos estudantes da UFFS (tanto entre os que evadem, quanto entre os que concluem o curso), sendo ainda mais elevada entre os homens e, principalmente homens pretos e pardos. Além disso, em termos relativos a participação de homens é maior em cursos de bacharelados, com relação às mulheres, e em geral esses cursos possuem prazos de integralização maiores, o que pode sinalizar que as menores chances de conclusão de curso dos homens em relação às mulheres também podem estar associadas a mais reprovações. Com relação aos homens negros, há de se considerar que, em geral, eles ingressam com maior idade quando comparados com os demais grupos de estudantes, sendo este um marcador social importante junto com as desigualdades estruturais de raça, que são traduzidas em maiores desvantagens da população negra desde a educação básica.

O desempenho acadêmico antes e a partir do ingresso na Universidade, traduzido por meio das notas, embora não expressa toda a condição de aprendizagem, é um aspecto importante a ser considerado nos desfechos dos estudantes, tanto da saída do curso antes de concluir e, principalmente, na conclusão do curso. O resultado na nota de redação do Enem, e demais componentes desta prova, é um fator que contribui inclusive 
para o acesso a determinados cursos e Instituições, mais ou menos seletivas. O desempenho, em alguma medida, expressa algumas características socioeconômicas dos estudantes, principalmente ao longo do seu percurso na educação básica: estudantes brancos e com maior poder aquisitivo apresentam maiores vantagens, e, principalmente, os meninos pretos, com menor nível socioeconômico e de escolas públicas tendem a um desempenho menor (Ernica; Rodrigues, 2020; Senkevics; Carvalho, 2020).

Na UFFS, a análise da nota na redação no Enem dos ingressantes esteve mais associada ao aumento das chances de conclusão de curso, principalmente, nas coortes de 2013 e de 2014, quando esta nota em geral foi menor em relação à coorte de 2010. De algum modo, o desempenho antes do ingresso pode influenciar o desempenho no curso e sua trajetória a partir do ingresso e, nesse contexto, as políticas institucionais de permanência estudantil e de apoio pedagógico podem fazer muita diferença.

Conforme analisado nesta Tese, no caso da coorte de ingressantes de 2013, e resguardadas às limitações pelo fato de considerar as médias simples de notas, o desempenho acadêmico após o ingresso representa um fator importante associado à permanência e à conclusão dos cursos.

Ao cruzar o rendimento acadêmico entre os que haviam evadido e os que haviam concluído o curso, constatamos que a maioria evadida apresentava média de nota inferior a 6,0. Como se trata apenas de evasão de curso, questiona-se, por exemplo, se aqueles que apresentaram médias de notas superiores a 6,0, estariam mesmo evadindo do sistema ou apenas realizando uma troca de curso e/ou de IES? De todo modo, os dados indicam que existe uma associação entre o baixo desempenho acadêmico e a evasão de curso. Conforme destaca De Paula (2021), seria a nota considerada uma variável independente que explicaria a própria aprendizagem, a desmotivação e a saída do curso ou seria a própria intenção de sair daquele curso que provocaria um desinvestimento naquele curso? Entre aqueles que registraram média de nota igual a zero, por exemplo, é possível que tenha ocorrido a desistência do curso sem mesmo ter cursado ou muito antes de ter finalizado o semestre.

Entre as características socioeconômicas dos estudantes, destacamos, por exemplo que as variáveis de sexo e raça mostraram estar associadas com o desempenho, mesmo com pouca diferença: entre os que evadiram do curso, os homens negros, apresentaram menor desempenho, seguido de homens brancos. Entre os concluintes, as mulheres brancas apareceram com desempenho superior, em relação aos demais grupos que 
apresentaram médias de notas mais próximas (mulheres negras, homens brancos e negros).

A renda familiar é um marcador social que não mostrou efeito na evasão e conclusão de curso, mas apontou algumas diferenças com relação ao desempenho: estudantes com maior renda familiar (acima de 6 s.m) apresentaram média de nota levemente superior aos demais grupos, principalmente entre os que evadiram do curso. Esse fato pode indicar uma aproximação com as diferentes motivações da evasão, sendo de forma mais voluntária entre estudantes com maior poder aquisitivo e mais apoiada financeiramente entre estudantes com menor poder aquisitivo (De Paula, 2021). Compreender melhor a dinâmica da evasão de curso na UFFS e suas motivações é uma questão importante a ser considerada por novas pesquisas, especialmnte com abordagem qualitativa.

Outra característica importante e que apresenta diferenciação quanto ao desempenho dos estudantes é o tipo de escola cursada no ensino médio: em termos de conclusão ou de evasão de curso, não existem diferenças entre estudantes oriundos ou não da escola pública, embora a verificação da média de notas entre os que finalizaram o curso, mostre médias de notas superiores entre os que não cursaram escola pública e uma pequena diferenciação de notas entre os que agregavam os critério escola pública e racial (pretos, pardos e indígenas).

A idade no ingresso dos estudantes é uma característica importante e tem efeitos nas chances de evasão e conclusão de curso. Com relação ao desempenho, observamos apenas diferenças de notas entre os que evadiram do curso: aqueles que ingressaram na faixa etária acima de 20 anos apresentaram notas menores, em relação aos mais jovens. Entre os que concluíram o curso, não foram observadas diferenças nas médias de notas, considerando a idade no ingresso.

De um modo geral, verificamos que o desempenho dos estudantes também possui um comportamento bastante associado ao tipo de curso: as áreas de conhecimento de Educação (licenciaturas) e de Saúde, em geral possuem médias de notas superiores, principalmente entre os estudantes que concluíram o curso. Ter notas superiores não indica necessariamente índices maiores de conclusão de curso. A área de Agricultura, por exemplo, possui o menor desempenho acadêmico, mas é uma das áreas com os maiores percentuais de conclusão. O contrário ocorre com a área da Educação, cujo desempenho tende a ser superior e com índices menores de conclusão em seus cursos. 
Neste sentido, destacamos a importância de análises futuras que possam fazer essas desagregações, buscando sempre analisar evasão, conclusão e mesmo retenção, em relação a determinado tipo de curso, área de conhecimento e/ou grau acadêmico. Sugere-se, ainda, que o curso de Medicina possa ser analisado de forma desagregada dos demais cursos da área de Saúde, devido às suas especificidades, como o próprio perfil dos estudantes, que em geral ingressam com mais idade. Em termos de desempenho, por exemplo, quando desagregamos a análise por campus, conseguimos perceber o alto desempenho do Campus Passo Fundo, que possui apenas o curso de Medicina, mesmo no grupo dos que evadiram do curso.

Principalmente na questão do desempenho, as características socioeconômicas indicam diferenciações desde a educação básica que de algum modo continuam se manifestando no ensino superior. Esse resultado reforça a importância das políticas institucionais de permanência estudantil para mitigar as desigualdades educacionais e permitir a conclusão nos cursos e a redução da evasão de curso, da instituição e do sistema. Ter notas mais baixas, portanto, não é sinônimo de evasão, e os dados analisados nesta pesquisa não permitem verificar se esta evasão foi, de fato, definitiva. Ainda assim, conseguimos verificar que, em geral, os estudantes que evadem dos cursos possuem notas menores, sendo, portanto, o desempenho uma característica importante e que pode ser melhor explorado por meio de pesquisas futuras.

A experiência de inclusão social da UFFS apresenta avanços no enfrentamento das desigualdades sociais e raciais no ensino superior e permite a este estudo se somar as contribuições de outros estudos para a avaliação da Lei de $\operatorname{Cotas}^{76}$, que vai completar uma década e tem previsão de revisão em 2022. Os resultados dessa pesquisa indicam que é possível continuar abrindo as portas para estudantes das camadas populares, e que, ao trazer as desigualdades para dentro da Universidade, os desafios maiores se colocam no sentido de promover a igualdade de oportunidades na permanência e na conclusão de cursos e também no mercado de trabalho.

\footnotetext{
${ }^{76}$ O Projeto de Lei n. 1.788/2021, que está tramitando na Câmara dos Deputados, prevê a transferência da revisão da Lei de Cotas para 2042, dada a sua importância para o acesso e inclusão social no ensino superior público. Conforme mencina o autor do projeto, o deputado Bira do Pindaré (PSB-MA): "Talvez não tenha havido a exata dimensão de que a lei, uma década após sua edição, continuaria extremamente atual e, sobretudo, necessária". (Agência Câmara de Notícias, 07/07/2021, disponível em: https://www.camara.leg.br/noticias/781991-proposta-transfere-revisao-da-lei-de-cotas-no-ensinosuperior-para-2042).
} 
Chegando neste ponto, algumas provocações se fazem necessárias: Como a Universidade se coloca diante destes novos desafios, ela promove a inclusão social ou reproduz ainda mais as desigualdades sociais e raciais? Que adaptações curriculares podem dar conta da redução das reprovações, por exemplo? Que ações institucionais podem ser pensadas no sentido de aumentar a permanência e a conclusão do curso de estudantes que ingressam com maior idade e de homens negros, por exemplo? Que novos desafios se apresentam para o acesso e permanência ao ensino superior neste cenário da Pandemia de Covid 19, e, num contexto político e econômico de desinvestimento na política educacional? Pode ser uma "inclusão interrompida", conforme destaca Maria Luíza Matos de Oliveira (2021)? Agravado por esta crise sanitária, assistimos ao acirramento da desigualdade social, do desemprego e da fome, o que pode intensificar a evasão escolar e mesmo o não acesso de muitos jovens ao ensino superior.

Ainda que novas e/ou velhas barreiras ainda persistam no contexto de expansão do ensino superior, conforme mencionam Senkevics \& Carvalho (2020), esta pesquisa constatou que experiências de inclusão social, como a da UFFS, vêm contribuindo de forma significativa para o enfrentamento da desigualdade de oportunidades sociais e raciais no ensino superior, com ênfase principalmente nos jovens das camadas populares, negros, indígenas e da zona rural. Conjugada com as políticas de acesso, as políticas de permanência estudantil na UFFS se mostraram muito aliadas na promoção de equidade não somente de acesso, mas também de resultados, conforme destacam Feliceti \& Morosini (2009). 


\section{Referências}

ADACHI, A. A. C. T. Evasão de estudantes de cursos de graduação da USP: ingressantes nos anos de 2002, 2003 e 2004. 2017, 294p. Tese (Doutorado) Universidade de São Paulo, São Paulo, 2017.

AGUIAR NETO, J. M. Da escola à universidade: trajetórias de sucesso escolar. 239f. Tese (Doutorado em Sociologia). Pontifícia Universidade Católica do Rio Grande do Sul, Porto Alegre, 2019.

AGRESTI, A.; FINLAY, B. Métodos estatísticos para as ciências sociais. Tradução de Lori Viali. 4 ed., Porto Alegre: Penso Editora, 2012.

ALMEIDA, A.M.F.; ERNICA, M. Inclusão e segmentação social no Ensino Superior público no Estado de São Paulo (1990-2012). Educ. Soc. [online]. 2015, vol.36, n.130, p.63-83.

ALON, S. The influence of financial aid in leveling group differences in graduating from elite institutions. Economics of Education Review, v. 26, n. 3, p. 296-311, 2007.

The evolution of class inequality in Higher Education: Competition, exclusion, and adaptation. American Sociological Review, v.74, n.5, p.731-755, 2009.

AMBIEL, R. A. M. Construção da escala de motivos para evasão do ensino superior. Avaliação Psicológica, v. 14, n. 1, p. 41-52, 2015.

ANDRADE, C.Y. Jovens, raça e renda: o alcance limitado das políticas de inclusão e a permanência das desigualdades educacionais. Anais do XXI Encontro Nacional de Estudos Populacionais. ABEP, p. 1-18, 2019.

ASSOCIAÇÃO NACIONAL DOS DIRIGENTES DAS INSTITUIÇÕES FEDERAIS DE ENSINO SUPERIOR (Andifes). V Pesquisa Nacional de Perfil Socioeconômico e Cultural dos (as) Graduandos (as) das IFES. Brasília: Fórum Nacional de Pró-Reitores de Assuntos Comunitários e Estudantis (FONAPRACE), 2019. Disponível em: http://www.andifes.org.br/v-pesquisa-nacional-de-perfil-socioeconomico-e-culturaldos-as-graduandos-as-das-ifes-2018/. Acesso em 20 mai. 2020.

ÁVILA, R. Estudantes de camadas populares e o ingresso na vida universitária. Revista Brasileira de Estudos Pedagógicos, 2011, vol. 92, no 232.

BACCARO, T. A.; SHINYASHIKI, G. T. Relação entre desempenho no vestibular e rendimento acadêmico no ensino superior. Revista Brasileira de Orientação Profissional, vol. 15, n. 2, p. 165-176, 2014.

BAGGI, C. A. S. LOPES, D. A. Evasão e avaliação institucional no ensino superior: uma discussão bibliográfica. Avaliação: Revista da Avaliação da Educação Superior (Campinas), v. 16, n. 2, p. 355-374, 2011. 
BAIRROS, L. Nossos Feminismos Revisitados. Dados, v.3, n. 3, p. 458-463, 1995.

BARBOSA, P.F.; CAMPOS, L.H.R. Interiorização dos Institutos e Universidades federais: uma análise do perfil dos alunos e seus possíveis efeitos. Revista Brasileira de Gestão e Desenvolvimento Regional, v. 16, n. 3, 2020.

BARBOSA, M. L. O. Democratização ou massificação do Ensino Superior no Brasil? Revista de Edução PUC-Campinas, Campinas, SP, 24 (2), p. 240-253, maio/ago., 2019.

BEAN, J. Dropouts and turnover: the synthesis and test of a causal model of student attrition. Research in Higher Education, Switzerland, v. 12, n. 2, p. 155-187, Spr. 1980.

BERTOLIN, J.; AMARAL, A.; ALMEIDA, L.; Os cursos de graduação podem compensar a falta de capital cultural e background de estudantes? Educação e Pesquisa, São Paulo, v. 45, e185453, 2019.

BORGES, E. H. N. Modelos teóricos de análise da evasão no ensino superior aplicados à pesquisa sobre acompanhamento acadêmico dos discentes do setor público. Enfoques, Rio de Janeiro, Edição Especial, XX Jornada PPGSA, pp. 83-95, 2019.

BRASIL. Presidência da República. Lei n. 10.172 de 09 de janeiro de 2001. Aprova o Plano Nacional de Educação e dá outras providências. Diário Oficial da União, Brasília, DF, Seção 1, p. 1, 10 de jan. 2001a.

Lei n. 10.260, de 12 de julho de 2001. Dispõe sobre o Fundo de Financiamento ao estudante do Ensino Superior e dá outras providências. Diário Oficial [da] República Federativa do Brasil, Brasília, DF, Seção 1. p. 2-3, 13 jul. 2001 b.

Lei n. 11.096, de 13 de janeiro de 2005. Institui o Programa Universidade para Todos - ProUni, regula a atuação de entidades beneficentes de assistência social no ensino superior; altera a Lei n. 10.891, de 9 de julho de 2004, e dá outras providências. Diário Oficial da União, Brasília, DF, Seção 1, p. 7, 14 jan. 2005.

Decreto n. 6.096, de 24 de abril de 2007. Institui o Programa de Apoio a Planos de Reestruturação e Expansão das Universidades Federais - Reuni. Diário Oficial da União, Brasília, DF, Seção 1, p. 7, 25 abr. 2007.

Lei n. 12.029, de 15 de setembro de 2009. Dispõe sobre a criação da Universidade Federal da Fronteira Sul. Diário Oficial da União, Brasília, DF, Seção 1, p. 1,16 set. 2009.

Decreto n. 7.234, de 19 de julho de 2010. Dispõe sobre o Programa Nacional de Assistência Estudantil - Pnaes. Diário Oficial da União, Brasília, DF, Seção 1, p. 5, 20 jul. 2010.

Lei n. 12.711 em 29 de agosto de 2012. Dispõe sobre o ingresso nas universidades federais e nas instituições federais de ensino técnico de nível médio e dá outras providências. Diário Oficial da União, Brasília, DF, Seção 1, p. 1, 30 ago. 2012. 
Lei n. 13.409, de 28 de dezembro de 2016. Altera a Lei no 12.711, de 29 de agosto de 2012, para dispor sobre a reserva de vagas para pessoas com deficiência nos cursos técnico de nível médio e superior das instituições federais de ensino. Diário Oficial da União, Brasília, Seção 1, p. 3, 29 dez. 2016.

BRASIL. Ministério da Educação. Portaria Normativa MEC n. 2, de 26 de janeiro de 2010. Institui e regulamenta o Sistema de Seleção Unificado. Disponível em: <http://portal.mec.gov.br/index.php?option=com_docman\&view=download\&alias=270 4-sisuportarianormativa2\&Itemid=30192> . Acesso em 19 nov. 2021.

Portaria Normativa MEC n. 21, de 5 de novembro de

2012. Dispõe sobre o Sistema de Seleção Unificada - SiSU. Disponível em: <http://www.sisu.furg.br/images/portaria21mec.pdf>. Acesso em 19 nov. 2021.

BRASIL. Ministério da Educação. Secretaria de Educação Superior. A democratização e expansão da educação superior no país 2003-2014. Brasília, DF, 2014.

BOUDON, R. A desigualdade das oportunidades: a mobilidade social nas sociedades industriais. Trad. De Carlos Alberto Lamback. Brasília, Editora Universidade de Brasília, 1981, 284p.

BRITO, M.M. A. Novas tendências ou velhas persistências? Modernização e expansão educacional no Brasil. Cadernos de Pesquisa. [online]. vol.47, n.163, p.224-263, 2017.

BUCKNER, E.; ZAPP, M. Institutional Logics in the Global Higher Education Landscape: Differences in Organizational Characteristics by Sector and Founding Era. Minerva, 2021, vol. 59, no 1, p. 27-51.

CABRERA, A. et al. The convergence between two theories of college persistence. The Journal of Higher Education, London, v. 63, n. 2, p. 143-164, Mar./Apr. 1992.

CARVALHAES, F. et al. O impacto da lei de cotas nos Estados: um estudo preliminar. Rio de Janeiro, Textos para discussão GEMAA (IESP-UERJ), n. 1, 2013, pp. 1-17.

CARVALHAES, F.; RIBEIRO, C.A. Estratificação horizontal da educação superior no Brasil: desigualdades de classe, gênero e raça em um contexto de expansão educacional. Tempo Social, Revista de Sociologia da USP, v. 31, n. 1, p. 195-233, jan.-abr., 2019.

CASEIRO, L. C. Z. Desigualdade de acesso à educação superior no Brasil e o Plano Nacional de Educação. Série PNE em Movimento, n. 3, p. 40-40, 2016.

COLLINS, P. Em direção a uma nova visão: raça, classe e gênero como categorias de análise e conexão. MORENO, R. (org.) Reflexões e Práticas de Transformação Feminista, São Paulo: SOF, 2015.

COSTA, F. P. Acesso e permanência no ensino superior: uma análise para as universidades federais brasileiras. 81f. Dissertação (Mestrado profissional em Políticas Públicas). Universidade Federal de Pernambuco. Recife, 2018. 
COSTA, O. S. da; GOUVEIA, L. B. Modelos de retenção de estudantes: abordagens e Perspectivas. REAd. Revista Eletrônica de Administração (Porto Alegre), v. 24, n. 3, p. 155-182, 2018.

COSTA, A. L.; PICANÇO, F. Para além do acesso e da inclusão impactos da raça sobre a evasão e a conclusão no ensino Superior. Novos estudos CEBRAP, v. 39, n. 2, p. 281$306,2020$.

CUNHA, L. A. O ensino superior no octênio FHC. Educação \& Sociedade, Campinas, v. 24, n. 82, p. 37-61, abr. 2003.

CRENSHAW, K. Demarginalizing the intersection of race and sex: a black feminist critique of anti discrimination doctrine, feminist theory and antiracist politics. University of Chicago Legal Forum, 1989, p.139-167.

DAFLON, V. T.; FERES JÚNIOR, J.; CAMPOS, L. A. Ações afirmativas raciais no ensino superior público brasileiro: um panorama analítico. Cadernos de Pesquisa, v. 43, n. 148, p. 302-27, 2013.

DAMBRÓS, M. Dilemas na constituição dos sentidos atribuídos ao popular na universidade Federal da Fronteira Sul. 109 f. Dissertação (Mestrado em Educação). Universidade Federal da Fronteira Sul, Chapecó, 2015.

DEMARCO, S. M.; MAIA, C. M. A universidade federal da fronteira sul: uma política pública em processo de implementação na perspectiva de uma construção social e interesses regionais. Revista Brasileira de Planejamento e Desenvolvimento, v. 2, n. 2, p. 80-93, 2013.

DE PAULA, G. B.; NOGUEIRA, C. M.M. Evasão de curso no ensino superior federal análise de coorte dos ingressantes de 2012. In: OLIVEIRA, M.L.B. A expansão desigual do ensino superior no Brasil. - 1 ed - Curitiba: Appris, 2020.

DE PAULA, G. B. Desigualdades sociais e evasão no ensino superior. Uma análise em diferentes níveis do setor federal brasileiro. 208 f. Tese (Doutorado em Educação). Universidade Federal de Minas Gerais, Belo Horizonte, 2021. (Não publicado).

DE OLIVEIRA, A.L.M. Educação Superior brasileira no início do século XXI: inclusão interrompida? Tese (Doutorado em Desenvolvimento Econômico) - Instituto de Economia, Universidade Estadual de Campinas, Campinas, 2019.

DIAS, C.E.S.B.; SAMPAIO, H. Serviços de apoio a estudantes em universidades federais no contexto da expansão do ensino superior no Brasil. In: DIAS, C. E. S. B. et al. (Orgs.). Os serviços de apoio pedagógico aos discentes no ensino superior brasileiro. São Carlos: Pedro \& João Editores, 2020. 518 p.

DUBET, F. Qual democratização do ensino superior? Cadernos $C R H$, Salvador, v. 28, n. 74, p. 255-266, maio/ago. 2015. 
DURU-BELLAT, M.; KIEFFER, A.; REIMER, D. Patterns of social inequalities in access to higher education in France and Germany. International journal of comparative sociology, v. 49, n. 4-5, p. 347-368, 2008.

ELLER, C. C. Superficially Coupled Systems: The Organizational Production of Inequality in Higher Education. Annenberg EdWorkingPaper, n. 19-70, 2019.

ELLER, C. C.; DIPRETE, T. A. The paradox of persistence: explaining the black-white gap in bachelor's degree completion. American Sociológica Review, v. 83, n. 6, p. 1171-1214, 2018.

ERNICA, M. RODRIGUES, E. C. Desigualdades educacionais em metrópoles: território, nível socioeconômico, raça e gênero. Educação \& Sociedade, Campinas, v. 41, 2020.

FASSINA, A.L. Conciliação entre estudo e trabalho e sua influência na permanência de estudantes de graduação da UFFS. 110 f. Dissertação (Mestrado em Educação) Universidade Federal da Fronteira Sul. Chapecó, 2018.

FELICETTI, V. L.; MOROSINI, M. C. Equidade e iniquidade no ensino superior: uma reflexão. Ensaio: Avaliação e políticas públicas em educação, 2009, vol. 17, no 62, p. 9-24.

FERRÃO, M. E.; ALMEIDA, L. S. Modelagem multinível de persistência no ensino superior. Ensaio: Avaliação e Políticas Públicas em Educação, v. 26, n. 100, p. 664683, 2018.

FIGUEIRÊDO, E. NOGUEIRA, L.; SANTANA, F. L. Igualdade de Oportunidades: Analisando o papel das circunstâncias no desempenho do ENEM. Revista Brasileira de Economia, 2014, vol. 68, no 3, p. 373-392.

FRASER, N. Da redistribuição ao reconhecimento? Dilemas de justiça numa era póssocialista (trad. Julio Simões). Cadernos de campo, São Paulo, n. 14/15, p.1-382, 2006.

FREITAS, J. B. de. et al. As Políticas de Ação Afirmativa nas Universidades Federais e Estaduais (2003-2018). Levantamento das políticas de ação afirmativa (GEMAA), IESP-UERJ, 2020, p. 1-33.

FRESNEDA, B. Desigualdades educacionais no ensino médio brasileiro: avanços e persistências. 2012, 209 f. Tese (Doutorado) - Universidade do Estado do Rio de Janeiro, Instituto de Estudos Sociais e Políticos, Rio de Janeiro, 2012.

FRITSCH, R.; JACOBUS, A. E.; VITELLI, R. F. Diversificação, mercantilização e desempenho da educação superior brasileira. Avaliação: Revista da Avaliação da Educação Superior (Campinas), v. 25, n. 1, p. 89-112, 2020.

GERBER, T. P.; CHEUNG, S. Y. Horizontal Stratification in Postsecondary Education: Forms, Explanations, and Implications. Annu. Revista Sociológica, vol, 34, p. 299-318, 2008. 
GERRING, J. Pesquisa de estudo de caso: princípios e práticas. Tradução de Caesar Souza. - Petrópolis, RJ: Vozes, 2019.

GIDDENS, A.; SUTTON, P.W.; tradução Claudia Freire. Conceitos essenciais de Sociologia. - 1 ed. - São Paulo: Editora Unesp Digital, 2017.

GILIOLI, R. S. P. Evasão em instituições federais de ensino superior no Brasil: expansão da rede, SiSU e desafios. Brasília: Câmara dos Deputados, p. 49, 2016.

GOLDTHORPE, J. H. "Cultural Capital": Some Critical observations. Sociologica, v. 1, n. 2, p. 0-0, 2007.

HERINGER, R. Pertencer e permanecer na universidade: reflexões a partir das políticas de acesso e permanência na Universidade do Texas - Austin (EUA). 44 ${ }^{\circ}$ Encontro Anual da ANPOCS, GT 06 - Ciências Sociais e Educação, dezembro/2020a.

Políticas de ação afirmativa e os desafios da permanência no ensino superior. In: DIAS, C. E. S. B. et al. (Orgs.). Os serviços de apoio pedagógico aos discentes no ensino superior brasileiro. São Carlos: Pedro \& João Editores, 2020b. 518 p.

HOUT, M. Maximally maintained inequality and essentially maintained inequality: Crossnational comparisons. Sociological Theory and Methods, v. 21, n. 2, p. 237-252, 2006.

INSTITUTO BRASILEIRO DE GEOGRAFIA E ESTATÍSTICA (IBGE). Censo Demográfico: Tabela 3175 - População residente, por cor ou raça, segundo a situação do domicílio, o sexo e a idade. 2010a. Sistema IBGE de Recuperação Automática (SIDRA). Disponível em: https://sidra.ibge.gov.br/tabela/3175. Acesso em 08 jun. 2019.

Censo Demográfico: Tabela 761 - População residente, por situação do domicílio, com indicação da população urbana residente na sede municipal - Sinopse. 2010b. Sistema IBGE de Recuperação Automática (SIDRA). Disponível em: https://sidra.ibge.gov.br/Tabela/761\#resultado. Acesso em 13 nov. 2021.

Cidades. 2019a. Disponível em: <http://cidades.ibge.gov.br/xtras/home.php>. Acesso em: 14 jun. 2019.

Desigualdades sociais por cor ou raça no Brasil. Estudos e pesquisas. Informação demográfica e socioeconômica, N. 41, 2019b. Disponível em: https://biblioteca.ibge.gov.br/visualizacao/livros/liv101681_informativo.pdf. Acesso em 30 set. 2021.

Inepdata. Painel de Monitoramento do PNE. Disponível em: https://inepdata.inep.gov.br/analytics/saw.dll?Dashboard. Acesso em 27/09/2021.

INSTITUTO NACIONAL DE ESTUDOS E PESQUISAS EDUCACIONAIS. Sinopse estatística do ensino superior: graduação 1999. - Brasília: O Instituto, 2000. Disponível em: https://www.gov.br/inep/pt-br/acesso-a-informacao/dados-abertos/sinopsesestatisticas/educacao-superior-graduacao. Acesso em 30 set. 2020. 
INSTITUTO NACIONAL DE ESTUDOS E PESQUISAS EDUCACIONAIS ANÍSIO TEIXEIRA. Sinopse Estatística da Educação Superior 2002. Brasília, Inep, 2002. Disponível em: https://www.gov.br/inep/pt-br/acesso-a-informacao/dadosabertos/sinopses-estatisticas/educacao-superior-graduacao. Acesso em 30 set. 2020.

Sinopse Estatística da Educação Superior 2009. Brasília, Inep, 2009. Disponível em: https:/www.gov.br/inep/pt-br/acesso-a-informacao/dadosabertos/sinopses-estatisticas/educacao-superior-graduacao. Acesso em 24 jun. 2021.

Censo da educação superior 2012: resumo técnico. Brasília: Instituto Nacional de Estudos e Pesquisas Educacionais Anísio Teixeira, 2014.

Metodologia de Cálculo dos Indicadores de Fluxo da Educação Superior.

Brasília, $2017 . \quad$ Disponível em: http://download.inep.gov.br/informacoes_estatisticas/indicadores_educacionais/2017/m etodologia_indicadores_trajetoria_curso.pdf. Acesso em 20 ago. 2019. Acesso em 24 jun. 2021.

. Manual de Preenchimento do censo da educação superior / 2017. Módulo Aluno. Brasília, 2018.

Manual para classificação de cursos de Graduação e sequenciais: CINE Brasil 2018. Brasília: Inep, 2019.

Sinopse Estatística da Educação Superior 2019. Brasília: Inep, 2020a. Disponível em: https://www.gov.br/inep/pt-br/acesso-a-informacao/dadosabertos/sinopses-estatisticas/educacao-superior-graduacao. Acesso em 24 jun. 2021.

. Sinopse estatística da Educação Básica 2019. Brasília, Inep, 2020b. Disponível em: http://inep.gov.br/sinopses-estatisticas-da-educacao-basica. Acesso em 24 jun. 2021.

KNOP, M. N. H. Retenção e resiliência no ensino superior brasileiro: determinantes das chances de conclusão. Tese (Doutorado em Sociologia). Universidade de Brasília (UNB). Brasília, 2020.

LI, D. L. O novo Enem e a plataforma Sisu: efeitos sobre a migração e a evasão estudantil. 2016. Dissertação (Mestrado em Ciências) - Universidade de São Paulo, São Paulo, 2016. 108 p.

LI, D. L.; CHAGAS, A. L. S. Efeitos do SiSU sobre a migração e a evasão estudantil. XV Encontro Nacional da Associação Brasileira de Estudos Regionais e Urbanos. Anais. São Paulo: Aber, 2017.

LIMA, M.; CAMPOS, L. A. Apresentação: inclusão racial no ensino superior impactos, consequências e desafios. Novos estudos CEBRAP, v. 39, n. 2, p. 245-254, 2020.

LIMA JUNIOR, P. et al. Taxas longitudinais de retenção e evasão: uma metodologia para estudo da trajetória dos estudantes na educação superior. Ensaio: Avaliação de Políticas Públicas Educacionais, Rio de Janeiro, v.27, n.102, p. 157-178, jan./mar. 
2019.

LUCAS, S. Effectively Maintained Inequality: Education Transitions, Track Mobility, and Social Background Effects. American Journal of Sociology, v. 106, n. 6, p. 164290, 2001.

LUCAS, S. R; BYRNE, D. Effectively Maintained Inequality in Education: An Introduction. American Behavioral Scientist, Berkeley, CA, Vol. 61(1), p. 3-7, 2017.

LUZ, D. L. P. Movimentos Sociais e Educação Superior: a atuação do MST na promoção da justiça cognitiva. 2018. 148 f. Dissertação (Mestrado) - Universidade Federal da Fronteira Sul, Programa de Pós Graduação em Educação, Chapecó, 2018.

MACHADO, M.; BESSA, Á.; FERES JÚNIOR, J. Evolução da Lei n. 12.711 nas universidades federais (2003-2017). Levantamento das políticas de ação afirmativa. (GEMAA), IESP-UERJ, 2019, p. 1-21.

MARE, R. Social Background and School Continuation Decisions. Journal of the American Statistical Association, v. 75, n. 370, p. 295-305, 1980.

MARE, R.; CHANG, H.C. Family Attainment Norms and Educational Stratification: The Effects of Parents' School Transitions. UCLA CCPR Population Working Papers, 2005.

MARIANO, D. A. Novos modelos de Educação Superior: um estudo sobre as matrizes institucional e curricular da Universidade Federal da Fronteira Sul sob a ótica da inclusão da diversidade cultural e epistemológica. Dissertação (Mestrado em Educação) Programa de Pós-Graduação em Educação da Universidade Nove de Julho PGE/Uninove. São Paulo, 2016.

MARTINS, C.B. A reforma universitária de 1968 e a abertura para o ensino superior privado no Brasil. Educação \& Sociedade, Campinas, vol. 30, n. 106, pp. 15-35, 2009.

McCOWAN, T. The Developmental University. In: Higher Education for and beyond the Sustainable Development Goals. Palgrave Studies in Global Higher Education. Palgrave Macmillan, Cham, 2019. https://doi.org/10.1007/978-3-030-19597-7_4

MDA/INCRA - Ministério do Desenvolvimento Agrário. Instituto Nacional de Colonização e Reforma Agrária. Edital PRONERA $n^{\circ}$ 03, julho de 2012.

MEDEIROS, R. S. Interseccionalidade e políticas públicas: aproximações conceituais $e$ desafios metodológicos. In: PIRES, R. R. C. (Organizador). Implementando desigualdades: reprodução de desigualdades na implementação de políticas públicas. Rio de Janeiro: Ipea, 2019. 730 p.

MELLO, U. M.; SENKEVICS, A. S. Os cursos de graduação das universidades federais antes e depois da Lei de Cotas. In: BARBOSA, M. L. O. (Org.). A expansão desigual do ensino superior no Brasil. Curitiba: Appris, 2020. p. 83-108. 
MENDES JUNIOR, A. A. F. Uma análise da progressão dos alunos cotistas sob a primeira ação afirmativa brasileira no ensino superior: o caso da Universidade do Estado do Rio de Janeiro. Ensaio: avaliação e políticas públicas em educação, v. 22, n. 82, p. 31-56, 2014.

MENDONÇA, A. W. A Universidade no Brasil. Revista Brasileira de Educação, Mai/Jun/Jul/Ago 2000.

MINISTÉRIO DA EDUCAÇÃO E CULTURA (MEC). Diplomação, Retenção $e$ Evasão nos Cursos de Graduação em Instituições de Ensino Superior Públicas. Comissão Especial de Estudos Sobre a Evasão Nas Universidades Públicas Brasileiras. Brasília: Andifes/Abruem, SESu, MEC, 1996.

MINISTÉRIO DA EDUCAÇÃO (MEC). Portaria n. 389, de 9 de maio de 2013. Cria o Programa de Bolsa Permanência e dá outras providências. Disponível em: http://portal.mec.gov.br/docman/programas-e-acoes/programa-bolsapermanencia/68911-portaria-389-09052013/file. Acesso em 29 mai. 2020.

MONT`ALVÃO, A. A dimensão vertical e horizontal da estratificação educacional. Programa de Pós-Graduação em Ciências Sociais - UFRJ, v.11, n. 1, jan/junh. 2016.

MORAES, C. A. S. et al. O estudante do ensino superior: identificando categorias de análise. Vértices, Campos dos Goytacazes/RJ, v. 13, n. 3, p. 205-218, set./dez. 201.

MOROSINI, M. C. et al. A evasão na Educação Superior no Brasil: uma análise da produção de conhecimento nos periódicos Qualis entre 2000-2011. In: ICLABES. Primera Conferencia Latinoamericana sobre el Abandono en la Educación Superior. EUIT de Telecomunicación, 2012.

MUNIZAGA, F.; CIFUENTES, M. B.; BELTRÁN, A. Retención y Abandono Estudiantil en la Educación Superior Universitaria en América Latina y el Caribe: Una Revisión Sistemática. Education Policy Analysis Archives, v. 26, 2018.

NIEROTKA, R. L. Políticas de acesso e ações afirmativas na educação superior: a experiência da Universidade Federal da Fronteira Sul. 2015. 179 f. Dissertação (Mestrado em Educação) - Universidade Federal da Fronteira Sul. Chapecó, 2015.

NIEROTKA, R. L.; TREVISOL, J.V. Os jovens das camadas populares na universidade pública: acesso e permanência. Revista Katálysis, v. 19, n. 1, p. 22-32, 2016.

NOGUEIRA, M.A; CATANI, A. (Orgs.). Pierre Bourdieu: Escritos de Educação. 16. Ed. - Petrópolis, RJ: Vozes, 2015.

NOGUEIRA, C. M.M.; NOGUEIRA, M.A. A sociologia da educação de Pierre Bourdieu: limites e contribuições. Educação \& Sociedade, vol. 23, n. 78, Campinas, Apr. 2002.

OECD. Education at a Glance 2021: OECD Indicators, OECD Publishing, Paris, 2021, https://doi.org/10.1787/b35a14e5-en 
PEDROSA, R. et al. Educational and socioeconomic background of undergraduates and academic performance: consequences for affirmative action programs at a Brazilian research university. Imhe, 2006.

PEIXOTO, A. L. A. et al. Cotas e desempenho acadêmico na UFBA: um estudo a partir dos coeficientes de rendimento. Avaliação: Revista da Avaliação da Educação Superior (Campinas), v. 21, n. 2, p. 569-592, 2016.

PEREIRA, O. A. V. Desigualdade de oportunidades educacionais no Brasil: o caso do ensino superior. 2015. 204 f. Tese (doutorado) - Programa de Pós-Graduação em Ciências Sociais, Instituto de Ciências Humanas, Universidade Federal de Juiz de Fora, Juiz de Fora, 2015.

- Desigualdades de Oportunidades educacionais: perspectivas teóricas contemporâneas. Pesquisa e Debate em Educação. Juiz de Fora, vol. 6, n. 1. p. 9-27, 2016.

PICANÇO, F. Juventude por cor e renda no acesso ao ensino superior. Somando desvantagens, multiplicando desigualdades? Revista Brasileira de Ciências Sociais, v. 30 , n. 88 , p. 145-179, 2015.

PICANÇO, F.; MORAIS, J. Estudos sobre estratificação educacional: síntese dos principais argumentos e desdobramentos. Educação \& Sociedade, Campinas, vol. 37, n..135, p.391-406, abr.-jun., 2016.

POWER, D. A.; XIE, Y. Statistical methods for categorical data analysis. London: Academic Press, 2000.

PRÓ-REITORIA DE ASSUNTOS ESTUDANTIS. Universidade Federal da Fronteira Sul. (PROAE/UFFS). Instrução Normativa n.1/PROAE/UFFS/2018 (Revogada por Instrução Normativa n. 1/PROAE/UFFS/2020). Dispõe sobre os procedimentos normativos dos Planos de Acompanhamento para estudantes de graduação no âmbito da Universidade Federal da Fronteira Sul. Disponível em: https://www.uffs.edu.br/atosnormativos/instrucao-normativa/proae/2018-0001

Relatório n. 1/2020 - PROAE. 24 jan. 2020. Disponível em: https://www.uffs.edu.br/institucional/pro-reitorias/assuntosestudantis/publicacoes/informes/relatorio-no-1-2020-proae. Acesso em 24 jun. 2021.

QUEIROZ, Z. C. L. S., et al. A lei de cotas na perspectiva do desempenho acadêmico na Universidade Federal de Uberlândia. Revista Brasileira de Estudos Pedagógicos, 96(243), 299-320, 2015.

RAFTERY, A; HOUT, M. Maximally Maintained Inequality: Expansion, Reform, and Opportunity in Irish Education, 1921-75. Sociology of Education, v. 66, n.1, p. 41-62, 1993.

RECHE, D. A produção do espaço urbano de pequenas cidades no contexto regional de inserção da Universidade Federal da Fronteira Sul. 317p. Tese (Doutorado) - 
Universidade Federal do Rio Grande do Sul, Faculdade de Arquitetura, Porto Alegre, 2018.

REIS, K. C. Evasão na educação superior: um estudo de caso dos cursos de graduação da Universidade Federal da Fronteira Sul - Campus Erechim. 238f. Dissertação (Mestrado) - Universidade Federal da Fronteira Sul, Campus Erechim, Erechim, 2019.

RIBEIRO, C. A. C. Desigualdade de Oportunidades no Brasil. - Belo Horizonte, MG: Argvmentvm, 2009.

RIBEIRO, J. L. L. S.; MORAIS, V. G. A possível relação entre o SiSU e a evasão nos primeiros semestres dos cursos universitários. Revista Brasileira de Educação, v. 25, 2020.

RISTOFF, D. I. Considerações sobre evasão. In: RISTOFF, D. I. Universidade em foco: reflexões sobre a educação superior. Florianópolis: Insular, 1999, 240p.

RISTOFF, D. I. Democratização do campus: impacto dos programas de inclusão sobre o perfil da graduação. Cadernos do GEA, v. 9, p. 5-62, 2016.

Pelos (des)caminhos da evasão. Educa 2022. 28 jan. 2021. Disponível em https://www.educa2022.com/post/pelos-des-caminhos-da-evas\%C3\%A3o. Acesso em 29 mai. 2021.

RORATO, G. Z. Expansão do ensino superior federal, atores territoriais e emergência de novas escalas de poder e gestão: a Universidade Federal da Fronteira Sul (UFFS). 257 f. Tese (Doutorado). Universidade Federal do Rio Grande do Sul. Porto Alegre, 2016.

ROTEM, N.; YAIR, G.; SHUSTAK, E. Open the gates wider: affirmative action and dropping out. Higher Education, vol. 81, no 3, p. 551-566, 2021.

SACCARO, A.; FRANÇA, M. T. A.; JACINTO, P. A. Fatores Associados à Evasão no Ensino Superior Brasileiro: um estudo de análise de sobrevivência para os cursos das áreas de Ciência, Matemática e Computação e de Engenharia, Produção e Construção em instituições públicas e privadas. Estudos Econômicos (São Paulo), v. 49, n. 2, p. 337-373, 2019.

SALATA, A. Ensino Superior no Brasil das últimas décadas: redução nas desigualdades de acesso?. Tempo Social, v. 30, n. 2, p. 219-253, 2018.

SALES JUNIOR, J. S. et al. Fatores Associados à Evasão e Conclusão de Cursos de Graduação Presenciais na UFES. Revista Meta: Avaliação, Rio de Janeiro, v. 8, n. 24, p. 488-514, 2016.

SANTOS, F. M.; ALMEIDA, F.M.; CASTRO, S.O.C. Qualidade do ensino superior em Universidades Federais e sistema de cotas. IV Encontro Brasileiro de Administração Pública. João Pessoa, PB, 24 e 25 de maio de 2017. 
SANTOS, M. O. Cotas Raciais nas Universidades Federais Brasileiras: Desigualdade no Acesso e Estratificação Horizontal em 2010 e 2016. 126 f. Dissertação (Mestrado em Demografia). Universidade Estadual de Campinas. Campinas, SP, 2018.

SANTOS, J. A. F.; BERNARDINO, B. S. Estratificação Educacional: análise da variável sexo na realização escolar. Teoria e Cultura, v. 11, n. 1, p. 71-85, 2016.

SANTOS JUNIOR, J. S.; REAL, G. C. M. Fator institucional para a evasão na educação superior. Revista Internacional de Educação Superior, Campinas, SP, v. 6, p. 1-22, 2020.

SCHER, A.; OLIVEIRA, E. M. Acesso e permanência estudantil na Universidade Federal da Fronteira Sul-Campus Realeza/PR. Avaliação: Revista da Avaliação da Educação Superior (Campinas), v. 25, n. 1, pp. 5-26, 2020.

SENKEVICS, A. S.; CARVALHO, M. P. Novas e velhas barreiras à escolarização da juventude. Estudos Avançados, v. 34, n. 99, p. 333-352, 2020.

SENKEVICS, A. S.; MELLO, U. M. O perfil discente das Universidades federais mudou pós-Lei de Cotas? Cadernos de Pesquisa. São Paulo, v.49 n.172, p.184-208 abr./jun. 2019.

SILVA, A. P. Reforma e Seletividade: fronteiras das desigualdades no acesso à Universidade. 2016. 171f.. Tese (doutorado) - Programa de Pós-Graduação em Sociologia, Centro de Estudos Sociais, Universidade Estadual do Rio de Janeiro. Rio de Janeiro, 2016.

SILVA FILHO, R. L. L. et al. A evasão no ensino superior brasileiro. Cadernos de pesquisa, v. 37, n. 132, p. 641-659, 2007.

TINTO, V. Dropout from higher education: A theoretical synthesis of recent research. Review of Educational Research, 45(1), p. 89-125, 1975.

Research and practice of student retention: What next?. Journal of college student retention: Research, Theory \& Practice, v. 8, n. 1, p. 1-19, 2006.

2017.

Reflexões sobre a persistência do aluno. Sucesso dos Alunos, v. 8, n. 2, p. 1-9,

TISCHER, W. Ensino superior público e desenvolvimento regional: criação, implantação e expansão da Universidade Federal da Fronteira Sul (UFFS) na Mesomercosul. 160 f. Dissertação (Mestrado Profissional) - Universidade do Estado de Santa Catarina, 2016.

TODOS PELA EDUCAÇÃO. Anuário Brasileiro da Educação Básica 2019. 2019. Disponível em: https://www.todospelaeducacao.org.br/_uploads/_posts/302.pdf. Acesso em: 30 ago. 2019. 
TREVISOL, J. V.; CORDEIRO, M. H.; HASS, M. (org.). Construindo agendas e definindo rumos: I Conferência de Ensino, Pesquisa e Extensão da UFFS. Chapecó: UFFS, 2011.

TREVISOL, J. V. O ensino superior público na Mesorregião Fronteira Sul: a implantação da UFFS. In: História da Fronteira Sul. RADIN, J. C.; VALENTINI, D. J.; ZARTH, P. A. (Orgs.). -- Chapecó: Ed. UFFS, 2016, p. 352.

TROW, M. Reflections on the transition from elite to mass to universal access: forms and phases of higher education in modern societies since WWII. In P. Altbach (Ed.), International Handbook of Higher Education. Kluwer, 2005.

UFFS - UNIVERSIDADE FEDERAL DA FRONTEIRA SUL. Edital $n$. 003/UFFS/2009. 25 de nov. 2009.

UFFS. Domínio comum. Síntese e resultados das discussões. Pró-Reitoria de Graduação, set. 2012a. Disponível em: https://www.uffs.edu.br/institucional/proreitorias/graduacao/projetos-pedagogicos/dominios. Acesso em: 20. nov. 2021.

Resolução n. 006/2012 - CONSUNI/CGRAD. Aprova o modelo de implantação da reserva de vagas para a política de ingresso nos cursos de graduação da UFFS. Sala das Sessões da Câmara de Graduação do Conselho Universitário, Chapecó, SC, 03 dez. 2012b.

Resolução n. 25/2013 - CONSUNI. Cria e autoriza o funcionamento de cursos de graduação no âmbito da UFFS. Sala das Sessões do Conselho Universitário, $6^{\mathbf{a}}$ Sessão Ordinária, Chapecó, SC, 16 jul. 2013a.

Resolução n. 32/2013 - CONSUNI. Institui o Programa de Acesso à Educação Superior da UFFS para estudantes haitianos - PROHAITI e dispõe sobre os procedimentos para operacionalização das atividades do programa. Sala das Sessões do Conselho Universitário, $11^{\text {a }}$ Sessão Ordinária, Chapecó, SC, 12 dez. 2013 b.

Resolução n. 33/2013 - CONSUNI. Institui o Programa de Acesso e Permanência dos Povos Indígenas (PIN) da Universidade Federal da Fronteira Sul. Sala das Sessões do Conselho Universitário, 11 ${ }^{a}$ Sessão Ordinária, Chapecó, SC, 12 dez. 2013c.

UFFS conquista Prêmio Guia do Estudante - Destaques de 2014 na categoria Inclusão. 2014a. Disponível em: http://historico.uffs.edu.br/index.php?option=com_content\&limitstart=925. Acesso em 15 out. 2020.

Decisão n. 2/2014 - CONSUNI/CGRAD. Autoriza a alteração do texto do Histórico Institucional da UFFS constante dos projetos pedagógicos dos cursos de graduação. Sala das Reuniões da Câmara de Graduação do Conselho Universitário, $4^{\mathrm{a}}$ Reunião Ordinária, Chapecó, SC, 25 abr. 2014b.

Resolução N. 4/2014 - CONSUNI/CGRAD. Aprova o Regulamento da Graduação da Universidade Federal da Fronteira Sul. Sala das Sessões da Câmara de 
Graduação do Conselho Universitário, 6ª Sessão Ordinária, Chapecó-SC, 26 jun. 2014c.

Resolução n. 13/2014 - CONSUNI/CGRAD/UFFS/2014. Aprova o Projeto Pedagógico do Curso de Graduação em Agronomia - Bacharelado, em regime de alternância (relativo ao Edital PRONERA n. 3, de 10 de julho de 2012), do Campus Erechim da UFFS. Sala das Reuniões da Câmara de Graduação do Conselho Universitário, $11^{a}$ Reunião Ordinária, Chapecó, SC, 18 nov. 2014d.

Resolução n. 8/CONSUNI CGAE/UFFS/2016. Altera a Resolução n. 006/2012CONSUNI/CGRAD, que aprova o modelo de implantação da reserva de vagas para a política de ingresso nos cursos de graduação da UFFS. Sala das Sessões da Câmara de Graduação e Assuntos Estudantis do Conselho Universitário, 9a Reunião Ordinária, Chapecó, SC, 25 out. 2016a.

Resolução n. 10/2016/CONSUNI/CGAE/2016 (alterada). Estabelece regras para a realização de análise socioeconômica e habilitação para inscrição nos auxílios socioeconômicos. Sala das Sessões da Câmara de Graduação e Assuntos Estudantis do Conselho Universitário, 10ª Reunião Ordinária, Chapecó, SC, 25 nov. 2016 b.

Edital n. 530/UFFS/2017. Processo Seletivo UFFS/2017.2. 2017. Disponível em: https://www.uffs.edu.br/atos-normativos/edital/gr/2017-0530. Acesso em 20 nov. 2020.

Relatório PROGRAD Graduação UFFS - 2013 - 2017. Pró-Reitoria de Graduação, Chapecó, Abr./Jun. 2018.

Edital n. 530/GR/UFFS/2019. Processo Seletivo Regular da Graduação UFFS/2019.2. 2019a. Disponível em: https://www.uffs.edu.br/atosnormativos/edital/gr/2019-0530. Acesso em 18 nov.2020.

Relatório Anual de Atividades - 2018. Pró-Reitoria de Assuntos Estudantis, Chapecó, 2019b.

Resolução n. 10/CONSUNI/CGAE/UFFS/2019. Institui a Política de Assistência Estudantil no âmbito da Universidade Federal da Fronteira Sul. Câmara de Graduação e Assuntos Estudantis, do Conselho Universitário, $1^{a}$ Sessão Extraordinária, Chapecó, SC, 27 ago. 2019c.

Edital n. 159/GR/UFFS/2019. Processo Seletivo para Auxílio Emergencial 2019. 2019d. Disponível em: https://www.uffs.edu.br/atos-normativos/edital/gr/20190159. Acesso em 21 nov. 2020.

Edital n. 59/GR/UFFS/2019. Processo Seletivo para Auxílio Ingresso 2019. Disponível em: https://www.uffs.edu.br/atos-normativos/edital/gr/2019-0059, 2019e.

Edital n. 173/GR/UFFS/2019. Processo Seletivo para o Auxílio à Permanência dos Povos Indígenas na UFFS. 2019f. Disponível em: https://www.uffs.edu.br/atosnormativos/edital/gr/2019-0173. Acesso em 22 nov. 2020. 
Edital n. 181/GR/UFFS/2019. Seleção de estudantes monitores para o projeto de Promoção à Saúde do Estudante Universitário na UFFS 2019. 2019g. Disponível em: https://www.uffs.edu.br/atos-normativos/edital/gr/2019-0181. Acesso em 22 nov. 2020.

VARGAS, H.; HERINGER, R. Políticas de permanência no ensino superior público em perspectiva comparada: Argentina, Brasil e Chile. Arizona, Estados Unidos, Archivos Analíticos de Políticas Educativas, Vol.25, N. 72, 2017.

VALLE SILVA, N.; SOUZA, A. Um modelo para análise da estratificação educacional no Brasil. Cadernos de Pesquisa, São Paulo, Ago. p. 49-57, 1986.

VIDI, L. A Evasão nos Cursos de Graduação da Universidade Federal da Fronteira Sul. 97 p. Dissertação (Mestrado em Administração). Universidade Federal de Santa Catarina, Florianópolis, 2020.

WAINER, J.; MELGUIZO, T. Políticas de inclusão no ensino superior: avaliação do desempenho dos alunos baseado no Enade de 2012 a 2014. Educação e Pesquisa, 44, 1$15,2017$.

ZAGO, N. Do acesso à permanência no ensino superior: percursos de estudantes universitários de camadas populares. Revista Brasileira de Educação, v. 11, n. 32, p. 226-237, 2006.

Migração rural-urbana, juventude e ensino superior. Revista Brasileira de Educação, v. 21, n. 64, p. 61-78, 2016.

ZAGO, N.; PAIXÃO, L. P.; PEREIRA, T. I. Acesso e permanência no ensino superior: problematizando a evasão em uma nova universidade federal. Educação em Foco, v. 19, n. 27, p. 145-169, 2016. 


\section{Apêndices}

Apêndice 1 - Quadro de cargos e média salarial com referência aos cursos de graduação da UFFS

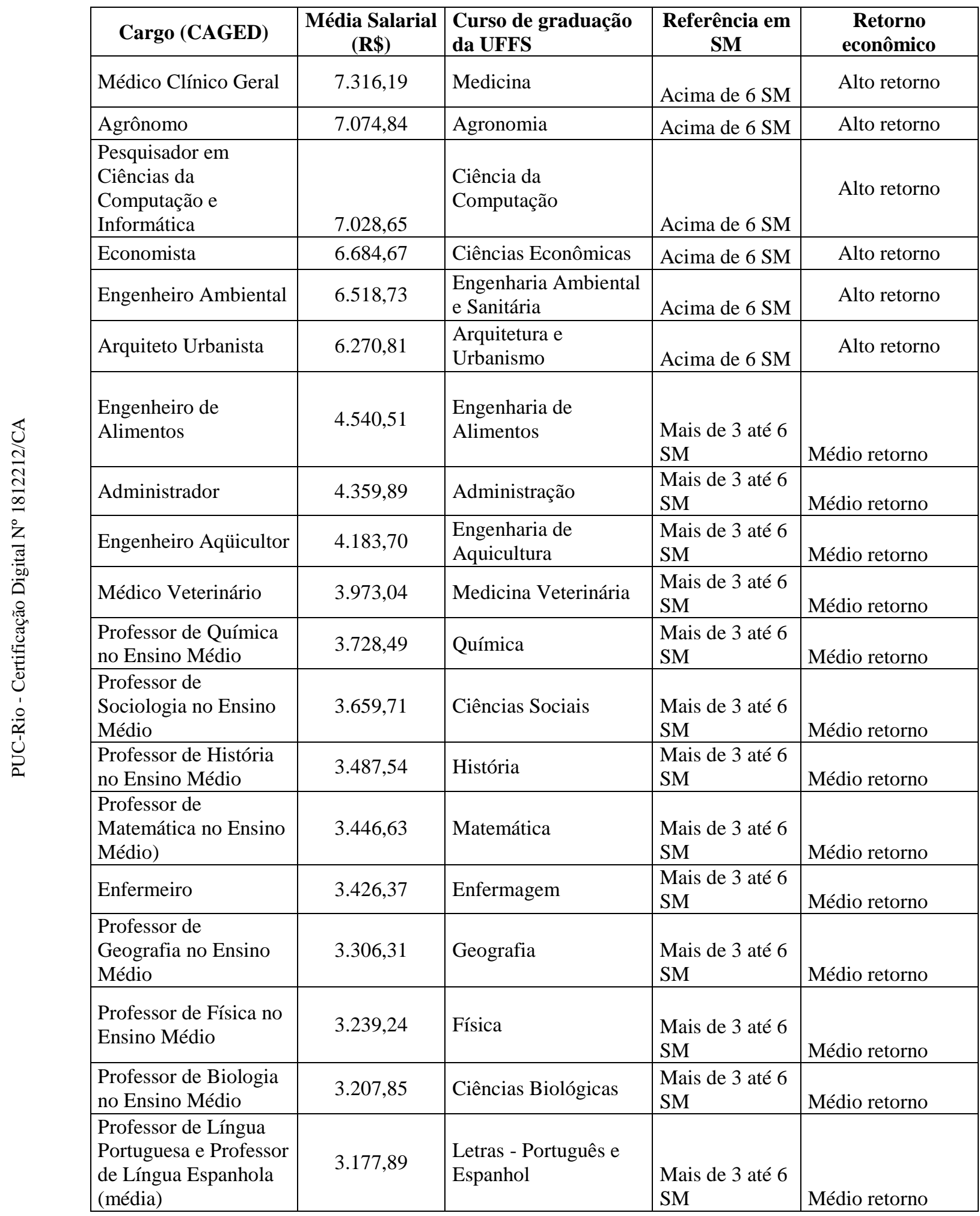




\begin{tabular}{|c|c|c|c|c|}
\hline $\begin{array}{l}\text { Professor de Filosofia } \\
\text { no Ensino Médio }\end{array}$ & $2.958,51$ & Filosofia & \begin{tabular}{|l} 
Até $3 \mathrm{SM}$ - \\
3.135
\end{tabular} & Baixo retorno \\
\hline $\begin{array}{l}\text { Professor de Ciências } \\
\text { Naturais no Ensino } \\
\text { Fundamental de } 5^{\mathrm{a}} \text { a } 8^{\mathrm{a}} \\
\text { Série }\end{array}$ & $2.891,75$ & Ciências Naturais & Até 3 SM & Baixo retorno \\
\hline $\begin{array}{l}\text { Professor de Ciências } \\
\text { Exatas e Naturais do } \\
\text { Ensino Fundamental }\end{array}$ & $2.891,75$ & $\begin{array}{l}\text { Interdisciplinar em } \\
\text { Educação do Campo - } \\
\text { Ciências Naturais, } \\
\text { Matemática e Ciências } \\
\text { Agrárias }\end{array}$ & Até 3 SM & Baixo retorno \\
\hline Nutricionista & $2.845,90$ & Nutrição & Até $3 \mathrm{SM}$ & Baixo retorno \\
\hline $\begin{array}{l}\text { Professor de Nível } \\
\text { Superior do Ensino } \\
\text { Fundamental } \\
\text { (Primeira a Quarta } \\
\text { Serie) / Professor das } \\
\text { séries iniciais }\end{array}$ & $2.539,15$ & Pedagogia & Até $3 \mathrm{SM}$ & Baixo retorno \\
\hline
\end{tabular}

Nota: SM = salário mínimo, com referência ao salário mínimo de $2020=\mathrm{R} \$ 1045$

Fonte: Elaboração própria com base em Salario.com.br - Novo CAGED/eSocial/Empregador Web 
Apêndice 2 - Distribuição do percentual de ingressantes de origem da escola pública, segundo campus, curso e turno - 2010 a 2018

\begin{tabular}{|c|c|c|c|c|c|c|c|c|c|}
\hline Campus /curso/turno & 2010 & 2011 & 2012 & 2013 & 2014 & 2015 & 2016 & 2017 & 2018 \\
\hline CH - Ciência da Computação - Vesp. & 97,9 & 98,1 & 98,0 & 91,7 & 87,8 & 92,0 & 90,0 & 90,0 & 82,0 \\
\hline CH - Ciência da Computação - Not. & 98,0 & 100 & 100 & 88,9 & 89,8 & 94,0 & 92,0 & 90,0 & 91,7 \\
\hline CH - Eng. Ambiental e Sanitária - Int. & 97,8 & 97,9 & 100 & 88,0 & 85,1 & 87,5 & 90,0 & 94,0 & 93,5 \\
\hline CH - Enfermagem - Int. & 100 & 100 & 100 & 92,5 & 92,5 & 92,5 & 92,5 & 95,0 & 92,3 \\
\hline $\mathrm{CH}$ - Agronomia - Int. & 100 & 100 & 100 & 94,2 & 92,7 & 86,0 & 94,0 & 88,0 & 95,3 \\
\hline CH - Administração - Mat. & 88,0 & 98,1 & 100 & 87,2 & 93,9 & 92,0 & 90,0 & 90,0 & 88,0 \\
\hline CH - Administração - Not. & 100 & 100 & 95,3 & 92,3 & 89,6 & 94,1 & 88,5 & 94,0 & 96,0 \\
\hline CH - Filosofia - Mat. & 89,7 & 100 & 88,9 & 100 & - & - & - & - & - \\
\hline CH - Filosofia - Not. & 87,5 & 95,8 & 94,1 & 89,2 & 90,7 & 90,5 & 93,9 & 88,9 & 95,5 \\
\hline CH - Geografia - Mat. & 92,6 & 95,2 & 88,9 & 85,0 & 90,5 & - & - & - & - \\
\hline CH - Geografia - Not. & 97,8 & 93,3 & 87,0 & 90,0 & 85,7 & 91,5 & 94,1 & 88,1 & 96,9 \\
\hline $\mathrm{CH}$ - História - Mat. & 84,8 & 83,8 & 97,6 & 82,4 & 93,5 & - & - & - & _ \\
\hline CH - História - Not. & 87,5 & 93,8 & 91,5 & 97,7 & 95,2 & 92,9 & 91,8 & 87,8 & 91,7 \\
\hline CH - Pedagogia - Mat. & 89,5 & 97,9 & 96,0 & 95,8 & 98,0 & - & 94,0 & 94,0 & 88,1 \\
\hline CH - Pedagogia - Not. & 98,0 & 98,1 & 97,7 & 96,0 & 94,6 & 98,0 & 96,1 & 92,0 & 90,0 \\
\hline CH - Ciências Sociais - Mat. & 81,8 & 93,8 & 84,0 & 87,5 & 91,7 & - & - & - & - \\
\hline CH - Ciências Sociais - Not. & 90,5 & 94,0 & 88,4 & 97,7 & 96,0 & 97,2 & 86,4 & 88,1 & 96,9 \\
\hline CH - Letras - Port. e Esp. - Mat. & 100 & 76,7 & 87,1 & 80,0 & 96,2 & - & - & - & - \\
\hline CH - Letras - Port. e Esp. - Not. & 96,7 & 100 & 95,8 & 96,7 & 100 & 91,7 & 93,8 & 92,0 & 86,1 \\
\hline CH - Matemática - Not. & - & - & - & - & 92,5 & 96,0 & 88,0 & 94,0 & 97,9 \\
\hline $\mathrm{CH}$ - Medicina - Int. & - & - & - & - & - & 87,5 & 87,5 & 82,5 & 84,4 \\
\hline LS - Engenharia de Alimentos - Int. & 93,6 & 100 & 100 & 97,6 & 87,8 & 89,7 & 95,9 & 92,9 & 90,5 \\
\hline LS - Agronomia - Int. & 100 & 100 & 98,3 & 96,1 & 94,3 & 95,9 & 96,0 & 95,9 & 98,0 \\
\hline LS - Engenharia De Aquicultura - Int. & 93,3 & 97,7 & 98,1 & 97,1 & 97,1 & 100 & 97,8 & 92,9 & 94,9 \\
\hline $\begin{array}{l}\text { LS - Ed. Campo: Ciências Naturais, } \\
\text { Matemática e Ciências Agrárias - Int. }\end{array}$ & 100 & 100 & 100 & 100 & 96,3 & 100 & 95,8 & 100 & 100 \\
\hline $\begin{array}{l}\text { LS - Ed. Campo: Ciências Naturais, } \\
\text { Matemática e Ciências Agrárias - Not. }\end{array}$ & 100 & 95,8 & 100 & 100 & 100 & 100 & 95,0 & 100 & - \\
\hline LS - Ciências Econômicas - Not. & 97,4 & 95,1 & 98,4 & 94,0 & 93,9 & 100 & 98,0 & 98,0 & 98,0 \\
\hline LS - Pedagogia - Not. & 100 & - & - & - & - & - & - & - & 100 \\
\hline RE - Física - Not. & 90,0 & 100 & 100 & 96,8 & 100 & 100 & 93,3 & 96,6 & 96,7 \\
\hline RE - Química - Not. & 100 & 100 & 100 & 93,3 & 100 & 100 & 100 & 86,7 & 96,6 \\
\hline RE - Ciências Biológicas - Not. & 100 & 100 & 100 & 97,6 & 95,0 & 95,0 & 97,5 & 92,5 & 97,4 \\
\hline RE - Ciências Naturais - Not. & 98,8 & - & - & - & - & - & - & - & - \\
\hline RE - Nutrição - Int. & 100 & 100 & 100 & 97,5 & 100 & 100 & 100 & 95,0 & 97,5 \\
\hline RE - Medicina Veterinária - Int. & 97,7 & 100 & 100 & 92,5 & 88,0 & 86,0 & 88,0 & 90,0 & 91,8 \\
\hline RE - Letras - Port. E Esp. - Not. & 100 & 100 & 100 & 100 & 96,8 & 96,7 & 90,0 & 96,7 & 100 \\
\hline CL - Física - Not. & 100 & 100 & 93,3 & 93,3 & 88,9 & 93,3 & 100 & 93,5 & 95,5 \\
\hline CL - Química - Not. & 85,7 & 100 & 100 & 93,3 & 90,0 & 100 & 93,1 & 96,3 & 100 \\
\hline CL - Ciências Biológicas - Int. & 100 & 100 & 97,3 & 98,2 & 96,4 & 94,1 & 98,3 & 98,0 & 93,2 \\
\hline CL - Eng. Ambiental e Sanitária - Int. & 97,9 & 100 & 100 & 100 & 93,9 & 98,0 & 92,0 & 96,0 & 95,7 \\
\hline CL - Agronomia - Int. & 100 & 100 & 100 & 91,8 & 92,0 & 96,4 & 94,0 & 90,0 & 92,0 \\
\hline CL - Administração - Int. & 85,2 & 97,7 & 100 & 96,1 & 98,0 & 95,7 & 98,0 & 96,0 & 98,0 \\
\hline CL - Letras - Port.e Esp. - Not. & 100 & 96,9 & 97,1 & 96,7 & 96,6 & 96,7 & 96,7 & 96,7 & 93,3 \\
\hline
\end{tabular}




\begin{tabular}{lrrrrrrrrr}
\hline ER - Eng. Ambiental e Sanitária - Int. & 97,7 & 100 & 100 & 93,0 & 92,1 & 91,7 & 86,0 & 91,5 & 90,3 \\
ER - Agronomia - Int. & 98,0 & 100 & 100 & 96,2 & 94,1 & 96,0 & 96,0 & 100 & 96,0 \\
ER - Arquitetura e Urbanismo - Int. & 100 & 100 & 98,0 & 90,2 & 89,8 & 88,0 & 88,0 & 86,0 & 90,0 \\
ER - Filosofia - Not. & 82,5 & 83,3 & 92,0 & 87,5 & 76,7 & 91,2 & 90,6 & 80,8 & 80,8 \\
ER - Geografia - Not. & 83,7 & 92,2 & 90,2 & 90,2 & 90,9 & 88,1 & 90,9 & 95,7 & 92,6 \\
ER - História Not. & 91,3 & 100 & 94,0 & 85,4 & 90,9 & 90,2 & 90,7 & 95,6 & 92,9 \\
ER - Pedagogia - Not. & 100 & 98,0 & 100 & 96,0 & 97,9 & 90,0 & 100 & 98,0 & 96,0 \\
ER - Ciências Sociais - Not. & 85,1 & 88,2 & 88,5 & 88,2 & 95,7 & 89,7 & 97,4 & 87,1 & 91,7 \\
\hline PF - Medicina - Int. & - & - & - & 90,5 & 94,7 & 92,3 & 93,5 & 85,7 & 88,7 \\
\hline Total & 95,1 & 96,9 & 96,7 & 93,4 & 93,2 & 93,6 & 93,4 & 92,4 & 93,4 \\
\hline
\end{tabular}

Nota: $\mathrm{CH}=$ Chapecó; $\mathrm{LS}=$ Laranjeiras do Sul; RE = Realeza; $\mathrm{CL}=$ Cerro Largo; ER = Erechim; PF = Passo Fundo. Vesp = Vespertino; Not. = Noturno; Mat. = Matutino; Int. = Integral

Fonte: Elaboração própria com base em dados do SGA/UFFS 
Apêndice 3 - Distribuição do percentual de ingressantes pretos, pardos e indígenas (PPIs), segundo campus, curso e turno - 2010 a 2018

\begin{tabular}{|c|c|c|c|c|c|c|c|c|c|}
\hline C & 2010 & 2011 & 2012 & 2013 & 2014 & 2015 & 2016 & 2017 & 2018 \\
\hline putação - Vesp. & 10,4 & 19,2 & 7,8 & 22,9 & 16,3 & 20,0 & 16,0 & 24,0 & 12,0 \\
\hline CH - Ciência da Computação - Not. & 13,7 & 25,5 & 17,0 & 17,8 & 28,6 & 18,0 & 20,0 & 20,0 & 27,1 \\
\hline $\mathrm{CH}$ - Eng. Ambiental e $\mathrm{S}$ & 8,9 & 16,7 & 8,2 & 16,0 & 12,8 & 8,3 & 26,0 & 20,0 & 32,3 \\
\hline $\mathrm{CH}$ - Enfermagem - Int. & 2,5 & 13,5 & 9,8 & 30,0 & 7,5 & 17,5 & 15,0 & 25,0 & 15,4 \\
\hline $\mathrm{CH}$ - Agronomia - Int. & 4,0 & 10,9 & 11,5 & 15,4 & 2,4 & 18,0 & 20,0 & 26,0 & 20,9 \\
\hline CH - Administração - Mat. & 16,0 & 17,0 & 10,0 & 12,8 & 14,3 & 12,0 & 22,0 & 18,0 & 24,0 \\
\hline CH - Administração - Not. & 12,0 & 7,7 & 16,3 & 25,6 & 12,5 & 13,7 & 13,5 & 18,0 & 28,0 \\
\hline $\mathrm{CH}$ - Filosofia - Mat. & 10,3 & 20,0 & 22,2 & 15,4 & & - & - & - & - \\
\hline & 25,0 & 22,9 & 23,5 & 10,8 & 14,0 & 14,3 & 12,2 & 22,2 & 22,7 \\
\hline $\mathrm{CH}-\mathrm{Geog}$ & 3,7 & 9,5 & 14,8 & 10,0 & 28,6 & - & - & - & - \\
\hline $\mathrm{CH}-\mathrm{C}$ & 6,7 & 17,8 & 13,0 & 15,0 & 28,6 & 19,1 & 21,6 & 16,7 & 21,9 \\
\hline $\mathrm{CH}-\mathrm{Hi}$ & 21,2 & 24,3 & 22,0 & 0,0 & 15,2 & - & - & - & - \\
\hline CH - História - Not. & 22,9 & 20,8 & 17,0 & 18,6 & 19,0 & 14,3 & 26,5 & 24,5 & 22,9 \\
\hline CH - Peda & 18,4 & 18,8 & 10,0 & 25,0 & 22,0 & - & 18,0 & 24,0 & 19,0 \\
\hline CH - Pedagogia - Not. & 10,0 & 17,0 & 11,4 & 18,0 & 10,8 & 22,0 & 25,5 & 26,0 & 30,0 \\
\hline $\mathrm{CH}-\mathrm{Ci}$ & 9,1 & 12,5 & 20,0 & 25,0 & 50,0 & - & - & - & - \\
\hline CH - Ciências Sociais - Not. & 19,0 & 20,0 & 16,3 & 16,3 & 30,0 & 16,7 & 20,5 & 23,8 & 25,0 \\
\hline $\mathrm{CH}$ - Letra & 8,3 & 23,3 & 9,7 & 20,0 & 11,5 & - & - & - & - \\
\hline CH - Letras - Port. e Esp. - Not. & 13,3 & 18,8 & 12,5 & 16,7 & 9,1 & 22,9 & 20,8 & 34,0 & 25,0 \\
\hline $\mathrm{CH}-\mathrm{N}$ & - & - & - & - & 22,5 & 26,0 & 22,0 & 26,0 & 25,5 \\
\hline CH - Medicina - Int. & - & - & - & - & - & 12,5 & 15,0 & 22,5 & 22,2 \\
\hline LS - Eng & 17,0 & 10,9 & 18,9 & 26,2 & 26,8 & 27,6 & 36,7 & 40,5 & 33,3 \\
\hline LS - Agronomia - Int. & 10,6 & 20,4 & 8,3 & 21,6 & 30,2 & 22,4 & 30,0 & 42,9 & 38,0 \\
\hline LS - Engenharia De Aquicultura - Int. & 20,0 & 22,7 & 3,8 & 32,4 & 32,4 & 25,8 & 41,3 & 39,3 & 48,7 \\
\hline $\begin{array}{l}\text { LS - Ed. C } \\
\text { Matemátic }\end{array}$ &, 4 & 5,9 & 9,4 & 16,0 & 29,6 & 43,5 & 41,7 & 35,7 & - \\
\hline & 22,6 & 25,0 & 30,0 & 18,5 & 33,3 & 28,0 & 45,0 & 53,8 & 29,5 \\
\hline LS - Ciências Econômi & 7,9 & 17,1 & 14,3 & 30,0 & 24,5 & 30,0 & 42,0 & 24,5 & 34,0 \\
\hline & - & - & . & - & - & 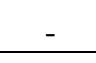 & . & - & 22,0 \\
\hline RE - Físi & 20,0 & 11,1 & 14,3 & 19,4 & 20,7 & 26,7 & 23,3 & 20,7 & 23,3 \\
\hline RE - Quí1 & 10,3 & 12,5 & 22,9 & 23,3 & 26,7 & 16,7 & 34,5 & 23,3 & 13,8 \\
\hline RE - Ciências Biológicas - Not. & 23,3 & 5,9 & 8,5 & 22,0 & 22,5 & 30,0 & 25,0 & 27,5 & 23,1 \\
\hline RE - Ciências Naturais - Not. & 18,3 & - & - & - & - & - & - & - & - \\
\hline RE - Nutrição - Int. & 10,8 & 10,0 & 18,4 & 12,5 & 18,9 & 36,8 & 22,5 & 32,5 & 22,5 \\
\hline RE - Medicina Veterinária - Int. & 14,0 & 10,2 & 8,0 & 32,1 & 32,0 & 32,0 & 30,0 & 32,0 & 24,5 \\
\hline RE - Letras - Port. e Esp. - Not. & 27,6 & 25,7 & 22,6 & 26,7 & 25,8 & 26,7 & 40,0 & 40,0 & 30,0 \\
\hline CL - Física - Not. & 0,0 & 13,3 & 6,7 & 16,7 & 22,2 & 6,7 & 29,0 & 25,8 & 18,2 \\
\hline CL - Química - Not. & 14,3 & 9,1 & 18,8 & 6,7 & 13,3 & 6,7 & 27,6 & 25,9 & 20,8 \\
\hline CL - Ciências Biológicas - Int. & 14,9 & 10,0 & 19,2 & 17,9 & 17,9 & 27,5 & 31,7 & 17,6 & 20,5 \\
\hline CL - Eng. Ambiental e Sanitária & 8,3 & 3,9 & 11,1 & 22,0 & 8,2 & 16,3 & 26,0 & 26,0 & 19,1 \\
\hline CL - Agronomia - Int. & 6,0 & 7,5 & 13,0 & 12,2 & 10,0 & 14,3 & 16,0 & 20,0 & 22,0 \\
\hline
\end{tabular}




\begin{tabular}{lrrrrrrrrr}
\hline CL - Administração - Int. & 11,1 & 9,3 & 7,0 & 29,4 & 18,0 & 10,6 & 22,4 & 20,0 & 18,0 \\
CL - Letras - Port. e Esp. - Not. & 10,3 & 12,5 & 8,6 & 16,7 & 13,8 & 16,7 & 30,0 & 30,0 & 13,3 \\
\hline ER - Eng. Ambiental e Sanitária - Int. & 4,5 & 2,2 & 11,4 & 9,3 & 10,5 & 14,6 & 16,0 & 12,8 & 25,8 \\
ER - Agronomia - Int. & 2,0 & 4,1 & 7,8 & 15,1 & 9,8 & 16,0 & 22,0 & 24,0 & 6,0 \\
ER - Arquitetura e Urbanismo - Int. & 2,3 & 2,3 & 6,1 & 21,6 & 14,3 & 10,0 & 14,0 & 14,0 & 24,0 \\
ER - Filosofia - Not. & 15,0 & 10,4 & 8,0 & 18,8 & 20,0 & 32,4 & 31,3 & 15,4 & 19,2 \\
ER - Geografia - Not. & 12,2 & 7,8 & 7,8 & 17,6 & 15,9 & 28,6 & 22,7 & 26,1 & 29,6 \\
ER - História Not. & 19,6 & 12,0 & 22,0 & 18,8 & 15,9 & 17,1 & 20,9 & 28,9 & 21,4 \\
ER - Pedagogia - Not. & 16,3 & 9,8 & 5,9 & 20,0 & 18,8 & 12,0 & 18,4 & 12,0 & 24,0 \\
ER - Ciências Sociais - Not. & 19,1 & 11,8 & 15,4 & 21,6 & 10,6 & 35,9 & 23,1 & 45,2 & 16,7 \\
\hline PF - Medicina - Int. & - & - & & 28,6 & 21,1 & 15,4 & 19,4 & 28,6 & 22,6 \\
\hline Total & 13,1 & 14,1 & 13,0 & 19,8 & 18,7 & 20,0 & 24,1 & 25,3 & 23,7 \\
\hline Nota: CH = Chapecó; LS = Laranjeiras do Sul; RE Realeza; CL = Cerro Largo; ER = Erechim; PF = \\
Passo Fundo. Vesp = Vespertino; Not. = Noturno; Mat. = Matutino; Int. = Integral \\
Fonte: Elaboração própria com base em dados do SGA/UFFS
\end{tabular}


Apêndice 4 - Descrição e frequências das variáveis dependente e independentes

\section{Variável dependente}

\begin{tabular}{lll}
\hline Desfecho em 2019.1 & Frequência & Percentual \\
\hline Evasão de curso & 1157 & 69,2 \\
Conclusão & 515 & 30,8 \\
Total & 1672 & 100,0
\end{tabular}

Fonte: Elaboração própria, conforme base de dados da UFFS

Variáveis independentes

\begin{tabular}{|c|c|c|}
\hline Idade (Faixa etária) & Frequência & Porcentual \\
\hline 17 a 20 anos & 929 & 55,6 \\
\hline 21 a 24 anos & 333 & 19,9 \\
\hline 25 anos ou mais & 410 & 24,5 \\
\hline Total & 1672 & 100,0 \\
\hline \multicolumn{3}{|c|}{ Sexo_raça } \\
\hline Mulher branca (Cat. Refer.) & 796 & 48,5 \\
\hline Mulher negra & 191 & 11,6 \\
\hline Homem branco & 526 & 32,1 \\
\hline Homem negro & 128 & 7,8 \\
\hline Total & 1641 & 100 \\
\hline Ausente no sistema & 31 & \\
\hline \multicolumn{3}{|c|}{ Renda familiar } \\
\hline Até 3 s.m. & 1114 & 66,6 \\
\hline De 3 a 6 s.m. & 417 & 24,9 \\
\hline Acima de 6 s.m. & 141 & 8,4 \\
\hline Total & 1672 & 100,0 \\
\hline \multicolumn{3}{|c|}{ Escolaridade da mãe } \\
\hline Não estudou/ não informou /até a $4^{\circ}$ série & 625 & 37,4 \\
\hline Ensino Fundamental & 380 & 22,7 \\
\hline Ensino Médio & 420 & 25,1 \\
\hline Ensino Superior & 247 & 14,8 \\
\hline \multicolumn{3}{|l|}{ Total } \\
\hline \multicolumn{3}{|c|}{ Situação de trabalho antes do ingresso } \\
\hline Não (Cat. Refer.) & 762 & 45,6 \\
\hline Sim & 910 & 54,4 \\
\hline Total & 1672 & 100,0 \\
\hline \multicolumn{3}{|c|}{ Localização de moradia } \\
\hline Zona rural (Cat. Refer.) & 422 & 25,2 \\
\hline Zona urbana & 1250 & 74,8 \\
\hline Total & 1672 & 100,0 \\
\hline
\end{tabular}




\begin{tabular}{|c|c|c|}
\hline Estudou na EP & 1563 & 93,5 \\
\hline Não estudou na EP & 109 & 6,5 \\
\hline Total & 1672 & 100,0 \\
\hline \multicolumn{3}{|c|}{ Cotas e ampla concorrência } \\
\hline Ampla concorrência & 202 & 12,1 \\
\hline Escola pública e cota racial & 266 & 15,9 \\
\hline Escola pública parcial ou integral & 1204 & 72,0 \\
\hline \multicolumn{3}{|c|}{ Apoio social } \\
\hline Não (Cat. refer.) & 1150 & 68,8 \\
\hline Sim & 522 & 31,2 \\
\hline Total & 1672 & 100,0 \\
\hline \multicolumn{3}{|c|}{ Turno do curso } \\
\hline Integral (Cat. refer.) & 680 & 40,7 \\
\hline Noturno & 770 & 46,1 \\
\hline Matutino ou vespertino & 222 & 13,3 \\
\hline Total & 1672 & 100,0 \\
\hline \multicolumn{3}{|c|}{ Área de conhecimento } \\
\hline Educação (Cat. refer.) & 871 & 52,1 \\
\hline Negócios, administração, direito e ciências sociais & 166 & 9,9 \\
\hline $\begin{array}{l}\text { Computação e Tecnologias da Informação e } \\
\text { Comunicação (TIC) }\end{array}$ & 77 & 4,6 \\
\hline Engenharia, produção e construção & 199 & 11,9 \\
\hline Agricultura, Silvicultura, Pesca e Veterinária & 256 & 15,3 \\
\hline Saúde e bem-estar & 103 & 6,2 \\
\hline Total & 1672 & 100 \\
\hline \multicolumn{3}{|c|}{ Campus } \\
\hline Chapecó & 629 & 37,6 \\
\hline Laranjeiras do Sul & 213 & 12,7 \\
\hline Realeza & 195 & 11,7 \\
\hline Cerro Largo & 260 & 15,6 \\
\hline Erechim & 340 & 20,3 \\
\hline Passo Fundo & 35 & 2,1 \\
\hline \multicolumn{3}{|c|}{ Reprovação } \\
\hline Não teve reprovação & 320 & 19,1 \\
\hline Teve reprovação & 1352 & 80,9 \\
\hline Total & 1672 & 100 \\
\hline Idade de ingresso (variável numérica) & \multicolumn{2}{|l|}{ Estatísticas } \\
\hline Média & \multicolumn{2}{|l|}{22,8} \\
\hline Mediana & \multicolumn{2}{|l|}{20,0} \\
\hline
\end{tabular}




\begin{tabular}{|l|l|}
\hline Mínimo & 17 \\
\hline Máximo & 67 \\
\hline Total & 1672 \\
\hline & \\
\hline Média de nota (variável numérica) & Estatísticas \\
\hline Média & 4,8 \\
\hline Mediana & 5,2 \\
\hline Mínimo & 0,0 \\
\hline Máximo & 9,4 \\
\hline Total válido & 1608 \\
\hline Ausente no sistema & 64 \\
\hline & \\
\hline Reprovações (variável numérica) & Estatísticas \\
\hline Média & 7 \\
\hline Mediana & 5 \\
\hline Mínimo & 0 \\
\hline Máximo & 72 \\
\hline Total válido & 1672 \\
\hline
\end{tabular}

Fonte: Elaboração própria, conforme base de dados da UFFS 


\section{Anexos}

Anexo 1 - Termo de responsabilidade e Termo de liberação de dados para pesquisa

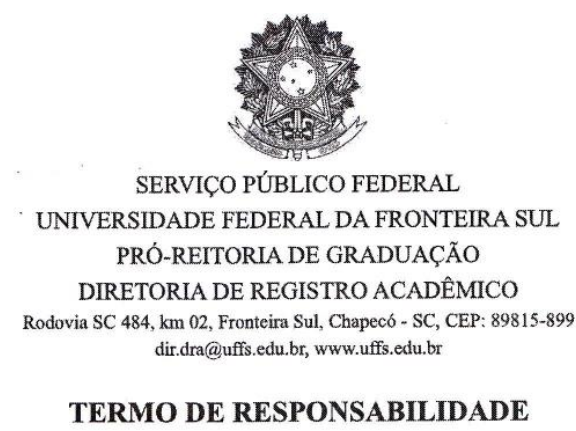

LEI DE ACESSO A INFORMAÇÃO

Lei $\mathrm{n}^{\circ} 12.527$, de 18 de novembro de 2011, regulamentada pelo Decreto $\mathrm{n}^{\circ} 7.724$, de 16 de maio de 2012

\section{ROSILEIA LUCIA NIEROTKA}

Acadêmica de Doutorado em Educação, junto ao Programa de Pós-Graduação em Educação (PPGE/PUC-Rio), orientanda da Profa. Dra. Alícia Maria Catalano de Bonamino.

1. Considerando a solicitação de acesso a informações dirigido à Diretoria de Registro Acadêmico - DRA - da Pró-reitoria de Graduação - PROGRAD - por meio do Ofício número 01/2019, a DRA disponibilizará as informações descritas abaixo através de planilhas eletrônicas para o e-mail informado (rnierotka@gmail.com) até a data prevista de 30 de setembro de 2019:

I. Banco de dados com todos os/as candidatos/as que se inscreveram nos processos seletivos da UFFS e os que ingressaram no período de 2010 a 2018, por opção de curso (primeira ou segunda opção); por curso; por campus, tipo e modalidade de inscrição (Ex. ENEM - modalidade de inscrição/cota; Processo seletivo especial (PIN/PROHAITI/ PRONERA); transferência, retorno de graduado;

II. Banco de dados com todas as perguntas e respostas do questionário socioeconômico aplicado no Processo Seletivo de 2010 a 2013 dos inscritos e dos ingressantes na UFFS neste período, com o respectivo $\mathrm{CPF}$, curso e campus, para fins de cruzamento de dados com demais bases;

III. Informações dos estudantes matriculados (CPF; Número de matrícula; Turno do Curso; Data de Nascimento; Sexo; Raça; Nacionalidade; País de origem; Necessidade especial; Cidade de endereço; U.F. de endereço; Ano de conclusão de E.M.; Mês de conclusão do E.M.; Cidade de conclusão do E.M.; U.F. de conclusão do E.M.; Escola pública; Grupo de inscrição no P.S.; Modo de ingresso; Matriz do aluno; Índice de aproveitamento acumulado (IAA); Percentual de Integralização do curso); e

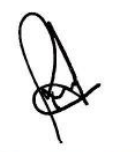




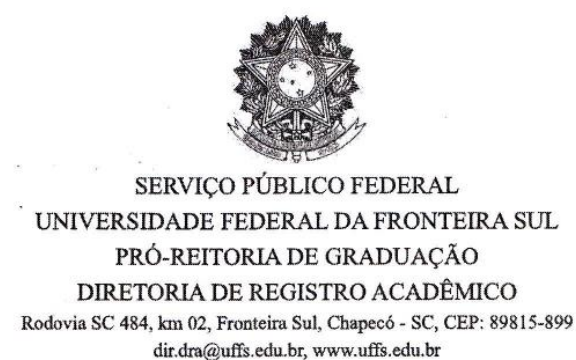

IV. Dados enviados à Procuradoria Educacional Institucional e Diretoria de Sistemas de Informação para a coleta anual do Censo da Educação Superior referente ao período de 2010 a 2019.

2. Declaro, sob as penas da Lei, que é de minha inteira responsabilidade o acesso as informações que serão disponibilizadas por esta Diretoria, nos termos dos art. $4^{\circ}$, inciso IV e art.31, $\S 3^{\circ}$, inciso II da Lei $\mathrm{n}^{\circ} 12.527 / 2011$, e dos art. 57, inciso II, art. 60, caput, e art $61, \S 1^{\circ}$ e $\$ 2^{\circ}$ do Decreto $\mathrm{n}^{\circ} 7.724 / 2012$, destacando sobretudo minha responsabilidade:

I. pela utilização, guarda e não divulgação a terceiros(as) de todas as informações e dados fornecidos descritos no item 1 em virtude da solicitação efetuada;

II. por todo e qualquer prejuízo decorrente de sua cessão proposital ou não a terceiros(as), ainda que em caráter emergencial ou por qualquer outra necessidade;

III. pela utilização dos dados e informações exclusivamente para os fins que fundamentaram a autorização do acesso, sendo vedada sua utilização de maneira diversa.

3. Declaro estar ciente de que a DRA e a PROGRAD estão isentas de quaisquer responsabilidades quanto ao uso e guarda indevidos das informações que serão fornecidas.

Ciente e de acordo:

Chapecó, SC, $1^{\circ}$ de agosto de 2019.

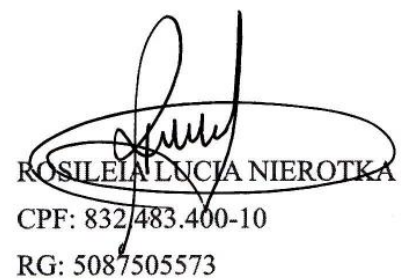




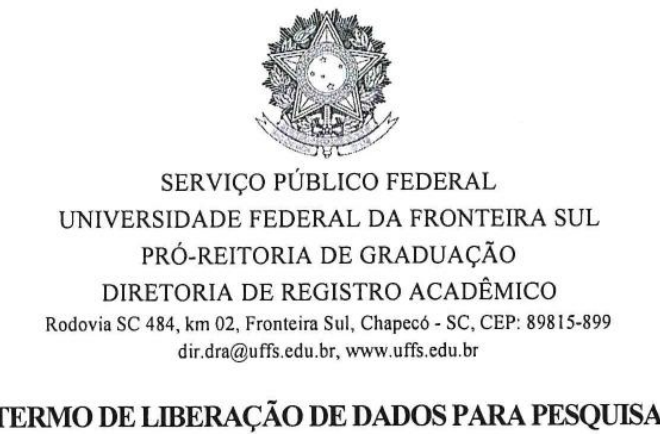

1. Considerando a solicitação de acesso a informações dirigido à Diretoria de Registro Acadêmico - DRA - da Pró-reitoria de Graduação - PROGRAD, da UFFS, por meio do Ofício número 01/2019 e a assinatura de um termo de responsabilidade assinado pela pesquisadora Rosileia Lucia Nierotka (aluna de Doutorado em Educação, junto ao Programa de Pós-Graduação em Educação (PPGE/PUC-Rio), orientanda da Profa. Dra. Alícia Maria Catalano de Bonamino), a DRA autoriza a disponibilização das informações descritas abaixo através de planilhas eletrônicas para o e-mail informado (rnierotka@gmail.com) até a data prevista de 30 de setembro de 2019:

L Banco de dados com todos os/as candidatos/as que se inscreveram nos processos seletivos da UFFS e os que ingressaram no período de 2010 a 2018, por opção de curso (primeira ou segunda opção); por curso; por campus, tipo e modalidade de inscrição (Ex. ENEM - modalidade de inscrição/cota; Processo seletivo especial (PIN/PROHAITI/ PRONERA); transferência, retorno de graduado;

II. Banco de dados com todas as perguntas e respostas do questionário socioeconômico aplicado no Processo Seletivo de 2010 a 2013 dos inscritos e dos ingressantes na UFFS neste período, com o respectivo $\mathrm{CPF}$, curso e campus, para fins de cruzamento de dados com demais bases;

III. Informações dos estudantes matriculados (CPF; Número de matrícula; Turno do Curso; Data de Nascimento; Sexo; Raça; Nacionalidade; País de origem; Necessidade especial; Cidade de endereço; U.F. de endereço; Ano de conclusão de E.M.; Mês de conclusão do E.M.; Cidade de conclusão do E.M.; U.F. de conclusão do E.M.; Escola pública; Grupo de inscrição no P.S.; Modo de ingresso; Matriz do aluno; Índice de aproveitamento acumulado (IAA); Percentual de Integralização do curso); e

IV. Dados enviados à Procuradoria Educacional Institucional e Diretoria de Sistemas de Informação para a coleta anual do Censo da Educação Superior referente ao período de 2010 a 2019.

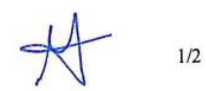




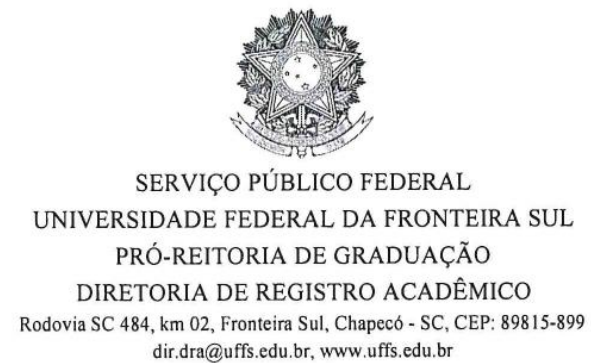

2 .

A PROGRAD e a DRA declaram que os dados liberados não ferem o anonimato dos estudantes (potenciais participantes da pesquisa). A informação referente ao CPF dos estudantes foi substituída por um código que garante o anonimato dos alunos. Os dados relativos aos nomes das escolas de pertencimento dos estudantes não foram liberados, para garantir a não identificação dos participantes individuais da pesquisa.

3. É de inteira responsabilidade da pesquisadora o acesso as informações que serão disponibilizadas por esta Diretoria, nos termos dos art. $4^{\circ}$, inciso IV e art. $31, \S 3^{\circ}$, inciso II da Lei $n^{\circ}$ 12.527/2011, e dos art. 57, inciso II, art. 60, caput, e art $61, \S^{\circ}$ e $\mathbf{2}^{\circ}$ do Decreto $\mathrm{n}^{\circ} 7.724 / 2012$, destacando sobretudo a responsabilidade:

I. pela utilização, guarda e não divulgação a terceiros(as) de todas as informações e dados fornecidos descritos no item 1 em virtude da solicitação efetuada;

II. por todo e qualquer prejuízo decorrente de sua cessão proposital ou não a terceiros(as), ainda que em caráter emergencial ou por qualquer outra necessidade;

III. pela utilização dos dados e informações exclusivamente para os fins que fundamentaram a autorização do acesso, sendo vedada sua utilização de maneira diversa.

4. A DRA e a PROGRAD estão isentas de quaisquer responsabilidades quanto ao uso e guarda indevidos das informações que serão fornecidas.

Chapecó, SC, 28 de novembro de 2019

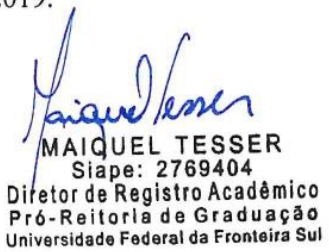


Anexo 2 - Despacho de aprovação de uso de dados protegidos do Inep

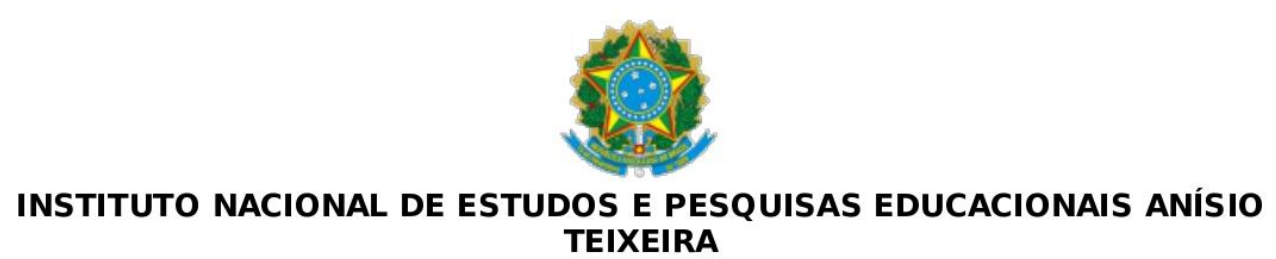

Despacho № 0495664/2020/SEDAP/CIBEC/DIRED

Assunto: Análise de Projeto de Pesquisa.

1. A pesquisadora do Projeto "Desigualdade de oportunidades na educação superior: um estudo sobre a Universidade Federal da Fronteira Sul" por meio do Serviço de Acesso aos Dados Protegidos (SEDAP), da Dired/Inep, nos termos da Portaria № 637, de 17 de julho de 2019, preencheu formulário de solicitação para acesso a informações sigilosas informando que, pelo escopo da pesquisa apresentada, necessita de acesso às seguintes bases de dados protegidos:

- ENEM (2009-2017); e

- CENSO DA EDUCAÇÃO SUPERIOR (2010-2017).

2. A pesquisa também fará uso da base externa:

- Sistema de Gestão Acadêmica (SGA) da UFFS (2010-2018): acesso restrito, com autorização entregue.

3. $\quad \mathrm{O}$ desenvolvimento de projeto de pesquisa tem como objetivo analisar como no contexto de expansão e mudanças nas formas de ingresso ao ensino superior a estratificação horizontal se caracteriza na UFFS e como ou se as mudanças e permanências observadas na instituição impactam na evasão, conclusão e retenção dos ingressantes. O projeto está vinculado ao desenvolvimento de tese de doutorado na Pontifícia Universidade Católica do Rio de Janeiro, PUC-Rio.

4. Avaliando-se a proposta de estudo apresentada pela pesquisadora, depreende-se que as informações solicitadas serão utilizadas exclusivamente para cruzamentos estatísticos que garantam a precisão dos resultados. As informações disponibilizadas na sala segura não poderão, sob nenhuma hipótese, serem publicizadas, uma vez que se encontram protegidas pela Lei de Acesso à Informação - LAl.

5. Observadas as ressalvas apresentadas neste parecer e a legislação vigente, considera-se aprovada a solicitação de acesso às informações sigilosas para fins de pesquisa científica.

É o parecer.

Atenciosamente, 
MARCO CÉSAR ARAUJO PEREIRA

Técnico Responsável do Sedap

ceil Documento assinado eletronicamente por Marco César Araujo Pereira,

Sel. 9 Servidor Público Federal, em 04/03/2020, às 14:08, conforme horário $\begin{aligned} & \text { assinatura } \\ & \text { eletronica }\end{aligned}$
8 de outubro de 2015 .

A autenticidade deste documento pode ser conferida no site

http://sei.inep.gov.br/controlador externo.php?

acao $=$ documento conferir\&id orḡao acesso externo $=0$, informando 0

U. 


\section{Anexo 3 - Parecer da Comissão de Ética da PUC-Rio}

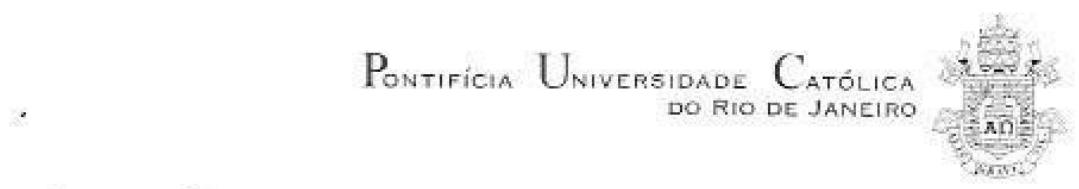

CÃMARA DE ÉTICA EM PESQUISA DA PUC-RIo

Parecer da Comissão de Etica em Pesquisa da PUC-Rio 110/2019 - Protocolo 109/2019

A Camara de Ética em Pesquisa da PUC-Rio foi constituida como uma Câmara especifica do Conselho de Ensino e Pesquisa conforme decisào deste órgào colegiado com atribuiçâo de avaliar projetos de pesquisa do ponto de vista de suas implicap̃oses èticas.

Identificaçāo:

Titulo: "Desigualdade de oportunidades na educaçāo superior: um estudo sobre a Universidade Federal da Fronteira Sul"' (Departamento de Educaçäo da PUC-Rio)

Autor: Rosileia Lucia Nierotka (Doutoranda do Departamento de Educação da PUC-Rio).

Orientadora: Alicia Maria Catalano de Bonamino (Professora do Departamento de Educação da PUCRio)

Apresentação: Pesquisa de estudo de caso, dentro do sistema federal de ensino superior brasileiro, tomando como local de pesquisa os diferentes campi e cursos da Universidade Federal da Fronteira Sul - UFFS, considerando a origem social dos estudantes e sua relaça com o alcance educacional A fonte de colete de dados será documental, cuja busca será secundária, a partir de informaçōes e banco de dados ja existentes. A pesquisa será de cunho quanti-qualitativo. Objetiva analisar como no contexto de expansáo e mudanças nas formas de ingresso ao ensino superior, a estratificaçäo horizontal se caracteriza na UFFS, e como ou se as mudanças e pemanéncias observadas na instituiçāo impactam na evasāo, conclusāo e retençāo dos ingressantes.

Aspectos éticos: O projeto e o Pedido de Dispensa do Termo de Consentimento Livre e Esclarecido aprosentados estāo de acordo com os princípios e valores do Marco Referencial, Estatuto e Regimento da Universidade no que se refere as responsabilidades de seu corpo docente e discente. 0 Pedido de Dispensa é justificado pela caracteristica de ser um estudo com base documental näo intervencionista, sem coleta de informaçāo direta com as participantes. Garante a confidencialidade dos dados e o anonimato quanto à identificaçäo pessoal e a confidencialidade dos dados coletados

Parecer: Aprovado

Prof. Jose Ricardo Bergmann

Presidente do Conselho de Ensino e Pesquisa da PUC-Rio

Profilfora Loper Rodrines da siva

Comissão de Ética em Pesquisa da PuC-Rio

Rio de Janeiro, 05 de dezembro de 2019

Vice-Reikaria jara Assumbes Auzulimicxs Cunara de Frica em Pesquisa da PUC-Rio - CEP 4 PUC-Rin Rua Marques de Sin Vicente, 25 - Gaver - 22453-90il Ruv de Jincino - RJ - Tel. (1021) 3527-1612/3527-1618

$$
\text { conal sakcugus:riube }
$$

